\title{
A Aplicação do Conhecimento Científico na Engenharia Elétrica
}

João Dallamuta

Henrique Ajuz Holzmann

(Organizadores)

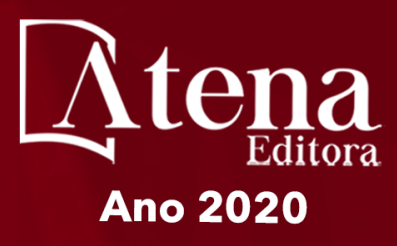




\section{A Aplicação do Conhecimento Científico na Engenharia Elétrica}

João Dallamuta

Henrique Ajuz Holzmann

(Organizadores)

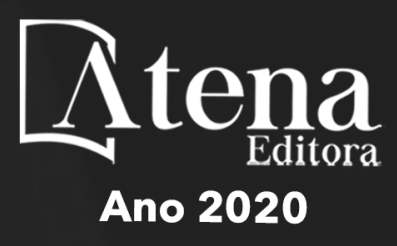




\author{
2020 by Atena Editora \\ Copyright (C) Atena Editora \\ Copyright do Texto (C) 2020 Os autores \\ Copyright da Edição (c) 2020 Atena Editora \\ Editora Chefe: Prof $^{\mathrm{a}} \mathrm{Dr}^{\mathrm{a}}$ Antonella Carvalho de Oliveira \\ Diagramação: Karine de Lima \\ Edição de Arte: Lorena Prestes \\ Revisão: Os Autores
}

Todo o conteúdo deste livro está licenciado sob uma Licença de Atribuição Creative

Commons. Atribuição 4.0 Internacional (CC BY 4.0).

O conteúdo dos artigos e seus dados em sua forma, correção e confiabilidade são de responsabilidade exclusiva dos autores. Permitido o download da obra e o compartilhamento desde que sejam atribuídos créditos aos autores, mas sem a possibilidade de alterá-la de nenhuma forma ou utilizá-la para fins comerciais.

\title{
Conselho Editorial
}

\section{Ciências Humanas e Sociais Aplicadas}

Prof $^{a}$ Dr $^{a}$ Adriana Demite Stephani - Universidade Federal do Tocantins

Prof. Dr. Álvaro Augusto de Borba Barreto - Universidade Federal de Pelotas

Prof. Dr. Alexandre Jose Schumacher - Instituto Federal de Educação, Ciência e Tecnologia de Mato Grosso

Prof. Dr. Antonio Carlos Frasson - Universidade Tecnológica Federal do Paraná

Prof. Dr. Antonio Gasparetto Júnior - Instituto Federal do Sudeste de Minas Gerais

Prof. Dr. Antonio Isidro-Filho - Universidade de Brasília

Prof. Dr. Carlos Antonio de Souza Moraes - Universidade Federal Fluminense

Prof. Dr. Constantino Ribeiro de Oliveira Junior - Universidade Estadual de Ponta Grossa

Prof $^{\mathrm{a}} \mathrm{Dr}^{\mathrm{a}}$ Cristina Gaio - Universidade de Lisboa

Prof $^{a}$ Dr $^{a}$ Denise Rocha - Universidade Federal do Ceará

Prof. Dr. Deyvison de Lima Oliveira - Universidade Federal de Rondônia

Prof. Dr. Edvaldo Antunes de Farias - Universidade Estácio de Sá

Prof. Dr. Eloi Martins Senhora - Universidade Federal de Roraima

Prof. Dr. Fabiano Tadeu Grazioli - Universidade Regional Integrada do Alto Uruguai e das Missões

Prof. Dr. Gilmei Fleck - Universidade Estadual do Oeste do Paraná

Prof $^{a} \mathrm{Dr}^{\mathrm{a}}$ Ivone Goulart Lopes - Istituto Internazionele delle Figlie de Maria Ausiliatrice

Prof. Dr. Julio Candido de Meirelles Junior - Universidade Federal Fluminense

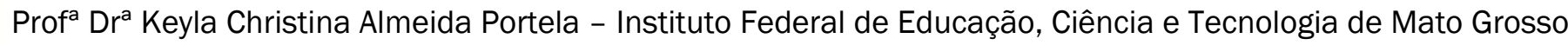

Prof $^{a}$ Dr $^{a}$ Lina Maria Gonçalves - Universidade Federal do Tocantins

Prof $^{a}$ Dr $^{a}$ Natiéli Piovesan - Instituto Federal do Rio Grande do Norte

Prof. Dr. Marcelo Pereira da Silva - Universidade Federal do Maranhão

Prof $^{\mathrm{a}} \mathrm{Dr}^{\mathrm{a}}$ Miranilde Oliveira Neves - Instituto de Educação, Ciência e Tecnologia do Pará

Prof $^{a}$ Dr $^{\text {a }}$ Paola Andressa Scortegagna - Universidade Estadual de Ponta Grossa

Prof $^{a}$ Dr $^{\mathrm{a}}$ Rita de Cássia da Silva Oliveira - Universidade Estadual de Ponta Grossa

Prof $^{a} \mathrm{Dr}^{\mathrm{a}}$ Sandra Regina Gardacho Pietrobon - Universidade Estadual do Centro-Oeste

Prof $^{a}$ Dr $^{\text {a }}$ Sheila Marta Carregosa Rocha - Universidade do Estado da Bahia

Prof. Dr. Rui Maia Diamantino - Universidade Salvador

Prof. Dr. Urandi João Rodrigues Junior - Universidade Federal do Oeste do Pará

Prof $^{a}$ Dr $^{a}$ Vanessa Bordin Viera - Universidade Federal de Campina Grande

Prof. Dr. William Cleber Domingues Silva - Universidade Federal Rural do Rio de Janeiro

Prof. Dr. Willian Douglas Guilherme - Universidade Federal do Tocantins

\section{Ciências Agrárias e Multidisciplinar}

Prof. Dr. Alexandre Igor Azevedo Pereira - Instituto Federal Goiano

Prof. Dr. Antonio Pasqualetto - Pontifícia Universidade Católica de Goiás

Prof $^{\mathrm{a}} \mathrm{Dr}^{\mathrm{a}}$ Daiane Garabeli Trojan - Universidade Norte do Paraná

\section{贝tena


Prof $^{a}$ Dra $^{a}$ Diocléa Almeida Seabra Silva - Universidade Federal Rural da Amazônia

Prof. Dr. Écio Souza Diniz - Universidade Federal de Viçosa

Prof. Dr. Fábio Steiner - Universidade Estadual de Mato Grosso do Sul

Prof. Dr. Fágner Cavalcante Patrocínio dos Santos - Universidade Federal do Ceará

Prof $^{a}$ Dr $^{a}$ Girlene Santos de Souza - Universidade Federal do Recôncavo da Bahia

Prof. Dr. Júlio César Ribeiro - Universidade Federal Rural do Rio de Janeiro

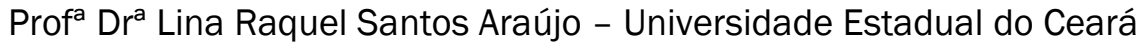

Prof. Dr. Pedro Manuel Villa - Universidade Federal de Viçosa

Prof $^{\mathrm{a}} \mathrm{Dr}^{\mathrm{a}}$ Raissa Rachel Salustriano da Silva Matos - Universidade Federal do Maranhão

Prof. Dr. Ronilson Freitas de Souza - Universidade do Estado do Pará

Prof $^{\mathrm{a}} \mathrm{Dr}^{\mathrm{a}}$ Talita de Santos Matos - Universidade Federal Rural do Rio de Janeiro

Prof. Dr. Tiago da Silva Teófilo - Universidade Federal Rural do Semi-Árido

Prof. Dr. Valdemar Antonio Paffaro Junior - Universidade Federal de Alfenas

\section{Ciências Biológicas e da Saúde}

Prof. Dr. André Ribeiro da Silva - Universidade de Brasília

Prof $^{\mathrm{a}} \mathrm{Dr}^{\mathrm{a}}$ Anelise Levay Murari - Universidade Federal de Pelotas

Prof. Dr. Benedito Rodrigues da Silva Neto - Universidade Federal de Goiás

Prof. Dr. Edson da Silva - Universidade Federal dos Vales do Jequitinhonha e Mucuri

Prof $^{a}$ Dr $^{a}$ Eleuza Rodrigues Machado - Faculdade Anhanguera de Brasília

Prof $^{a} \mathrm{Dr}^{\mathrm{a}}$ Elane Schwinden Prudêncio - Universidade Federal de Santa Catarina

Prof. Dr. Ferlando Lima Santos - Universidade Federal do Recôncavo da Bahia

Prof. Dr. Gianfábio Pimentel Franco - Universidade Federal de Santa Maria

Prof. Dr. Igor Luiz Vieira de Lima Santos - Universidade Federal de Campina Grande

Prof. Dr. José Max Barbosa de Oliveira Junior - Universidade Federal do Oeste do Pará

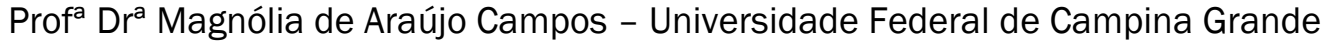

Prof $^{\mathrm{a}} \mathrm{Dr}^{\mathrm{a}}$ Mylena Andréa Oliveira Torres - Universidade Ceuma

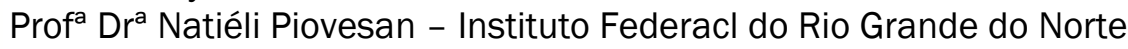

Prof. Dr. Paulo Inada - Universidade Estadual de Maringá

Prof $^{a}$ Dr ${ }^{\mathrm{a}}$ Vanessa Lima Gonçalves - Universidade Estadual de Ponta Grossa

Prof $^{\mathrm{a}} \mathrm{Dr}^{\mathrm{a}}$ Vanessa Bordin Viera - Universidade Federal de Campina Grande

\section{Ciências Exatas e da Terra e Engenharias}

Prof. Dr. Adélio Alcino Sampaio Castro Machado - Universidade do Porto

Prof. Dr. Alexandre Leite dos Santos Silva - Universidade Federal do Piauí

Prof. Dr. Carlos Eduardo Sanches de Andrade - Universidade Federal de Goiás

Prof $^{\mathrm{a}} \mathrm{Dr}^{\mathrm{a}}$ Carmen Lúcia Voigt - Universidade Norte do Paraná

Prof. Dr. Eloi Rufato Junior - Universidade Tecnológica Federal do Paraná

Prof. Dr. Fabrício Menezes Ramos - Instituto Federal do Pará

Prof. Dr. Juliano Carlo Rufino de Freitas - Universidade Federal de Campina Grande

Prof. Dr. Marcelo Marques - Universidade Estadual de Maringá

Prof $^{\mathrm{a}} \mathrm{Dr}^{\mathrm{a}}$ Neiva Maria de Almeida - Universidade Federal da Paraíba

Prof $^{a}$ Dra $^{a}$ Natiéli Piovesan - Instituto Federal do Rio Grande do Norte

Prof. Dr. Takeshy Tachizawa - Faculdade de Campo Limpo Paulista

\section{Conselho Técnico Científico}

Prof. Msc. Abrãao Carvalho Nogueira - Universidade Federal do Espírito Santo

Prof. Msc. Adalberto Zorzo - Centro Estadual de Educação Tecnológica Paula Souza

Prof. Dr. Adaylson Wagner Sousa de Vasconcelos - Ordem dos Advogados do Brasil/Seccional Paraíba

Prof. Msc. André Flávio Gonçalves Silva - Universidade Federal do Maranhão

Prof $^{a} \mathrm{Dr}^{\mathrm{a}}$ Andreza Lopes - Instituto de Pesquisa e Desenvolvimento Acadêmico

Prof ${ }^{a}$ Msc. Bianca Camargo Martins - UniCesumar

Prof. Msc. Carlos Antônio dos Santos - Universidade Federal Rural do Rio de Janeiro

Prof. Msc. Claúdia de Araújo Marques - Faculdade de Música do Espírito Santo

Prof. Msc. Daniel da Silva Miranda - Universidade Federal do Pará

Prof $^{a}$ Msc. Dayane de Melo Barros - Universidade Federal de Pernambuco 
Prof. Dr. Edwaldo Costa - Marinha do Brasil

Prof. Msc. Eliel Constantino da Silva - Universidade Estadual Paulista Júlio de Mesquita

Prof. Msc. Gevair Campos - Instituto Mineiro de Agropecuária

Prof. Msc. Guilherme Renato Gomes - Universidade Norte do Paraná

Prof $^{a}$ Msc. Jaqueline Oliveira Rezende - Universidade Federal de Uberlândia

Prof. Msc. José Messias Ribeiro Júnior - Instituto Federal de Educação Tecnológica de Pernambuco

Prof. Msc. Leonardo Tullio - Universidade Estadual de Ponta Grossa

Prof ${ }^{a}$ Msc. Lilian Coelho de Freitas - Instituto Federal do Pará

Prof $^{a}$ Msc. Liliani Aparecida Sereno Fontes de Medeiros - Consórcio CEDERJ

Prof $^{a}$ Dr $^{a}$ Lívia do Carmo Silva - Universidade Federal de Goiás

Prof. Msc. Luis Henrique Almeida Castro - Universidade Federal da Grande Dourados

Prof. Msc. Luan Vinicius Bernardelli - Universidade Estadual de Maringá

Prof. Msc. Rafael Henrique Silva - Hospital Universitário da Universidade Federal da Grande Dourados

Prof ${ }^{a}$ Msc. Renata Luciane Polsaque Young Blood - UniSecal

Prof ${ }^{a}$ Msc. Solange Aparecida de Souza Monteiro - Instituto Federal de São Paulo

Prof. Dr. Welleson Feitosa Gazel - Universidade Paulista

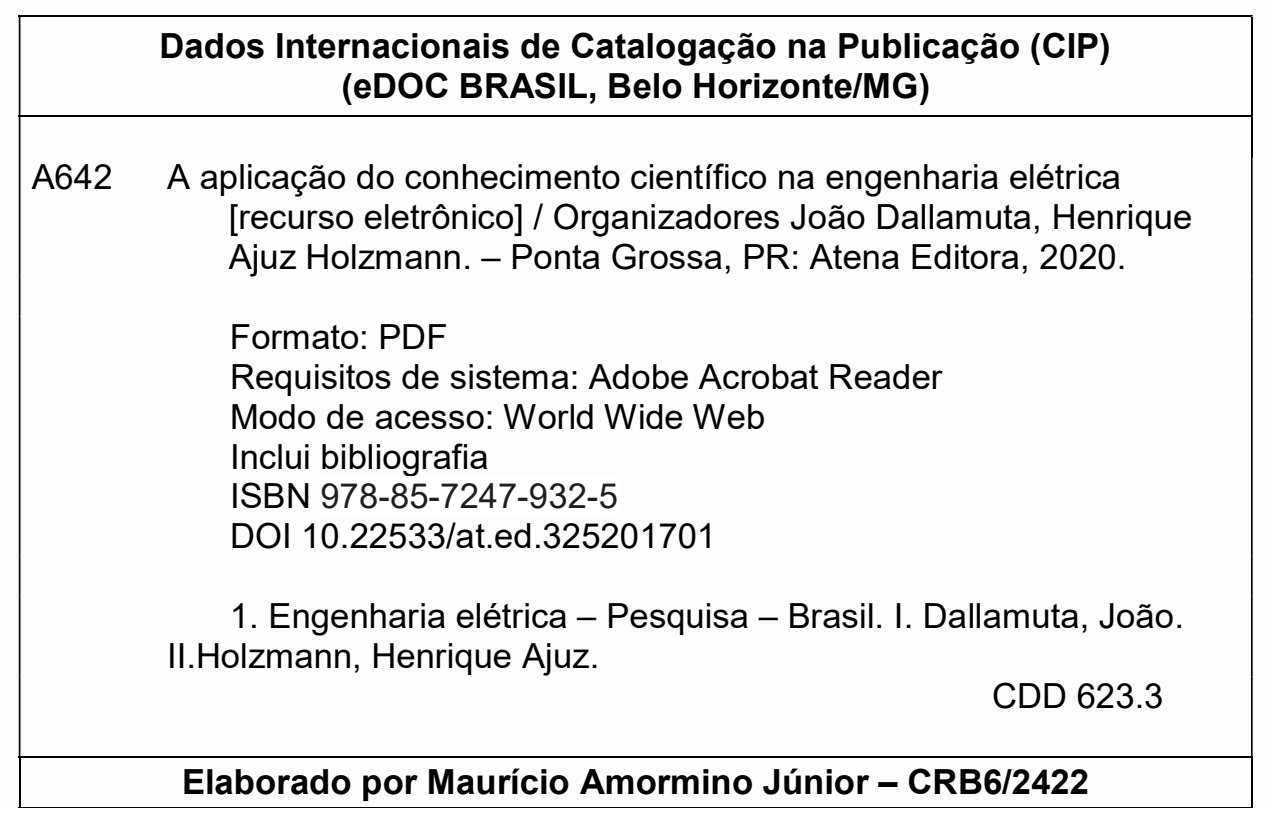

Atena Editora

Ponta Grossa - Paraná - Brasil

www.atenaeditora.com.br

contato@atenaeditora.com.br 


\section{APRESENTAÇÃO}

A engenharia elétrica tornou-se uma profissão há cerca de 130 anos, com o início da distribuição de eletricidade em caráter comercial e com a difusão acelerada do telégrafo em escala global no final do século XIX.

$\mathrm{Na}$ primeira metade do século $\mathrm{XX}$ a difusão da telefonia e da radiodifusão além do crescimento vigoroso dos sistemas elétricos de produção, transmissão e distribuição de eletricidade, deu os contornos definitivos para a carreira de engenheiro eletricista que na segunda metade do século, com a difusão dos semicondutores e da computação gerou variações de ênfase de formação como engenheiros eletrônicos, de telecomunicações, de controle e automação ou de computação.

Produzir conhecimento em engenharia elétrica é portando pesquisar em uma gama enorme de áreas, subáreas e abordagens de uma engenharia que é onipresente em praticamente todos os campos da ciência e tecnologia.

Neste livro temos uma diversidade de temas, níveis de profundidade e abordagens de pesquisa, envolvendo aspectos técnicos e científicos. Aos autores e editores, agradecemos pela confiança e espírito de parceria.

João Dallamuta

Henrique Ajuz Holzmann 


\section{SUMÁRIO}

CAPÍTULO 1

PANORAMA ATUAL E CENÁRIO 2025 DA ENERGIA SOLAR FOTOVOLTAICA NO BRASIL

Isabela Valpecovski Urbanetz

Allana de Moura Netto

Bruno Scolari

Vicente Leite

Jair Urbanetz Junior

DOI 10.22533/at.ed.3252017011

CAPÍTULO 2

GESTÃO EFICIENTE DAS ANUIDADES REGULATÓRIAS NA CEMIG DISTRIBUIÇÃO

Rosane de Pinho Matos

Viviane Fernanda de Aguiar Pereira

DOI 10.22533/at.ed.3252017012

CAPÍTULO 3

DESAFIOS DA REVISÃO PERIÓDICA DE AJUSTES DE GRANDES SISTEMAS -NORMAS, PROCEDIMENTOS E FERRAMENTAS

Rodrigo A. Benes Ferreira

Mario Roberto Bastos

Nilson José Francischetti Júnior

DOI 10.22533/at.ed.3252017013

CAPÍTULO 4 36

AVALIAÇÃO ECONÔMICA E ENERGÉTICA DE UM SISTEMA INTEGRANDO MÁQUINA BIOPEIXES E REATOR MULTIFUNCIONAL PARA PRODUÇÃO DE ENERGIA ELÉTRICA

Francisco de Assis da Silva Mota

Francisco Francielle Pinheiro dos Santos

Paula Cristina de Amorim Andrade

DOI 10.22533/at.ed.3252017014

CAPÍTULO 5

ANÁLISE DE PERDAS TÉCNICAS EM SISTEMAS DE DISTRIBUIÇÃO

Francisco Jeandson Rodrigues da Silva

Ailson Pereira de Moura

Adriano Aron Freitas de Moura

Douglas Aurélio Carvalho Costa

Obed Leite Vieira

DOI 10.22533/at.ed.3252017015

CAPÍTULO 6 61

CARACTERIZAÇÃO E ESTRATIFICAÇÃO DOS SFVCR NO BRASIL: CENÁRIO ATUAL E PERSPECTIVAS FUTURAS

Diego Plazza Hilgert

Jair Urbanetz Junior

DOI 10.22533/at.ed.3252017016 
GEOCORTE CEMIG D: SELEÇÃO ÓTIMA DE ALVOS DE CORTE USANDO GEORREFERENCIAMENTO: DESENVOLVIMENTO SAP/CCS

Wellington Fazzi Cancian Andre Luiz Soares

Charles Ramos Pimenta

\section{DOI 10.22533/at.ed.3252017017}

CAPÍTULO 8

ÍNDICES DE REFERÊNCIA PARA APLICAÇÃO DA TECNOLOGIA CABOS PARA-RAIOS ENERGIZADOS

José Ezequiel Ramos

Alexandre Piantini

Ary D'Ajuz

Valdemir Aparecido Pires

Paulo Roberto de Oliveira Borges

DOI 10.22533/at.ed.3252017018

CAPÍTULO 9

A EXPERIÊNCIA DA COPEL COM RELIGADORES MONOFÁSICOS

Maurício Varassim Hernandes

Oscar Kim Júnior

Fausto Aurélio Portella Garcia

Guilherme Fernandes Gonçalves

DOI 10.22533/at.ed.3252017019

CAPÍTULO 10

SISTEMA DE MONITORAMENTO DA REDE DE DISTRIBUIÇÃO DE ENERGIA COM VISTAS A MELHORIA DA QUALIDADE DE SERVIÇO

Klendson Marques Canuto

Avilez Batista de Oliveira Lima

Paulo Roberto de Oliveira Braga

Juraci Gomes de Aguiar Filho

André Ribeiro da Costa

DOI 10.22533/at.ed.32520170110

CAPÍTULO 11

TÉCNICA DE RESGATE PARA TRABALHOS EM INSTALAÇÕES ENERGIZADAS - MÉTODO AO POTENCIAL

Fernando César Pepe

Wlademir Braido

DOI 10.22533/at.ed.32520170111

CAPÍTULO 12 128

MONITORAMENTO DE DESGASTE DE CONTATOS DOS DISJUNTORES DA SUBESTAÇÃO ISOLADA À GÁS DA UHE BELO MONTE

Davi Carvalho Moreira

DOI 10.22533/at.ed.32520170112 
COMPARAÇÃO ENTRE TRANSFORMADORES A ÓLEO E A SECO

Marco Antonio Ferreira Finocchio

Márcio Mendonça

Lucas de Oliveira Antunes

Jeferson Gonçalves Ferreira

DOI 10.22533/at.ed.32520170113

CAPÍTULO 14

OTIMIZAÇÃO POR ENXAME DE PARTÍCULAS APLICADA A CONTROLADORES DE CORRENTE PARA INVERSORES CONECTADOS À REDE

Lucas Cielo Borin

lury Cleveston

Caio Ruviaro Dantas Osorio

Gustavo Guilherme Koch

Fabricio Moretto Bottega

Vinicius Foletto Montagner

DOI 10.22533/at.ed.32520170114

CAPÍTULO 15

OTIMIZAÇÃO DA CONFIABILIDADE PELA ALOCAÇÃO DE CHAVES AUTOMÁTICAS E USO DE GERAÇÃO DISTRIBUÍDA EM ILHAMENTO

Railson Severiano de Sousa

Camilo Alberto Sepúlveda Rangel

Criciéle Castro Martins

Mauricio Sperandio

Luciane Neves Canha

DOI 10.22533/at.ed.32520170115

CAPÍTULO 16

COMO SELECIONAR TRANSISTORES DE POTÊNCIA PARA APLICAÇÕES EM CONVERSORES ESTÁTICOS?

Edemar de Oliveira Prado

Pedro Cerutti Bolsi

Mateus José Tiburski

Éder Bridi

Hamiltom Confortin Sartori

José Renes Pinheiro

DOI 10.22533/at.ed.32520170116

CAPÍTULO 17

METODOLOGIA DE PROJETO DE CONVERSORES BOOST PARA APLICAÇÕES DE ALTA EFICIÊNCIA E ELEVADO GANHO DE TENSÃO

Mateus José Tiburski

Éder Bridi

Edemar Oliveira Prado

Pedro Cerutti Bolsi

Hamiltom Confortin Sartori

José Renes Pinheiro

DOI 10.22533/at.ed.32520170117 
INFLUÊNCIA DO PONTO DE OPERAÇÃO DE CONVERSORES ESTÁTICOS NO VOLUME E PERDAS DE DIFERENTES MATERIAIS MAGNÉTICOS

Pedro Cerutti Bolsi

Edemar de Oliveira Prado

Mateus José Tiburski

Éder Bridi

Hamiltom Confortin Sartori

José Renes Pinheiro

DOI 10.22533/at.ed.32520170118

CAPÍTULO 19

WIRELESS CHARGER MANUFACTURING USING INDUCTIVE METHOD

Maryam Liaqat

Sulman Joseph

Shamsa Maqsood

Ali Raza

Sana Aslam

Waseem Imtiaz

Muhammad Furqan Shoukat

DOI 10.22533/at.ed.32520170119

CAPÍTULO 20

TRANSFORMADOR DE ATERRAMENTO EM REDE DE DISTRIBUIÇÃO

Djair Pamplona sos Santos

DOI 10.22533/at.ed.32520170120

CAPÍTULO 21

OTIMIZAÇÃO DE CONVERSORES BOOST INTERCALADO DE ALTO GANHO DE TENSÃO E ALTA EFICIÊNCIA

Éder Bridi

Mateus José Tiburski

Edemar Oliveira Prado

Pedro Cerutti Bolsi

Hamiltom Confortin Sartori

José Renes Pinheiro

DOI 10.22533/at.ed.32520170121

CAPÍTULO 22 262

DETERMINAÇÃO DE PROCEDIMENTO PARA AVALIAR A INCERTEZA NA PREVISÃO DE PRECIPITAÇÃ̃O E VAZÃO AFLUENTE POR SISTEMAS HIDRO METEOROLÓGICOS PARA AUXÍLIO NA OPERAÇÃO DOS RESERVATÓRIOS E PLANEJAMENTO HIDROENERGÉTICO

Reinaldo Bomfim da Silveira

Anderson Nascimento de Araujo

Mino Viana Sorribas

Camila Freitas

Rafael Schinoff Mércio Pereira

Ângelo Breda

José Eduardo Gonçalves

DOI 10.22533/at.ed.32520170122 


\section{PANORAMA ATUAL E CENÁRIO 2025 DA ENERGIA SOLAR FOTOVOLTAICA NO BRASIL}

Data de aceite: 03/01/2020

Isabela Valpecovski Urbanetz Universidade Tecnológica Federal do Paraná Curitiba - Paraná

Allana de Moura Netto Universidade Tecnológica Federal do Paraná Curitiba - Paraná

Bruno Scolari Universidade Tecnológica Federal do Paraná Curitiba - Paraná

Vicente Leite Instituto Politécnico de Bragança Bragança - Distrito de Bragança

Jair Urbanetz Junior Universidade Tecnológica Federal do Paraná Curitiba - Paraná

RESUMO: A energia solar fotovoltaica no Brasil teve seu crescimento impulsionado pela Resolução Normativa $n^{\circ}$ 482/2012 da ANEEL, onde foi regulado os sistemas de micro e mini geração no sistema de compensação, e pelos leilões específicos para usinas fotovoltaicas realizadas pelo governo federal. Porém, o país ainda possui pouca representatividade da energia solar em sua matriz elétrica, cerca de $0,13 \%$, com aproximadamente $1 \%$ da capacidade instalada de geradores de energia elétrica considerando todas as fontes, ambos os valores são referentes ao ano de 2017. Nos momentos iniciais de uma tecnologia, seu crescimento se dá de forma irregular e por existir pouca capacidade instalada, qualquer valor adicionado pode ocasionar saltos nas variações percentuais de um ano para outro, ou seja, seu crescimento ainda não segue um padrão sustentável, o que deve se regularizar em torno do ano de 2025, seguindo a tendência mundial de crescimento de aproximadamente $30 \%$ a cada ano. Como cenário para 2025, a potência total dos SFVCR no Brasil será de aproximadamente $75,6 \mathrm{GWp}$ o que representará 98,3 TWh de energia elétrica produzida por esta fonte, considerando a demanda de energia elétrica estimada para 2025 de 800 TWh, resultará na contribuição de $12,3 \%$ da energia por fonte solar fotovoltaica.

PALAVRAS-CHAVE: Energia Solar Fotovoltaica, Cenário Energético, Capacidade Instalada.

\section{CURRENT PANORAMA AND 2025 SCENARIO OF PHOTOVOLTAIC SOLAR ENERGY IN BRAZIL}

ABSTRACT: The photovoltaic solar energy in Brazil was boosted by Normative Resolution No. 482/2012 of ANEEL, which regulated the micro and mini generation systems in the compensation system, and by the specific 
auctions for photovoltaic plants carried out by the federal government. However, the country still has little representation of the solar energy in its electrical matrix, about $0.13 \%$, with approximately $1 \%$ of the installed capacity of electricity generators considering all the sources, both values refer to the year 2017. In the initial moments of a technology, its growth occurs irregularly and because there is little installed capacity, any added value can cause jumps in the percentage variations from one year to another, that is, its growth still does not follow a sustainable standard, which should be regularized around the year 2025, following the worldwide trend of growth of approximately $30 \%$ each year. As a scenario for 2025 , the total power of the SFVCR in Brazil will be approximately 75.6 GWp which will represent 98.3 TWh of electric energy produced by this source, considering the estimated electric energy demand for 2025 of $800 \mathrm{TWh}$, will result in the contribution of $12.3 \%$ of the energy by solar photovoltaic source.

KEYWORDS: Photovoltaic Solar Energy, Energy Scenario, Installed Capacity.

\section{I INTRODUÇÃO}

A partir de 2012, com a Resolução Normativa n 482/2012 da Agência Nacional de Energia Elétrica (ANEEL), a energia solar fotovoltaica passou a figurar como uma importante opção de produção de energia elétrica de forma limpa e sustentável. Especialmente, os Sistemas Fotovoltaicos Conectados à Rede Elétrica (SFVCR) possuem total aproveitamento da energia gerada por não necessitar de equipamentos armazenadores de energia, tais como as baterias. Os SFVCR utilizam a concessionária como fornecedora em horários sem produção e como armazenadora em horários de alta produtividade (TONIN,2017; SCOLARI e URBANETZ, 2018).

O crescimento da utilização dos SFVCR no Brasil se deu de forma tímida nos primeiros anos, seguido de um crescimento expressivo nos anos seguintes. Este crescimento foi de tal intensidade que superou as expectativas feitas em relação a geração distribuída pela ANEEL em sua Nota Técnica nº056/2017-SRD. O valor real da potência instalada até o dia 31/07/2018, data de corte definida para análise do artigo, foi superior à prevista para o ano inteiro (ANEEL, 2017a, b, c). É importante salientar que no ano de 2017, ano da publicação da Nota Técnica, também foi ultrapassado o valor de potência instalada previsto para micro e mini geração fotovoltaica amparados pela Resolução Normativa n 482/2012 da ANEEL.

Devido às inconsistências dos estudos anteriormente citados, torna-se necessário e importante a realização de uma nova análise do estado atual e do crescimento desta fonte de energia que se encontra em constante expansão.

\section{I OBJETIVO}

O presente artigo tem a finalidade de apresentar a capacidade instalada atual dos Sistemas Fotovoltaicos Conectados à Rede Elétrica (SFVCR) no Brasil. O estudo 
apresentado engloba tanto a mini e micro geração, amparadas pela Resolução Normativa $n^{\circ} 482 / 2012$, quanto a geração centralizada.

A fim de caracterizar o cenário atual brasileiro são demonstrados os dados de energia produzida anualmente, quanto esta energia representa percentualmente na matriz energética brasileira e a proporção desta fonte frente as demais fontes geradoras de energia elétrica no país.

Posteriormente, através de uma análise crítica e cuidadosa dos dados atuais e das previsões, é apresentado um possível cenário com as estimativas para os anos seguintes até o ano de 2025.

\section{I MÉTODO}

Para o desenvolvimento desta pesquisa serão utilizados dados dos SFVCRs disponibilizados pela ANEEL no Banco de Informações de Geração (BIG) e nos relatórios sobre as Unidades Consumidoras com Geração Distribuída cadastradas como micro ou mini geração, além de relatórios da Empresa de Pesquisa Energética (EPE) que apresentam cenários de consumo de energia elétrica no Brasil para os próximos anos.

Com base nestas informações são apresentados gráficos com os dados compilados, expondo o cenário atual da energia solar fotovoltaica no Brasil, de maneira a entender como ocorre o desenvolvimento desta tecnologia no país.

Na formação do cenário futuro é considerado uma previsão de potência instalada com base no crescimento atual. Posteriormente, para uma expectativa de produção de energia condizente com a potência esperada, sabendo-se que o YIELD anual no território brasileiro varia de $1.100 \mathrm{kWh} / \mathrm{kWp}$ a $1.800 \mathrm{kWh} / \mathrm{kWp}$ (PEREIRA et al, 2017), foi atribuído um YIELD anual de $1.300 \mathrm{kWh} / \mathrm{kWp}$ a fim de obter um valor estimado de energia que será produzido em cada ano analisado. Estes valores, juntamente com as previsões totais de carga no Brasil nos estudos da EPE, resultarão nos percentuais da participação da energia produzida por esta fonte na demanda anual do país.

\section{I RESULTADOS E DISCUSSÕES}

Para início desta análise torna-se imporante perceber que o aumento da quantidade de SFVCRs no país não ocorreu espontaneamente. Este foi impulsionado pela Resolução Normativa $n^{\circ} 482 / 2012$ da ANEEL que regulamentou o sistema de compensação de energia, similar ao net metering. Aliado a este fato, o aumento massivo de estudo e informação neste tema contribuiu para a criação de incentivos governamentais e o desenvolvimento científico acerca de temas relacionados, como geração de energia limpa e sustentável. Estes progressos são extremamente relevantes para toda a sociedade brasileira.

A capacidade instalada de SFVCRs de mini e micro geração tem triplicado, como 
é mostrado no gráfico da Figura 1, levando-se em consideração a potência instalada desde 2012, ano em que surgiu a possiblidade de geração distribuída. Apesar da geração distribuída englobar outras fontes energéticas além da fotovoltaica, esta última é a que possui maior influência no montante de geração distribuída devido a sua baixa manutenção de operação e relativa facilidade de instalação.

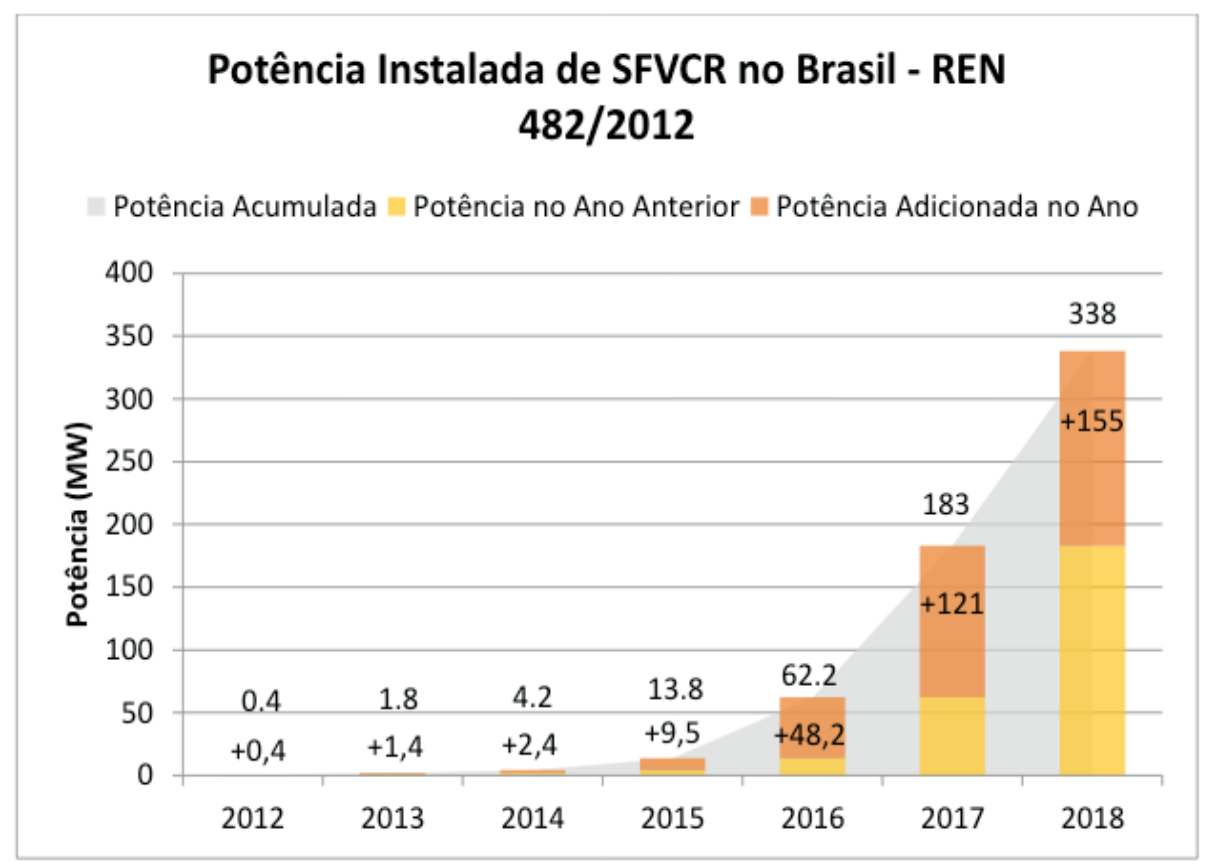

Figura 1 - Evolução da potência instalada de micro e mini geração fotovoltaica no Brasil. Fonte: Dados compilados pelos autores com base em (ANEEL, 2017b).

Por sua vez, nas usinas de geração centralizada o aumento da potência instalada é mais irregular, dado que está vinculado a existência dos leilões de energia por parte do governo federal. Ocorreu um grande aumento destas usinas no ano de 2017, resultando em um impacto na potência total superior ao da geração distribuída. Esta mudança abrupta no ano de 2017 está explicitada no gráfico da Figura 2. 


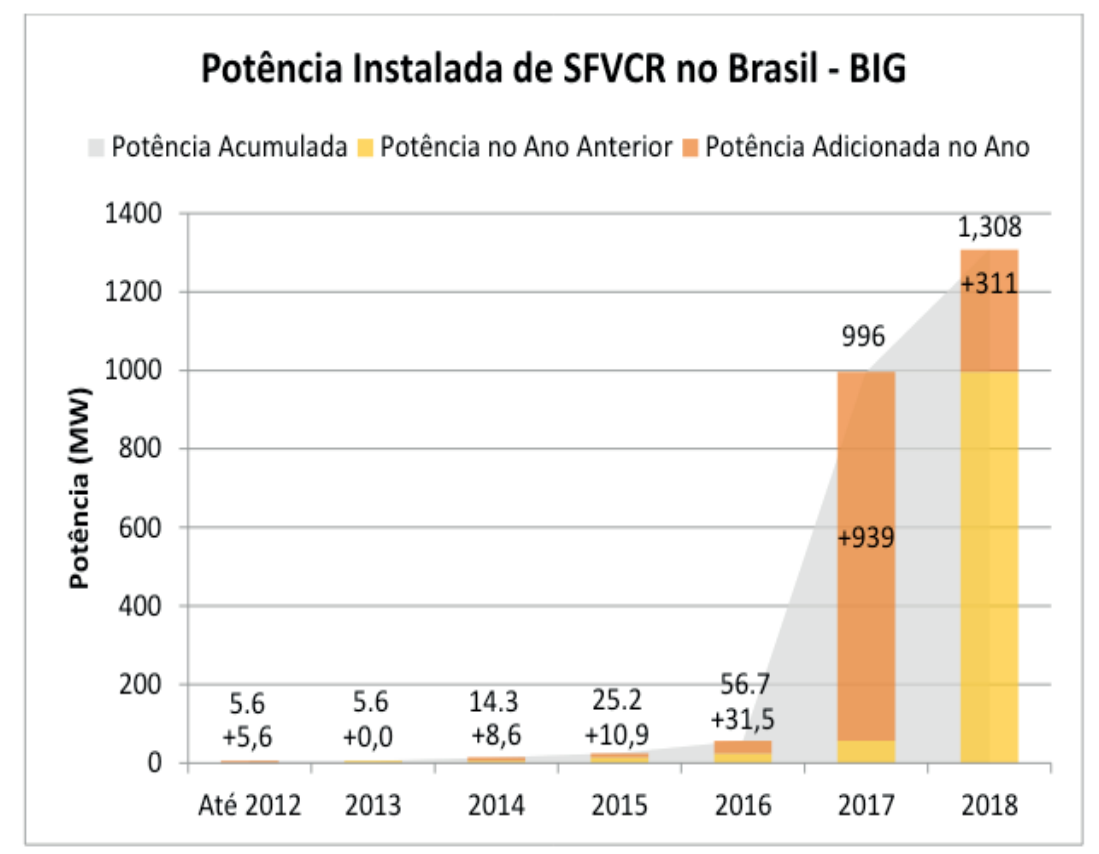

Figura 2 - Evolução da potência instalada na geração fotovoltaica centralizada no Brasil. Fonte: Dados compilados pelos autores com base em (ANEEL, 2017c).

Com a junção destes dois gráficos pode-se obter a situação atual desta fonte de energia, observada no gráfico da Figura 3. O valor da capacidade adicionada de SFVCRs apresentado para o ano de 2018 refere-se até a data de 31/07/2018, resultando em uma potência instalada total no Brasil, até esta data, de 1,65 GWp.

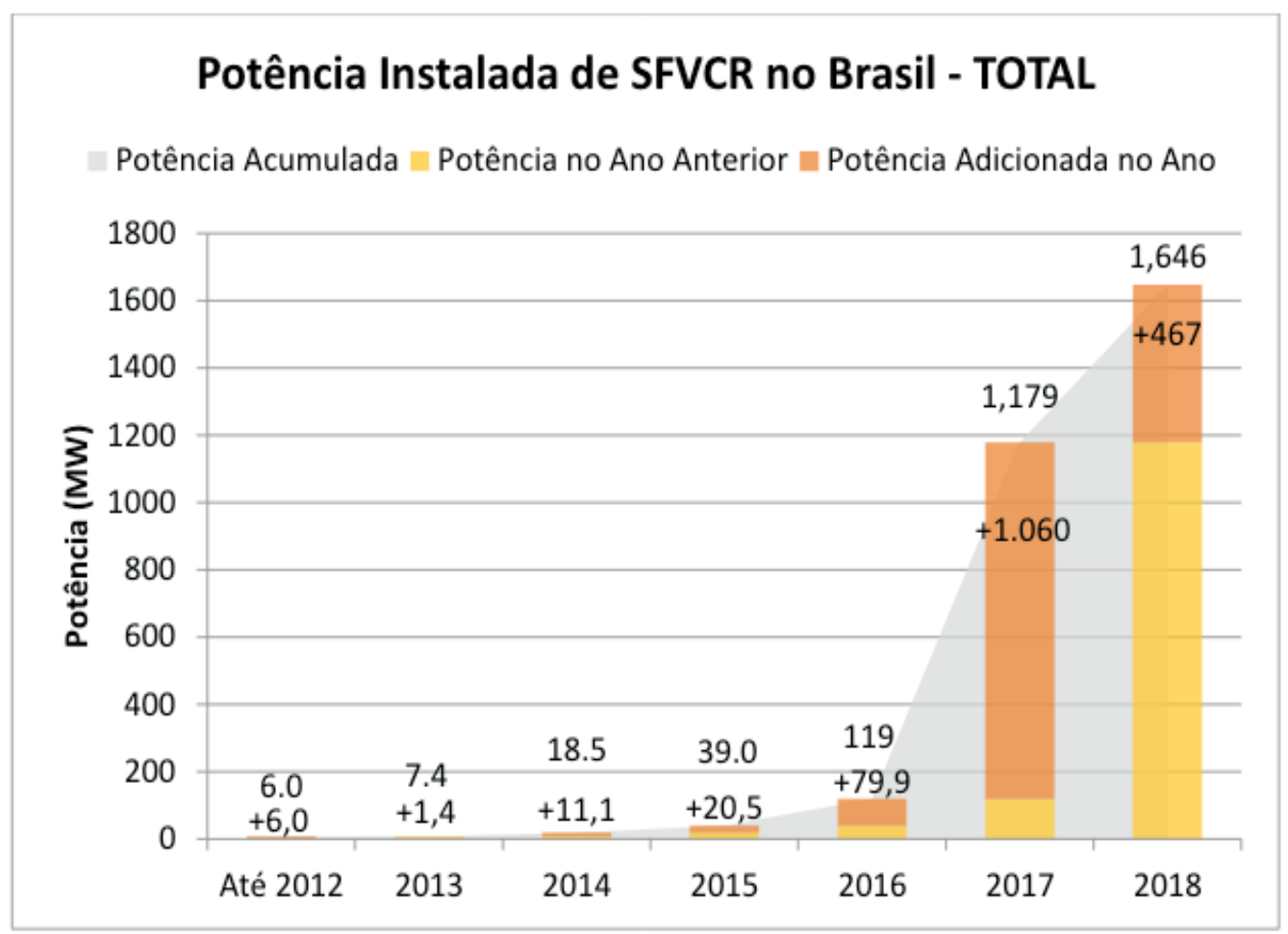

Figura 3 - Evolução da potência instalada fotovoltaica no Brasil. Fonte: Dados compilados pelos autores com base em (ANEEL, 2017b, c).

Segundo ANEEL, (2017b), a potência total instalada no Brasil, englobando todas as fontes geradoras de energia elétrica, é de 159,97 GW. Considerando a potência 
instalada de SFVCRs, esta resulta em aproximadamente $1 \%$ em relação à potência instalada de fontes geradoras de energia elétrica conectadas ao Sistema Interligado Nacional (SIN).

Um conceito importante a ser definido neste momento do estudo é a diferenciação de percentual de potência instalada e percentual de energia fornecida para a matriz elétrica. Em 2017, a quantidade ofertada de energia elétrica no SIN foi de 624,3 TWh. Deste valor, $832 \mathrm{GWh}$ foi gerado pelos sistemas fotovoltaicos, o que representou aproximadamente $0,13 \%$ do total (MME, 2018).

O ano de 2018, apesar de estar ainda em curso, também apresenta um aumento considerável no valor da potência fotovoltaica adicionada.

A Figura 4 apresenta a participação percentual da energia elétrica disponibilizada no Brasil no ano de 2017 por tipo de fonte.

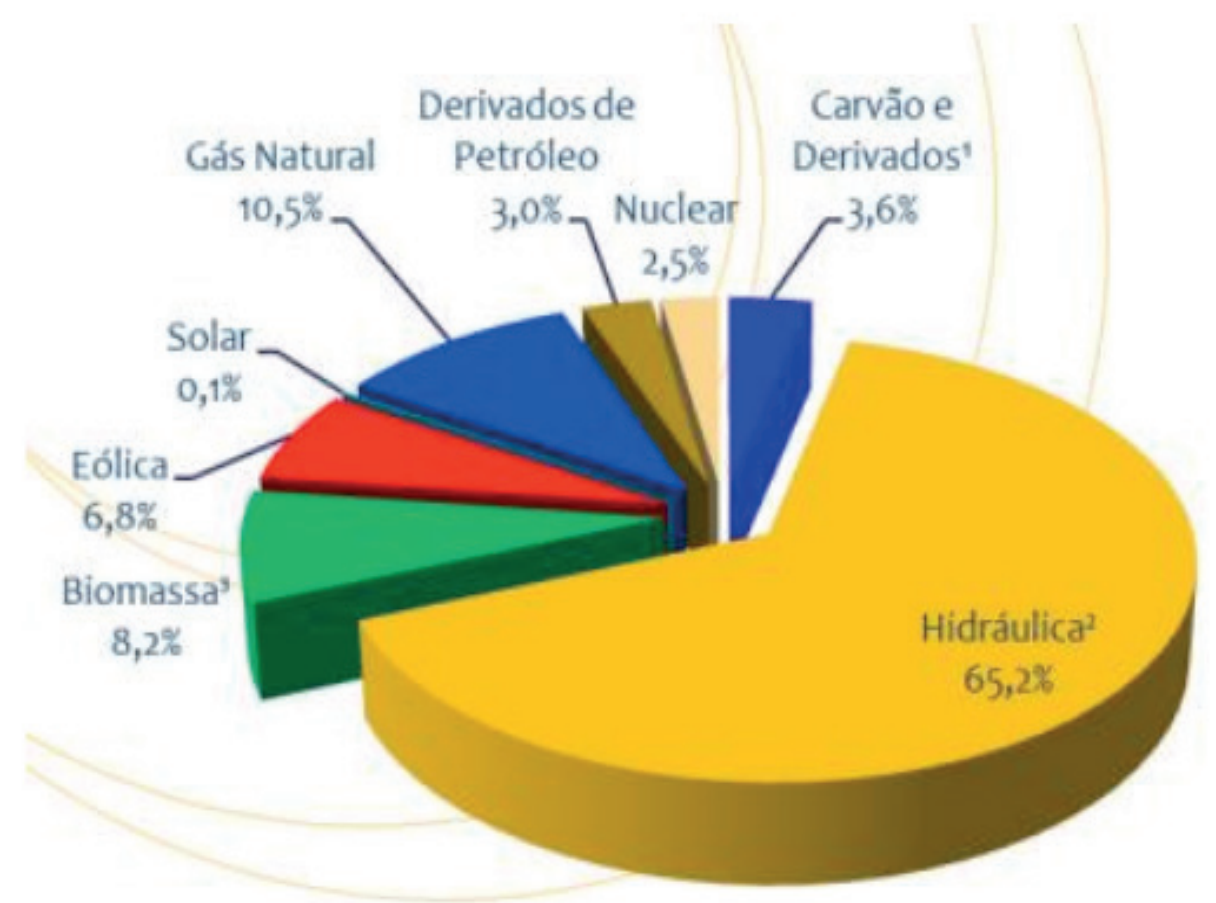

Figura 4 - Distribuição percentual da energia elétrica no Brasil por tipo de fonte. Fonte: (MME, 2018).

Como observado na Figura 4, o percentual de utilização da energia solar fotovoltaica ainda é pouco significativo na matriz elétrica brasileira em relação à outras fontes, tais como hidráulica e térmica. Com isto, a energia solar fotovoltaica possui grande potencial de crescimento no país.

A partir da data de 31/07/2018 os valores ilustrados correspondem a um possível cenário para a energia solar fotovoltaica no Brasil.

O aumento da energia solar fotovoltaica no Brasil, como se pode observar nos gráficos das Figuras 1, 2 e 3, que relatam o cenário atual, ainda não segue um padrão fixo ou um crescimento sustentável. Observa-se grandes variações nos percentuais de crescimento ao longo dos anos, tanto nos sistemas de geração distribuída como nas 
usinas. Este fato é mais visível na geração centralizada, pois quando são construídas usinas de grande porte, como de 2016 para 2017, a quantidade adicionada de potência tem um grande salto em relação ao ano anterior.

Essa característica de crescimento irregular, aparentemente imprevisíveis da energia solar fotovoltaica no Brasil pode ser explicada devido a esta tecnologia ter sido recentemente regulamentada. Nos momentos iniciais, qualquer valor adicionado de potência causa grande variação no valor total. Por isso, ocorrem os saltos observados nos gráficos, que correspondem a variações percentuais acentuadas de um ano para outro.

Porém, em âmbito mundial, a tecnologia já segue estabelecida e com crescimento estável. O percentual adicionado da potência instalada anualmente segue em torno de $30 \%$ em relação ao valor anterior (REN21, 2018). A tendência é que ao longo dos anos os países nos quais a tecnologia ainda está iniciando atinjam esse percentual de crescimento sustentável.

Particularmente, no Brasil, o percentual de crescimento ainda é bem elevado por ter baixa potência instalada em seu território. Porém, a medida em que a energia solar fotovoltaica no Brasil vai ganhando representatividade frente ao parque energético, seu crescimento passará a se estabilizar, seguindo a tendência mundial. Desta forma, é esperado que o percentual diminua gradativamente para os anos seguintes, até chegar em 2025. No gráfico da Figura 5 é mostrado o valor estimado de potência instalada no Brasil até 2025 e o quanto seria adicionado anualmente.

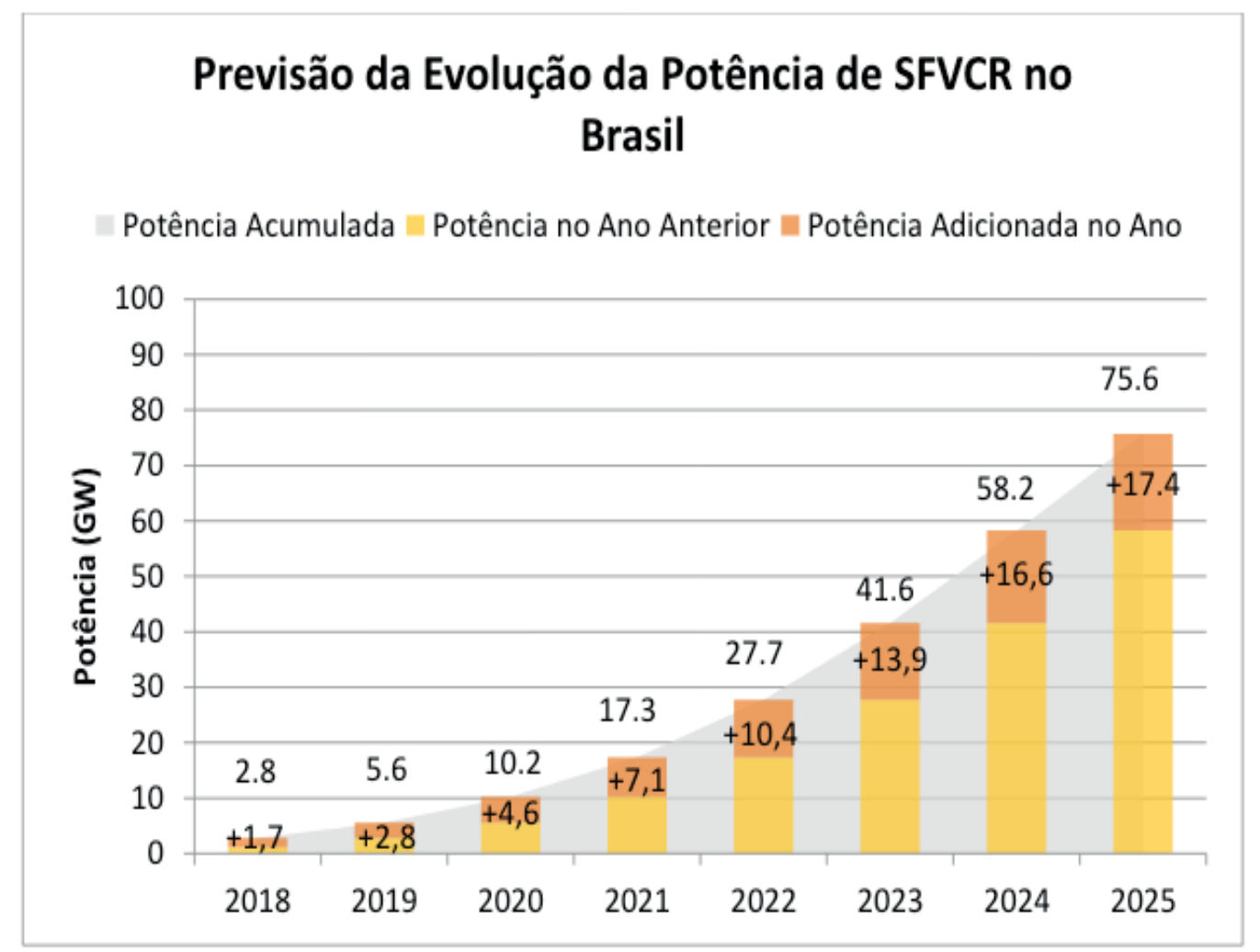

Figura 5 - Cenário de previsão da evolução do total de SFVCR no Brasil no horizonte 2025. Fonte: Autoria própria. 
No gráfico da Figura 5 é projetada uma potência instalada no Brasil para os SFVCRs de 75,6 GWp em 2025. Com isso, utilizando-se um YIELD médio de 1.300 kWh/kWp.ano atribuído neste estudo, obtém-se o valor de energia a ser produzida naquele ano, resultando em 98,3 TWh de energia elétrica.

Segundo TIEPOLO et al, (2017), a estimativa da energia elétrica que será demandada pelo país em 2025 será em torno de 800 TWh. Se deste montante de energia, 98,3 TWh for produzida pela energia solar fotovoltaica, isso representará 12,3\% do total de energia elétrica demandada no país naquele ano, uma parcela expressiva, porém factível de ser atingida. Entretanto, com o aumento expressivo de demanda, a produção de energia também deve aumentar na mesma proporção. Devido ao seu grande potencial de crescimento, a energia solar fotovoltaica deve ser considerada como uma opção extremamente viável de fornecimento de energia elétrica.

\section{I CONSIDERAÇÕES FINAIS}

Através do desenvolvimento deste trabalho foi possível caracterizar o panorama atual e criar um cenário com a previsão até o ano de 2025 dos SFVCRs no Brasil.

Atualmente, nota-se que a capacidade instalada de SFVCRs de mini e micro geração tem aumentado de maneira regular, enquanto que nas usinas de geração centralizada o aumento da potência instalada é mais descontínuo. Portanto, o crescimento da energia solar fotovoltaica no Brasil, representado pela soma das capacidades de SFVCRs de mini e micro geração e usinas de geração centralizada, ainda não segue um padrão fixo ou um crescimento sustentável. Esse cenário é justificado por tratar-se de uma tecnologia nova e recentemente regulamentada.

Outro aspecto relevante deste estudo, foi identificar que as previsões de crescimento dos SFVCRs no Brasil divulgadas pelos órgãos oficiais brasileiros foram superadas, principalmente nos anos de 2016 e 2017, ano em que não só atingiu a marca de $1 \mathrm{GWp}$ de capacidade instalada, como também neste mesmo ano foi adicionado mais de $1 \mathrm{GWp}$ como observa-se no gráfico da Figura 3.

No que diz respeito à previsão do crescimento de SFVCR no Brasil, espera-se que com o amadurecimento dessa tecnologia o crescimento da potência instalada torne-se relativamente estável. Apesar da pouca expressividade da energia solar fotovoltaica na matriz elétrica brasileira atual, essa fonte possui grande potencial de crescimento no país. A previsão realizada indica que a energia proveniente dessa fonte poderá alcançar em torno de 12,3\% da energia elétrica total demandada em 2025 no Brasil.

\section{REFERÊNCIAS}

Agência Nacional de Energia Elétrica (ANEEL), 2017a. Nota Técnica $n^{\circ}$ 0056/2017-SRD/ANEEL Atualização das Projeções de Consumidores Residenciais e Comerciais com microgeração solar fotovoltaicos no horizonte 2017- 2024, Brasília. Disponível em: < http://www.aneel.gov.br/ documents/656827/15234696/Nota+T\%C3\%A9cnica_0056_PROJE\%C3\%87\%C3\%95ES+GD+2017/3 8cad9ae-71f6-8788-0429-d097409a0ba9>. Acesso em: 05/08/2018. 
Agência Nacional de Energia Elétrica (ANEEL), 2017b. Outorgas e Registros de Geração:

Unidades Consumidoras com Geração Distribuída. Disponível em: < http://www2.aneel.gov.br/scg/ gd/gd.asp >. Acesso em: 10/08/2018.

Agência Nacional de Energia Elétrica (ANEEL), 2017c. Banco de Informações de Geração (BIG). Disponível em :< http://www2.aneel.gov.br/aplicacoes/capacidadebrasil/capacidadebrasil.cfm >. Acesso em: 10/08/2018.

MME, Ministério de Minas e Energia. Balanço Energético Nacional 2018: Relatório Síntese: Ano Base 2017. Disponível em < http://www.epe.gov.br/sites-pt/publicacoes-dados-abertos/publicacoes/ PublicacoesArquivos/publicacao-303/topico-397/Relat\%C3\%B3rio\%20S\%C3\%ADntese\%202018ab\%202017vff.pdf > Acesso em: 12/08/2018.

PEREIRA, E. B., MARTINS, F. R., GONÇALVES, A. R., COSTA, R. S., LIMA, F. J. L., RUTHER, R., ABREU, S. L., TIEPOLO, G. M., PEREIRA, S. V., SOUZA, J. G. Atlas Brasileiro de Energia Solar. São José dos Campos, 2017.

REN21, Renewables 2018 - Global Status Report. Disponível em < http://www.ren21.net/wp-content/ uploads/2018/06/17-8652_GSR2018_FullReport_web_final_.pdf> Acesso em: 06/08/2018.

SCOLARI, B.; URBANETZ JR, J. Panorama dos Sistemas Fotovoltaicos Conectados à Rede Elétrica amparados pela REN $\mathbf{n}^{\circ} \mathbf{4 8 2 / 2 0 1 2}$ da ANEEL no Brasil. VII Congresso Brasileiro de Energia Solar - VII CBENS, Gramado, 2018.

TIEPOLO, G. M., PEREIRA, E. B., URBANETZ JR. J., PEREIRA, S. V., GONÇALVES, A. R., LIMA, F. J. L., COSTA, R. S., ALVES, A. R. Atlas de Energia Solar do Estado do Paraná. Curitiba, 2017.

TONIN, F. S. Caracterização de Sistemas Fotovoltaicos Conectados à Rede Elétrica na Cidade de Curitiba. Dissertação (Mestrado em Engenharia Elétrica) Programa de Pós-Graduação em Sistemas de Energia, Universidade Tecnológica Federal do Paraná (UTFPR), Curitiba, 2017. 


\section{GESTÃO EFICIENTE DAS ANUIDADES REGULATÓRIAS NA CEMIG DISTRIBUIÇÃO}

Data de aceite: 03/01/2020

\section{Rosane de Pinho Matos} CEMIG Distribuição S.A.

Belo Horizonte - MG

Viviane Fernanda de Aguiar Pereira

CEMIG Distribuição S.A.

Belo Horizonte - MG

RESUMO: Este documento apresenta o modelo adotado pela CEMIG Distribuição para a gestão das Anuidades Regulatórias que foi implantado no $3^{\circ}$ CRTP (Ciclo de Revisão Tarifária Periódica), tendo sido aperfeiçoado para o 4 - CRTP e replicado, inclusive, para a CEMIG Geração e Transmissão. Essa prática vem permitindo que os resultados da Companhia sejam potencializados e, ao mesmo tempo, os gastos em bens e instalações vinculados às anuidades estejam adequados à cobertura financeira definida pelo regulador.

PALAVRAS-CHAVE: AIS, BRR, BAR, CAIMI, Anuidades

ABSTRACT: This document presents the model adopted by CEMIG Distribution for the management of Regulatory Annuities that was implemented in the 3rd CRTP (Periodic Tariff Review Cycle), having been improved for the 4th CRTP and even replicated for CEMIG Generation and Transmission. This practice has allowed the Company's results to be boosted and, at the same time, the expenses on goods and facilities linked to the annuities are adjusted to the financial coverage defined by the regulator. KEYWORDS: AIS, BRR, BAR, CAIMI, Annuities

\section{I INTRODUÇÃO}

A Agência Nacional de Energia Elétrica - ANEEL, denomina como Ativo Imobilizado em Serviço - AIS o conjunto de todos os bens, instalaçõesedireitosque, diretaouindiretamente, concorram, exclusiva e permanentemente, para a manutenção das atividades da concessionária de serviço público de energia elétrica. Esses ativos são remunerados mediante a Base de Remuneração Regulatória - BRR.

Para a definição da BRR, são excluídos aqueles bens e instalações não reversíveis ao término da concessão, que são: softwares, hardwares, terrenos administrativos, edificações, obras civis, benfeitorias administrativas, máquinas e equipamentos administrativos, veículos, móveis e utensílios. Esses ativos não elétricos constituem a Base de Anuidade Regulatória - BAR. A remuneração referente à BAR é dada em forma de anuidades e cabe a cada Distribuidora decidir como aplicar 
esse recurso. Por isso, a importância da construção de um plano de negócios que considere as opções econômico-financeiras mais vantajosas para a empresa e, assim, definir a combinação adequada entre a compra e a locação desses bens.

Este trabalho apresentará a lógica regulatória para a definição das anuidades e a metodologia de gestão desse recurso na CEMIG Distribuição, com foco nos investimentos, demonstrando as oportunidades de otimização verificadas e as ações implementadas a partir do $3^{\circ}$ CRTP (Ciclo de Revisão Tarifária Periódica) que vêm possibilitando a gestão eficiente das anuidades.

\section{I DESENVOLVIMENTO}

\subsection{Cobertura Regulatória ANEEL}

A cobertura regulatória para as anuidades é definida pela ANEEL durante o processo de revisão tarifária. Para que se tenha uma dimensão dos montantes da CEMIG Distribuição, segue a Estrutura Tarifária aprovada para o $4^{\circ} \mathrm{CRTP}$ (Ciclo de Revisão Tarifária Periódica), 2018-2022, publicado na Nota Técnica ANEEL 122/2018:

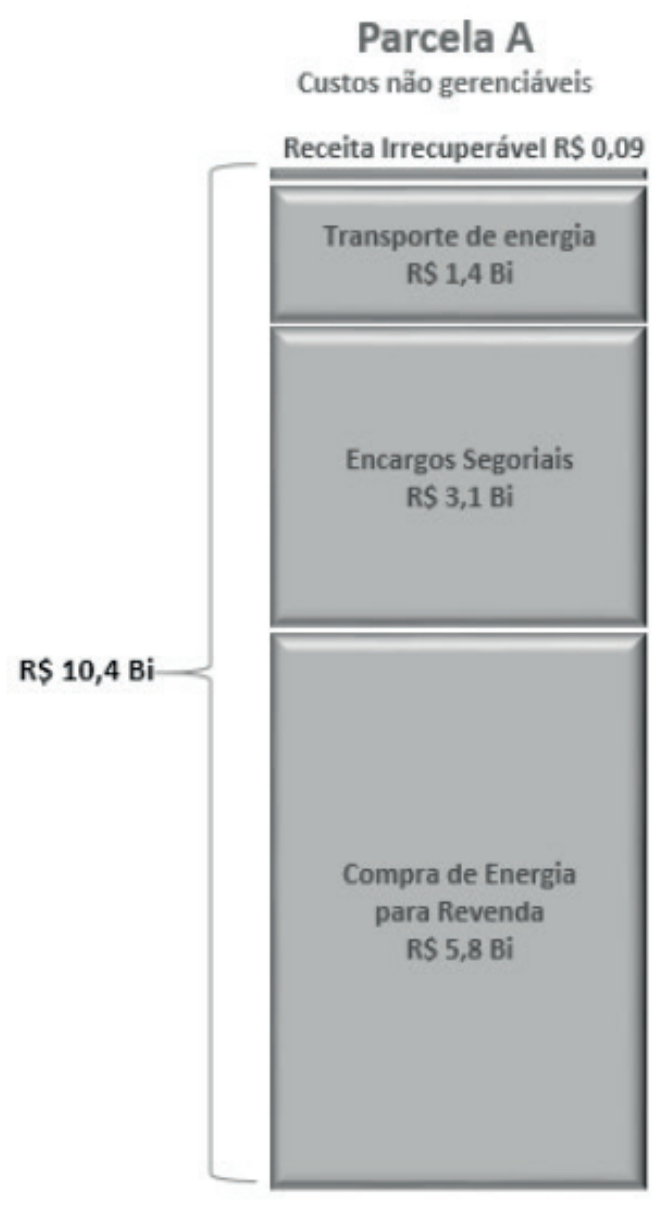

\section{Parcela B}

Custos gerenciáveis

\section{A - Parcela A}

O valor da Parcela A é calculado, considerando-se o mercado de referência e as condições vigentes na data da revisão tarifária periódica e compreende os custos com 
aquisição de energia elétrica, os custos com conexão e uso dos sistemas de distribuição e/ou transmissão, os custos com encargos setoriais e as receitas irrecuperáveis.

\section{B - Parcela B}

A Parcela B compreende as despesas com a prestação do serviço de distribuição de energia. São custos inerentes da atividade de distribuição, que estão sujeitos ao controle e influência das práticas gerenciais adotadas pela concessionária e, por definição, são repassadas por meio de valores regulatórios. São dois os itens que compõem a Parcela B:

- custos operacionais: custos necessários para a empresa prover os serviços de distribuição de energia; e

- custo de capital: inclui o montante investido pela concessionária ainda não depreciado, chamado base de remuneração que, multiplicada pela taxa de retorno, irá determinar o total da remuneração de capital investido. Também é incluída a quota de reintegração regulatória, que representa a recomposição dos investimentos realizados para a prestação do serviço de distribuição ao longo da vida útil dos bens e direitos.

VPB - Valor da Parcela B

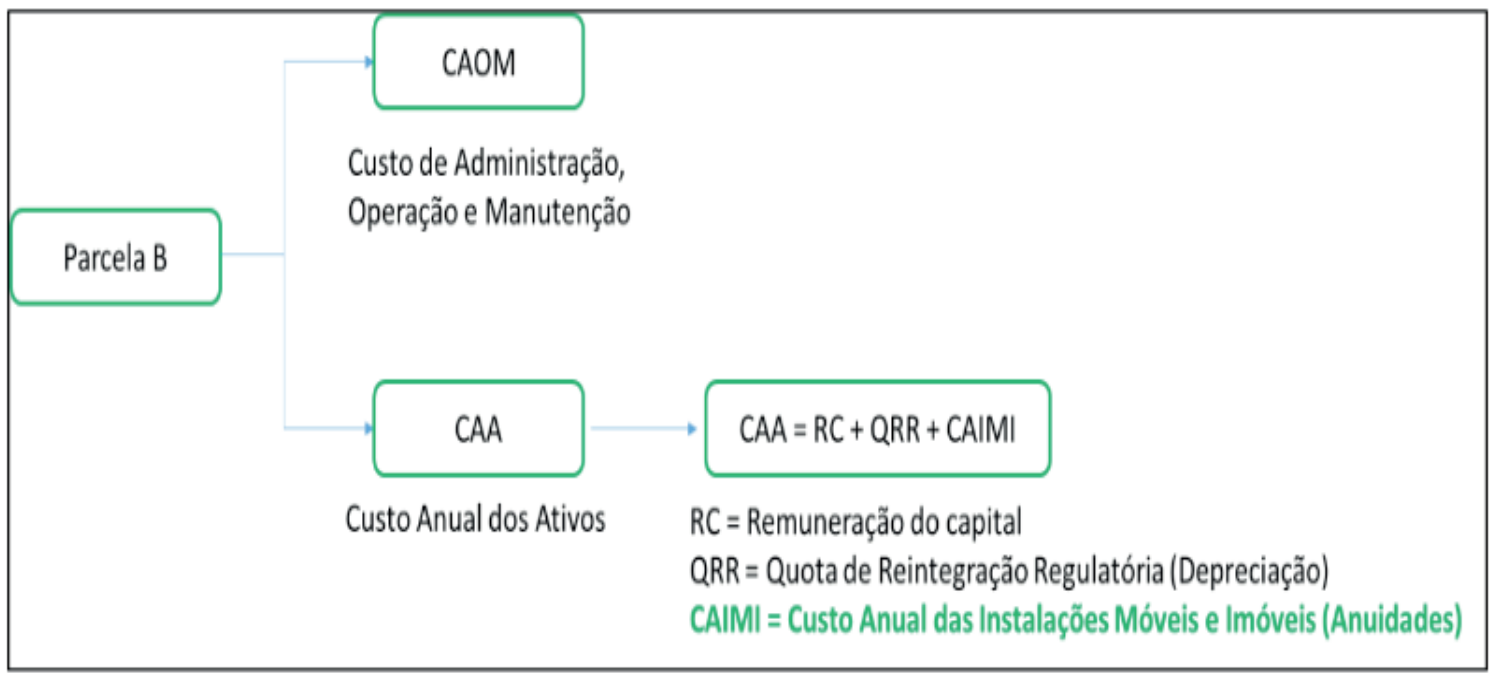

O custo anual dos ativos (CAA) é dado pela soma dos componentes abaixo:

$$
\mathrm{CAA}=\mathrm{RC}+\mathrm{QRR}+\mathrm{CAIMI}
$$

$$
\mathrm{CAA}=\mathrm{RC}+\mathrm{QRR}+\mathrm{CAIMI}
$$

Onde:

CAA: Custo Anual dos Ativos

RC: Remuneração do capital

QRR: Quota de Reintegração Regulatória (depreciação); e

CAIMI: Custo Anual das Instalações Móveis e Imóveis (Anuidades). 
O Custo Anual das Instalações Móveis e Imóveis (CAIMI), também denominado Anuidades, refere-se aos investimentos de curto período de recuperação, tais como os realizados em hardware, software, veículos, e em toda a infraestrutura de edifícios de uso administrativo. Este custo é calculado a partir da Base de Anuidade Regulatória que é determinada por uma proporção do AIS.

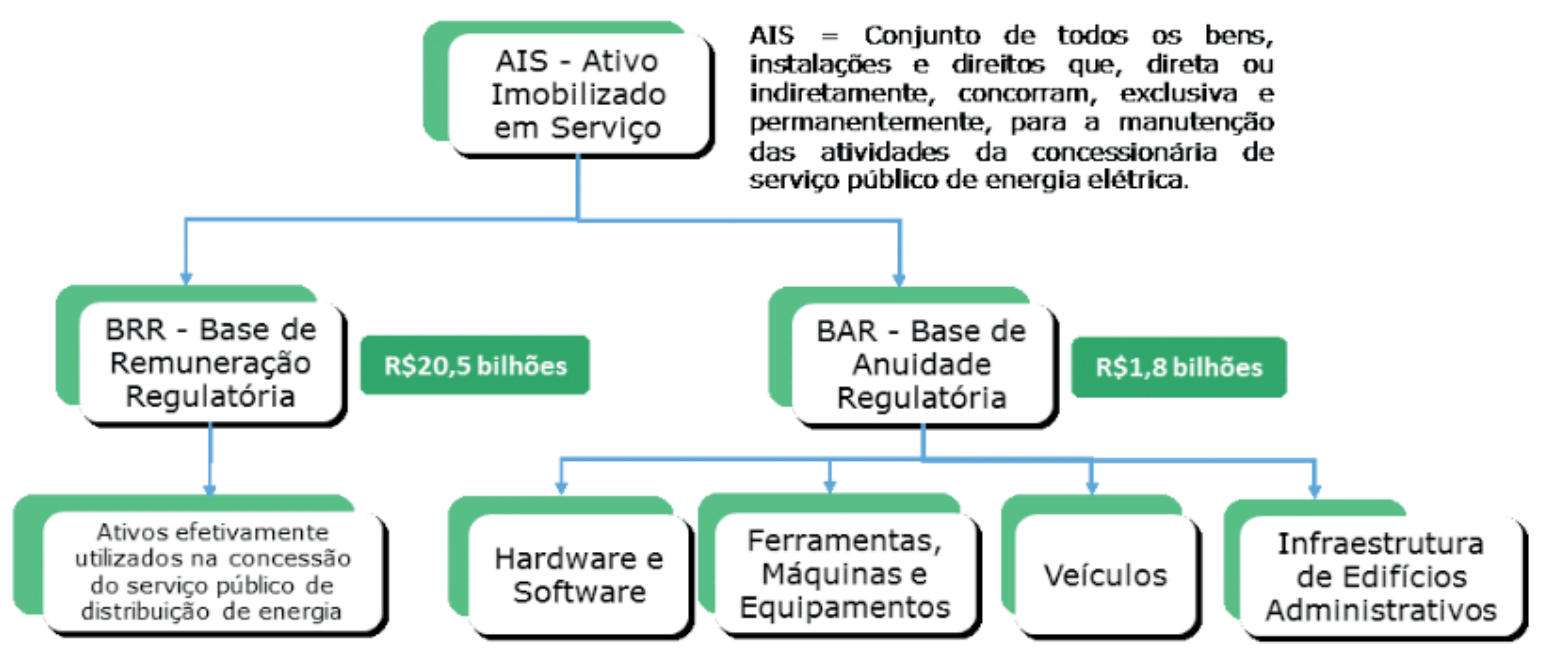

Uma vez definida a base de anuidade regulatória, para o cálculo da anuidade, é necessário segregar em 3 grupos de ativos, conforme a tabela seguir:

\begin{tabular}{lr}
\hline Grupo de Ativos $\%$ da BAR \\
\hline Aluguéis (CAL) & $45 \%$ \\
Veículos (CAV) & $12 \%$ \\
Sistemas (CAI) & $43 \%$ \\
\hline
\end{tabular}

Uma vez segregadas, as Anuidades são dadas por:

CAIMI - CAL + CAV + CAI

Onde:

CAIMI: Custo Anual das Instalações Móveis e Imóveis

CAL : Custo Anual dos Aluguéis

CAV: Custo Anual de Veículos

CAI: Custo Anual de Sistemas de Informática

A tabela a seguir resume os valores relativos ao CAIMI: 
1.825 .877 .322

(2) Base de Anuidade - Infraestrutura de imóveis e móveis administrativos (BARA) $\quad 821.644 .795$

(3) Base de Anuidade - Veículos (BARV)

(4) Base de Anuidade - Sistemas de Informática (BARI)

219.105.279

(5) Anuidade - Infraestrutura de imóveis e móveis administrativos (CAL)

785.127 .248

(6) Anuidade - Veículos

Por se tratar de uma anuidade regulatória, definida a partir dos valores médios observados pelos agentes de distribuição, não há interferência da ANEEL quanto a sua aplicação, ficando a critério da concessionária optar pela aquisição (investimentos em anuidades) ou contratação de serviços/locação (despesas de anuidades), escolhendo a opção mais vantajosa após análises econômico-financeiras, de tal forma a minimizar o custo global.

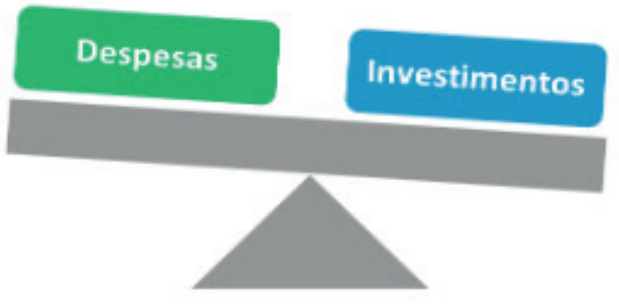

\subsection{Definição de limites para investimentos}

Baseada na cobertura com anuidades definida pela ANEEL, a CEMIG construiu um modelo de processo com o objetivo de definir uma carteira de investimento que fosse aderente aos tetos regulatórios.

1. Projeção das anuidades regulatórias para o ciclo (5 anos) considerando os limites definidos pela ANEEL.

2. Levantamento das despesas com anuidades já previstas ou compromissadas no orçamento de despesa operacional da Empresa.

3. Dedução do limite com anuidade regulatória da projeção das despesas com anuidade.

O processo de definição dos investimentos iniciou-se com a projeção das anuidades regulatórias para o ciclo (5 anos) considerando os limites definidos pelo órgão regulador.

Em seguida, foram levantadas as despesas com anuidades já previstas ou compromissadas no orçamento de despesa operacional da Empresa. Essas informações foram extraídas do orçamento aprovado, projetado para o quinquênio.

A CEMIG Distribuição possui um orçamento anual de despesas operacionais, 
intitulado OPEX (Operational Expenditures) Gerencial, que congrega todos os desembolsos em administração, em operação, em manutenção, em despesas com anuidades e em outras rubricas. Não há separação das despesas com anuidades das demais despesas, até mesmo porque não é tarefa simples destacar essa parcela do gasto das demais. A divisão entre despesas operacionais e despesas em anuidades deve ser analisada em cada contrato ou classe de custo, separadamente.

Exemplificando: uma mesma despesa pode ter uma parte classificada como custo operacional e outra como anuidades. No caso de veículos, se a empresa avaliar que a melhor opção econômica é alugar veículos, ao invés de comprar, esse contrato de locação terá uma parcela destinada à manutenção, ao pagamento de taxas e aos gastos administrativos, que são qualificados como despesa operacional. Já os custos propriamente ditos da locação são considerados despesas em anuidades. Como o aluguel de veículos é lançado em uma classe de custo única pelo plano de contas, será necessário um estudo para separar o que é despesa em anuidades dos demais custos operacionais.

Sendo assim, para obter o valor do orçamento para investir em ativos não elétricos, a CEMIG Distribuição deduz do limite com anuidade regulatória (CAIMI) a projeção das despesas em anuidade.

\subsection{Política de Investimentos em anuidades na CEMIG Distribuição}

Os investimentos em anuidades na CEMIG Distribuição são norteados por uma política interna da Companhia e são denominados investimentos em infraestrutura, ou seja, aqueles bens não diretamente ligados ao serviço público de distribuição de energia e que não são reversíveis ao final da concessão.

De acordo com essa norma, são classificados como investimentos em infraestrutura os desembolsos com instalações prediais, máquinas e equipamentos, móveis e utensílios, ferramentas, segurança patrimonial e industrial, tecnologia da informação (abrangendo telecomunicações corporativa e microinformática), sistemas de informática e veículos, e devem estar alinhados aos limites da cobertura regulatória.

As diretrizes para esses investimentos são:

- Aderência aos limites financeiros requeridos para adequação da CEMIG Distribuição ao Regulatório;

- Priorização de projetos que reduzam despesas operacionais recorrentes ou que agreguem valor para a Companhia;

- Priorização de sistemas críticos para o negócio Distribuição;

- Atendimento de demandas regulatórias, legais e ambientais;

- Manutenção dos ativos não elétricos em boas condições de uso, preservando a qualidade dos processos e rotinas da infraestrutura. 
Os investimentos em infraestrutura são categorizados em uma estrutura de macroprojetos, conforme a seguir:

Ferramentas: conjunto de investimentos destinados à execução de serviços de campo, abrangendo equipamentos para testes e comissionamentos em subestações e redes de distribuição, para manutenção em linhas e redes de distribuição, estações de comunicação, medidores específicos (fator de potência, termo visores etc.), ferramentas especiais, notebooks e dispositivos móveis de processos entre outros.

Edificações e Complementos: conjunto de investimentos destinados a instalações prediais, máquinas e equipamentos, móveis e Utensílios e segurança Patrimonial

Tais empreendimentos de Edificações e Complementos são destinados apenas a finalidades administrativas, incluindo adaptações em áreas administrativas provocadas por obras ambientais ou para fins de telecomunicações.

Telecomunicações - Ativo não elétrico: investimentos em telecomunicação corporativa não destinados aos ativos elétricos.

Microinformática: conjunto de investimentos relativos a aquisição/substituição de microcomputadores, dispositivos móveis (notebooks e outros) e softwares associados.

Sistemas de Informática: conjunto de investimentos relativos a aquisição/ implementação/substituição de sistemas centrais e corporativos para atender às necessidades de infraestrutura da Distribuidora.

Veículos: conjunto de investimentos e despesas de locação relativos à implementação / substituição das soluções de transporte da Distribuidora. Abrangemse veículos leves, médios e pesados e suas respectivas adaptações para atender à demanda de serviços (cestas aéreas, carrocerias e outros afins).

\subsection{Processo de priorização e aprovação de investimentos na Cemig Distribuição}

$\mathrm{Na}$ estrutura organizacional da CEMIG, a Superintendência de Serviços Corporativos - SC é responsável pela controle e gestão dos investimentos em infraestrutura, cabendo coordenar o processo de definição desse portfólio de investimentos.

No primeiro momento, as demandas de investimento foram levantadas pelos gestores dos principais processos envolvidos e o montante final demonstrou ser muito acima dos limites disponíveis para investimento. Diante disso, a CEMIG teve como grande desafio a priorização desses investimentos e a adequação ao limite estabelecido, priorizando os investimentos mais aderentes ao negócio da Distribuidora e às diretrizes da empresa.

Com o objetivo de se construir uma carteira ótima de investimentos, há uma agenda de planejamento: 


\subsubsection{Captação Orçamentária}

Na primeira etapa, a captação orçamentária, os diversos órgãos da Empresa revisam suas demandas iniciais para qualificação do projeto:

A finalidade, a justificativa e os riscos de não execução do empreendimento;

O cronograma de desembolsos e indicadores físicos para acompanhamento do projeto

O valor agregado como redução de despesas e/ou ganhos em produtividade e possíveis receitas auferidas e as possíveis receitas auferidas com a implantação do projeto, como alienação de materiais, terrenos, edificações;

As despesas com a implantação do empreendimento (recorrentes ou não recorrentes) e após a sua implementação, deverão estar refletidas no orçamento de despesas da Companhia.

\subsubsection{Seminário de Investimentos em Infraestrutura}

Após a consolidação do portfólio preliminar, é realizado o Seminário de Anuidades em Infraestrutura para a priorização dos empreendimentos. Esse evento reúne profissionais do corpo gerencial e representantes dos diversos órgãos relacionados ao tema (áreas de regulação, financeira, demandantes de projetos e prestadores de serviços de infraestrutura) e tem o patrocínio e o apoio da Diretoria Executiva. $O$ seminário é estruturado em mesas temáticas e a composição dos grupos considera os principais demandantes e responsáveis por assunto.

O objetivo principal desse evento é a priorização dos projetos adequando o portfólio à estratégia empresarial do negócio e ao limite de investimento para o ciclo. Além disso, o seminário permite explorar, de maneira eficaz, as restrições e oportunidades regulatórias, buscando o aprendizado contínuo e a excelência na gestão dos investimentos para contribuir com o enquadramento da CEMIG Distribuição à cobertura regulatória. Durante o evento, os participantes têm a oportunidade de aperfeiçoar seus conhecimentos em regulação e tarifa, com a Gerência de Regulação de Preços, Tarifas e Comercialização - RE/TF apresentando a metodologia da ANEEL para a definição da cobertura para as anuidades. 
No Seminário de Anuidades da Distribuição são deliberados os ajustes do planejamento para a definição da carteira de projetos priorizada que são iniciados nesse dia de trabalho e concluídos no período que sucede ao evento, como a consolidação do programa de investimento, a adequação nas curvas de desembolso e do planejamento físico e financeiro.

\subsubsection{Análise Financeira e Aprovação do Programa de Investimentos}

Após a definição da carteira ótima de investimentos em infraestrutura, inicia-se a fase de análise econômico financeira e aprovação do portfólio de investimento.

A CEMIG possui em sua estrutura organizacional, uma área responsável pela análise e acompanhamento de todos os projetos de investimento da Empresa, sejam em Distribuição, Geração ou Transmissão. A Superintendência de Planejamento e Controle Corporativo - PP tem como uma de suas principais atribuições analisar a viabilidade econômico financeira dos projetos, emitindo pareceres técnicos que são apresentados ao Comitê de Investimentos e Gestão - CIG.

O CIG é formado por superintendentes com domínio de funções relacionadas ao gerenciamento de investimentos/projetos ou detentores de conhecimento técnico, científico ou empresarial reconhecidamente capaz de agregar valor à gestão do portfólio de investimentos das empresas do grupo CEMIG. Esse Comitê tem como atribuição analisar os projetos de investimento para posterior apreciação e deliberação pela Diretoria Executiva e/ou Conselho de Administração.

A figura a seguir demonstra o fluxo de análise e aprovação dos investimentos:

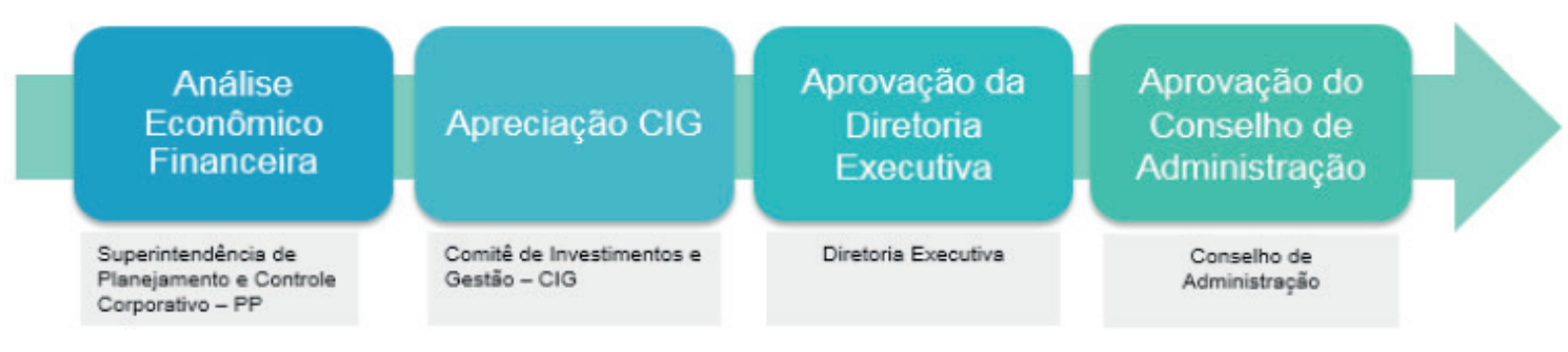

\subsection{Gestão do Programa de Investimentos em Infraestrutura}

Após a aprovação, a execução físico-financeira do Programa de Investimentos em Infraestrutura é acompanhada sistematicamente pela Superintendência de Serviços Corporativos - SC, que também realiza reuniões periódicas com os profissionais envolvidos para tratar da gestão dos projetos e equacionar possíveis entraves na execução desses empreendimentos contribuindo para o cumprimento do cronograma aprovado.

Além disso, nesses encontros é possível definir ações corretivas e de melhoria na gestão, adequar o portfólio dos projetos às diretrizes empresariais e demandas do 
negócio Distribuição (repriorização), bem como otimizar a aplicação dos recursos de anuidades.

\subsection{Resultados do ciclo 2013-2017}

O ciclo de investimentos em infraestrutura 2013-2017 trouxe um aprimoramento considerável no processo de priorização e definição da carteira de investimentos. Foi possível solucionar e realocar projetos em andamento que foram transferidos do ciclo anterior (2008/2012), manter os ativos não elétricos em boas condições de uso, executar importantes projetos estruturantes em sistemas de informática que atendem ao negócio, além de implementar os empreendimentos associados a riscos estratégicos, operacionais e de conformidade com impacto significativo na CEMIG Distribuição.

O ciclo 2013-2017 apresentou o melhor resultado na execução dos investimentos em anuidades já verificado na Companhia, tendo sido realizado $94 \%$ do total do programa de investimentos em infraestrutura para Distribuição no ciclo 2013-2017. O trabalho de planejamento, acompanhamento e otimização propiciou a economia da ordem de $13 \%$ do orçamento inicial aprovado para o quinquênio, contribuindo para a adequação da CEMIG Distribuição às coberturas regulatórias.

A metodologia adotada para definição da carteira foi tão bem-sucedida que foi utilizada para a priorização dos investimentos no ciclo atual (2018-2022) para definição dos Programa de Investimento em Infraestrutura da CEMIG Distribuição e CEMIG Geração e Transmissão. A realização do Seminário de Priorização de Investimentos, envolvendo todas as áreas de Negócio, propiciaram uma visão mais ampla dos investimentos e permitiram uma otimização dos recursos, com ganhos de escala e eliminação de sombreamentos entre projetos.

O modelo de definição dos limites para investimento utilizado na Distribuição foi replicado para a Transmissão, devido às semelhanças regulatórias dos dois negócios.

\section{I OPORTUNIDADES DE MELHORIA}

Alguns equipamentos adquiridos para o Negócio Transmissão são, em geral, equipamentos robustos que por suas características específicas poderiam ser reconhecidos na Base de Remuneração Regulatória ou em outra forma de cobertura.

\section{I CICLO 2018-2022}

As principais considerações em relação ao ciclo atual são:

- Possibilidade de migração de recursos entre as despesas compromissadas com anuidades e seus respectivos investimentos (em cada macroprojeto).

- Revisão do Programa de Investimento prevista para fevereiro de 2020, onde serão revisitados os valores de despesa e investimento de cada parcela do CAIMI (aluguéis, veículos e sistemas de informática). 
- Performance do Programa de Investimentos da CEMIG Distribuição = 73\%.

\section{I CONCLUSÕES}

Considerando os resultados obtidos no Programa de Investimentos em Infraestrutura da Distribuição, ciclo 2013-2017, pode-se afirmar que a metodologia desenvolvida pela CEMIG para priorização e adequação da carteira de investimentos ao limite regulatório por meio do seminário com mesas temáticas demonstrou ser um forte instrumento de sensibilização e alinhamento dos envolvidos.

A análise e priorização da carteira de investimentos através dos seminários multidisciplinares propiciou a evolução da visão por processo para a visão por Negócio, com priorização dos investimentos alinhados às estratégias da empresa.

O processo de análise e aprovação do Programa de Investimentos, desde o estudo de viabilidade econômico-financeira elaborado por uma área com atribuições específicas para analisar corporativamente todos os projetos de investimento da Empresa e pela análise de um comitê constituído por profissionais de alta performance, dão ao processo de análise e aprovação confiabilidade e resultados mais acurados, propiciando à Diretoria e Conselho de Administração uma clareza, confiança e conforto nos programas que são submetidos às suas apreciações.

E por fim, deve-se ressaltar que os esforços dispendidos nesse processo e os resultados alcançados indicam que a Distribuidora tende a ficar adequada ao limite regulatório no ciclo 2018-2022, incluindo as coberturas regulatórias de OPEX e Anuidades.

\section{REFERÊNCIAS}

ANEEL. AGÊNCIA NACIONAL DE ENERGIA ELÉTRICA. Legislação. Disponível em http://www.aneel. gov.br/, acessado em: 20 de março de 2018. 


\section{DESAFIOS DA REVISÃO PERIÓDICA DE AJUSTES DE GRANDES SISTEMAS -NORMAS, PROCEDIMENTOS E FERRAMENTAS}

Data de aceite: 03/01/2020

\section{Rodrigo A. Benes Ferreira SIEMENS}

Nasceu em Volta Redonda - RJ em 1982, gradouse em Engenharia Elétrica pela Universidade do Estado do Rio de Janeiro (UERJ - 01/2008) possui pós-graduação em Proteção de Sistemas

Elétricos pela Universidade Santa Cecília (UNISANTA - 12/2010) e atualmente trabalha na SIEMENS EM DG (Energy Management Digital Grid) em projetos de proteção e controle

de sistemas de energia de concessionárias e Indústrias. Possui experiência em comissionamento, projetos e estudos de Sistema

Elétricos.

\section{Mario Roberto Bastos} CTEEP

Nasceu em Franca - SP, graduou-se em Engenharia Elétrica pela Universidade Federal de Itajubá (UNIFEI-1985), possui MBA em Tecnologia da Informação (2002) e Mestrado em Engenharia Elétrica (2006), ambos pela Escola Politécnica da Universidade de São Paulo. Atualmente trabalha no Departamento de Estratégia e Inovação da Companhia de Transmissão de Energia Elétrica Paulista (CTEEP) e possui 31 anos de experiência na área de supervisão e controle. É Membro

IEEE/PES e CIGRE.

\section{Nilson José Francischetti Júnior} CTEEP

Nasceu em São Paulo - SP em 1972, graduou- se em Engenharia Elétrica pela Faculdade de Engenharia São Paulo (FESP-1998), possui pósgraduação em Administração para Engenheiros pela Escola de Administração e Negócios (ESAN2000) e Pós Graduação em Sistema de Proteção pela Universidade Federal do Rio de Janeiro (UFRJ-2004). Atualmente trabalha na Companhia

de Transmissão de Energia Elétrica Paulista (CTEEP) e possui 27 anos de experiência da área de estudos de proteção.

RESUMO: O artigo proposto tem o objetivo de discutir a realidade brasileira em relação aos processos para revisão dos ajustes empregados atualmente, as modificações propostas pela NERC PRC-027-1 para 0 mercado americano, e ferramentas disponíveis que possibilitam um gerenciamento das informações e automatização do processo de revisão de ajustes com o objetivo de diminuir o trabalho da equipe e evitar erros humanos. Será apresentado um estudo de caso utilizando o software SIGUARD PSA demonstrando a verificação automática da coordenação das proteções. O sistema elétrico e os relés de proteção são modelados no software PSS Sincal. Os resultados são apresentados de uma forma visual, possibilitando a identificação da região com problema e minimizando o trabalho do especialista que poderá focar seus esforços na revisão dos ajustes. 
PALAVRAS-CHAVE: Proteção de Sistemas Elétricos, Ajustes de proteção, NERC PRC-027-1, Siguard PSA, PSS Sincal.

\section{I INTRODUÇÃO}

Está em processo de aprovação regulatória, nos Estados Unidos, a revisão da norma PRC-027-1 (Coordination of Protection System Performance During Faults) editada pelo NERC (North American Electric Reliability Corporation's), autoridade internacional reguladora sem fins lucrativos que é responsável por assegurar a confiabilidade do sistema interligado norte americano, denominado BES (Bulk Electric System). Esta norma estabelece requisitos para coordenação de proteção e em sua revisão determina que os agentes de transmissão, geração e distribuição que fazem parte do BES devem desenvolver um processo para revisão periódica dos ajustes de proteção com o objetivo de garantir a confiabilidade do sistema, isolando corretamente a falta, reduzindo o risco de instabilidades e desligamentos em cascata, deixando o restante do sistema operacional e mais capaz de suportar a próxima contingência. Atualmente, os ajustes de proteção são revisados e atualizados devido a substituição do dispositivo de proteção, novas conexões do sistema, alterações em equipamentos primários, alterações de topologia, evolução do nível de curto-circuito, atuações indevidas, etc., porém, com uma abrangência limitada devido a limitação de tempo e disponibilidade das equipes de estudos elétricos e proteção.

A revisão da norma Americana traz à tona a revisão periódica dos ajustes como uma questão fundamental para a confiabilidade do sistema. Alguns trabalhos relacionados ao gerenciamento, revisão dos ajustes e avaliação da performance do sistema de proteção também vêm sendo abordado pelo Cigre, como por exemplo a brochura técnica B5.31 (Life-time Management of Relay Settings) e pelo grupo de trabalho, em atividade, B5-47 (Network Protection Performance Audits) demonstrando a atualidade e relevância do tema.

\section{I O SISTEMA ELÉTRICO AMERICANO}

Como o sistema elétrico americano apresenta diferenças em relação ao sistema elétrico brasieiro torna-se necessária uma breve decrição dos agentes responsáveis pela normatização, regulação e operação deste sistema.

\subsection{Normatização}

O NERC desenvolve e impõe padrões de confiabilidade, avalia anualmente a confiabilidade sazonal e de longo prazo, monitora o BES através da conscientização do sistema, assim como educa, treina, e certifica o pessoal da indústria. A área de responsabilidade do NERC abrange os Estados Unidos, o Canadá e a porção norte da Baja California, no México. O NERC é a organização de confiabilidade elétrica 
(ERO) para a América do Norte, sujeita à supervisão da Comissão Federal Reguladora de Energia (FERC-Federal Energy Regulatory Commission) e às autoridades governamentais no Canadá. A jurisdição do NERC inclui usuários, proprietários e operadores do BES, que atende a mais de 334 milhões de pessoas (1).

O BES Norte Americano é dividido em oito entidades regionais distribuídas conforme a Figura 1. A Tabela 1 descreve as siglas de cada entidade.

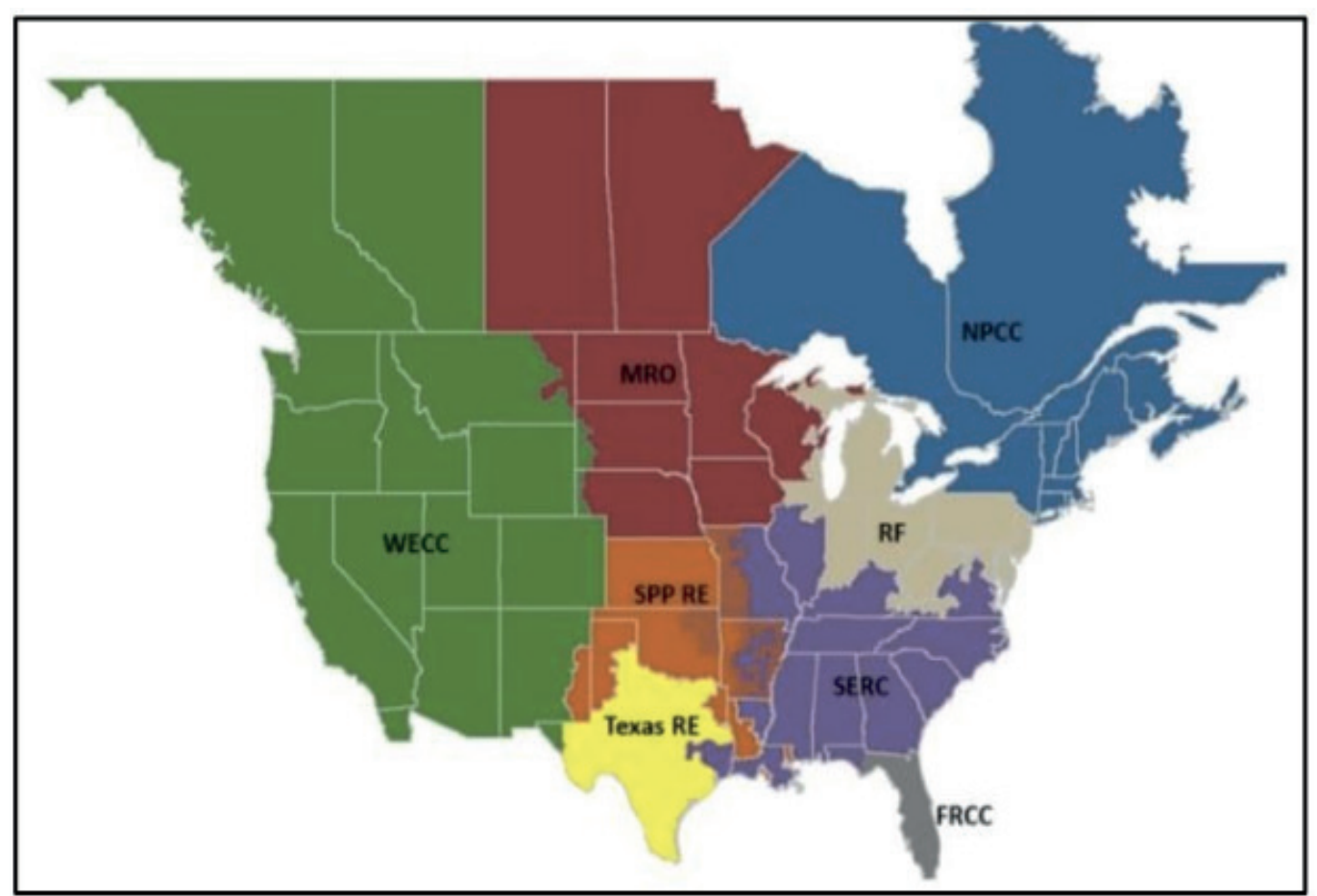

Figura 1 - Entidades Regionais do BES (1)

\begin{tabular}{|c|c|}
\hline FRCC & Florida Reliability Coordinating Council \\
\hline MRO & Midwest Reliability Organization \\
\hline NPCC & Northeast Power Coordinating Council \\
\hline RF & Reliability First \\
\hline SERC & SERC Reliability Corporation \\
\hline SPP RE & Southwest Power Pool Regional Entity \\
\hline Texas RE & Texas Reliability Entity \\
\hline WECC & Western Electricity Coordinating Council \\
\hline
\end{tabular}

Tabela 1 - Siglas das Entidades Regionais do BES

Estas entidades regionais são conhecidas como RRO (Regional Reliability Organizations) e são delegadas pelo NERC para fazerem auditorias nos operadores e aplicarem multas por não cumprimento das normas.

A definição de BES foi aprovada pela FERC em 2014 e define o seguinte: BES (Bulk Electric System) são todos elementos de transmissão operados em $100 \mathrm{kV}$ ou acima e os recursos de potência ativa ou reativa conectados em $100 \mathrm{kV}$ ou acima. Isto não inclui equipamentos utilizados na distribuição local de energia elétrica (2). 


\subsection{Regulação}

A regulação do mercado de transmissão de energia norte americano é feita pela FERC (Federal Energy Regulatory Commission) que tem a função de Regular a transmissão de energia, gás natural e óleo. No mercado de energia elétrica ela tem como principais funções regular toda venda de eletricidade, revisar fusões e aquisições das empresas de eletricidade, monitorar e investigar este mercado, licenciar novos projetos e aprovar as normas para o sistema (3).

\subsection{Operação}

As empresas que atuam no mercado podem ser donas do ativo, operadoras ou ambos. Os proprietários de sistemas de transmissão são fragmentados em centenas de proprietários. Os proprietários podem ser entidades privadas ou públicas.

Com o objetivo de tornar o sistema elétrico mais confiável e mais eficiente em termos econômicos, foi criado um Mercado organizado que é gerido por entidades de supervisão regional chamadas de RTO (Regional Transmission Organization) e ISO (Independent System Operator), criadas pelas partes interessadas regionais em resposta às ordens 2000 do FERC e 888, respectivamente. Estas entidades fazem o planejamento, operação e comercialização da energia. RTO e ISO têm funções similares, porém, a ISO é responsável por uma área menor e usualmente opera em um único estado. Este modelo de mercado representa dois terços da energia transmitida nos Estados Unidos (4).

Há, porém, uma parte que ainda não aderiu ao mercado organizado onde são seguidos acordos bilaterais tradicionais na comercialização de energia.

\section{I A NORMA NERC-PRC-027-1}

\subsection{Introdução}

O NERC iniciou em 2007 o projeto 2007-06 com o objetivo de substituir a norma PRC-001-1.1(ii) que trata da coodenação da proteção do sistema. Esta revisão atendeu à necessidade da indústria envolvida no sentido de que a coordenação de proteção entre os sistemas interconectados envolvendo diferentes proprietários é fundamental para a confiabilidade do sistema interligado americano (BES).

O projeto se deu em duas fases, sendo a primeira destinada à elaboração da nova norma de confiabilidade PRC-027-1 para estabelecer a performance da coordenação de proteção durante faltas. Estes novos requisitos substituíram or requisitos R3 e R4 da norma substituída PRC-001-1.1. A segunda fase atualizou os requisitos restantes R1, R2, R5 e R6, apresentou novas definições para OPA (Operational Planning Analysis), RTA (Real-time Assessment) e propôs a PER-006-1 que trata do treinamento dos profissionais ligados a operação em tempo real do sistema.

Em 2016 o projeto foi encaminado para aprovação da FERC. A norma passará 
a vigorar 24 meses após aprovação. Até o momento de elaboração do artigo a norma ainda encontra-se em tramitação (5).

A norma PRC-027-1 tem o seguinte título: Coordenação do sistema de proteção para performance durante faltas

O objetivo da norma é manter a coordenação do sistema de proteção instalado, detectar e isolar faltas nos elementos do sistema interligado americano (BES) de forma que tais proteções operem em uma sequência adequada durante faltas, tornando o sistema mais confiável e reduzindo o risco de instabilidades e atuações em cascata. O Foco da norma está nas principais proteções para eliminação de falta (21/21, 50/51, 67). Outras funções são tratadas em outras normas e não foi objetivo do projeto NERC 2007-06.

A norma é aplicada aos proprietários de ativos de transmissão, geração e distribuição (sistemas de proteção destinado a eliminação de falta no BES). Nesta revisão, a NERC modificou a responsabilidade da coordenação da proteção que conforme a norma anterior PRC-001 era do operador, passou agora a ser do proprietário do sistema.

\subsection{DESTAQUES DA NORMA NERC-PRC-027-1}

A seguir serão abordados os principais pontos da norma.

\section{Requisito R1:}

"Cada proprietário de sistemas de transmissão geração e distribuição deve estabelecer um processo para desenvolver novos ajustes e atualizar os existentes de modo que o sistema de proteção opere na sequência pretendida durante a ocorrência de faltas. O processo deve incluir:

1.1 A revisão e atualização do modelo de curto-circuito para o elemento do BES sob estudo

1.2 A revisão dos ajustes do sistema de proteção

1.3 Para sistemas de proteção que estão eletricamente unidos por diferentes entidades devem:

1.3.1 Fornecer a proposta de ajuste para a entidade conjunta

1.3.2 Responder a qualquer proprietário que fornecer sua proposta de ajuste de acordo com o item 1.1.3 identificando qualquer questão de coordenação ou afirmando sua conformidade com o mesmo"

\section{Medida M1:}

"Evidências aceitáveis podem incluir, mas não limitadas a, dados eletrônicos ou documentações físicas para demonstrar que a entidade responsável estabeleceu um processo para desenvolver configurações para o sistema de proteção de acordo com 
O requisito $\mathrm{R} 1$ formaliza o objetivo da norma estabelecendo um processo para que ocorra a correta coordenação da proteçao. O primeiro item, 1.1, assegura que os dados utilizados para o cálculo do curto-circuito reflitam precisamente o sistema de potência em questão, formando uma base confiável para os estudos de coordenação de proteção. A responsabilidade de atualização do modelo fica prioritáriamente com as entidades de transmissão, sendo que as entidades de geração e distribuição podem não manterem os modelos de curto-circuito, e neste caso devem solicitar os dados de curto-circuito à entidade transmissora.

O item 1.2 estabelece a revisão dos ajustes que através do processo elaborado deve reduzir a probabilidade de erros humanos e garantir que os padrões estabelecidos sejam seguidos. Os critérios para desenvolvimento de ajustes podem variar entre as entidades responsáveis, conforme a topogia do sistema, tecnologia de proteção utilizada e o conhecimento histórico do sistema. Um criterío único para a coordenação de proteção não foi considerado prático, portanto cada entidade deve elaborar o seu critério. Neste item a norma deixa em aberto a utilização de ferramentas e programas que possam facilitar este processo.

O item 1.3 destaca a importância da comunicação entre entidades que se interligam no sistema identificando possíveis problemas de coodenação antes de sua implementação.

\section{Requisito R2:}

"Cada proprietário de transmissão, geração e distribuição, para cada elemento do BES com funções de proteção identificados no anexo $A$, deve:

Opção 1: Executar um estudo de coordenação de proteção do sistema em um intervalo que não exceda 6 anos; ou

Opção 2: Comparar o valor da corrente de falta atual com uma estabelecida corrente de falta base e executar o estudo de coordenação de proteção quando a comparação identificar um desvio maior que $15 \%$ nos valores de corrente de falta (trifásicos ou fase-terra) em um barramento ao qual o elemento do BES está conectado. Todo processo não deve ultrapassar 6 anos; ou

Opção 3: usar uma combinação das duas opções anteriores."

\section{Medida M2:}

"Evidências aceitáveis podem incluir, mas não limitadas a, dado eletrônico ou documentação física que demonstre a que a entidade responsável executou o estudo de coordenação de proteção elou comparação da corrente de falta conforme o requisito R2."

$\mathrm{O}$ requisito $\mathrm{R} 2$ estabelece como deve ser executado o item 1.2 do requisito 
R1. Ele apresenta três opções que seriam: realizar o estudo de coordenação a cada período ou avaliar a variação do do curto-circuito comparando o valor atual com a base (último estudo de coordenação) e só realizar o estudo de coordenação caso esta variação seja maior que $15 \%$ ou uma terceira opção que seria uma combinação das duas opções anteriores.

Foi estabelecido também a periodicidade de 6 anos que este processo deve ocorrer. Este tempo foi escolhido como um balanço entre os recursos necessários para a elaboração do estudo e o potêncial impacto na confiabilidade criados pelas modificações no sistema que aumentam a corrente de curto circuito com o tempo.

O Anexo A, citado, define as funções que devem ser observadas no estudo de coordenação, são elas:

21 - Distância

50 - Sobrecorrente instantânea (tempo definido)

51 - Sobrecorrente temporizada (curva de tempo inverso)

67 - Sobrecorrente direcional (se usada em um sistema sem teleproteção)

A corrente de base de comparação citada na opção dois deve ser definida quando um novo elemento do BES é instalado ou após o estudo de coordenação de proteção ter sido feito. Outro detalhe importante é que ao escolher a opção dois, ela deve efetuar a verificação da evolução da corrente de curto e se ela ficar abaixo de 15\%, nenhuma outra ação é necessária dentro do período, porém, se for detectado uma variação maior que $15 \%$ na corrente de curto, o estudo de coordenação de proteção deve ser realizado ainda dentro do período de 6 anos.

A opção 3 pode ser utilizada por exemplo para aplicar uma metodologia diferente de acordo com a critcidade da instalação: Em uma instalação mais crítica seria utilizado a opção 1 e em uma instalação menos crítica poderia ser utilizado a opção 2.

\section{$\underline{\text { Requisito } R 3}$}

"Cada Proprietário de transmissão, geração ou distribuição deve utilizar o processo estabelecido no requisito $R 1$ para desenvolver novos e revisar os ajustes do sistema de proteção para elementos do BES."

\section{Medida M3}

"Evidências aceitáveis podem incluir, mas não limitadas a,dado eletrônico ou documentação física que demonstre que a entidade responsável utilizou o processo de desenvolvimento de ajustes estabelecido no requisito $R 1$ como especificado no requisito $R 3 . "$

O requisito R3 tem o objetivo de estabelecer o uso dos critérios elaborados conforme o requisito $\mathrm{R} 1$. 


\section{I A REALIDADE BRASILEIRA}

Regulamentando o Sistema de Transmissão Brasileiro, temos o submódulo 11.5 do ONS que trata do Diagnóstico dos Sistemas de Proteção e Controle e tem o objetivo estabelecer diretrizes e responsabilidades para a avaliação e adequação dos sistemas de proteção e controle das instalações e consequente aumento da segurança do SIN (6).

Neste submódulo é destacado a importancia da coordenação dos ajustes de proteção e a revisão periódica do mesmo, conforme o item 1.2 abaixo:

“1.2: ...Logo é necessário que as avaliações das coordenações dos ajustes das proteções instaladas na Rede Básica e nas instalações que se conectam ao barramento de transformador de fronteira sejam realizadas periodicamente."

O acompanhamento da evolução dos níveis de curto-circuito é citado no item 1.3:

"1.3 A importância dos sistemas de proteção e controle justifica o cuidado no estabelecimento de requisitos mínimos definidos nos Submódulos 2.6, 2.7 e 3.6, no acompanhamento dos desempenhos conforme os Submódulos 11.2, 22.7, 25.9 e 25.12 e no acompanhamento da evolução do SIN por meio da avaliação dos níveis de curto-circuito (Submódulo 11.3).

A análise das pertubações também são importantes para a melhoria do desempenho de proteção e é citada no item 1.4:

"1.4 As perturbações ocorridas no SIN são analisadas sistematicamente, objetivando-se determinar as causas de anormalidades e estabelecer recomendações para a correção das deficiências identificadas."

As responsabilidades do ONS e das concessionárias são tratadas no item 5 do submódulo 11.5. O ONS é o responsável pela definição de quais instalações serão objeto de análise e os critérios para o diagnóstico do sistema de proteção e controle. A elaboração do diagnóstico e do plano de ação para implementação das adequações nos sistemas de proteção e controle e o plano de ajustes de proteção deve ser feito pelo ONS em conjunto com os agentes. Os agentes devem fornecer as informações do sistema de proteção e controle, as filosofias de atuação das proteções, propor prazos e prioridades para implementação do plano de ação e executar o plano de ação nas instalações de sua responsabilidade. O ONS deve acompanhar a execução do plano de ação e tratar como não conformidade os descumprimentos das obrigações estabelecidas no plano.

A priorização é dada confome o item 7.1 descrito abaixo. Este item também 
estabelece uma variação mínima de $10 \%$ do curto-circuito no horizonte de 3 anos a frente bem como a avaliação do desempenho da proteção para a elaboração do disgnóstico e plano de ação e ajuste.

"7.1 O ONS deve priorizar as subestações da Rede Básica, incluindo as instalações que se conectam ao barramento de transformador de fronteira, que serão objeto do Diagnóstico dos sistemas de proteção e controle, do Plano de ação para implementação de adequações nos sistemas de proteção e controle e do Plano de ajustes das proteções, considerando no mínimo:

(a) variação maior ou igual a $10 \%$ (dez por cento) do nível de curto-circuito em cada barra da Rede Básica ou em cada barra de transformador de fronteira, no horizonte de três anos à frente;

(b) desempenho dos sistemas de proteção conforme Submódulo 11.2;

(c) demandas oriundas de estudos específicos realizados pelo ONS e agentes;

(d) solicitação da ANEEL ou MME; ou

(e) relatórios de análises de perturbações."

O item 7.2 define as instalações e a periodicidade para elaboração do diagnóstico e do plano;

“7.2 Todas as subestações da Rede Básica, incluindo as instalações que se conectam ao barramento de transformador de fronteira, deverão ser objeto do Diagnóstico dos sistemas de proteção e controle, do Plano de ação para implementação de adequações nos sistemas de proteção e controle e do Plano de ajustes das proteções com uma periodicidade máxima de 6 (seis) anos, independente da priorização do item (7.1)."

Neste processo, as seguintes práticas são geralmente adotadas:

- Quando há modificação de equipamento primário (transformador, linha, etc.)

É executada uma avaliação nas contribuições de curto-circuito identificando a necessidade de revisão no estudo de seletividade da proteção a fim de atender a substituição do equipamento ou alteração de topologia e se garantir a perfeita coordenação das proteções no SIN.

- Na ocorrência de atuação indevida

Identificada uma atuação indevida, inicia-se um processo de revisão dos ajustes e caso constate que o problema é restrito ao bay será corrigido apenas este bay, porém, se detectado que o problema é sistêmico (vários bay's) todos os equipamentos afetados terão os seus estudos revisados.

O uso de softwares de curto-circuito que permitam a modelagem dos ajustes e que tenham interface com a base de dados de ajustes sinaliza com a possibilidade de 
melhorias neste processo de revisão de ajustes, apesar de não serem utilizados por todos os agentes.

Devido à evolução do sistema elétrico e equipes mais enxutas nas empresas do setor, as demandas de manutenção, engenharia e revisões podem levar a necessidade de contratação de serviço externo, para elaboração de estudos de proteção.

Processos totalmente automatizados para avaliação das necessidades de alteração de ajustes por evolução do sistema elétrico também não são de uso habitual, assim como se tem que a aplicação dos ajustes é efetuada de modo manual.

\section{I AVALIAÇÃO AUTOMÁTICA DE AJUSTES}

Diante do desafio da revisão periódica de ajustes proposto pela norma NERCPRC-027-1 às equipes de estudos elétricos responsáveis por grandes sistemas elétricos de potência, surge a necessidade de ferramentas que possam auxiliar o trabalho dos especialistas otimizando seu tempo e reduzindo possíveis erros humanos.

Dentro deste contexto uma das ferramentas existentes, foi desenvolvida pela Siemens, o software SIGUARD PSA (Protection Security Assessment) simula e avalia a performance do sistema de proteção em todo sistema modelado, possibilitando a avaliação automática de diversas condições de falta (7)

Primeiramente é necessário que o sistema esteja modelado em um software de curto circuito que possibilite a inclusão do dispositivo de proteção e sua simulação diante dos diversos tipos de falta. A Figura 2 mostra um sistema exemplo modelado no software PSS SINCAL (8).

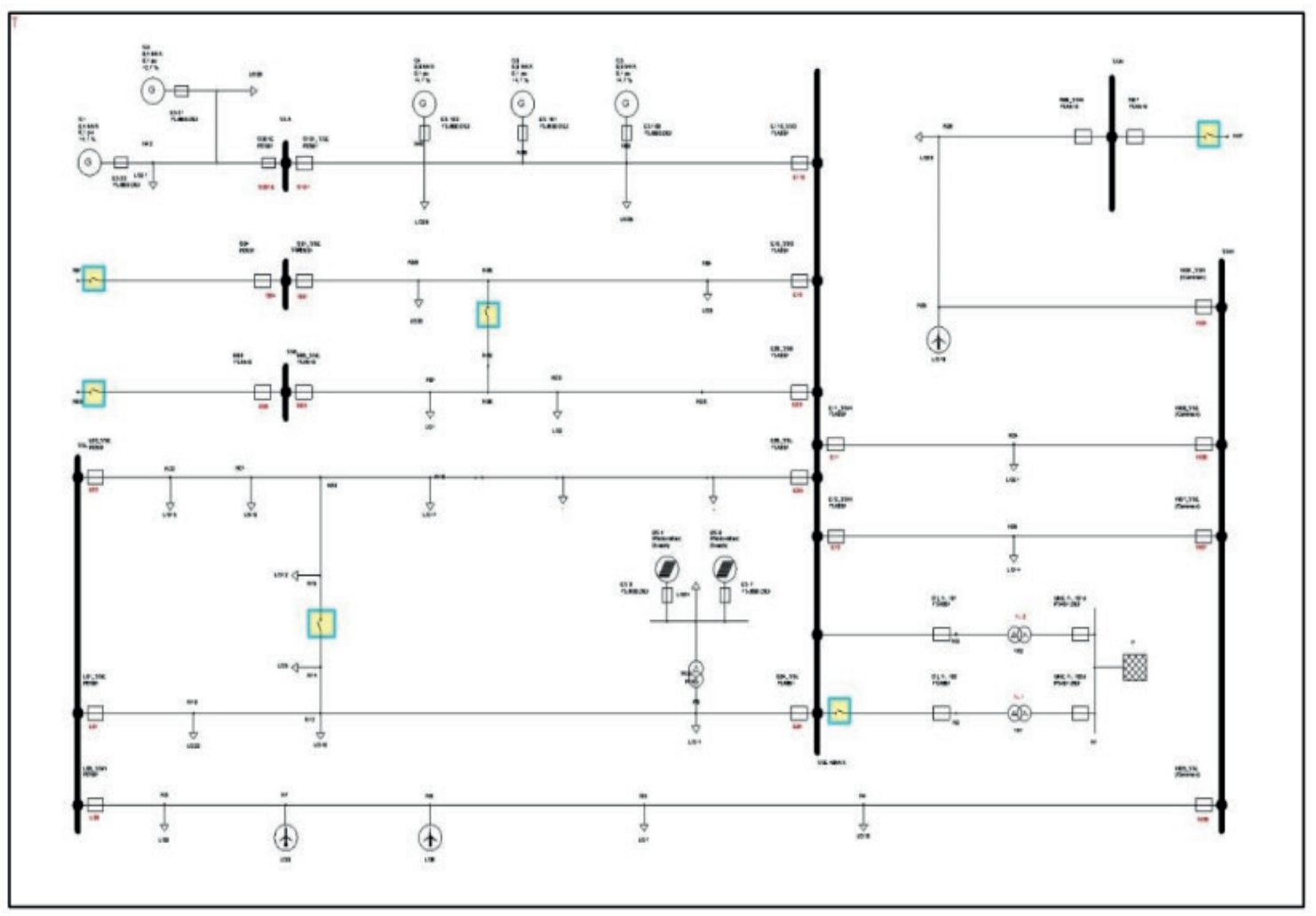

Figura 2 - Sistema Exemplo 
Os elementos em retângulo na Figura 2, localizados nos terminais das linhas e saídas de geradores representam os relés de proteção. Foram modelados funções de distância, sobretensão, subtensão e sobrecorrente.

Com o modelo no PSS SINCAL, é possível executar simulações variando-se a impedância de falta, a localização da falta e outras condições operacionais, porém neste caso, o processo é feito um a um, a partir da modificação de parâmetros e execução da simulação. O SIGUARD PSA possibilita a importação destes dados, a execução automática de uma grande quantidade de simulações e a visualização do resultado de forma gráfica ou relatório.

$\mathrm{Na}$ Tabela 2, observamos os resultados para a avaliação da proteção principal para o curto-circuito trifásico, com resistência de falta zero e com uma variação em passos de $10 \%$ da localização da falta nas linhas. Cada linha representa uma zona de proteção e cada coluna representa a porcentagem da zona onde foi aplicada a falta. A cor verde indica que o sistema está seletivo, a cor amarela indica que ocorreu sobrealcance de alguma proteção, a cor laranja subalcance e vermelho indica que a falta não foi eliminada.

\begin{tabular}{|c|c|c|c|c|c|c|c|c|c|c|c|c|c|c|}
\hline \multirow[b]{2}{*}{ Fault Path } & \multicolumn{11}{|c|}{ Lines } & \multicolumn{2}{|c|}{ Transformers } & \multirow[b]{2}{*}{ ID } \\
\hline & $1 \%$ & $10 \%$ & $20 \%$ & $30 \%$ & $40 \%$ & $50 \%$ & $60 \%$ & $70 \%$ & $80 \%$ & $90 \%$ & $99 \%$ & $1 \%$ & $99 \%$ & \\
\hline Zone1:B05_SSE-1-L33 & & & & & & & & & & & & & & 1 \\
\hline Zone1:E09_SSB-1-L33 & & & & & & & & & & & & & & 2 \\
\hline Zone1:B05_SSE-1-E09_SSB & & & & & & & & & & & & & & 3 \\
\hline Zone2:B08-1-L2 & & & & & & & & & & & & & & 4 \\
\hline Zone5:E04_SSL-1-LO24 & & & & & & & & & & & & & & 5 \\
\hline Zone5:E04_SSL-1-L23 & & & & & & & & & & & & & & 6 \\
\hline Zone5:E04_SSL-1-L01_SSE & & & & & & & & & & & & & & 7 \\
\hline Zone5:L01_SSE-1-LO24 & & & & & & & & & & & & & & 8 \\
\hline Zone5:L01_SSE-1-L23 & & & & & & & & & & & & & & 9 \\
\hline Zone6:E05_SSL-1-LO12 & & & & & & & & & & & & & & 10 \\
\hline Zone6:E05_SSL-1-L02_SSE & & & & & & & & & & & & & & 11 \\
\hline Zone6:L02_SSE-1-LO12 & & & & & & & & & & & & & & 12 \\
\hline Zone7:E10_SSO-1-O01_SSE & & & & & & & & & & & & & & 13 \\
\hline Zone8:E110_SSO-1-O101_SSE & & & & & & & & & & & & & & 14 \\
\hline Zone9:E11_SSW-1-W06_SSE & & & & & & & & & & & & & & 15 \\
\hline Zone10:E12_SSW-1-W07_SSE & & & & & & & & & & & & & & 16 \\
\hline Zone11:L03_SSW-1-W05_SSL & & & & & & & & & & & & & & 17 \\
\hline Zone12:N03_SSW-1-W04_SSN & & & & & & & & & & & & & & 18 \\
\hline Zone13:N07-1-L4 & & & & & & & & & & & & & & 19 \\
\hline Zone14:O04-1-L3 & & & & & & & & & & & & & & 20 \\
\hline Zone15:O201E-1-LO27 & & & & & & & & & & & & & & 21 \\
\hline Zone15:O201E-1-LO28 & & & & & & & & & & & & & & 22 \\
\hline Zone16:UMZ Tr. 101d-1-N3 & & & & & & & & & & & & & & 23 \\
\hline Zone17:UMZ Tr. 102d-1-N2 & & & & & & & & & & & & & & 24 \\
\hline
\end{tabular}

Tabela 2 - Resultado Curto Trifásico, resistência de falta $0.0 \Omega$

Nas linhas de ID 5 e 8 da Figura 2, verifica-se que uma falta na baixa do 
transformador não foi eliminada (sinalização vermelha a 99\% do transformador). Simulando a mesma falta no PSS-Sincal observa-se que realmente a falta não é eliminada, pois, apesar dos relés ES7 e ES8 terem atuado, os relés E04_SSL e L01_ SSE não atuaram, conforme Figura 3. Para correção do problema foi adicionado um relé de sobrecorrente no primário do transformador para que esta falta fosse eliminada corretamente.

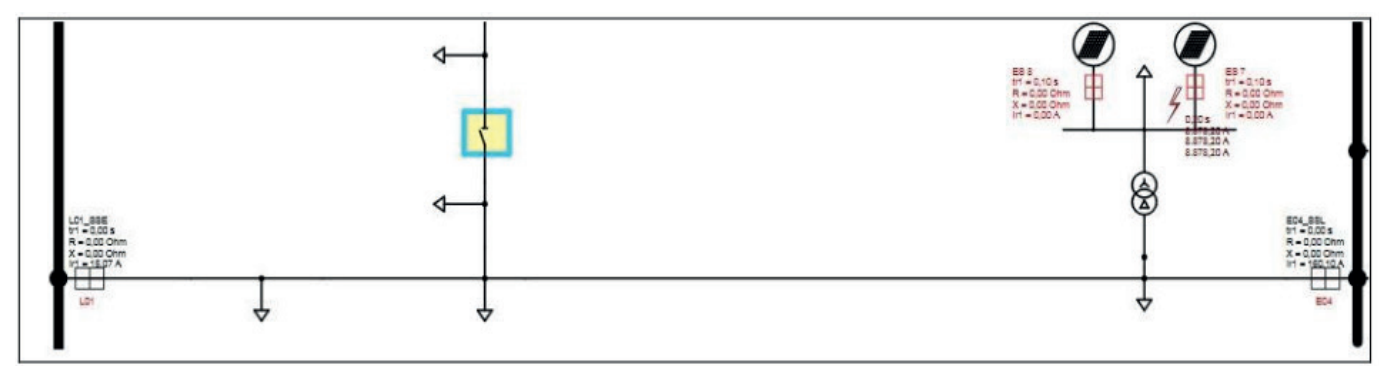

Figura 3 - Caso 1 (Falta não eliminada)

Na linha de ID 4 da Tabela 2 temos um sobrealcance e um subalcance em 90 e 99\% da linha L2. Simulada falta nestas distâncias no PSS Sincal confirma-se que, para a falta em 90\% da linha L2 ocorre atuação indevida do relé E09_SSB, em sobrealcance (Figura 4) e em 99\% da linha o relé B08 não atua, subalcance (Figura 5). Neste caso foi efetuada a revisão do ajuste da zona 2 de ambos os relés, obtendo a correta seletividade.

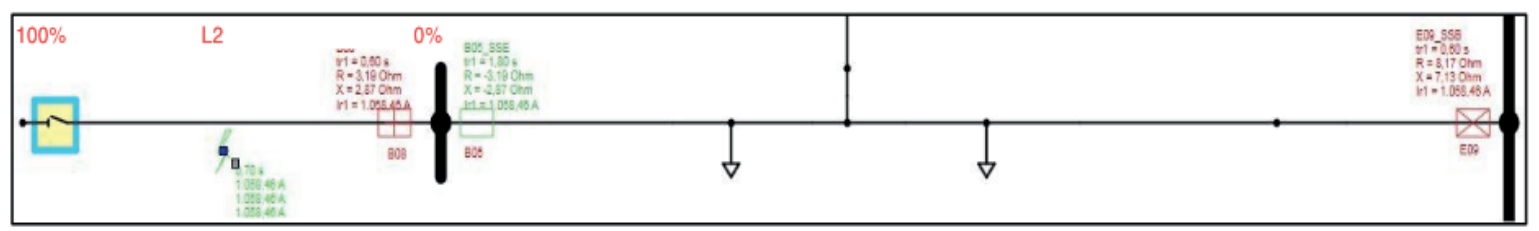

Figura 4 - Caso 2 (sobrealcance)

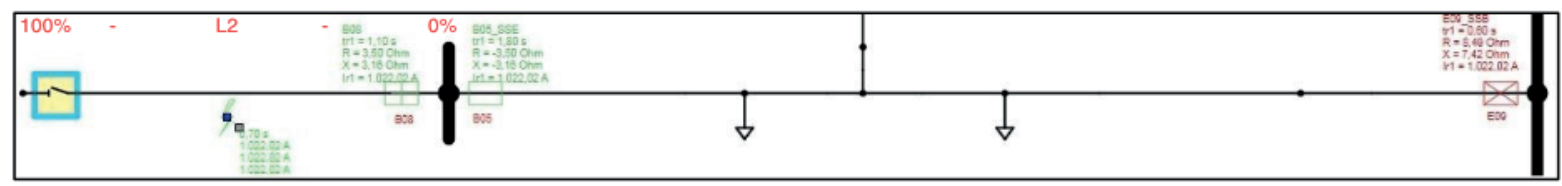

Figura 5 - Caso 2 (subalcance)

Na linha de ID 14 da Tabela 2 temos um subalcance nos primeiros 30\% da linha. No PSS Sincal confirma-se que o relé O101_SSE realmente não atua para esta região (Figura 6), portanto, neste caso foi adicionado um esquema de teleproteção: um TDD é enviado pelo relé E110_SSO para o relé O101_SSE quando ocorrer trip de zona1. 


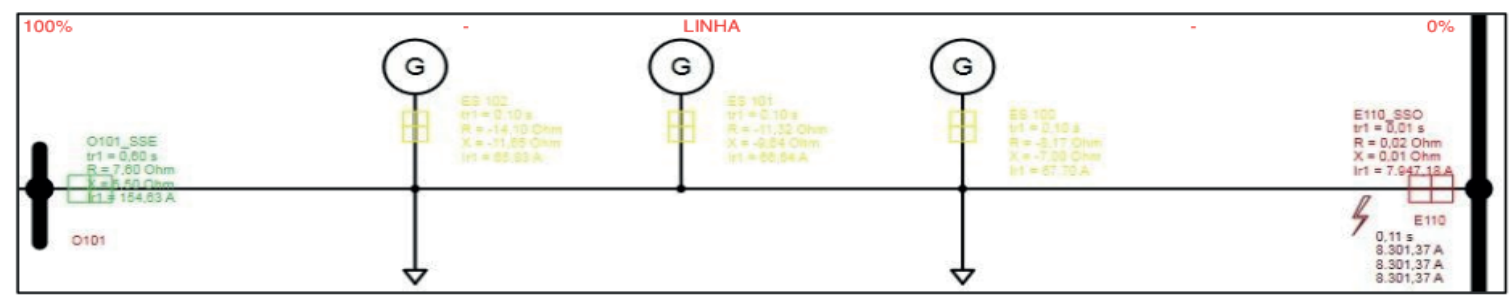

Figura 6 - Caso 2 (subalcance)

As soluções adotadas para os casos apresentados têm o objetivo de exemplificar os passos para a solução do problema, mas não esgotam todas as avaliações necessárias para revisão definitiva do sistema de proteção, porém, com eles é possível ter uma avaliação do processo e observar as seguintes otimizações:

- Redução de tempo na simulação e avaliação do sistema como um todo. A Tabela 2 gerada pelo Siguard PSA resume a simulação e avaliação de 272 casos.

- Localização imediata dos pontos críticos, possibilitando o foco do especialista na solução do problema e não na busca dos problemas.

- Facilidade de se obter uma reavaliação global a qualquer momento para verificar se um determinado ajuste modificado não gerou outro problema que não havia inicialmente.

Finalizando as soluções de todos os problemas indicados na Tabela 2 e avaliando o sistema final com o Siguard PSA, obtemos o resultado da Tabela 3.

\begin{tabular}{|c|c|c|c|c|c|c|c|c|c|c|c|c|c|c|}
\hline \multirow[b]{2}{*}{ Fault Path } & \multicolumn{11}{|c|}{ Lines } & \multicolumn{2}{|c|}{ Transformers } & \multirow[b]{2}{*}{ ID } \\
\hline & $1 \%$ & $10 \%$ & $20 \%$ & $30 \%$ & $40 \%$ & $50 \%$ & $60 \%$ & $70 \%$ & $80 \%$ & $90 \%$ & $99 \%$ & $1 \%$ & $99 \%$ & \\
\hline Zone1:B05_SSE-1-E09_SSB & & & & & & & & & & & & & & 1 \\
\hline Zone1:B05_SSE-1-L33 & & & & & & & & & & & & & & 2 \\
\hline Zone1:E09_SSB-1-L33 & & & & & & & & & & & & & & 3 \\
\hline Zone2:B08-1-L2 & & & & & & & & & & & & & & 4 \\
\hline Zone5:E04_SSL-1-L23 & & & & & & & & & & & & & & 5 \\
\hline Zone5:E04_SSL-1-N10 & & & & & & & & & & & & & & 6 \\
\hline Zone5:L01_SSE-1-N10 & & & & & & & & & & & & & & 7 \\
\hline Zone5:E04_SSL-1-L01_SSE & & & & & & & & & & & & & & 8 \\
\hline Zone5:L01_SSE-1-L23 & & & & & & & & & & & & & & 9 \\
\hline Zone6:E05_SSL-1-LO12 & & & & & & & & & & & & & & 10 \\
\hline Zone6:E05_SSL-1-L02_SSE & & & & & & & & & & & & & & 11 \\
\hline Zone6:L02_SSE-1-LO12 & & & & & & & & & & & & & & 12 \\
\hline Zone7:E10_SSO-1-O01_SSE & & & & & & & & & & & & & & 13 \\
\hline Zone8:E110_SSO-1-O101_SSE & & & & & & & & & & & & & & 14 \\
\hline Zone9:E11_SSW-1-W06_SSE & & & & & & & & & & & & & & 15 \\
\hline Zone10:E12_SSW-1-W07_SSE & & & & & & & & & & & & & & 16 \\
\hline Zone11:E13_TR3-1-LO24 & & & & & & & & & & & & & & 17 \\
\hline Zone12:L03_SSW-1-W05_SSL & & & & & & & & & & & & & & 18 \\
\hline Zone13:N03_SSW-1-W04_SSN & & & & & & & & & & & & & & 19 \\
\hline Zone14:N07-1-L4 & & & & & & & & & & & & & & 20 \\
\hline Zone15:004-1-L3 & & & & & & & & & & & & & & 21 \\
\hline Zone16:O201E-1-LO27 & & & & & & & & & & & & & & 22 \\
\hline Zone16:O201E-1-LO28 & & & & & & & & & & & & & & 23 \\
\hline Zone17:UMZ Tr. 101d-1-N3 & & & & & & & & & & & & & & 24 \\
\hline
\end{tabular}


Tabela 3 - Resultado Curto Trifásico, resistência de falta $0.0 \Omega$, após reavaliação da proteção.

Além da avaliação da proteção principal, variando-se a resistência de falta, sua localização e o seu tipo, é possível também avaliar, de forma semelhante, a proteção de retaguarda (backup). Neste caso, é simulada a falha de um relé e avaliado o comportamento dos demais relés diante desta falta. Os resultados podem ser visualizados em forma de relatórios ou tabelas.

\section{I CONCLUSÃo}

A revisão periódica de ajustes de proteção continua sendo um desafio para profissionais e empresas do setor elétrico de todo o mundo. Uma solução única não é possível, pois esta depende da organização de cada mercado e das especificidades de cada sistema, porém, avaliando as realidades americana e brasileira, identificamos como uma boa prática a realização da avaliação da evolução do curto-circuito, seja de forma periódica ou diante de uma modificação do sistema, e a sua comparação com o valor de curto obtido na última realização do estudo de coordenação de proteção. Outra constatação importante é que uma avaliação global do sistema de proteção, em destaque para as funções de sobrecorrente direcional e para zonas de sobrealcance (zonas 2 e 3 caso utilizada) da proteção de distância, que tem forte impacto devido a evolução do curto-circuito, é fundamental para a manutenção da seletividade do sistema, e neste sentido, os softwares que automatizam etapas deste processo são fundamentais para execução deste trabalho, viabilizando uma análise mais completa e mais ágil.

\section{REFERÊNCIAS}

NERC - North American Electric Reliability Corporation, "Bulk Electric System - Public Case Notes," 2016.

NERC - North American Electric Reliability Corporation, "Bulk Electric System Definition Reference Document," 2014.

FERC - Federal Energy Regulatory Commisssion, 2017. Disponível: https://www.ferc.gov.

IRC ISO/RTO COUNCIL, 2017. Disponível: http://www.isorto.org.

NERC - North American Electric Reliability Corporation, "Petition of the North American Electric Reliability corporation for Approval of Proposed Reliability Standards PRC-027-1 and PER-006-1 and retirement of PRC-001-1.1(ii)," 2016.

Operador Nacional Do Sistema Elétrico (ONS), "Submódulo 11.5 - Diagnóstico dos Sistemas de Proteção e Controle," 2016.

SIEMENS AG, "SIGUARD - Power System Supervision," 2017. Disponível: http://www.siemens.com/ 
siguard.

SIEMENS AG, "PSS SINCAL - Integrated Power System Engineering Software," 2017. Disponível: http://www.siemens.com/sincal.

SIEMENS AG, "Power Technologies International," 2017. Disponível: www.siemens.com/powertechnologies. 
Data de submissão: 29/10/2019

Data de aceite: 03/01/2020

Francisco de Assis da Silva Mota Universidade Federal do Piauí, Dep. do curso de Engenharia de Produção

Teresina - Piauí

http://lattes.cnpq.br/9509458964109076

Francisco Francielle Pinheiro dos Santos Universidade Federal do Piauí, Dep. do curso de

Engenharia de Produção

Teresina - Piauí

http://lattes.cnpq.br/3702880420054515

Paula Cristina de Amorim Andrade Universidade Federal do Piauí, Dep. do curso de

Engenharia de Produção

Teresina - Piauí

http://lattes.cnpq.br/6398108441133432

RESUMO: Este trabalho teve como objetivo avaliar a capacidade de produção de energia elétrica para comunidades isoladas a partir de um grupo gerador alimentado com biodiesel produzido com óleo extraído de vísceras de peixe. Para tanto, foram utilizadas tecnologias desenvolvidas e já patenteadas. $O$ estudo revelou que o biodiesel de Tilápia, em conjunto com a maquina biopeixes e reator multifuncional é capaz de gerar, após sua combustão, uma energia de 980.64 kW.h. Este valor é obtido com a combustão de 111.5 litros de biodiesel. Uma única batelada de biodiesel produzido de vísceras de tilápia e capaz de produzir $7.845,12$ kW.h de energia e alimentar 176 casas em único dia. Para a instalação dos sistemas, observou-se que os sistemas apresentam valores que variam de $R \$ 88.863,03$ a $R \$$ 152.622,40. Ou seja, a unidade multifuncional destinada a produção de biodiesel poderá chegar a representar um valor de apenas 10\% de sistemas já apresentados no mercado. Os valores das unidades final para instalação foi de $\mathrm{R} \$ 383.258,75$ para completo de $50 \mathrm{~kg} / \mathrm{h}$ e $\mathrm{R} \$ 447.018,12$ para a produção de $150 \mathrm{~kg} / \mathrm{h}$. No caso de o sistema vir a processar óleo vegetal, o valor do biodiesel processado ainda apresentará um custo elevado. Isso ocorre do fato dos altos custos apresentados na compra da matéria prima. Uma vez que, atualmente, o preço do óleo vegetal, utilizado na simulação da produção de biodiesel no reato, foi da ordem de $R \$ 3,000$ reais por litro consumido. Sabe-se, porém, que, para o caso de o processo utilizar óleo de resíduos de peixes, o valor do biodiesel final poderá cair de forma significativa devido a retirada dos custos com esse insumo.

PALAVRAS-CHAVE: Geração de energia, comunidades isoladas, biodiesel, vísceras de peixes. 
ABSTRACT: The main goal of this present work was to evaluate the capacity of electricity production for isolated communities from a biodiesel-powered generator set produced with oil extracted from fish offal. To that end, it was used already developed and patented technologies. This study revealed that Tilapia biodiesel, together with the biopeixes machine and the multifunctional reactor, is capable of generating, after combustion, $980.64 \mathrm{kWh}$ of energy. This value is obtained by combustion of 111.5 liters of biodiesel. For the systems installation, it was observed that the systems have values ranging from $R \$ 88,863.03$ to $R \$ 152,622.40$. That is, the multifunctional unit designated for biodiesel production could represent a value of only $10 \%$ of systems already on the market. Final units for installation has values of $\mathrm{R} \$ 383,258.75$ for the production of $50 \mathrm{~kg} / \mathrm{h}$ and $\mathrm{R} \$ 447,018.12$ for the production of $150 \mathrm{~kg} / \mathrm{h}$. In the case of the system process vegetable oil, the value of the processed biodiesel will still have an expensive cost. This is because there are high costs associated with purchasing the raw material, since, currently, the price of vegetable oil used to simulate the production of biodiesel in the reactor was around $\mathrm{R} \$ 3,000$ per liter consumed. It is known, however, that to the case where the process uses fish waste oil, the final biodiesel value may drop significantly due to the removal of costs with this input.

KEYWORDS: Energy generation, isolated communities, biodiesel, fish offal.

\section{I INTRODUÇÃO}

Atualmente a população mundial é estimada, aproximadamente, em 7.318.413 habitantes. Com isso, a necessidade de aumento na produção de alimentos e energia tende a crescer de maneira compatível a suprir essas necessidades do crescimento populacional. Estimativas revelam que será produzir nos próximos 40 anos a mesma quantidade de alimentos produzidos nos últimos 8.000 anos

A necessidade de novas fontes de energias renováveis é algo bastante estudado na atualidade. Em vários países a busca por novas fontes de matérias-primas para produção de biodiesel estão sendo avaliadas e utilizadas (WANG et al., 2008; WU et al., 2014; dentre estas fontes está a utilização de rejeitos de gorduras animal (VIDOTTI et al., 2003). Neste contexto, a utilização de rejeitos de pescados está sendo avaliada e aplicada como uma fonte intensiva na produção de biodiesel (GARCIA-MORENO et al, 2014; MOTA et al., 2016; MOTA et, al 2019; GEORGIANNIA et al., 2008; HASSENTRABELSI et al., 2015).

No entanto, o desenvolvimento de tecnologias que possam tornar viável e extração destas gorduras ainda é um fator determinante na utilização integral destes rejeitos. Este estudo apresenta a avaliação da utilização das vísceras de Tilápia do Nilo, cultivadas em cativeiro, na produção de óleo e sua utilização na cadeia produtiva do biodiesel (GHOBADIAN et al., 2013; MOTA et al., 2016; VOORT et al., 2009; HU 
et al.,2017; LEE et al, 2013). A destinação correta dos resíduos da piscicultura é hoje um problema sério para os piscicultores e empresas extrativistas (LIN et al., 2009; SCHIEWERS et al., 2011; SILA et al., 2015).

A necessidade de tornar viável o acesso a tecnologias e distribuição de energia é algo que, atualmente, não está acessível a toda a população brasileira. Isso se deve, em parte, a imensa extensão territorial do Brasil. Um exemplo disso é a região amazônica que possui o mais baixo índice de eletrificação rural do país, reflexo do modelo tradicional de fornecimento de eletricidade adotado no Brasil, baseado na geração de grandes blocos de energia conectados à rede de distribuição. Seu modelo de eletrificação rural é composto predominantemente por sistemas isolados com diesel-geradores. Esta solução tem se revelado pouco satisfatória, na medida em que a aquisição e o transporte de óleo diesel para as localidades isoladas, assim como a manutenção dos equipamentos, tem um alto custo financeiro no contexto da região.

Uma forma de diminuir esses custos e sanar os problemas seria produzir o próprio biodiesel na comunidade e com isso permitir a geração de energia satisfatória.

Baseado nisso, este trabalho visa avaliar a capacidade de produção de biodiesel a partir de óleo extraído das vísceras de peixe oriundos de pequenas cooperativas de pescadores e com este biodiesel produzido alimentar gerador de energia elétrica para que este supra a necessidade de pequenas comunidades isoladas de moradores. Para tanto, será utilizada a tecnologia já desenvolvida do Reator Multifuncional para produção de Biodiesel e Máquina Biopeixes (MOTA et al., 2014; MOTA et al., 2016; MOTA et, al 2019).

\section{I MATERIAIS E MÉTODOS}

\subsection{Consumo energético}

Para buscar obter uma estimativa da quantidade de energia consumida por residência foi realizado estudo bibliográfico. Com estes obtivemos um consumo médio da energia consumida por residência.

\subsection{Balanço de massa maquina biopeixes}

A máquina Biopeixes é um projeto desenvolvido e patenteado por Mota et al. (2014). Neste trabalho foi descrito a quantidade de matéria prima e óleo produzido pelo sistema. Com isso, obteve-se as etapas necessárias a extração do óleo e suas respectivas operações unitárias (Figura 1), além disso utilizou-se deste estudo já realizado para obter uma estimativa de produtividade em termos de óleo de vísceras de pescados. 


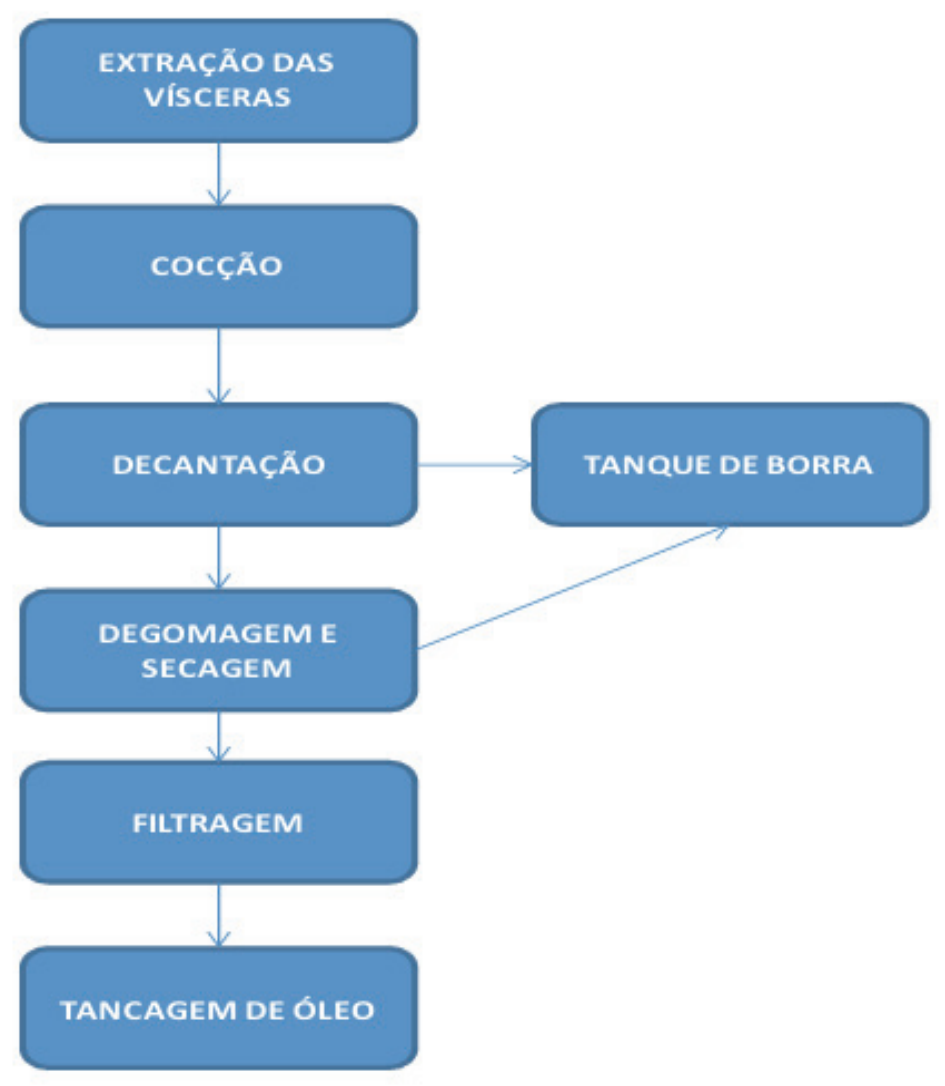

Figura 1 - Fluxograma de Blocos Sistema Biopeixes

\subsection{Reator multifuncional}

O projeto reator multifuncional é um projeto desenvolvido por Mota et al. (2010). Neste trabalho foi mostrada a viabilidade do desenvolvimento de um reator multifuncional destinado à produção de biodiesel. Este reator, ao contrário de plantas de pequena escala para produção de biodiesel, possui a característica de em um único equipamento realizar as etapas de transesterificação, decantação, lavagem e secagem. Nas avaliações realizadas foi comprovado que este equipamento possui um valor aproximando de $1 / 6$ quando comparado com fornecedores desta tecnologia. A seguir, a Figura 2 ilustra o fluxograma de processos do sistema e a Tabela 1 apresenta as TAG's dos equipamentos.

\begin{tabular}{cc}
\hline Codificação & Operação Unitária \\
\hline RO1 & Reação \\
TP01 & Tanque de Condensados \\
TOP2 & Tanque Pulmão \\
CR1 & Torre de Lavagem 1 \\
CR2 & Torre de Lavagem 2 \\
TP03 & Tanque de Rejeitos \\
TP04 & Tanque de Biodiesel \\
XC01 & Trocador de Calor \\
TR01 & Torre de Refrigeração \\
CD01 & Caldeira Elétrica \\
\hline
\end{tabular}

Tabela 1: TAG'S dos equipamentos 


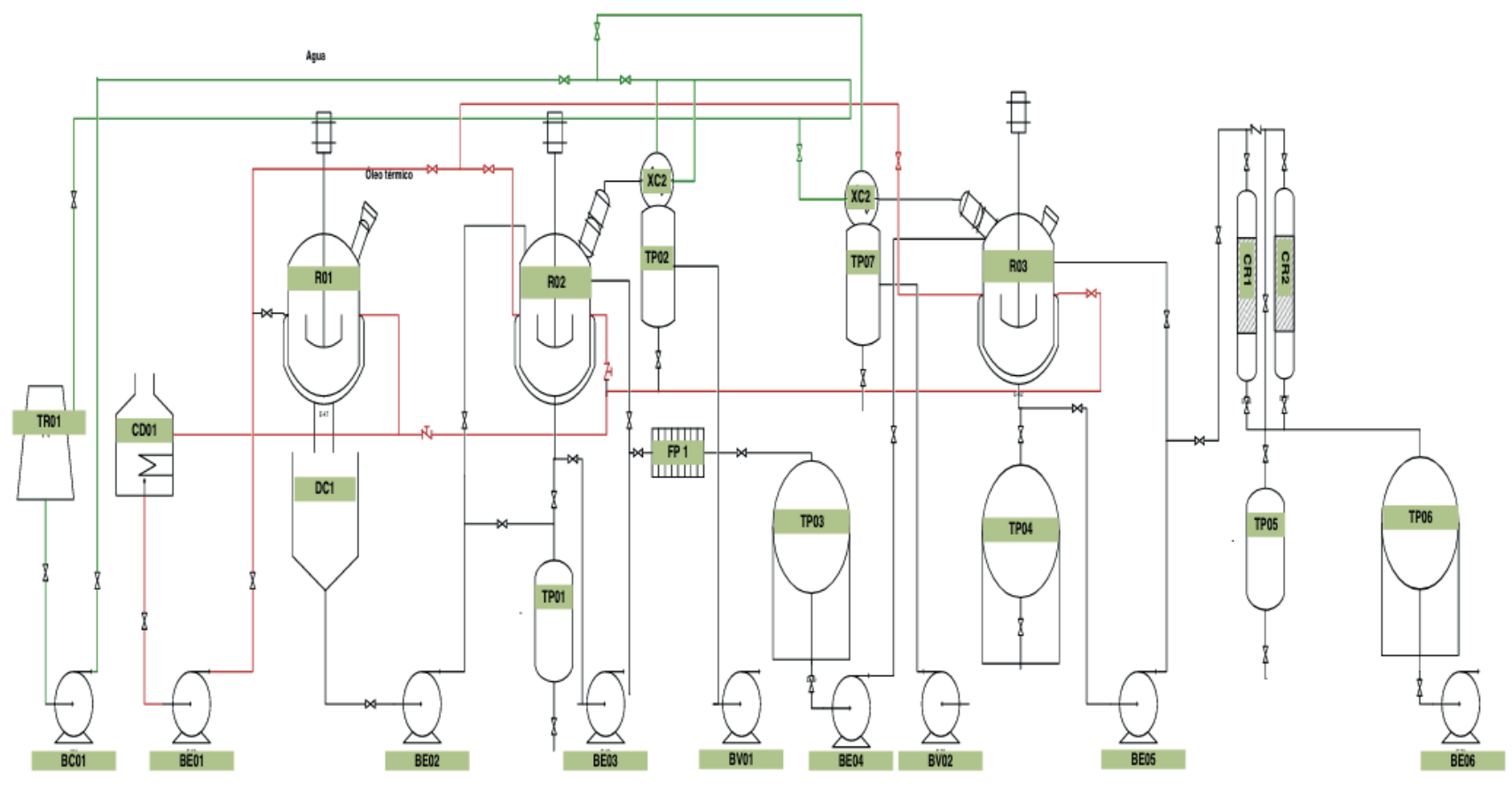

Figura 2: Fluxograma P\&ID da planta piloto

\subsection{Avaliação do poder calorífico do biodiesel produzido}

Para avaliar o poder calorífico do biodiesel de óleo de peixe foi utilizado Bomba Calorimétrica Automática Fabricante: IKA Modelo: C-200.

\subsection{Moto gerador}

Para analisar o consumo de biodiesel referente à potência requerida ao longo do dia foi verificado em um catálogo da Cummins, empresa fabricante de geradores Diesel, os valores específicos de consumo de combustível em relação à carga do grupo gerador modelo C35 D6 do tipo Prime.

\subsection{Avaliação econômica}

O investimento total exigido para um novo processo pode ser divido em cinco partes: investimento na planta, investimento nas utilidades, investimentos em obras civis, taxas de engenharia e capital de giro. Neste trabalho não foram contabilizados os custos em obras civis. O custo de um equipamento especifico será função dos seguintes itens: dimensão, material de construção, pressão e temperatura de operação. $O$ custo é, frequentemente, apresentado como o custo versus a capacidade do equipamento ou expresso como uma de potência.

$$
C_{E}=C_{B}\left(\frac{Q}{Q_{B}}\right)^{M} f_{m} f_{p} f_{T}
$$


Em que CE é o custo do equipamento com capacidade $Q, C B$ é o custo conhecido de um equipamento com capacidade conhecida, $M$ é uma constante que depende do tipo de equipamento, fm fator de correção para o material de construção, fp fator de correção para pressão de operação e fT fator de correção para temperatura de operação.

Além do custo de cada equipamento existem os custos com: custo de instalação; tubulação e válvulas; sistema de controle; fundações e estrutura, sistema elétricos; sistema de segurança; honorários de engenharia e contingências. Há os custos com utilidades: geração de eletricidade; distribuição de eletricidade; geração e distribuição de vapor; tratamento de água; sistema de arrefecimento; tratamento de efluentes; sistema de compressão de gás; sistema de inertização e sistema combate de incêndio. O custo total da planta pode ser obtido multiplicando os diversos fatores que compõem uma planta de processo pelo custo individual de cada equipamento (CF).

$$
C_{F}=\sum_{i}\left(1-f_{p i p}\right) C_{E, i}+\Sigma\left(f_{E R}+f_{I N}+f_{U t i}+f_{C}+f_{c o n t}+f_{W s} \sum_{i} C_{E, i}\right)
$$

Em que fER é custo de construção (envolve custo com engenharia, preparação da obra, prédios, off-sites, custo de entrega de equipamentos), fIN é custo de com instrumentação e controle e instalação elétrica, fUti é custo da utilidades, fpip é custo com tubulação, fcont é custo com contingência, fWs é custo com capital giro e fc é custo com capital.

Para calcular o custo do combustível produzido é utilizada a metodologia de custo nivelado do combustível, elaborado através do Índice Custo-benefício (ICB). Para tanto é considerado:

$$
I C B=C_{I}+C O M+C C
$$

Em que: $\mathrm{Cl}$ é o custo anual do investimento na planta de biodiesel em $\mathrm{R} \$ /$, dado por:

$$
C_{I}=\frac{C F x F R U}{N}
$$

Em que: CF - custo total do investimento na usina, inclusive juros, durante a construção, em $\mathrm{R} \$$; que é calculado utilizando as equações 3.1 e 3.2. N - total de litros produzidos por ano. FRU - fator de recuperação do capital para vida útil econômica da usina, expresso por: 


$$
F R U=\frac{i x(1+i)^{v}}{(1+i)^{v}-1}
$$

Em que i - é taxa anual de desconto; $v$ - vida útil da planta em anos;

COM - custo anual de operação e manutenção da planta, em \$/l, dado por:

$$
C O M=\frac{O M}{N}
$$

Em que: OM - é o custo de operação e manutenção da planta, em \$/l.

$\mathrm{CC}$ - custo anual de insumos da planta em $\$ /$, dado por:

$$
C C=\frac{C U I x Q C I}{N}
$$

Em que: CUI - custo unitário dos insumos, em $\$$ / ou $\$ / \mathrm{kg}$. QCl - quantidade de insumos, em $\mathrm{kg}$ ou I.

\section{I RESULTADOS E DISCUSSÃO}

Foram avaliadas as características típicas de cargas elétricas utilizadas por consumidores residenciais no Brasil de maneira a tomar como base para quantificar a potência máxima requerida em horário de pico e o consumo médio mensal de energia em uma residência. Essas características, segundo Francisquini (2006) são mostradas na Tabela 2.

\begin{tabular}{cc}
\hline Equipamento & Consumo energético (\%) \\
\hline Aquecedores de água & $26,0 \%$ \\
Ferro elétrico & $6,0 \%$ \\
Refrigeração & $32,0 \%$ \\
lluminação & $24,0 \%$ \\
Outros & $6,0 \%$ \\
\hline
\end{tabular}

Tabela 2 - Características de cargas residenciais.

Fonte: Francisquini, 2006

Segundo Francisquini (2006), a curva de carga de um consumidor residencial caracteriza-se por um consumo praticamente constante durante o dia inteiro com um aumento no fim da tarde e um pico de demanda, provocado pelo uso do chuveiro elétrico e outros equipamentos (entre 18 e 21 horas). De acordo com este mesmo autor, 
a carga de um dia útil de um consumidor real e constante é igual a aproximadamente 330 kWh por mês. Segundo este autor, a potência máxima se encontra na "demanda de pico" e equivale a 1,4 kW e a potência requerida no restante do dia é um valor em torno de $0,4 \mathrm{~kW}$.

Uma vez que o elemento final da cadeia na geração de energia por combustão e o gerador, de acordo com o catálogo do fabricante esse modelo possui uma potência nominal igual a $32 \mathrm{~kW}$, suficiente para alimentar 22 casas. Os dados de consumo de diesel em faixas de horários são apresentados com auxílio da Tabela 3.

\begin{tabular}{cc}
\hline Faixa de Horário $(\mathrm{h})$ & Consumo $(\mathrm{L} / \mathrm{h})$ \\
\hline 00:00 -17:00 & 3,5 \\
22:00-24:00 & 9,00 \\
\hline
\end{tabular}

Tabela 3 - Consumo de diesel pelo gerador.

Fonte: Francisquini, 2006

Com os dados da Tabela 2 temos,

$$
\text { Consumo }_{24 h o r a s}=3,5\left(\frac{L}{h}\right) \times 19(h)+9\left(\frac{L}{h}\right) \times 5(h)=111,5 L(\text { diários }) \quad \text { eq.01 }
$$

Ou seja, necessitamos de apenas 11,5 litros de biodiesel para alimentar uma comunidade de 22 casas.

A máquina Biopeixe, Figura 3(a) desenvolvida por Mota et al. (2014) possui uma capacidade produtiva de 25 litros de óleo de tilápia por hora. Ou seja, a unidade irá necessitar produzir e estocar uma quantidade de óleo para posteriormente utilizar no reator multifuncional. No entanto, em uma relação produtiva de 1:6 (um mol de óleo e seis de álcool) serão necessários um pouco mais de 100 litros de óleo para que o reator multifuncional possa operar com carga máxima.

O Reator Multifuncional, desenvolvido para produzir Biodiesel em escalas reduzidas e que seja de baixo custo é apresentado na Figura 3(b). Este equipamento tem como característica principal a multifuncionalidade de atividades de processamento. Ele transesterifica, decanta, purifica e retira a umidade. $O$ biodiesel produzido a partir da transesterificação do óleo de vísceras de peixes apresentou como valor de poder calorífico o valor de $8.890,00 \mathrm{Kcal} / \mathrm{Kg}$. Com isso, temos que ao final de uma batelada de 8 horas o reator multifuncional ira produzir uma carga de $680 \mathrm{Kg}$ de biodiesel. $\mathrm{Ou}$ seja, o processo produtivo de biodiesel a partir do óleo de restos de tilápia poderá produzir, ao fim de uma batelada, uma carga energética de 6.045.200,00 Kcal de energia. Uma vez que o reator multifuncional produz em cada batelada um volume de 800 Litros de biodiesel e que, segundo Mota et al. (2014), a densidade do Biodiesel de tilápia e da ordem de $850 \mathrm{Kg} / \mathrm{m}^{3}$. 


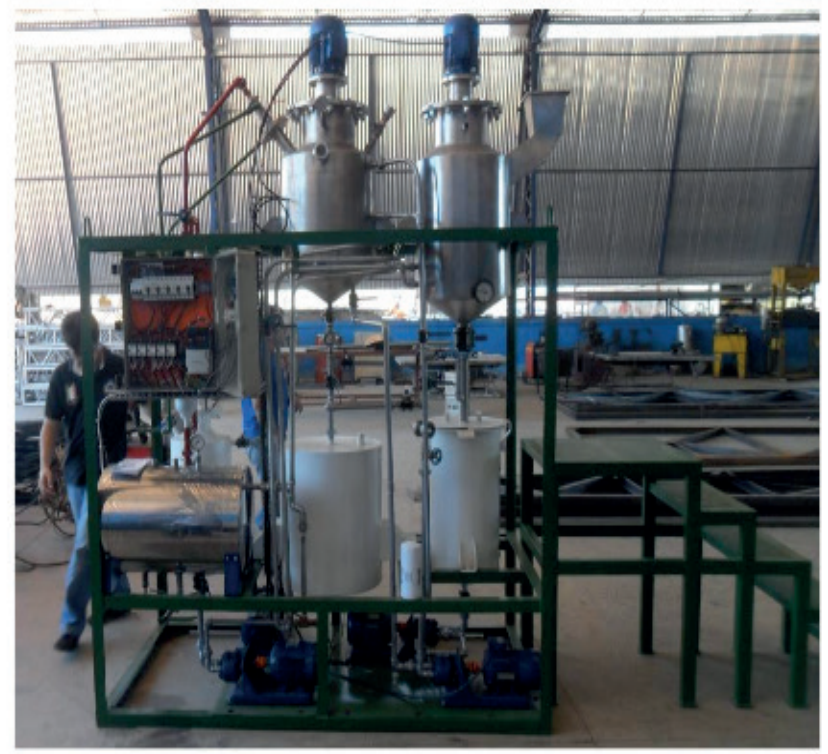

(a)

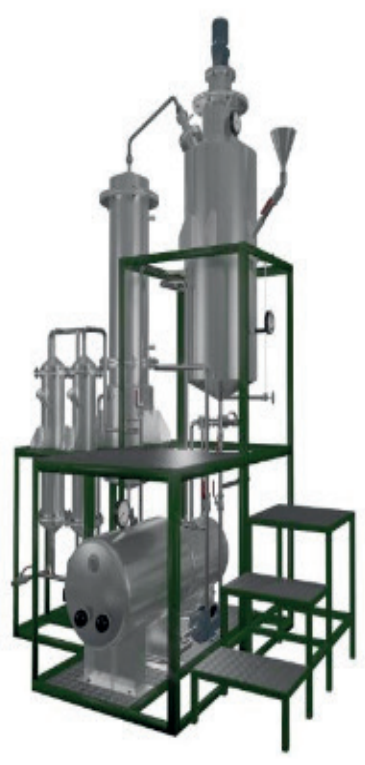

(b)

Figura 3 - Maquina Biopeixes (a) - Reator Multifuncional (b)

Com estes dados foi possível construir a Tabela 4. Nesta temos um resumo da energia produzida e carga de material destinada ao sistema.

\begin{tabular}{|c|c|c|c|c|}
\hline Equipamento & Consumo & $\begin{array}{c}\text { Produção } \\
\text { (h) }\end{array}$ & $\begin{array}{c}\text { Tempo de } \\
\text { operação (h) }\end{array}$ & $\begin{array}{c}\text { Produção } \\
\text { (dia) }\end{array}$ \\
\hline $\begin{array}{c}\text { Maquina } \\
\text { Biopeixes }\end{array}$ & $\begin{array}{c}625,0 \mathrm{Kg} \text { de } \\
\text { Vísceras }\end{array}$ & $25,0(\mathrm{~L} / \mathrm{h})$ & $10(\mathrm{~h})$ & $250,0(\mathrm{~L})$ \\
\hline $\begin{array}{c}\text { Reator } \\
\text { Multifuncional }\end{array}$ & $\begin{array}{c}800,00 \mathrm{~L} \\
(\text { óleo)/160,00 } \\
\text { L(álcool) }\end{array}$ & $\begin{array}{c}100,0 \\
(\mathrm{~L} / \mathrm{h})\end{array}$ & $8(\mathrm{~h})$ & $800,0(\mathrm{~L})$ \\
\hline
\end{tabular}

Tabela 4 - Produtividade Reator e Maquina Biopeixes

Com os dados apresentados na Tabela 4 podemos compor a energia total produzida em um dia de operação da maquina biopeixes e reator multifuncional. Estes dados são apresentados na Tabela 5.

\begin{tabular}{ccccc}
\hline Equipamento & $\begin{array}{c}\text { Consumo } \\
\text { diário de } \\
\text { Biodiesel (L) }\end{array}$ & $\begin{array}{c}\text { Emergia } \\
\text { Gerada em } \\
\text { Kcal }\end{array}$ & $\begin{array}{c}\text { Energia } \\
\text { Gerada } \\
\text { em KW.h }\end{array}$ & $\begin{array}{c}\text { Numero de casas } \\
\text { Abastecidas }\end{array}$ \\
\hline Gerador de Energia & 111,5 & $842.549,75$ & 980,64 & 22 \\
\hline
\end{tabular}

Tabela 5 - Energia gerada com a combustão do Biodiesel de Tilápia 
Com os dados mostrado na Tabela 5 e possível observar que a utilização desta tecnologia é algo viável. O conceito de geração de energia e aproveitamento de resíduos sólidos torna-se uma prática sustentável e que poderá beneficiar a população em povoados em que as redes de distribuição de energia ainda são precárias. Uma única batelada de biodiesel produzido de vísceras de tilápia é capaz de produzir 7.845,12 KW.h de energia e alimentar 176 casas em único dia.

Os valores dos equipamentos, para produção de biodiesel utilizando o reator multifuncional, em termos de capacidades produtivas são apresentados na Tabela 06 . Observa-se que os sistemas apresentados apresentam valores que variam de $\mathrm{R} \$$ $88.863,03$ a $\mathrm{R} \$ 152.622,40$. Ou seja, a unidade multifuncional destinada a produção de biodiesel poderá chegar a representar um valor de bastante reduzido, quando comparada a outras unidades produtivas em funcionamento no mercado.

A unidade Biopeixes, apresentada por Mota et al. (2019), foi avaliada na ordem de US\$ 73,598.72 (aproximadamente $\mathrm{R} \$ 294.395,72$ ). Com isso, a instalação do conjunto reator multifuncional e maquina Biopeixes dependerá da capacidade a ser processada no reator.

Para o caso da utilização de óleos vegetais, o valor do biodiesel processado, no reator multifuncional, ainda apresenta um custo elevado. Isso ocorre do fato dos altos custos apresentados na compra da matéria prima. Uma vez que, atualmente, o preço do óleo vegetal esta na ordem de $\mathrm{R} \$ 3,000$ reais por litro consumido. Sabe-se, porém, que, no caso do processamento do óleo de rejeitos de pescados, o valor do biodiesel final poderá cair bruscamente devido a retirada dos custos com esse insumo.

\begin{tabular}{ccc}
\hline Capacidade $(\mathrm{kg} / \mathrm{h})$ & Custo da planta $(\mathrm{R} \$)$ & Preço do biodiesel $(\mathrm{R} \$ / \mathrm{l})$ \\
\hline 50 & $88.863,03$ & 3,17 \\
100 & $110.188,93$ & 3,14 \\
150 & $152.622,40$ & 3,12 \\
\hline
\end{tabular}

Tabela 6 - Valores das Unidades de produção

Ainda ressaltando, em unidades de grande capacidade, como de 200 toneladas por dia, já mencionadas, embora o custo produtivo siga as mesmas verificações realizadas neste trabalho, a corporação tende a obter uma maior lucratividade pois fora o biodiesel o sistema ainda produz alguns derivados produtivos como ácidos graxos, torta de grãos etc.

A configuração que se espera após a instalação desta tecnologia em locais remotos nos quais a distribuição de energia ainda e de difícil acesso e mostrado na Figura 4. 


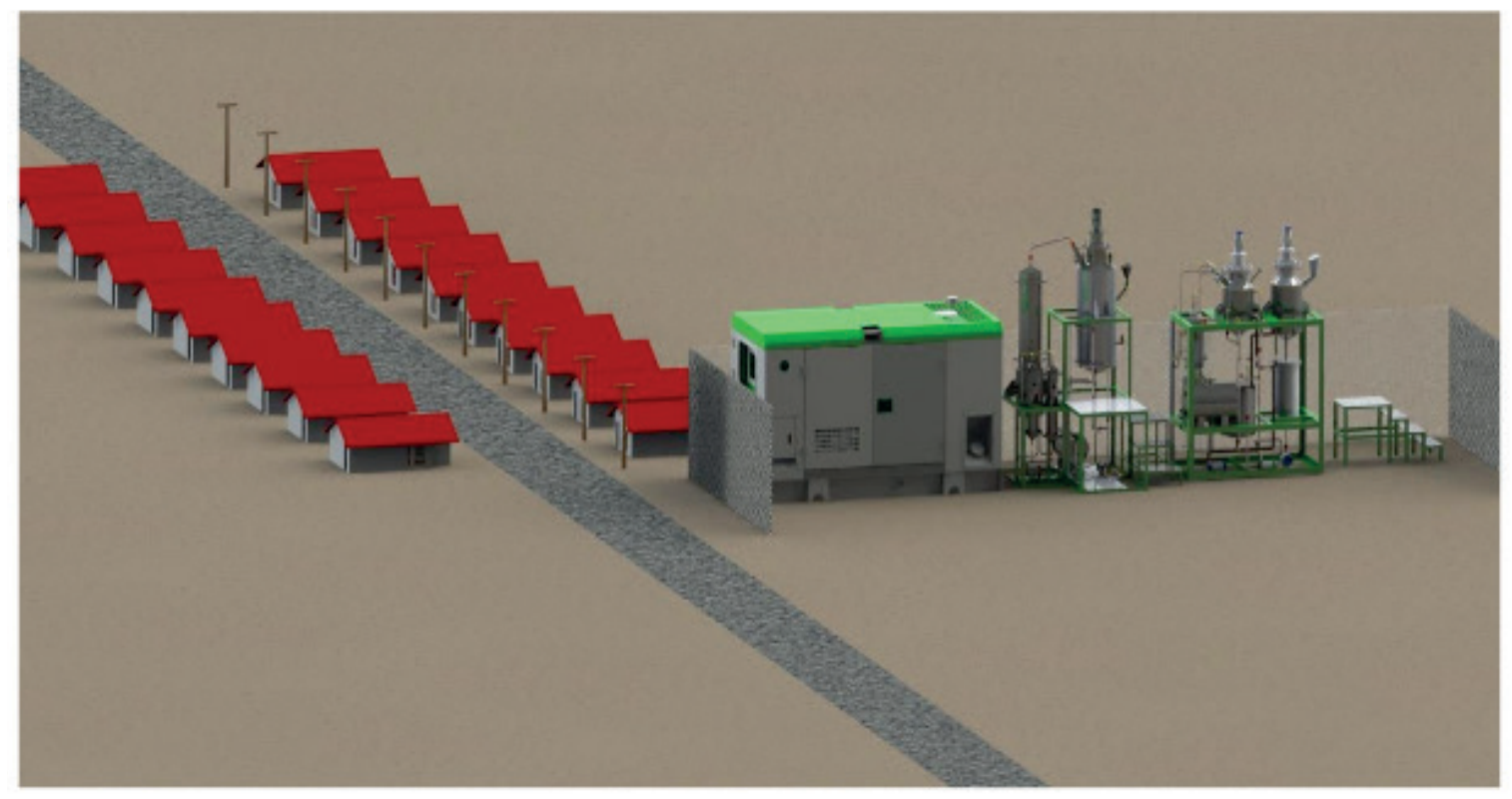

Figura 4 - Ilustração mostrando o conjunto"Máquina Biopeixes", "Reator Multifuncional” e Grupo Gerador

\section{4 | CONCLUSÕES}

O Sistema "Maquina Biopeixes" em conjunto com "Reator Multifuncional" e Grupo Gerador se mostrou viável para produção de energia a partir de óleo extraído das vísceras de peixes quando analisado a demanda real de energia de vilas isoladas e sem acesso às linhas de distribuição de energia, necessitando baixa quantidade de pescado para suprir a necessidade de óleo diária para geração de energia para a comunidade podendo se tornar uma fonte de renda, promovendo uma melhor qualidade de vida, crescimento econômico sustentável e qualificação profissional. Observou-se que o conjunto desenvolvido tem capacidade de gerar 980,64 KW.h com apenas 111,5 litros de biodiesel de tilápia. Os valores das unidades, final para instalação, foi de $\mathrm{R} \$$ $383.258,75$ para completo de $50 \mathrm{~kg} / \mathrm{h}$ e $447.018,12$ para a produção de $150 \mathrm{~kg} / \mathrm{h}$. Desta forma, a instalação destas unidades produtivas poderá proporcionar uma melhoria socioeconômico de populações que não possuem fácil acesso à energia elétrica.

\section{REFERÊNCIAS}

GARCIA-MORENO, P.G.; GUADIX, A.; GUADIX, E.M. et al. Optimization of biodiesel production from wast fish oil. Renewable Energy, n.68, p.618-624, 2014.

GHOBADIAN, B, YAHYAEE R, NAJAFI G. Waste fish oil biodiesel as a source of renewable fuel in Iran. Renew. Sustainable Energy Reviews, 2013; 17: 312-19.

GEORGIANNIA, K.G.; KONTOMINASA, M.G.; POTONISA, P.J. et al. Conventional and in situ transesterification os sunflower oil for the production of biodiesel. Fuel processing technology, $v, 89$, p. 503-509, 2008.

HASSEN-TRABELSI, A.B.; KRAIEM, T.; NAOVI, S. et al. Characterization of the líquid products obtained of the liquid products obtained from Tunisian wast fish fats using the pyrolysis process. Fuel processing Technology, n.138, p.404-412, 2015. 
LEE, S.B.; PARK, J.W.; HONG, I.K. Optimization of fish- oil based biodiesel synthesis. Journal of industrial and industrial Engineering chemistry, n.19, p.764-768, 2013

LIN, C.Y.; LI. R.J. Engine performance and characteristics of marine fish-oil biodiesel produced from the discarced parts of marine fish. Fuel processing Technology, n. 90, p.883-888, 2009.

MOTA, F.A. S, SANTOS, F.F.P.D., LIMA, A.A.S., MALVEIRA, J. D. Q., \& COSTA Filho, J. T.Desenvolvimento de uma unidade piloto destinada a extração do óleo de vísceras de tilápia para posterior utilização na cadeia produtiva de biodiesel. GEINTEC-Gestão, Inovação e Tecnologias, Vol. 4,n.3, p.1252-1269, 2014.

MOTA., F.A.S.; COSTA FILHO, J. T.; BARRETO, G. A. Characterization of the Nile Tilapia (sarotherodon niloticus) viscera waste (Dregs). Latin American Applied Research, v. 47, p. 125/47129, 2017.

MOTA, FRANCISCO A.S.; COSTA FILHO, J.T.; BARRETO, G.A. The Nile tilapia viscera oil extraction for biodiesel production in Brazil: An economic analysis. Renewable \& Sustainable Energy Reviews. v.108, p.1 - 10, 2019.

SCHIEWERS, S.; HOREL, A. Influence of flutuation temperature on biodegradation rates of fish biodiesel blends contaminating Alaskan Sand. Chemosphere, n.83, p. 652-660, 2011.

SILA, J.D.; SANTOS, C.E.; ZINANI, F. et al. Oil from the acid of Nile Tilapia wast: Physicochemical characteristics for its application as biofuel. Renewable Energy, n.80, p.331-337, 2015.

HU, J; HUE, B.T.H.; TURN, S.Q. Oxidation stability of biodiesel derived from waste catfish oil. Fuel, v, 202, p. 455-463, 2017.

VIDOTTI, R.M.; VIEGAS, E.M.M.; CARNEIRO, D.J. Amino acid composition of processed fish using diferent raw material. Animal Feed Science and Technology, v.105, p.199-204, 2003.

VOORT, F.R.V.; SIMPSOM, B.K.; ARYEE, A.M.A. FTIR determination of free fatty acids in fish oils intended for biodiesel production. Process Biochemistry, n.44, p.401-405, 2009.

WANG, J.; PRETO, F.; ZHONG, F. A study on using fish oil as an alternative fuel for conventional combustors. Fuel, v.87, p.2258-2268, 2008.

WU, Y.P.; HUANY, Y.J.; LIN, Y.F. et al. Mackerel biodiesel production from the wast water containing fish oil. Energy, n.70, p. 43-48, 2014. 


\section{ANÁLISE DE PERDAS TÉCNICAS EM SISTEMAS DE DISTRIBUIÇÃO}

Francisco Jeandson Rodrigues da Silva Professor do Centro Universitário 7 de Setembro (Uni7) e do Centro Universitário UniFanor Wyden (UniFanor). Aluno de doutorado do programa de pós-Graduação em Engenharia Elétrica da Universidade Federal do Ceará (UFC)

Fortaleza - Ceará

http://lattes.cnpq.br/9254887329263444

Ailson Pereira de Moura

Professor da Universidade Federal do Ceará

Fortaleza - Ceará

http://lattes.cnpq.br/7100954284070403

Adriano Aron Freitas de Moura Professor da Universidade Federal Rural do SemiÁrido (UFERSA) Mossoró - Rio Grande do Norte http://lattes.cnpq.br/7699437598190399

Douglas Aurélio Carvalho Costa Professor do Instituto Federal de Ensino, Ciência e Tecnologia do Ceará - Campus Cedro Cedro - Ceará http://lattes.cnpq.br/8501411209058844

Obed Leite Vieira Universidade Federal do Ceará (UFC) Fortaleza - Ceará http://lattes.cnpq.br/4112562673257492
RESUMO: Tradicionalmente, a análise de perdas técnicas em sistemas de distribuição é feita usando um programa de fluxo de carga. No entanto, a aplicação de uma metodologia usando dados de medição e simulação juntos não foi feita. Este artigo utiliza a demanda média de um dia representativo, medida no secundário dos transformadores de 69/13.8 $\mathrm{kV}$ de um alimentador do regional Sobral do sistema elétrico da Enel Distribuição Ceará, para calcular as perdas técnicas nesse alimentador. Os programas utilizados foram o de análise de redes elétricas (ANAREDE) e o programa Form do centro de pesquisas de energia elétrica (CEPEL). Os resultados mostram que o fluxo de potência ativa obtido nas oitos linhas primárias referente as simulações realizadas nos meses de agosto e setembro se aproximaram das medições de demanda das fronteiras. As variações em todas as linhas primárias ficaram abaixo $1 \mathrm{MW}$, consideradas normais. Já as variações de demanda em algumas linhas secundárias obtiveram grandes distorções, algumas chegando a valores acima de $1 \mathrm{MW}$, consideradas anormais. A partir das análises feitas criou-se um plano de projeto de obras e investimentos que tem data prevista para execução entre os anos de 2017 e 2021, visando a melhoria das perdas técnicas da regional SBD. 
PALAVRAS-CHAVE: Fluxo de Potência, Anarede, Perdas Técnicas.

\section{ANALYSIS OF TECHNICAL LOSSES IN DISTRIBUTION SYSTEMS}

ABSTRACT: Traditionally, the analysis of technical losses in distribution systems is done using a load flow program. However, the application of a methodology using measurement and simulation data together was not done. This paper uses the average demand of a representative day, measured on the secondary of the 69 / $13.8 \mathrm{kV}$ transformers of an Enel Distribuição Ceará regional electric system Sobral feeder, to calculate the technical losses in this feeder. The programs used were the analysis of electrical networks (ANAREDE) and the program form of the Center for research of electric energy (CEPEL). The results show that the active power flow obtained in the eight primary lines referring to the simulations performed in August and September approached the border demand measurements. Variations in all primary lines were below $1 \mathrm{MW}$, considered normal. Demand variations in some secondary lines had great distortions, some reaching values above $1 \mathrm{MW}$, considered abnormal. Based on the analyzes made, a project plan for works and investments was created, which is scheduled to be executed between 2017 and 2021, aiming at improving the technical losses of the regional SBD.

KEYWORDS: Power Flow, Anarede, Technical Losses.

\section{I INTRODUÇÃO}

No contexto atual em que vivemos, a energia elétrica deixou de apenas proporcionar conforto e passou a ser um produto essencial para o funcionamento e desenvolvimento de todos os setores. Todo o desenvolvimento, expansão e modernização do país está diretamente vinculado e dependente ao setor elétrico. Desse modo, torna-se necessário aumentar a eficiência dos sistemas de energia, elevando seu nível de confiabilidade através da redução de perdas aliado a diminuição dos custos provenientes das mesmas (FISCHER \& PAIXÃO \& SAUSEN, 2017, p. 2).

Os métodos para a resolução do problema de fluxo de potência nos sistemas de distribuição começaram a serem criados na década de 1950, com o método de (WARD \& HALE, 1956, p. 398-404). Pouco tempo depois surgiu o método de NewtonRaphson (VAN NESS, 1959, p. 583-588) \& (TINNEY \& HART, 1967, p. 1449-1456). Em seguida, na década de 1970 foram surgindo novos métodos, como por exemplo, os métodos desacoplados, já com base no método de Newton-Raphson (STOTT \& ALSAÇ, 1974, p. 859-869). Atualmente, já existem programas computacionais que rapidamente resolvem problema de fluxo de carga, como por exemplo, o ANAREDE e PSCAD. Desta forma, os métodos de análises de fluxo potência vem cada vez mais se aperfeiçoando.

Os estudos de fluxo de potência para distribuição eram realizados com pouca ênfase, por esse motivo, os sistemas de distribuição eram superdimensionados. Com 
o passar dos anos, as redes elétricas foram submetidas a um aumento constante de demanda de carga, fazendo com que estes sistemas chegassem a sua capacidade máxima e impactando no aumento das perdas por efeito joule (MARTINS, 2018, p. 6).

Os estudos de fluxos de potência são de muita importância no planejamento e desenho dos sistemas de potência como também na determinação das melhores condições de operação, controle e supervisão dos sistemas existentes. A determinação do estado da rede é essencial a qualquer sistema de energia elétrica. O fluxo de carga ou fluxo de potência consiste em determinar os módulos e ângulos da tensão em todas as barras ou nós do sistema, para uma determinada condição de geração e carga. 0 cálculo do fluxo de potência é a base da análise de um sistema de potência, sendo utilizado desde o planejamento até operação em tempo real (MARTINS, 2018, p. 1).

As concessionárias devem ter como meta central manter o fornecimento contínuo de energia e para isto precisam ampliar seus sistemas e melhorar a confiabilidade, o que implica em grandes investimentos. Se violarem os indicadores de continuidade, definidos pela ANEEL, pagam multas elevadas. Logo, se preocupam, quando na realização do planejamento da expansão da rede, não somente em minimizar custos de investimentos, mas também em considerar o atendimento aos critérios de confiabilidade requeridos para o sistema (MILOCA, 2012, p. 3).

Em estudos de planejamento voltados para perdas, é usual que se represente o carregamento do transformador como sendo um carregamento equivalente global, sem distinguir as suas parcelas constituintes, ou seja, o consumo de energia faturado, as perdas comerciais, e as perdas técnicas. As perdas técnicas são relativamente conhecidas e monitoradas, e se originam da circulação de correntes nos elementos das redes elétricas, sendo calculadas sistematicamente nos estudos de planejamento da operação (OLIVEIRA et. al., 2016, p. 2).

Todas estas mudanças trazem novos desafios aos profissionais que atuam nas empresas do setor elétrico, particularmente aqueles que atuam nas empresas de distribuição, que constitui o elo de conexão dos consumidores com o sistema (KAGAN \& OLIVEIRA \& ROBBA, 2010, p. 1-325).

A motivação surgiu durante um estudo realizado quando o cálculo do balanço de energia em alta tensão estava em fase de desenvolvimento, cujo objetivo principal era criar uma metodologia que pudesse de fato ser aplicada ao sistema real e que envolvam critérios para detectar em quais trechos estavam as maiores perdas, de modo que o planejador da concessionária pudesse utilizá-la de forma a auxiliar de modo eficiente no seu trabalho de planejamento da expansão da rede.

O objetivo deste trabalho é demonstrar as etapas de uma simulação do fluxo de potência das linhas primárias e secundarias, utilizando a demanda média de um dia representativo e observar em quais trechos possuem as maiores perdas técnicas da regional SBD que compõe o sistema na Enel Distribuição Ceará.

O trabalho está dividido em cinco tópicos, descritos a seguir: Metodologia Aplicada, Análise dos Resultados, Projeto de Obras e Investimento, Conclusões 
e Referências Bibliográficas. O segundo tópico aborda em detalhes a metodologia utilizada. O tópico três mostra os resultados e as análises das simulações. O tópico quatro mostra as ações tomadas para planejamento de obras e investimentos. $\mathrm{Na}$ conclusão são apresentados os resultados encontrados e as considerações finais do estudo e nas referências bibliográficas são citadas as principais fontes utilizadas.

\section{I METODOLOGIA APLICADA}

Para o desenvolvimento dessa técnica foram realizadas pesquisas bibliográficas sobre fluxo de potência e em manuais dos programas utilizados. Inicialmente foram consideradas todas as medições de fronteiras das linhas de distribuição (LD) em $69 \mathrm{kV}$ da regional SBD e as respectivas medições de saída dos transformadores de 69/13,8 kV conectadas no seu secundário. Portanto, as LD's em 69 kV primárias consideradas foram a SBD - 02J1, SBD - 02J2, SBD - 02J3, SBD - 02J4, SBD - 02J5, SBD 02J6, SBD - 02J7 e SBD - 02J8 e para a segmentação por eixo secundário foram considerados todos os trechos que estão conectadas com as mesmas. As linhas atendem as cargas do interior do estado do Ceará, conforme é mostrado na Figura 1.

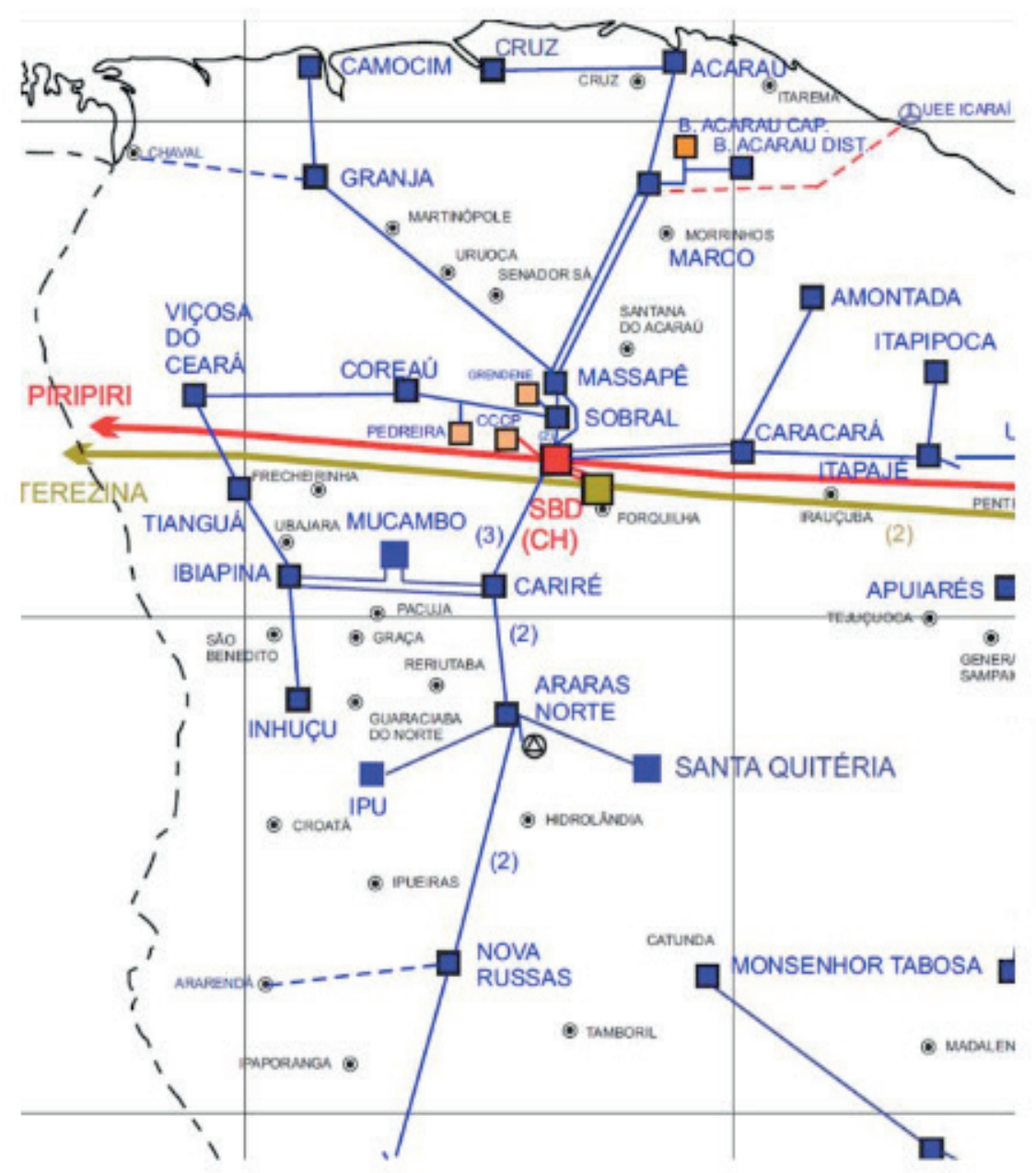

Figura 1 - Mapa elétrico da rede básica do regional Sobral (SBD) 
Após escolher as linhas para a realização do estudo, foi necessário obter alguns dados do sistema para realizar as comparações entre as potências medidas e as potências simuladas das medições de fronteira e também para a análise segmentada das perdas técnicas por eixo. As medições de fronteira primárias das LD's (Input do sistema) foram adquiridas através do sistema de Telemetria PIM (Plataforma Integrada de Medição), enquanto que os dados medidos de demanda (Output do sistema - saída dos Trafos) foram adquiridos pela plataforma Enterprise, ambos sistemas corporativos da Enel.

As simulações foram realizadas usando o programa ANAREDE e Form que são utilizados nas áreas de planejamento e operação das concessionárias de energia elétrica. O ANAREDE é o mais utilizado no Brasil para análise de sistemas elétricos de potência em regime permanente. Reúne programas de fluxo de potência, equivalente de redes, análise de contingências, análise de sensibilidade de tensão e de fluxo, e análise de segurança de tensão (CEPEL, 2017).

As simulações tiveram foco apenas na regional SBD devido ao alto índice de perdas técnicas em alta tensão, quando comparado com as outras regionais existentes. Foram utilizadas as demandas médias de um dia representativo de cada um dos dois meses analisados (agosto e setembro de 2016) para minimizar os efeitos de possíveis transferências de cargas que interferem nos resultados.

Após definido o dia mais próximo da demanda média dos meses citados foi alimentado a planilha (ver Figura 2) para gerar os casos com extensão PWF e logo depois processado o fluxo de carga no ANAREDE. Em seguida, foi gerado o relatório form a partir dos dados medidos das medições de saídas do secundário dos transformadores 69/13,8 kV para a análise das linhas primárias.

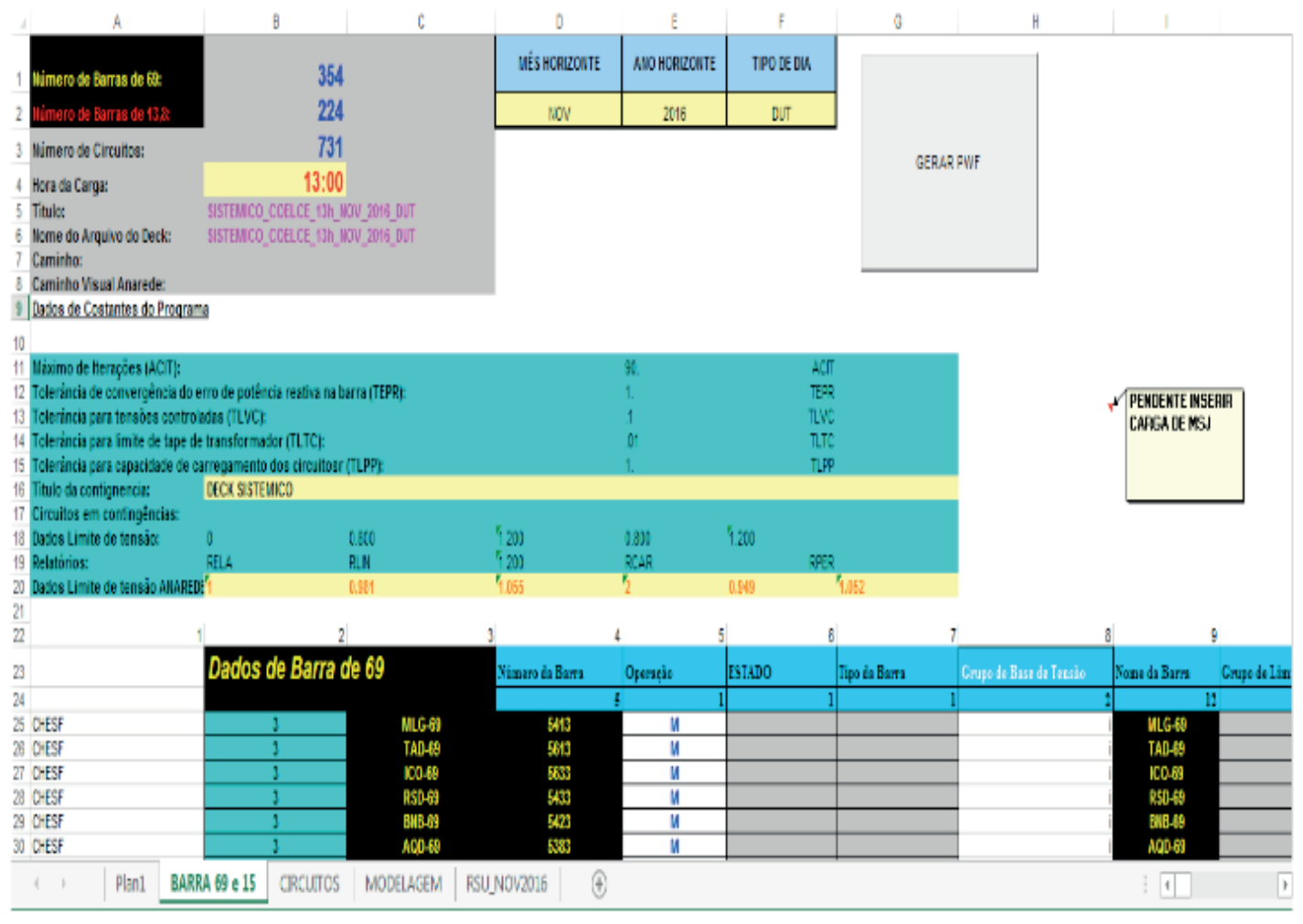


Por fim, após adquiridos todos os dados realizou-se o fluxo de potência referente a cada trecho primário e secundário da regional e observou-se no diagrama elétrico as perdas detalhadas por eixo para as análises das linhas.

\section{I ANÁLISE DOS RESULTADOS}

Para a análise das perdas técnicas das linhas de distribuição primárias foi necessário realizar simulações em dois meses, com o objetivo também de garantir que as medições de fronteira das respectivas linhas estejam sem nenhum problema com o registro de demanda e não venha a interferir nos resultados simulados nas linhas secundárias. Neste período iniciou-se as análises através da metodologia descrita no capitulo 2 e a partir daí identificou-se que a regional SBD possui um alto índice de perdas em algumas linhas secundárias, assim foi possível mostrar com mais detalhes a confiabilidade da sistemática de análise através da metodologia aplicada.

O Gráfico 1 mostra as perdas acumuladas/ano de 2016 das 11 regionais que compõem o sistema da companhia. A regional SBD acumulou uma perda de 84,3 GWh correspondente a 5,51\%, sendo muito superior as outras regionais, desta forma motivou um estudo detalhado da respectiva região.

$=$ ENERGIA (GWh) $\quad$ -

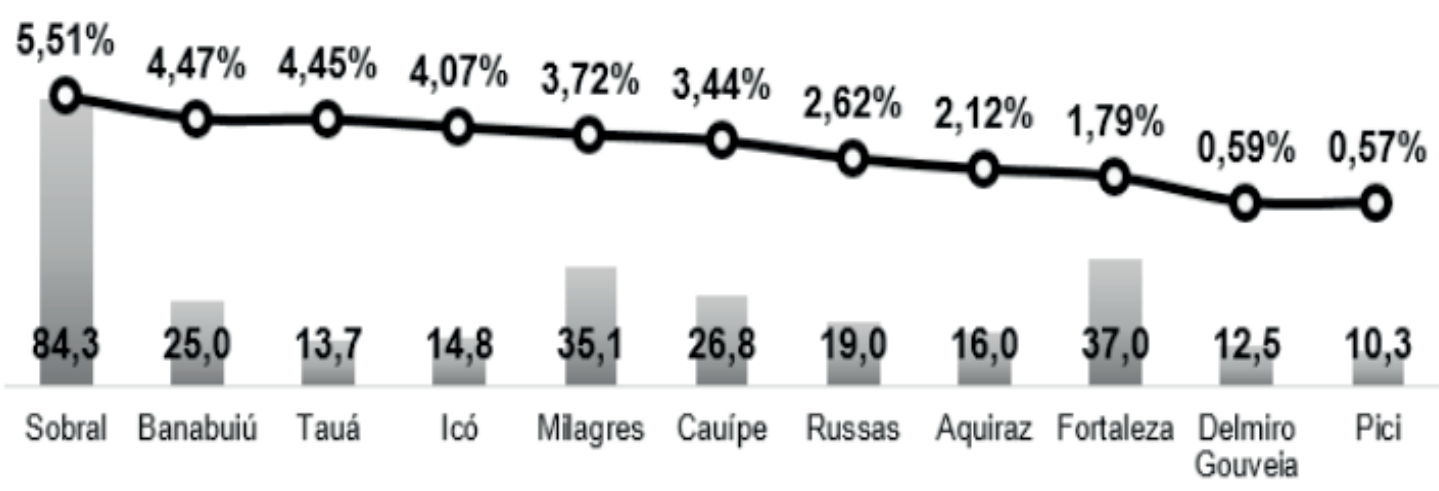

Gráfico 1 - Perdas técnicas acumuladas do ano de 2016 das regionais

O sistema de alta tensão da companhia possui 173 medições no secundário dos transformadores de 69/13,8 kV, 11 geradoras alternativas conectadas diretamente no barramento de $69 \mathrm{kV}$ das subestações, 35 clientes livres e 24 clientes cativos todos com tensão de fornecimento de $69 \mathrm{kV}$. O diagrama unifilar mostrado na Figura 3 resume a localização das medições do sistema em alta tensão. 


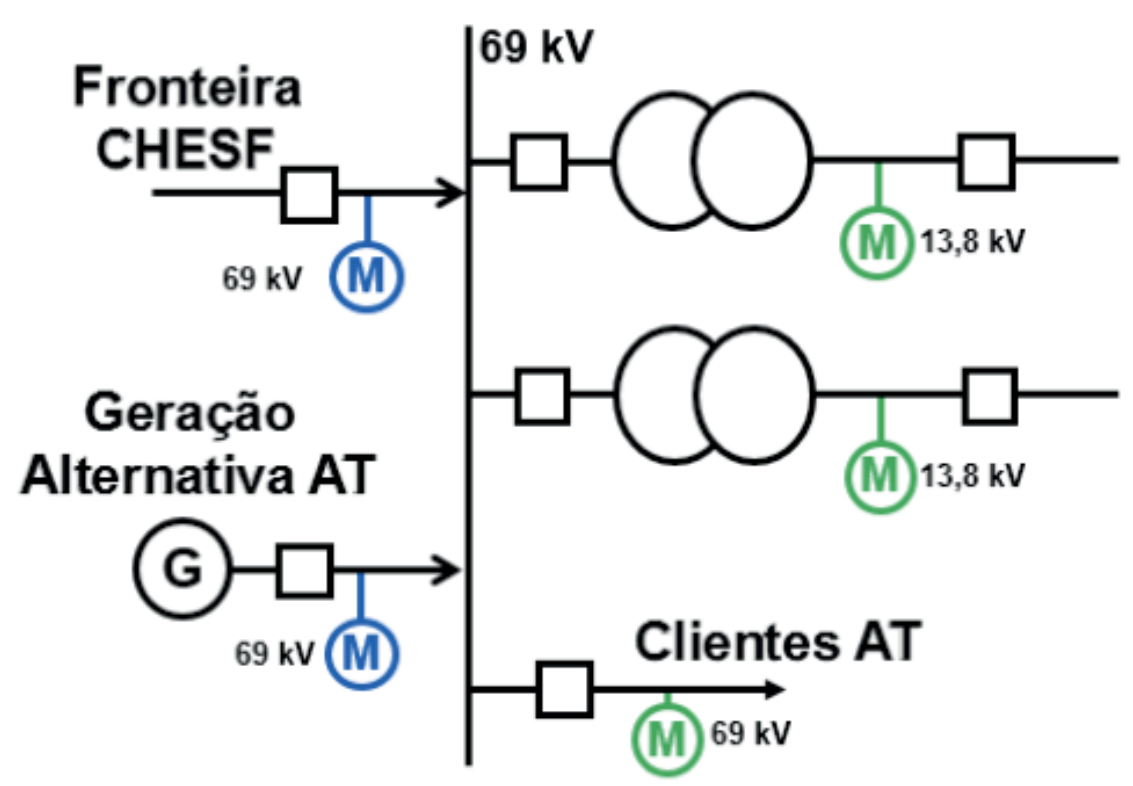

Figura 3 - Diagrama unifilar do sistema de alta tensão da Enel Ceará

Na Tabela 1 é destacado os resultados do ANAREDE dos fluxos de potência ativa referente à simulação realizada no mês de agosto das linhas primárias da regional SBD, que foram estimadas a partir dos dados medidos das cargas de saídas conectadas nas respectivas linhas.

\begin{tabular}{|c|c|c|c|c|c|c|}
\hline \multicolumn{5}{|c|}{ ANAREDE } & \multicolumn{2}{|c|}{ Mediçăo } \\
\hline Nome da barra 'DA' & Nome da barra 'PARA' & LDAT & $\begin{array}{l}\text { Número do } \\
\text { circuito }\end{array}$ & $\begin{array}{c}\text { Fluxo de potência ativa } \\
\text { entre as barras } \mathrm{K} \text { e } M \text { [MW] }\end{array}$ & Balanço AT & Variação \\
\hline SBD-69 & CRE - 69 & $02 \mathrm{~J} 1$ & 1 & 22,7064 & 23,3336 & 0,6272 \\
\hline SBD-69 & SBU -69 & $02 \mathrm{~J} 3$ & 2 & 38,0687 & 37,5697 & $-0,4990$ \\
\hline SBD-69 & SBU - 69 & $02 \mathrm{~J} 4$ & 1 & 37,9237 & 37,5417 & $-0,3820$ \\
\hline SBD-69 & MSP -69 & $02 \mathrm{~J} 5$ & 1 & 20,6363 & 20,8529 & 0,2166 \\
\hline SBD-69 & Drv1.CRE- 69 & $02 \mathrm{~J} 6$ & 1 & 20,8600 & 20,8325 & $-0,0275$ \\
\hline SBD-69 & CRE -69 & $02 \mathrm{~J} 7$ & 2 & 20,7503 & 20,5004 & 0,2499 \\
\hline SBD-69 & CRC -69 & 0212 & 2 & 14,5574 & 14,7071 & 0,1497 \\
\hline SBD-69 & CRC -69 & 0218 & 1 & 14,5008 & 14,3553 & $-0,1455$ \\
\hline
\end{tabular}

Tabela 1 - Comparação do fluxo de potência gerado pelo relatório form e as medições de fronteira das linhas primárias referente ao mês de agosto

Os resultados do fluxo de potência ativa das oitos linhas primárias referente as simulações realizadas no mês de agosto se aproximaram das medições de demanda das fronteiras. As variações em todas as linhas ficaram abaixo $1 \mathrm{MW}$, consideradas normais.

No mês de setembro os resultados também foram satisfatórios, apesar das linhas 02J3 e 02J4 apresentarem uma variação maior que no mês de agosto, mas ainda ficou com um patamar de variação normal. As demais linhas ficaram com variações abaixo de $1 \mathrm{MW}$, conforme é mostrado na Tabela 2. 


\begin{tabular}{|c|c|c|c|c|c|c|}
\hline \multicolumn{5}{|c|}{ ANAREDE } & \multicolumn{2}{|c|}{ Medição } \\
\hline Nome da barra 'DA' & Nome da barra 'PARA' & LDAT & $\begin{array}{c}\text { Número do } \\
\text { circuito }\end{array}$ & $\begin{array}{c}\text { Fluxo de potência ativa } \\
\text { entre as barras } K \text { e M [MW] }\end{array}$ & Balanço AT & Variação \\
\hline SBD-69 & CRE - 69 & $02 \mathrm{~J} 1$ & 1 & 24,4020 & 24,9917 & 0,5897 \\
\hline SBD-69 & SBU -69 & $02 \mathrm{J3}$ & 2 & 34,8409 & 33,7492 & $-1,0917$ \\
\hline SBD-69 & SBU- 69 & $02 \mathrm{J4}$ & 1 & 34,9719 & 33,7284 & $-1,2435$ \\
\hline SBD-69 & MSP - 69 & $02 \mathrm{J5}$ & 1 & 21,3640 & 21,5639 & 0,1999 \\
\hline SBD-69 & Dr1.CRE-69 & $02 \mathrm{~J} 6$ & 1 & 22,4178 & 22,3058 & $-0,1120$ \\
\hline SBD-69 & CRE - 69 & $02 \mathrm{J7}$ & 2 & 22,2998 & 21,9778 & $-0,3220$ \\
\hline SBD-69 & CRC - 69 & $02 \mathrm{~J} 2$ & 2 & 14,5526 & 14,6620 & 0,1094 \\
\hline SBD-69 & CRC - 69 & 02.J8 & 1 & 14,4979 & 14,6620 & 0,1641 \\
\hline
\end{tabular}

Tabela 2 - Comparação do fluxo de potência gerado pelo relatório form e as medições de fronteira das linhas primárias referente ao mês de setembro

Para uma análise mais detalhada foram simuladas as perdas nas linhas secundárias. As análises foram segmentadas em três eixos: Sobral/Massapê, Caracará e Cariré. Na Figura 4 é ilustrado os eixos citados anteriormente e as suas respectivas subestações correspondentes.

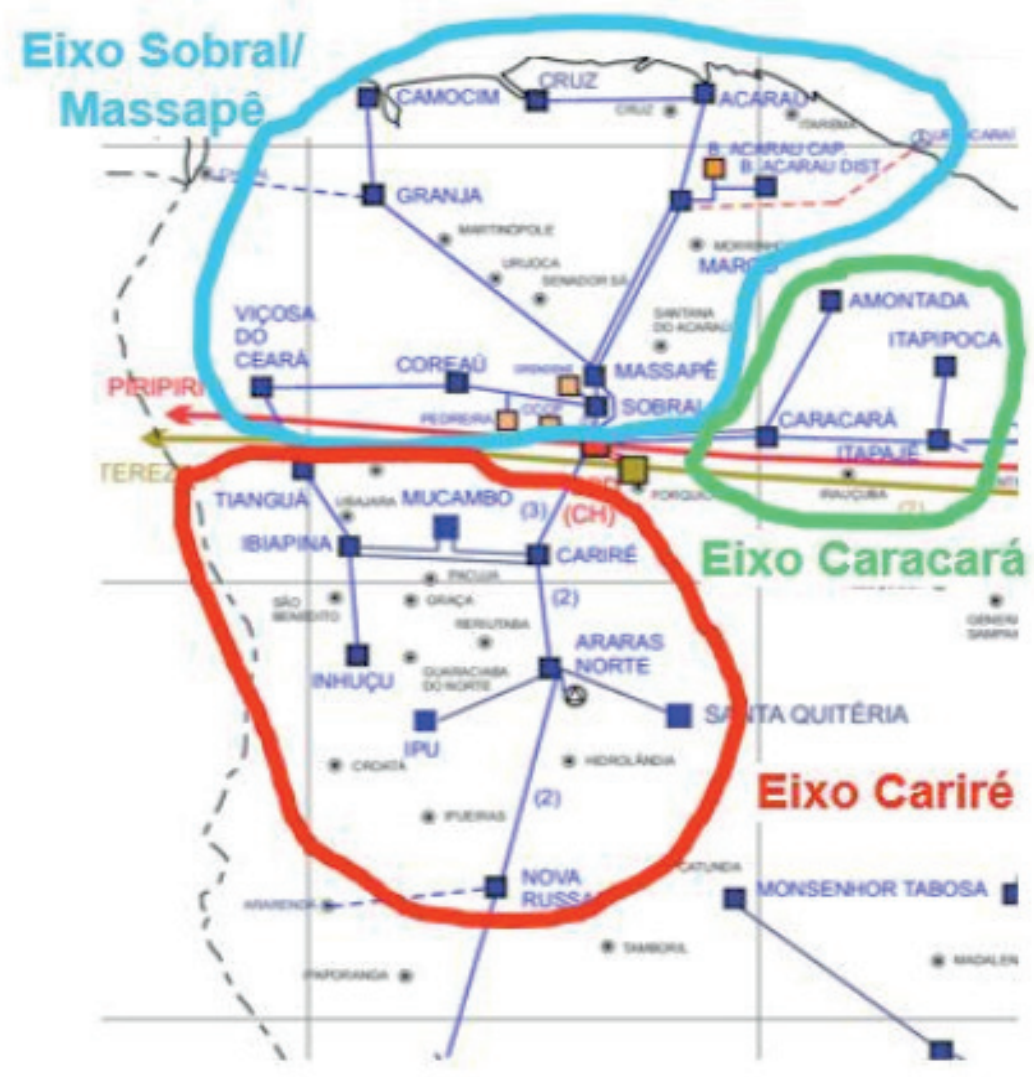

Figura 4 - Mapa elétrico da rede básica com a divisão dos eixos da regional SBD

O eixo Sobral/Massapê possui as linhas primárias SBD 02J3, 02J4 e 02J5 que fazem fronteira com a Chesf. As linhas secundárias foram analisadas detalhadamente trecho a trecho conforme é mostrado na Tabela 3. Os trechos secundários destacados em verde foram os que obteram resultados de perdas técnicas por demanda aceitável, já os destacados em vermelho foram as linhas secundárias que tiveram os maiores 
índices. O trecho que chamou atenção foi o Massapê (MSP) - Granja (GRJ) com valores de perdas em porcentagem (\%) de 4,62 e 5,95 para os meses de agosto e setembro respectivamente.

\begin{tabular}{|c|c|c|c|c|c|c|c|c|c|c|c|c|c|c|}
\hline \multicolumn{6}{|c|}{ EIXO Sobral/Massapê } & \multicolumn{4}{|c|}{ AGOSTO/2016 } & \multicolumn{4}{|c|}{ SETEMBRO/2016 } & \multirow{2}{*}{ DIST. (KM) } \\
\hline & CIRCUITO & LT - front. 1 & LT $\cdot 69$ & & LT-69 & PONTO: & PONTO 2 & PERDA (MW) & PERDA (\%) & PONTO1 & PONTO: & PERDA (MM) & PERDA (\%) & \\
\hline \multirow{22}{*}{ CHESF } & 2 & $\rightarrow S_{B D}-0223$ & & $\cdots+\cdots$ & SBU & 38,1 & 38,0 & 0,1 & $0,26 \%$ & 35,0 & 34,9 & 0,1 & $0,29 \%$ & 2,81 \\
\hline & 3 & $\rightarrow \rightarrow S B D-024$ & & $\ldots \rightarrow$ & SBU & 37,9 & 37,8 & 0,1 & $0,26 \%$ & 34,8 & 34,8 & 0,0 & $0,00 \%$ & 2,81 \\
\hline & 4 & $\rightarrow$ SBD - 0225 & & $\cdots \rightarrow$ & MSP & 18,9 & 18,6 & 0,3 & $1,59 \%$ & 21,4 & 20,9 & 0,5 & $2,34 \%$ & 22,25 \\
\hline & 14 & & CRU & $\ldots$ & ves & 3,4 & 3,4 & 0,0 & $0,00 \%$ & 3,7 & 3,7 & 0,0 & $0,00 \%$ & $0, \infty$ \\
\hline & 15 & & Dev2P & $\cdots$ & CRU & 6,5 & 6,4 & 0,1 & $1,54 \%$ & 7,7 & 7,6 & 0,1 & $1,30 \%$ & 22,80 \\
\hline & 16 & & Dev2.P & $\cdots$ & PDR & 0,1 & 0,1 & 0,0 & $0,00 \%$ & 0,1 & 0,1 & 0,0 & $0,00 \%$ & $0, \infty$ \\
\hline & 17 & & Dev1p & $\cdots$ & Dev2PDF & 6,5 & 6,5 & 0,0 & $0,00 \%$ & 7,8 & 7,7 & 0,1 & $1,28 \%$ & 14,68 \\
\hline & 18 & & Dev1s & $\cdots$ & Dev1.PDA & 6,6 & 6,5 & 0,1 & $1,52 \%$ & 7,8 & 7,8 & 0,0 & $0,00 \%$ & 14,91 \\
\hline & 19 & & Dev1s & $\ldots . .>$ & $S B Q$ & 3,3 & 3,3 & 0,0 & $0,00 \%$ & 4,8 & 4,8 & 0,0 & $0,00 \%$ & 2,41 \\
\hline & 20 & & SBU & $\ldots$ & Dev1.sBd & 9,8 & 9,8 & 0,0 & $0,00 \%$ & 12,6 & 12,6 & 0,0 & $0,00 \%$ & 0,63 \\
\hline & 21 & & SBU & $\cdots$ & GRN & 12,8 & 12,8 & 0,0 & $0,00 \%$ & 4,2 & 4,2 & 0,0 & $0,00 \%$ & 3,92 \\
\hline & 22 & & SBU & $\ldots$ & MSP & 18,9 & 18,6 & 0,3 & $1,59 \%$ & 20,3 & 19,9 & 0,4 & $1,97 \%$ & 18,96 \\
\hline & 23 & & MSP & $\ldots \rightarrow$ & GRJ & 13,0 & 12,4 & 0,6 & $4,62 \%$ & 16,8 & 15,8 & 1,0 & $5,95 \%$ & 70,54 \\
\hline & 24 & & GRJ & $\cdots$ & CMM & 7,1 & 6,9 & 0,2 & $2,82 \%$ & 7,6 & 7,3 & 0,3 & $3,95 \%$ & 24,00 \\
\hline & 25 & & MSP & $\cdots$ & MRC & 9,9 & 9,6 & 0,3 & $3,03 \%$ & 8,1 & 7,9 & 0,2 & $2,47 \%$ & 53,44 \\
\hline & 26 & & MSP & $\ldots$ & MRC & 10,4 & 10,2 & 0,2 & $1,92 \%$ & 8,6 & 8,4 & 0,2 & $2,33 \%$ & 50,64 \\
\hline & 27 & & MRC & $\cdots$ & ACA & 17,2 & 16,7 & 0,5 & $2,91 \%$ & 19,9 & 19,2 & 0,7 & $3,52 \%$ & 33,70 \\
\hline & 28 & & ACA & $\cdots$ & CRZ & 4,7 & 4,6 & 0,1 & $2,13 \%$ & 6,2 & 6,1 & 0,1 & $1,61 \%$ & 39,46 \\
\hline & 29 & & MRC & $\cdots$ & Dev2 BXD & 6,3 & 6,3 & 0,0 & $0,00 \%$ & 5,8 & 5,8 & 0,0 & $0,00 \%$ & 3,18 \\
\hline & 30 & & EAA & $\cdots$ & MRC & 8,7 & 8,5 & 0,2 & $2,30 \%$ & 13,4 & 12,9 & 0,5 & $3,73 \%$ & 53,44 \\
\hline & 31 & & Dev28 & $\cdots$ & $\mathrm{BXU}$ & 0,0 & 0,0 & 0,0 & \#DIV/0! & 0,0 & 0,0 & 0,0 & HDIV/0! & 0,99 \\
\hline & 32 & & Dev2.8 & $\ldots$ & BXD & 6,3 & 6,3 & 0,0 & $0,00 \%$ & 5,8 & 5,7 & 0,1 & $1,72 \%$ & 7,69 \\
\hline
\end{tabular}

Tabela 3 - Resultados do relatório form com os fluxos de potência ativa das linhas primárias e secundárias da regional SBD referente ao mês de setembro e agosto

Para o eixo Cariré que possui as linhas primárias 02J1, 02J6 e 02J7 a quantidade de trechos com perdas elevadas foi maior que no eixo Sobral/Massapê. Os que mais se destacaram foram o Cariré (CRE) - Ibiapina (IBP) com valor de 5,03\% e a derivação do barramento existente entre Nova Russas (NVR) e Araras do Norte (ARU) que é o fct.NVR com índice de $4,17 \%$ e no mês de setembro os resultados foram $4,86 \%$ e $5,41 \%$ respectivamente, como especificado na Tabela 4.

\begin{tabular}{|c|c|c|c|c|c|c|c|c|c|c|c|c|c|c|}
\hline \multicolumn{6}{|c|}{ EIXO Cariré } & \multicolumn{4}{|c|}{ AGOSTO/2016 } & \multicolumn{4}{|c|}{ SETEMBRO/2016 } & \multirow{2}{*}{ DIST. (KM) } \\
\hline & $\overline{\text { CIRCUITO }}$ & LT - front. & $\overline{L T}-69$ & & $\begin{array}{ll}\text { LT }-69 \\
\end{array}$ & PONTO 1 & PONTO 2 & PERDA (MW) & PERDA (\%) & \begin{tabular}{|l|} 
PONTO 1 \\
\end{tabular} & PONTO 2 & PERDA (MW) & PERDA (\%) & \\
\hline \multirow{17}{*}{ CHESF } & 1 & $\ldots$ SBD - 021 & & 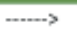 & CRE & 22,7 & 21,9 & 0,8 & $3,52 \%$ & 24,4 & 23,5 & 0,9 & $3,69 \%$ & 31,80 \\
\hline & 5 & $\ldots$ SBD-0216 & & $\rightarrow \rightarrow$ & Drv1CRE & 20,9 & 20,6 & 0,3 & $1,44 \%$ & 22,4 & 22,1 & 0,3 & $1,34 \%$ & 34,62 \\
\hline & 6 & $\rightarrow \rightarrow$ SBD-02J7 & & $\rightarrow-\rightarrow$ & CRE & 20,8 & 20,0 & 0,8 & $3,85 \%$ & 22,3 & 21,5 & 0,8 & $3,59 \%$ & 36,12 \\
\hline & 7 & & CRE & .....> & CRE & 2,2 & 2,2 & 0,0 & $0,00 \%$ & 2,7 & 2,7 & 0,0 & $0,00 \%$ & $0, \infty$ \\
\hline & 8 & & CRE & $\ldots$ & $\mathrm{IBP}$ & 19,9 & 18,9 & 1,0 & $5,03 \%$ & 18,5 & 17,6 & 0,9 & $4,86 \%$ & 49,00 \\
\hline & 9 & & CRE & $\ldots$ & MCB & 18,0 & 17,3 & 0,7 & $3,89 \%$ & 17,3 & 16,6 & 0,7 & $4,05 \%$ & 40,00 \\
\hline & 10 & & MCB & $\ldots$ & $\mathrm{IBP}$ & 12,8 & 12,6 & 0,2 & $1,56 \%$ & 10,8 & 10,7 & 0,1 & $0,93 \%$ & 19,33 \\
\hline & 11 & & $\mathrm{IBP}$ & $\ldots$ & INH & 11,1 & 10,9 & 0,2 & $1,80 \%$ & 10,7 & 10,5 & 0,2 & $1,87 \%$ & 23,50 \\
\hline & 12 & & IBP & $\ldots$ & TNG & 11,4 & 11,2 & 0,2 & $1,75 \%$ & 11,3 & 11,1 & 0,2 & $1,77 \%$ & 26,70 \\
\hline & 13 & & TNG & .....> & Disc).VCS & 0,0 & 0,0 & 0,0 & HDIV/0! & 0,0 & 0,0 & 0,0 & moIV/0! & 27,91 \\
\hline & 33 & & CRE & ….-> & ARU & 10,7 & 10,5 & 0,2 & $1,87 \%$ & 13,5 & 13,3 & 0,2 & $1,48 \%$ & 27,16 \\
\hline & 34 & & CRE & .....> & ARU & 11,4 & 11,2 & 0,2 & $1,75 \%$ & 14,4 & 14,2 & 0,2 & $1,39 \%$ & 29,00 \\
\hline & 35 & & ARU & .....> & Fct.NVR & 2,4 & 2,4 & 0,0 & $0,00 \%$ & 3,7 & 3,7 & 0,0 & $0,00 \%$ & 3,33 \\
\hline & 36 & & Fct.NV & $\ldots$ & NVR & 2,4 & 2,3 & 0,1 & $4,17 \%$ & 3,7 & 3,5 & 0,2 & $5,41 \%$ & 66,00 \\
\hline & 37 & & ARU & $\ldots$ & NVR & 4,9 & 4,8 & 0,1 & $2,04 \%$ & 6,7 & 6,5 & 0,2 & $2,99 \%$ & 67,40 \\
\hline & 38 & & ARU & .....> & SQT & 3,2 & 3,2 & 0,0 & $0,00 \%$ & 3,3 & 3,3 & 0,0 & $0,00 \%$ & 38,41 \\
\hline & 39 & & ARU & .....> & IPU & 4,9 & 4,8 & 0,1 & $2,04 \%$ & 4,9 & 4,8 & 0,1 & $2,04 \%$ & 29,63 \\
\hline
\end{tabular}

Tabela 4 - Resultados do relatório form com os fluxos de potência ativa das linhas primárias e secundárias da regional SBD referente ao mês de setembro e agosto do eixo Cariré 
Já o eixo Caracará que entre os três é o de menor extensão $(214,12 \mathrm{Km})$ as linhas primárias são a SBD 02J2 e a SBD 02J8 que estão conectadas diretamente no barramento de $69 \mathrm{kV}$ da subestação de Caracará (CRC). O trecho que apresentou a maior variação em MW foi o Caracará (CRC) - Itapajé (ITE) com valor de 1,1 e em porcentagem (\%) de 5,39 para o mês de agosto e em setembro as variações foram 0,9 MW e 4,74\%, conforme a Tabela 5.

\begin{tabular}{|c|c|c|c|c|c|c|c|c|c|c|c|c|c|c|}
\hline \multicolumn{6}{|c|}{ EIXO Caracará } & \multicolumn{4}{|c|}{ AGOSTO/2016 } & \multicolumn{4}{|c|}{ SETEMBRO/2016 } & \multirow{2}{*}{ DIST. (KM) } \\
\hline & CIRCUITO & LT - front. & $L T-69$ & & $L \mathrm{LT}-69$ & PONTO 1 & PONTO 2 & PERDA (MW) & PERDA (\%) & PONTO 1 & PONTO 2 & PERDA (MM) & PERDA (\%) & \\
\hline \multirow{8}{*}{ CHESF } & 1 & $\rightarrow>S B D-02 \sqrt{2}$ & & $\cdots>$ & CRC & 14,5 & 14,1 & 0,4 & $2,76 \%$ & 14,5 & 14,1 & 0,4 & $2,76 \%$ & 43,00 \\
\hline & 2 & $\rightarrow$ SBD - 0288 & & $\ldots$ & CRC & 14,6 & 14,1 & 0,5 & $3,42 \%$ & 14,6 & 14,1 & 0,5 & $3,42 \%$ & 44,86 \\
\hline & 3 & & CRC & $\cdots$ & CRC & 3,4 & 3,4 & 0,0 & $0,00 \%$ & 3,8 & 3,8 & 0,0 & $0,00 \%$ & $0, \infty$ \\
\hline & 4 & & CRC & $\ldots$ & AMT & 4,5 & 4,4 & 0,1 & $2,22 \%$ & 5,4 & 5,3 & 0,1 & $1,85 \%$ & 43,22 \\
\hline & 5 & & CRC & $\ldots$ & ITE & 20,4 & 19,3 & 1,1 & $5,39 \%$ & 19,0 & 18,1 & 0,9 & $4,74 \%$ & 50,00 \\
\hline & 6 & & ITE & $\cdots$ & ITK & 12,0 & 11,7 & 0,3 & $2,50 \%$ & 10,6 & 10,4 & 0,2 & $1,89 \%$ & 33,04 \\
\hline & 7 & & ITE & $\ldots->$ & ITE & 0,0 & 0,0 & 0,0 & \#DIV/O! & 0,0 & 0,0 & 0,0 & mOIV/o! & $0, \infty$ \\
\hline & 8 & & ITE & $\ldots \rightarrow$ & ITE & 7,3 & 7,3 & 0,0 & $0,00 \%$ & 7,4 & 7,4 & 0,0 & $0,00 \%$ & $0, \infty$ \\
\hline
\end{tabular}

Tabela 5 - Resultados do relatório form com os fluxos de potência ativa das linhas primárias e secundárias da regional SBD referente ao mês de setembro e agosto do eixo Caracará

No eixo Sobral/Massapê observou-se que a linha secundária que apresentou o maior índice de perdas técnicas foi a de maior distância $(70,54 \mathrm{Km})$, no entanto não foi a linha que circulou a maior magnitude de demanda em ambos os meses. Contudo essa mesma análise não se concretizou no eixo Cariré que para o mês de agosto a maior perda não foi na linha de maior distância e nem na que circulou o maior volume de demanda, já no mês de setembro a maior perda foi na linha de maior distância (66 $\mathrm{Km}$ ) que foi a derivação do barramento fct.NVR existente entre ARU para NVR, porém não foi a que circulou o maior volume de demanda. A Tabela 6 mostra um resumo das linhas com as maiores perdas.

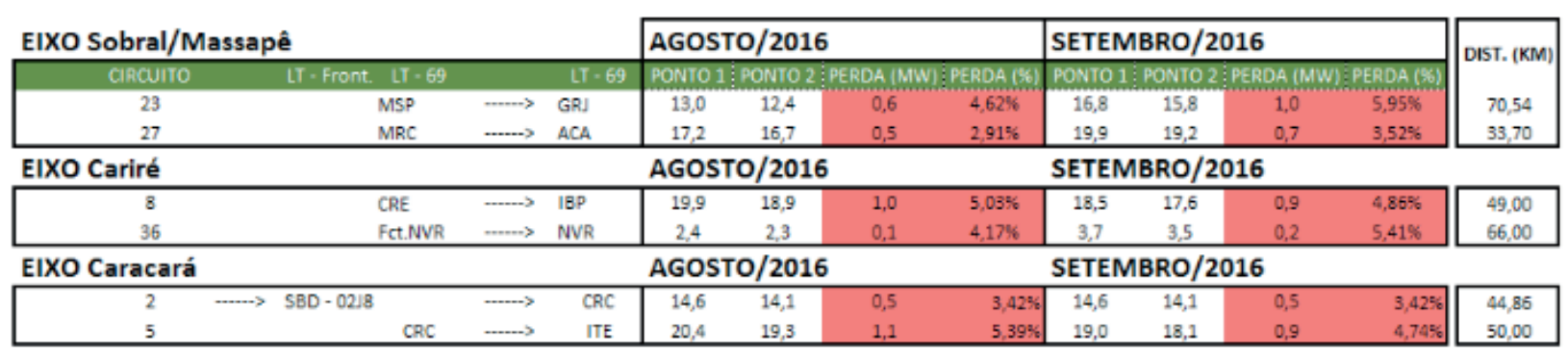

Tabela 6 - Resumo das linhas que obtiveram as maiores perdas técnicas

Para o eixo Caracará a linha secundária CRC para ITE foi a que se destacou com maior índice, a mesma tem a maior distância $(50 \mathrm{Km})$ e também foi a que circulou o maior volume de demanda quando comparado com as outras linhas em ambos os meses analisados. 


\section{I PROJETO DE OBRAS E INVESTIMENTO}

A partir das análises feitas, foi desenvolvido um plano de projeto de obras e investimentos que tem data prevista para execução entre os anos de 2017 e 2021, visando a redução das perdas técnicas da regional SBD. No esquema mostrado na Figura 5, a linha azul mostra o sistema atual do eixo Sobral/Massapê e a linha em vermelho as modificações elétricas planejadas. Está previsto entrar em operação do ponto de suprimento Acaraú II a construção de duas linhas de distribuição de alta tensão (LDAT) ACD I/ACA e ACD II/MRC. O investimento previsto para as obras no eixo é de MMR\$ 0,525 (meio milhão e vinte e cinco mil reais).

\section{Sistema Atual}

Projeto (2017-2021)

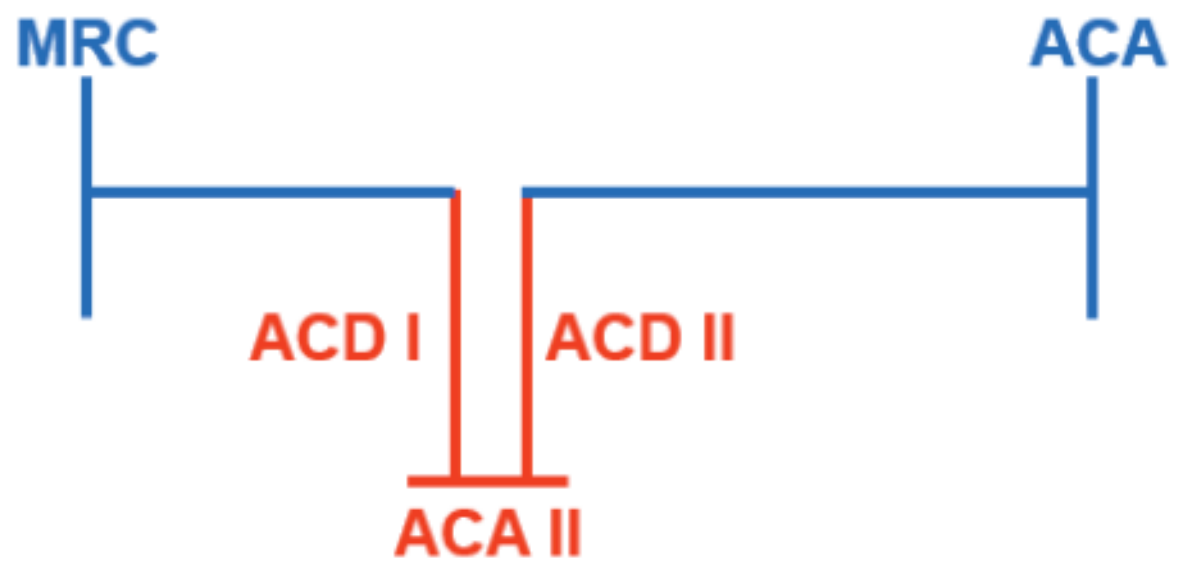

Figura 5 - Diagrama elétrico do sistema atual e das obras previstas para a melhoria da rede do eixo Sobral/Massapê

Já para o eixo Caracará (CRC) as obras previstas são de energizar a SED SBV, utilizando os dois circuitos de SBD/CRC; realizar a transferências da SED SBV para a linha de distribuição de alta tensão (LDAT) SBD/CRE para o recondutoramento do trecho SBD/SBV; construir uma nova LDAT SBD/CRC (terceiro Circuito); construir outra LDAT de Amontada (AMT) para Itapipoca (ITK) (fechamento do anel) e entrar uma nova LDAT CRC - ITE (segundo circuito). Na Figura 6 é mostrado o diagrama planejado das obras do eixo. Está estimado um investimento de MMR\$ 59,1 (cinquenta e nove milhões e cem mil reais). 


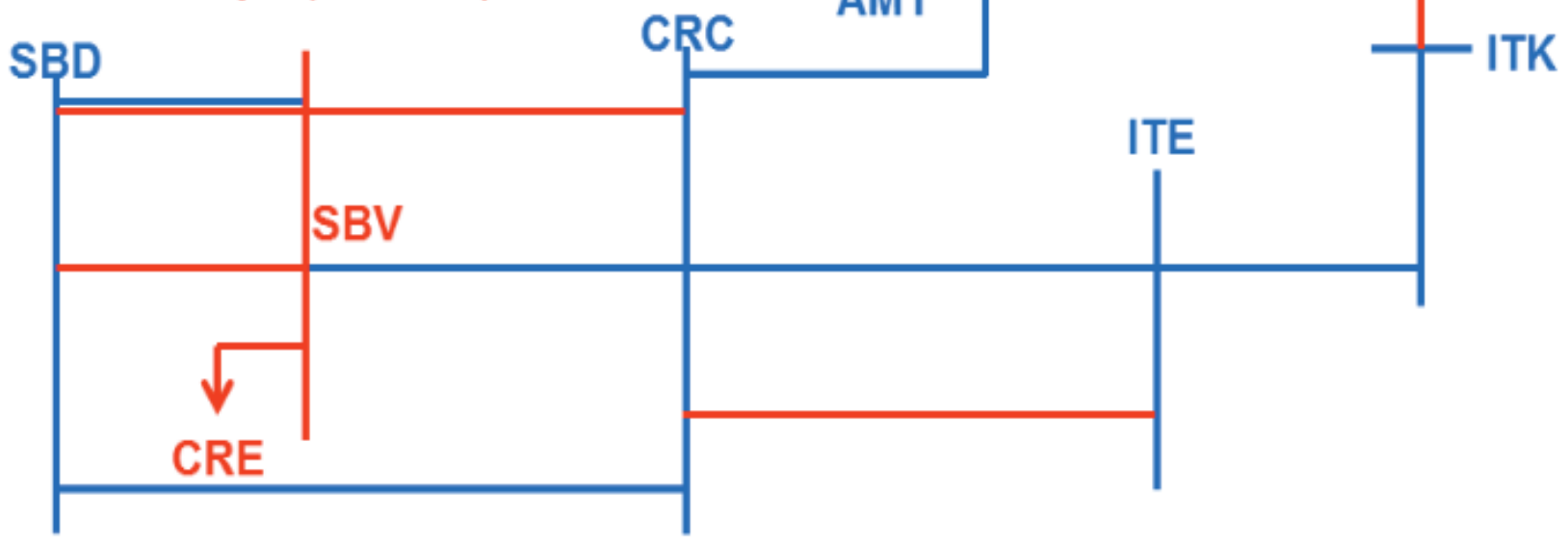

Figura 6 - Diagrama elétrico do sistema atual e das obras prevista para melhoria da rede do eixo CRC

Para o eixo Cariré está previsto a entrada em operação da LDAT Ibiapina (IBP II) para Ibiapina (IBP) e Ibiapina (IBP II) para Tianguá (TNG). Na Figura 7 a linha azul são as LD's atuais e em vermelho são as LD's previstas para construção. A aplicação para a criação das linhas é de MMR \$21,5 (vinte e um milhões e quinhentos mil reais).

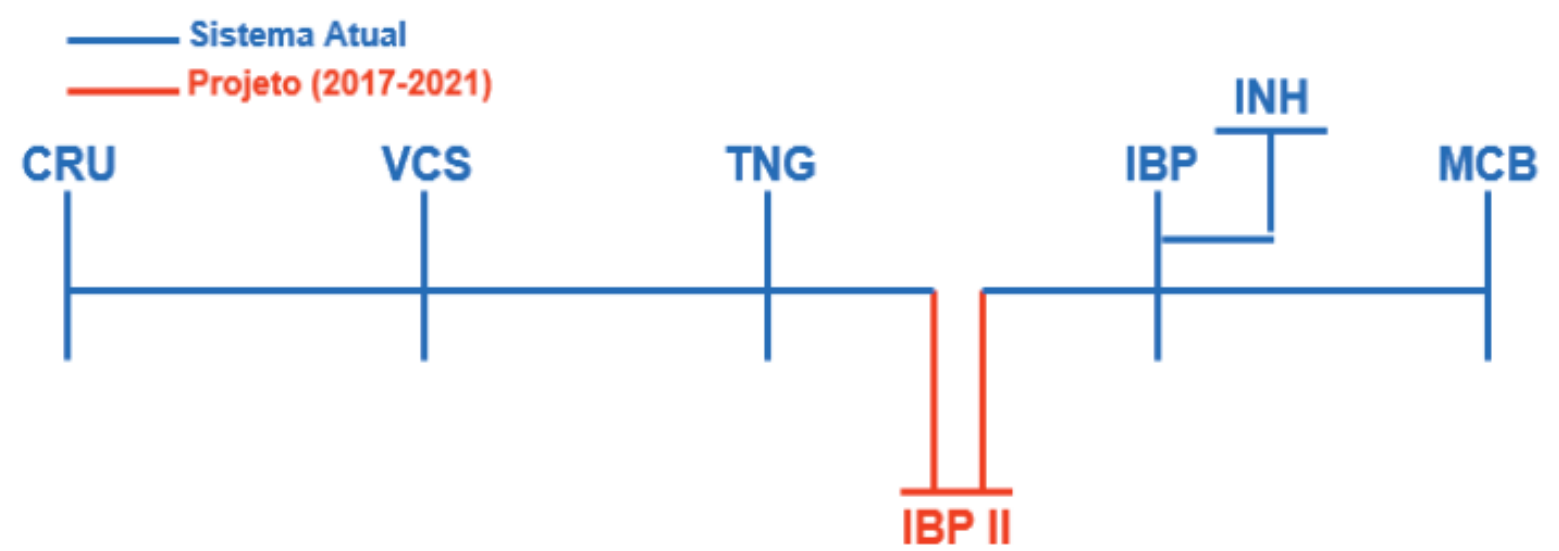

Figura 7 - Diagrama elétrico do sistema atual e das obras previstas para a melhoria da rede do eixo Cariré

No cenário sem obras, considerando todas as linhas de entrada correspondentes do regional SBD, possui o valor de demanda/ano de 290,4 MW para o input e de 261,9 MW para output resultando em uma perda de 28,5 MW. No cenário com a obra do eixo Sobral/Massapê o input é estimado em 286,2 MW e uma carga de 263,8 MW resultando em uma perda de 22,4 MW. No eixo CRC o input previsto é de 287,3 MW e um output de 262,7 MW com perda de 24,6 MW e para o eixo CRE um input de 285,6 MW e um output de 266,7 MW resultando em uma perda de 18,9 MW. Portanto, percebe-se que as perdas em todos os eixos tendem a reduzir com as realizações das obras. $O$ total de investimento para as obras dos três eixos é de MMR $\$ 81,125$ (oitenta e um milhões e cento e vinte e cinco mil reais). 


\section{I CONCLUSÕES}

A utilização direta de programas computacionais de fluxo potência em conjunto com a criação de novas metodologias de análises ainda são bastantes usados na solução de problemas de distribuição de energia elétrica. Neste caso, tem-se uma aplicação direta entre um método proposto utilizando dados de medições reais e um simulador de fluxo de carga. A partir desta técnica, foi possível determinar os trechos com as maiores perdas técnicas e melhor assertividade na criação de novas linhas de distribuição em pontos críticos, visando minimizar as perdas elétricas.

Com isso, conclui-se com este estudo que a metodologia proposta mostrou resultados satisfatórios. Foi possível traçar um planejamento de obras e investimentos para os pontos mais críticos da regional SBD para ser executado entre os anos de 2017 e 2021. O payback para o investimento citado no capitulo 4 foi estimado em 24,43 anos.

\section{REFERÊNCIAS}

FISCHER, D. R.; PAIXÃO, J. L.; SAUSEN, J. P. Minimização de Perdas em uma Rede de Distribuição Através do Problema de Transporte. Revista Científica Semana Acadêmica. Fortaleza, ano MMXVII, N ${ }^{\circ}$. 000110, 11/08/2017, p. 2. Disponível em: <https://semanaacademica.org.br/artigo/ minimizacao-de-perdas-em-uma-rede-d $\mathrm{s}$.

WARD, J. B. and HALE, H. W. Digital computer solution of power flow problems. AIEE Transactions on Power Apparatus and Systems, vol. i5, p. 398-404, 1956.

VAN NESS, J. E. Iteration methods for digital load flow studies. Transactions IEEE (Power Apparatus and Systems). v. 78A, pt. III, p. 583-588, 1959.

TINNEY, W. F. and HART, C. E. Power flow solution by Newton's method. IEEE Transactions on Power Apparatus and Systems, vol. PAS-86, pp. 1449-1456, 1967.

STOTT, B.; ALSAÇ, O. Fast Decoupled Load Flow. IEEE Transactions on Power Systems, v. PAS93, n. 3, p. 859-869, 1974.

MARTINS, C. C. C. Fluxo de Carga em Redes de Distribuição Operação em Emergência. Dissertação de Mestrado, Programa de Pós-Graduação em Engenharia de Eletricidade (PPGEE), Universidade Federal do Maranhão (UFMA), p. 1 e 6, São Luís - MA, Brasil, janeiro de 2018.

MILOCA, S. A. Planejamento da Expansão em Redes de Distribuição de Energia Elétrica com Indicadores de Confiabilidade e Base de Dados Georreferenciada. Tese apresentada ao Programa de Pós-Graduação em Métodos Numéricos em Engenharia da Universidade Federal do Paraná, 2012, p. 3.

OLIVEIRA, R. C.; MANITO, A. R. A.; VIEIRA, J. P. A; SOARES, T. M.; BEZERRA, U. H.; TOSTES, M. E. L.; JUNIOR, P. R. A. V.; NUNES, M. V. A. Metodologia para Cálculo de Perdas Comerciais em Redes de Distribuição via Estudos de Fluxo de Carga. XXII Seminário Nacional de Distribuição de Energia Elétrica (SENDI), Curitiba - PR - Brasil, 2016, p. 2.

KAGAN, N.; OLIVEIRA, C.; ROBBA, E. J. Introdução aos Sistemas de Energia Elétrica. 2nd. ed. São Paulo: Blucher, 2010, p. 1-325.

Brasil. CEPEL. ANAREDE - Análise de Redes Elétricas, website. Acessado em: 23/02/2018, disponível em: <http://www.cepel.br/produtos/anarede-analise-de-redes-eletricas.htm>. 


\section{CAPÍTULO 6}

\section{CARACTERIZAÇÃO E ESTRATIFICAÇÃO DOS SFVCR NO BRASIL: CENÁRIO ATUAL E PERSPECTIVAS FUTURAS}

Data de aceite: 03/01/2020

\section{Diego Plazza Hilgert} Universidade Tecnológica Federal do Paraná, PPGSE Curitiba - Paraná

Jair Urbanetz Junior Universidade Tecnológica Federal do Paraná, PPGSE Curitiba - Paraná

RESUMO: Este documento apresenta uma análise das informações contidas no banco de dados da Agência Nacional de Energia Elétrica (ANEEL) sobre as instalações de geração distribuída amparadas pela resolução normativa (REN) da No482/2012. Apresentase um breve histórico da referida resolução e da evolução das instalações desde 2012, na sequência é ilustrada a metodologia utilizada no trabalho e a definição das faixas de potência a serem usadas na estratificação, originada de um levantamento dos modelos de inversores disponíveis no Brasil. Nas seções de resultados e discussões, são apresentados os gráficos obtidos com a aplicação da metodologia e uma análise dos mesmos, procurando entender como se dá a expansão dos SFVCR de acordo com a classe do consumidor, comparando este comportamento com a estratificação utilizada, e buscando encontrar tendências futuras.

PALAVRAS-CHAVE: Energia Solar Fotovoltaica, Resolução Normativa ANEEL №482/2012, Geração Distribuída.

CHARACTERIZATION AND STRATIFICATION OF THE GRID CONNECTED PHOTOVOLTAIC SYSTEMS IN BRAZIL: CURRENT STATE AND FUTURE PERSPECTIVES

ABSTRACT: This document presents an analysis of the information contained in the data bank of the Agência Nacional de Energia Elétrica (ANEEL) regarding the distributed generation supported by the normative resolution (REN) $\mathrm{N}^{\circ} 482 / 2012$. First it presents a brief history of the referred normative and the evolution of the installations since 2012, after that, the methodology used in the paper is explained, and the power range that are used in the stratification, originated from a collection of the on-grid inverters available in the national market. In the results and discussion sections, the graphics obtained by applying the methodology are presented, with an analysis of them, aiming to understand how the expansion of the grid connected photovoltaic systems happens according to the consumer's class, comparing this behavior with the stratification used and searching for future tendencies.

KEYWORDS: Photovoltaic Solar Power; ANEEL 


\section{I INTRODUÇÃO}

A resolução normativa $n^{\circ} 482$ da ANEEL, de 17 de abril de 2012, que foi posteriormente atualizada pela REN n 687 de 24 de novembro de 2015, define a microgeração distribuída como "central geradora de energia elétrica, com potência instalada menor ou igual a $75 \mathrm{~kW}$ e que utilize cogeração qualificada, conforme regulamentação da ANEEL, ou fontes renováveis de energia elétrica, conectada na rede de distribuição por meio de instalações de unidades consumidoras" (ANEEL, 2012).

Na prática, esta resolução permite que o consumidor seja recompensado através dos descontos concedidos em sua conta de energia elétrica utilizando como base o mesmo valor que os clientes finais pagam pelo $\mathrm{kWh}$, limitado pelo seu consumo, valor este que é superior ao pago em leilões.

Este é um dos fatos que fez com que o crescimento do número de consumidores que têm aderido à esta opção tenha crescido de forma exponencial desde 2012, hoje já são mais de 32.816 unidades consumidoras com uma potência total instalada de 396,90 MW, segundo dados da ANEEL considerando sistemas incluídos até o dia 30 de junho de 2018. A Figura 1 detalha este crescimento ano a ano, considerando os dados do Banco de Dados de Unidades Consumidoras de Micro e Minigeração Distribuída amparadas pela REN N 482/2012 (ANEEL, 2019).

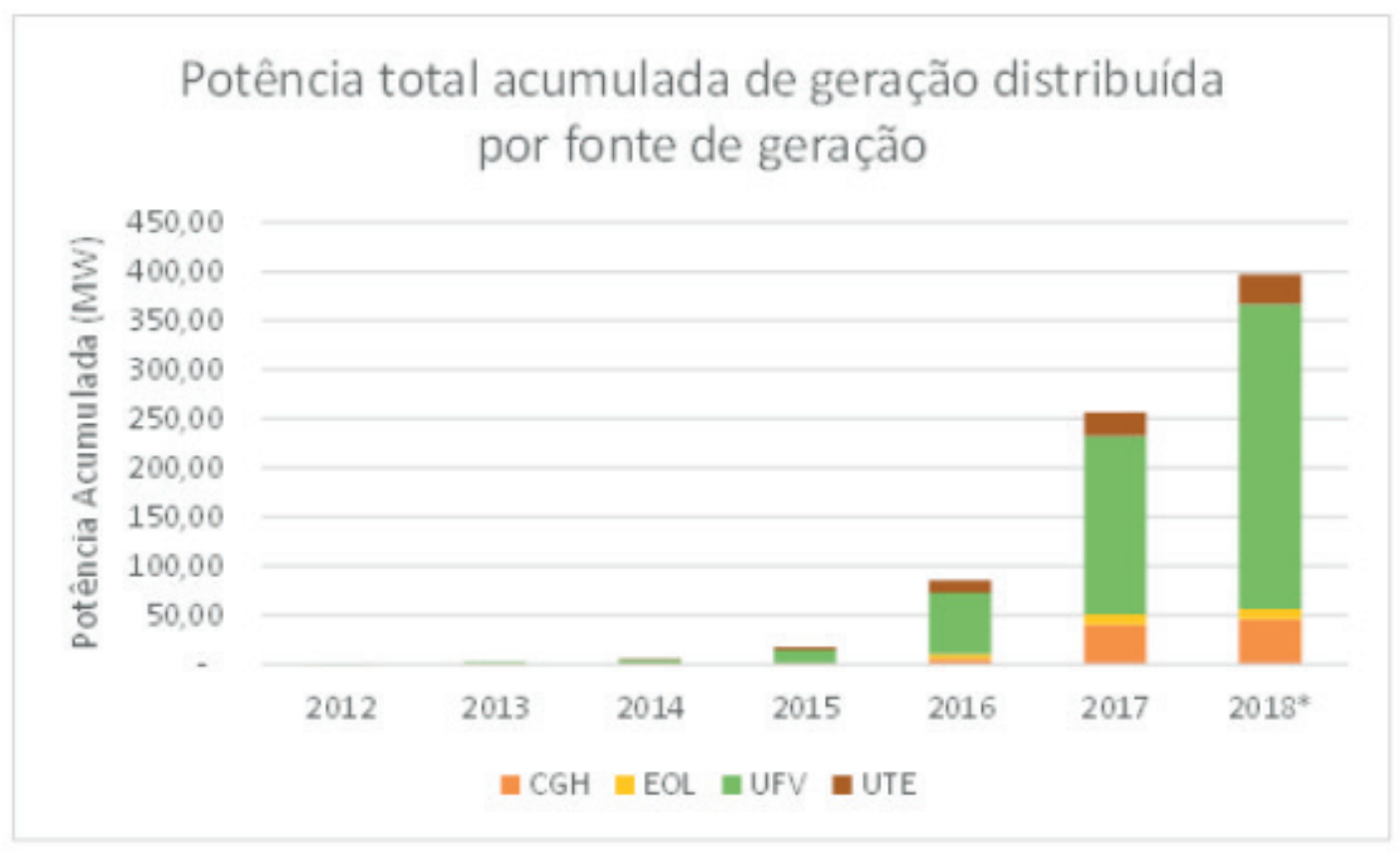

Figura 1- Potência instalada de geração distribuída amparada pela REN N82/2012 no Brasil. Fonte: Adaptado de ANEEL, 2019

A fonte com grande destaque dentre as amparadas pela REN N ${ }^{\circ} 482 / 2012$ é a 
solar, representando $99,38 \%$ dos sistemas instalados e $78,10 \%$ da potência instalada. A Figura 2 representa o crescimento apenas dos sistemas em que a fonte de geração é a solar, ou seja, sistemas fotovoltaicos conectados à rede (SFVCR). A potência adicionada até o meio do ano de 2018 já é superior à 2017.

Um dos fatores que contribuiu de forma relevante para este aumento exponencial são a forte queda dos preços dos kits fotovoltaicos entre 2012 e 2017, sendo que o mesmo apresenta uma alta no segundo semestre de 2017 devido à relação cambial entre o Real e o Dólar, conforme estudo do mercado fotovoltaico brasileiro (GREENER, 2018) apresentado na Figura 3.

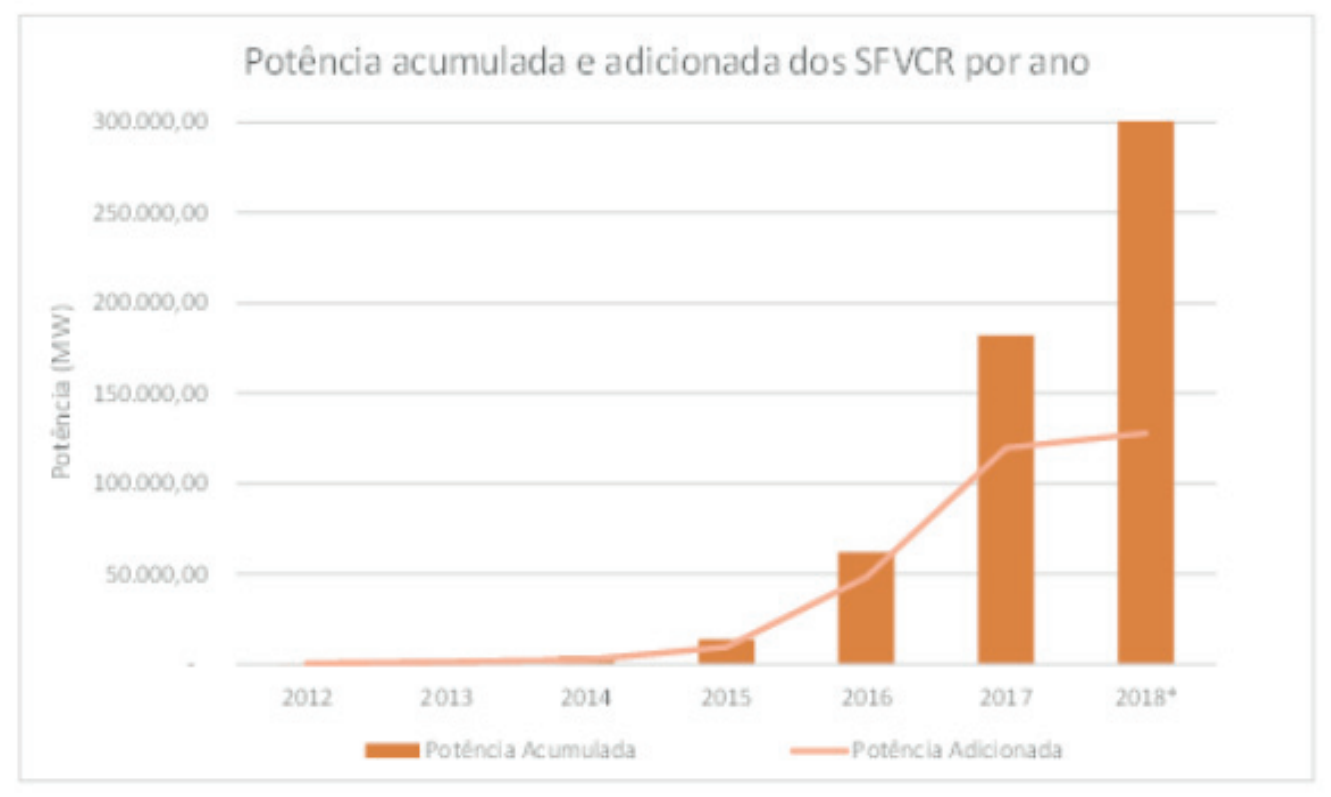

Figura 2 - Potência acumulada e instalada por ano dos SFVCR amparados pela REN Nº482/2012 no Brasil.

Fonte: Adaptado de ANEEL, 2019

Outro fator é o aumento dos valores do kWh cobrado pelas distribuidoras, também conhecida como inflação tarifária de energia, que nos últimos anos têm obtido altas acima da inflação. Segundo EPE (2017), a tarifa média no Brasil para consumidores do grupo B (valores sem impostos) em 2013 era de 272,67 R\$/MWh, já em 2016 este valor era de 434,32 R\$/MWh, um aumento de 59,3\%, já o IPCA acumulado do período foi de 25,17\% (IBGE, 2018), menos da metade da inflação energética. 


\section{Preços dos Kits Fotovoltaicos}

De junho de 2016 até janeiro de 2018

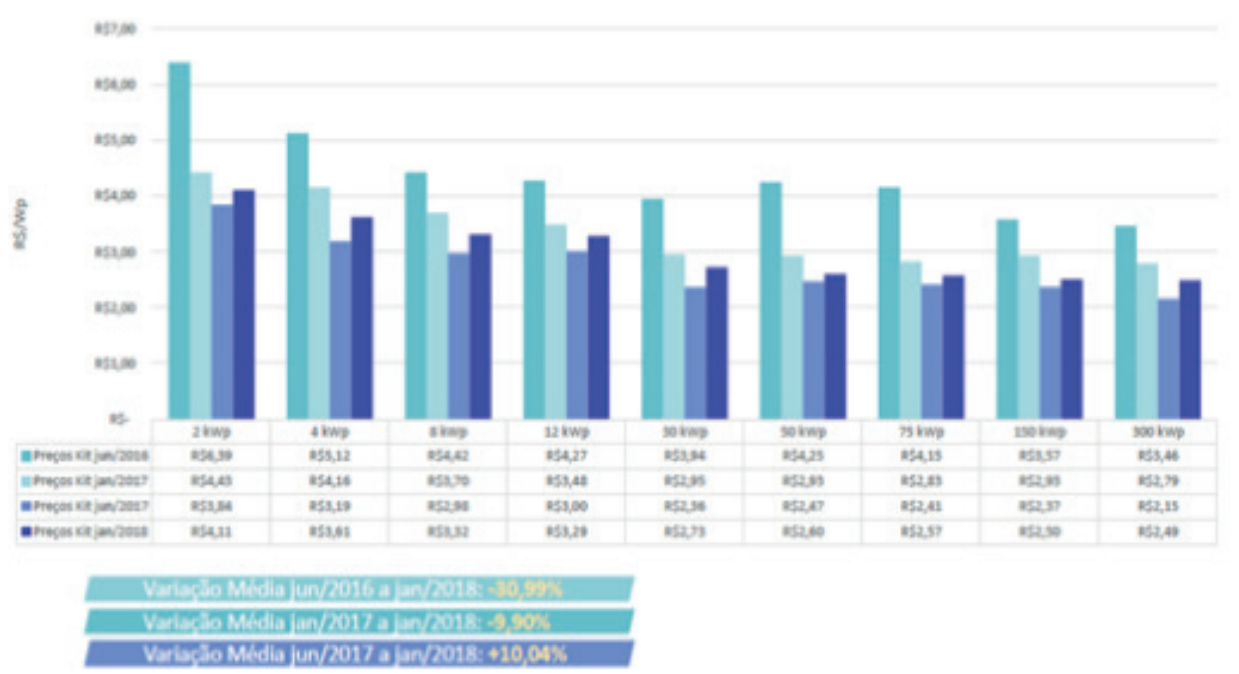

Figura 3 - Preço médio dos kits fotovoltaicos no Brasil.

Fonte: Greener, 2018

\section{I OBJETIVO}

Se comparados aos valores totais de potência instalada da matriz energética brasileira estes valores ainda são irrisórios, já que os 0,36 GW instalados de geração distribuída representam apenas $0,24 \%$ da potência total instalada no final de 2016 no Brasil, mais importação, de 156,3 GW, conforme Figura 4.

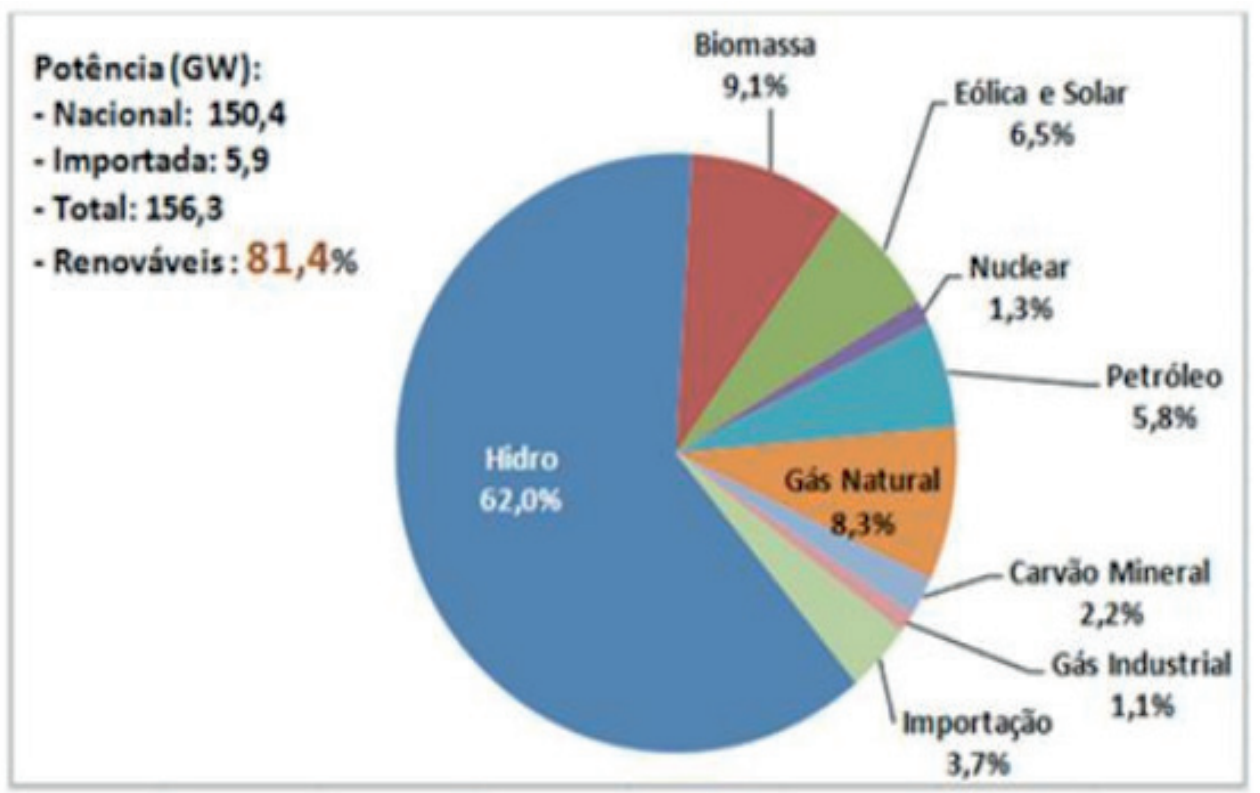

Figura 4 - Oferta de potência de geração elétrica.

Fonte: Ministério de Minas e Energia, 2017

De qualquer forma, devido à fatores como a maior importância que as energias 
renováveis vêm obtendo mundialmente e ao grande crescimento da potência instalada, que deve continuar nos próximos anos, o estudo da caracterização destes sistemas, bem como a forma como se dá o crescimento, como a potência media e a distribuição entre os tipos de sistema, é de fundamental importância e o momento é propicio já que está aberta a Consulta Pública 010/2018 pela ANEEL, que tem como objetivo "obter subsídios ao aprimoramento das regras aplicáveis à micro e minigeração distribuída, estabelecidas pela Resolução Normativa n 482/2012" (ANEEL, 2018).

\section{I MÉTODOS}

A análise apresentada neste documento foi feita com base nos relatórios sobre as Unidades Consumidoras com Geração Distribuída, disponibilizados pela Aneel, que é o banco de dados oficial de todas as Unidades Consumidoras cadastradas no sistema de compensação de energia de acordo com a REN Nº482/2012 (ANEEL, 2019). Portanto, por tratar-se da análise dos dados coletados utilizando técnicas estatísticas, trata-se de uma pesquisa quantitativa (MICHEL, 2005).

Todas as informações disponibilizadas foram introduzidas em uma planilha do Excel, filtradas para considerar apenas as usinas a qual a fonte de geração é "Radiação solar", e a partir deste ponto demais filtros e fórmulas foram aplicadas ao banco de dados para obtenção dos dados necessários.

Importante ressaltar que, devido a este banco de dados ser constantemente atualizado, o estudo se limitou a considerar as informações inseridas até o dia 30 de julho de 2018, e realizou um corte no banco de dados para considerar apenas sistemas incluídos até o dia 30 de junho de 2018.

Para escolha dos limites de estratificação dos sistemas fotovoltaicos, primeiramente foram pesquisados quais as marcas de inversores com maior representatividade no mercado nacional. Como não existe um dado oficial sobre market share dos inversores para sistemas fotovoltaicos, foi considerado como base para definição dos fabricantes mais relevantes o estudo realizado pela Greener (2018), com mais de 550 empresas integradoras de todo o Brasil, onde um dos itens avaliados é o "\% de empresas que utiliza a marca de inversor", conforme Figura 5. 

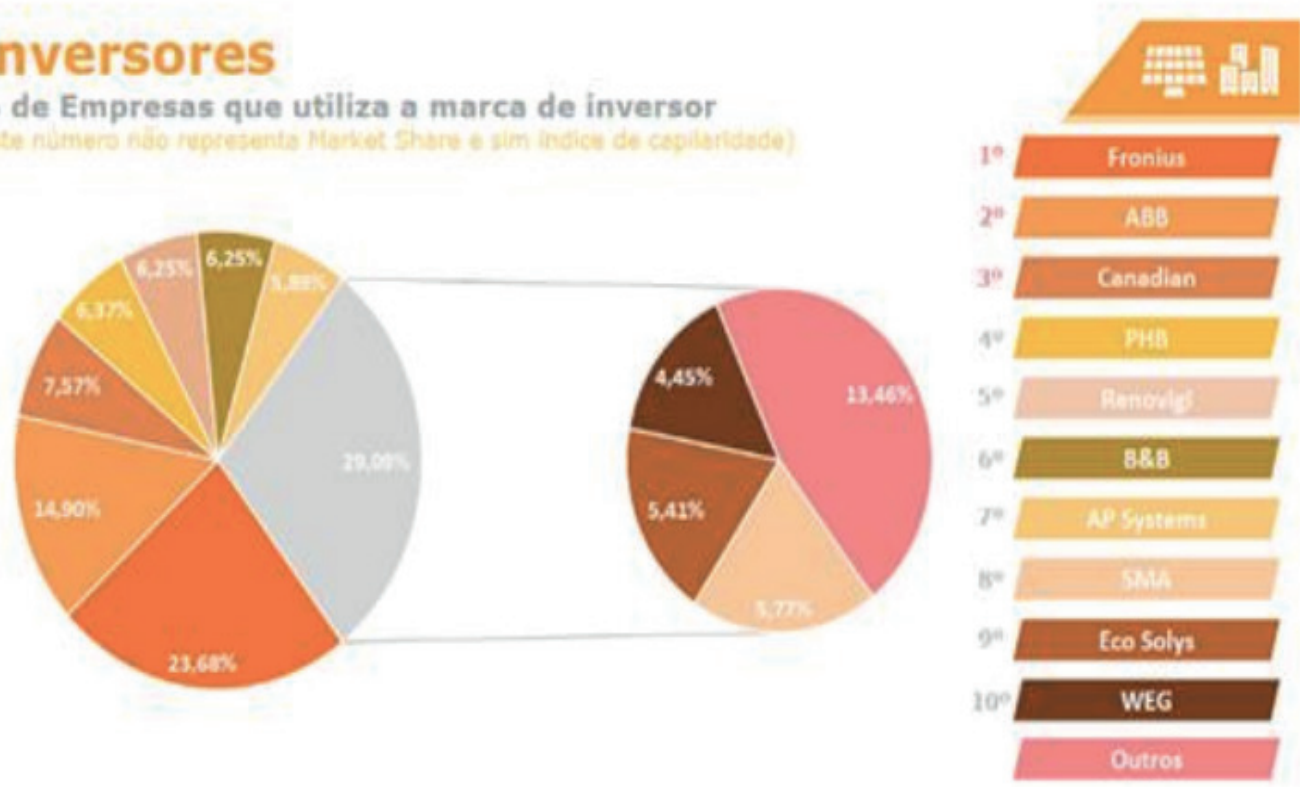

Figura 5 - Índice de capilaridade de diferentes fabricantes de inversores.

Fonte: Greener, 2018

Ao se considerar as 9 empresas com maior percentual é atingido um índice de capilaridade de $82,27 \%$ do mercado nacional. De posse desta lista de fabricantes, o próximo passou foi pesquisar junto a cada fabricante as potências dos modelos vendidos no Brasil, ao que se chegou à Tabela 1.

Por esta tabela pode-se ver que os valores mais comuns, com mais de 3 fabricantes com a mesma potência, são 3 kW, 5 kW, 20 kW e 25 kW. Parte-se destes valores para definir os limites da estratificação, incluindo os valores de 1,5 kW e de $7,5 \mathrm{~kW}$ devido à alta representatividade de potências próximas a estes valores. $\mathrm{O}$ valor de $10 \mathrm{~kW}$ também será incluído por ser um dos limites da ANEEL/INMETRO (sistemas com potência superior a $10 \mathrm{~kW}$ necessitam de documentação extra, bem como os inversores acima deste valor não são validados pelo Inmetro e devem ser apresentados os certificados), assim como o valor de $75 \mathrm{kWp}$, que define o limite para microgeração (ANEEL, 2012). Distribuindo uniformemente os valores faltantes tem-se a Tabela 2, que será a estratificação a ser considerada.

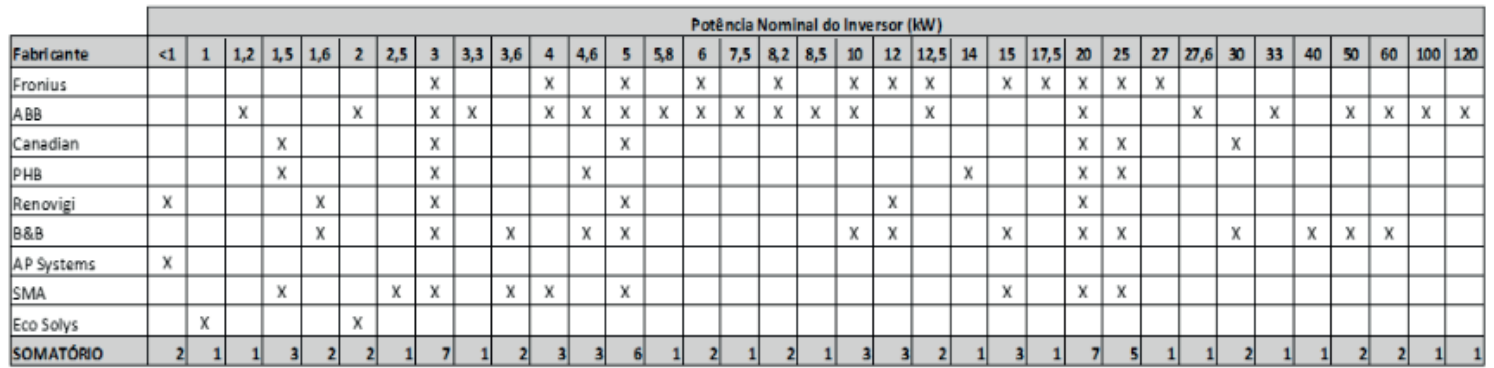

Tabela 1 - Potência nominal dos inversores fotovoltaicos por fabricante presentes no mercado nacional.

Fonte: Compilação de dados feita pelo autor. 


\begin{tabular}{|c|r|r|}
\hline Intervalo & $\begin{array}{c}\text { Limite inferior } \\
\text { (acima de) }\end{array}$ & $\begin{array}{c}\text { Limite superior } \\
\text { (inferior ou igual a) }\end{array}$ \\
\hline $\mathbf{1}$ & - & 1,5 \\
\hline $\mathbf{2}$ & 1,5 & 3,0 \\
\hline $\mathbf{3}$ & 3,0 & 5,0 \\
\hline $\mathbf{4}$ & 5,0 & 7,5 \\
\hline $\mathbf{5}$ & 7,5 & 10,0 \\
\hline $\mathbf{6}$ & 10,0 & 15,0 \\
\hline $\mathbf{7}$ & 15,0 & 20,0 \\
\hline $\mathbf{8}$ & 20,0 & 25,0 \\
\hline $\mathbf{9}$ & 25,0 & 30,0 \\
\hline $\mathbf{1 0}$ & 30,0 & 50,0 \\
\hline $\mathbf{1 1}$ & 50,0 & 75,0 \\
\hline $\mathbf{1 2}$ & 75,0 & $5.000,0$ \\
\hline
\end{tabular}

Tabela 2 - Estratificação da potência a ser considerada para o estudo.

Fonte: $\mathrm{O}$ autor.

\section{I RESULTADOS}

A fonte que mostra maior adesão às regras impostas pela REN Nº482/2012, tanto em número de sistemas como potência instalada, devido às facilidades e menores custos, é a energia fotovoltaica, conforme Figura 6, onde observa-se que a fonte "radiação solar" tem se mantido entre 70 e $80 \%$ do total da potência instalada, com um valor de $78 \%$ até junho de 2018.

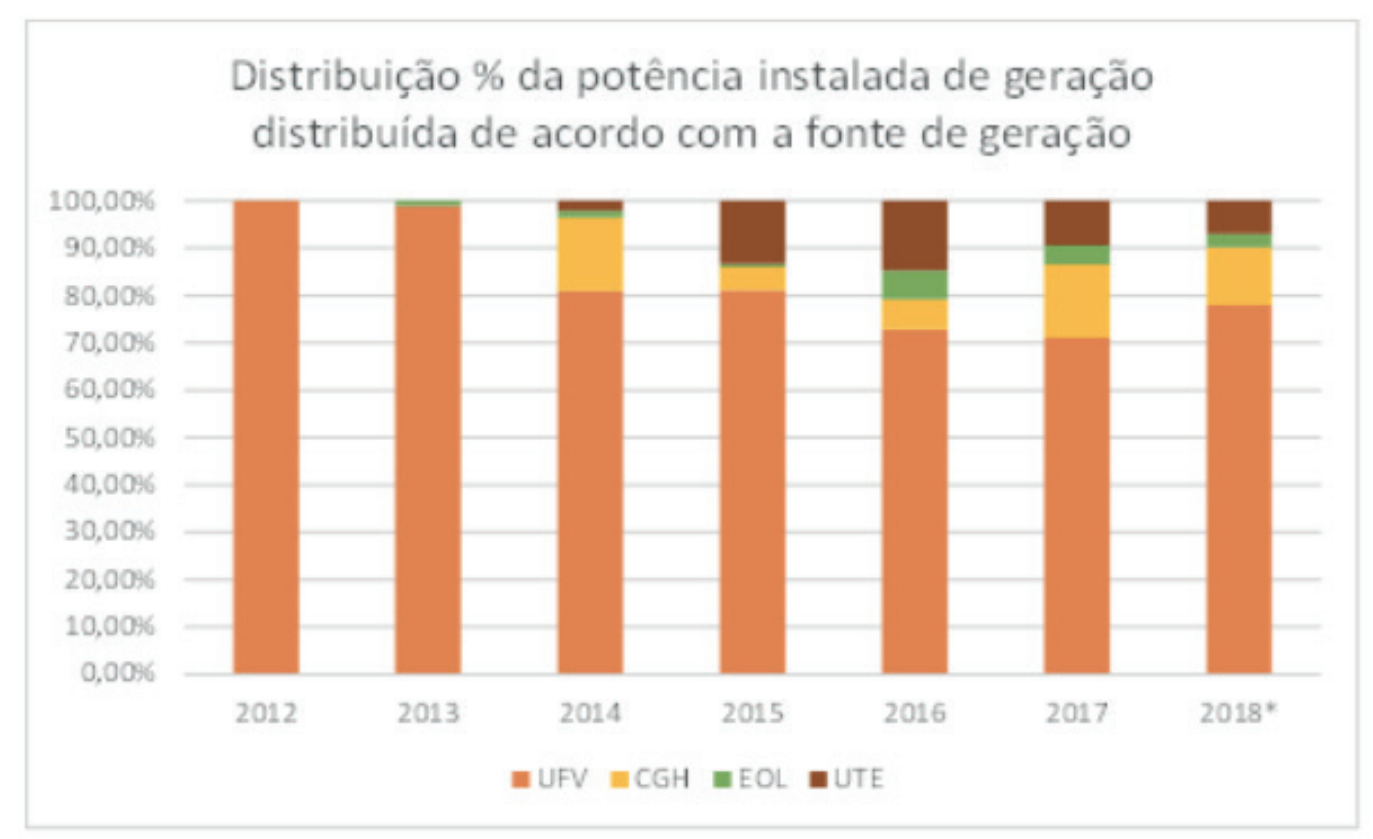

Figura 6 - Distribuição do \% da potência instalada por ano de acordo com a fonte de geração.

Fonte: Compilado conforme dados de ANEEL, 2019 
Considerando apenas a geração solar, os dados podem ser separados de acordo com a classe ao qual se enquadram. Conforme a Tabela 3, a grande maioria dos sistemas instalados hoje são residenciais $(77,1 \%)$, mas o setor comercial representa a maior parte da potência instalada $(43,6 \%)$, pois a potência média de um sistema comercial é 5,48 vezes maior que a de um residencial, e, juntas, estas duas classes representam $93,2 \%$ do número de sistemas instalados e $81,7 \%$ da potência total instalada. As classes Rural e Industrial possuem uma menor representatividade devido à suas tarifas mais baixas que as tarifas residências e comerciais, tornando os SFVCR menos atrativos para estas classes.

\begin{tabular}{|c|c|c|c|c|c|}
\hline Classe & $\begin{array}{l}\text { Quantidade } \\
\text { de Sistemas }\end{array}$ & $\begin{array}{c}\text { Potência } \\
\text { Total (kW) }\end{array}$ & $\begin{array}{c}\text { Potên cia } \\
\text { Média (kW) }\end{array}$ & $\begin{array}{l}\text { \% em número } \\
\text { de sistemas }\end{array}$ & $\begin{array}{c}\% \text { em potência } \\
\text { total }\end{array}$ \\
\hline Comercial & 5.244 & $135.115,65$ & 25,77 & $16,1 \%$ & $43,6 \%$ \\
\hline Iluminação Pública & 7 & 80,70 & 11,53 & $0,0 \%$ & $0,0 \%$ \\
\hline Industrial & 799 & $27.011,15$ & 33,81 & $2,5 \%$ & $8,7 \%$ \\
\hline \begin{tabular}{|l|} 
Poder Público \\
\end{tabular} & 267 & $10.591,59$ & 39,67 & $0,8 \%$ & $3,4 \%$ \\
\hline Residencial & 25.142 & $118.256,57$ & 4,70 & $77,1 \%$ & $38,1 \%$ \\
\hline Rural & 1.108 & $17.385,36$ & 15,69 & $3,4 \%$ & $5,6 \%$ \\
\hline Serviço Público & 45 & $1.543,11$ & 34,29 & $0,1 \%$ & $0,5 \%$ \\
\hline TOTAL & 32.612 & 309.984 & 9,51 & $100,0 \%$ & $100,0 \%$ \\
\hline
\end{tabular}

Tabela 3 - Distribuição dos SFVCR por classe.

Fonte: O autor.

A Tabela 3 também mostra a baixa relevância de instalações públicas deste universo, representando apenas $1 \%$ das instalações e 3,9\% da potência instalada, indicando que poderia haver um incentivo maior do governo com um maior número de instalações.

Também é interessante analisar como esta divisão das classes evolui ao longo do tempo, conforme Figura 7. Pode-se ver que desde 2015 existe pouca variação na distribuição dos percentuais, o que indica uma tendência de que estas classes continuem sendo as grandes responsáveis pelo aumento da potência instalada. Devido a este fato as próximas análises se limitaram principalmente a estas duas classes. 


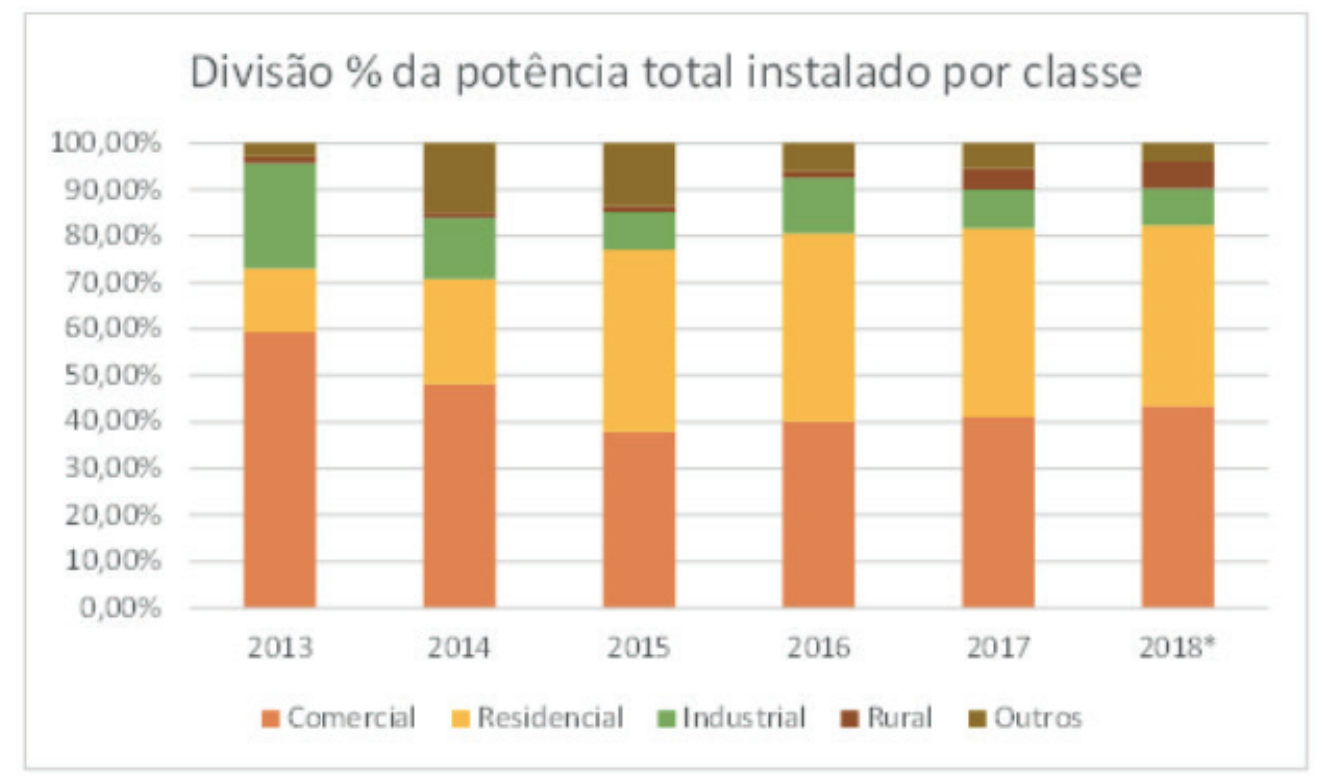

Figura 7 - Distribuição do \% da potência instalada por classe de consumo.

Fonte: Compilado conforme dados de ANEEL, 2019

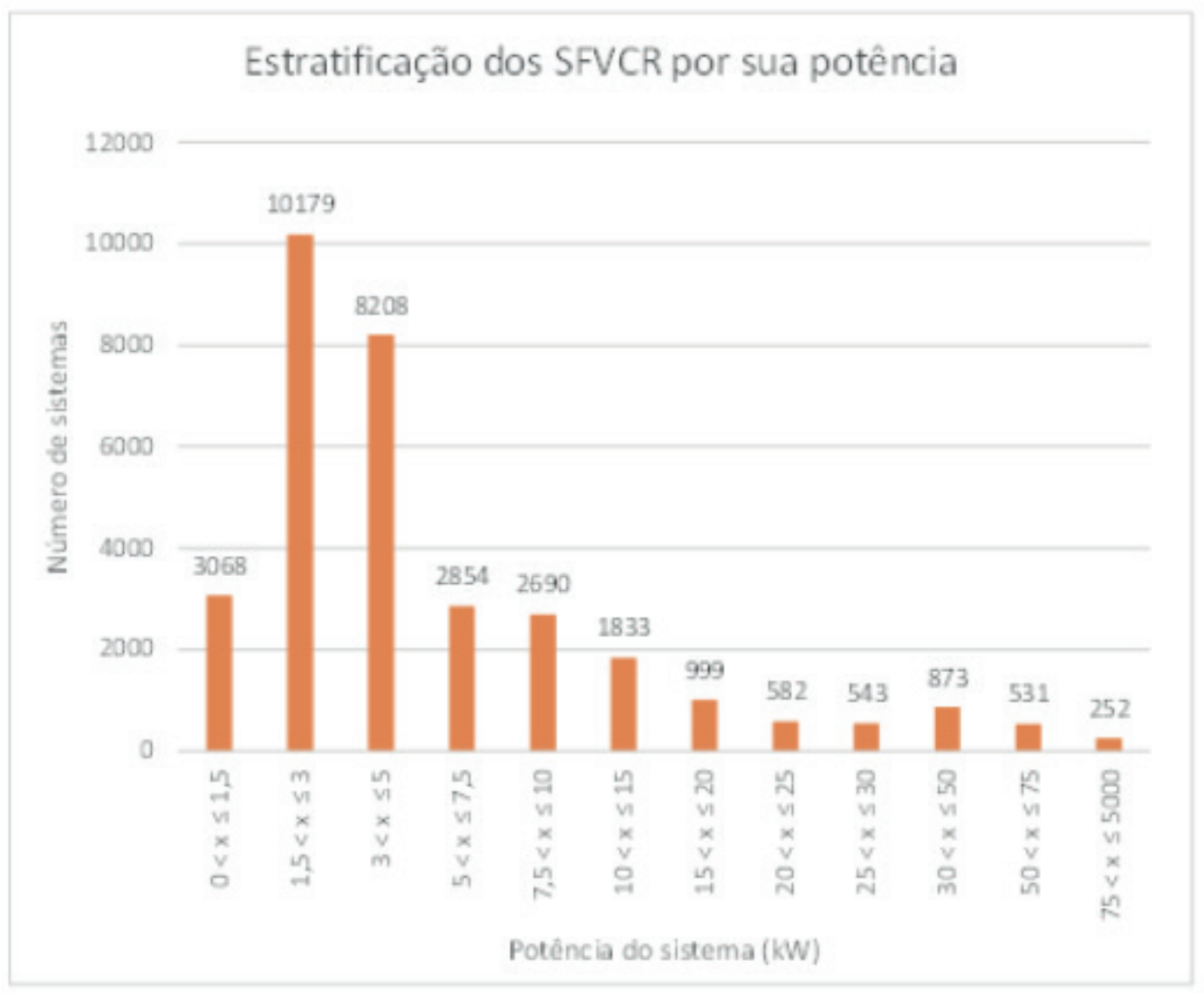

Figura 8 - Estratificação dos SFVCR por sua potência.

Fonte: Compilado conforme dados de ANEEL, 2019

Aplicando a estratificação proposta tem-se o resultado apresentado na Figura 8 , onde é possível ver que aproximadamente $75 \%$ dos sistemas instalados até 30 de junho tem uma potência de até $7,5 \mathrm{~kW}$, enquanto os sistemas enquadrados em 
minigeração (acima de $75 \mathrm{~kW}$ ) representam apenas $0,77 \%$ do total de sistemas instalados. Realizando a mesma estratificação, mas agora para as classes residenciais e comerciais, é possível visualizar a distribuição dos sistemas entre as potências conforme Figura 9.

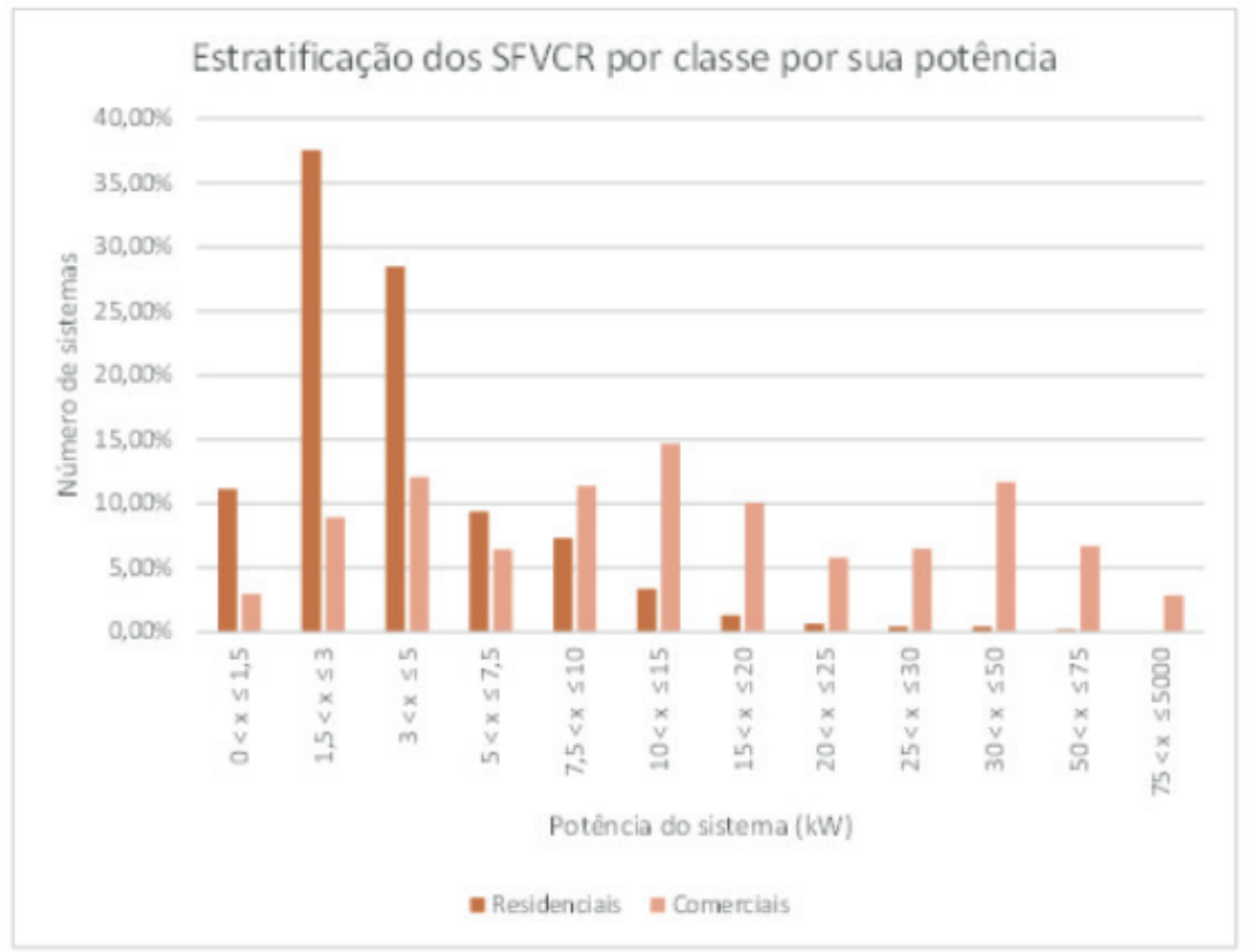

Figura 9 - Estratificação dos SFVCR por potência e classe.

Fonte: Compilado conforme dados de ANEEL, 2019

A estratificação de sistemas comerciais concentra-se em faixas de potências maiores que nas residenciais, como 10 a $15 \mathrm{~kW}(14,71 \%)$ e 30 a $50 \mathrm{~kW}(11,31 \%)$, enquanto nos sistemas residências $54,16 \%$ dos sistemas estão na faixa de até $3 \mathrm{~kW}$. Esta faixa coincide com a que possui maior quantidade de inversores, pois observase da Tabela 2 que 7 fabricantes possuem inversores de valor nominal de $3 \mathrm{~kW}$ e 6 fabricantes possuem inversor de valor nominal de $5 \mathrm{~kW}$, além de ter-se 10 valores nominais diferentes na faixa de 1,5 a $5 \mathrm{~kW}$ e do fato de que a maioria dos fabricantes possuem um inversor desta faixa. Na faixa maior de potência, a concentração dos fabricantes está nas potências nominais de $20 \mathrm{~kW}$ (7 fabricantes) e $25 \mathrm{~kW}$ (5 fabricantes), e olhando a tabela acima, nota-se que uma estratégia interessante para estas faixas é focar no público comercial.

Outro fato que merece destaque é a falta de opções de inversores na faixa de 7,5 a $10 \mathrm{~kW}$, que está entre as 5 mais representativas tanto dos sistemas residenciais como de sistemas comerciais, e possui apenas 4 opções de potência de três fabricantes distintos. 


\section{I DISCUSSÃO}

Quanto às perspectivas futuras para os SFVCR, separando as instalações em até final de 2017 e as realizadas em 2018, conforme Figura 10, percebe-se uma tendência de crescimento da potência dos sistemas, destacando-se o forte crescimento de todas as faixas entre 7,5 até $75 \mathrm{~kW}$, que representam crescimento expressivo, enquanto há uma diminuição considerável da representatividade, em percentual de sistemas instalados, nas faixas de 0 até $3 \mathrm{~kW}$. Mesmo sendo a faixa de 1,5 a $3 \mathrm{~kW}$ a com maior representatividade, está também foi a que apresentou maior diminuição.

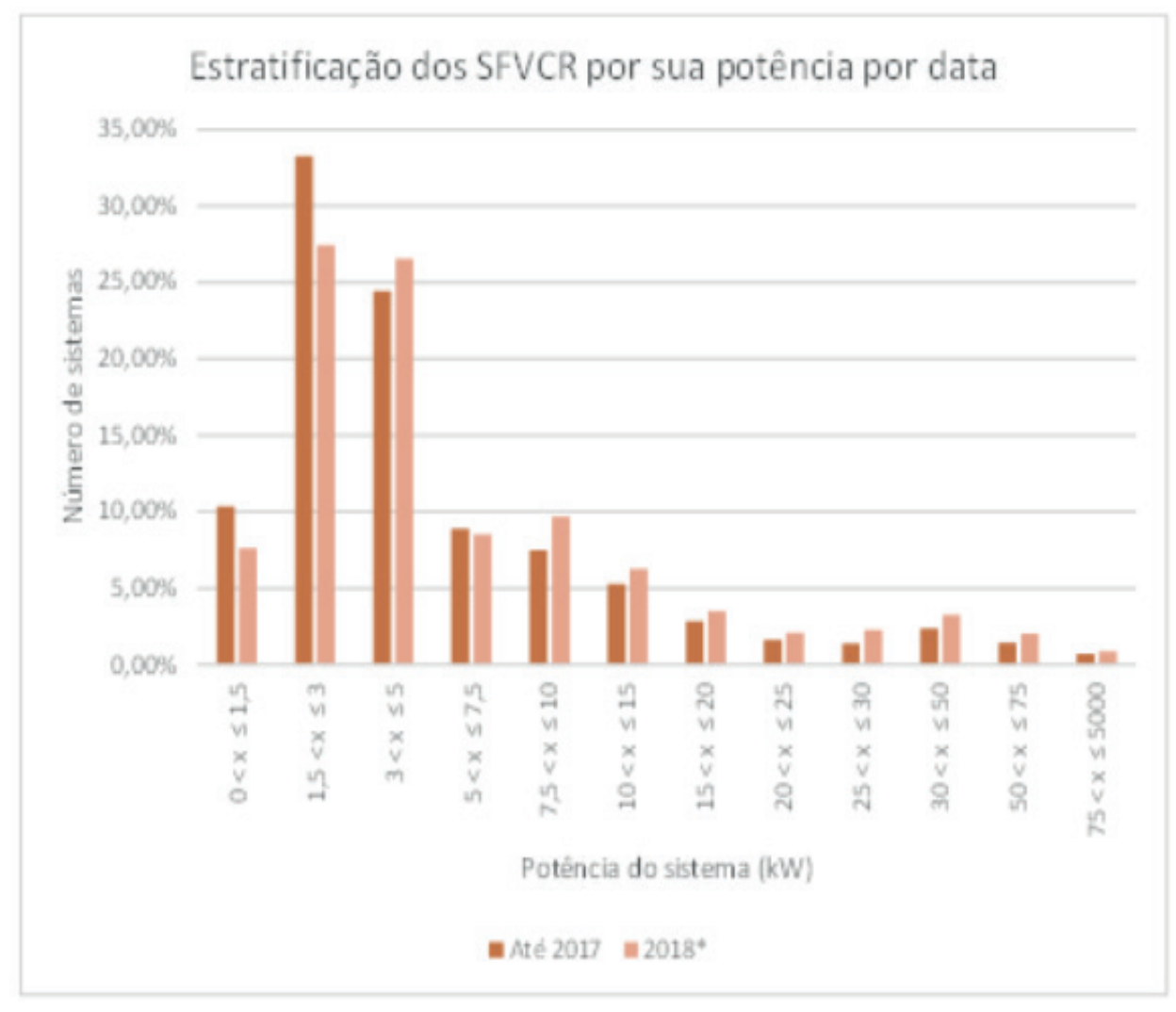

Figura 10 - Estratificação dos SFVCR por sua potência e por sua data de instalação. Fonte: Compilado conforme dados de ANEEL, 2019

Um fator preponderante para esta migração dos sistemas para faixas maiores é a diminuição do preço para instalação dos sistemas. A Tabela 4 detalha a evolução dos valores médios para instalação de sistemas de 2 e 4 kWp, que são o ponto médio das faixas mais representativas. Pode-se ver que em janeiro de 2018 o valor pago para um sistema de $4 \mathrm{kWp}$ é apenas um pouco maior que o valor pago por um sistema de 2 kWp em junho de 2016.

\begin{tabular}{|c|r|r|r|r|}
\hline \multirow{2}{*}{$\begin{array}{c}\text { Potência } \\
(\mathrm{kW} \text { p) }\end{array}$} & \multicolumn{4}{|c|}{ Preço médio do sistema instalado } \\
\cline { 2 - 5 } & jun/16 & jan/17 & jun/17 & jan/18 \\
\hline 2 & RS $20.900,00$ & RS $18.860,00$ & RS 15.620,00 & RS 14.260,00 \\
\hline 4 & RS $35.080,00$ & RS 30.960,00 & RS 26.080,00 & RS 23.320,00 \\
\hline
\end{tabular}


Em relação ao crescimento do número de sistemas instalados a cada ano, ao avaliar o número de sistemas e a potência instalada mês a mês, chega-se a Figura 11 e 12. Observar-se que tanto 2016 como 2017 apresentavam uma clara tendência de crescimento no número de sistemas instalados a cada mês, o mesmo não pode ser dito de 2018. Entretanto, como os dados de 2018 não estão completos, não é possível afirmar que isto indica uma desaceleração do mercado nacional.

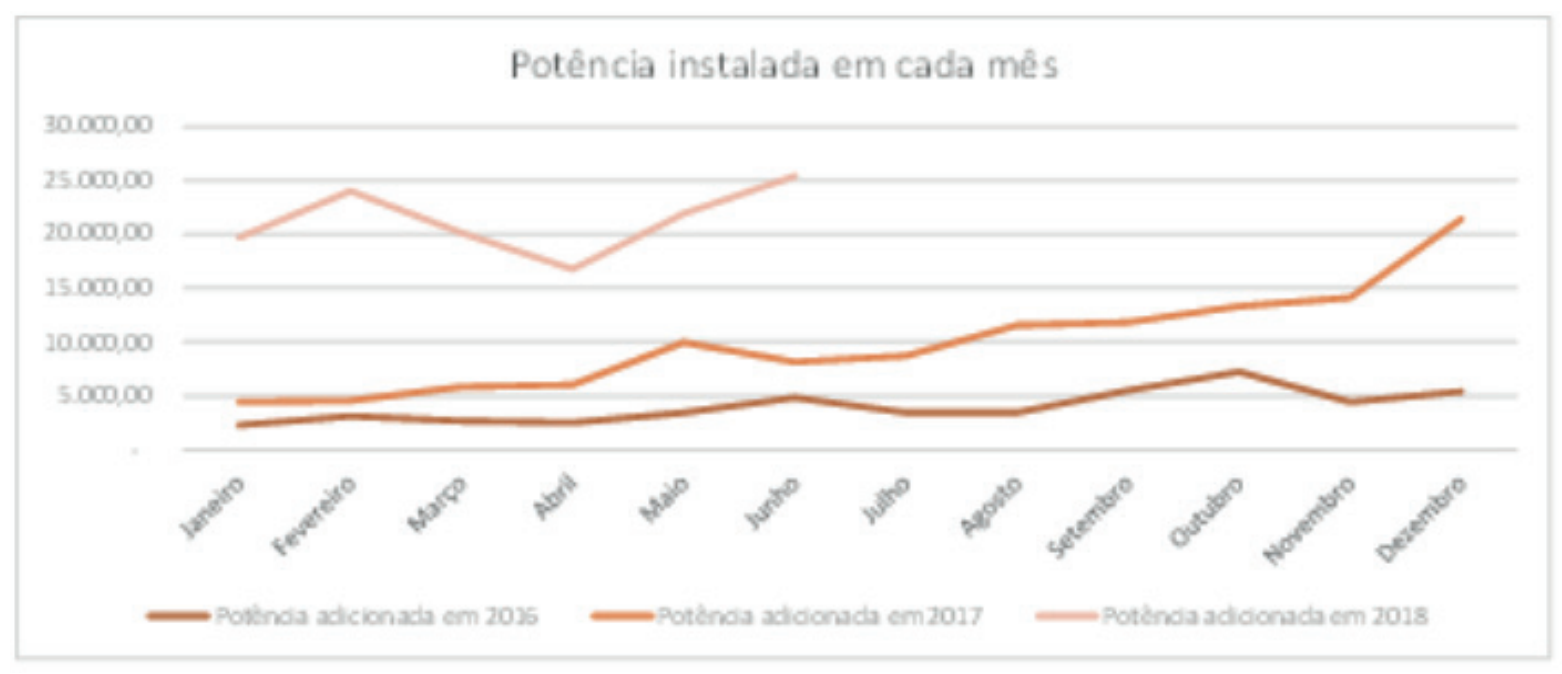

Figura 11 - Potência instalada de SFVCR por mês.

Fonte: Compilado conforme dados de ANEEL, 2019

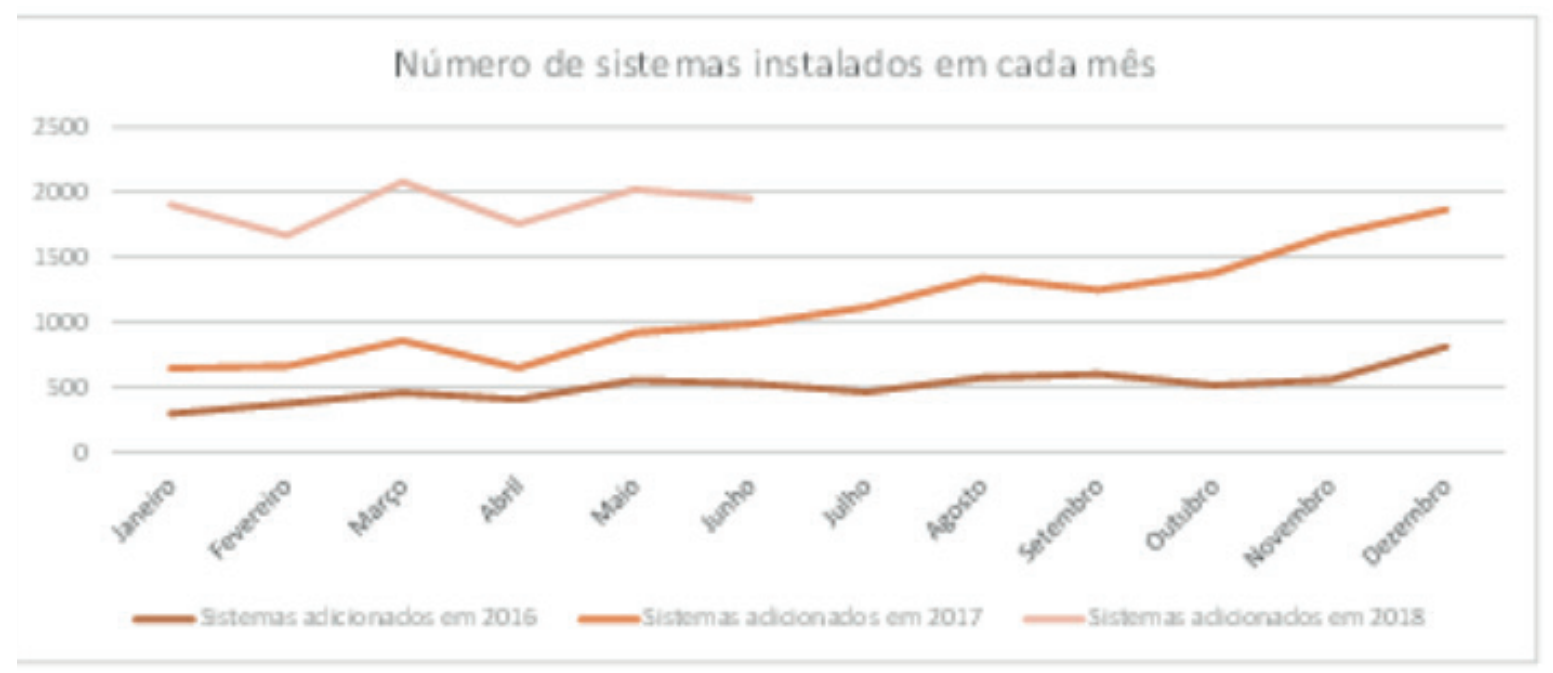

Figura 12 - Número de SFVCR instalados por mês

Fonte: Compilado conforme dados de ANEEL, 2019

Os dados de potência adicionada de geração distribuída mês a mês, no geral, acompanham os dados de número de sistemas instalados. Neste gráfico, apesar de não haver uma indicação clara de crescimento, destaca-se o fato de que todos os 
meses de 2018 ficaram acima do mês de novembro de 2017, que até então havia sido o mês com maior potência instalada.

\section{I CONCLUSÕES}

Através das análises realizadas foi possível identificar a distribuição da potência dos SFVCR de geração distribuída amparados pela REN N 482 de 2012 dentro de faixas de estratificação pré-definidas, bem como analisar suas perspectivas futuras.

Verificou-se que, dentre as possíveis fontes de geração amparadas pela REN No $482 / 2012$, a geração fotovoltaica corresponde à $78 \%$ da potência instalada, e dentro destes 78\%, 93,2\% dos sistemas instalados são da classe "comercial" ou "residencial", já a potência total instalada destas duas classes são muito similares apesar da diferença na potência média do sistema, de 4,70 kW e 25,77 kW respectivamente.

Ao mapear como se distribui a potência dos inversores dos maiores fabricantes disponíveis no mercado brasileiro e criar uma estratificação baseada nesta distribuição, foi possível identificar em quais casos a concentração de sistemas fotovoltaicos corresponde à maior opção de inversores disponíveis e em quais casos existe uma "falta" de opções disponíveis no mercado. Por fim, a análise das perspectivas futuras para SFVCR no Brasil indicou uma possível desaceleração no número de sistemas instalados e uma manutenção do aumento da potência média dos sistemas instalados.

Estes fatores são importantes para se ampliar a compreensão de como se dá a evolução do mercado de geração distribuída no Brasil, permitindo tanto que empresas possam tomar decisões estratégicas em relação a seus produtos como que o governo possa ter uma base de dados para implementação de políticas públicas de incentivo ao setor, e os dados obtidos deixam clara a tendência de forte crescimento.

\section{REFERÊNCIAS}

AGÊNCIA NACIONAL DE ENERGIA ELÉTICA (ANEEL). Consulta 010/2018. ANEEL, Brasília, 2018.

AGÊNCIA NACIONAL DE ENERGIA ELÉTICA (ANEEL). Outorgas e registros de geração:

unidades consumidoras com geração distribuída. ANEEL, Brasília, 2018.

AGÊNCIA NACIONAL DE ENERGIA ELÉTICA (ANEEL). Resolução Normativa № 482, de 17 de abril de 2012. ANEEL, Brasília, 2012.

EMPRESA DE PESQUISA ENERGÉTICA (EPE). Anuário estatístico de eneria elétrica 2017, ano base 2016. EPE, Brasília, 2017.

GREENER. Estudo estratégico: mercado fotovoltaico de geração distribuída $1^{\circ}$ semestre 2018. Enova Solar Energia LTDA, São Paulo, 2018.

INSTITUTO BRASILEIOR DE GEOGRAFIA E ESTATÍSTICA (IBGE). Séries históricas IPCA. Disponível em: < https://ww2.ibge.gov.br/home/estatistica/indicadores/precos/inpc_ipca/ defaultseriesHist.shtm>. Acesso em: 20 jun. 2018. 
MICHEL, M. H. Metodologia e pesquisa científica em ciências sociais: um guia prático para acompanhamento da disciplina e elaboração de trabalhos monográficos. 1 ed. São Paulo, Atlas, 2005.

MINISTÉRIO DE MINAS E ENERGIA (MME). Resenha energética brasileira, exercício de 2016, edição junho de 2017. MME, Brasília, 2017. 


\section{GEOCORTE CEMIG D \\ SELEÇÃO ÓTIMA DE ALVOS DE CORTE USANDO GEORREFERENCIAMENTO: DESENVOLVIMENTO SAPICCS}

Data de aceite: 03/01/2020

\section{Wellington Fazzi Cancian Andre Luiz} Soares CEMIG Distribuição S.A. CEMIG Distribuição S.A. CEMIG Distribuição S.A. wfcancian@cemig.com.br alsoares@cemig.com.br crp@cemig.com.br

Charles Ramos Pimenta CEMIG Distribuição S.A. CEMIG Distribuição S.A. CEMIG Distribuição S.A.

RESUMO: Com o crescimento do número de inadimplentes em função do cenário macroeconômico, redução da distribuição de orçamento para execução dessas atividades - definido pela incessante busca por eficiência operacional (tarifária) - e pelo interesse da sociedade/órgãos de proteção ao consumidor por atuação mais ágil e flexível na cobrança, é desejável que distribuidoras busquem gestão ótima da inadimplência, especialmente em sua atividade mais efetiva e comum: a suspensão de fornecimento por inadimplemento.

A agilidade, eficácia e flexibilidade da cobrança, demonstra aversão à inércia da distribuidora e inclusive, evitao surgimento de leis flexíveis que podem chegar a serem benéficas aos inadimplentes, como a vedação de execução de corte para um determinado público ou idade do débito.

Este artigo visa propor funcionalidade SAP/CCS, denominada GEOCORTE, capaz de realizar seleção de agrupamentos geográficos ótimos, alvos de corte, o mais próximo possível da realidade de campo, considerando modelagem matemática e restrições como deslocamento de eletricistas nas áreas (urbano e rural). Como resultado, espera-se uma seleção de alvos de corte mais apurada, que permita maior recuperação de receita para distribuidora, redução do crescimento de alvos, melhoria de produtividade e custo ótimo (segurança, combustível, manutenção e utilização da frota) de deslocamento das equipes executoras.

PALAVRAS-CHAVE: SAP/CCS, Corte de Energia Seleção de Alvos Data Mining, Clusterização (Agrupamento) Georreferenciada Otimização Combinatória

\section{I INTRODUÇÃO}

Atualmente, a emissão de serviços de suspensão de fornecimento (BRASIL, 1995, p. 1) - o famigerado "Corte de Energia - é baseada na seleção das instalações maiores inadimplentes de um determinado território (mesorregião, município, localidade ou até mesmo bairro), de forma ordenada decrescente, observando basicamente o montante envolvido 
para cada uma destas.

Esta forma de seleção garante que os clientes maiores inadimplentes terão a emissão de notas de serviços de Corte, porém não necessariamente que tais instalações terão efetivamente o fornecimento de energia elétrica, tendo em vista os deslocamentos necessários para realização de cada serviço, - que compromete a produtividade das equipes executoras - especialmente nos grandes centros urbanos, áreas mais adensadas ou rurais.

Ou seja, no momento da execução, as equipes podem não conseguir realizar todas as notas de serviços programadas ou, num caso mais agravante, realizar aquelas de menor valor agregado (clientes com menor dívida).

Diante desse contexto, surge um questionamento: como selecionar os melhores alvos para suspensão de fornecimento, considerando a limitação de deslocamento de eletricistas nas cidades e aumentando sua produtividade?

Este artigo busca contribuir para solução deste questionamento, visando permitir maior recuperação de créditos através da otimização da seleção de alvos de suspensão de fornecimento.

\section{I DESENVOLVIMENTO}

A metodologia consiste na busca de um lote de serviços para execução de Corte - suspensão do fornecimento de energia elétrica - , que possibilite o menor deslocamento para o(s) eletricista(s) executor(es) contendo os melhores alvos de recuperação de receita, esta última baseada no montante em dívida destes clientes, podendo ser dividido em 04 (quatro) etapas básicas:

- Conjunto de dados de Entrada e seu tratamento;

- Pré-Seleção dos alvos, através de agregação de dados;

- Execução da metodologia de otimização combinatória para seleção dos meIhores clusters (agrupamentos);

- Exibição dos resultados e seleção dos alvos para aplicação prática nos sistemas comerciais da distribuidora.

A Figura 1 apresenta a representação simplificada da metodologia proposta neste trabalho para seleção dos melhores clusters de clientes em condição de suspensão de fornecimento de energia elétrica, visando a maior recuperação de receita: 


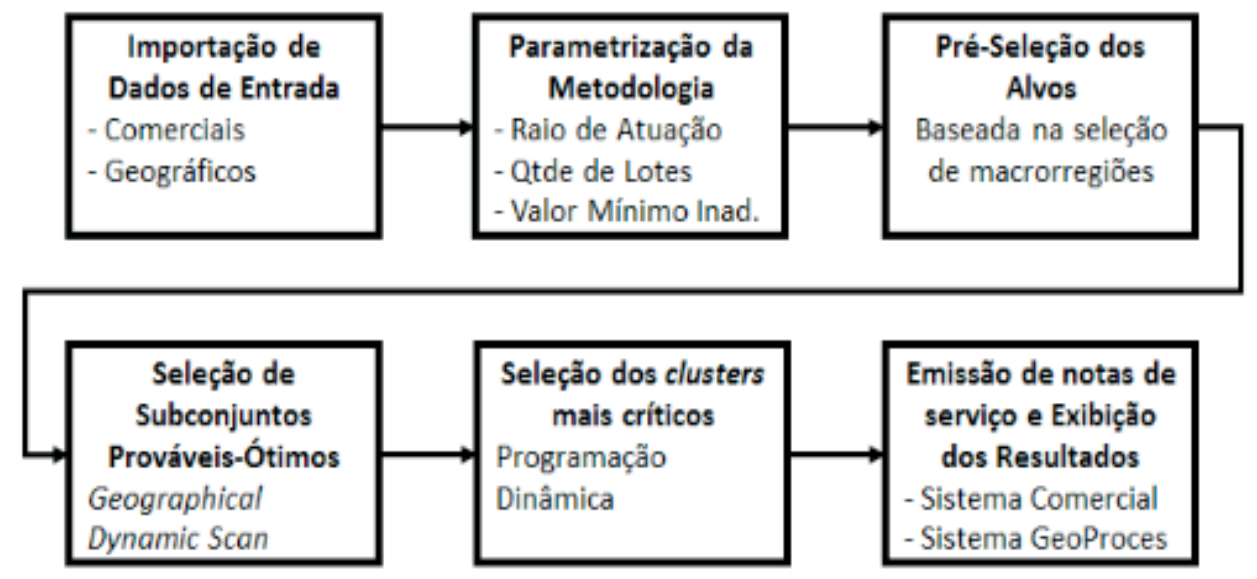

Figura 1 - Representação da metodologia para detecção ótima de agrupamentos espaciais, alvos de suspensão de corte.

A funcionalidade contemplou todos os clientes inadimplentes varejo (atendidos em Baixa Tensão) da área de concessão Cemig D, que atenderam aos critérios da regulação para suspensão de fornecimento de energia elétrica (ANEEL, 2010, p. 101).

As etapas são especificadas com maior ênfase nos tópicos seguintes.

\subsection{Conjunto de dados de Entrada e seu tratamento}

Os dados de entrada utilizados neste trabalho são aqueles dos sistemas comerciais (SAP/CCS) e GIS (Geographic Information System) das distribuidoras - no caso estudado da Cemig D, as informações georreferenciadas estão também disponíveis no SAP/CCS - sendo sendo sugerido o seguinte conjunto básico pelo modelo :

a. Sistema Comercial:

- Identificação e classificação da unidade consumidora - UC e do cliente;

- Procedimento de Advertência de Cobrança;

- Quantidade e montante em débitos pendentes;

- Razão e Rota de Leitura de Medidores;

- Localização da unidade consumidora (Urbano, Rural ou Povoado);

- Tipo de Medição (Direta ou Indireta).

b. Sistema de Informações Geográficas - GIS:

- Dados geodésicos das unidades consumidoras ou elemento de rede (poste ou transformador) mais próximo e vinculado à UC.

Importante ressaltar que o conjunto de dados sugeridos são não-exaustivos, visto que dependem diretamente do interesse de estudo da distribuidora na qual a metodologia será aplicada, devendo ser devidamente adequadas para este fim, 
bem como a forma de disponibilização destes dados nos bancos legados (exemplo: conceito de solvência; atuação prioritária em clientes que possuam parcelamentos ou que possuam débitos de consumo irregular).

Nesta fase também é realizada a higienização, conversão e enriquecimento da base de dados, caso necessário.

A atualização dos dados utilizados para este estudo tem a seguinte periodicidade mínima:

a. Dados do Sistema Comercial: diária;

b. Dados do Sistema de Informações Geográficas - GIS: trimestral e realizada por delta (inclusão somente de novas conexões).

\subsection{A Parametrização da Metodologia}

A funcionalidade dispõe da possibilidade de parametrização de critérios de seleção, forma de programação do corte e características de entrada, com o objetivo de atender aos anseios do programador da seleção, ou seja, o usuário parametriza no SAP/CCS as condições que devem ser utilizadas para que a seleção de corte contemple a estratégia da equipe gestora.

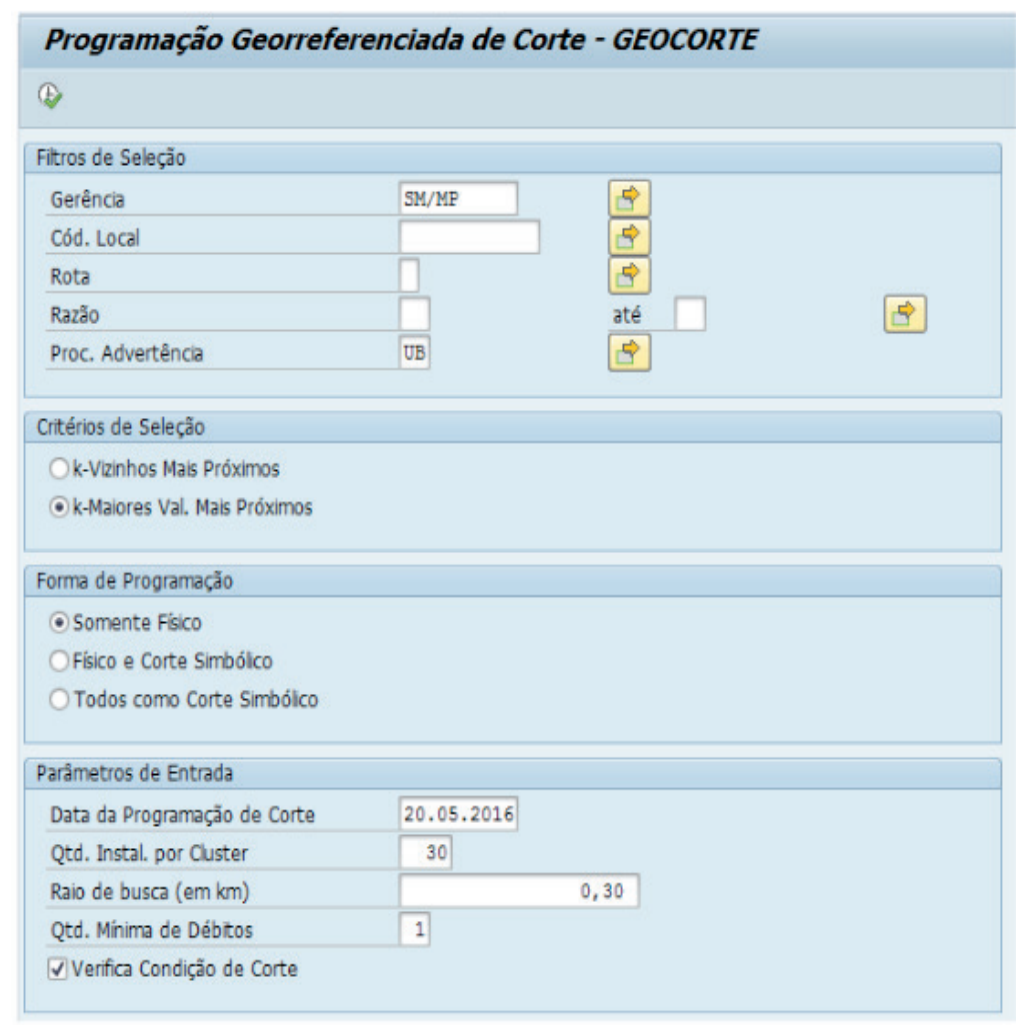

Figura 2 - Tela inicial da funcionalidade SAP/CCS GEOCORTE - "Programação Georreferenciada de Corte"

a. Forma de Programação: Estão disponíveis 3 tipos 
- "Somente Corte Físico": emissão de notas de serviço (NS) para corte na caixa, poste ou remoto (telecomandado);

- "Todos como Corte Simbólico": emissão de NS para corte simbólico no disjuntor (corte com selo, geralmente executado por eletricistas-motoqueiros);

- "Corte Físico e Simbólico": emissão de NS de ambos tipos - depende do procedimento de advertência docliente;

b. Caracterísitcas de entrada:

- "Quantidade de instalações por lote": representa o número de NS que serão emitidas para cada eletricista (critério de produtividade). Também é o parâmetro k do critério de seleção;

- "Raio de busca": representa a distância máxima entre os alvos de suspensão, medida em quilômetros;

- "Verificação prévia da condição de corte": identifica e filtra, já na pré-seleção, os alvos que estão em condição de corte, conforme estabelecido na Resolução Normativa n 414/2010 (se débitos vencidos até 90 dias e o cliente recebeu notificação/aviso de suspensão, basicamente) e;

- Outras características como: "Quantidade Mínima de Débitos", "Valor Mínimo por Gerência Regional" e "Valor Mínimo por tipo de equipe";

c. Critérios de Seleção:

- "k-Vizinhos mais Próximos": direcionar a funcionalidade para buscar os k vizinhos geograficamente mais próximos da instalação chamada "Ponto Focal" - maiores detalhes na seção 2.3 desse documento;

- "k-Maiores Valores mais Próximos": direcionar a funcionalidade para buscar os vizinhos que possuam os maiores valores pendentes com a distribuidora, que estejam mais próximos da instalação "Ponto Focal" e dentro do raio de busca;

\begin{tabular}{|c|c|c|c|c|c|}
\hline \multicolumn{6}{|c|}{ Exibir visão "Limites para Cortes": síntese } \\
\hline \multicolumn{6}{|l|}{ 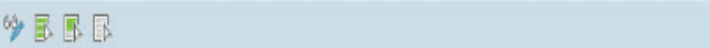 } \\
\hline \multicolumn{6}{|l|}{ Limtes para Cortes } \\
\hline Nome da varível & Valor Lmte & Uimte 0 & Limte ODES & Lmte 0055 & 四 \\
\hline ZARC_LIT_CORTE_IE & 500,00 & 800,00 & $1.000,00$ & $2.500,00$ & \\
\hline ZARC_LITY_CORTE_MQ & 600,00 & 800,00 & $1.000,00$ & $2.500,00$ & \\
\hline 2ARC LIM CORIE UI & 600,00 & 800,00 & $1.000,00$ & $2.500,00$ & \\
\hline 2ARC_LIM_CORTE_OE & 600,00 & 800,00 & 560,00 & $2.500,00$ & \\
\hline 2ARC_LIM_CORTE_SO & 600,00 & 800,00 & $1.000,00$ & $2.500,00$ & \\
\hline ZARC_LIM_CORTE_IA & 600,00 & 800,00 & $1.000,00$ & $2.500,00$ & \\
\hline 2ARC_LIM_CORTE_TELE & 300,00 & 300,00 & 300,00 & 300,00 & \\
\hline \multicolumn{5}{|c|}{ 1, $\square$} & 1 \\
\hline
\end{tabular}

\begin{tabular}{|c|c|c|c|c|c|c|}
\hline \multicolumn{7}{|c|}{ Exibir visão "Tabela de parâmetros para Codes de Nota de Corte"; sínte } \\
\hline \multicolumn{7}{|l|}{ 的區国 } \\
\hline \multicolumn{7}{|c|}{ Tabela de parimetros par codes de llota de cote } \\
\hline PC St.nst & Inst.Apoup & Too Med. Code & conto & Relev. Cort 5 & st 10 & \\
\hline JD st5 suapens: & 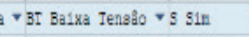 & - NROO ap11 O ODRR & D & $\nabla$ & & - \\
\hline Jש st5 suapena: & 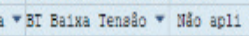 & - NBO AP11 PODRE & Q & Q & ( & \\
\hline Je LIf Ligada & BT Ba1xa Tenąo - Máo apl1 & 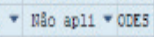 & $\nabla$ & D & v & \\
\hline Jo 505 5uapena: & Mr Med1a Tenato - Măo ap11 & - DBO ap11 $・$ AP99 & 0 & $\nabla$ & D & \\
\hline Je LIG Ligada & MT Média Tenalo $~$ Măo apl1 & - DBO ap11 $・$ APO4 & 0 & $\nabla$ & $\nabla$ & \\
\hline J7 LIG Ligada & $\checkmark$ BI Ba1xa Tenolo $>5$ Sin & 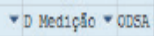 & 0 & 0 & $\mathrm{v}$ & \\
\hline Jf LIG Ligada & BIT Ba1xa Tenato $\sim \mathrm{K}$ Häo & - DBO ap11 O ODSE & 0 & 0 & 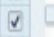 & \\
\hline Jf LIO Ligada & 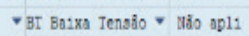 & - I Mediç̧äo ODSB & 0 & 0 & $\mathrm{v}$ & \\
\hline JH LIG Ligads & BI Baixa Tensío $\mathrm{S}$ Sin & D D Yediçáa $>0 D S A$ & $\square$ & ए & 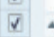 & . \\
\hline JH LIG Ligods & 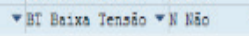 & - Dä́ Apli O ODSR & 0 & 0 b & $\nabla$ & - \\
\hline$\cdots$ & $\#$ & & & & .) & \\
\hline
\end{tabular}

Figura 3 - Tela para configuração: "Valor Mínimo por Regional”, "Valor Mínimo por tipo de equipe" e "Tipo de Corte". 


\subsection{Pré-Seleção dos Alvos}

Geralmente, a maior dificuldade de algoritmos para a detecção de agrupamentos georreferenciados (espaciais) é identificar dentre todos os subconjuntos de dados aquele que corresponda ao padrão ou solução desejada. E a avaliação de todos os subconjuntos é computacionalmente inviável para grande conjunto de dados (MOREIRA, 2011, p. 19), que enquadra adequadamente ao caso estudado.

Para contornar a dimensionalidade do problema sem interferir no resultado final, sugere-se a etapa de "Pré-Seleção dos alvos". Esta etapa ocorre através da subdivisão do problema em pacotes menores, em processo semelhante ao tradicionalmente aplicado na programação de notas de corte, em zonas que não se sobrepõem (por exemplo: gerência regional, município, ou bairro).

Para cada subdivisão, a funcionalidade SAP/CCS prevê a disponibilização da valor global em dívida e a quantidade de unidades consumidoras vinculadas a esta região, bem como sua respectiva média de valor em dívida para cada uma.

Através destas informações, o tomador de decisão poderá selecionar sobre os subconjuntos a serem tratados na fasede execução do GEOCORTE. Esta decisão pode ser baseada no número de equipes disponíveis para execução das atividades, orçamento, regulação de mercado (evitar crescimento da inadimplência em determinada região) ou expectativa de maior recuperação de receita.

Os resultados apresentados neste artigo considerou, como decisão dos subconjuntos, exclusivamente o parâmetro "expectativa de maior recuperação de receita".

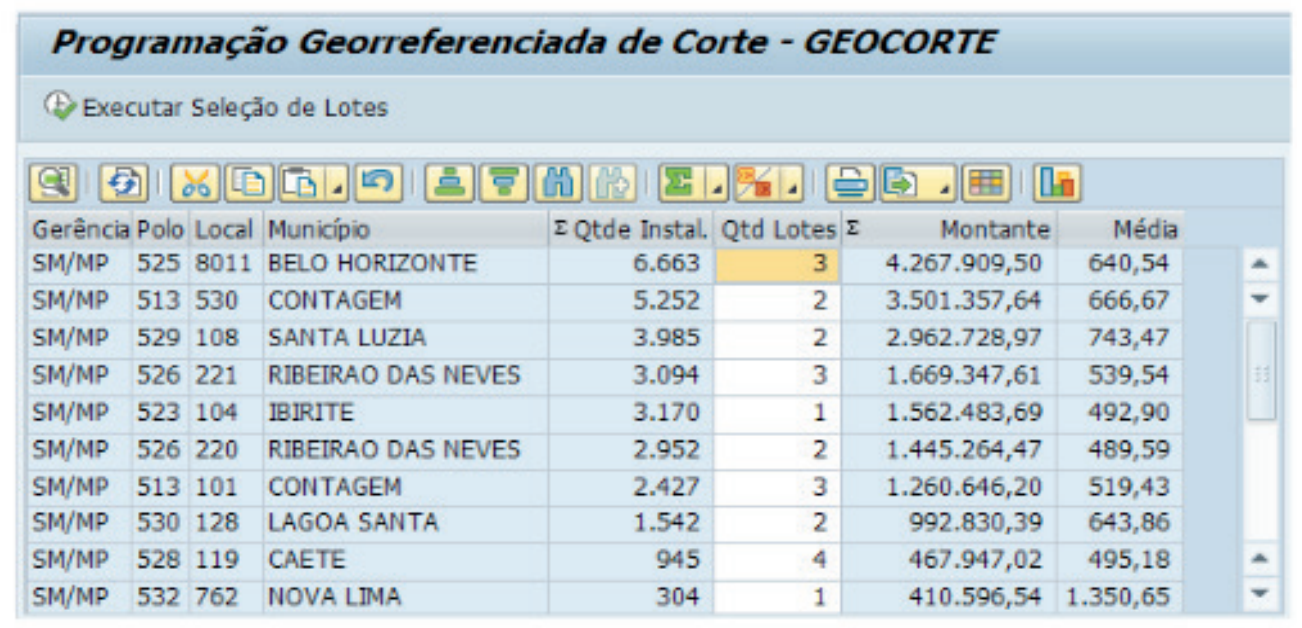

Figura 4 - Tela de exibição da pré-seleção de alvos, considerando localidades (subdivisão de um município).

\subsection{Seleção dos agrupamentos ótimos (melhores clusters)}

A metodologia prevê a utilização de técnicas de otimização combinatória, visando a seleção dos melhoresagrupamentos de unidades consumidoras, considerando como restrições a menor distância a ser percorrida pela equipe executora ("k- Vizinhos mais próximos") ou maiores inadimplentes de uma área ("k-Maiores Valores mais próximos") 
- o que tende a ampliar a produtividade - e limitação da quantidade de serviços a serem executados diariamente, este último em função do tempo de execução e de disponibilidade da equipe (horário de trabalho).

A seleção ótima dos clusters inicia-se a partir de uma unidade consumidora qualquer ("Ponto Focal" ou centroide) - podendo ser ou não a mais inadimplente dentro do subconjunto - agrupando outras unidades consumidoras mais próximas da primeira e que possuam considerável valor em dívida pendente, respeitando as restrições definidas.

O grande propósito da rotina é obter um conjunto de potenciais candidatos a melhores agrupamentos/clusters para tomada de decisão do operador.

Tecnicamente, a funcionalidade SAP/CCS considerou a utilização dum algoritmo baseado no método de otimização Simplex (BAZARAA \& SHERALI, 2008, p. 103) para solução de modelagem semelhante a um problemas clássicos de otimização combinatória (KARP, 1972, p. 95) denominado "Problema da Mochila" -Knapsack Problem (MARTELLO \& TOTH, 1990, p. 13), utilizando o método de Varredura Geográfica Dinâmica - Geographical Dynamic Scan (MOREIRA, 2011, p. 19) para definição dos subconjuntos que comporão as restrições da modelagem.

Por ser algortimo que demanda muitas iterações, nessa etapa a funcionalidade GEOCORTE considerou o paralelismo de execuções no ambiente SAP/CCS (emissão de vários JOBs para conclusão da tarefa).

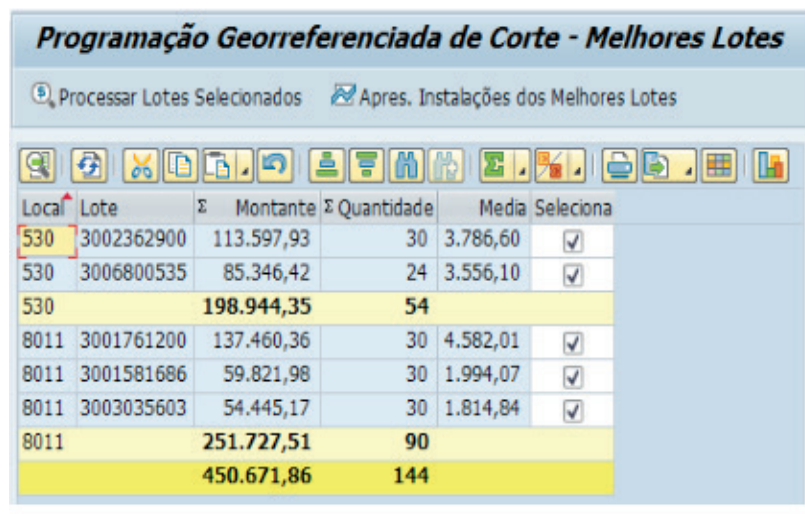

(a)

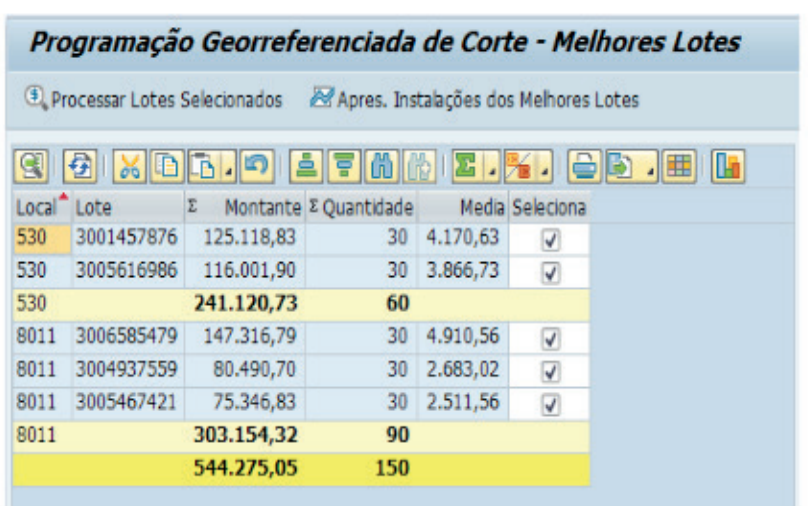

(b)

Figura 5 - Tela de resumo da da seleção dos melhores lotes/clusters, considerando os parâmetros iniciais. (a) Utilizando o critério de seleção "k-Vizinhos mais Próximos" e (b) utilizando o critério de seleção "k-Maiores Valores mais Próximos".

Assim como esperado, a utilização do segundo critério tende a buscar lotes com maior valor pendente.

Nesse ponto da funcionalidade, o GEOCORTE SAP/CCS exibirá ao tomador de decisão o resumo dos lotes selecionados para cada localidade, informando: o lote (instalação "Ponto Focal" ou centroide), o montante inadimplido desse lote, a quantidade de instalações encontradas mais próximas (por distância ou maior valor), a média em inadimplência do lote a a opção do tomador de decisão utilizar ou não esse cluster na programação de corte (efetiva emissão de Notas de Serviço). 
2.5 Exibição dos resultados e seleção dos alvos para aplicação prática nos sistemas comerciais da distribuidora

\subsubsection{Exibição dos resultados}

Caso o usuário selecione um dos lotes, a funcionalidade GEOCORTE SAP/CCS ainda exibe as instalações contidas nesse lote, conforme apresentado na Figura 6, abaixo:

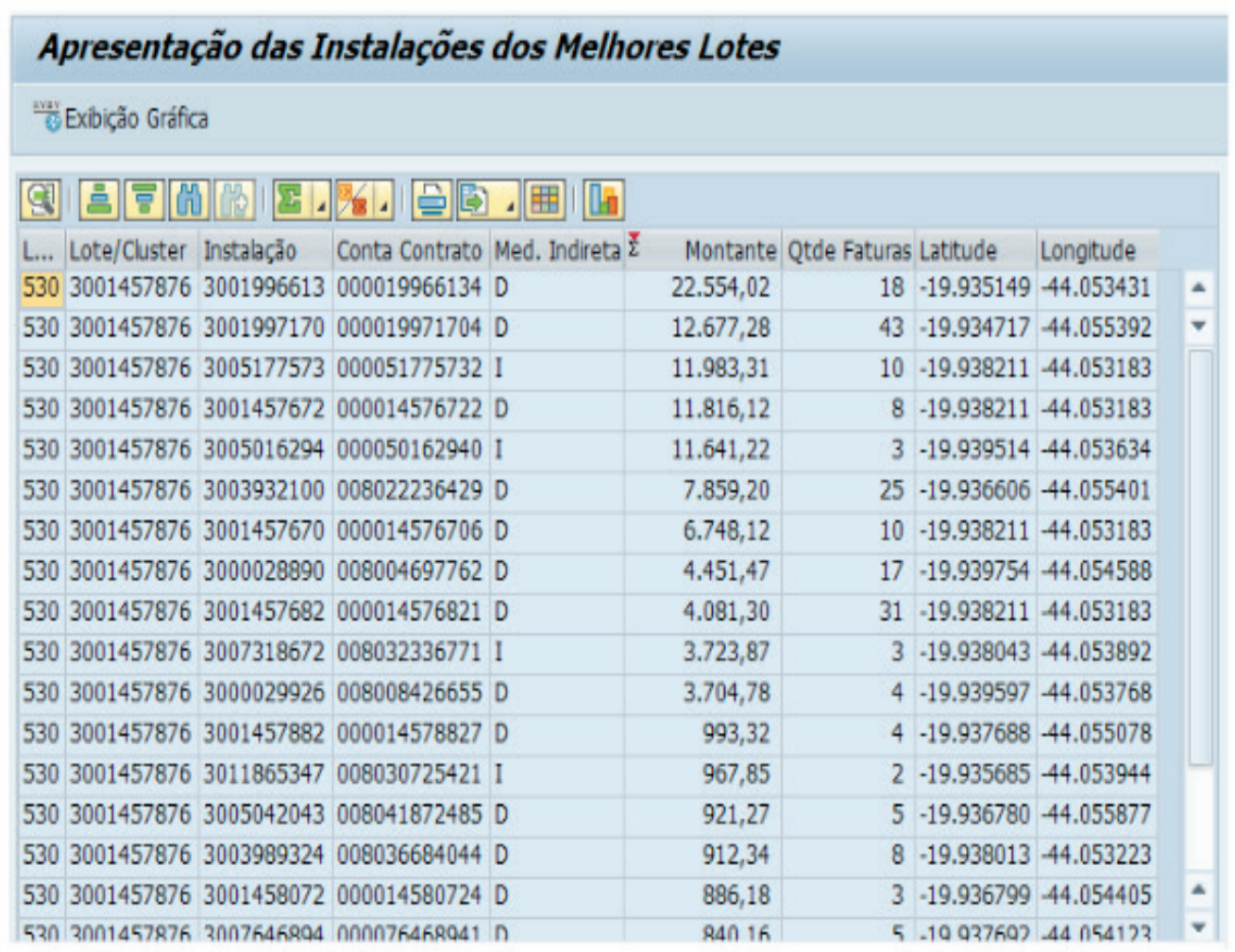

Figura 6 - Apresentação das instalações contidas num dos melhores lotes.

Caso for ainda de interesse do tomador de decisão, a funcionalide GEOCORTE SAP/CCS dispõe da apresentação gráfica da distribuição das instalações contidas num dos melhores lotes, integrada com a plataforma de geoprocessamento Google Earth $^{\mathrm{TM}}$, conforme visto na Figura 7: 


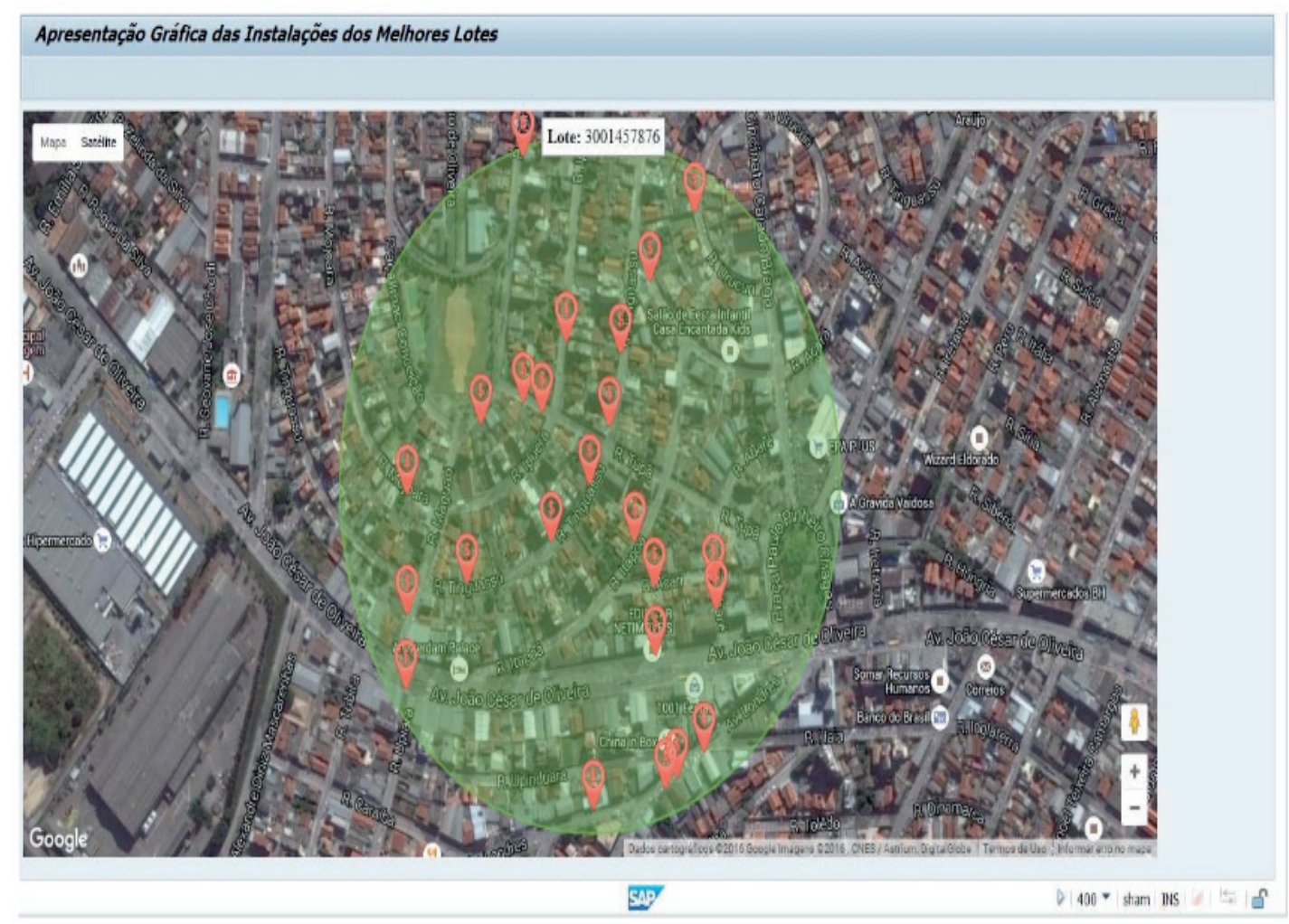

Figura 7 - Apresentação Gráfica das instalações, integrada com a plataforma de geoprocessamento Google Earth ${ }^{\mathrm{TM}}$.

Para efeitos de comparação, apresentamos também a distribuição das instalações quando o critério de seleção for "k- Vizinhos mais Próximos" ou "k-Maiores Valores mais Próximos". Pecebemos que no método de "k-Maiores Valores mais Próximos", a distribuição das instalações é mais dispersa se comparada à primeira, dispondo de instalações próximas ao limite do raio de atuação definido, entretanto não o ultrapassando.
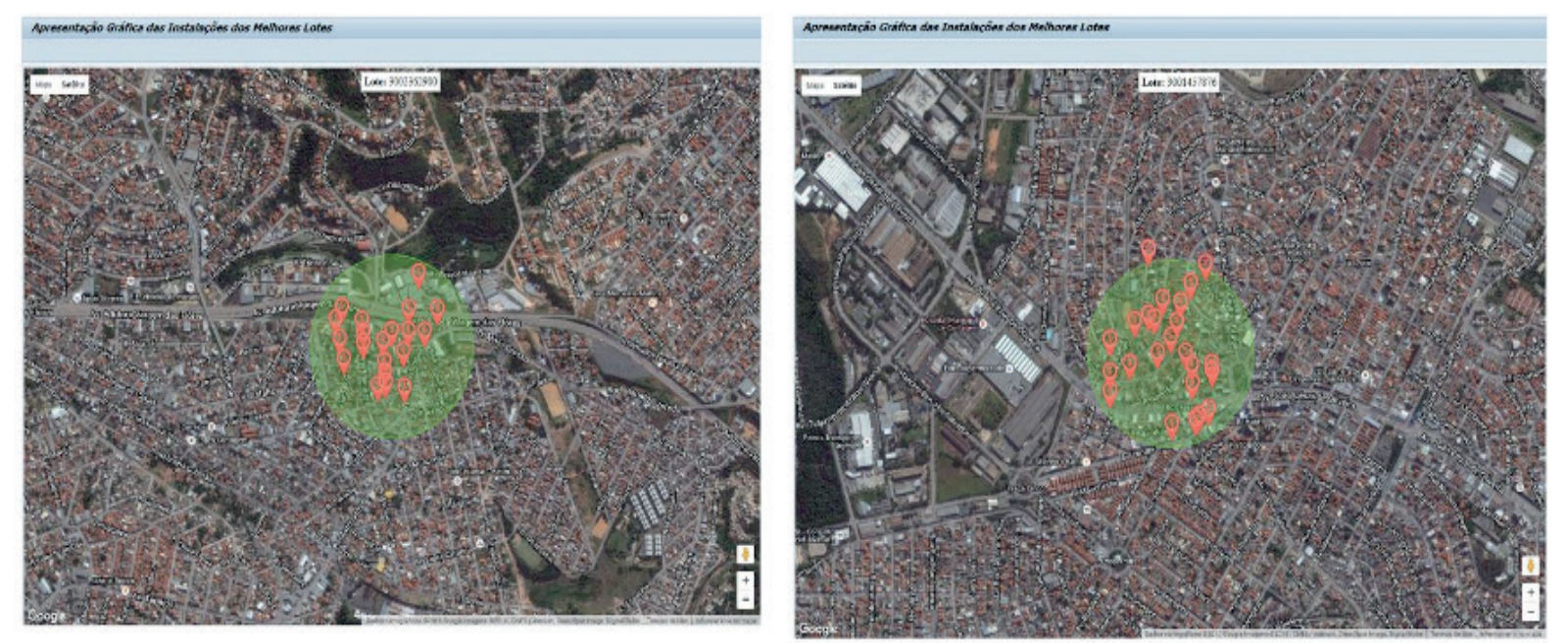

Figura 8 - Comparação entre os critérios de seleção "k-Vizinhos mais Próximos" e "k-Maiores Valores mais Próximos". 
O passo final de funcionalidade SAP/CCS GEOCORTE é a programação das notas de corte para a próxima janelaBatch ou a efetiva emissão dessas NS's.

Para emissão/programação das notas, basta o tomador de decisão selecionar os lotes interessantes (como padrão/

default, todos os lotes são previamente selecionados pela funcionalidade) e clivar em "Processar Lotes selecionados".

A funcionalidade avaliará ainda a situação e características de cada instalação para emissão da melhor nota de corte, indicando às equipes executoras o perfil do lote selecionado, conforme tabela de configuração apresentada na Figura 3 desse artigo. Dentre as características relevantes estão: valor do débito, tipo de medição (remota, indireta ou direta), seu tipo de agrupamento (individual ou conjunta: prédios, caixa 1/ caixa 2 , etc), nível da atividade na régua deDunning (Corte Simbólico ou Físico).

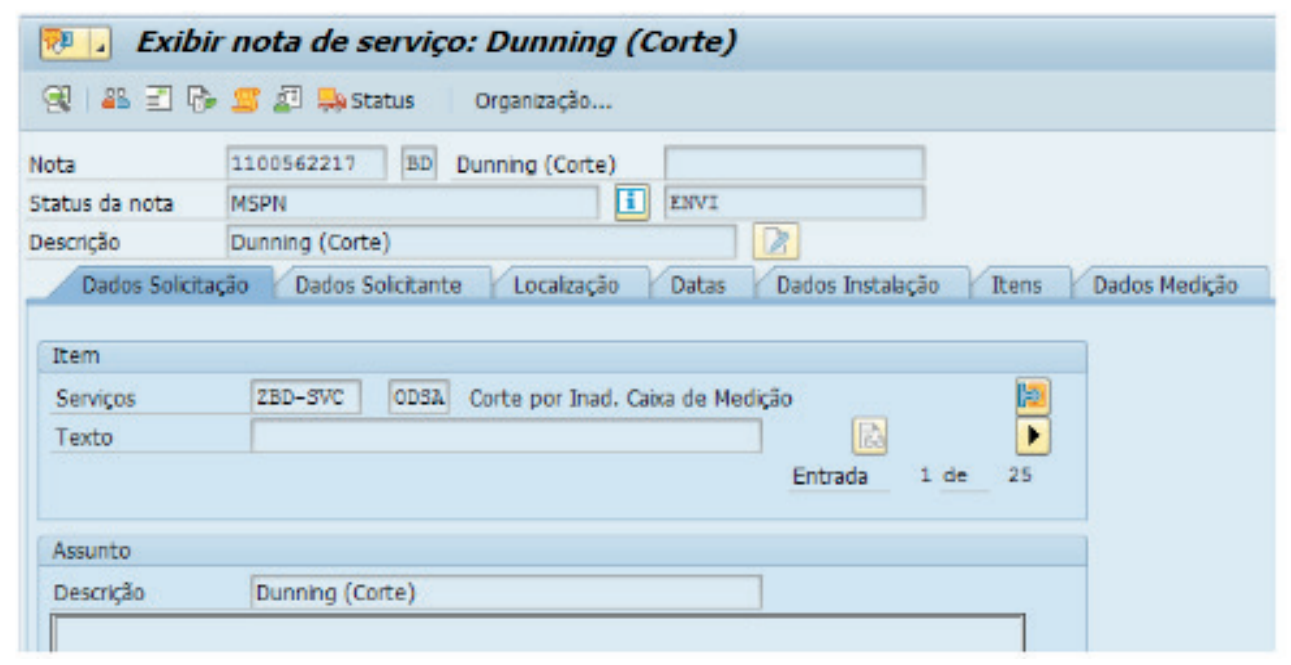

Figura 9 - Efetiva emissão de notas de serviço de corte no SAP/CCS. Módulo de exibição standard da IW53.

\subsection{Aplicação da metodologia: Resultados e Discussão}

Nesta seção, será apresentada a avaliação da aplicação da metodologia de detecção ótima de agrupamentos espaciais alvos de suspensão de fornecimento de energia elétrica proposta neste artigo em comparação com a programação convencional utilizado normalmente nas distribuidoras: Seleção dos melhores alvos dos mais inadimplentes para os menos inadimplentes, independentemente de sua proximidade.

Para a avaliação, foi considerada como amostragem as unidades consumidoras inadimplentes região do município de Belo Horizonte. A fim de preservar a integridade e confiabilidade dos dados comerciais da empresa, as informações de inadimplência aqui apresentadas são hipotéticas e foram geradas aleatoriamente, considerando o perfil real da amostra.

Como métrica de avaliação, para fins de comparação de resultados, foram 
considerados seguintes parâmetros:

- Quantidade máxima de notas de serviço por equipe: 40;

- Distância (raio) máximo do centroide - programação convencional: Limitada somente à maior distância apurada dentre as instalações da amostra;

- Distância (raio) máximo do centroide - GEOCORTE: 1 km;

- Tempo de execução da tarefa: 8 horas (Tempo médio de execução por atividade: 15 minutos);

- Velocidade média de deslocamento no trânsito: 15 km/h;

- Taxa de arrecadação por unidade consumidora suspensa (hipotético): 95\%.

O tempo global devido aos deslocamentos percorridos pela equipe executora no trânsito foi contabilizado e descontado do tempo global para execução da tarefa, equivalente a 8 horas. Com tudo, a métrica de avaliação considerará o seguinte resultado comparativo entre as metodologias:

$$
\text { ef }=\frac{\text { Montante_Dívida } a_{\text {método_proposto }}}{\text { Montante_Dívida }}
$$

Caso o resultado da métrica tiver resultado superior a 1, significa que a metodologia proposta tem resultado melhor que a convencional.
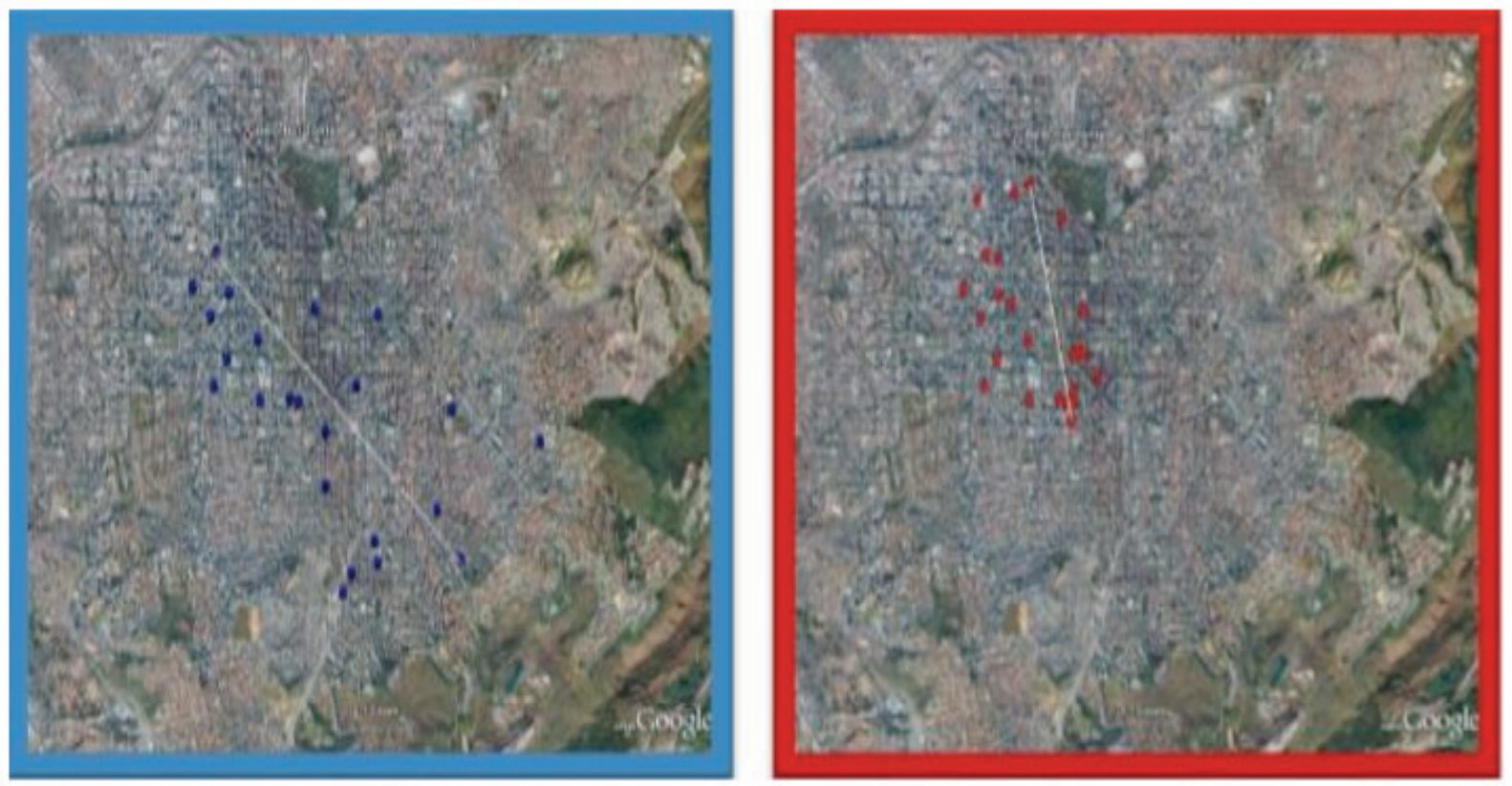

Figura 10 - Comparação da distância a ser percorrida pela equipe executora utilizando o método convencional (azul) e o proposto (vermelho). Para o método convencional, deslocamente de 28,9km (máxima de 3,3km), atuando em 23 UC's.

Para o método GEOCORTE SAP/CCS, 18,0km (máxima de 1,9km), atuando em 26. 
Aplicando a a funcionalidade SAP/CCS GEOCORTE no mercado estudado e a métrica supracitada adotada, observa-se resultados melhores que a utilização do método convencional, especialmente quando a quantidade de equipes executora se eleva, conforme apresentado nas figuras 10, 11 e 12:
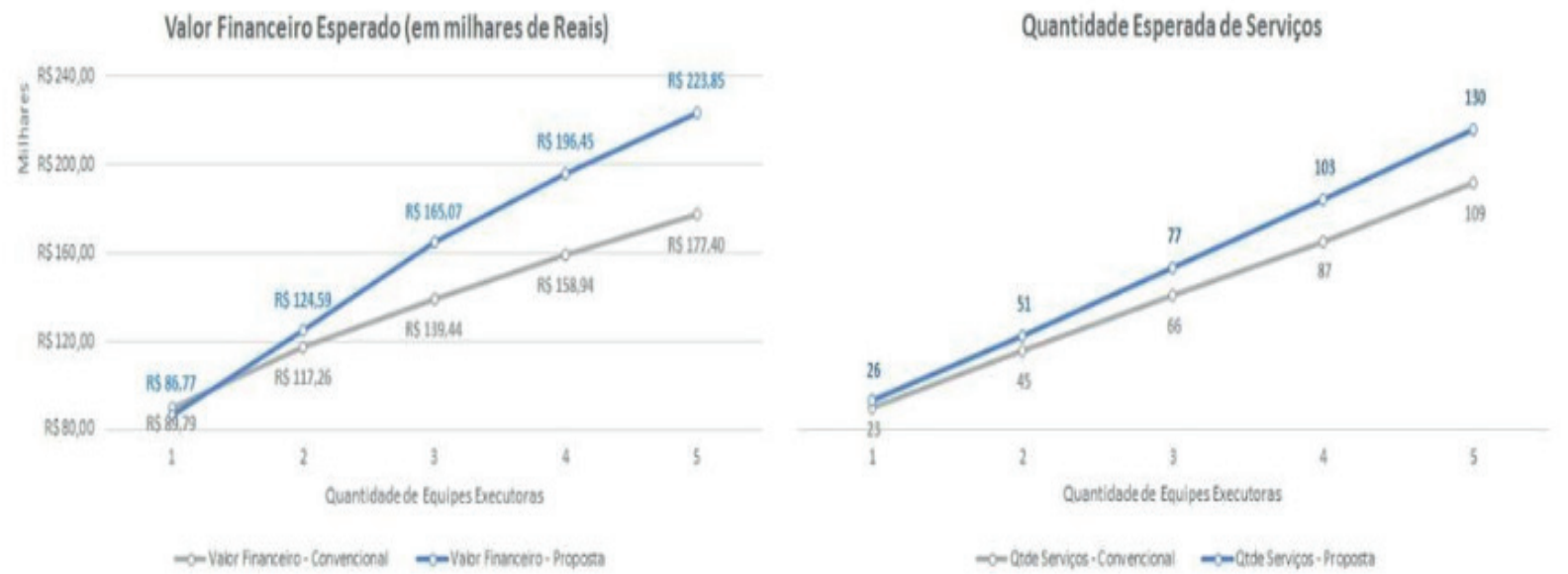

Figura 11 - Comparação das metodologias proposta e convencional na perspectiva de "Valor Financeiro Esperado" e "Quantidade Esperada de Serviços".
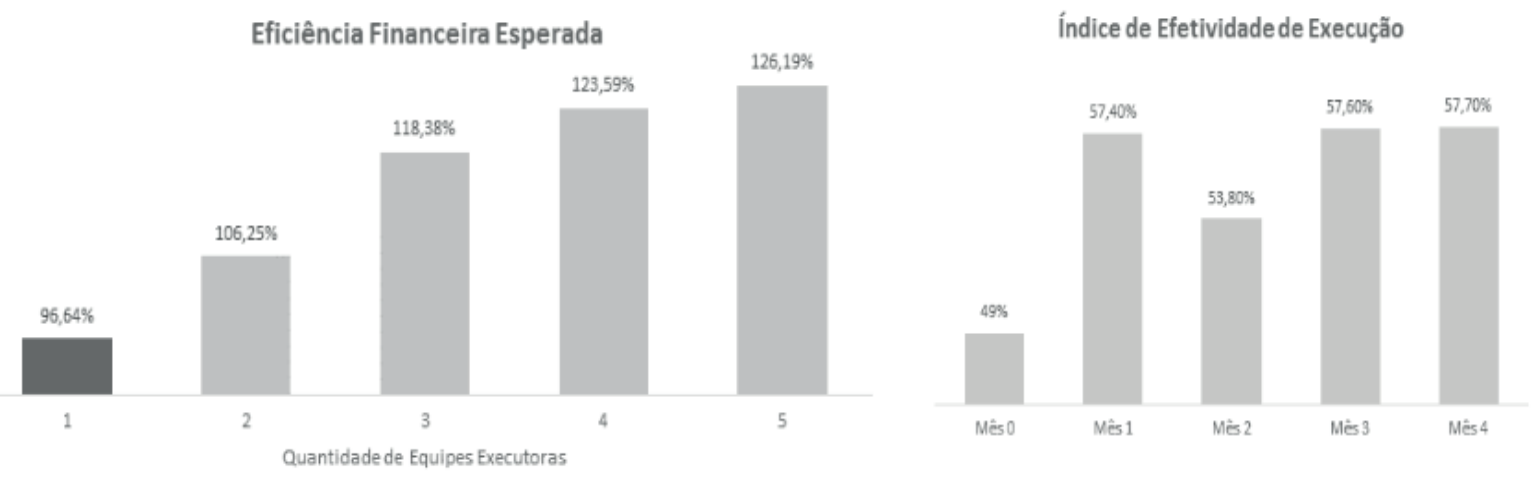

Figura 12 - Lado Esquerdo: Evolução do índice de Eficiência financeira esperada em função da quantidade de equipes executoras disponíveis. Lado Direito: evolução do índice de efetividade de execução apurado em 4 meses de utilização da metodologia no estudo de caso proposto.

No caso estudado, a eficiência da utilização do GEOCORTE SAP/CCS teve resultado próximo à convencional, sendo que, para as demais situações, obteve resultados superiores em aproximadamente $6 \%$ em cada etapa.

\section{I CONCLUSÕES}

Com a implantação da funcionalidade GEOCORTE SAP/CCS permitiu, além dos resultados apresentados na seção 2.5 deste artigo, eficiência operacional da equipe tomadora de decisões, a elevação da produtividade e a execução efetiva de suspensões de fornecimento (cortes) das equipes executoras em 16\% em média (ver Figura 12).

Além dos ganhos de produtividade na execução e da maior recuperação de 
receita, o GEOCORTE SAP/CCS permite também reduzir drasticamente o tempo de análise das equipes de programação corte (chamado nesse artigo de "tomador de decisão"), normalmente lotados nas gerências de cobrança das distribuidoras.

Para garantir a eficácia da metodologia e contribuir ainda mais com melhoria da produtividade das equipes executoras,é importante informações precisas e que reflitam a realidade em campo. Portanto pode ser classificado como indispensável a manutenção da base de dados comercial e geográfica, bem como a relação atualizada de equipes de executores em suas respectivas bases de atuação. De maneira análoga, a conclusão do mapeamento geográfico, com coordenadas, das áreas restritas para deslocamento (como cruzamento de grandes avenidas) também permitirá refinamento da funcionalidade SAP/CCS GEOCORTE.

Uma etapa complementar e subsequente ao último passo da metodologia que também poderia contribuir com a produtividade das equipes executoras, seria a roteirização interna dos clusters, permitindo aos executores percorrer o menor caminho possível. Tal funcionalidade pode ser implementada por algoritmos solucionadores da modelagem do "Problema do Caixeiro Viajante" - Travelling Salesman Problem.

Para trabalhos futuros, recomenda-se também a utilização de dado "Conceito de Solvência do Cliente (Qualidade Pagadora)", de forma opcional para o modelo especialmente aplicado à seção 2.1 deste artigo - o que poderia agregar à acurácia dos resultados.

Consideramos que a modelagem do problema da forma pretendida, utilizando o "Problema da Mochila" e as técnicas para sua solução, Geographical Dynamic Scan e método Simplex de Otimização, mostrou-se eficiente e suficientemente aplicável, o que pode despertar interesses por esta área de estudo em outros trabalhos. Qualquer manifestação, contribuição ou crítica para melhoria dos resultados e da metodologia são primordiais pra a evolução do trabalho.

\section{REFERÊNCIAS}

ANEEL, Agência Nacional de Energia Elétrica. Resolução Normativa N¹4/2010 - Condições Gerais de Fornecimento de Energia Elétrica. Brasília, DF - Brasil. 2010.

BAZARAA, Mokhtar S.; JARVIS, John J.; Sherali, Hanif D.. Linear Programming and Network Flows 4th Edition. Atlanta, GA - United States of America. 2008.

CORREIOS, Empresa Brasileira de Correios e Telégrafos. Estrutura do CEP - Código de Endereçamento Postal. Brasília, DF - Brasil. 1971. Disponível em: http://www.correios.com.br/ servicos/cep/cep_estrutura.cfm. Acesso em: 26.Abr.2014.

KARP, Richard M.. Reducibility Among Combinatorial Problems. Berkeley, CA - United States of America. 1972.

BRASIL. Lei Federal N`8.987 de 13 de Fevereiro de 1995. Dispõe sobre o regime de concessão e permissão da prestação de serviços públicos previsto no art. 175 da Constituição Federal, e dá outras providências. Brasília, DF - Brasil. 1995. 
MARTELLO, Silvano; TOTH, Paolo. Knapsack Problems - Algorithms and Computer Implementations. Bologna - Italia. 1990.

MOREIRA, Gladston Juliano Prates. The Detection of Spatial Clusters: Graph and Dynamic Programming Methods. Belo Horizonte, MG - Brasil. 2011.

* : Este artigo é dedicado à memória de André Luiz Soares, mentor intelectual deste projeto. 


\section{CAPÍTULO 8}

\section{ÍNDICES DE REFERÊNCIA PARA APLICAÇÃO DA TECNOLOGIA CABOS PARA-RAIOS ENERGIZADOS}

Data de Submissão: 10/11/2019

Data de aceite: 03/01/2020

José Ezequiel Ramos Fundação Universidade Federal de Rondônia (UNIR) - Porto Velho - Rondônia

Alexandre Piantini Instituto de Energia e Ambiente (IEE/USP) São Paulo - São Paulo Ary D'Ajuz Universidade Federal de Itajubá (UNIFEI) Brasília - Distrito Federal Valdemir Aparecido Pires Energisa Rondônia

Porto Velho - Rondônia

Paulo Roberto de Oliveira Borges Fundação Universidade Federal de Rondônia (UNIR)

Porto Velho - Rondônia

RESUMO: Este artigo apresenta os resultados da pesquisa sobre o desempenho operacional da tecnologia cabos para-raios energizados (PRE) implantada em Rondônia, nas localidades de Jaru e Itapuã do Oeste, visando obter um conjunto de índices, aqui denominados de índices operacionais de referência. Para obtenção desses índices foram analisados os registros de mais de 180 meses de operação do
PRE Rondônia. Além disso, foram analisadas as incidências de descargas atmosféricas na região, assim como os índices de chuvas, sendo encontrada alta correlação entre esses eventos e as interrupções causadas por descargas atmosféricas.

PALAVRAS-CHAVE: Tecnologia PRE, interrupções, índices operacionais, descargas atmosféricas.

\section{REFERENCE INDEXES FOR APPLICATION OF ENERGIZED SHIELD WIRE LINE TECHNOLOGY}

ABSTRACT: This paper presents the results of the operational performance of the energized shield wire line (SWL) technology implemented in Rondônia, in the localities of Jaru and Itapuã do Oeste, aiming to get a set of indexes, here called operational indexes. To obtain these indexes were analyzed the records of more than 180 months of operation of the SWL of Rondônia. In addition the incidences of lightning in the region were evaluated, as well as indices of rain, being found a high correlation between these events and the interruptions caused by lightning.

KEYWORDS: SWL technology, interruptions, operating indexes, lightning. 


\section{I INTRODUÇÃO}

Apesar da viabilidade técnica e econômica da tecnologia PRE, demonstradas por Iliceto et al. (2000), Ramos et al. (2009, 2011, 2014), como tal tecnologia poderá ser incluída no conjunto de outras alternativas se ela não é suficientemente conhecida? Esse é o grande desafio enfrentado pelas novas tecnologias, como afirmam Souza et al. (2004) na avaliação que fazem sobre as barreiras e facilitadores para a produção e difusão de tecnologias renováveis na região amazônica. A falta de conhecimento das tecnologias existentes no mercado nacional e internacional, bem como de resultados de experiências aplicadas na região, leva à rejeição da tecnologia em certas situações e ao retrabalho de pesquisa em outras.

Para o enfrentamento desse desafio, adotou-se como uma das alternativas a análise detalhada das interrupções verificadas ao longo de todo o período de operação do PRE Jaru (de 1996 a 14/11/2000) e do PRE Itapuã, desde sua entrada em operação, ocorrida em 22/09/1997, até 31 de dezembro de 2007. Os índices de referência resultantes dessa análise são: duração equivalente de interrupção por unidade consumidora (DEC) e frequência equivalente de interrupção por unidade consumidora (FEC). A partir desses índices são também obtidos: o tempo médio de restabelecimento (TMR), a taxa de falhas (TF) e a confiabilidade por consumidor (Cpc).

Cumpre esclarecer que os sistemas elétricos das localidades de Jaru e Itapuã do Oeste, onde a tecnologia PRE foi implantada, são aqui denominados de PRE Jaru e PRE Itapuã. Também são adotadas as expressões Sistema PRE para designar qualquer uma das instalações ou especificamente a tecnologia PRE em Rondônia.

\section{I MATERIAL E MÉTODOS}

O objeto de estudo é a tecnologia PRE no esquema trifásico (lliceto et al., 1989). Essa tecnologia é baseada na utilização dos cabos para-raios de uma linha de transmissão em corrente alternada (LTCA), de forma que, sem comprometer a função básica de proteção dos condutores da linha contra as descargas atmosféricas, os cabos para-raios podem ser também utilizados para transportar energia elétrica, tornando possível reunir, em uma mesma infraestrutura, um sistema de Alta ou Extra Alta Tensão com um sistema de Média Tensão. Na Figura 1 são apresentadas as principais características da tecnologia PRE. 


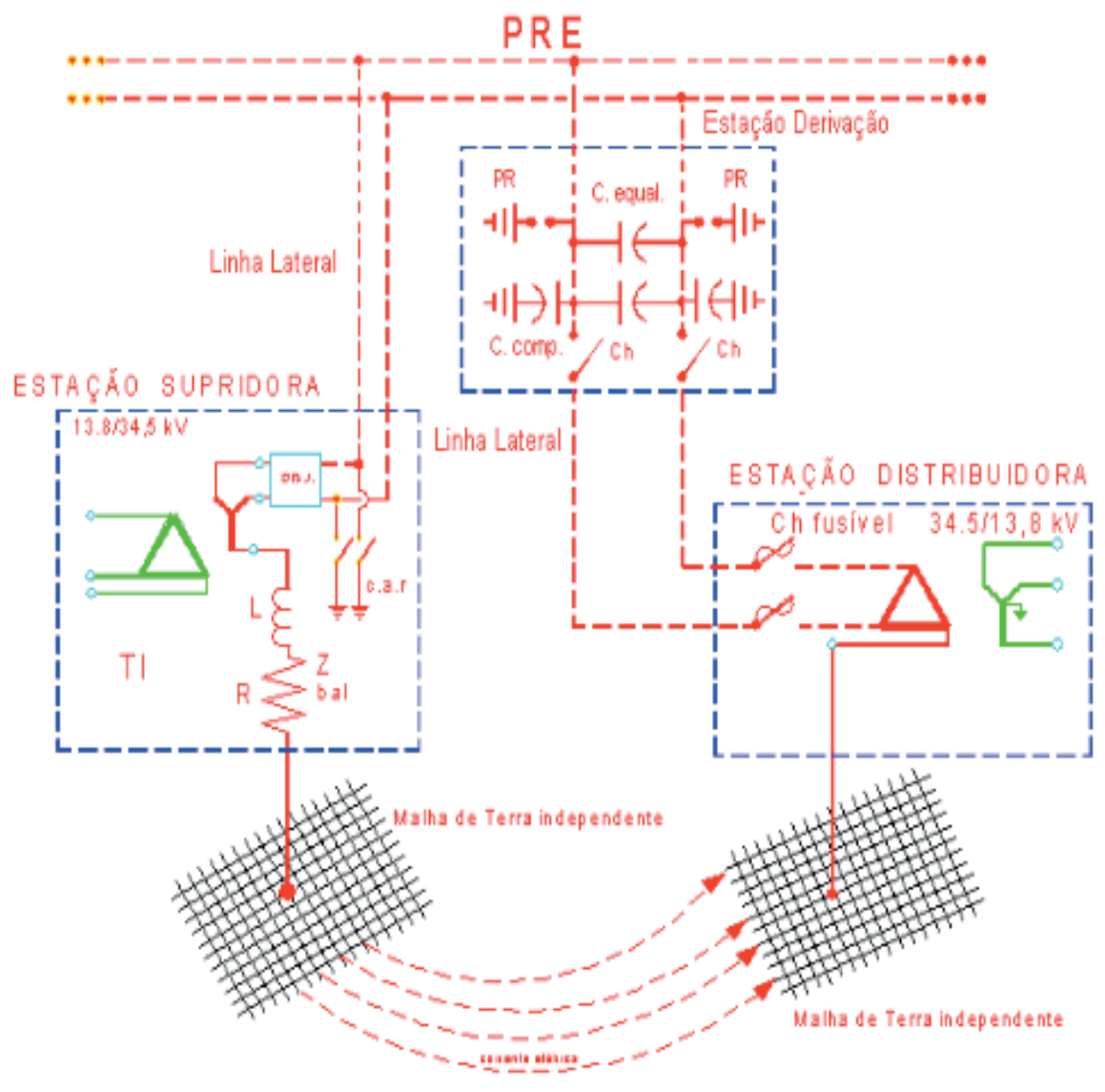

Figura 1. Diagrama ilustrativo da tecnologia PRE no esquema trifásico

O material utilizado para análise das interrupções foi obtido dos seguintes documentos: a) livro de operação das instalações PRE; b) relatórios de desligamentos; d) informações diárias produzidas pelo Centro de Operação de Sistemas (COS); e) livro de ocorrências com registros feitos pela coordenação da localidade de Itapuã do Oeste; f) dias de trovoadas registradas pela Estação Meteorológica de Porto Velho.

No que diz respeito ao método, as interrupções foram classificadas de acordo com as recomendações contidas em ELETROBRAS/CODI (1982), ou seja, as interrupções foram classificadas segundo a origem e segundo a causa. A metodologia utilizada para o cálculo dos índices de continuidade foi baseada na Resolução 024 da Agência Nacional de Energia Elétrica (ANEEL, 2000).

Para obtenção dos índices representativos do desempenho operacional do sistema PRE, inicialmente os dados das interrupções que dizem respeito somente ao desempenho operacional do PRE Jaru e PRE Itapuã foram somados e totalizados em relação a cada mês, obtendo-se, dessa forma, um valor médio para cada mês. Ao final, os valores médios mensais de DEC e FEC de cada PRE foram somados e, em seguida, foram extraídas as médias aritméticas, resultando nos índices mensais representativos do sistema PRE Rondônia. 


\section{I RESULTADOS E DISCUSSÃO}

Durante os 4,875 anos de operação do PRE Jaru foram registrados DEC = 143,65 horas e FEC $=318$ interrupções, sendo esses resultados de origem interna, ou seja, que dizem respeito somente à tecnologia PRE. Da mesma forma, nos 10,28 anos de operação do PRE Itapuã, foram registradas DEC $=443,45$ horas e FEC $=659$ interrupções.

As Figuras 2 e 3 mostram claramente que o comportamento do Sistema PRE é determinado basicamente pelo evento descargas atmosféricas, indicado no gráfico como o númeero de interruções por descargas atmosféricas (NIDA). Visando confirmar esse comportamento, de característica sazonal, foram utilizados, no escopo dessa pesquisa, os dados de descargas atmosféricas registrados pela rede "Brazil Lightning Detection Network" (BLDN) no período de 2000 a 2004, cujo perfil está indicado na Figura 4.

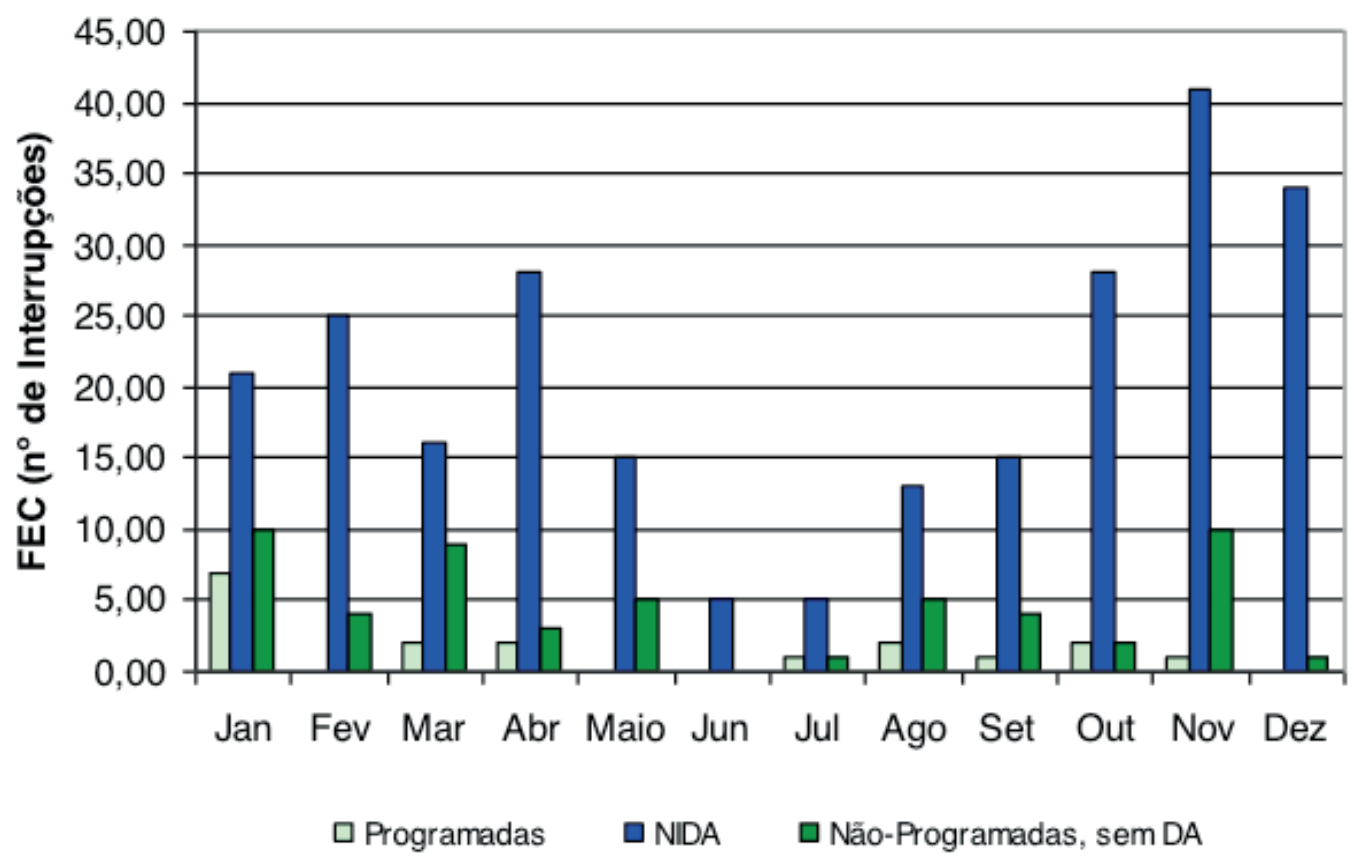

Figura 2. Comportamento característico do FEC associado ao PRE Jaru, no período de 1996 a $14 / 11 / 2000$ 


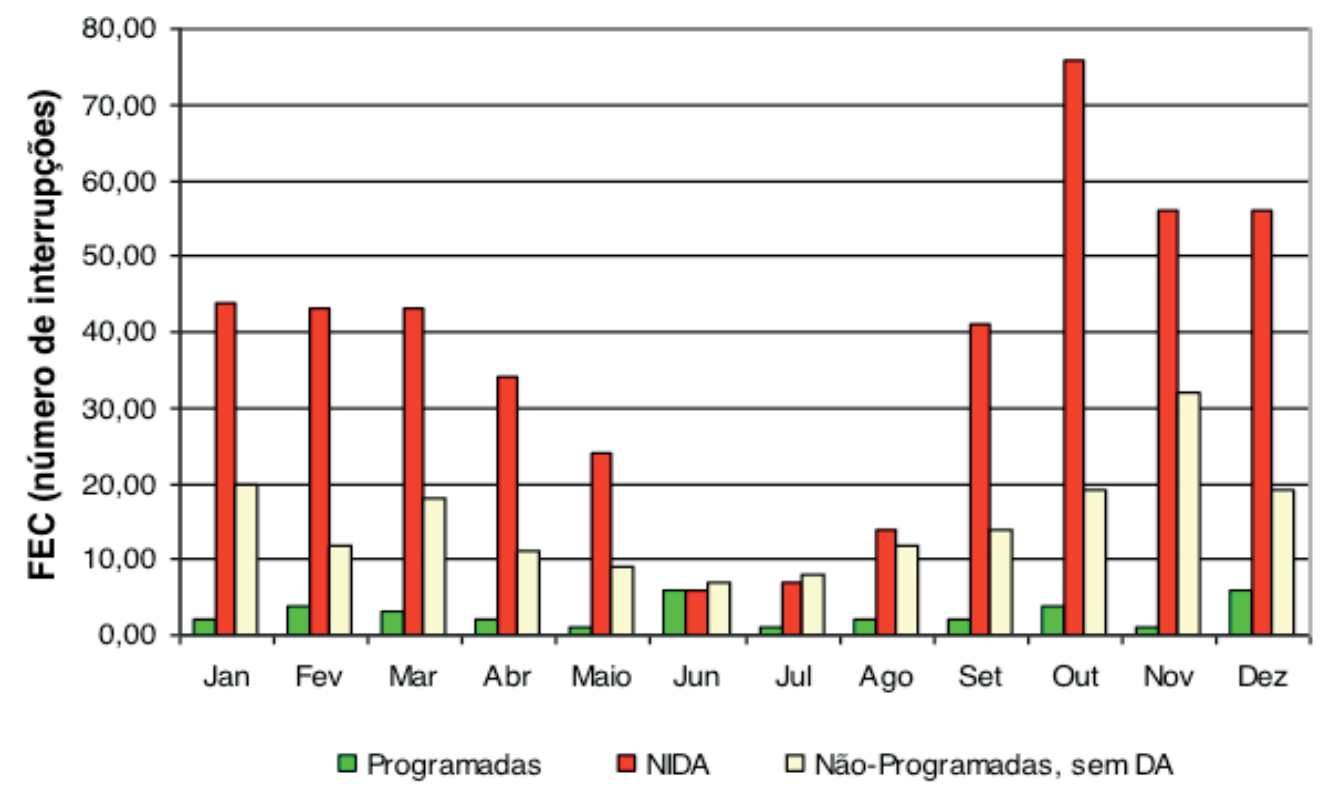

Figura 3. Comportamento característico do FEC associado ao PRE Itapuã, no período de 22/09/1997 a 2007

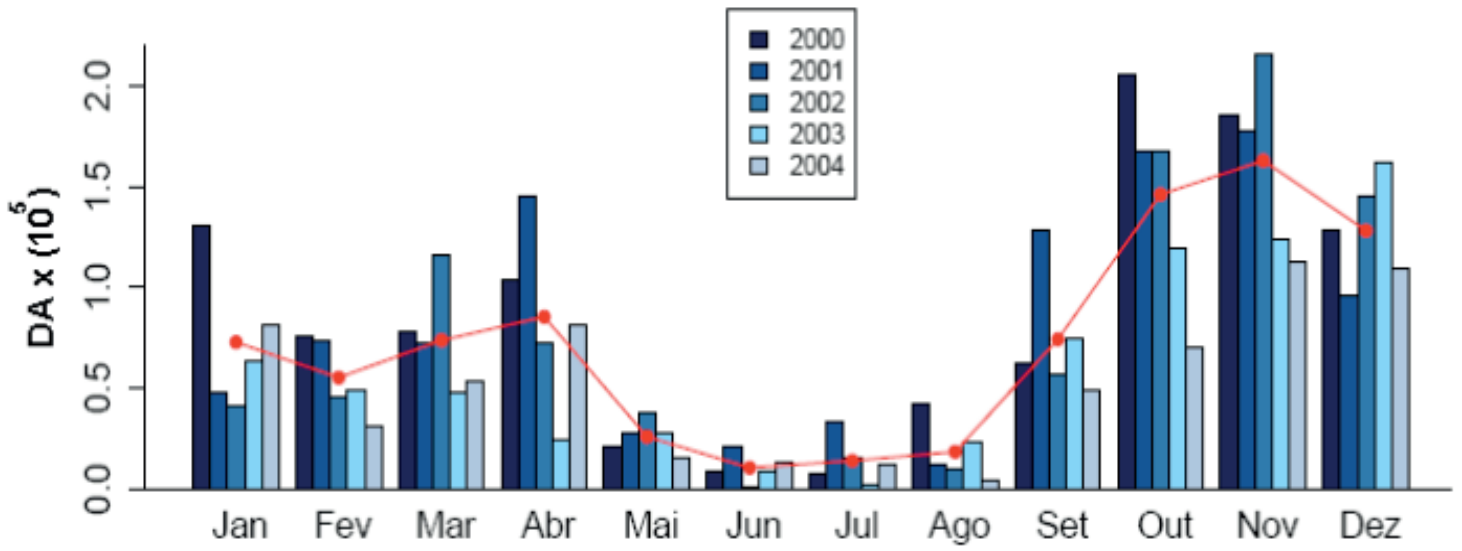

Figura 4. Distribuição mensal do número de descargas atmosféricas no Estado de Rondônia, medidos pela rede BLDN

Fonte: adaptado de Albrecht (2008)

Comparando-se o gráfico da Fig. 4 com aqueles mostrados nas Figuras 2 e 3, observa-se nítida semelhança com o comportamento das interrupções por descargas atmosféricas. Isso demonstra, sobretudo, que os critérios de classificação das descargas atmosféricas foram acertados. Também foram correlacionados estatisticamente os dados de chuvas na região com os registros de interrupções por descargas atmosféricas, sendo encontrada alta correlação entre eles.

Uma vez que os sistemas PRE de Jaru e Itapuã têm comportamentos semelhantes, seus índices foram somados e, do resultado, extraída a média aritmética, resultando, dessa forma, no conjunto de índices representativos do sistema PRE, conforme apresentado a seguir:

- $\mathrm{DEC}=36,16$ horas/ano; FEC = 64,94 interrupções/ano; 
- $\mathrm{TMR}=0,56$ hora/interrupção/ano; TF = 0,82 falha/km/ano;

- $\operatorname{TF}(\mathrm{NIDA})=0,60$ falha/km/ano; $\mathrm{Cpc}=0,9959$.

\section{I CONCLUSÕES}

A metodologia utilizada para classificação das interrupções, especialmente em relação às suas causas, mostrou-se acertada, uma vez que os dados resultantes formatam um perfil de falhas que dialoga com os dados de descargas atmosféricas medidos pela BLDN, além de apresentarem alta correlação com os índices de chuva na região. Portanto, se o comportamento da tecnologia PRE é basicamente determinado pelas interrupções provocadas por descargas atmosféricas, os índices operacionais aqui apurados são confiáveis. Dessa forma, esses resultados permitem afirmar que os índices representativos de todo o sistema PRE podem ser considerados como índices de referência para a aplicação da tecnologia PRE em regiões cuja densidade de descargas atmosféricas seja semelhante à de Rondônia e cuja geometria das torres das linhas de transmissão sejam semelhantes àquela da LT $230 \mathrm{kV}$ no trecho entre a UHE Samuel e Ji-Paraná.

\section{REFERÊNCIAS}

ANEEL. Resolução 024 de 27 de janeiro de 2000. Brasília, 2003.

ELETROBRAS. CODI. Desempenho de sistemas de distribuição. Rio de Janeiro, Campus/ Eletrobras, 1982, coleção distribuição de energia elétrica, v.3.

Iliceto, F.; E. Cinieri, L.; Casely-Hayford, and G. Dokyi, New concepts on MV distribution from insulated shield wires of HV lines: operation results or an experimental system and applications in Ghana. IEEE Transactions on Power Delivery, vol. 4, nº. 4, pp. 2130-44, Oct. 1989.

Iliceto, F; Gatta, F. M.; Dokyi, G. O. Three-phase and single-phase electrification in developing countries using the insulated shield wires of HV lines energized at MV. Operation experience in Ghana. In: International Conference on Power Systems Operation and Planning, 4, Accra, Ghana, July-August, 2000, paper $\mathrm{n}^{\circ}$ 20-2E01.

SOUZA, Rubens César Rodrigues; DERZI, Silva Rodrigues; CORREIA, José de Castro. Barreiras e facilitadores para a produção e difusão de tecnologias de energias renováveis na região amazônica. Revista Brasileira de Energia. Itajubá: SBPE, 2004. v.10, n.1, p. 99-115. $2^{\circ}$ semestre de 2004.

Rachel Ifanger Albrecht. Eletrificação dos sistemas precipitantes na região Amazônica: processos físicos e dinâmicos do desenvolvimento de tempestades. São Paulo: USP, 2008. 97p. Tese Doutorado.

Ramos, José Ezequiel; Piantini A.; Pires, Valdemir Aparecido; D’Ajuz, Ary. The Brazilian experience with the use of the shield wire line technology (SWL) for energy distribution. IEEE Latin America Transaction, v.7, n.6, p.650-656, Dec. 2009.

Ramos, J. E.; Pires, V. A.; Piantini, A.; Obase, P. F., Neto, A. Silva; Carvalho, T. O.; Borges, P. R. O. 
Analysis of the effect of lightning on the energized shield wire line technology. In: International Symposium on Lightning Protection, 11 (XI SIPDA), Fortaleza, 2011, Proceedings, IEE/USP, São Paulo, 2011, CD Rom.

Ramos, José Ezequiel; Piantini A.; Pires, Valdemir Aparecido; D’Ajuz, Ary; Borges, Paulo Roberto de Oliveira. Alternativas tecnológicas para fornecimento de energia elétrica a pequenas cargas. In: Congresso Técnico Científico da Engenharia e da Agronomia, CONTECC 2014 e Semana Oficial da Engenharia e Agronomia, 71, Teresina, 2014. Anais, Teresina, 2014, CD Rom, ano 1, v. 1. 


\section{A EXPERIÊNCIA DA COPEL COM RELIGADORES MONOFÁSICOS}

Data de submissão: 10/11/2019

Data de aceite: 03/01/2020

Maurício Varassim Hernandes

Copel Distribuição

Curitiba - Paraná

http://lattes.cnpq.br/8929213248130565

Oscar Kim Júnior

Copel Distribuição

Curitiba - Paraná

http://lattes.cnpq.br/0164312701259395

Fausto Aurélio Portella Garcia

Copel Distribuição

Curitiba - Paraná

http://lattes.cnpq.br/8224120709515354

Guilherme Fernandes Gonçalves

Universidade Federal do Paraná

Curitiba - Paraná

http://lattes.cnpq.br/1928154474807277

RESUMO: Este artigo apresenta os resultados dos projetos pilotos, estudos realizados e aplicação em grande escala dos religadores monofásicos simplificados. Estes religadores são uma tecnologia nova pois toda a eletrônica está embutida no mecanismo de interrupção da corrente, sendo então constituídos de uma peça única, não tendo um controle eletrônico separado. Esta tecnologia facilita a instalação e manutenção, e devido ao preço reduzido pode ser adquirido em maiores quantidades quando comparado aos religadores monofásicos convencionais. A aplicação em grande escala comprovou redução no DEC e nos custos operacionais quando da instalação no lugar de/ ou em conjunto com chaves fusíveis.

PALAVRAS-CHAVE: Religador monofásico, chave fusível, qualidade de energia, DEC, custo operacional

\section{COPEL'S EXPERIENCE WITH SINGLE- PHASE RECLOSERS}

ABSTRACT: This article presents the results of pilot projects, studies and large-scale application of simplified single-phase reclosers These reclosers are a new technology as all electronics are built into the current interruption mechanism and are therefore made of a single piece and do not have a separate electronic control. This technology facilitates installation and maintenance, and due to the reduced price it can be purchased in larger quantities compared to conventional single phase reclosers. Large scale application has proven reduction in SAIDI and operating costs when installing in place of / or in combination with power fuses.

KEYWORDS: Single-phase recloser, power fuse, electric power quality, SAIDI, operating cost 


\section{I INTRODUÇÃO}

Em função das metas dos indicadores de qualidade de energia determinados pela ANEEL (Agência Nacional de Energia Elétrica) para as concessionárias de Distribuição de Energia do Brasil visando a manutenção de sua concessão [1], a Copel Distribuição realizou estudos de novas tecnologias com o objetivo da adoção de equipamentos que contribuíssem na melhoria progressiva destes indicadores (os valores propostos de DEC - Duração Equivalente de Interrupção por Unidade Consumidora e FEC Frequência Equivalente de Interrupção por Unidade Consumidora para os próximos anos para a Copel podem ser observados na Figura 1 e Figura 2). Dando continuidade a projetos pilotos já concluídos foi criado um Grupo de Trabalho na Copel Distribuição para aprofundamento e estudo dos religadores monofásicos. O Grupo de Trabalho foi criado em agosto de 2015 e foi finalizado em janeiro de 2016. As atribuições do grupo foram: avaliar as tecnologias de religadores monofásicos disponíveis no mercado, elaborar especificação técnica e preparar seu processo de aquisição. Estes objetivos foram totalmente concluídos e serão detalhados no desenvolvimento deste artigo.

Com relação aos projetos pilotos os mesmos foram efetuados através da aquisição e empréstimos de equipamentos. Foram utilizados dois religadores monofásicos simplificados diferentes: o Tripsaver e o Fusesaver. Após o Grupo de Trabalho, em 2016 foram adquiridos 685 Fusesavers e 480 Tripsavers. Em 2017 foram adquiridos mais 1.875 Tripsavers. Todos já foram instalados. Em 2018 foram adquiridos mais 9.650 Tripsavers. Os resultados da instalação destes equipamentos foram muito positivos tendo impactado em redução do DEC nos circuitos instalados bem como nos custos operacionais.

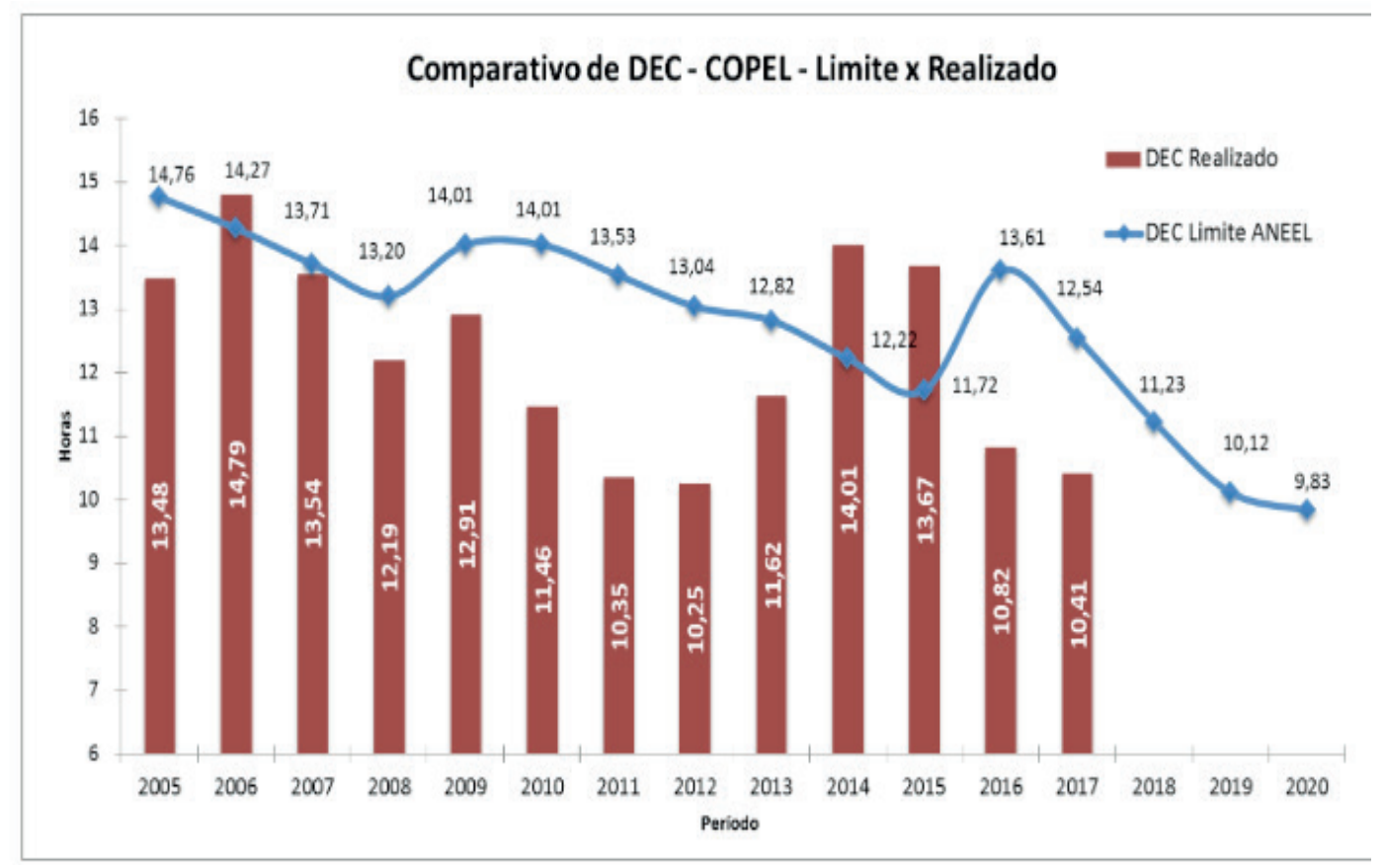

FIGURA 1 - Valores realizados e metas de DEC 


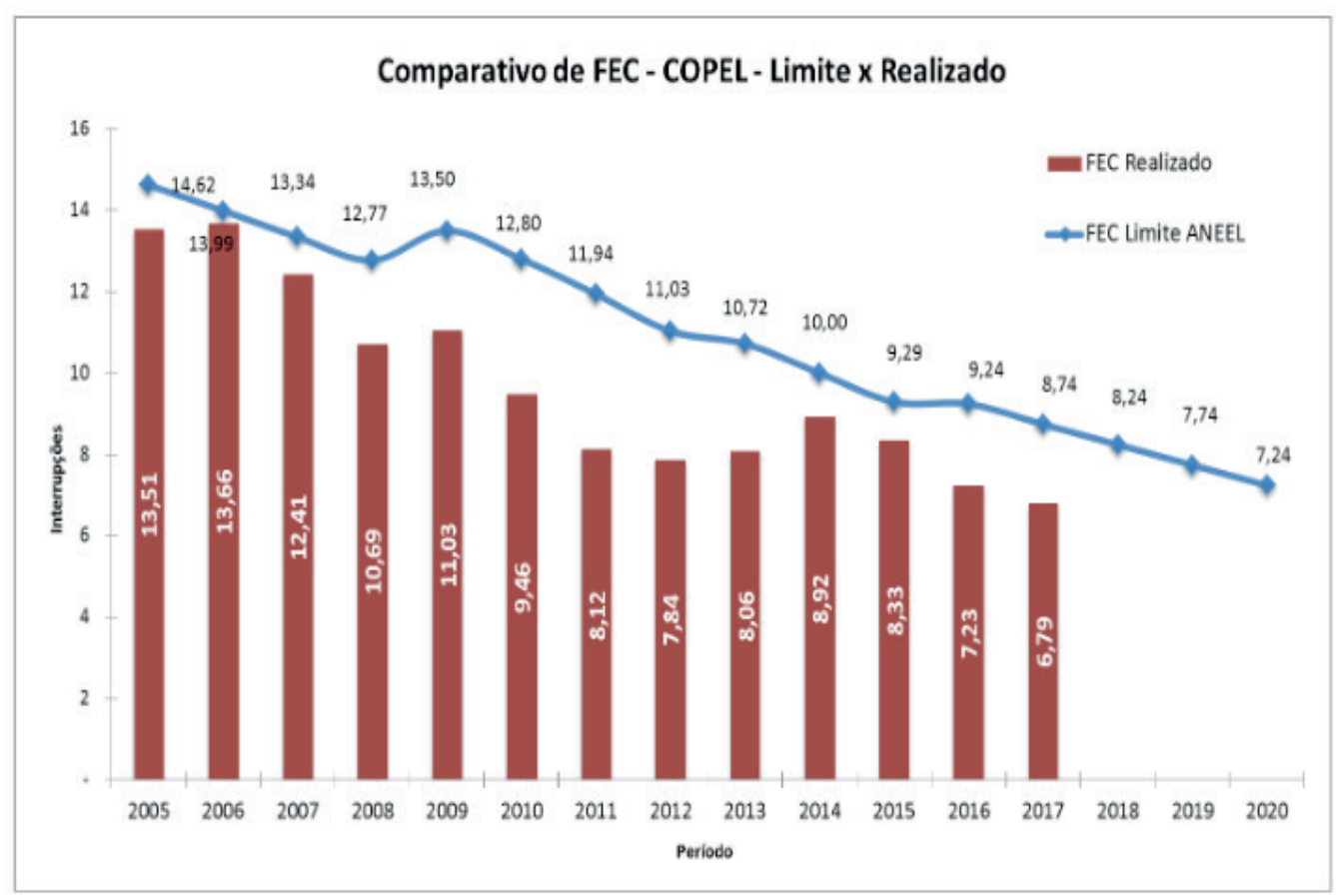

FIGURA 2 - Valores realizados e metas de FEC

\section{I PROJETOS PILOTOS}

Os projetos pilotos podem ser divididos em duas etapas.

\subsection{Primeira Etapa}

O primeiro projeto piloto foi feito com o religador Tripsaver. O Tripsaver é um religador monofásico simplificado que deve ser instalado diretamente nas bases de chaves fusíveis. Funciona com uma sequência de operação abre-fecha-abre-bloqueio. Quando o equipamento chega ao final do ciclo abre e cai, permitindo a visualização de sua abertura. Fotos do Tripsaver podem ser observadas na Figura 3 - (a), equipamento na base da chave fusível e na Figura 3 - (b), equipamento visivelmente aberto quando no estado de bloqueio.

Foi instalado um conjunto trifásico em cada uma das Regionais de Maringá, Ponta Grossa e Cascavel. Na Regional de Maringá, os equipamentos foram colocados no lugar de chave-fusível do Alimentador Tropical da Subestação Santos Dumont. A observação compreendeu o período de 31/01/2013 até agosto de 2015. Foram observadas 29 faltas temporárias na fase A, 15 faltas temporárias na fase B e 18 faltas temporárias na fase $\mathrm{C}$. No período ocorreram 4 faltas permanentes. Foram evitadas 62 trocas de fusíveis, que correspondem às faltas temporárias religadas pelos Tripsavers. Na Regional de Ponta Grossa, os equipamentos foram colocados no lugar de chave repetidora do Alimentador Quero-Quero da Subestação Palmeira. A observação compreendeu o período de 10/07/2013 até agosto de 2015. Houve a contabilização de 4 faltas permanentes. Não foi contabilizada o número de faltas temporárias. $\mathrm{Na}$ Regional de Cascavel os equipamentos foram instalados no lugar de elo-fusível do Alimentador Figueira da Subestação Concórdia. A observação compreendeu o período 
de 12/12/2012 até agosto de 2015. Foram observadas 35 faltas temporárias na fase $A$, 35 faltas temporárias na fase B e 13 faltas temporárias na fase $\mathrm{C}$. No período ocorreram 6 faltas permanentes. Desta maneira foram evitadas 83 trocas de elos fusíveis.

Ressalta-se que este piloto foi feito com a primeira versão do Tripsaver. Hoje a versão mais nova, o Tripsaver II disponibiliza diversas informações em um display digital no equipamento e pode fazer até três religamentos. Possui uma gama de curvas IEC, IEEE e Recloser que permite estudos de coordenação com os demais elementos de proteção da rede de distribuição (religadores trifásicos, elos fusíveis, etc.).

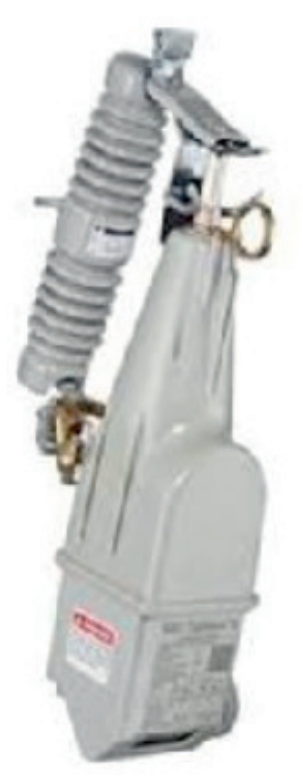

FIGURA 3 - (a) - Tripsaver na base

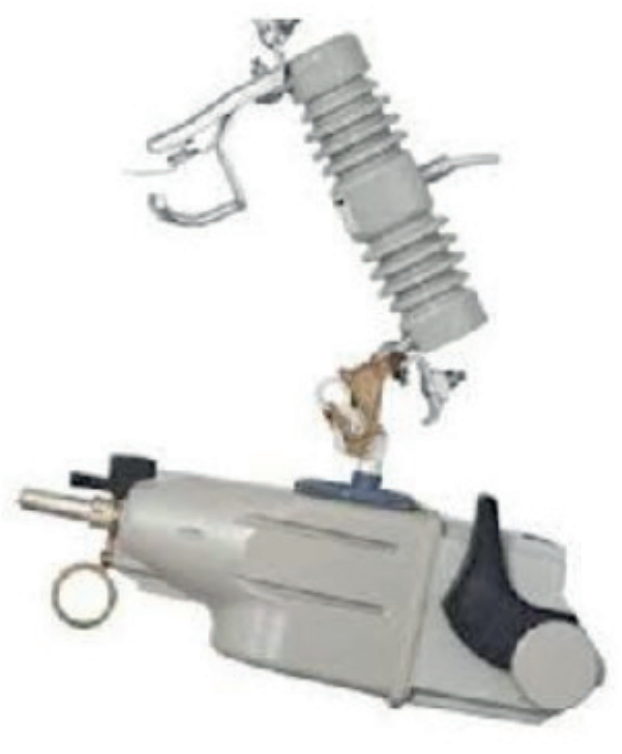

FIGURA 3 - (b) - Tripsaver em estado de bloqueio

\subsection{Segunda Etapa}

O segundo projeto piloto foi feito com o Fusesaver. O Fusesaver é um religador monofásico simplificado, que pode ser instalado diretamente nos cabos da média tensão. É projetado para ser instalado em série com o fusível. Quando reconhece uma corrente de falta, ele abre e se mantém aberto por um período de tempo prédeterminado e então fecha. Em caso de falta permanente ocorre a queima do fusível. Uma foto do Fusesaver pode ser observada na Figura 4, a seguir :

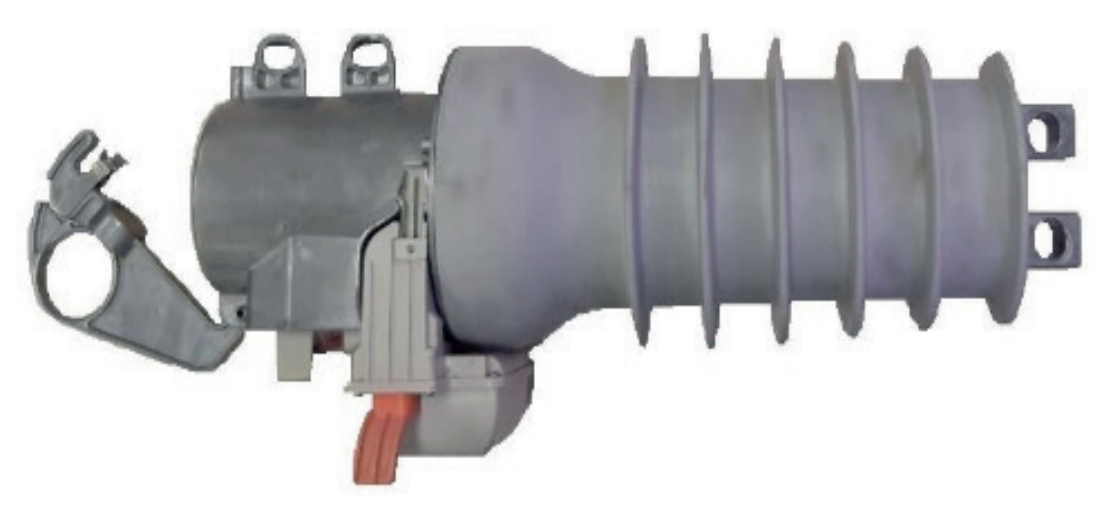

FIGURA 4 - Religador Monofásico Fusesaver 
O religador Fusesaver foi apresentado para a Copel no início de 2013. Em junho do mesmo ano foram realizados os primeiros testes iniciando-se pela montagem do equipamento em rede didática. Durante o ano de 2014 foram analisados e definidos os pontos em que seriam instalados os equipamentos no projeto piloto assim como criado um Manual de Instruções Técnicas referente ao mesmo.

No primeiro semestre de 2015 foram instalados 6 unidades na regional de Ponta Grossa e 6 na de Cascavel e baixadas algumas leituras de eventos para começar a medir o desempenho de funcionamento. A partir das coletas dos eventos registrados nos equipamentos, foram resumidos os dados de faltas temporárias e permanentes na Tabela 1 abaixo.

\begin{tabular}{|c|c|c|c|c|}
\hline Regional & Circuito & Período de Análise & Faltas temporárias & Faltas permanentes \\
\hline \multirow{4}{*}{ Cascavel } & Anahi & $18 / 03 / 2015$ - $11 / 09 / 2015$ & 4 & 0 \\
\hline & Autódromo & $18 / 03 / 2015$ - $22 / 08 / 2015$ & 1 & 0 \\
\hline & Cotrefal & $12 / 02 / 2015$ - 18/09/2015 & 20 & 4 \\
\hline & Expresso Caxias & $18 / 03 / 2015$ - 14/09/2015 & 1 & 0 \\
\hline \multirow{2}{*}{ Ponta Grossa } & Guaragi & $10 / 02 / 2015$ - 30/09/2015 & 52 & 1 \\
\hline & Imbaú & $12 / 02 / 2015-02 / 10 / 2015$ & 37 & 15 \\
\hline \multicolumn{3}{|c|}{ Total } & 115 & 20 \\
\hline
\end{tabular}

TABELA 1 - RESUMO DAS QUANTIDADES DE FALTAS REGISTRADAS NOS FUSESAVERS

O desempenho do equipamento foi satisfatório no período analisado. Observase pelas informações da Tabela 1 que foram obtidas ao todo 115 faltas temporárias e 20 permanentes o que implica em uma taxa total de aproximadamente $85 \%$ de elos fusíveis cuja queima foi evitada. Este total de faltas temporárias registradas salvou seu respectivo fusível parceiro e evitou deslocamentos desnecessários de equipes ao local.

Pela Tabela 2, abaixo, observa-se que, com exceção dos circuitos Expresso Caxias, que teve um evento muito acima da média no mês de março e o circuito Imbaú, que teve muitas faltas permanentes, os demais tiveram redução no DEC. Para aqueles circuitos os indicadores poderiam ter sido ainda maiores, principalmente para o circuito Imbaú onde houve um número significativo de faltas temporárias, se não fosse a implantação dos religadores monofásicos. 


\begin{tabular}{|c|c|c|c|c|c|c|c|c|c|c|c|c|}
\hline Circuito & Ano & Fevereiro & Março & Abril & Maio & Junho & Julho & Agosto & Setembro & Outubro & DEC Acumulado & Reduç3̃o \% DEC \\
\hline \multirow{2}{*}{ Autódromo } & 2014 & & 0 & 0 & 2,03 & 48,92 & 0 & 0 & & & 50,95 & \\
\hline & 2015 & & 0 & 0 & 0 & 0 & 0 & 0 & & & 0 & $100 \%$ \\
\hline \multirow{2}{*}{ Anahi } & 2014 & & 6,52 & 3,59 & 2,32 & 15,27 & 0 & 3,04 & 15,34 & & 46,08 & \\
\hline & 2015 & & 0 & 0 & 0 & 0 & 0 & 0 & 3,02 & & 3,02 & $93 \%$ \\
\hline \multirow{2}{*}{ Cotrefal } & 2014 & 0 & 0 & 1,43 & 1,49 & 1,64 & 0 & 0 & 14,76 & & 19,32 & \\
\hline & 2015 & 0 & 7,25 & 0 & 8,18 & 1,31 & 0 & 1,64 & 0,78 & & 19,16 & $1 \%$ \\
\hline \multirow{2}{*}{$\begin{array}{c}\text { Expresso } \\
\text { Caxias }\end{array}$} & 2014 & & 0,89 & 0 & 0 & 0 & 0 & 1,52 & 2,37 & & 4,78 & \\
\hline & 2015 & & 12,21 & 0 & 0 & 2,39 & 0 & 0 & 0 & & 14,6 & $-205 \%$ \\
\hline \multirow{2}{*}{ Guaragi } & 2014 & 4,84 & 0,68 & 2,35 & 0 & 0 & 1,56 & 0 & 0 & & 9,43 & \\
\hline & 2015 & 3,01 & 0 & 0 & 0 & 0 & 0 & 0 & 0 & & 3,01 & $68 \%$ \\
\hline \multirow{2}{*}{ Imbaú } & 2014 & 14,22 & 0 & 0 & 14,24 & 0 & 0 & 0 & 0 & 0 & 28,46 & \\
\hline & 2015 & 0 & 4,58 & 3,45 & 1,2 & 13,07 & 7,02 & 16,63 & 25,08 & 8,48 & 79,51 & $-179 \%$ \\
\hline
\end{tabular}

TABELA 2 - RESUMO DOS VALORES DE DEC EM HORAS DOS CIRCUITOS

Outra fase deste projeto piloto contou com a instalação em outubro de 2015, na regional Leste, no município de Morretes, de um conjunto trifásico de Fusesaver com uma UCR - Unidade de Controle Remoto, que com comunicação por celular permitiu o equipamento ser monitorado e operado remotamente pelo Centro de Operação de Santa Quitéria em Curitiba. A UCR apresentou bom desempenho.

Ressalta-se que este piloto foi feito com a primeira versão do Fusesaver. Hoje a versão mais atual além de permitir a sequência de operações abre e fecha em parceria com o fusível, permite fazer uma segunda abertura, ou seja, abre, religa e abre sem necessidade do fusível.

\subsubsection{Redução de Custos Operacionais}

Para o segundo projeto piloto, a partir das informações das ocorrências de faltas dos equipamentos, foi possível calcular os custos envolvidos e evitados devido à utilização do Fusesaver, levando em consideração os seguintes custos :

- Custo médio que uma equipe composta por dois profissionais habilitados leva para percorrer um circuito para encontrar o defeito e trocar o elo fusível: $\mathrm{R} \$ 750,00$;

- Custo estimado de um equipamento monofásico: $\mathrm{R} \$ 6.000,00$. 


\begin{tabular}{|c|c|c|c|c|c|c|c|}
\hline \multirow{2}{*}{$\begin{array}{l}\text { Circuitos } \\
\text { Anahi } \\
\end{array}$} & \multicolumn{2}{|c|}{\begin{tabular}{|c|}
$\begin{array}{c}\text { Custo Operacional } \\
\text { Inicial }\end{array}$ \\
\end{tabular}} & \multicolumn{2}{|c|}{$\begin{array}{c}\text { Custo Operacional } \\
\text { Final }\end{array}$} & \multicolumn{2}{|c|}{\begin{tabular}{|c|} 
Custo Estimado dos \\
Equipamentos \\
\end{tabular}} & \multirow{2}{*}{$\begin{array}{l}\text { Custo Total } \\
\mathrm{R} \$ \quad 6.000,00\end{array}$} \\
\hline & $R S$ & $3.000,00$ & & & $\mathrm{RS}$ & $6.000,00$ & \\
\hline Autódromo & $\mathrm{RS}$ & 750,00 & & & $\mathrm{RSS}$ & $6.000,00$ & 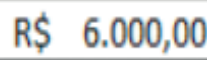 \\
\hline Cotrefal & $\mathrm{RS}$ & $18.000,00$ & $\mathrm{RS}$ & $3.000,00$ & $\mathrm{RS}$ & $18.000,00$ & $\mathrm{R} \$ 21.000,00$ \\
\hline Expresso Caxias & $\mathrm{RS}$ & 750,00 & & & $\mathrm{RS}$ & $6.000,00$ & $\mathrm{R} \$ \quad 6.000,00$ \\
\hline Guaragi & $\mathrm{RS}$ & $39.750,00$ & $\mathrm{R} \$$ & 750,00 & $\mathrm{RS}$ & $18.000,00$ & $\mathrm{R} \$ 18.750,00$ \\
\hline Imbaú & $\mathrm{RS}$ & $39.000,00$ & $\mathrm{R} \$$ & $11.250,00$ & $\mathrm{RS}$ & $18.000,00$ & $\mathrm{R} \$ 29.250,00$ \\
\hline Total & $\mathrm{R} \$$ & $101.250,00$ & $\mathrm{R} \$$ & $15.000,00$ & $\mathrm{RS}$ & $72.000,00$ & $\mathrm{R} \$ 87.000,00$ \\
\hline
\end{tabular}

TABELA 3 - CUSTOS ENVOLVIDOS NOS CIRCUITOS ANALISADOS

Como é mostrado na Tabela 3, para todos os circuitos analisados no período médio de seis a oito meses, considerando o custo médio de $R \$ 750,00$ para cada ocorrência, resultaria em um custo operacional inicial de $\mathrm{R} \$ 101.250,00$ se não houvesse nenhum equipamento instalado nesses pontos. Com os equipamentos instalados, o custo final de operação - agora apenas computados com as faltas permanentes - foi reduzido para $R \$ 15.000,00$. Ou seja uma redução de $R \$ 86.250,00$ no custo operacional.

Considerando o custo médio estimado de cada equipamento monofásico em $\mathrm{R} \$$ $6.000,00$ e que foram utilizados no total doze equipamentos no projeto piloto, sendo três pontos trifásicos e três pontos monofásicos, o custo total de compra dos equipamentos foi de $\mathrm{R} \$ 72.000,00$. Somando-se a este custo o operacional final, obteve-se um custo total de $\mathrm{R} \$ 87.000,00$.

Comparando-se o custo operacional inicial, de $\mathrm{R} \$ 101.250,00$, com o custo total, de $R \$ 87.000,00$, resultou em uma economia final de $R \$ 14.250,00$. Este valor implica que o ganho da presença dos equipamentos na rede, neste projeto piloto, foi de aproximadamente $20 \%$ do valor do investimento inicial com a compra dos mesmos.

A partir dessas análises, é possível afirmar que, embora o investimento na compra dos equipamentos seja elevado, a economia que eles geram é significativa e pode ser maior se houver um estudo realizado previamente na definição dos locais onde devem ser instalados: circuitos com histórico elevado de faltas temporárias devem ser priorizados. Além disso, deve-se considerar que cada equipamento poderá ainda gerar benefícios por um total de 2.000 operações mecânicas antes de ser necessária sua reposição.

\section{I GRUPO DE TRABALHO - ESTUDO DE RELIGADORES MONOFÁSICOS}

Baseado nos resultados dos projetos pilotos expostos acima e considerando o cenário desafiador para a manutenção da concessão foi criado um Grupo de Trabalho na Copel Distribuição para estudo dos religadores monofásicos.

Foram realizadas 20 reuniões do Grupo de Trabalho, sendo a primeira reunião 
no dia 07 de agosto de 2015 e a última no dia 22 de dezembro de 2015. Através de reuniões e contatos com fornecedores e outras Distribuidoras e pesquisas na internet foram verificadas as tecnologias de religadores monofásicos existentes.

Foi definida uma lista de critérios para fazer uma base de comparação entre os equipamentos (corrente nominal, capacidade de interrupção simétrica, comunicação, tensão nominal, NBI, funções, modelo de controle, abertura visível/indicação, tecnologia de extinção do arco, preço, local de fabricação, assistência técnica e fornecimentos).

Os equipamentos pesquisados foram divididos em dois conjuntos de tecnologias principais: religadores convencionais e religadores simplificados.

Os religadores monofásicos convencionais são caracterizados por equipamentos similares aos religadores trifásicos normalmente adquiridos pelas Concessionárias, com controles eletrônicos separados do mecanismo e necessidade de alimentação externa destes. Têm uma instalação complexa (aterramento, chaves de entrada, saída e by-pass) e têm preços mais elevados que os religadores simplificados.

Os religadores monofásicos simplificados são caracterizados pela ausência de controles eletrônicos, tendo uma eletrônica embarcada onde são feitas as medições e inseridos os ajustes de proteção. São autoalimentados, não necessitando de alimentação externa e têm uma instalação simples e rápida, sem a necessidade de para-raios e chaves de entrada, de saída e de by-pass. O seu preço reduzido possibilita a aquisição de maiores quantidades.

Baseado na Especificação Técnica dos Religadores Trifásicos existente na Copel foi elaborada a Especificação Técnica dos Religadores Monofásicos Convencionais. Verificou-se que a diferença de preço entre os religadores monofásicos de $15 \mathrm{kV}$ e 25 $\mathrm{kV}$ é pequena. Visando colher as vantagens de um equipamento de classe de tensão maior, optou-se por religadores de $25 \mathrm{kV}$ na rede de $13,8 \mathrm{kV}$.

Para a rede de $34,5 \mathrm{kV}$ verificou-se que não é possível aplicar religadores monofásicos simplificados de $25 \mathrm{kV}$ em ramais bifásicos ou trifásicos, mesmo sendo a tensão fase-terra de 19,92 kV, pois uma falta bifásica ou trifásica pode gerar uma tensão de restabelecimento que alcança a tensão nominal de linha de 34,5 kV [2]. A disponibilidade no mercado de religadores monofásicos simplificados é somente para as tensões de $15 \mathrm{kV}$ e $25 \mathrm{kV}$. Para os ramais monofásicos $34,5 \mathrm{kV}$, conhecidos como MRT-Monofásico com Retorno pela Terra, cuja tensão fase-terra é de 19,92 kV é possível aplicar os religadores monofásicos simplificados de $25 \mathrm{kV}$. Definiu-se que na rede de 13,8 kV serão aplicados apenas religadores monofásicos simplificados de 25 $\mathrm{kV}$.

Foram definidos os critérios para instalação dos religadores convencionais e simplificados. Os critérios podem ser ilustrados pelas Figura 5-(a) e Figura 5-(b) abaixo para as redes de $34,5 \mathrm{kV}$ e $13,8 \mathrm{kV}$ respectivamente. 


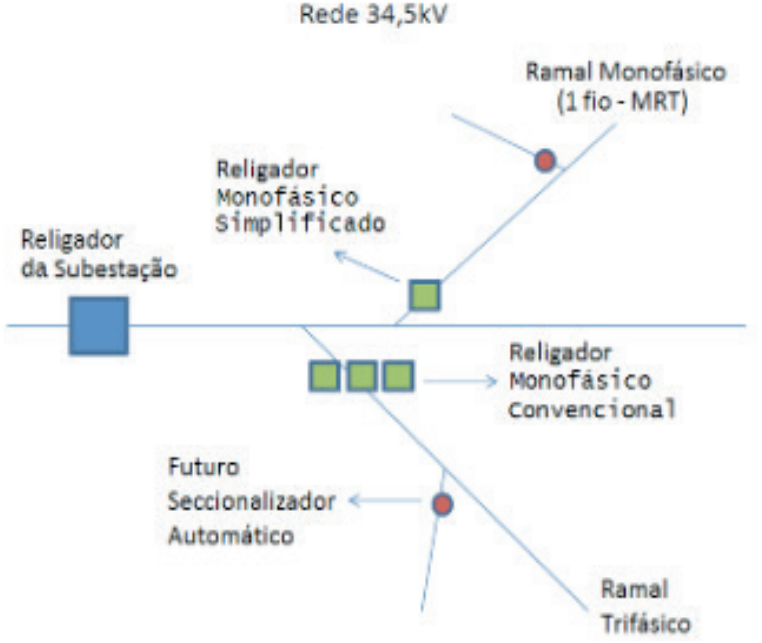

FIGURA 5 - (a) - Critérios rede 34,5 kV

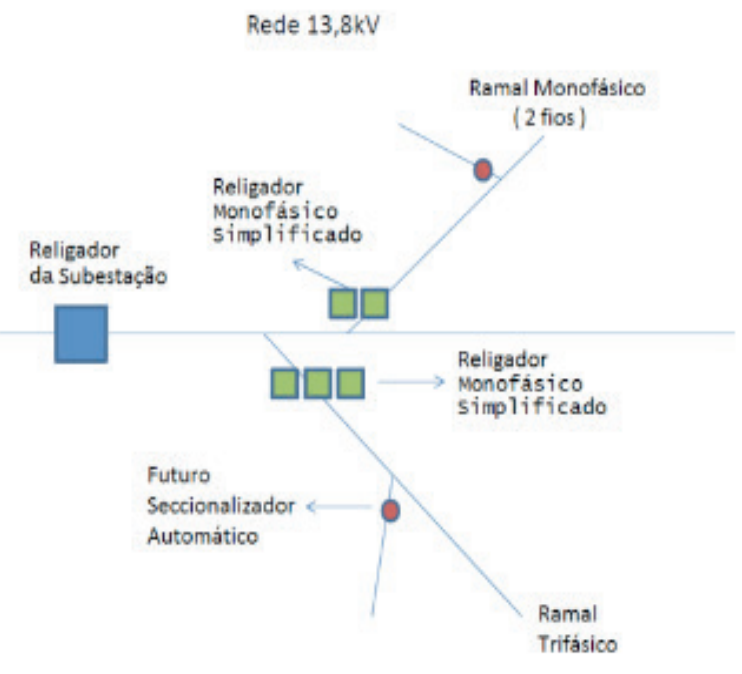

FIGURA 5 - (b) - Critérios rede 13,8 kV

Verificando cotações de fornecedores observou-se que o menor preço para os religadores monofásicos convencionais, apresentou um valor muito acima do esperado. Em análise do Grupo, tal condição inviabilizou a aquisição de religadores monofásicos convencionais, pois a instalação de três religadores monofásicos convencionais seria mais cara que a instalação de um religador trifásico. Foi decidido pela aquisição de apenas religadores monofásicos simplificados.

Aproveitando as discussões realizadas durante as reuniões do Grupo e a Especificação Técnica dos religadores convencionais foi elaborada a Especificação Técnica dos religadores simplificados.

Visando diminuir a possibilidade de recursos e atrasos no processo de compra foi feito um processo de homologação anterior à licitação dos religadores. Somente os fornecedores que tiveram a ficha técnica aprovada puderam participar dos processos licitatórios.

Foi realizada uma compra em 2016 de 685 Fusesavers II e 480 Tripsavers II. Em 2017 foi realizada uma compra de 1875 Tripsavers II. Todos já foram instalados no lugar de chaves fusíveis em todo o estado do Paraná, beneficiando 157 mil consumidores diretamente. Em 2018 foram adquiridos mais 9.650 Tripsavers II.

\section{I INSTALAÇÃO EM LARGA ESCALA}

O critério utilizado para a escolha dos pontos onde são instalados os equipamentos, dentre todos os 46 mil pontos com chaves fusíveis da área de concessão da Copel, considera o histórico de maior consumidor $\mathrm{x}$ hora desligado nos três anos anteriores e o número de faltas temporárias. Foram excluídos os pontos onde a chave estava próxima de subestações de 69, 138 ou 230 kV onde normalmente o nível de curtocircuito é mais elevado.

Foi solicitado aos fornecedores que os equipamentos já viessem com os ajustes configurados de fábrica. A primeira operação foi ajustada com curva rápida e as 
demais operações com ajustes que correspondem aos elos fusíveis que os religadores monofásicos simplificados substituem, ou seja, 6K, 10K, 15K, 25K, 40K e 65K. Para cada ajuste foi definido um código de cores. Através de etiquetas coloridas coladas nos equipamentos e suas embalagens assegura-se que a empreiteira/instalador recolha os equipamentos corretos nos almoxarifados e que o fiscal de obra possa verificar se o equipamento com o ajuste necessário foi instalado no local correto.

O processo de instalação desta maneira fica facilitado, indo o equipamento do fornecedor para o almoxarifado e deste direto para o local das obras, sem passar pelas áreas de proteção para estudos e/ou implantação de ajustes. Verificou-se durante as instalações dos meses de agosto a dezembro de 2018, uma média de 500 equipamentos instalados por mês em todo o Estado do Paraná.

\section{I DESEMPENHO}

Os equipamentos adquiridos armazenam internamente de forma circular eventos relativos a sua atuação bem como valores de corrente associados. Nos projetos pilotos e no início da instalação em grande escala eram levantados os dados diretamente dos equipamentos, sendo feitas as leituras em campo com notebooks através dos softwares de comunicação de cada fornecedor. Com a elevação do número de equipamentos instalados esta leitura de dados em campo tornou-se inviável.

A atual medição do desempenho considera a comparação do $\mathrm{CHI}$ - Consumidor Hora Interrompido anterior e posterior à instalação do equipamento em determinado ponto bem como a quantidade de interrupções transitórias. Mensalmente é adicionada à base de dados os religadores instalados no último mês. Para cada um dos pontos é verificado o $\mathrm{CHI}$ e a quantidade de interrupções no período de 120 dias antes da instalação de cada um. Compara-se então os 120 dias anteriores da instalação com os últimos 120 dias anteriores à geração dos dados. Caso uma chave tenha sido recentemente substituída por um religador monofásico simplificado e com isso o período de análise não atinja 120 dias, a comparação ocorre entre a quantidade de dias pós instalação com o mesmo total de dias do período anteriores à instalação.

Na medição de desempenho do dia 29 de dezembro de 2018 foram considerados 1416 pontos, o que corresponde a 3200 religadores monofásicos simplificados instalados. Houve uma redução do $\mathrm{CHI}$ de $63 \%$ enquanto que as interrupções diminuíram em aproximadamente $64 \%$. Todas as análises já realizadas mostraram redução no $\mathrm{CHI}$. Os valores variaram de $30 \%$ a $64 \%$.

\section{I CONCLUSÕES}

Com relação ao projeto piloto verificou-se que houve grande impacto no DEC para os alimentadores, quando comparados com o mesmo período do ano anterior, visto que as 260 faltas temporárias foram sanadas em menos de 3 minutos (tempo 
mínimo para contabilização do DEC). Adicione-se que os deslocamentos evitados muitas vezes são de horas pois os novos religadores monofásicos foram colocados em chaves da área rural e de difícil acesso.

Com relação ao Grupo de Trabalho, as seguintes conclusões foram alcançadas :

a) Concluiu-se que nos ramais trifásicos de $34,5 \mathrm{kV}$ não podem ser utilizados religadores monofásicos de $25 \mathrm{kV}$, sendo necessários os religadores monofásicos convencionais de $34,5 \mathrm{kV}$, pois uma falta bifásica ou trifásica pode gerar uma tensão de restabelecimento que alcança a tensão nominal de linha de 34,5 kV;

b) Decidiu-se em adquirir religadores monofásicos simplificados sem exigir características de supervisão e controle remotos. Tal conclusão baseou-se :

- No alto valor dos equipamentos de comunicação envolvidos (remotas) que disponibilizam a supervisão e controle e na dificuldade de implantação de um sistema de comunicação em lugares remotos;

- Nem todos os religadores monofásicos simplificados dos principais fornecedores têm possibilidade de supervisão e controle remotos porém há sinalização de desenvolvimento futuro;

- Na necessidade de ganhos imediatos de DEC.

Com relação aos resultados da instalação em larga escala conclui-se que o desempenho destes equipamentos foi muito satisfatório. Foram muitas faltas temporárias sanadas pelos equipamentos, que evitaram queimas de elos fusíveis e deslocamentos desnecessários de equipes ao locais para troca dos mesmos. Os números indicam ganhos expressivos no Consumidor Hora Interrompido com impactos positivos no DEC dos alimentadores e indicam o correto critério na definição dos pontos.

Outros ganhos podem ser considerados:

- a maior disponibilidade das equipes de campo para outros serviços no lugar da troca de fusíveis;

- o incremento da base de remuneração. Segundo o Banco de Preços Referencial da ANEEL, para os religadores monofásicos em redes rurais, os valores de COM - Componentes Menores, que correspondem basicamente aos acessórios dos equipamentos e CA - Custos Adicionais, que envolvem projeto, gerenciamento, montagem e frete são $\mathrm{R} \$$ 659,33 e $\mathrm{R} \$ 3.351,54$, respectivamente [3];

- foram evitadas 2922 interrupções com economia em custos operacionais na ordem de $R \$ 2.191 .500,00$, considerando um custo de $R \$ 750,00$ para troca de cada elo fusível.

Importante mencionar que há por parte dos eletricistas e técnicos das regionais boa aceitação dos equipamentos e pouca manutenção foi necessária nos equipamentos no período analisado.

Adicionalmente, destaca-se que os religadores monofásicos simplificados estão sendo instalados prioritariamente na área rural da Copel. O DEC da área rural representa aproximadamente $45 \%$ do DEC total e o FEC rural $35 \%$ do FEC total da 
Copel. Desta maneira, objetiva-se um ganho maior de qualidade nesta área onde os processos como avicultura, produção de leite, suinocultura e fumicultura são cada vez mais automatizados e exigentes de qualidade de energia e são fundamentais na economia do Estado.

Pelo conhecimento obtido no grupo de trabalho de religadores monofásicos, pelos resultados dos projetos pilotos e da instalação em larga escala, evidencia-se que a aplicação dos religadores monofásicos simplificados é seguramente um dos vetores para a redução de custos operacionais e do DEC, e que pode auxiliar as Distribuidoras a atender os indicadores de qualidade de energia propostos pela ANEEL.

\section{REFERÊNCIAS}

(1) Anexo da Nota Técnica $n^{\circ}$ 0335/2015-SCT-SFE-SFF-SRD-SRM/ANEEL, disponível em http:// www2.aneel.gov.br/aplicacoes/audiencia/arquivo/ 2015/038/resultado/nt0335_2015_sct.pdf

(2) R.E. KOCH and J. H. EASLEY, "Voltage Rating of Current-Limiting Fuses for Use on Three-Phase Systems", in 1976 Underground Transmission and Distribution Conference, Convention Hall, Atlantic City, N.J., Sept. 27-Oct. 1, 1976, IEEE Power Engineering Society.

(3) Banco de Preços Referencial da ANEEL, disponível em http://www.aneel.gov.br/processo-tarifarioe-licitatorio. 


\section{SISTEMA DE MONITORAMENTO DA REDE DE DISTRIBUIÇÃO DE ENERGIA COM VISTAS A MELHORIA DA QUALIDADE DE SERVIÇO}

Data de aceite: 03/01/2020

\section{Klendson Marques Canuto}

Enel Distribuição Ceará

Fortaleza - Ceará

Avilez Batista de Oliveira Lima Paulo Roberto de Oliveira Braga

Juraci Gomes de Aguiar Filho

André Ribeiro da Costa

Enel Distribuição Ceará

Fortaleza - Ceará

RESUMO: A implementação de ações de otimização no monitoramento da rede de distribuição de energia influencia diretamente na duração das interrupções. O fator que mais contribui para a diminuição do tempo médio de interrupção é, sem dúvidas, a rapidez na localização do ponto de ocorrência dainterrupção e a velocidade das tomadas de decisão para o restabelecimento do fornecimento. Assim, foi desenvolvido um sistema de monitoramento da rede de Baixa Tensão - BT e ramais de Média Tensão - MT, chamado de AutodistBT, o qual surgiu da necessidade de se buscar novas tecnologias que permitissem identificar de forma rápida e precisa a localização do ponto de ocorrência da interrupção, antes mesmo da entrada de quaisquer reclamações por parte dos clientes afetados. Tal solução é composta de monitores remotos instalados em campo dotado de comunicação via celular e responsáveis pela verificação da ausência ou da queda dos níveis de tensão de cada fase da rede de distribuição secundária com interação direta com o Centro de Controle do Sistema - CCS da Enel Distribuição Ceará EDC, através de um software especificamente desenvolvido para receber e identificar as chamadas de tais monitores. Como resultado foi evidenciado os ganhos nos indicadores de tempos médios de atendimentos emergenciais e a redução da duração das ocorrências. PALAVRAS-CHAVE: Qualidade de Energia; Monitoramento Digital; Continuidade do Fornecimento; Indicadores de Qualidade de Serviço.

\section{ENERGY DISTRIBUTION NETWORK MONITORING SYSTEM FOR IMPROVING QUALITY OF SERVICE}

ABSTRACT: The implementation of optimization actions in monitoring the power distribution network directly influences the duration of the interruptions. The factor that most contributes to decreasing the average interruption time is undoubtedly the speed in locating the interruption point and the speed of decision making to reestablish the supply. Thus, a monitoring system for the Low Voltage Network - BT and Medium 
Voltage branches - MT, called AutodistBT, was developed in need to seek new technologies that allow fast and accurate identification of the occurrence's location even before complaints are received from affected customers. The solution consists of remote monitors installed in a field of mobile phone communication that is responsible for verifying the loss or fall of voltage levels of each phase of the secondary distribution network with direct interaction with Enel's System Control Center, through a software designed to receive and identify the calls of these monitors. As a result, it was testified gains in the indicators in the average time of emergency outage and the reduction of the outage. time KEYWORDS: Energy Quality; Digital monitoring; Continuity of Supply; Quality of Service Indicators.

\section{I INTRODUÇÃO}

A fim de assegurar a contínua disponibilidade e a qualidade do serviço de distribuição de energia elétrica, é fundamental que toda a rede elétrica seja monitorada para que sejam evitadas ocorrências ou falhas na rede de distribuição. A característica de distribuição geográfica de grande escala está dentre os fatores que adicionam maior dificuldade no processo de monitoramento e manutenção dos sistemas de distribuição de energia elétrica.

Dois aspectos devem ser observados para um bom monitoramento do sistema de distribuição de energia: qualidade e custo. Com o objetivo de fornecer soluções para viabilizar esta qualidade de fornecimento ao consumidor, a EDC, desenvolveu um projeto cujo objetivo é a aplicação de equipamentos para sensoriamento e monitoramento das redes de distribuição secundária através de um equipamento especialmente desenvolvido para esta finalidade, denominado Monitor de Ramais.

Além do baixo custo, o sistema será de grande auxílio na observância dos indicadores de qualidade de energia, na obtenção de informações estatísticas para fins de planejamento, operação, monitoramento da rede de distribuição e diagnóstico de falhas.

\section{I DESENVOLVIMENTO}

\subsection{Planejamento da Estratégia do Monitoramento.}

Foi desenvolvido um equipamento de detecção de interrupção de energia elétrica utilizando um sistema de detecção de falta de fase acoplado a um sistema microcontrolado, atuando sobre um modem celular, o qual é o responsável pelo envio da informação da localização do ponto de ocorrência da interrupção ao Centro de Controle, que poderá ser um falta na rede de distribuição secundária de um determinado transformador de BT ou de todo um ramal de MT. Outra vantagem do sistema desenvolvido é que quando da ocorrência de alguma interrupção de energia, serão conhecidos todos os clientes afetados e as providências tomadas de decisão 
pela concessionária beneficiarão a um maior número de pessoas e não apenas aquela unidade consumidora monitorada, otimizando sobremaneira o processo de atendimento emergencial da concessionária, visto que, a mesma terá conhecimento da interrupção antes do registro de quaisquer reclamações de clientes afetados via Call Center da empresa.

Com vistas a estratégia de operação e com a finalidade de definir quais os circuitos para implantação do monitoramento, o corpo técnico da concessionária indicou dois critérios para definição dos pontos de monitoramento. Os critérios definidos foram:

I. Chaves de ramal com histórico de falha e com uma grande quantidade de clientes cadastrados;

II. Cobertura de serviço de telefonia celular - Definição da melhor operadora.

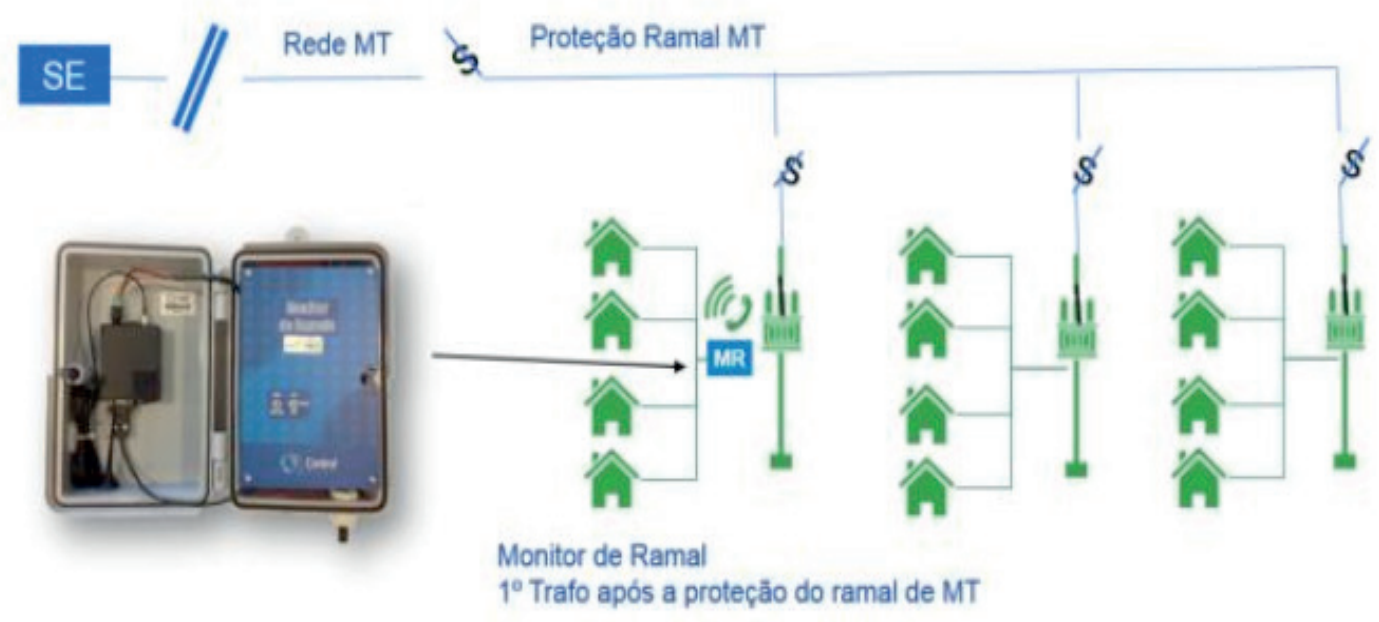

Figura 1 - Esquema de instalação dos monitores de ramais

A recomendação da equipe técnica foi a instalação do Monitor de Ramal na rede BT no primeiro transformador após uma Chave Fusível - CF de proteção de um ramal de MT com uma grande quantidade de clientes. Seguindo esta estratégia tanto a rede de BT do transformador, como o ramal estarão sendo monitorados por uma possível falta de tensão em uma das fases. Abaixo imagem do Monitor de Ramal instalado no secundário do transformador de distribuição. 


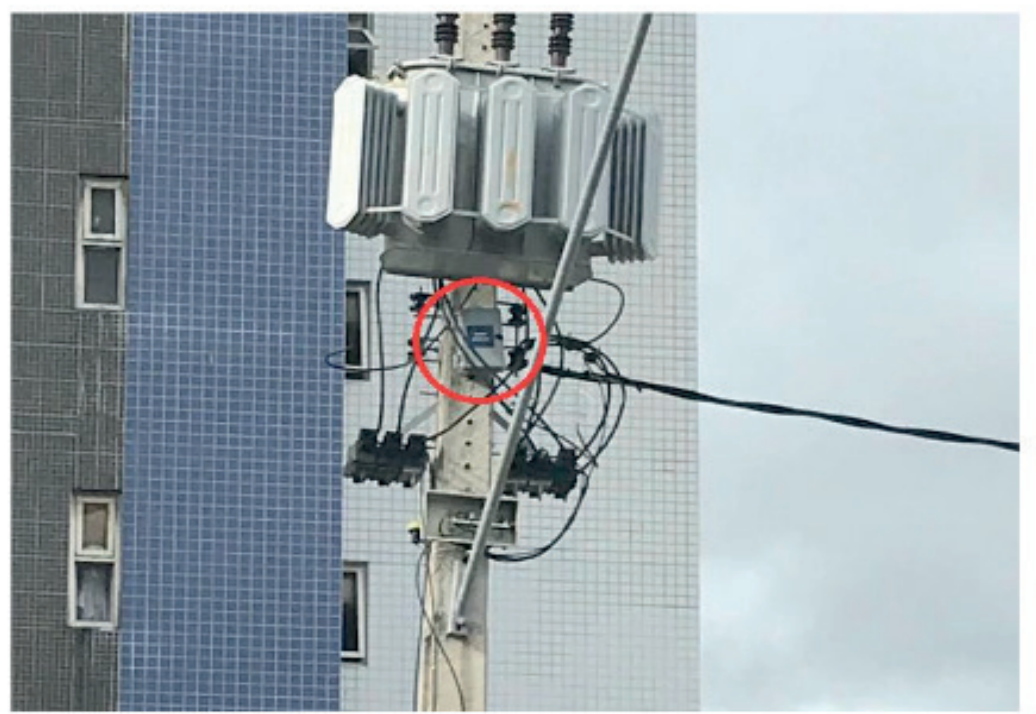

Figura 2 - Esquema de instalação dos monitores de ramais

\subsection{Descrição das Características do Sistema}

O Monitor de Ramais foi desenvolvido para supervisionar a rede de baixa tensão e ramais de média tensão, além de realizar comunicação com o centro de operações das concessionárias de energia, visando conter o crescimento das taxas de Duração Equivalente de Interrupção - DEC e de Tempo Médio de Atendimento Emergencial TMAE.

O sistema é capaz de detectar e informar imediatamente aos responsáveis pela manutenção e ao centro de controle via modem a localização da interrupção do fornecimento de energia ou a falta de uma ou mais fases do circuito monitorado, diminuindo o tempo de restabelecimento dos clientes afetados.

O dispositivo utiliza cabos e conexões que garantem ao operador facilidade na instalação. O mesmo conta com um sistema próprio de recarga da bateria.

O Monitor de Ramais opera em conjunto com o software supervisório AutodisBT. A aplicação cadastra todas as informações referentes aos circuitos monitorados e serve de interface para avisar ao Centro de Controle as falhas apontadas pelo equipamento.

Em seguida é mostrado na Figura 3 o diagrama em blocos do sistema. 

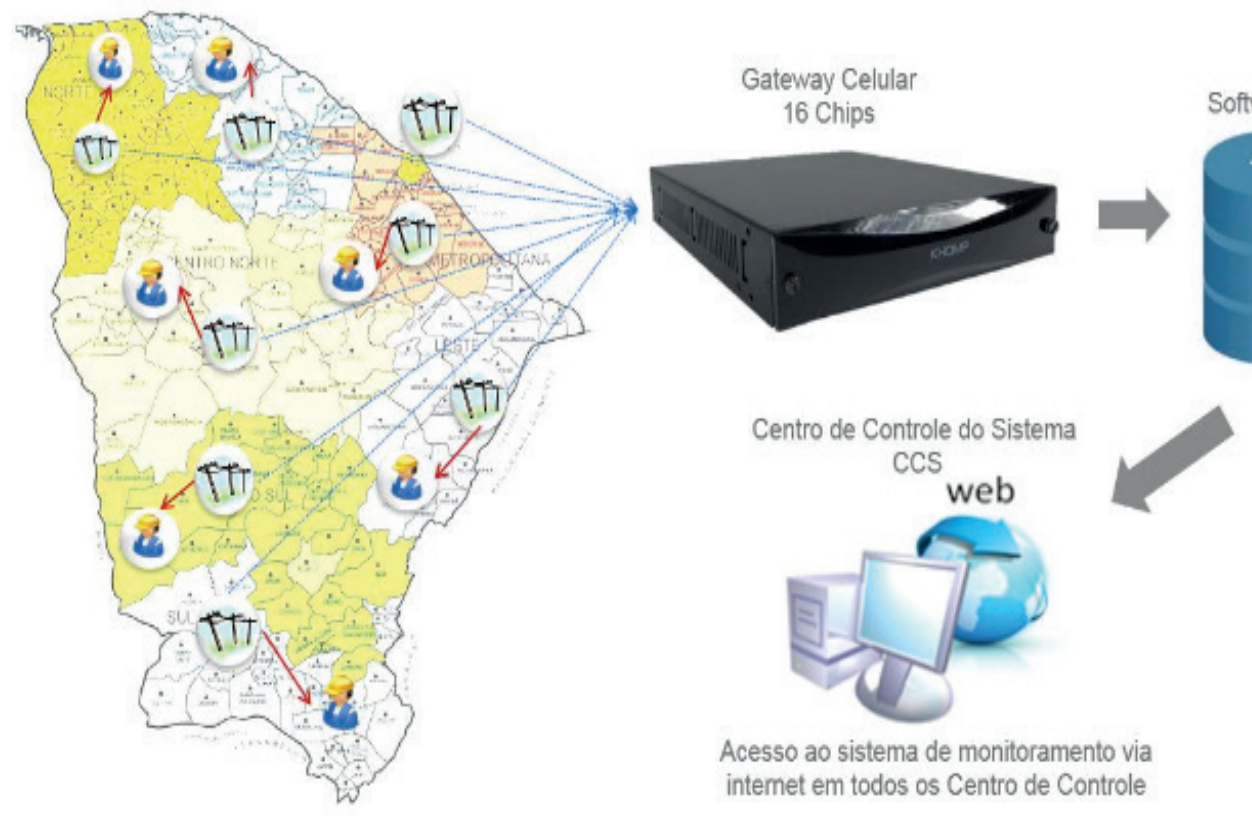

internet em todos os Centro de Controle

Figura 3 - Diagrama de blocos do sistema de monitoramento

O sistema de supervisão da rede de BT e ramais de MT da Enel é composto dos seguintes módulos:

\subsubsection{Monitor de Ramais}

Este módulo do sistema foi desenvolvido para ser sensibilizado não só pela total interrupção do fornecimento, ou seja, tensão zero, mas, também, para detectar a ocorrência em chaves fusíveis, como por exemplo, quando da abertura de uma das chaves de ramal ou do transformador, a tensão cairá para um valor diferente de zero e o sistema deverá responder a esta ocorrência através do acionamento do monitor. Este circuito possui um sensor independente para cada fase do transformador, o que permite sua utilização em transformadores monofásicos, bastando, para tanto, unir as entradas e conectá-las ao transformador.

O Monitor de Ramais é composto de uma unidade totalmente microcontrolada conectada a um modem celular compatível com qualquer operadora de telefonia celular. O equipamento é montado em caixa de polipropileno, sendo resistente ao sol, água e poeira (IP65) e impactos (1K10). Possui uma bateria do tipo chumbo ácida de $1.300 \mathrm{mAh}$ em12V, garantindo uma autonomia em média de 17 horas quando houver falta ou queda de tensão. 


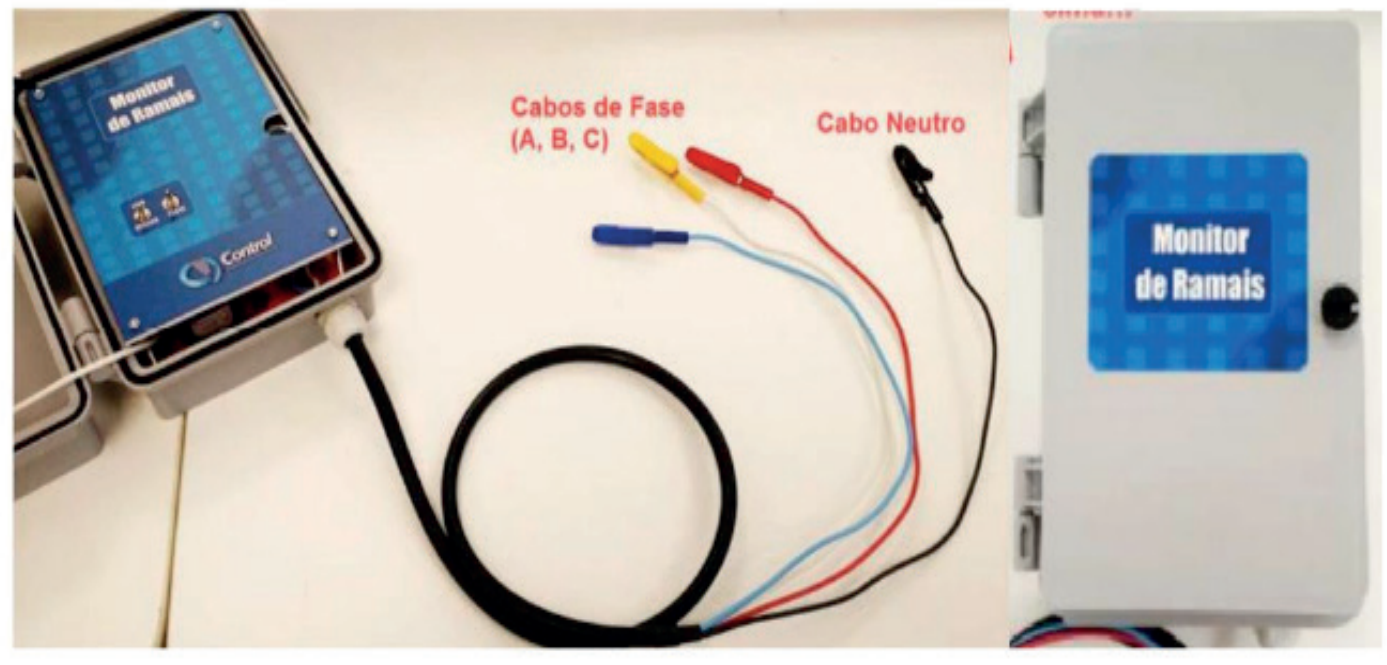

Figura 4 - Monitor de Ramais

O equipamento trabalha com o modem desligado e somente é acionado quando identificado a ausência de tensão em pelo menos uma das fases. Neste momento o modem realiza 3 (três) ciclos de chamadas para 4 (quatro) números de telefones previamente cadastrados na memória do SIM Card. Sendo que os 3 primeiros números são de dispositivos moveis comuns (celulares) utilizado por equipe de campo e responsáveis pelas instalações. Para o caso do quarto número, este é dedicado exclusivamente para o número do Gateway Celular.

Quando é detectada uma falta de tensão na rede, o equipamento entra em operação e dá início ao procedimento de discagem. O processo conta com três ciclos de quatro chamadas, com intervalo entre ligações definido pelo usuário, para os números gravados em seu chip SIM. O procedimento está ilustrado na Figura 5 a seguir:

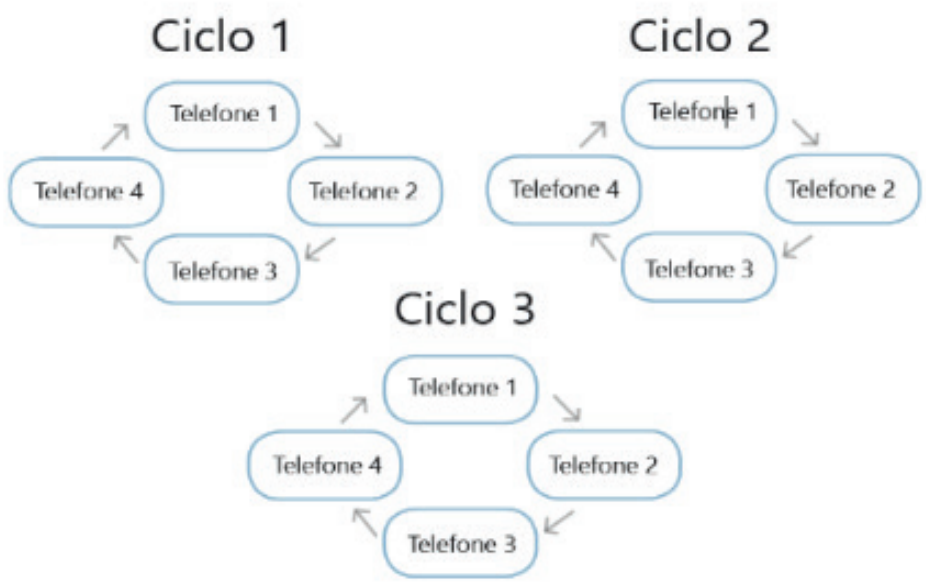

Figura 5 - Procedimento de Discagem do Monitor de Ramais

Depois de concluído os três ciclos de chamadas, caso ainda permaneça a falta de tensão, o monitor fica realizando chamadas para o número do Gateway, a cada 1 minuto, indefinidamente até a tensão retornar ou a bateria descarregar. 
Importante ressaltar que uma das grandes vantagens deste equipamento é que o mesmo utiliza apenas o canal de voz da operadora de celular, sem a necessidade de utilização de dados, o que o torna bastante atrativo com relação a custos. Uma outra vantagem é que as ligações realizadas pelo monitor, no momento da falta, não são completadas, assim não geram custos de ligação.

\subsubsection{Gateway Celular}

Trata-se de um módulo compacto com capacidade de até 16 canais de celular em um único equipamento e tem a função de gerenciar as chamadas recebidas provenientes dos monitores instalados em campo, podendo gerenciar até 16 chamadas simultâneas. O gateway tem a capacidade para dois SIM Cards por canal, sendo um ativo e outro stand-by, permitindo diferentes operadoras no mesmo módulo.

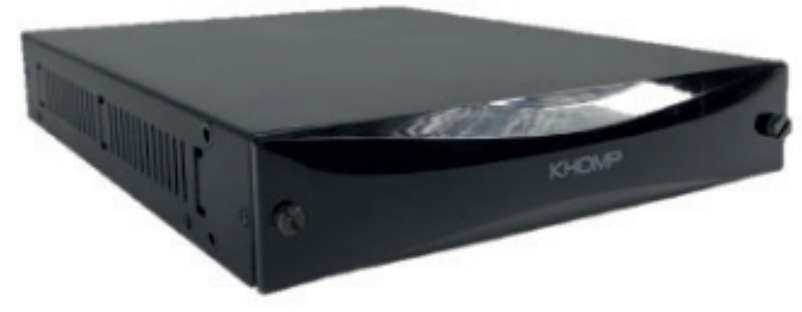

Figura 6 - Gateway celular utilizado no gerenciamento das chamadas.

\subsubsection{Sistema de Monitoramento}

Em conjunto com os equipamentos remotos instalados em campo, foi desenvolvido um sistema chamado AutodistBT, que reúne as funções de gestão e base de dados com o cadastro de localização de cada monitor remoto e demais informações como:

- Alimentador;

- Código Estrutura do transformador onde está instado o monitor;

- Quantidade de clientes cadastrados no transformador onde está instalado o monitor;

- Código da chave fusível de ramal a montante do transformador com monitor instalado;

- Quantidade de clientes atendidos pela chave fusível de ramal monitorada;

- Localidade supervisionada;

- Clientes Especiais;

- Eletrodependentes. 
O sistema está disponível em uma página na internet e pode ser acessado por qualquer computador coorporativo sendo controlado os perfis de acesso para administração do sistema, edição e consulta de informações. A Figura 7 mostra a tela de controle e gestão de usuários.

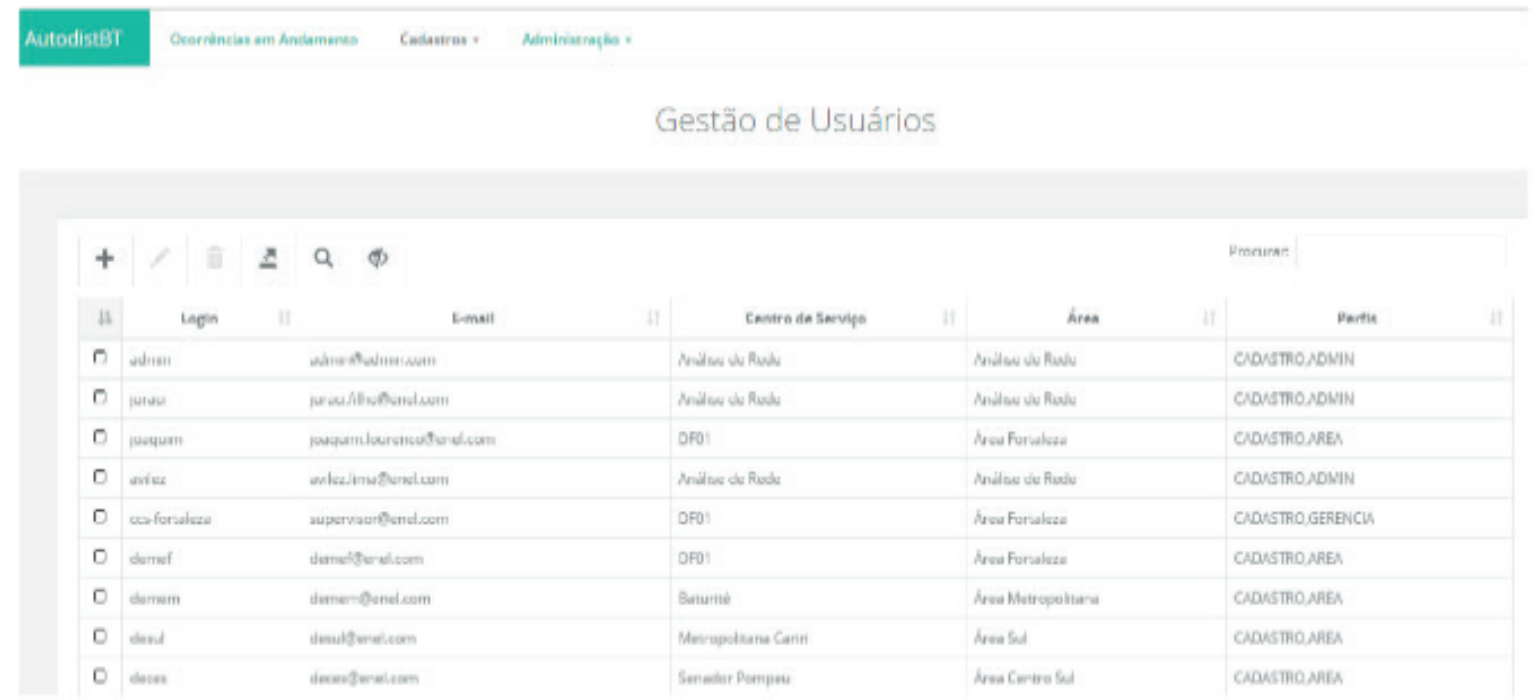

Figura 7 - Tela de Gestão de Perfis de Usuários do AutodistBT.

No momento em que há uma ocorrência em campo e a mesma é detectada pelo respectivo monitor remoto, o mesmo realiza várias chamadas, das quais uma é direcionada para o Gateway GSM. O hardware do Gateway está conectado à rede coorporativa da Enel e disponibiliza o gerenciamento das chamadas na tela mostrada na Figura 8 abaixo.

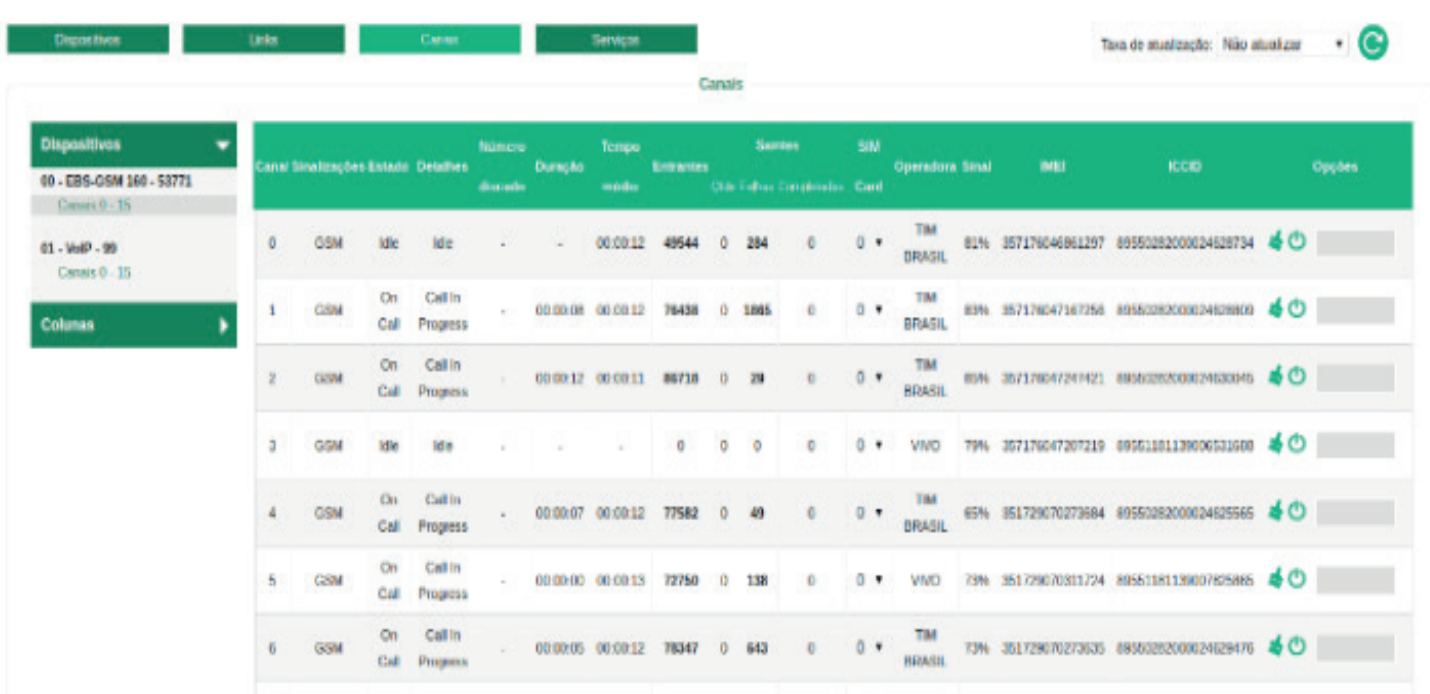

Figura 8 - Tela do sistema da Gateway GSM mostrando as chamadas em andamento.

O sistema AutodistBT executa rotina de leitura na base de dados do Gateway GSM, lendo as informações das chamadas e compara o código do número que está chamando com os dados do banco de dados. Caso a chamada seja de um número 
cadastrado, será mostrado um Pop-up no canto superior direito da tela por 30 segundos e também é registrado uma linha na tela com todos os dados de localização do equipamento, inclusive com os horários da primeira e última chamada.

Este sistema guarda todas as ocorrências em um banco de dados para posterior consulta e, na tela Ocorrências em Andamento, só permanecem ativas as ocorrências em andamento, de forma que o operador volte toda a sua atenção para a solução das mesmas, ficando as ocorrências finalizadas no histórico de ocorrências. A seguir, é mostrada na Figura 9, com a tela de Ocorrências em Andamento.

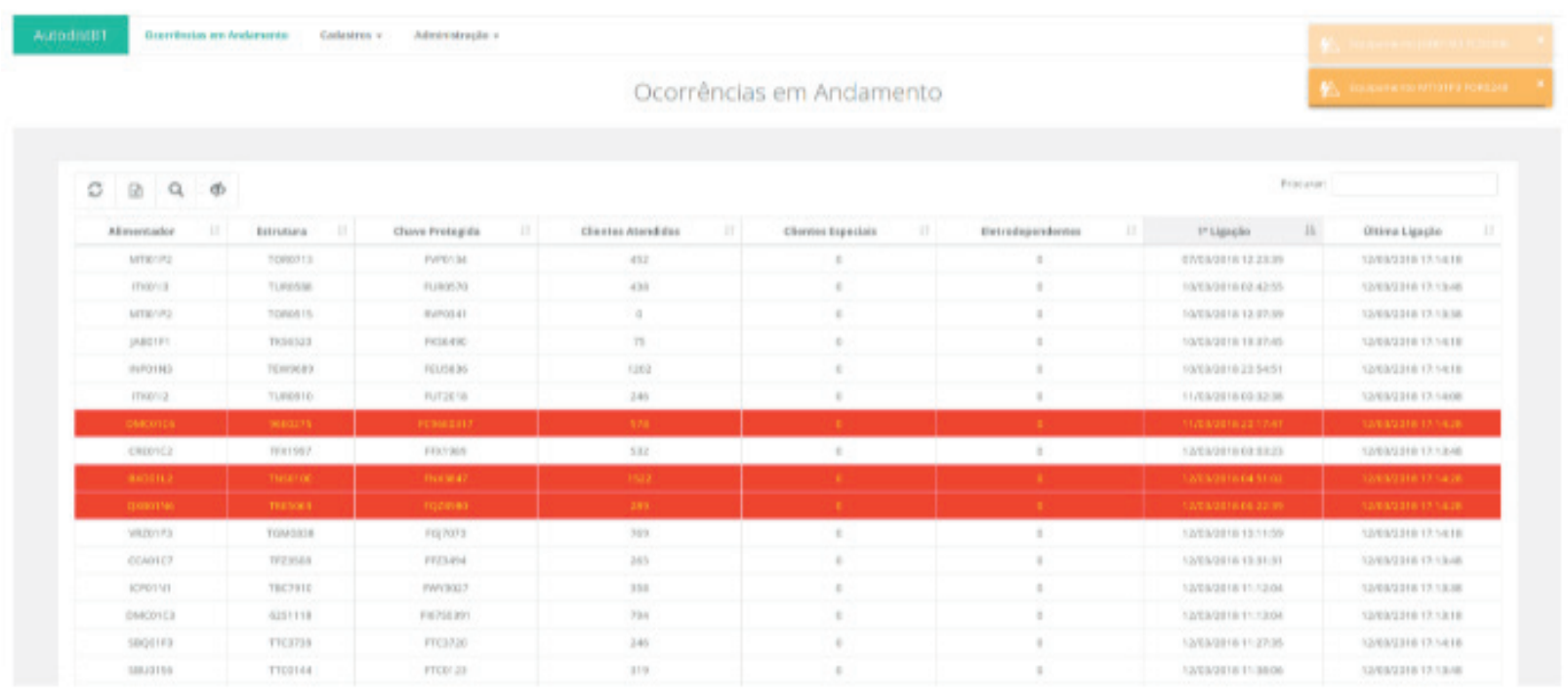

Figura 9 - Tela de Gerenciamento das Ocorrências em Andamento.

Vale salientar que o monitor só interromperá o ciclo de chamadas quando a ocorrência for normalizada e, com base nesta característica, o AutodistBT é capaz de informar até a duração da interrupção do fornecimento.

O sistema AutodistBT está preparado com telas especificas para a gestão de dados dos equipamentos monitorados. A Figura 10 mostra as opções de Cadastro, podendo o usuário inserir novos equipamentos e editar informações já cadastradas.

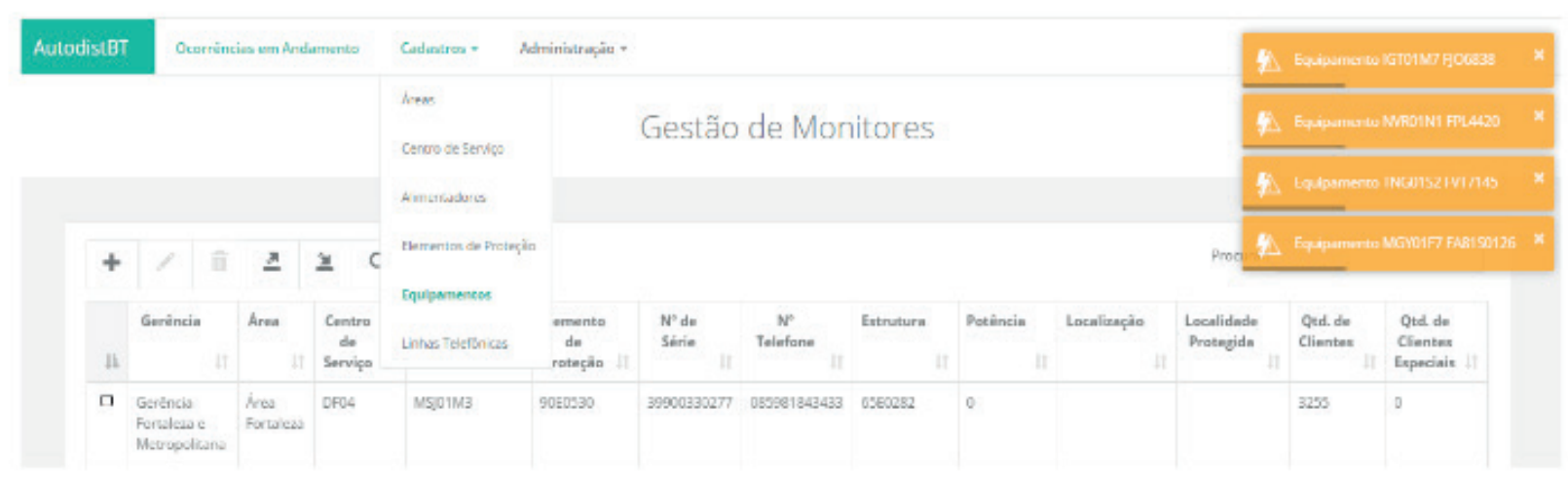

Figura 10 - Tela de edição e cadastro de informações dos Monitores Remotos. 


\subsection{Resultados}

A estratégia de implantação dos monitores foi a identificação de chaves fusíveis de ramais com uma grande quantidade de clientes protegidos. Foi levantado um total de 67.458 chaves fusíveis no sistema de média tensão da EDC. A Figura 11 mostra a quantidade de chaves fusíveis por regional.

\section{Quatidade Chaves Fusível - Geral}

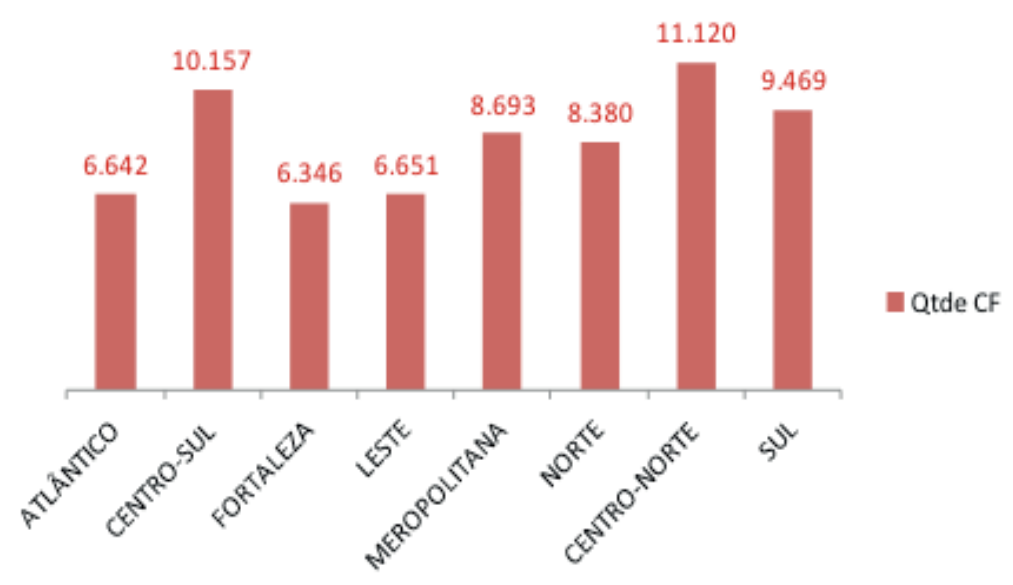

Figura 11 - Quantidade de chaves fusíveis por regional.

Em seguida as chaves foram segregadas por faixa de clientes de forma a identificar as chaves com a maior quantidade de clientes. Foram priorizadas inicialmente as 1.112 chaves de ramais que afetavam mais de 500 clientes. Depois foram colocados monitores em chaves com afetação menor que 500 clientes. A Figura 12 mostra a quantidade de chaves de ramal por faixa de clientes afetados.

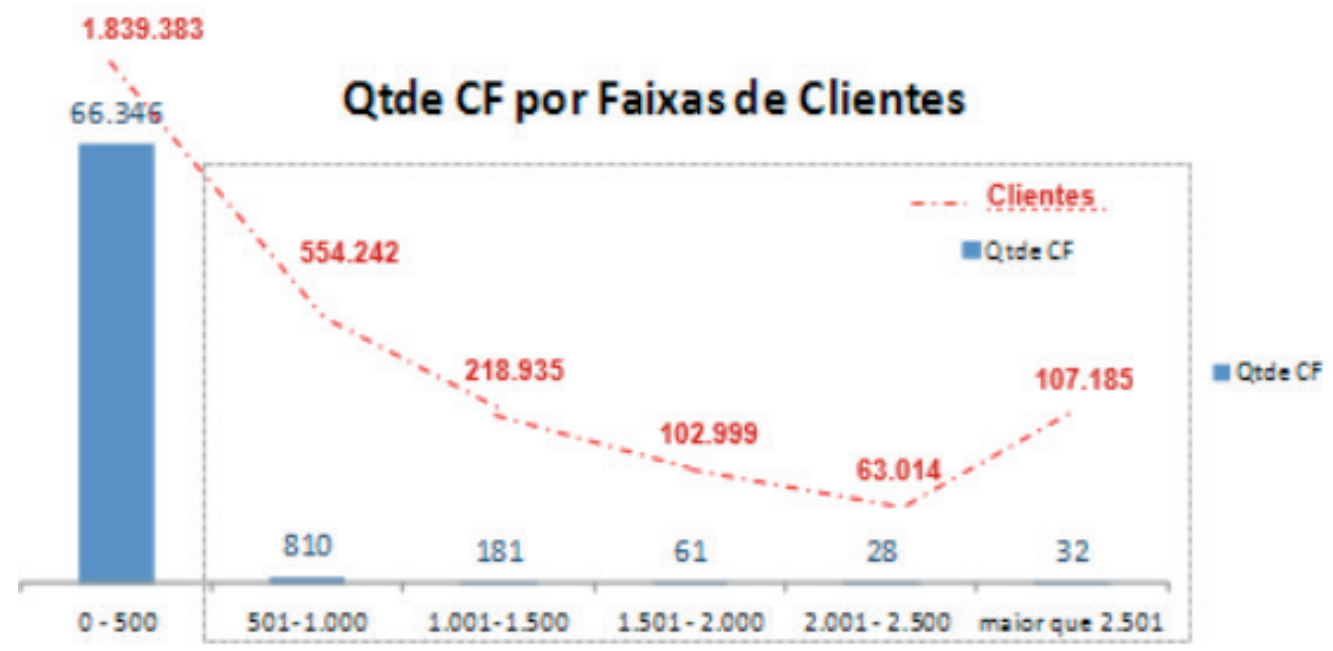

Figura 12 - Quantidade de chaves de ramal por faixa de clientes afetados.

Atualmente a Enel DC possui 3.101 monitores instalados em transformadores, que corresponde a $2 \%$ dos transformadores totais MT/BT. A Figura 13 mostra a 
distribuição dos monitores por regional.

Distribuição do Monitores Remotos

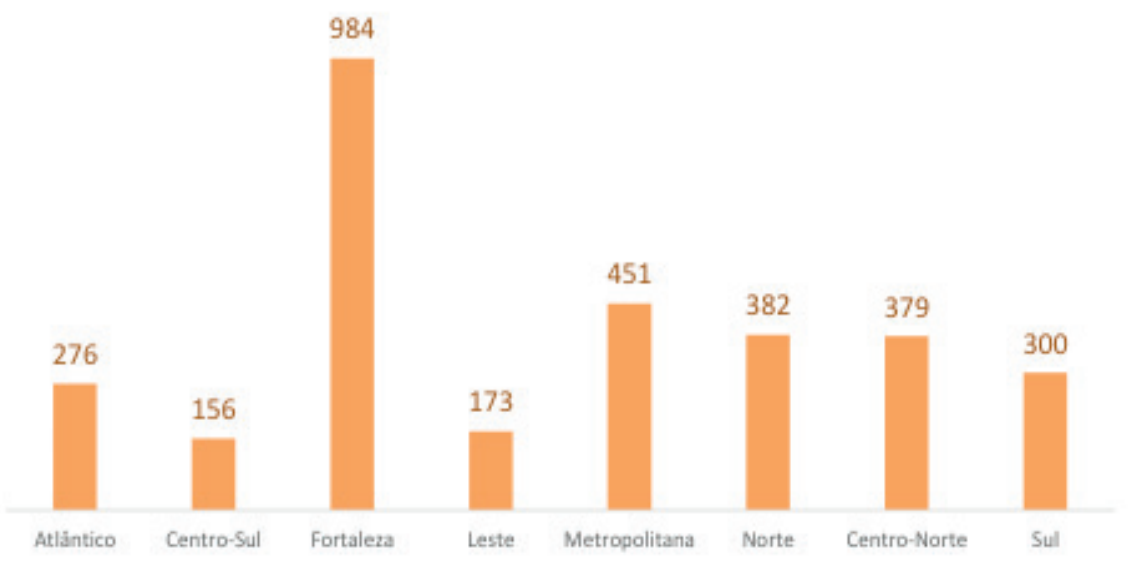

Figura 13 - Distribuição dos monitores por regional da Enel DC.

O principal ganho do Monitor de Ramais é a redução no tempo de atendimento quando da ocorrência de alguma interrupção de energia, onde serão conhecidas as quantidades de clientes afetados e assim serão antecipadas as tomadas de decisões de priorização de atendimentos. Os ganhos serão balizados pelo conhecimento prévio das interrupções antes dos registros de quaisquer reclamações de clientes afetados via Call Center da empresa.

Neste sentido o cálculo dos ganhos nos indicadores de qualidade de serviço foi baseado no Tempo Médio de Preparação - TMP das ocorrências emergenciais. O TMP mede a eficiência dos meios de comunicação das ocorrências, a disponibilidade das equipes de atendimento e o fluxo de informação dos Centros de Controle. O TMP é a diferença do tempo do registro da reclamação até o horário onde foi alocada uma equipe para atendimento à ocorrência. A Figura 14 mostra que o TMP corresponde a primeira parcela de tempo para o cálculo do Tempo Médio de Atendimento Emergencial - TMA. 


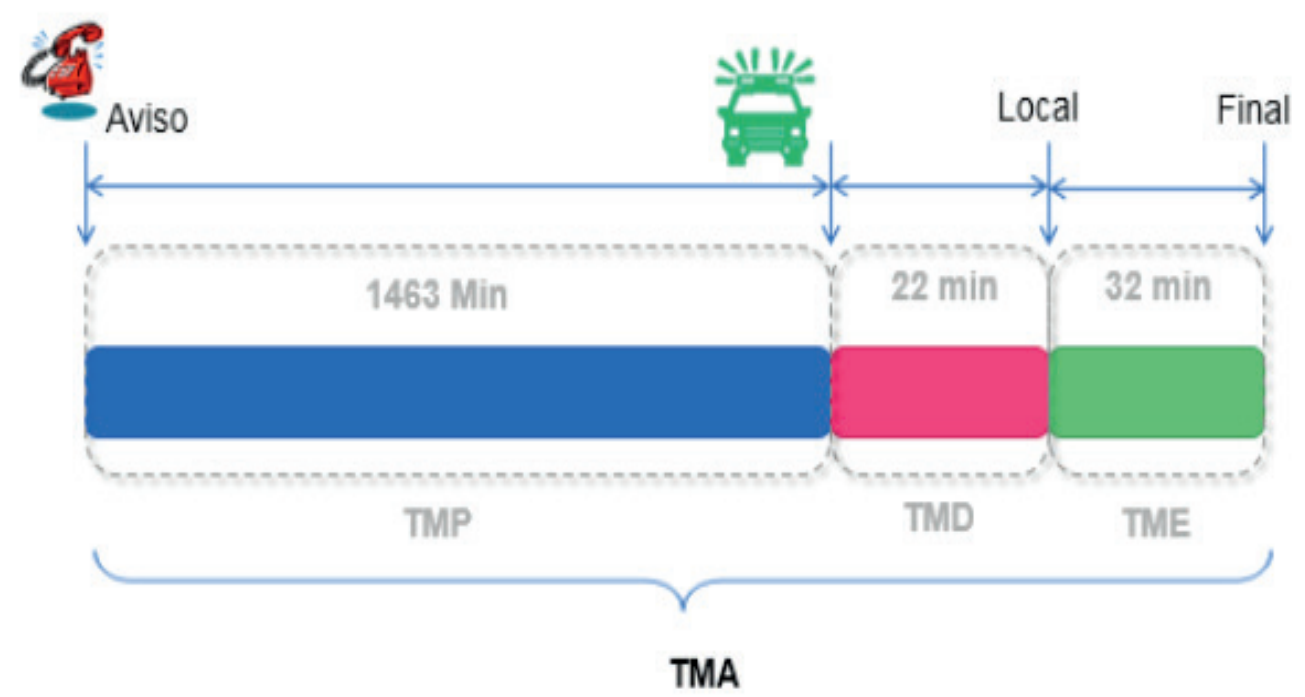

Figura 14 - llustração das parcelas de tempos médios de atendimento emergencial.

Para o cálculo ganho dos Monitores de Ramais foram utilizados os registros históricos dos TMP de cada dispositivo contemplado com o monitoramento remoto. Foram utilizadas a base histórica de indicadores e atendimento emergencial do ano de 2017. Como resultado foi construído uma base com todos os TMPs de cada dispositivo, assim como a quantidade de clientes interrompidos pela atuação de cada dispositivo monitorado. A diferença dos TMP de 2017 e 2018 de cada dispositivo é multiplicado pela quantidade de clientes afetados pelo dispositivo, o resultado é divido pela quantidade de clientes do alimentador, calculando assim o ganho em minutos. O Quadro 1 abaixo mostra um exemplo de memória de cálculo para o ganho dos monitores.

\begin{tabular}{|c|c|c|c|c|c|c|}
\hline $\begin{array}{c}\text { TMP dispositivo } \\
\text { histórico }\end{array}$ & $\begin{array}{c}\text { TMP dispositivo } \\
\text { atual }\end{array}$ & Diferença dos TMP & $\begin{array}{c}\text { Cliente afetado } \\
\text { peLo dispositivo }\end{array}$ & Cliente x Tempo & $\begin{array}{c}\text { Quantidade de } \\
\text { Clientes do } \\
\text { Alimentador }\end{array}$ & $\begin{array}{c}\text { Ganho minutos } \\
\text { no alimentador }\end{array}$ \\
\hline $\mathbf{1 0 0}$ & $\mathbf{7 0}$ & $\mathbf{3 0}$ & $\mathbf{1 0 0 0}$ & $\mathbf{3 0 0 0 0}$ & $\mathbf{2 0 0 0 0}$ & $\mathbf{1 , 5}$ \\
\hline
\end{tabular}

Quadro 1 - Memória de cálculo dos ganhos dos monitores de ramais.

Os monitores de ramais foram instalados ao longo do ano de 2017, com início em outubro e finalizado no final de dezembro de 2017. Os ganhos nos indicadores foram calculados em 2018 onde verificou-se excelentes resultados, com um ganho acumulado de 28,5 minutos no indicador de qualidade (DEC). A previsão de target para o final de 2018 era um ganho de 31,5 minutos. A Figura 14 mostra os ganhos mensais em 2018 e o valor acumulado em linha com o valor previsto para 2018. 


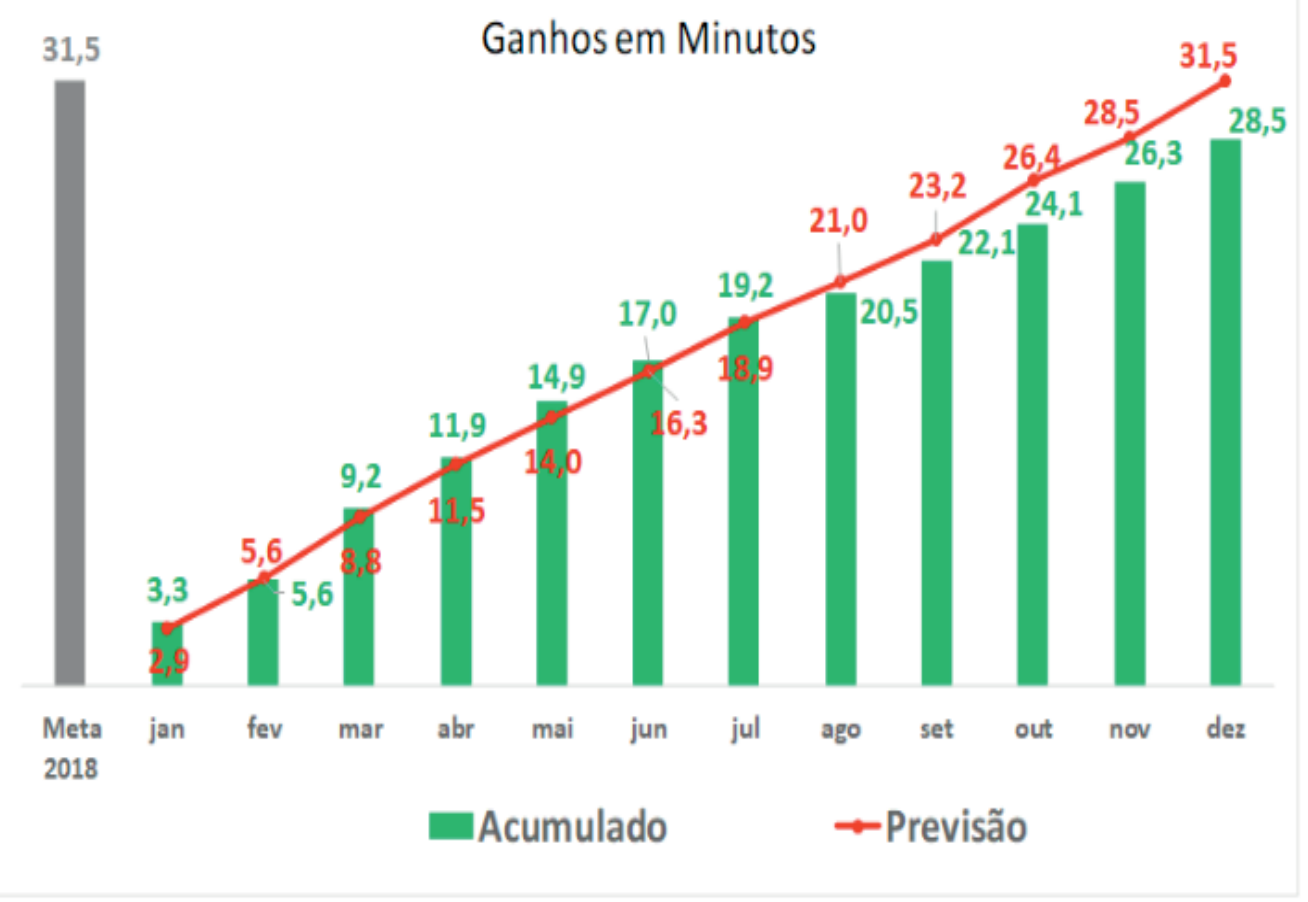

Figura 14 - Resultado dos ganhos mensais e acumulado em 2018.

\section{I CONCLUSÕES}

Conforme exposto, verifica-se que a utilização em larga escala do sistema de supervisão da rede de BT e ramais de MT trazem grandes benefícios às concessionárias e seus clientes, no tocante à redução do tempo de interrupção do fornecimento às áreas sob monitoramento e a otimização do desempenho das equipes de manutenção. Além disto, o referido sistema propõe várias inovações tecnológicas, dentre as quais podemos destacar:

- Utilização de equipamentos sensores utilizando sistema de comunicação móvel celular instalados em transformadores de distribuição;

- Sistema computacional de gerenciamento compatível com os equipamentos sensores de interrupções de energia, integrado ao sistema corporativo e ao processo de atendimento emergencial da concessionária;

- Conhecimento exato da duração da interrupção de energia detectada (início e final);

- Utilização de inteligência artificial e banco de dados para monitoramento e análise das interrupções de energia, identificando o segmento de sua ocorrência, se em baixa ou em média tensão;

- Conhecimento imediato da quantidade de clientes afetados pela interrupção, antes mesmo que haja qualquer reclamação por parte dos clientes;

- Otimização do processo de atendimento emergencial da concessionária;

- Monitoramento das interrupções de energia em transformadores de distribuição e em ramais de média tensão estratégicos (eletrodependentes e 
Hospitais).

Importante ressaltar que uma das grandes vantagens deste equipamento é que o mesmo utiliza apenas o canal de voz da operadora de celular, sem a necessidade de utilização de dados, o que o torna bastante atrativo com relação a custos. Uma outra vantagem é que as ligações realizadas pelo monitor, no momento da falta, não são completadas, assim não geram custos de ligação.

Desta forma, a Enel DC tem a seu dispor uma poderosa ferramenta de supervisão das redes de $\mathrm{BT}$ e ramais de $\mathrm{MT}$ proporcionando a maior acurácia possível na detecção de ocorrências em seu sistema e como consequência uma maior agilidade no atendimento destas.

\section{REFERÊNCIAS}

ANEEL. Procedimentos de Distribuição de Energia Elétrica no Setor Elétrico Nacional PRODIST. Módulo 1 -Introdução. Acesso em 02/03/2018, disponível em:

<http://www.aneel.gov.br/documents/656827/14866914/\%C3\%B3dulo1_Revisao_9/1b78da82-6503-

4965-abc1-a2266eb5f4d7>.

ANEEL. Procedimentos de Distribuição de Energia Elétrica no Setor Elétrico Nacional PRODIST. Módulo 8 -Qualidade da Energia Elétrica. Acesso em 02/03/2018, disponível em: <http:// www2.aneel.gov.br/arquivos/PDF/M\%C3\%B3dulo8_Revis\%C3\%A3o_7.pdf>.

MEHL, L. M. Qualidade de Energia Elétrica. Acesso em 07/03/2018, disponível em: http://www.eletrica.ufpr.br/mehl/downloads/qualidade-energia.pdf.

MARTINS, C. M.; SELLITO, M. A. Análise de Estratégia de Manutenção de uma Concessionária de Energia Elétrica com base em Estudos de Confiabilidade. In: XXVI ENCONTRO NACIONAL DE ENGENHARIA DE PRODUÇÃO,

Fortaleza, 2006. 


\section{CAPÍTULO 11}

\section{TÉCNICA DE RESGATE PARA TRABALHOS EM INSTALAÇÕES ENERGIZADAS - MÉTODO AO POTENCIAL}

Data de aceite: 03/01/2020

\section{Fernando César Pepe}

Wlademir Braido

\section{INTRODUÇÃO}

Visando a segurança e integridade física dos colaboradores que atuam em instalações energizadas e no cumprimento legal das normas regulamentadoras:

\section{NR 10, EM SEUS ITENS}

10.4 - Segurança na construção, montagem, operação e manutenção

10.4.2 Nos trabalhos e nas atividades referidas devem ser adotadas medidas preventivas destinadas ao controle dos riscos adicionais, especialmente quanto a altura, confinamento, campos elétricos e magnéticos, explosividade, umidade, poeira, fauna e flora e outros agravantes, adotando-se a sinalização de segurança.

\subsection{2 - Situação de emergência}

10.12.1 As ações de emergência que envolvam as instalações ou serviços com eletricidade devem constar do plano de emergência da empresa. 10.12.3 A empresa deve possuir métodos de resgate padronizados e adequados às suas atividades, disponibilizando os meios para a sua aplicação.

\section{NR 35 EM SEU ITEM}

\subsection{Emergência e Salvamento}

35.6.1 O empregador deve disponibilizar equipe para respostas em caso de emergências para trabalho em altura.

35.6.1.1 A equipe pode ser própria, externa ou composta pelos próprios trabalhadores que executam o trabalho em altura, em função das características das atividades.

35.6.2 O empregador deve assegurar que a equipe possua os recursos necessários para as respostas a emergências.

35.6.3 As ações de respostas às emergências que envolvam o trabalho em altura devem constar do plano de emergência da empresa.

35.6.4 As pessoas responsáveis pela execução das medidas de salvamento devem estar capacitadas a executar o resgate, prestar primeiros socorros e possuir aptidão física e mental compatível com a atividade a desempenhar.

No grupo CPFL realizamos atividades ao Potencial com o uso de cesto aéreo, andaime e escada isolados. Para tanto desenvolvemos 
técnicas de resgate para situações emergenciais.
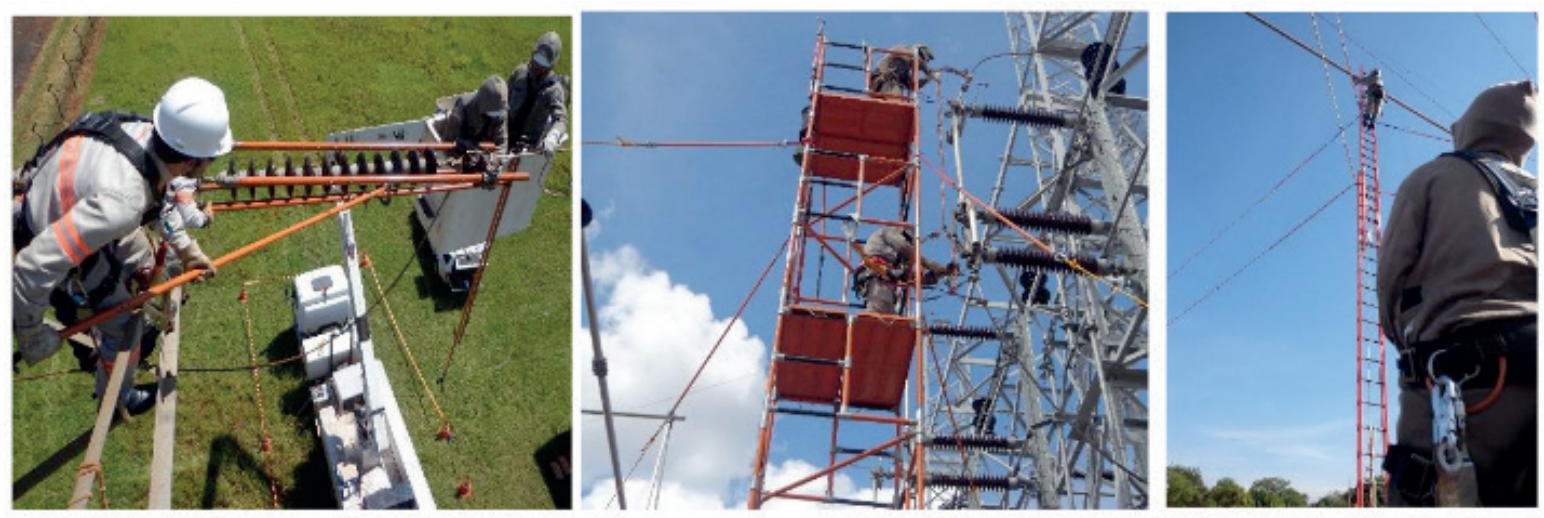

\section{TRABALHOS COM CESTO AÉREO}

Nossos equipamentos de cesto para trabalhos ao Potencial são todos over center, ou seja, descem até o solo para resgate do acidentado.

Na metodologia de equalização ao Potencial com o cesto aéreo, todas as partes metálicas do cesto e ponta da lança devem estar no mesmo potencial. O cesto é metálico e a equalização da vestimenta condutiva é feita no próprio cesto metálico.

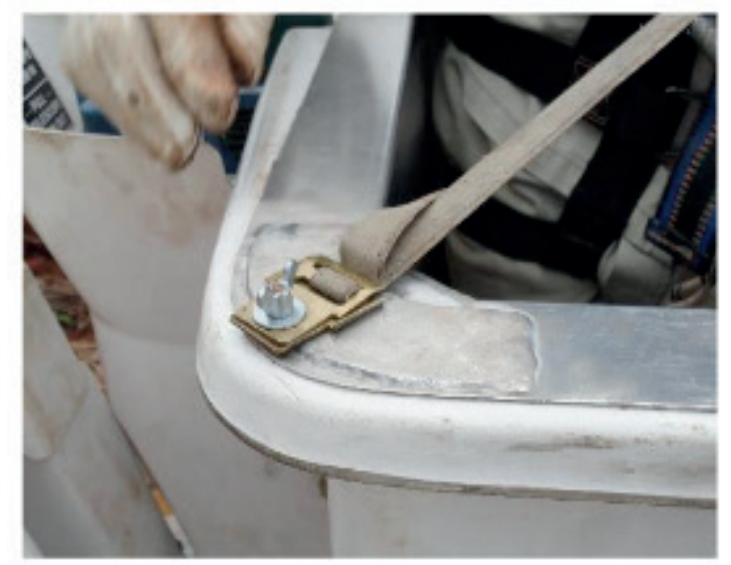

Para equalização a instalação energizada utilizamos cabos de cobre extra flexível de $35 \mathrm{~mm}^{2}$, presos ao cesto metálico e com grampos para conexão as partes energizadas.

Para uma situação emergencial, outro eletricista do solo transfere o comando do cesto para o solo e inicia o rebaixamento do equipamento para o resgate, mas como fazê-lo com o cesto conectado na instalação energizada??? 

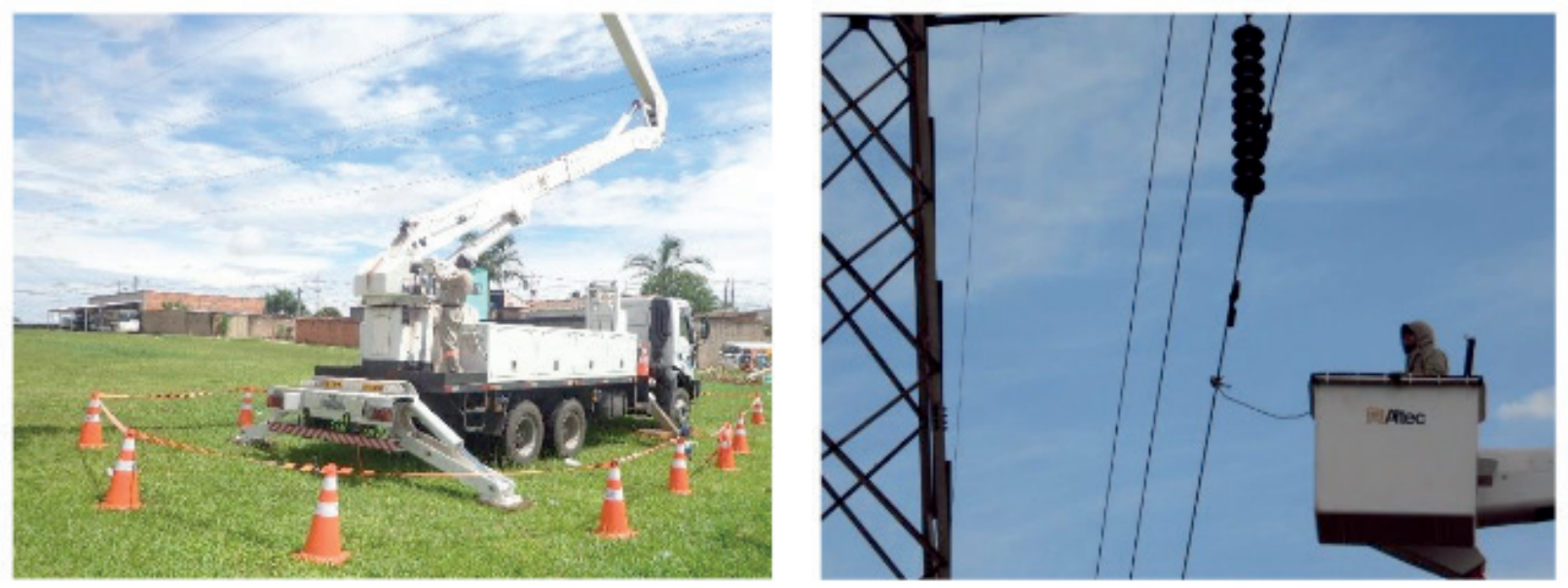

A solução encontrada foi desenvolvermos um acoplamento automático instalado no cabo de equalização do cesto aéreo, possibilitando o saque do equipamento da instalação.
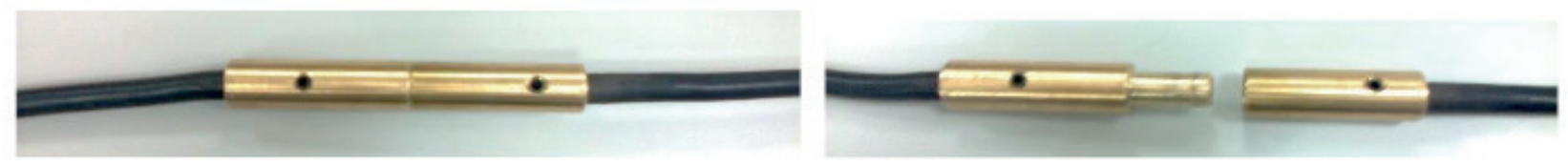

Com esse acoplamento automático, permite-se desacoplar o cesto aéreo da instalação energizada e proceder o rebaixamento do equipamento até o solo.

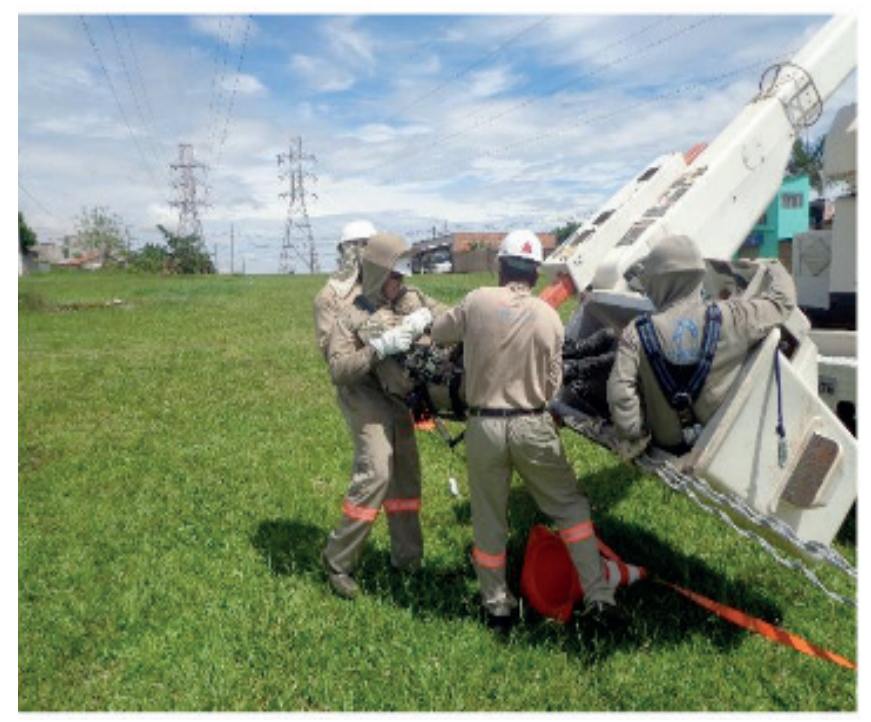

\section{TRABALHOS COM ANDAIME OU ESCADA}

Nas atividades ao Potencial no andaime ou na escada, em situação onde se precise resgatar os eletricistas ao Potencial, em nossos manuais a primeira ação é solicitar o desligamento da instalação, em seguida proceder com a técnica de resgate.

O desligamento e isolamento da instalação nem sempre ocorre de forma imediata 
e em situações emergenciais o tempo é crucial, devemos proceder com segurança no menor tempo possível.

Para realizar o resgate com a instalação energizada ou mesmo desenergizada, mas com tensão induzida, desenvolvemos metodologia, que segue abaixo:

Antes do início das atividades a corda do resgate deve ser testada com o testador de cordas para trabalhos em instalações energizadas.

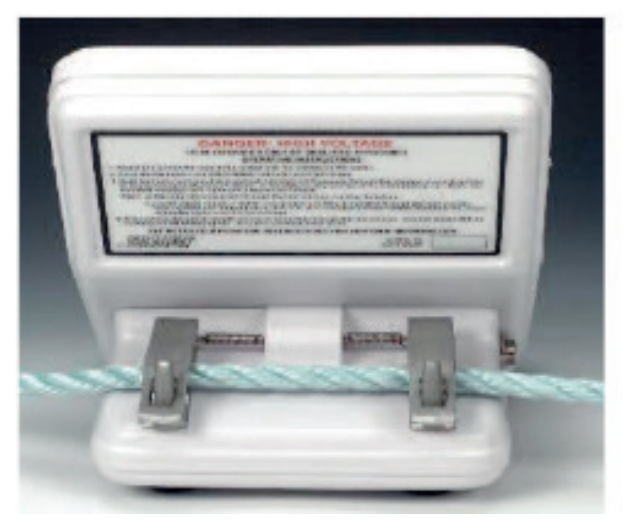

O HI-Test Testador de cordas tem o objetivo de testar cordas, fitas e cintas para trabalhos em LINHA-VIVA quanto a INTEGRIDADE Di-elétrica no período e local que ela está em uso.

Permite o uso em Cordas com diâmetros de 3/8" (9.5 mm) a 1.1/2" (38 mm).

A corda deve ser puxada através dos grampos a no máximo $30 \mathrm{~cm} / \mathrm{s}$.

A ferramenta gera uma tensão de 7 kVDC entre os dois grampos, com uma corrente elétrica variando entre 35 e 40 micro $A$.

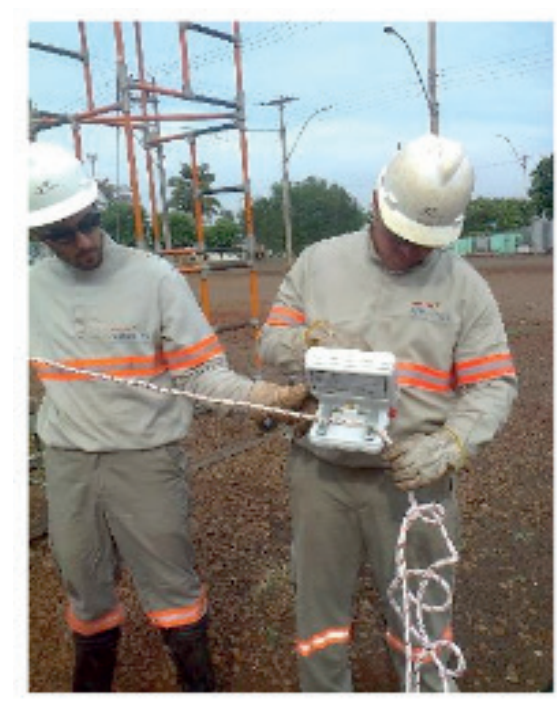

A corda para o resgate ao Potencial é de uso exclusivo para essa finalidade. Deve ser armazenada e receber os mesmos cuidados dos bastões isolados para linhas energizadas.

Durante toda a intervenção na instalação energizada, um dos participantes fica equipado no solo, com a vestimenta condutiva e cinto para quedista. A corda e os 
equipamentos de resgate ficam na lona;

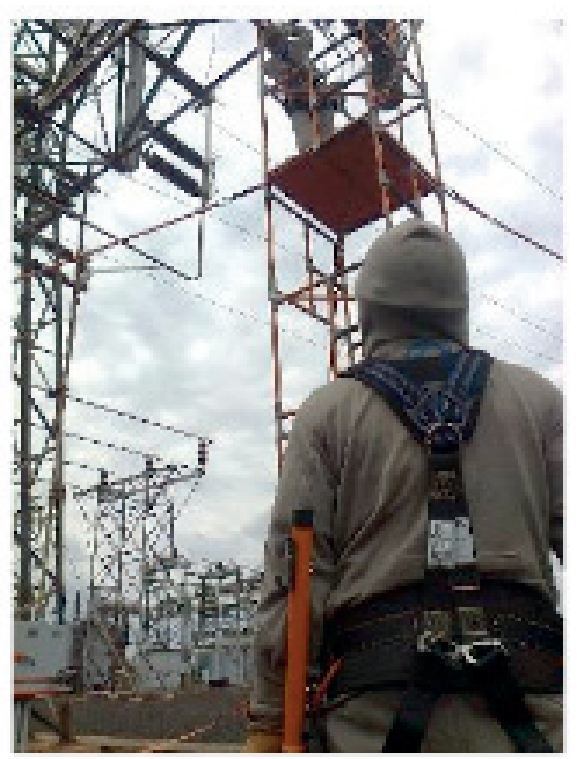

$\mathrm{Na}$ ocorrência de uma emergência, o resgatista escala o andaime portando os equipamentos de resgate: corda, mosquetão tripla trava, cinta de poliéster e polia;

O resgatista faz a equalização ao Potencial na própria roupa condutiva da vítima;

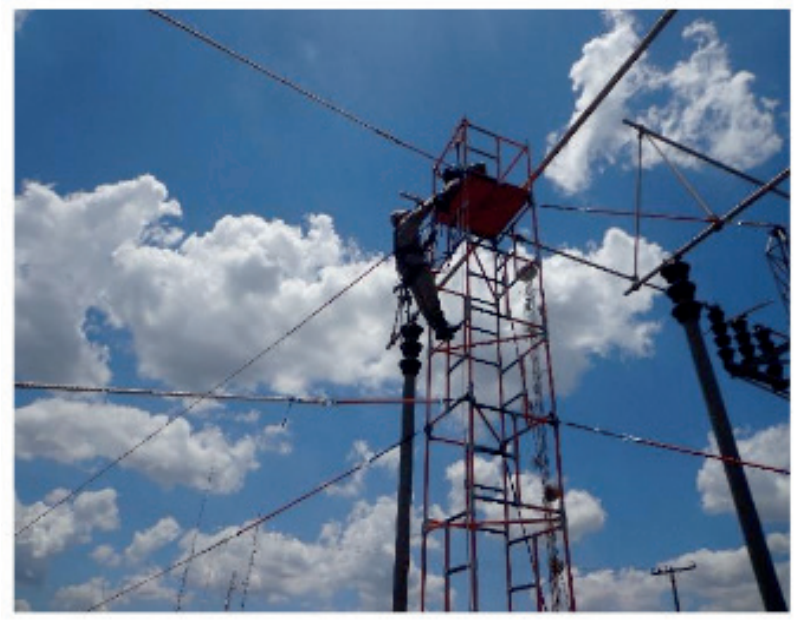

Em seguida instala os equipamentos para o resgaste no canto do andaime, afasta a vítima e tira a equalização da vítima do Potencial, saindo automaticamente do Potencial também; 


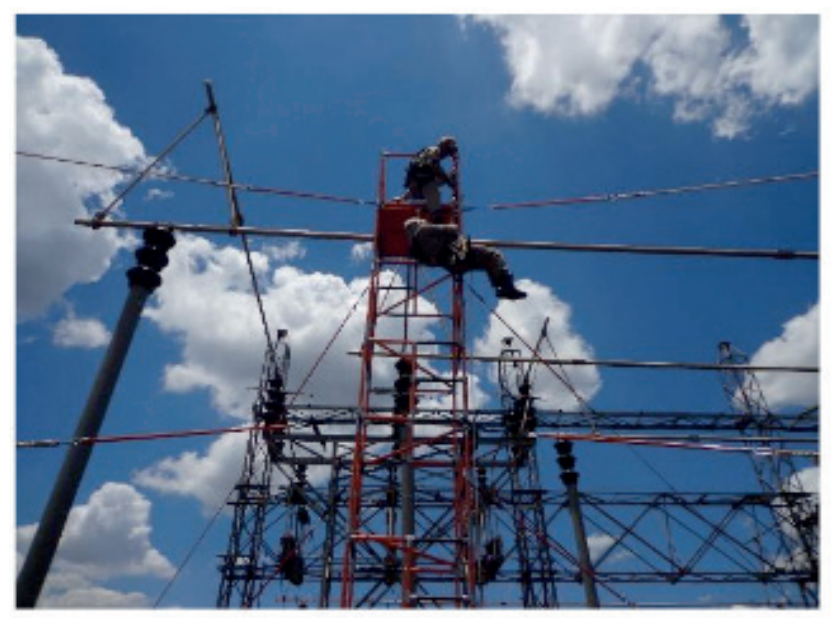

A corda de resgate é instalada na vítima para iniciar a descida;

Simultaneamente no solo é instalado o descensor ID'L e iniciasse a descida da vítima;

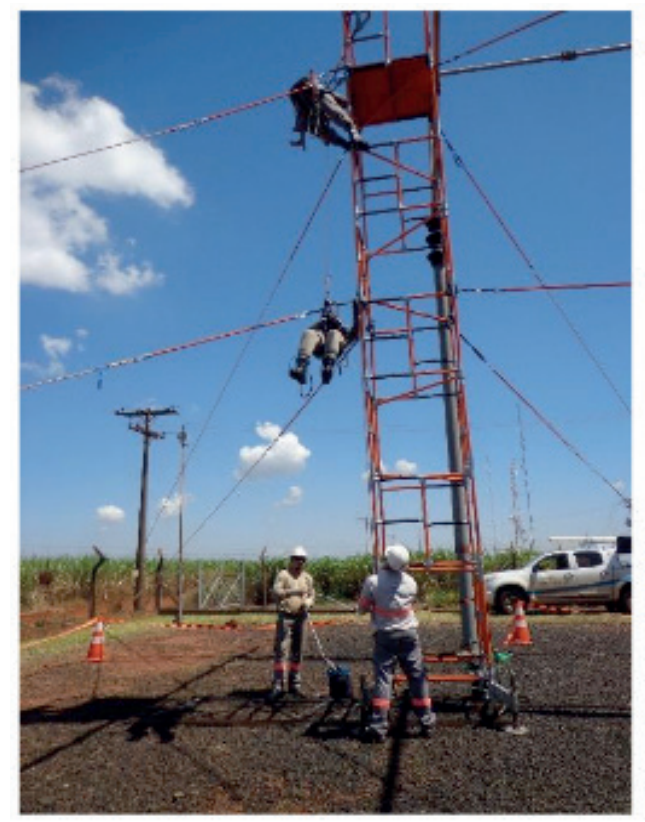

O resgate em altura só é concluído quando a vítima e o resgatista chegam ao solo. 


\section{MONITORAMENTO DE DESGASTE DE CONTATOS DOS DISJUNTORES DA SUBESTAÇÃO ISOLADA À GÁS DA UHE BELO MONTE}

Data de aceite: 03/01/2020

\section{Davi Carvalho Moreira} Centrais Elétricas do Norte do Brasil S.A

Tucuruí-Brasil

Lattes: http://lattes.cnpq.br/2413664649532144 ORCID: https://orcid.org/0000-0002-5974-3285

Data de submissão: 04/11/2019

RESUMO: Este artigo tem como objetivo apresentar o sistema de monitoramento online de desgaste dos contatos dos disjuntores instalados na subestação isolada a gás (SIG) da Usina Hidrelétrica de Belo Monte (UHE Belo Monte). Este monitoramento é baseado no critério de corrente interrompida acumulada que utiliza o número de operações, tempo de operação e corrente de interrupção do disjuntor para o cálculo do "Indicador de Desgaste" que é o principal direcionador para intervenção nos contatos do disjuntor. O sistema de monitoramento de desgaste dos contatos nos disjuntores da SIG 500kV da UHE Belo Monte, se mostrou um método prático, replicável em disjuntores de outras instalações e sua eficiência está sendo acompanhada.

PALAVRAS-CHAVE: Manutenção Preditiva - Monitoramento de Disjuntor - Desgaste de Contatos - Monitoramento On-line.
ABSTRACT: This paper aims to present the on-line monitoring system for contact breaker contacts installed in the gas insulated substation (GIS) of Belo Monte Hydroelectric Power Plant (Belo Monte Hydroelectric Power Plant). This monitoring is based on the accumulated interrupted current criterion that uses the number of operations, operating time, and breaker interrupt current to calculate the "Wear Indicator" which is the main driver for intervention on the breaker contacts. The contact wear monitoring system on the Belo Monte HPP SIG 500kV circuit breakers has proved to be a practical method, replicable on circuit breakers in other installations and its efficiency is being monitored.

KEYWORDS: Predictive Maintenance - Circuit Breaker Monitoring - Contact Wear - Online Monitoring.

\section{1 | INTRODUÇÃO}

Os disjuntores são equipamentos essenciais no sistema elétrico de potência. Eles são usados para alterar a topologia do sistema para acomodar várias configurações de fluxo da carga e também são usados para isolar partes defeituosas do sistema elétrico de potência, como parte da operação do relé de proteção [1]. À medida que os disjuntores operam durante 
sua vida útil, eles sofrem severas tensões elétricas, mecânicas e térmicas que podem degradar suas condições operacionais. Dessa forma, as condições de operação dos disjuntores necessitam ser continuamente observadas [2].

Os métodos de monitoramento das condições dos disjuntores são classificados como off-line, on-line e em tempo real. Em técnicas off-line, as medições podem ser obtidas de equipamentos desenergizados. Em métodos on-line, as medições podem ser capturadas a partir de aparatos energizados sempre que necessário, enquanto que em procedimentos em tempo real, as medições precisam ser tomadas continuamente usando amostragem em tempo real [3,4].

A importância da Usina Hidrelétrica de Belo Monte (UHE Belo Monte) para o setor elétrico brasileiro justifica a concepção de projeto do sistema de monitoramento dos disjuntores de alta tensão, seguir a tendência geral dos equipamentos de potência, de migração da manutenção preventiva para a manutenção preditiva, o que só foi possível através de sistemas de monitoramento on-line.

Até o final de 2018, a Subestação Isolada a Gás (SIG) da UHE Belo Monte possuía em operação 20 (vinte) disjuntores 500kV em operação e outros 10 (dez) em montagem e comissionamento. Esta SIG foi concebida em barra dupla com 18 (dezoito) vãos ligação de transformador, 5 (cinco) vãos de saída de linha, 2 (dois) vãos de interligação de barras e 2 (dois) vãos de seccionamento de barra, conforme mostrado na Figura 1.

Durante muito tempo, a integridade dos equipamentos nas subestações e usinas dependia da manutenção preventiva. Atualmente as empresas de energia e as indústrias convivem com reduzidas equipes de engenharia de manutenção, e torna-se necessário o desenvolvimento de ferramentas que auxiliem no processo de tomada de decisão para uma precisa intervenção [5]. É nesse contexto que este artigo apresenta o sistema de monitoramento on-line de desgaste dos contatos dos disjuntores instalados na SIG da UHE Belo Monte. 


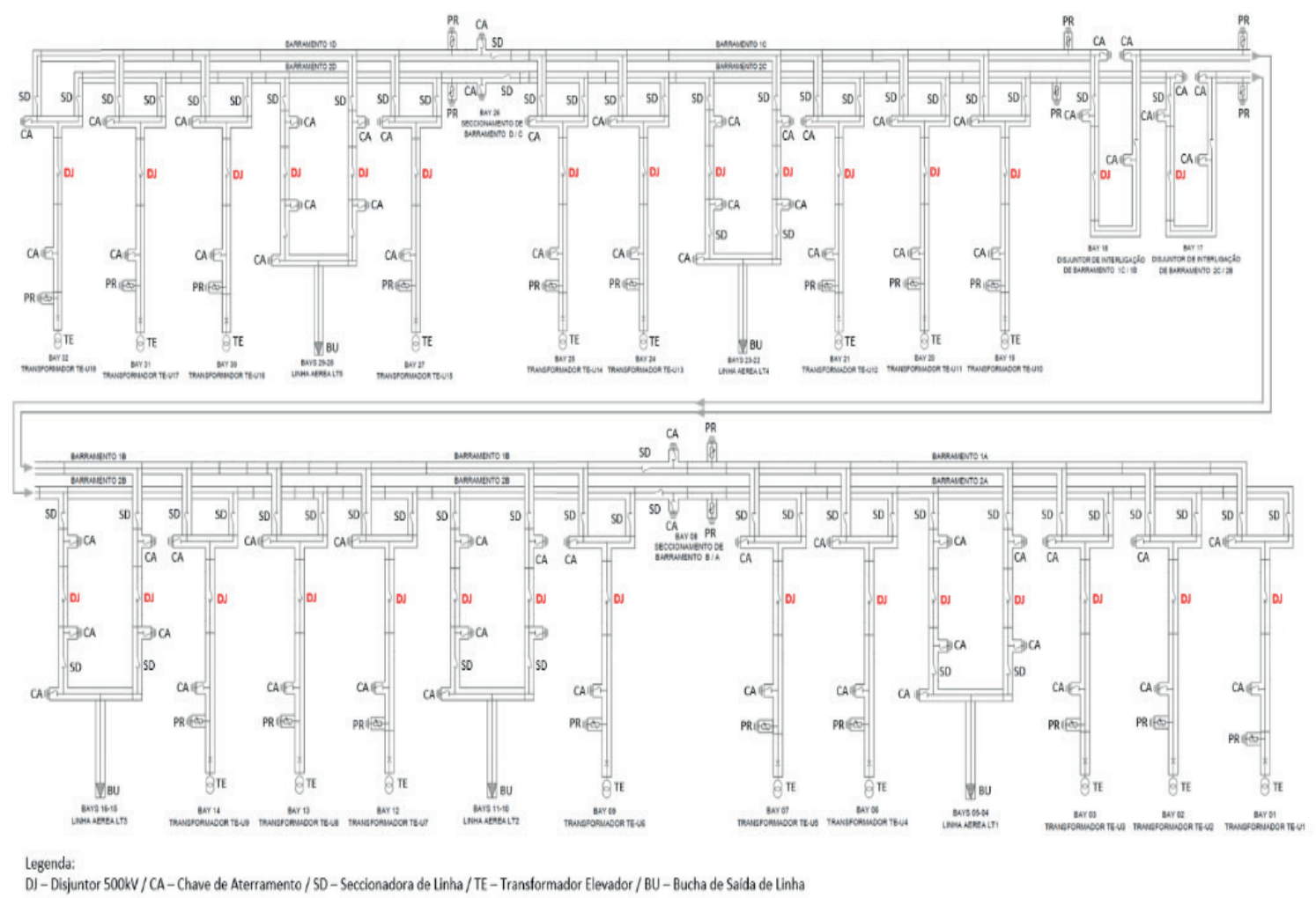

Figura 1 - Diagrama Unifilar da Subestação Isolada a Gás da UHE Belo Monte.

\section{I ESTRATÉGIAS DE MANUTENÇÃO EM DISJUNTOR}

Para manter o disjuntor em condições normais de operação, a manutenção adequada é muito importante durante sua vida útil. As estratégias de manutenção podem ser classificadas em manutenção corretiva e manutenção preventiva [6-8]. A manutenção corretiva ocorre após a falha no equipamento, e a manutenção preventiva é realizada antes da falha no equipamento. A estratégia de manutenção preventiva contribui para minimizar os custos de manutenção e o tempo de indisponibilidade do equipamento, e inclui principalmente manutenção baseada em tempo e manutenção baseada em condição. A aplicação de manutenção baseada na condição determina o cronograma de manutenção pelo estado real do equipamento, é mais realista e mais vantajosa de se aplicar do que a manutenção baseada no tempo [9].

Uma pesquisa abrangente de confiabilidade de disjuntores foi realizada pelo CIGRE Working Group 13.09 [10], que dividiu em cinco grupos de condições de operação e falhas em disjuntores que devem ser monitoradas e mantidas: (i) mecanismo de operação: a quebra de eixos, hastes e molas podem resultar em falhas graves dos disjuntores; (ii) componentes de controle e auxiliares: falhas de circuitos elétricos ou válvulas que podem não aceitar comando; (iii) partes de condução de corrente: que podem ser monitoradas ou diagnosticadas pela resistência de contato, temperatura de contato e corrente de carga; (iv) chaveamento: que inclui as características do percurso de contato, o tempo de operação, o tempo de arco e o desgaste do contato de arco; e (v) isolamento: falhas do meio de isolamento podem causar danos pesados aos disjuntores. Entre esses grupos, a maioria das falhas em disjuntor é devido ao 
mau funcionamento do mecanismo de operação e circuitos de controle [11].

Nos últimos anos, houveram vários trabalhos relacionados a manutenção baseada na condição aplicado à disjuntores, porém grande parte das pesquisas se concentrou no monitoramento automatizado de suas condições e pouca pesquisa foi dedicada ao monitoramento de desgaste de contatos dos disjuntores.

Braunovic et al. [12] discutiram a correlação entre a temperatura e a resistência de contato. Em [13] e [14], os autores propuseram alguns métodos para medir a resistência de contato.

Kezunovic et al. [1], com base em um registro de formas de onda tiradas do circuito de controle do disjuntor, os autores desenvolveram uma maneira automatizada usando processamento avançado de sinais e técnicas especializadas para monitorar e analisar a interrupção do disjuntor.

Hoidalen e Runde [15] e Meng et al. [16], apresentaram técnicas de monitoramento de condições contínuas de disjuntores usando análise de vibração.

Natti e Kezunovic [17] investigaram a avaliação da probabilidade de falha de disjuntores através dos dados do circuito de controle disponíveis usando a abordagem Bayesiana e alguns índices de desempenho. A maioria das falhas de disjuntores observadas no campo estão correlacionadas aos circuitos de operação mecânica e de controle auxiliar.

Zheng [18] criou uma estrutura de detecção de falhas baseada em modelo para disjuntores a vácuo por meio de análise de bobina de disparo. Seguindo essa ideia, Razi-Kazemi et al. [19] propuseram uma técnica de detecção de falha mecânica inteligente com base nos resultados da observação da forma de onda da corrente da bobina de abertura/fechamento.

Dehghanian et al. [20] propuseram uma abordagem para identificar os disjuntores defeituosos usando os dados de monitoramento baseados em condições e as avaliações de impacto baseadas em segurança. Eles apresentaram uma estrutura de risco baseada em segurança para o planejamento de manutenção e identificação dos disjuntores. Outras pesquisas sobre o monitoramento e manutenção de disjuntores foram apresentadas em [9], [21] e [22].

Feizifar e Usta [2] propuseram um algoritmo para monitoramento das condições dos contatos elétricos do disjuntor baseado na potência do arco elétrico e sua energia.

Wang e Yang [23] apresentaram um método para encontrar a equação da curva de vida útil do contato do disjuntor. Realizaram dois estudos de caso e compararam o planejamento da manutenção baseada na condição com o planejamento de manutenção tradicional recomendado pelos fabricantes, o método proposto foi mais eficaz em evitar manutenção excessiva. 


\section{I MONITORAMENTO DE DESGASTE DOS CONTATOS DO DISJUNTOR}

\subsection{Número dos Ciclos de Operação}

O método de monitoramento das condições do disjuntor mais simples é baseado na contagem dos ciclos de operação, que estima o desgaste mecânico do disjuntor. Neste método, existe um valor limite definido pelo fabricante, por exemplo, após 10.000 ciclos de operações, a inspeção ou manutenção do disjuntor é necessária. Este método não estima o desgaste elétrico dos contatos do disjuntor porque ignora o desgaste de contato causado por diferentes níveis de correntes interrompidas e o efeito de degradação das tensões de arco.

\subsection{Corrente Interrompida Acumulada}

O método de monitoramento chamado "Corrente Interrompida Acumulada" estima a condição de desgaste dos contatos principais do disjuntor através da aplicação da expressão matemática ( $k$ valor entre 1 e 2) de acordo com o tipo de disjuntor. Para aplicação dessa expressão é necessário realizar o monitoramento do número de operações, do tempo de arco e da corrente interrompida do disjuntor.

No caso específico do monitoramento dos disjuntores da SIG da UHE Belo Monte, o tempo do percurso dos contatos móveis é realizado por um transdutor rotativo instalado no mecanismo de movimentação da haste dos polos do disjuntor, conforme mostrado na Figura 2.

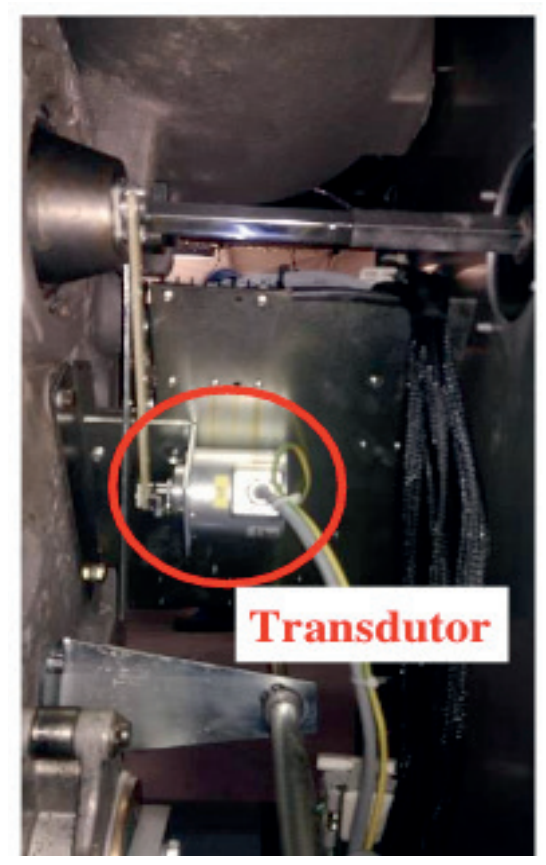

Figura 2 - Transdutor Rotativo do Mecanismo de Movimentação da Haste dos Polos do Disjuntor.

A corrente de interrupção é medida através de um transformador de corrente auxiliar conectado no secundário do transformador de corrente principal, conforme apresentado na Figura 3. Este tipo de projeto permite o registro das correntes durante 
as operações de abertura e fechamento dos disjuntores, sem intrusão nos sistemas de proteção, controle e supervisão, conforme diagrama funcional apresentado na Figura 4.

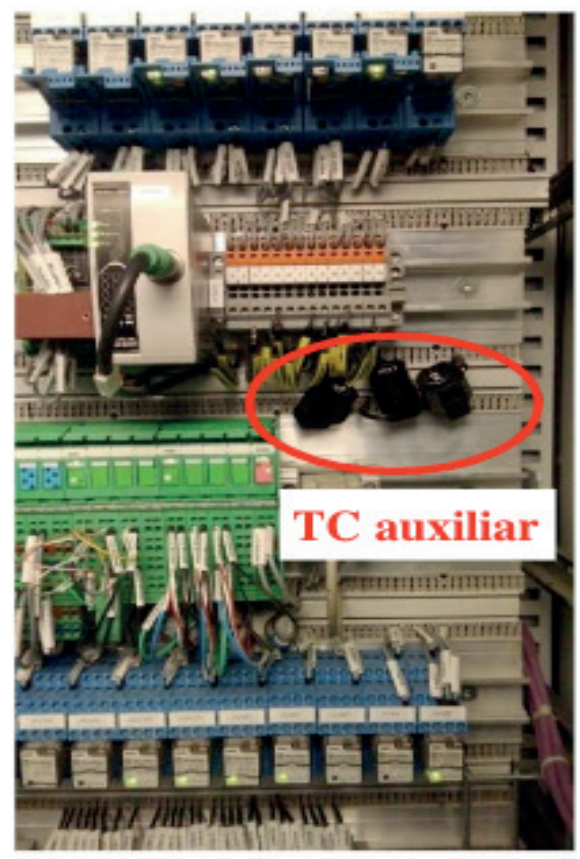

Figura 3 - Diagrama Funcional da Medição de Corrente Interrompida.

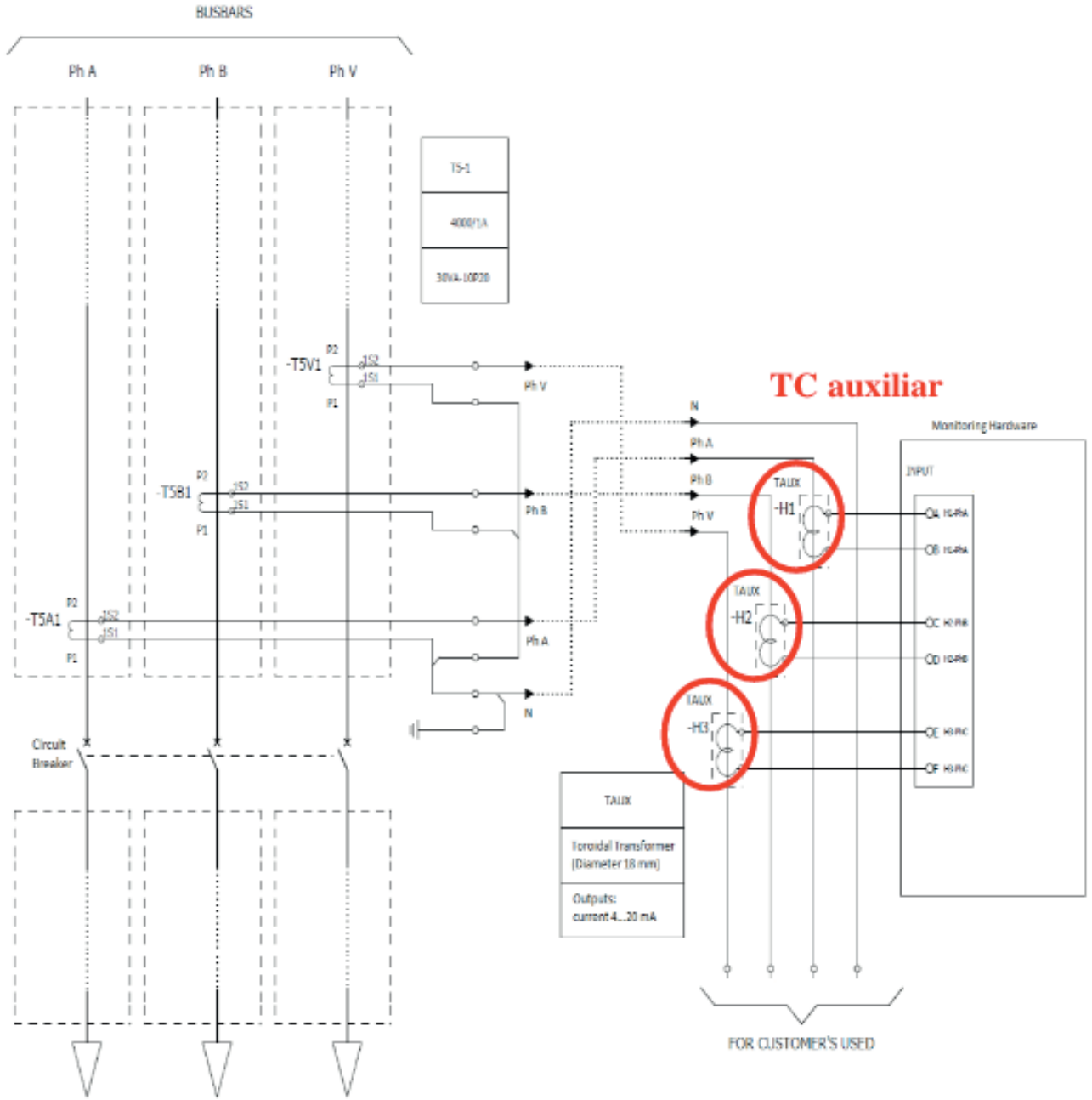

Figura 4 - Diagrama Funcional da Medição de Corrente Interrompida. 
Na tela do sistema de monitoramento do disjuntor, referente ao desgaste dos contatos (Figura 5), é apresentado duas informações importantes para análise da vida útil do contato do disjuntor. A primeira é o gráfico de barras indicando a quantidade de aberturas do disjuntor com interrupção de corrente nas faixas 0-10 kA, 10-30 kA, 30-60 kA, 60-100 kA. Observa-se na Figura 5 que o disjuntor do vão 03 (Vão do Transformador Elevador TE-U3) realizou 175 (cento e setenta e cinco) interrupções de corrente, todas dentro da faixa 0-10 kA. As quantidades admissíveis de abertura do disjuntor para cada nível de corrente são especificadas pelo fabricante através da curva de vida do contato do disjuntor. O sistema de monitoramento gera um alarme, quando as quantidades de aberturas do disjuntor associada as faixas de corrente, for maior que o especificado na curva de vida do contato do disjuntor.

A segunda informação relevante da Figura 5 é o "Indicador de Desgaste" que apresenta o cálculo da soma das correntes interrompidas pelo disjuntor,

Indicador de Desgaste $\left(k A^{2} . s\right)=\sum_{j=1}^{n} I_{j}^{2} t_{j}$

onde, $\mathrm{n}$ é o número de interrupções, I é a corrente interrompida (RMS) e t é o tempo de arco. A soma das correntes interrompidas associadas às operações de abertura do disjuntor é armazenada no sistema de monitoramento e comparada com um valor limite determinado pelo fabricante. Um gráfico de barra é utilizado para o acompanhamento visual do desgaste dos contatos do disjuntor e sistema de monitoramento gera um alarme quando o "Indicador de Desgaste" atingir um valor maior que o pré-estabelecido pelo fabricante. 


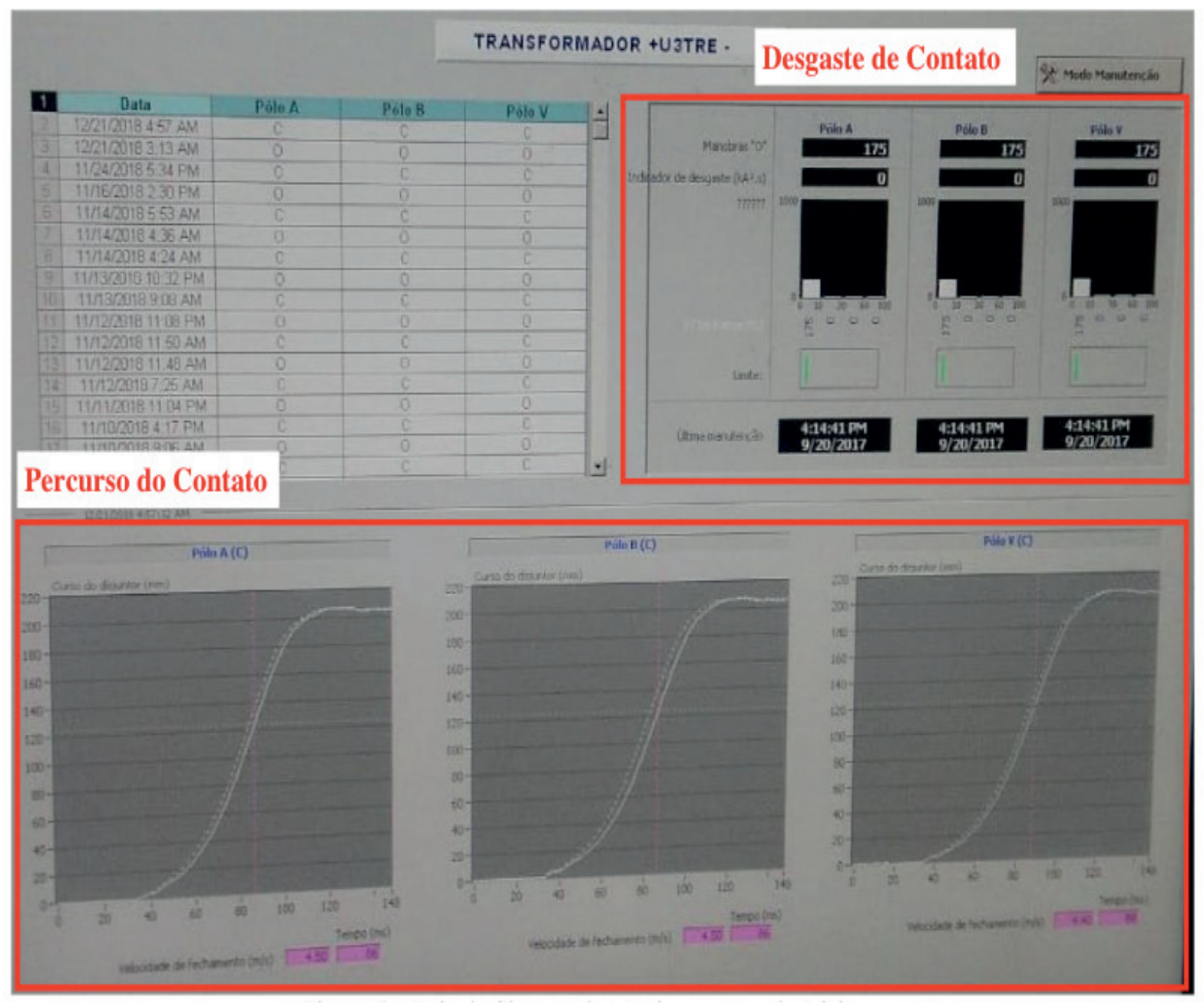

Figura 5 - Tela do Sistema de Monitoramento do Disjuntor.

\section{4 | DISCUSSÃO}

O sistema de monitoramento dos disjuntores da SIG da UHE Belo Monte entrou em operação com todas suas funcionalidades em meados de setembro de 2018, devido painel estar localizado entre os vãos 18 e 19. Dessa forma, atualmente está sendo realizado um acompanhamento do desgaste dos contatos dos disjuntores através do "Indicador de Desgaste" e do número de interrupções associadas as suas correntes.

Para avaliação da condição de desgaste de contato dos disjuntores da SIG da UHE Belo Monte, o "Indicado de Desgaste" será utilizado como indicador principal e o número de interrupção acumulado associado à corrente interrompida será utilizado como indicador secundário.

É importante ressaltar que a manutenção baseada na condição do disjuntor, especificamente relacionada ao desgaste dos contatos principais, está sendo aprimorada por fabricantes e pesquisadores. O método baseado na corrente interrompida acumulada ignora as tensões de arco, apesar do fato de que as tensões de arco realmente contribuem para o desgaste dos contatos do disjuntor.

Devido o instante inicial e final do arco elétrico serem desconhecidos quando da interrupção de corrente pelo disjuntor, o sistema de monitoramento realiza uma 
estimação do tempo de arco elétrico com base no tempo de percurso dos contatos.

Os gráficos da curva do percurso do contato, linha pontilhada da Figura 5, fornecem informações importantes relacionados ao desempenho do conjunto mecânico do disjuntor, detecção de falhas no dispositivo de amortecimento, verificação de deslocamentos excessivos dos contatos e monitoração da pressão da mola do sistema de acionamento mecânico. Durante o comissionamento de cada disjuntor foi realizado ajuste no transdutor rotativo e gerada uma "curva de referência" do percurso do contato do disjuntor, linha contínua da Figura 5 , que auxilia na análise comparativa entre as curvas.

\section{I CONCLUSÕES}

O sistema de monitoramento da SIG 500kV da UHE Belo Monte já em operação, se tornou uma ferramenta de uso das equipes de manutenção e proporcionou a adoção de uma filosofia de manutenção preditiva, permitindo assim acompanhar continuamente o desempenho e a degradação da vida útil dos disjuntores.

Os dados aquisitados e transformados em informações pelo sistema de monitoramento, determinam o momento ideal para intervenção nos disjuntores, proporcionando uma vida útil mais longa. A manutenção baseada na condição do disjuntor, utiliza métodos para diagnósticos eficazes e proporciona uma melhora na confiabilidade do equipamento, além de reduzir os custos de manutenção, pois somente após da ocorrência de alarme as causas serão analisadas.

A análise gráfica e numérica dos tempos de abertura e fechamento do disjuntor têm contribuído para detectar de forma preditiva anormalidades no conjunto mecânico do disjuntor.

O monitoramento dos contatos, por fase, do disjuntor da SIG 500kV da UHE Belo Monte, se mostrou um método prático, barato e confiável permitindo realizar com eficiência a manutenção preditiva, realizando a programação da manutenção do disjuntor com base nessa condição do desgaste de seus contatos.

\section{REFERÊNCIAS}

[1] M. Kezunovic, Z. Ren, G. Latisko, D.R. Sevcik, J. Lucey, W. Cook and E. Koch, "Automated Monitoring and Analysis of Circuit Breaker Operation", IEEE Transactions Power Delivery, Vol. 20, No. 3, pp. 1910-1918, Jul. 2005. https://doi.org/10.1109/TPWRD.2005.848466.

[2] B. Feizifar and O. Usta, "A Novel Arcing Power-Based Algorithm for Condition Monitoring of Electrical Wear of Circuit Breaker Contacts", IEEE Transactions Power Delivery (Early Access). https:// doi.org/10.1109/TPWRD.2018.2882013.

[3] IEEE Guide for Investigation, Analysis, and Reporting of Power Circuit Breaker Failures, IEEE Std C37.10-2011, 2010.

[4] IEEE Guide for the Selection of Monitoring for Circuit Breakers, IEEE Std C37.10.1-2000, 2001. 
[5] D.C.P. Araujo, M.E.G. Alves and F.A. Ribeiro, "Sistema de Monitoração de Disjuntores da SE Rio Verde - Uma Análise da Funcionalidade e Desempenho", in XXI Seminário Nacional de Produção e Transmissão de Energia Elétrica, Florianópolis, Out. 2011.

[6] J.R. Li, L.P Khoo and S.B Tor, "Generation of possible multiple components disassembly sequence for maintenance using a disassembly constraint graph", International Journal of Production Economics, Vol. 102, No. 1, pp. 51-65, Jul. 2006. https://doi.org/10.1016/j.ijpe.2005.01.012.

[7] G. Waeyenbergh and L. Pintelon, "Maintenance concept development: a case study", International Journal of Production Economics, Vol. 89, No. 3, pp. 395-405, Jun. 2004. https://doi.org/10.1016/j. ijpe.2003.09.008.

[8] S.O. Duffuaa, M. Ben-Daya, K.S. Al-Sultan and A.A. Andijani, "A generic conceptual simulation model for maintenance systems", Journal of Quality in Maintenance Engineering, Vol. 7, No. 3, pp. 207-219, 2001. https://doi.org/10.1108/13552510110404512.

[9] R. Ahmad and S. Kamaruddin, "An overview of time-based and condition-based maintenance industrial application", Computers \& Industrial Engineering, Vol. 63, No. 1, pp. 135-149, Aug. 2012. https://doi.org/10.1016/j.cie.2012.02.002.

[10] C. Jones, CIGRE working group 13.09 - monitoring and diagnostic techniques for switching equipment. Proceedings of the IEEE Power Engineering Society Transmission and Distribution Conference, pp. 1083-1087, 2001. https://doi.org/10.1109/TDC.2001.971403.

[11] CIGRE working group A3.12. Failure survey on circuit breaker control systems summary report for Electra. Electra, Vol. 216, pp. 48-59, 2004.

[12] M. Braunovic, V.V. Izmailov, A.E. Naumov and M.V. Novoselova, "Estimation of remaining lifetime of power connections using infrared thermography". Proceedings of the IEEE Holm Conference on Electrical Contacts, pp. 234-239, 2009. https://doi.org/10.1109/HOLM.2009.5284397.

[13] R.T. Souza and E.G. Costa, "Analysis of the correlation between the level of contact degradation and the dynamic resistance curve in circuit breakers". Journal of Energy and Power Engineering, Vol. 8, pp. 1104-1111, Jun. 2004. https://dx.doi.org/10.17265/1934-8975/2014.06.017.

[14] Z. Stanisic and R. Neimanis, "A new ultra lightweight method for static and dynamic resistance measurements. Proceedings of the IEEE International Symposium on Electrical Insulation, pp. 1-4, 2010. https://doi.org/10.1109/ELINSL.2010.5549820.

[15] H.K. Hoidalen and M. Runde, "Continuous monitoring of circuit breakers using vibration analysis", IEEE Transactions Power Delivery, Vol. 20, No. 4, pp. 2458-2465, Oct. 2005. https://doi.org/10.1109/ TPWRD.2005.855486.

[16] Y.P Meng, S. Jia and M. Rong, "Condition monitoring of vacuum circuit breakers using vibration analysis", Proceedings of the International Symposium on Discharges and Electrical Insulation in Vacuum, pp. 341-344, 2004. https://doi.org/10.1109/DEIV.2004.1422616.

[17] S. Natti and M. Kezunovic, "Assessing circuit breaker performance using condition-based data and Bayesian approach", Electric Power Systems Research, Vol. 81, No. 9, pp. 1796-1804, Jun. 2011. https://doi.ogr/10.1016/j.epsr.2011.04.010.

[18] Y. Zheng, "A model-based fault detection framework for vacuum circuit breaker by trip coil analysis", Journal of software, Vol. 9, No. 1, pp. 251-257, Jan. 2014. https://doi.org/10.4304/ jsw.9.1.251-257.

[19] A.A. Razi-Kazemi, M. Vakilian, K. Niayesh and M. Lehtonen, "Circuit-breaker automated failure tracking based on coil current signature", "IEEE Transactions Power Delivery, Vol. 29, No. 1, pp. 
[20] P. Dehghanian, M. Kezunovic, G. Gurrala, Y. Guan, "Security-based circuit breaker maintenance management", Proceedings of the IEEE Power and Energy Society General Meeting, pp. 1-5, 2013. https://doi.org/10.1109/PESMG.2013.6672293.

[21] A. Janssen, D. Makareinis and C.E. Sölver, "International surveys on circuit-breaker reliability data for substation and system studies", IEEE Transactions Power Delivery, Vol. 29, No. 2, pp. 808-814, Apr. 2014. https://doi.og/10.1109/TPWRD.2013.2274750.

[22] P. Westerlund, P. Hilber, T. Lindquist and S. Kraftnat S, "A review of methods for condition monitoring, surveys and statistical analyses of disconnector and circuit breakers", Proceedings of the International Conference on Probabilistic Methods Applied to Power Systems, pp. 1-6, 2014. https:// doi.org/10.1049/cp.2013.0668.

[23] J-M. Wang, M-T. Yang, "Realization of circuit breaker condition-based main-tenance using optimal contact wear equation by the modified NM-PSOalgorithm", International Transactions on Electrical Energy Systems, Vol. 26, No. 3, pp. 627-640, Jun. 2015. https://doi.org/10.1002/etep.2100. 


\section{CAPÍTULO 13}

\section{COMPARAÇÃO ENTRE TRANSFORMADORES A ÓLEO E A SECO}

Data de submissão: 31/10/2019

Data de aceite: 03/01/2020

\section{Marco Antonio Ferreira Finocchio} Universidade Tecnológica Federal do Paraná, Departamento Acadêmico de Engenharia Elétrica

(DAELE)

Cornélio Procópio - PR

http://lattes.cnpq.br/ 8619727190271505

Márcio Mendonça

Universidade Tecnológica Federal do Paraná,

Departamento Acadêmico de Engenharia Elétrica

(DAELE)

Cornélio Procópio - PR

http://lattes.cnpq.br/ 5415046018018708

Lucas de Oliveira Antunes Universidade Tecnológica Federal do Paraná, Departamento Acadêmico de Engenharia Elétrica

(DAELE)

Cornélio Procópio - PR

http://lattes.cnpq.br/ 4443266718969346

Jeferson Gonçalves Ferreira Universidade Tecnológica Federal do Paraná,

Programa de Pós-Graduação em Engenharia Mecânica (PPGEM)

Cornélio Procópio - PR

http://lattes.cnpq.br/ 4013858734001440
RESUMO: O crescente consumo de energia elétrica conduziu ao aumento na quantidade de transformadores instalados. Gerando um crescimento de consumo energético em todos os setores das atividades produtivas. Mas um fator passa despercebido, ou seja, qual o tipo de transformador será utilizado, pois essa preferência pode conjecturar num impacto ambiental. Geralmente os transformadores eleitos são os a óleo por desconhecimento tecnológico de soluções ecológicas mais corretas. Este artigo sugere a utilização de transformadores a seco no lugar dos transformadores a óleo, como uma alternativa ambiental. Os transformadores a seco apresentam menores dimensões, sendo indicado para instalações abrigadas que exigem segurança e confiabilidade, e sua manutenção é mais simples não oferecendo riscos ao meio ambiente que os transformadores a óleo.

PALAVRAS-CHAVE: Transformador a óleo, Transformador a seco, Isolamento.

\section{COMPARISON OF TRANSFORMERS OIL AND DRY}

ABSTRACT: The increasing consumption of electricity led to an increase in the amount of installed transformers. Generating growth of energy consumption in all sectors of productive activities. But a factor goes unnoticed, or what 
type of processor is used, as this can only conjecture preferably an environmental impact. Usually elected transformers are oil by technological ignorance more correct ecological solutions. This article suggests the use of dry transformer in place of transformer oil, as an alternative. The dry-type transformers have smaller, being suitable for indoor installations that require security and reliability, and maintenance is simpler not offering risk to the environment than oil transformers.

KEYWORDS: Transformer oil, Dry transformer, Insulation.

\section{I INTRODUÇÃO}

O transformador é um instrumento usado para registrar ou mudar a energia elétrica de um nível de tensão para outro, seja superior ou inferior, mantendo a frequência constante, por meio da ação de campo magnético. Ele também é relevante para o transporte da energia de um local para outro por conta da sua eficiência, transmissão e rapidez (CHAPMAN, 2012).

No cenário atual, tanto grandes indústrias, como empresas de distribuição de energia, shopping centers, hospitais, aeroportos e metrôs precisam de um número considerável de transformadores de tensão. Com a larga utilização de energia elétrica em edifícios comerciais, shoppings, estádios de futebol, estações de metrô e trem necessita-se que os transformadores sejam instalados o mais próximo possível das cargas permitindo também uma redução de custos com cabos de alimentação, melhor regulação de tensão e proteções contra fogo (STIGANT, FRANKLIN, 1983). Porém, para estas instalações internas é recomendada a utilização de transformadores secos, pois não possuem óleo, apresentam dimensões reduzidas, baixa necessidade de manutenção, simplicidade de instalação e ausência do risco de explosão (SANTOS, COVACIC, GEROMEL, 2011).

Com o objetivo de responder a esta demanda, tais empresas têm a sua disposição dois tipos de transformadores, os isolados a óleo e os transformadores isolados a seco.

Estes dois tipos de transformadores possuem grandes diferenças que superam fatores econômicos, como sua manutenção, local adequado para a instalação e, os impactos ambientais, são critérios a se considerar na escolha. Mas, geralmente a maioria das empresas predomina tão somente comparação entre os custos financeiros para tomada de decisão. Outros fatores deveria compor o rol de decisão somado a questão econômica tais como, os possíveis impactos que uma escolha inadequada poderia gerar em termos sociais e ambientais. Considerando isto, o presente artigo procura contribuir através da comparação entre os dois tipos de transformadores, primeiramente às empresas que precisam realizar a escolha de maneira consciente e lúcida, e em segundo momento, à sociedade que deve estar atenta aos impactos ambientais que esta escolha possa gerar. 


\section{I COMPARATIVO TÉCNICO}

Nesse estudo, foram tratados os dados das cinco maiores empresas para a comparação dos dois tipos de transformadores nos aspectos manutenção, vida útil, obras civis, segurança, proteção, restrições ambientais, ambiente e certificação ISO 14000 e NR-10, a qual está vinculada com a gestão ambiental em empresas. As vantagens e desvantagens dos dois tipos de isolação são apresentadas na Tabela 1 conforme (FINOCCHIO, 2010).

\begin{tabular}{|c|c|c|}
\hline \multirow[t]{2}{*}{ Item } & \multicolumn{2}{|c|}{ Material isolante } \\
\hline & Óleo isolante & Resina epóxi (seco) \\
\hline Manutenção & $\begin{array}{l}\text { Deve ser periódica. Necessitando } \\
\text { de substituições de óleo isolante, } \\
\text { juntas, guarnições e acessórios. }\end{array}$ & Isento \\
\hline Vida útil & 30 anos & 30 anos ou superior \\
\hline Obras civis & $\begin{array}{l}\text { Demanda de paredes e portas } \\
\text { corta-fogo, sistema contra incêndio } \\
\text { e poço para recolhimento de fluido } \\
\text { em caso de vazamento. }\end{array}$ & Não demanda obras especiais. \\
\hline Segurança & $\begin{array}{l}\text { Risco de explosão e incêndio, } \\
\text { vazamentos e contaminação do } \\
\text { ambiente. }\end{array}$ & $\begin{array}{l}\text { Não explode, não alimenta ou } \\
\text { propaga incêndios. }\end{array}$ \\
\hline Proteção & $\begin{array}{l}\text { Vários acessórios para proteção e } \\
\text { controle. }\end{array}$ & $\begin{array}{l}\text { Apenas sensores de temperatura } \\
\text { para alarme, desligamento e } \\
\text { medição de temperatura. }\end{array}$ \\
\hline $\begin{array}{l}\text { Restrições } \\
\text { ambientais }\end{array}$ & $\begin{array}{l}\text { Risco de contaminação pelo } \\
\text { vazamento do liquido isolante. }\end{array}$ & Sem restrições \\
\hline Ambiente & $\begin{array}{l}\text { São afetados pela umidade, } \\
\text { salinidade, oxidante, etc. }\end{array}$ & $\begin{array}{l}\text { Insensível à umidade e outros } \\
\text { fatores ambientais }\end{array}$ \\
\hline $\begin{array}{l}\text { Certificações } \\
\text { ISSO } 14000 \text { e } \\
\text { NR10 }\end{array}$ & $\begin{array}{c}\text { Recomenda cuidados com este tipo } \\
\text { de equipamento. Tendência a se } \\
\text { evitar esta execução. }\end{array}$ & $\begin{array}{c}\text { Não oferecer riscos ao ser } \\
\text { humano e ao meio ambiente. }\end{array}$ \\
\hline
\end{tabular}

Tabela 1 - Comparação entre transformadores.

Em pesquisa recente revelou que $89 \%$ das pessoas conhecem o transformador a óleo, e apenas $11 \%$ o a seco. Observou-se ainda que $26 \%$ das pessoas conhecem os riscos que transformadores podem gerar (CAVALHEIRO, PAVAN, 2013).

A Figura 1 são apresentados os dois tipos de transformadores de 300kVA. Na Figura 1 (b), a cor vermelha se deve ao pigmento adicionado a que envolve as suas bobinas. Essa resina é constituída de pó de quartzo que diminui a quantidade de metal no transformador fazendo com que sua massa, volume e susceptibilidade a oxidação diminuam. O transformador da Figura 1 (a) é um equipamento a óleo compostos seu núcleo basicamente de metal. Além de todo o metal usado na estrutura do transformador, há uma grande quantidade extra de metal utilizada na fabricação dos radiadores dos transformadores a óleo. 


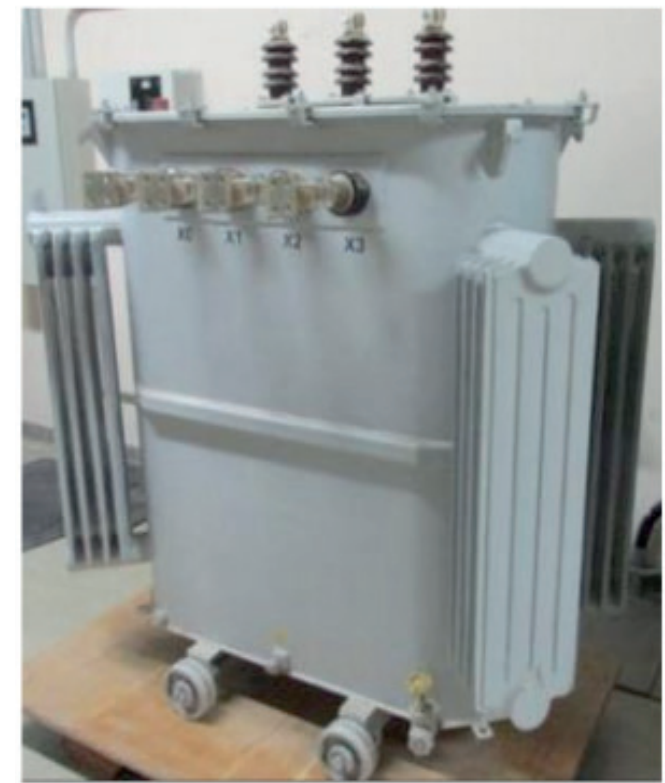

(a)

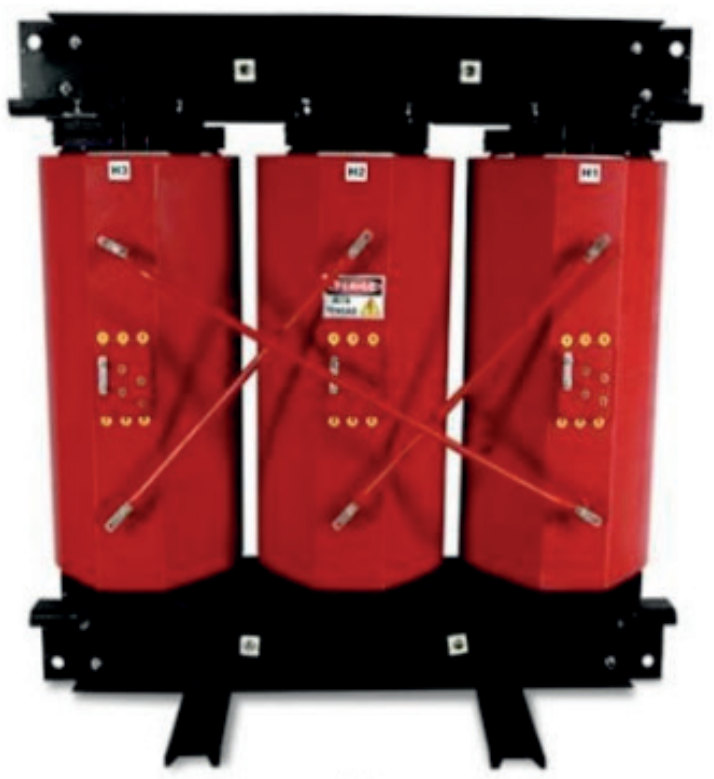

(b)

Figura 1 - Transformadores 300kVA: (a) a óleo e (b) a seco.

Os transformadores apresentam alto rendimento, devido às baixas perdas em relação à potência elétrica nominal. Na Tabela 2 são mostrados os valores típicos de rendimento para transformadores trifásicos respectivamente, os imersos em fluido isolante e a seco (GEROMEL, 2003). Ainda referente à Tabela 2 os rendimentos encontram-se classificados de acordo com a potência e a classe de tensão do equipamento (ABNT, 2014) e (ABNT, 2010).

\begin{tabular}{|c|c|c|c|c|c|c|c|c|}
\hline \multicolumn{9}{|c|}{ Transformadores Trifásicos imersos em óleo } \\
\hline \multirow{2}{*}{$\begin{array}{c}\text { Classe } \\
(\mathrm{kV})\end{array}$} & \multicolumn{8}{|c|}{ Potência (kV) } \\
\hline & 15 & 30 & 45 & 75 & 112,5 & 150 & 225 & 300 \\
\hline 15 & 96,52 & 97,07 & 97,35 & 97,66 & 97,88 & 98,04 & 98,15 & 98,27 \\
\hline 24,2 & 96,08 & 96,74 & 96,06 & 97,40 & 97,65 & 97,81 & 98,01 & 98,15 \\
\hline \multicolumn{9}{|c|}{ Transformadores Trifásicos a seco } \\
\hline \multirow{2}{*}{$\begin{array}{c}\text { Classe } \\
(\mathrm{kV})\end{array}$} & \multicolumn{8}{|c|}{ Potência (kV) } \\
\hline & 75 & 112,5 & 150 & 225 & 300 & 500 & 750 & 1000 \\
\hline 15 & 97,68 & 97,91 & 98,05 & 98,30 & 98,39 & 98,52 & 98,76 & 98,80 \\
\hline 24,2 & 97,40 & 97,91 & 97,94 & 98,00 & 98,23 & 98,44 & 98,72 & 98,74 \\
\hline
\end{tabular}

Tabela 2 - Rendimentos típicos para transformadores trifásicos.

Os valores de rendimentos apresentados na Tabela 2 consideram o transformador operando com $100 \%$ de sua carga nominal e à temperatura de $115^{\circ} \mathrm{C}$ (FINOCCHIO, 2010).

A Figura 3 representam os rendimentos percentuais médios de um lote de 30 transformadores para cada uma das seguintes potências: 75kVA, 112,5kVA, 150kVA, 225kVA e 300kVA. 


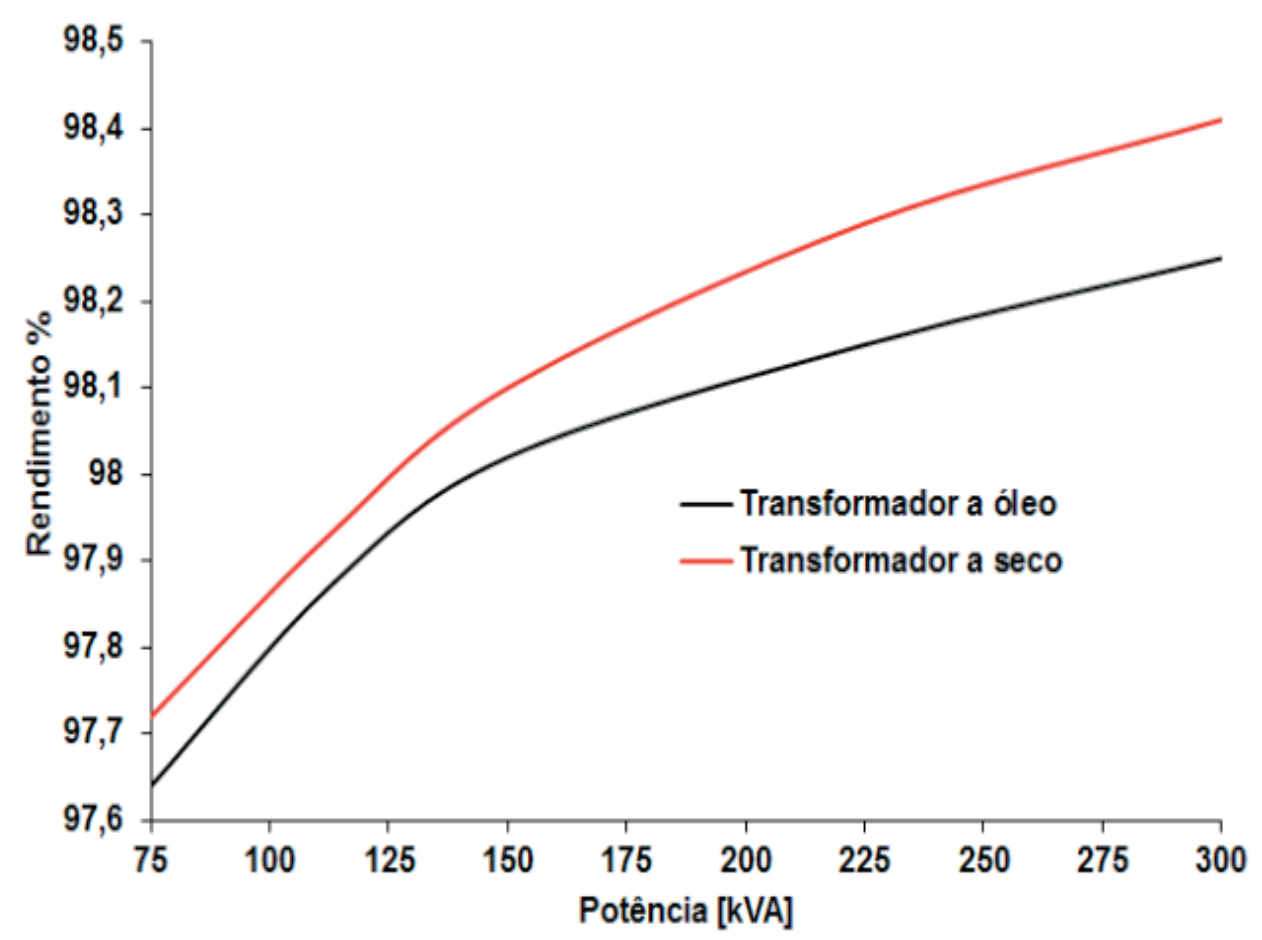

Figura 3 - Valores de rendimento \% de transformadores.

A essência de um sistema isolante depende, do tempo e da temperatura que o mesmo está exposto. A conexão entre tempo e temperatura e seus efeitos na isolação é estudado a décadas. Em 1930, Montsinger disse que a vida útil do sistema isolante se reduz à metade para cada aumento de $100 \mathrm{C}$ da temperatura da isolação (MONTISINGER, 1913).

Em (FUCHS, ROESLER, KOVACS, 1988), a estimativa da vida útil dos materiais isolantes é feita através da teoria clássica de "Arrhenius-Darkin". Que afirma que a vida útil da isolação está ligada à temperatura de serviço, e ao tempo de exposição da mesma. O fenômeno de deterioração do isolante baseia-se num processo químico, onde uma oxidação lenta e gradual causa o endurecimento do verniz isolante, resina epóxi ou óleo.

Desta forma, quebradiço, levando à perda da rigidez dielétrica e da flexibilidade mecânica. Isto retrata o envelhecimento gradativo do isolante no tempo, que vai perdendo suas propriedades isolantes (PIERCE, 1994), até não mais suporta a tensão aplicada e ocorrer um curto-circuito entre as partes energizadas.

Segundo (PACHECO, 2002), a degradação térmica de materiais orgânicos e inorgânicos de um equipamento elétrico, pode ser avaliada pela equação da taxa de reação formulada por Arrhenius, dada pela Equação 1:

$$
\frac{d E_{V u}}{d t}=A \cdot e^{\frac{-E}{k \cdot T}}
$$


onde:

$\frac{d E_{V u}}{d t}$ : taxa de redução da vida útil em relação ao tempo;

$E_{v u}$ : vida útil do isolamento do enrolamento;

$t$ : tempo de vida em anos;

$A$ : constante do material;

k: constante de Boltzann igual a 0,8617.10-4[eV];

$T$ : temperatura absoluta do ponto mais quente em graus Celsius;

$E$ : energia de ativação da reação de envelhecimento [eV].

A Figura 4 sintetiza diminuição da vida útil do transformador de acordo com o aumento a temperatura. Comprovando que o transformador a seco apresenta uma vida útil maior.

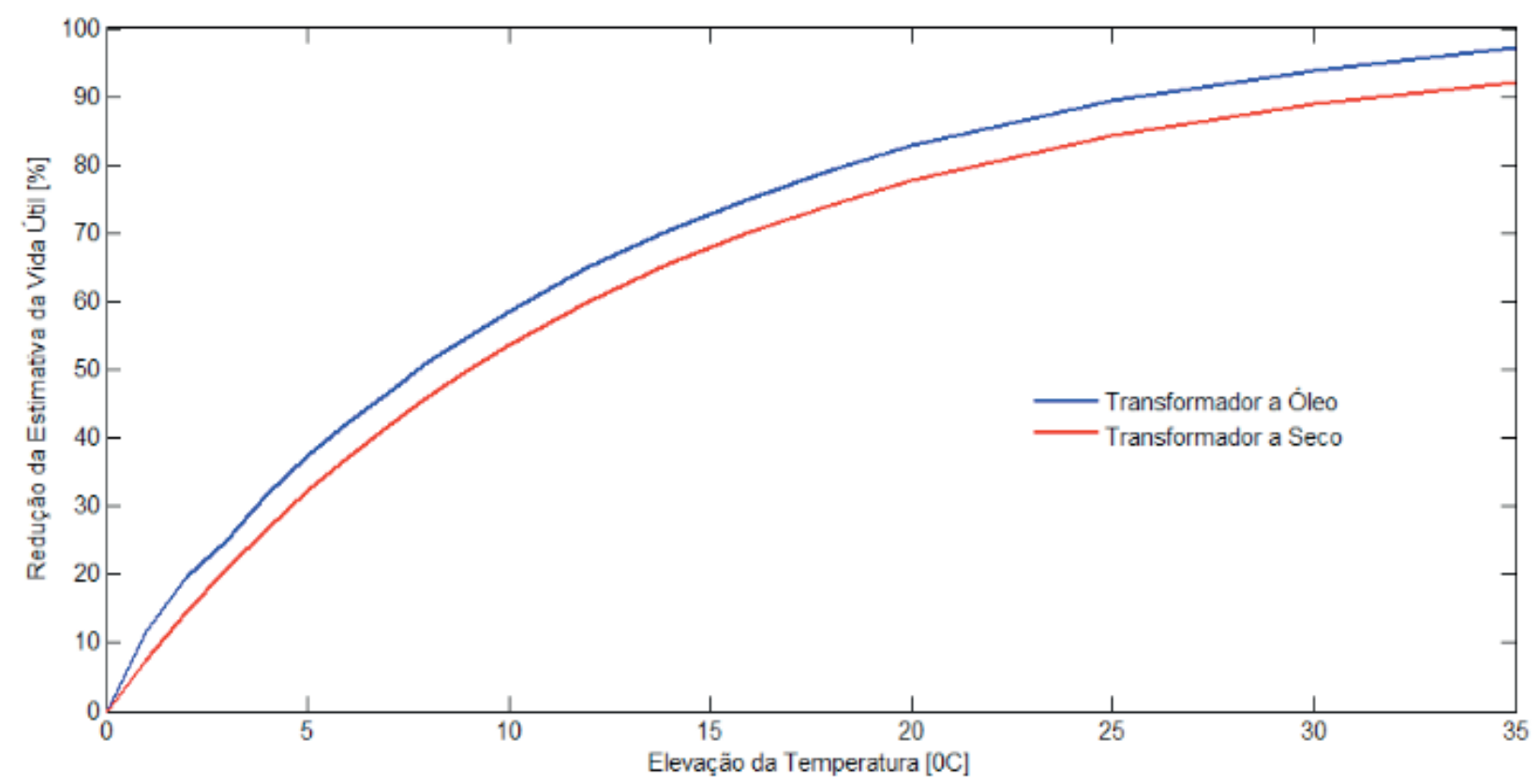

Figura 4 - Redução de vida útil com adicional de temperatura.

A Equação 1 fornece valores absolutos da vida útil de certo sistema isolante. Reconhece-se que o cálculo da vida útil a partir da temperatura de operação da isolação é trabalhoso. O motivo disto está na necessidade de se aguardar um longo período de tempo, até que a isolação sofra a primeira degradação, para poder avaliar o tempo de vida da mesma.

Evidências apontam que os transformadores a óleo não são perigosos apenas por causa do risco de explosão, mas também pelo risco iminente de vazamento de óleo e contaminação do ambiente. Até inicio dos anos 80, o óleo utilizado em transformadores era o Ascarel que foi proibido em 1981. Isto por apresentar na sua composição PCB's (Bifenila Policloradas) que pode causar lesões dermatológicas, alterações no fígado e rins, alterações psíquicas, perda da libido e cancerígenos (FINOCCHIO, 1997). Atualmente são utilizados outros óleos isolantes como silicone, óleo isolante mineral. Mesmo esses óleos oferecem risco de vazamentos, explosões e incêndios. 


\section{I CONSIDERAÇÕES FINAIS}

Atualmente, as empresas procuram a ISO-14001, que é uma norma internacionalmente reconhecida que define o que deve ser feito para estabelecer um Sistema de Gestão Ambiental (SGA). Portanto, é importante os requisitos e condições mínimas objetivando a implementação de medidas de controle e sistemas preventivos, para garantir a segurança e a saúde dos trabalhadores que, direta ou indiretamente, interajam em instalações elétricas e serviços com eletricidade. Desta forma vê-se que as empresas têm optado por transformadores a seco fazendo com que a escolha do equipamento transcenda apenas a questão de custo.

Quanto a segurança, o transformador a óleo possui maior suscetibilidade a falhas, oferecendo risco de explosão. Devido ao próprio funcionamento do transformador, o óleo isolante passa a conter alta concentração de gases dissolvidos, que se expandem rapidamente pelo corpo interno do transformador. Devido à presença do fluxo magnético devido a passagem de corrente elétrica, há a presença de calor dissipado pelo equipamento, que pode gerar risco de explosão destes gases.

Para o transformador a óleo, são gerados gastos com projeto, construção e montagem de alvenaria para compartimento separado por paredes corta-fogo, de bacia de contenção de óleo, de estruturas que permitam a coleta de eventuais vazamentos, com a construção de poço de contenção coletivo e com manutenção do equipamento.

A alternativa para substituição dos transformadores a óleo é os a seco, que não tem risco de vazamento, incêndio ou explosões, pois não tem material isolante liquido e são fabricados com material auto extinguível. Os transformadores a seco apresentam alta confiabilidade por terem maior vida útil e rendimento superior ao a óleo. Portanto, indicados para áreas com a presença de pessoas, como indústrias em geral, edifícios, prédios residenciais, hospitais, shopping centers.

\section{REFERÊNCIAS}

ASSOCIAÇÃO BRASILEIRA DE NORMAS TÉCNICAS. NBR 5356-3: Transformadores de Potência. Rio de Janeiro, 2014.

ASSOCIAÇÃO BRASILEIRA DE NORMAS TÉCNICAS. NBR 5440: Transformadores de Distribuição. Rio de Janeiro, 2010.

CAVALHEIRO, RENATO D.; PAVAN, ANDERSON D.. Estudo Comparativo entre Transformadores a Óleo e a Seco. Instituto de Biologia Animal. Campinas: UNICAMP, 2013.

CHAPMAN, S. J. Electric Machinery Fundamentals. 5ª ed. Nova York: McGraw-Hill, 2012.

DOS SANTOS, Elton Jeser Diniz; COVACIC, Márcio Roberto; GEROMEL, Luiz Henrique. Análise do Encapsulamento de Bobinas de Alta Tensão Utilizando Medição de Descargas parciais e Sistemas Inteligentes. DINCON 2011: $11^{\text {a }}$ Conferência Brasileira de Dinâmica, Controle e Aplicações. Águas de Lindóia, São Paulo, 2011.

GEROMEL, Luiz Henrique. Aplicação de Sistemas Inteligentes em Projetos de Transformadores de Potência. Tese de Doutorado. Campinas: UNICAMP, 2003. 
FINOCCHIO, Marco Antonio Ferreira. Determinação da Temperatura de Enrolamentos de transformadores a Seco e de suas Perdas Totais Baseado em Redes Neurais Artificiais. Dissertação de Mestrado. Universidade Estadual de Londrina. Londrina, 2010.

FINOCCHIO, Marco Antonio Ferreira. Ascarel um Risco Ocupacional e suas Alternativas de Substituição. Monografia de Pós-graduação. Universidade Estadual de Londrina. Londrina, 1997.

FUCHS, E. F.; ROESLER, D. J.; KOVACS, K. P., "Aging of Electrical Appliances due to Harmonics of the Power Systems Voltage", IEEE Transactions on Power Delivery, vol. PWRD-1 no 3, July 1988.

MONTSINGER, V. M., "Loading Transformers by Temperature", AIEE Transaction, vol. 32, 1913.

PIERCE, Linden W.. Thermal Considerations in Specifying Dry-Type Transformers. IEEE Transactions on Industry Applications, Vol. 30, no 4, July/August 1994.

PACHECO, Cláudio R.. Modelagem e Análise do Desempenho Térmico de Cabos Elétricos Isolados no Contexto da Qualidade da Energia Elétrica. Tese de Doutorado. Uberlândia: UFU, Abril/2002.

STIGANT, A. S.; FRANKLIN, J. S. C. The J\&P Transformer Book. Butterworth-Heinemann Ltd, Oxford, 1983. 


\section{OTIMIZAÇÃO POR ENXAME DE PARTÍCULAS APLICADA A CONTROLADORES DE CORRENTE PARA INVERSORES CONECTADOS À REDE}

Data de aceite: 03/01/2020

\section{Lucas Cielo Borin}

Universidade Federal de Santa Maria (UFSM)

Santa Maria - RS

Iury Cleveston

Universidade Federal de Santa Maria (UFSM)

Santa Maria - RS

Caio Ruviaro Dantas Osorio

Universidade Federal de Santa Maria (UFSM)

Santa Maria - RS

Gustavo Guilherme Koch

Universidade Federal de Santa Maria (UFSM)

Santa Maria - RS

Fabricio Moretto Bottega

Universidade Federal de Santa Maria (UFSM)

Santa Maria - RS

Vinicius Foletto Montagner

Universidade Federal de Santa Maria (UFSM)

Santa Maria - RS

RESUMO: Este trabalho apresenta o projeto de ganhos de controle por realimentação de estados obtidos por meio de otimização por enxame de partículas, aplicado em inversores monofásicos conectados à rede por meio de um filtro LCL. O controle é projetado off-line considerando incertezas na impedância de rede, atraso na implementação do sinal de controle e múltiplos controladores ressonantes. O algoritmo de otimização fornece os ganhos do controlador a partir da minimização de uma função objetivo baseada nos autovalores do sistema em malha fechada. O ganho fornecido garante resultados satisfatórios, nos domínios do tempo e da frequência, mostrando a conformidade das correntes de rede com a norma IEEE 1547 e a viabilidade da técnica para aplicações no controle de corrente de inversores.

PALAVRAS-CHAVE: Conversores conectados à rede, filtro LCL, otimização por enxame de partículas.

\section{PARTICLE SWARM OPTIMIZATION APPLIED TO CURRENT CONTROLLERS FOR GRID- CONNECTED INVERTERS}

ABSTRACT: This work presents the design of state feedback control gains obtained by means of particle swarm optimization, applied to single phase grid-connected inverters through an LCL filter. The control is designed off-line considering uncertainties in the grid impedance, a delay in the implementation of the control signal and multiple resonant controllers. The optimization algorithm provides the control gains from minimizing an objective function based on the closed-loop system eigenvalues. The control gains provided here ensure suitable results, in the time and frequency domains, showing the 
compliance of the grid currents with the IEEE 1547 Standard and the viability of the technique for applications in the current control of inverters.

KEYWORDS: Grid-connected inverters, LCL filter, particle swarm optimization.

\section{I INTRODUÇÃO}

Inversores conectados à rede são importantes no cenário de geração baseada em energias renováveis permitindo, por exemplo, controlar o fluxo de potência entre a fonte primária e a rede (TEODORESCU et al., 2011, MA, 2013; KJAER et al., 2005; ERICKSON, 1997). Neste contexto, um problema importante é o controle das correntes injetadas na rede, que devem respeitar limites rigorosos de distorção harmônica (IEEE Std., 2011). Dentre as estratégias de amortecimento ativo, destacam-se tanto as baseadas no domínio da frequência quanto as baseadas no domínio do tempo, como, por exemplo, os controladores por realimentação de estados (BLAABJERG et al., 2006; LISERRE et al., 2006; MACCARI, 2014; LIU, 2018). Um ponto comum ao projeto de controladores nesta aplicação é a necessidade de levar em consideração um compromisso adequado entre respostas transitórias rápidas, baixa distorção das correntes de rede em regime permanente, e um sinal de controle com limitações.

O algoritmo de otimização por enxame de partículas (do inglês, Particle swarm optimization - PSO), proposto em Eberhart e Kennedy (1995), é um exemplo de metaheurística utilizada em problemas de engenharia. Trata-se de um algoritmo simples comparado a outros algoritmos bio-inspirados, como algoritmos genéticos, por exemplo, modelando um sistema como uma população auto-organizada de indivíduos autônomos que interagem entre si e com seu ambiente (FLASíNSKI, 2016). Sobre aplicações em conversores de potência, em Veerachary e Saxena (2015), utiliza-se o PSO para otimizar componentes do estágio de potência de um conversor CC-CC de quarta ordem. Em da Silva et al. (2016), é ilustrada a eficiência do PSO para o controle de um sistema fotovoltaico monofásico conectado à rede. Já em Altinoz e Erdem (2010) e Emami et al. (2008), utiliza-se o PSO para otimizar parâmetros de um controlador proporcional integral derivativo (PID) para conversores Buck, e em Banerjee et al. (2017) na otimização para um conversor Boost intercalado com controlador TipoIII ideal. Nota-se que a utilização do algoritmo PSO para o projeto de controladores robustos aplicados especificamente a inversores conectados à rede é um ponto que merece maior investigação.

O presente trabalho apresenta a utilização do algoritmo PSO para obtenção de controladores por realimentação de estados para uma aplicação em conversores conectados por meio de filtro LCL. A incerteza na indutância de rede, o atraso de implementação digital do sinal de controle e controladores ressonantes de dimensão arbitrária são levados em conta no projeto. Em um estudo de caso, que inclui simulações em tempo real, mostra-se que os ganhos de controle fornecidos pelo PSO garantem a estabilidade robusta e bom desempenho em termos de rastreamento de 
referências senoidais frente a incertezas paramétricas, provendo correntes de rede em conformidade com os limites prescritos pela norma IEEE 1547 (IEEE Std., 2011).

\section{I MODELAGEM}

Considere o inversor conectado à rede por meio do filtro LCL, mostrado na Figura 1.

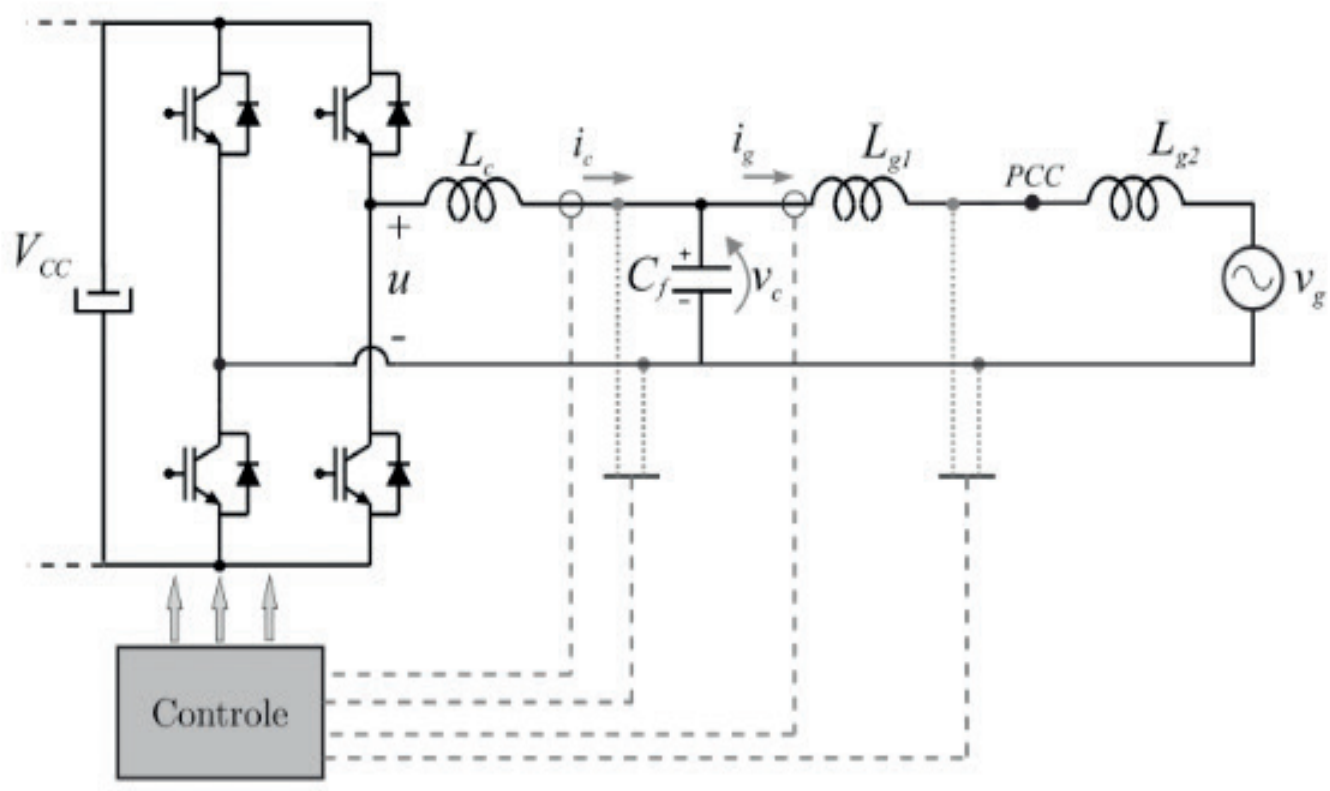

Figura 1. Inversor monofásico conectado à rede por meio de um filtro LCL.

Note que a rede neste caso é predominantemente indutiva. A indutância da rede, $L_{g 2}$, é suposta incerta e pertencente a um intervalo real $\mathcal{P}$ cujos extremos são conhecidos, representando a operação desde uma condição de impedância máxima até uma condição de impedância mínima.

No domínio do tempo contínuo, a planta da Figura 1 pode ser modelada no espaço de estados como

$$
\begin{aligned}
& \dot{x}=A_{c} x+B_{u c} u+B_{w c} v_{g} \\
& y=C x
\end{aligned}
$$

em que representa o vetor de estados, $u$ representa o sinal de controle, $v_{g}$ representa um distúrbio (tensão de rede), y é a saída a ser controlada (corrente de rede) e as demais matrizes são dadas por 


$$
A_{c}=\left[\begin{array}{ccc}
0 & -\frac{1}{L_{c}} & 0 \\
\frac{1}{C_{f}} & 0 & -\frac{1}{C_{f}} \\
0 & \frac{1}{L_{g 1}+L_{g 2}} & 0
\end{array}\right], B_{u c}=\left[\begin{array}{c}
\frac{1}{L_{c}} \\
0 \\
0
\end{array}\right], B_{w c}=\left[\begin{array}{c}
0 \\
0 \\
-\frac{1}{L_{g 1}+L_{g 2}}
\end{array}\right], C=\left[\begin{array}{lll}
0 & 0 & 1
\end{array}\right], x=\left[\begin{array}{c}
i_{c} \\
v_{c} \\
i_{g}
\end{array}\right]
$$

Objetivando a aplicação de uma técnica de controle digital, pode-se escrever um modelo discretizado da planta como (ÂSTRÖM, WITTENMARK, 2013)

$$
\begin{aligned}
& x(n+1)=A x(n)+B_{u} u(n)+B_{w} v_{g}(n) \\
& y(n)=C x(n)
\end{aligned}
$$

sendo que, para um período de discretização $T_{s}$ suficientemente pequeno, as matrizes discretas podem ser representadas por

$$
A=I+A_{c} T_{s}, B_{u}=B_{u c} T_{s}, B_{w}=B_{w c} T_{s}
$$

Adicionalmente, para a implementação do controle em um processador digital de sinais e para garantir rastreamento de referências senoidais, com rejeição de distúrbios com harmônicas, utilizam-se, respectivamente, um atraso na ação de controle e controladores ressonantes de dimensão arbitrária, levando à descrição (MACCARI et al., 2014)

$$
\begin{aligned}
x(n+1)= & A x(n)+B_{u} \phi(n)+B_{w} v_{g}(n) \\
\phi(n+1)= & u(n) \\
\xi(n+1)= & R \xi(n)+T\left(i_{r e f}(n)-C x(n)\right)
\end{aligned}
$$

em que $\phi$ representa o sinal de controle implementado com atraso, $i_{\text {ref }}$ é a referência para a corrente de rede, $\xi, T$ e $R$ representam, respectivamente, os estados internos e as matrizes dos controladores ressonantes.

O sistema aumentado (3)-(5) pode ser escrito como 


$$
\begin{aligned}
& {\left[\begin{array}{l}
x(n+1) \\
\phi(n+1) \\
\xi(n+1)
\end{array}\right]=\left[\begin{array}{ccc}
A & B_{u} & 0 \\
0 & 0 & 0 \\
-T C & 0 & R
\end{array}\right]\left[\begin{array}{l}
x(n) \\
\phi(n) \\
\xi(n)
\end{array}\right]+\left[\begin{array}{l}
0 \\
1 \\
0
\end{array}\right] u(n)+\left[\begin{array}{c}
B_{w} \\
0 \\
0
\end{array}\right] v_{g}(n)+\left[\begin{array}{l}
0 \\
0 \\
T
\end{array}\right] i_{r e f}(n)} \\
& y(n)=\left[\begin{array}{lll}
C & 0 & 0
\end{array}\right]\left[\begin{array}{l}
x(n) \\
\phi(n) \\
\xi(n)
\end{array}\right]
\end{aligned}
$$

ou, de forma mais compacta, como

$$
\begin{aligned}
& \rho(n+1)=A_{\text {aum }} \rho(n)+B_{\text {uaum }} u(n)+B_{\text {gaum }} v_{g}(n)+B_{\text {raum }} i_{r e f}(n) \\
& y(n)=C_{\text {aum }} \rho(n)
\end{aligned}
$$

A lei de controle por realimentação de estados a ser utilizada é dada por

$$
u(n)=K \rho(n)
$$

Para um estudo de caso, são considerados os parâmetros da planta vistos na Tabela 1 (MACCARI et al., 2014).

\begin{tabular}{c|c}
\hline Parâmetros & Valores \\
\hline$L_{c}$ & $1 \mathrm{mH}$ \\
$C_{f}$ & $62 \mu \mathrm{F}$ \\
$L_{g 1}$ & $0,3 \mathrm{mH}$ \\
$L_{g 2}$ & {$[0,1] \mathrm{mH}$} \\
Tensão do barramento & $400 \mathrm{~V}$ \\
Tensão de rede & $180 \mathrm{~V}($ pico $) ; 60 \mathrm{~Hz}$ \\
Frequência de amostragem & $20040 \mathrm{~Hz}$ \\
Frequência de comutação & $10020 \mathrm{~Hz}$ \\
Frequência dos ressonantes & $60,180,300,420 \mathrm{~Hz}$ \\
Fator de amortecimento dos ressonantes & 0,0001 \\
\hline
\end{tabular}

Tabela 1. Parâmetros da planta.

Note que serão utilizados 4 controladores ressonantes, o que leva a um vetor com 8 estados que, agregados aos 3 estados do filtro, $x$, e ao estado referente ao atraso, $\phi$, resulta em um ganho de controle com 12 elementos, dado por

$$
K=\left[\begin{array}{llll}
k_{1} & k_{2} & \ldots & k_{12}
\end{array}\right]
$$

Neste sentido, o problema a ser resolvido é a busca dos elementos do vetor de ganhos de controle em um espaço de busca dado pelo produto cartesiano dos intervalos $k_{i \min } \leq k_{i} \leq k_{i \max }, i=1, \ldots, 12$. A próxima seção traz uma solução para este 
problema utilizando um algoritmo PSO.

\section{I OTIMIZAÇÃO POR ENXAME DE PARTÍCULAS}

PSO é um algoritmo de otimização baseado em padrões de enxame observados na natureza. Conforme descrito em Eberhart e Kennedy (1995), no algoritmo PSO, um conjunto de partículas $i$ é chamado de enxame, sendo $s_{i}$ um vetor que descreve a posição de cada partícula deste enxame. Cada partícula utiliza uma equação de velocidade $v_{i}$ para atualizar sua posição e deslocar-se no espaço de busca no decorrer das épocas $m$. As equações do algoritmo podem ser escritas como

$$
\begin{gathered}
s_{i}(m+1)=s_{i}(m)+v_{i}(m+1) \\
v_{i}(m+1)=\omega v_{i}(m)+\gamma_{1} r_{1}\left(P_{i, b e s t}-s_{i}(m)\right)+\gamma_{2} r_{2}\left(G_{b e s t}-s_{i}(m)\right)
\end{gathered}
$$

em que $\omega$ é o fator de inércia, $\gamma_{1}$ e $\gamma_{2}$ são os coeficientes cognitivo e social, respectivamente, e $r_{1}$ e $r_{2}$ são números randômicos entre [0,1] para gerar um comportamento aleatório para as partículas.

O algoritmo armazena a posição que resultou o melhor valor da função objetivo que cada partícula já obteve, denominado de $P_{\text {i.best }}$, e a posição que resultou o melhor valor da função objetivo entre todas as partículas do enxame, denominado de $G_{\text {best }}$

O fluxo de execução do algoritmo PSO utilizado é descrito a seguir:

1) Inicializar aleatoriamente a posição das partículas do enxame dentro dos limites do espaço de busca definido.

2) Calcular a função objetivo de cada partícula.

3) Atualizar de cada partícula e do enxame.

4) Atualizar posição e velocidade das partículas utilizando (10) e (11).

5) Se o critério de parada for atingido, então fornecer a solução do problema de otimização () e finalizar a execução. Se não, retornar para 2).

\subsection{Obtenção dos ganhos de controle para o estudo de caso}

A lei de controle em (8) pode ser reescrita como

$$
u(n)=K \rho(n)=\left[\begin{array}{lll}
K_{x} & K_{\phi} & K_{\xi}
\end{array}\right]\left[\begin{array}{l}
x(n) \\
\phi(n) \\
\xi(n)
\end{array}\right]
$$

A Figura 2 mostra uma representação do sistema em malha fechada com a lei de controle (12). 


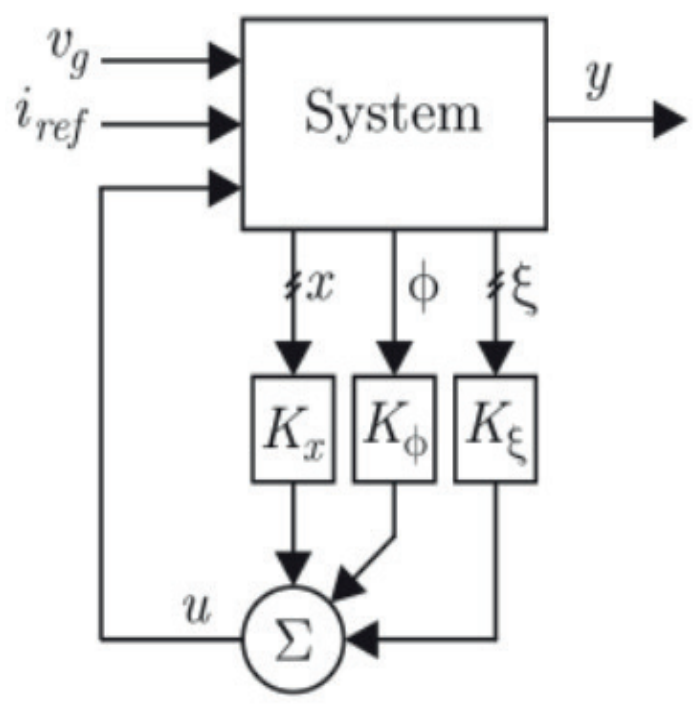

Figura 2. Diagrama de blocos evidenciando as entradas, saída e estados do sistema em malha fechada.

Aqui, tem-se como objetivo computar, off-line, o ganho fixo de controle, $K=\left[\begin{array}{lll}K_{x} & K_{\phi} & K_{\xi}\end{array}\right]$, de forma a garantir estabilidade frente à incertezas em $L_{g 2} \in \mathcal{P}$.

A função objetivo é definida por

$$
\sigma(K)=\max _{L_{g 2} \in \mathrm{P}}\left|\lambda\left(A_{\text {aum }}\left(L_{g 2}\right)+B_{\text {uaum }} K\right)\right|
$$

que provê o máximo módulo dos autovalores do sistema em malha fechada.

A partir desta função objetivo, o projeto do controlador pode então ser resolvido por meio de um problema de otimização dado por

$$
\min (\sigma(K)) \text { s.a } K \in \mathrm{K}
$$

em que K é o espaço de busca restrito do controlador, definido como um hiperretângulo em torno dos ganhos de um DLQR convencional, projetado para o ponto médio de $L_{g 2}$.

O PSO foi inicializado com coeficientes cognitivos e sociais de 0,5 , com número de partículas igual a 50 e número de épocas igual a 100, provendo boa convergência do algoritmo para a solução.

Ao final da execução, tem-se que a melhor partícula do enxame, que representa o ganho de controle $K$, é dada por 


$$
K^{\prime}=\left[\begin{array}{c}
\sigma(K)=0,9936 \\
-13,16108928784157 \\
-4,324263420719069 \\
-3,219230732731759 \\
-0,755616250730909 \\
57,02697975531543 \\
-56,58227640999129 \\
26,91066587139294 \\
-26,733811176937127 \\
17,789789865190922 \\
-19,141330280468985 \\
23,2316887459548 \\
-26,348007937950975
\end{array}\right]
$$

Para comprovar a viabilidade do ganho de controle em (15), simulações baseadas nos modelos matemáticos da Seção 2 e resultados baseados em um simulador operando em tempo real são apresentados a seguir.

\section{I RESULTADOS}

Inicialmente, para comprovar a robustez contra incerteza no parâmetro de indutância de rede , é feita a análise dos autovalores do sistema em malha fechada (ÂSTRÖM, WITTENMARK, 2013), mostrados na Figura 3.
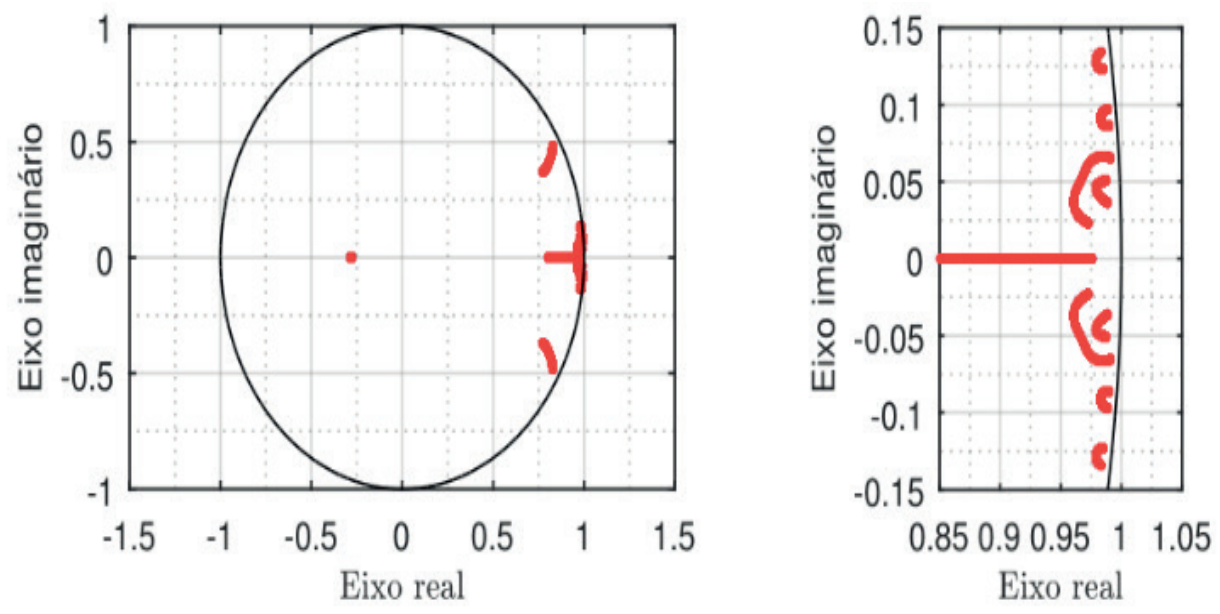

Figura 3. Autovalores do sistema em malha fechada para $L_{g 2 \min } \leq L_{g 2} \leq L_{g 2 \max }$ (à esquerda) e detalhamento dos autovalores mais próximos da borda do círculo de raio unitário (à direita).

Nota-se que todos os autovalores estão alocados no círculo de raio unitário, confirmando a estabilidade do sistema de malha fechada para toda a faixa de incerteza paramétrica. Além disso, os autovalores obedecem à restrição de raio menor que $\sigma$, dada em (15). 
Após, verificou-se o comportamento no domínio do tempo do sistema em malha fechada considerando o intervalo de incerteza paramétrica da indutância da rede. Para avaliar as respostas transitórias e o rastreamento de referência em regime permanente, foram realizadas simulações do sistema em malha fechada com uma referência senoidal de $60 \mathrm{~Hz}$ e com amplitude de $10 \mathrm{~A}$. O primeiro ensaio inclui a situação de rede com indutância mínima $\left(L_{g 2 m i n}\right)$, conforme mostrado na Figura 4.

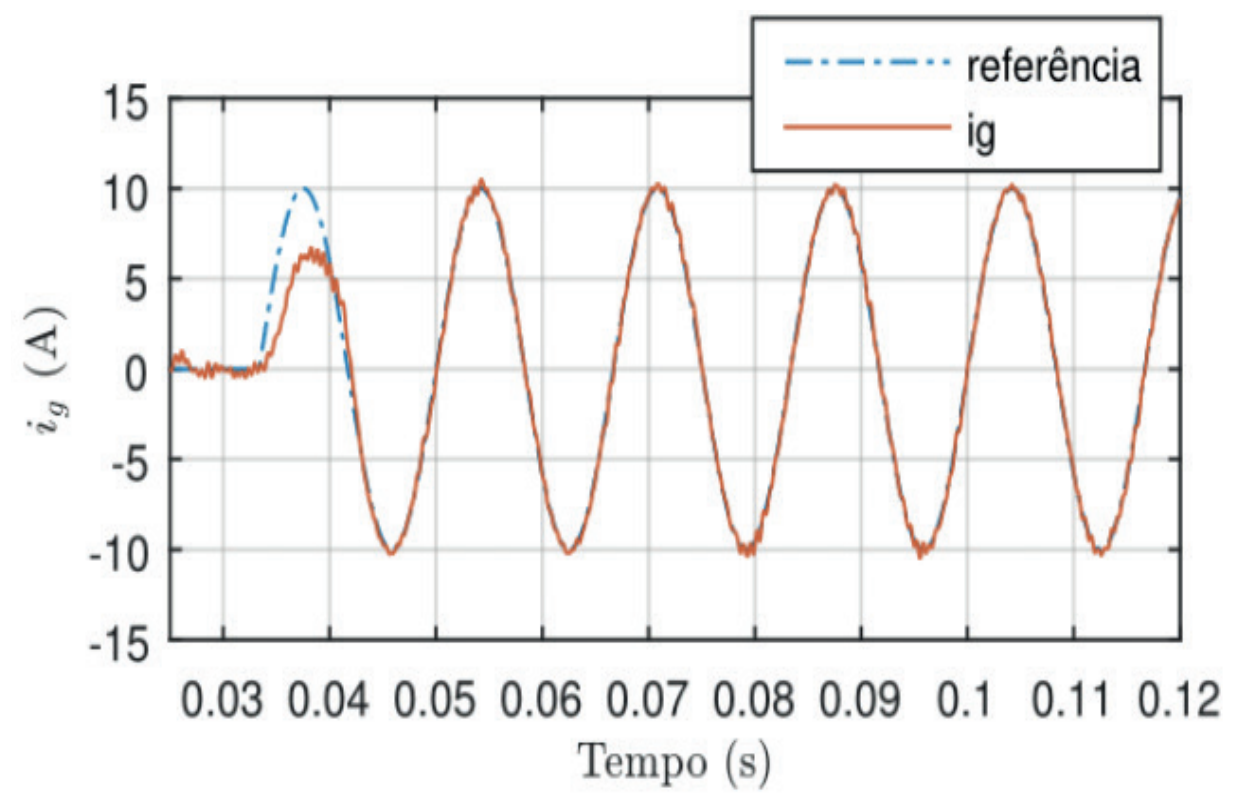

Figura 4. Simulação do sistema em malha fechada resultando na corrente $I_{g}$ para $L_{g 2 m i n}$, com referência senoidal de $60 \mathrm{~Hz}$ e com amplitude de $10 \mathrm{~A}$.

Nota-se que o sistema em malha fechada com os ganhos de controle em (15) apresenta rastreamento de referência adequado, em regime permanente e no transitório, com acomodação em menos de um ciclo da rede.

Um ensaio similar ao anterior, com rede operando com indutância máxima, $L_{g 2 m a x}$ foi realizado, provendo os resultados na Figura 5. Do mesmo modo que o ensaio para $L_{g 2 m i n}$, são obtidas boas respostas transitórias e em regime permanente, novamente com acomodação em menos de um ciclo da rede. 


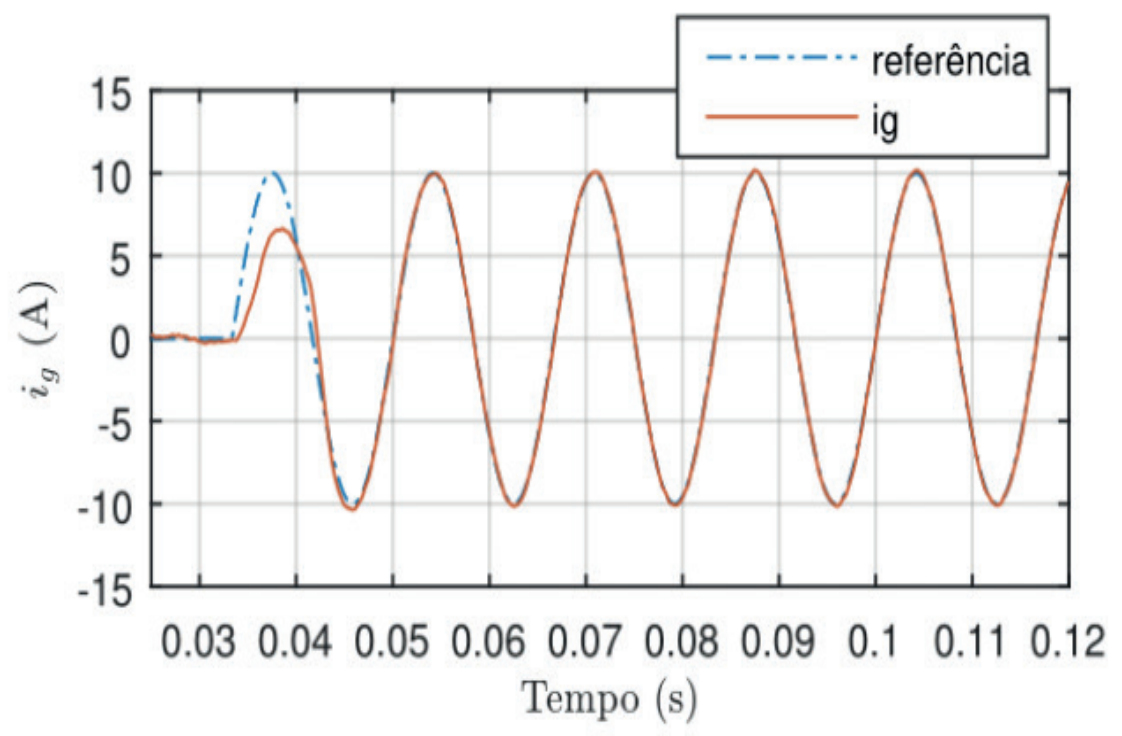

Figura 5. Simulação do sistema em malha fechada resultando na corrente $I_{g}$ para $L_{g 2 \max }$, com referência senoidal de $60 \mathrm{~Hz}$ e com amplitude de $10 \mathrm{~A}$.

Uma análise da qualidade da corrente de rede foi feita por meio da distorção harmônica total (do inglês, Total harmonic distortion - THD). O valor de THD foi, para o pior caso (ensaio com $L_{g 2 m i n}$ ), de 2,38\%, obedecendo ao limite prescrito pela norma IEEE 1547.

O desempenho satisfatório, apresentado nas Figuras 4 e 5, pode ser confirmado por meio da análise feita no domínio da frequência, na Figura 6, que mostra os diagramas de Bode do sistema em malha fechada da entrada $i_{\text {ref }}$ para a saída $i_{g}$, para operação com $L_{g 2 m i n}$ e com $L_{g 2 m a x}$. É possível observar um ganho de $0 \mathrm{~dB}$ e fase equivalente a $0^{\circ}$ na frequência de $60 \mathrm{~Hz}$, corroborando um bom rastreamento de referências senoidais nesta frequência.

Para confirmar a viabilidade do controlador projetado em uma condição muito próxima à da prática, a topologia apresentada na Figura 1 foi simulada em tempo real usando Hardware-in-the-loop (HIL) modelo 402, do fabricante Typhoon HIL (MAJSTOROVIC et al., 2011). O controlador foi implementado digitalmente usando um DSP Texas TMS32F28335. Para capturar os resultados, foi utilizado um osciloscópio Tektronix modelo MDO 4054-3, sendo a interface entre DSP, osciloscópio e HIL realizada pela placa ugrid 2.0. 


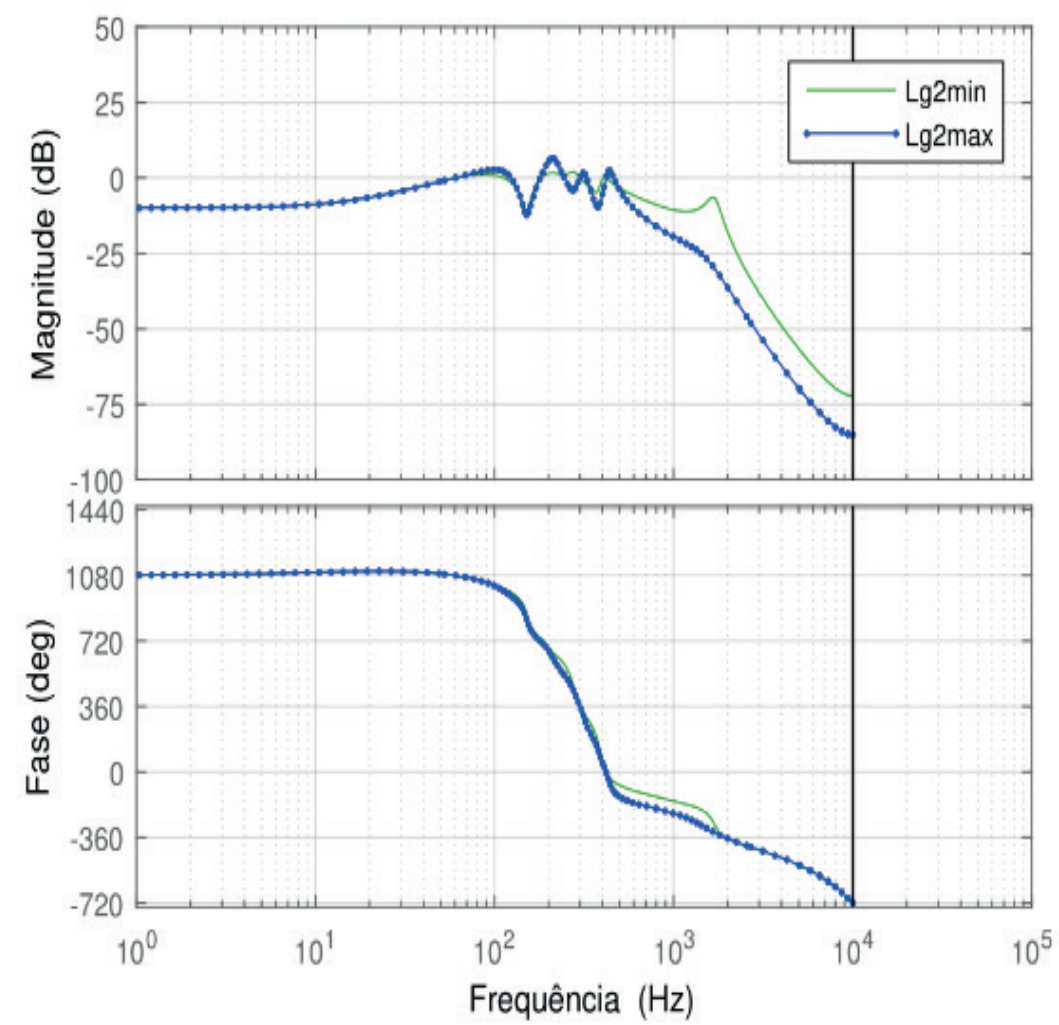

Figura 6. Diagramas de Bode do sistema em malha fechada tendo como entrada $i_{\text {ref }}$ e como saída $i_{g}$, para indutâncias de rede $L_{g 2 \min }$ e $L_{g 2 \max }$.

A Figura 7 mostra o transitório de partida do sistema em malha fechada, com uma referência senoidal em $60 \mathrm{~Hz}$ e $20 \mathrm{~A}$ de amplitude, para operação com indutância de rede dada por $L_{\text {grmax }}$ Nota-se o bom desempenho do sistema, com acomodação aproximadamente em um ciclo de rede, demonstrando boa correspondência com o resultado de simulação apresentado na Figura 5.

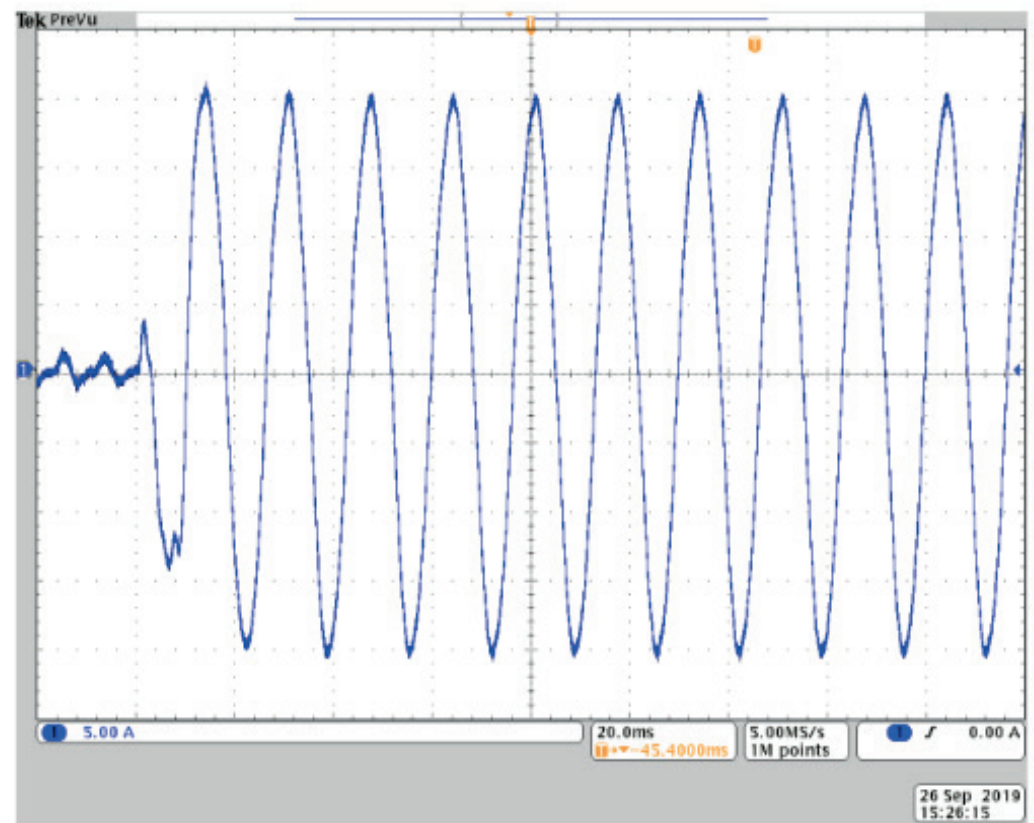

Figura 7. Resultado obtido com simulação utilizando HIL, mostrando o transitório de partida da corrente injetada na rede , para operação com indutância de rede igual a , e uma referência senoidal em $60 \mathrm{~Hz}$ e com $20 \mathrm{~A}$ de amplitude. 
A Figura 8 apresenta um detalhamento, do regime permanente da corrente mostrada na Figura 7. A análise harmônica da forma de onda na Figura 8 indica uma THD de 3,02\%. Uma análise das harmônicas individuais desta forma de onda permite concluir que as mesmas também estão em conformidade com os limites prescritos pela norma IEEE 1547 para harmônicas pares e ímpares, confirmando a boa qualidade dos resultados.

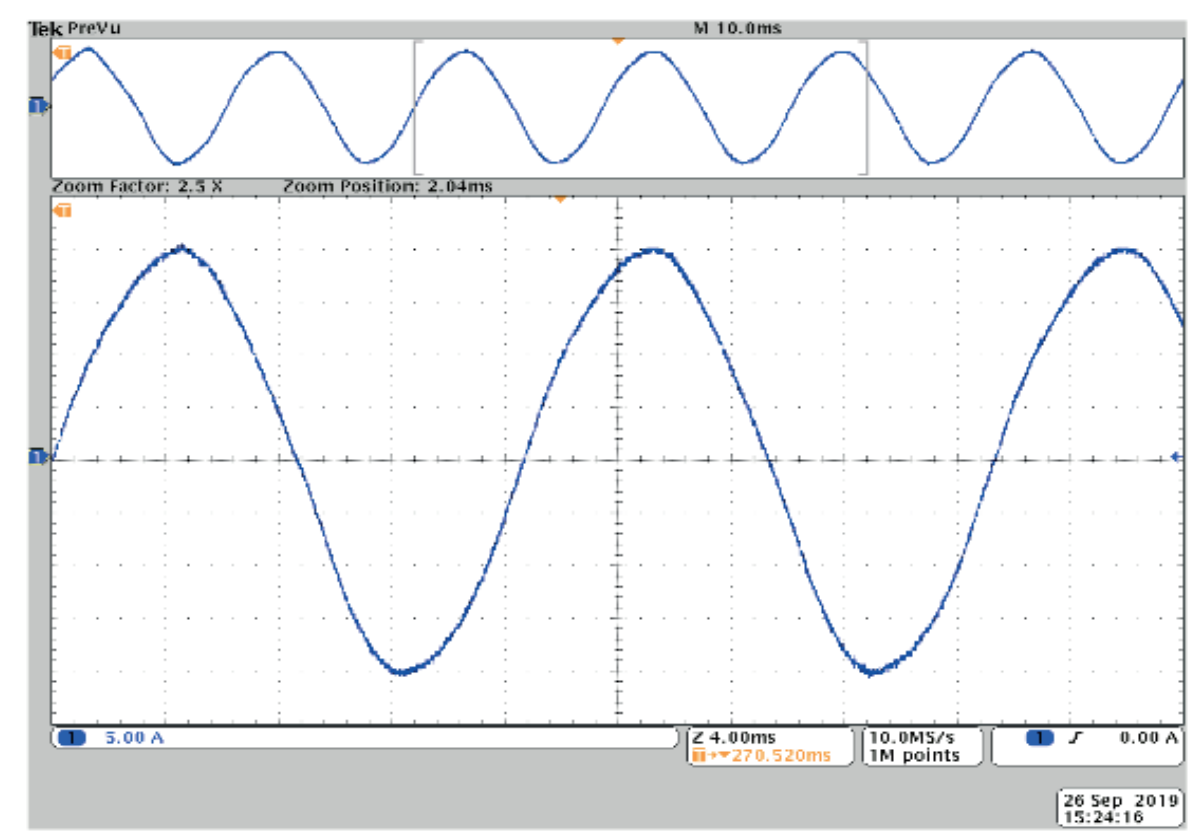

Figura 8. Resultado obtido com simulação utilizando HIL, mostrando detalhamento do regime permanente da forma de onda apresentada na Figura 7.

\section{I CONCLUSÃO}

Este trabalho apresentou o projeto de ganhos de controle por realimentação de estados por meio de um algoritmo PSO, com aplicação a inversores monofásicos conectados à rede. A otimização do controlador é baseada na minimização do máximo módulo dos autovalores do sistema em malha fechada sujeito a incertezas paramétricas na indutância de rede. O sistema em malha fechada operando com o controlador proposto, apresenta robustez contra incertezas paramétricas e boas respostas transitórias e em regime permanente, inclusive em simulações em tempo real. A análise das correntes injetadas na rede confirmam THD e harmônicas individuais compatíveis com os limites da norma IEEE 1547, indicando a viabilidade do controlador para esta aplicação.

\section{I AGRADECIMENTOS}

O presente trabalho foi realizado com apoio da Coordenação de Aperfeiçoamento de Pessoal de Nível Superior - Brasil (CAPES) - Código de Financiamento 001. Os 
autores também gostariam de agradecer ao INCT-GD e às agências de fomento CNPq, CAPES e FAPERGS (CNPq 465640/2014-1, CNPq Projeto 309536/2018-9, CAPES 23038.000776/2017-54 e FAPERGS 17/2551-0000517-1).

\section{REFERÊNCIAS}

ALTINOZ, O.; ERDEM, H., Evaluation function comparison of particle swarm optimization for buck converter, in Power Electronics Electrical Drives Automation and Motion (SPEEDAM), 2010 International Symposium on. IEEE, 2010, pp. 798-802.

ÂSTROM, K. J.; WITTENMARK, B. Computer-controlled systems: theory and design. Coureier Corporation, 2013.

BANERJEE, S.; GHOSH, A.; RANA, N., An improved interleaved boost converter with PSO-based optimal type-III controller, IEEE Journal of Emerging and Selected Topics in Power Electronics, vol. 5, no. 1, pp. 323-337, 2017.

BLAABJERG, F.; TEODORESCU, R.; LISERRE, M.; TIMBUS A., Overview of control and grid synchronization for distributed power generation systems, IEEE Transactions on Industrial Electronics, vol. 53, no. 5, pp. $1398-1409,2006$.

DA SILVA, S. A. O.; SAMPAIO, L. P.; DE OLIVEIRA, F. M.; DURAND, F. R., Feed-forward DC-bus control loop applied to a single-phase grid-connected PV system operating with PSO-based MPPT technique and active power-line conditioning, IET Renewable Power Generation, vol. 11, no. 1, pp. 183-193, 2016.

EBERHART, R.; KENNEDY, J., A new optimizer using particle swarm theory, in Micro Machine and Human Science, 1995. MHS'95., Proceedings of the Sixth International Symposium on. IEEE, 1995, pp. 39-43.

EMAMI, S.; POUDEH, M. B.; ESHTEHARDIHA, S., Particle swarm optimization for improved performance of PID controller on buck converter, in Mechatronics and Automation, 2008. ICMA 2008. IEEE International Conference on. IEEE, 2008, pp. 520-524.

ERICKSON, R. W., Fundamentals of Power Electronics. New York, NY: Chapman \& Hall, 1997.

FLASÍNSKI, M., Introduction to artificial intelligence. Springer, 2016.

IEEE, IEEE:1547 standard for interconnecting distributed resources with electric power systems, 2011.

KJAER, S.; PEDERSEN, J.; BLAABJERG, F., A review of single-phase grid-connected inverters for photovoltaic modules, Industry Applications, IEEE Transactions on, vol. 41, no. 5, pp. 12921306, 2005.

LISERRE, M.; TEODORESCU, R.; BLAABJERG, F., Multiple harmonics control for three-phase grid converter systems with the use of PI-RES current controller in a rotating frame, IEEE Transactions on Power Electronics, vol. 21, no. 3, pp. 836-841, 2006.

LIU, B.; WEI, Q.; ZOU, C.; DUAN S., Stability analysis of LCL-type grid-connected inverter under single-loop inverter-side current control with capacitor voltage feedforward, IEEE Transactions on Industrial Informatics, vol. 14, no. 2, pp. 691-702, 2018.

MACCARI JR., L. A.; MASSING, J. R.; SCHUCH, L.; RECH, C.; PINHEIRO, H.; OLIVEIRA, R. C. L. F.; MONTAGNER, V. F., LMI-based control for grid-connected converters with LCL filters under 
uncertain parameters, IEEE Transactions on Power Electronics, vol. 29, no. 7, pp. 3776-3785, 2014.

MAJSTOROVIC, D.; CELANOVIC, I.; TESLIC, N. D.; CELANOVIC, N.; KATIC, V. A., Ultralowlatency hardware-in-the-loop platform for rapid validation of power electronics designs. IEEE Transactions on Industrial Electronics, vol. 58, no. 10, pp. 4708-4716, 2011.

TEODORESCU, R.; LISERRE, M.; RODRÍGUEZ, P., Grid Converters for Photovoltaic and Wind Power Systems, ser. Wiley - IEEE. John Wiley \& Sons, 2011.

VEERACHARY, M.; SAXENA, A. R., Optimized power stage design of low source current ripple fourth-order boost DC-DC converter: A PSO approach, IEEE Transactions on Industrial Electronics, vol. 62, no. 3, pp. 1491-1502, 2015. 


\section{CAPÍTULO 15}

\section{OTIMIZAÇÃO DA CONFIABILIDADE PELA ALOCAÇÃO DE CHAVES AUTOMÁTICAS E USO DE GERAÇÃO DISTRIBUÍDA EM ILHAMENTO}

Data de aceite: 03/01/2020

Railson Severiano de Sousa Instituto Federal do Piauí, Departamento de Indústria, Segurança e Produção Cultural

Teresina - Piauí

Camilo Alberto Sepúlveda Rangel

Universidade Federal de Santa Maria,

Departamento de Eletromecânica e Sistemas de

Potência

Santa Maria - Rio Grande do Sul

Criciéle Castro Martins

Universidade Federal de Santa Maria,

Departamento de Eletromecânica e Sistemas de

Potência

Santa Maria - Rio Grande do Sul

Mauricio Sperandio

Universidade Federal de Santa Maria,

Departamento de Eletromecânica e Sistemas de

Potência

Santa Maria - Rio Grande do Sul

Luciane Neves Canha

Universidade Federal de Santa Maria, Departamento de Eletromecânica e Sistemas de

Potência

Santa Maria - Rio Grande do Sul um conjunto de alimentadores de distribuição de energia. No processo foi considerado a presença de geração distribuída (GD) e o seu uso ilhado, diante de situações de contingências. É discutido o uso ilhado das GDs, indicando quais fontes são mais bem utilizadas e quais não dificultam tal utilização. $A$ avaliação da alocação é feita a partir da matriz lógico estrutural e são considerados todos os equipamentos presentes na rede na avaliação dos indicadores de confiabilidade. A função objetivo avalia os custos com compensações, com energia não suprida, com a aquisição das chaves e possíveis custos operacionais do uso das GDs. Os resultados são apresentados e discutidos em termos da alocação e da viabilidade do uso das GDs de forma ilhada, considerando a capacidade da GD e a carga demandada da mesma, além dos efeitos sobre os indicadores individuais e coletivos.

PALAVRAS-CHAVE: Alocação de Recursos; Chaves Automáticas; Confiabilidade; Geração Distribuída; Ilhamento de Geração Distribuída.

\section{RELIABILITY OPTIMIZATION BY THE PLACEMENT OF AUTOMATIC SWITCHES AND ISLAND USE OF DISTRIBUTED GENERATION}

RESUMO: Esse estudo descreve uma ferramenta baseada em Algoritmo Genético para alocação de chaves automáticas em
ABSTRACT: This study describes a Genetic Algorithm-based tool for automatic switch placement in a set of power distribution feeders. 
The process considered the presence of distributed generation (DG) and its island operation, in contingency situations. The islanded operation of DGs is discussed, showing sources that better suit and which do not allow such use. Allocation evaluation is made through a structural logical matrix and all the equipment present in the network is considered in reliability indices. The objective function evaluates the offset costs, with non-supplied energy, acquisition of switches and possible operating costs of DGs operation. Results are presented and discussed in terms of the switch allocation and feasibility of DGs in an intentional island operation, considering the capacity of the DG and its demanded load, as well as the effects on individual and collective indices.

KEYWORDS: Resource allocation; Automatic Switches; Reliability; Distributed Generation; Island operation of Distributed Generation.

\section{I INTRODUÇÃO}

O sistema elétrico tem como função o fornecimento de energia elétrica para os consumidores de forma eficiente, segura e contínua. Diante de um sistema de distribuição com cada vez mais Geração Distribuída (GD), em geral baseadas em fontes renováveis, o fornecimento de energia se torna ainda mais complexo.

As GDs promovem um aumento significativo da complexidade do sistema elétrico e das incertezas associadas com o fornecimento, contudo podem ser uma forma de melhorar a confiabilidade da rede (GEORGILAKIS; HATZIARGYRIOU, 2015). Isso ocorre, pois como uma fonte de energia, a inserção da GD permite manter o fornecimento da energia para parte da carga, mesmo diante de uma falta da subestação do alimentador. Para isso é necessário que seja permitido o uso da GD ilhada, ou seja, fornecendo energia desconectada da fonte de geração centralizada oriunda da subestação (KADURU; GONDLALA, 2015; RAMBABU; PRASAD, 2014).

Muitos trabalhos se baseiam na correlação entre a presença de GDs no sistema de distribuição e a melhoria da confiabilidade decorrente (KADURU; GONDLALA, 2015; RAJALAKSHMI; DURAIRAJ, 2016; RAMBABU; PRASAD, 2014; REDDY; PRASAD; LAXMI, 2012). Nesse sentido, boa parte desses trabalhos propõe alocação de GDs em pontos estratégicos para aumentar o impacto da geração sobre a confiabilidade. Essa estratégia é eficaz, no entanto infactível, pois a fonte de geração, na maioria das situações, pertence ao cliente que a alocará conforme suas necessidades e peculiaridades que o levaram a se tornar um pequeno gerador de energia.

Além disso, outra característica dos sistemas de distribuição modernos é o aumento significativo da automatização, como as chaves de manobras (GEORGILAKIS; HATZIARGYRIOU, 2015). Autilização de equipamentos automáticos promove a atuação sobre o sistema de forma muito mais rápida, permitindo melhorar a confiabilidade. $O$ uso de chaves automáticas em locais estratégicos da rede de distribuição permite reduzir os impactos das faltas sobre os consumidores, sendo outra forma de melhorar os indicadores (BERNARDON et al., 2015). 
Assim, a confiabilidade do sistema passa a ser cada vez mais importante, principalmente do ponto de vista da continuidade do fornecimento. Isso acontece, porque por um lado, os consumidores e os reguladores demandam maior qualidade da distribuição e por outro, a complexidade e o maior custo de investimento demandam maior eficiência para um retorno desses investimentos (BERNARDON et al., 2015).

Nesse contexto, esse trabalho aborda uma avaliação da confiabilidade do sistema diante a inserção de GDs, de forma que se considera o uso das mesmas em conjunto com a alocação de chaves automáticas para incrementar a continuidade do sistema e diminuir a frequência de ocorrência das faltas. A alocação das chaves é feita utilizando uma ferramenta baseada em um algoritmo genético (AG), buscando potencializar a utilização de GDs na redução dos custos. Para tal foram avaliados os custos da alocação das chaves, da operação das GDs, da energia não suprida esperada e das compensações devidas aos clientes.

A discussão dos resultados permite avaliar a potencialização da operação ilhada da GD, as implicações de utilizar fontes renováveis nesse processo e as formas de ampliar a energia firme dessas fontes.

\section{I CONFIABILIDADE}

A confiabilidade do sistema elétrico de distribuição é a probabilidade de ele atender as cargas continuamente, nas condições de operação demandadas, em um horizonte de planejamento (BILLINTON; ALLAN, 1992). A interrupção, embora possua causas conhecidas, não pode ser evitada, o que consequentemente implica em impactos financeiros sobre o planejamento e a operação da distribuição, sendo que estas investem para reduzir os impactos, incrementado a confiabilidade do sistema. Nesse sentido, aumentar a confiabilidade da distribuição é melhorar a continuidade de seus pontos mais críticos, ou seja, os pontos mais prováveis a falharem (ALLAN; BILLINTON, 1993).

A avaliação da confiabilidade de faltas permanentes é realizada em termos da duração e da frequência das interrupções, o que pode ser observado em cada ponto de conexão de consumidor (individualmente) ou através de um conjunto de consumidores (ANEEL, 2017a). No Brasil a ANEEL avalia a Duração de Interrupção Individual por Unidade Consumidora (DIC) e a Frequência de Interrupção Individual por Unidade Consumidora (FIC) tal como descrito nas equações (1) e (2):

$$
\begin{gathered}
F I C=n \\
D I C=\sum_{i=1}^{n} t(i)
\end{gathered}
$$

No qual, 
n é o número de faltas;

t é a duração de cada falta.

No regulamento brasileiro em vigor os indicadores coletivos, tais como DEC e FEC (Duração e Frequência Equivalente por Unidade Consumidora, respectivamente), não possuem implicações sobre os custos da empresa, pois as compensações são avaliadas a partir de indicadores individuais. Ademais, qualquer descontinuidade com tempo inferior a três minutos não é considerado uma falta permanente, o que permite que diante de uma contingência uma ação rápida evite a contabilização de indicadores (ANEEL, 2017a).

Desta forma, alocar chaves automáticas, em pontos estratégicos, pode auxiliar a reduzir a área atingida após uma falta, diminuir o FIC e o DIC, e permitir que um menor número de consumidores seja atingido. Quando o uso das chaves está aliado a uma fonte de geração como uma GD, suas vantagens são potencializadas, tal qual é ilustrado na Fig. 1.

A Fig. 1 (a) ilustra a ocorrência de uma falta no sistema, na seção entre as cargas C2 e C3. Diante da falta, duas chaves as quais permanecem normalmente fechadas, são manobradas (abertas) a fim de isolar a falta, tal como é ilustrado na Fig. 1 (b). Neste exemplo, as cargas C1 e C2 são alimentadas somente pela subestação (SE), já a carga C4 é alimentada somente pela GD funcionando isolada do resto da rede, em uma microrrede ilhada. Por fim, a carga C3 somente será reenergizada quando ocorrer o reparo da falha e as chaves retornarem à posição normal.

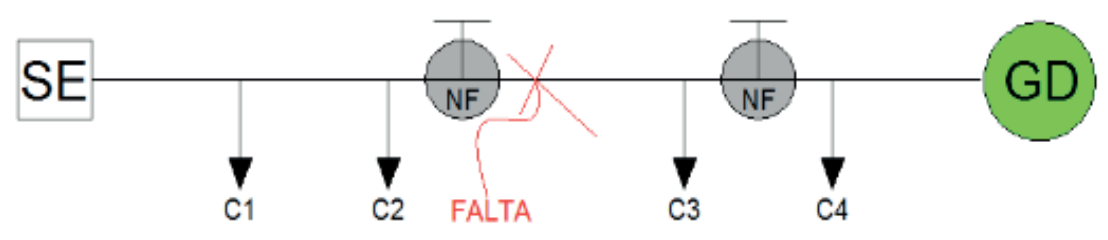

(a)

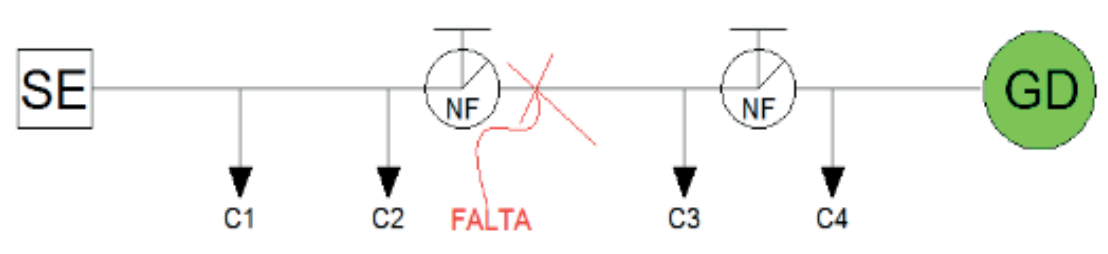

(b)

Fig. 1 (a) Ocorrência de Falta no Sistema de Distribuição (b) Manobra das Chaves

O posicionamento das chaves, é de fundamental importância para os efeitos da manobra, caso a chave entre C2 e a falta esteja posicionada mais à esquerda (montante), ou a outra chave mais à direita (jusante), a área isolada pela falta seria maior, consequentemente, mais cargas ficariam expostas a falta (SPERANDIO, 2008). De forma similar, caso a manobra de isolamento da falta transfira mais carga do que o fornecimento da GD, toda a carga transferida será desabastecida, pois a geração não 
teria capacidade de atender a demanda, ou seja, teria o mesmo efeito se caso a GD fosse removida da rede quando atingida por uma falta em seu ramo no alimentador.

Tais considerações tornam de vital importância à análise conjunta da alocação e do uso ilhado das GDs, para que seja possível minimizar os efeitos da descontinuidade sobre os consumidores. Além disso, é importante discutir qual a capacidade de geração real da GD utilizada diante de uma contingência do sistema, momento no qual a GD será a única (ou principal) fonte de energia da carga. Isso será discutido adiante, no tópico sobre a restrição no uso de fontes renováveis como suporte à confiabilidade do sistema de distribuição.

\subsection{Matriz Lógico Estrutural}

A Matriz Lógico Estrutural (MLE) é uma metodologia de previsão de indicadores para o sistema de distribuição que se utiliza das taxas de falha por ano $(\lambda)$, tempo de reparo ou restabelecimento (TR), do número de consumidores $(N)$ e carga $(L)$. Para exemplificar a montagem e sua utilização na obtenção dos indicadores será utilizado a Fig. 2.

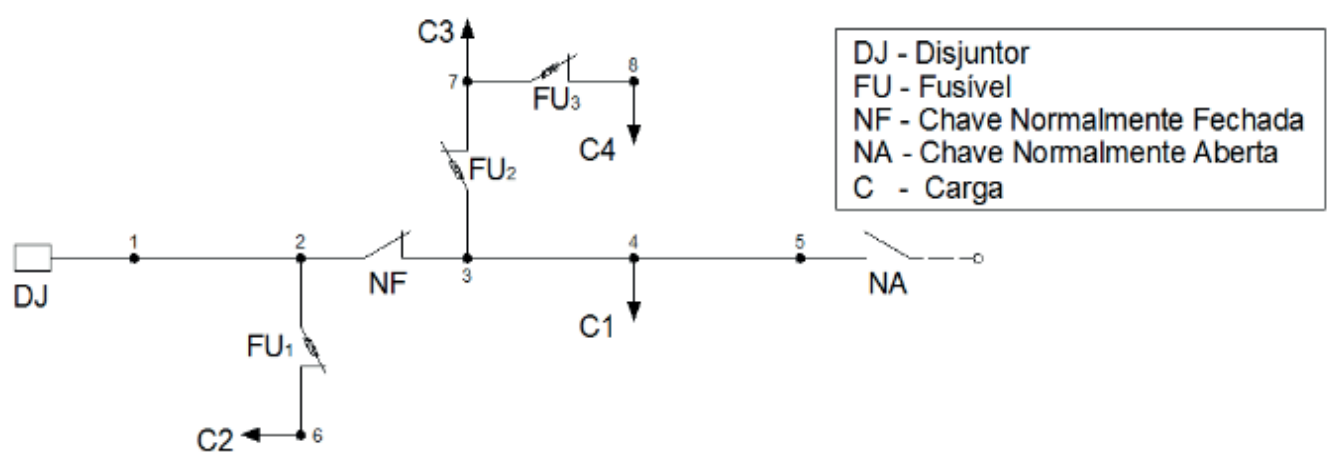

Fig. 2 Exemplo de Alimentador com Cargas e Dispositivos de Proteção

Na Fig. 2, caso ocorra uma falta no nó 6, haverá o rompimento do elo fusível o que evita que a interrupção afete os nós a montante do fusível (nó 2), já os nós a jusante permanecem desabastecidos por um tempo TR. Já a chave NF desconecta os nós a jusante, e reenergiza os nós a montante após um tempo TS (tempo de seccionamento). Quando a chave NA é acionada, todas as barras a jusante da NF são transferidas após um tempo TT (tempo de transferência) (SPERANDIO, 2008). Por fim, o disjuntor interrompe todo o circuito.

A utilização da MLE permite analisar os indicadores a partir de todos os equipamentos disponíveis no alimentador. Para isso, na construção da MLE, cada linha corresponde a um nó ou a um transformador, e cada coluna a um dispositivo de proteção ou a um nó. Considera-se que a transferência da carga efetuada pelo fechamento NA é factível, ou seja, que existe um alimentador capaz de suportar todas as cargas a jusante da NF (KNAK NETO et al., 2015). A Tabela I ilustra a MLE da Fig. 2 


\begin{tabular}{|c|c|c|c|c|c|c|}
\hline \multirow[b]{2}{*}{ Nó } & \multicolumn{6}{|c|}{ Equipamentos de Proteção e Manobra } \\
\hline & DJ & NF & NA & FU1 & FU2 & FU3 \\
\hline 1 & $\mathrm{TR}_{1} \lambda_{1}$ & $\mathrm{TS} \lambda_{3}$ & $\mathrm{TS} \lambda_{5}$ & 0 & 0 & 0 \\
\hline 2 & $\mathrm{TR}_{1} \lambda_{1}$ & $\mathrm{TS} \lambda_{3}$ & $\mathrm{TS} \lambda_{5}$ & 0 & 0 & 0 \\
\hline 3 & $\mathrm{TT} \lambda_{1}$ & $\mathrm{TR}_{3} \lambda_{3}$ & $\mathrm{TR}_{5} \lambda_{5}$ & 0 & 0 & 0 \\
\hline 4 & $\mathrm{TT} \lambda_{1}$ & $\mathrm{TR}_{3} \lambda_{3}$ & $\mathrm{TR}_{5} \lambda_{5}$ & 0 & 0 & 0 \\
\hline 5 & $\mathrm{TT} \lambda_{1}$ & $\mathrm{TR}_{3} \lambda_{3}$ & $\mathrm{TR}_{5} \lambda_{5}$ & 0 & 0 & 0 \\
\hline 6 & $\mathrm{TR}_{1} \lambda_{1}$ & $\mathrm{TS} \lambda_{3}$ & $\mathrm{TS} \lambda_{5}$ & $\mathrm{TR}_{6} \lambda_{6}$ & 0 & 0 \\
\hline 7 & $\mathrm{TT} \lambda_{1}$ & $\mathrm{TR}_{3} \lambda_{3}$ & $\mathrm{TR}_{5} \lambda_{5}$ & 0 & $\mathrm{TR}_{7} \lambda_{7}$ & 0 \\
\hline 8 & $\mathrm{TT} \lambda_{1}$ & $\mathrm{TR}_{3} \lambda_{3}$ & $\mathrm{TR}_{5} \lambda_{5}$ & 0 & $\mathrm{TR}_{7} \lambda_{7}$ & $\mathrm{TR}_{8} \lambda_{8}$ \\
\hline
\end{tabular}

TABELA I. Matriz Lógico Estrutural para a Fig. 2

A partir da MLE é possível obter os indicadores, tal que:

$$
D I C_{i}=\sum_{j=1}^{n n} M_{i, j}
$$

Já a energia não suprida pode ser obtida por:

$$
E N S=\sum_{i=1}^{n n}\left(\sum_{j=1}^{n n} M_{i, j}\right) L_{i}
$$

Onde:

$M_{i, j}$ é o elemento da linha i coluna $j$;

nn é o número de nós.

Por fim, o FIC pode ser obtido com uma MLE modificada, tal que são suprimidos os tempos, e utilizado somente as taxas de falha:

$$
F I C_{i}=\sum_{i=1}^{n n} M^{*}{ }_{i, j}
$$

sendo que

$\mathrm{M}^{*}{ }_{\mathrm{i}, \mathrm{j}}$ é o elemento da linha i coluna j, da MLE sem os tempos.

\subsection{Restrição no Uso de Fontes Renováveis como Suporte à Confiabilidade do}

\section{Sistema de Distribuição}

Diante de uma falta que provoque o funcionamento da GD ilhada, existe a probabilidade de a fonte conseguir fornecer a energia demandada ( $p f$ ). Do ponto de vista das cargas alimentadas pela GD ilhada, essa fonte deverá apresentar uma 
energia firme, suficiente para suprir a sua demanda (ADEFARATI; BANSAL, 2017; KADURU; GONDLALA, 2015).

Nesse cenário, cada fonte de energia apresenta uma probabilidade pf distinta, condizente com as incertezas que Ihe são próprias. Uma GD Solar Fotovoltaica (PV), por exemplo, só conseguirá atender a demanda quando ilhada, se a falta ocorrer durante o dia e não houver a incidência de nuvens que bloqueiem sua geração. Isso restringe pf a um valor bem inferior a 50\%, dependendo da região. Em (MA; YANG; LU, 2013) é avaliado que para atender satisfatoriamente a carga, quando a PV opera ilhada, a carga tem de ser entre 7,7\% e 9,5\% da potência nominal da GD. Por outro lado, uma geração térmica (por biomassa, por exemplo) pode atingir uma pf de 100\%, desde que possua combustível para o período de contingência.

Assim, não seria admissível no modelo atual o uso de painéis fotovoltaicos num ilhamento sob contingência. Outras fontes como a eólica e pequenas centrais hidrelétricas $(\mathrm{PCH})$ exigem um estudo mais aprofundado. Para o uso das fontes eólicas é interessante utilizar o estudo de fazenda eólica, associando as probabilidades em uma sobreposição de cadeias de Markov avaliando todos os estados possíveis tal como demonstra (SAYAS; ALLAN, 1996). Um processo semelhante pode ser executado diante das PCHs por uma análise dinâmica a ocorrer sob ilhamento, como um processo estacionário da vazão em uma análise de curto prazo (ROCHA, 2014).

Em ambos os casos a alocação de baterias junto as GDs propiciam uma forma de minimizar ou eliminar as intermitências naturais da fonte. Nessa perspectiva, o custo da alocação da bateria e o uso diante de uma contingência seriam considerados custos operacionais da GD para a concessionária. O mesmo ocorre com custos de uma possível gestão do ilhamento como uma microrrede ou uma Virtual Power Plant. Caso contrário, é admitido que o uso da GD ilhada não implique em custos à concessionária.

\section{I FERRAMENTA PROPOSTA}

Para a alocação das chaves automáticas buscou-se o maior impacto sobre a confiabilidade do sistema de distribuição com a presença de geração distribuída. Para tal, foi utilizada uma ferramenta baseada em algoritmo genético.

\subsection{Algoritmos Genéticos (AG)}

O AG é um mecanismo de busca simples e capaz de encontrar a solução ótima através de conceitos evolucionários. O funcionamento de um AG parte de um conjunto de soluções aleatórias (GOLDBERG, 1989):

- Avalia a aptidão das soluções, segundo a função objetivo;

- Seleciona parte das soluções para manipulação; 
- Produz manipulações genéticas tais como: cruzamento, mutação, migração e elitismo;

- Repete os passos anteriores até atingir um critério de parada.

A ferramenta utiliza como método de seleção o método da roleta, e como manipulações genéticas, o cruzamento e a migração. Na solução do problema foi utilizada uma codificação inteira, na qual cada número era uma barra de um dos alimentadores, passível de receber uma chave automática. Um conjunto de chaves NF foi alocado concomitantemente nos alimentadores em busca da melhor solução de acordo com a função objetivo descrita a seguir.

\subsection{Função Objetivo}

As concessionárias devem manter os indicadores abaixo do limite estabelecido pela reguladora (ANEEL, 2017a), caso contrário, devem compensar financeiramente cada um dos i consumidores lesados de acordo com (6) (7):

$C_{D I C}=\left(\frac{D I C}{D I C_{p}}-1\right) D I C_{p} * \frac{E U S D_{\text {médio }}}{730} k e i$

De forma análoga tem que a compensação para o FIC é dada por:

$$
C_{F I C}=\left(\frac{F I C}{F I C_{p}}-1\right) D I C_{p} * \frac{E U S D_{\text {médio }}}{730} k e i
$$

tal que

$D I C_{p}$ e $F I C_{P}$ são limites definidos aos indicadores DIC e FIC, respectivamente;

$E U S D_{\text {médio }}$ e encargo médio do uso do sistema de distribuição;

kei é o coeficiente de majoração.

Além do custo das compensações, são avaliados também o custo da Energia Não Suprida (ENS) esperada em relação ao crescimento de carga, da aquisição das chaves automáticas $\left(\mathrm{C}_{\mathrm{chA}}\right)$ e da operação da $\mathrm{GD}\left(\mathrm{C}_{\mathrm{opGD}}\right)$. Sendo que o custo total está demonstrado na equação (9).

$$
C_{E N S}=C_{e} E N S \sum_{k=1}^{H}\left(1+t x_{c r e s c}\right)^{k-1}
$$

Onde:

$\mathrm{C}_{\mathrm{e}}$ é o custo da Energia;

$\mathrm{tx}_{\text {cresc }}$ é a taxa de crescimento da carga; 
H é o horizonte de planejamento.

$$
C_{T o t}=C_{D I C}+C_{F I C}+C_{E N S}+C_{c h A}+C_{o p G D}
$$

A função objetivo (FO) busca a minimização dos custos e é definida por:

$$
F O=\operatorname{Minimizar}\left(C_{T o t}\right)
$$

A FO está sujeita a um conjunto de restrições como:

- Manter a radicalidade do alimentador, não sendo permitida a operação em anel;

- Alocar pelo menos uma chave nos alimentadores com GD;

- A carga assumida pela GD durante o ilhamento não pode ser superior a pf.

\section{I RESULTADOS}

O sistema teste utilizado para avaliar o modelo descrito anteriormente compreende uma subestação com sete alimentadores da CELESC (Centrais Elétricas de Santa Catarina) do município de Florianópolis, ao qual foram inseridas algumas gerações, sem grande preocupação com a posição das GDs. O conjunto possui 310 fusíveis, 68 chaves NF, 29 chaves NA. Atendendo mais de 16.300 consumidores, suprindo uma carga de 74,2 MW. Nesse sistema real, considerou-se a presença de quatro GDs, todas térmicas à biomassa, cujas posições são ilustradas na Fig. 3 por quadrados cinza. As GDs no alimentador 1 e 4 têm capacidade de 1,5 MW, já as GDs dos alimentadores 3 e 5 possuem uma capacidade de $1 \mathrm{MW}$.

A Fig. 3 ainda exibe as chaves NFs já presentes no alimentador e a topologia apresentada por toda rede, com a diferenciação de cada alimentador por cor. 


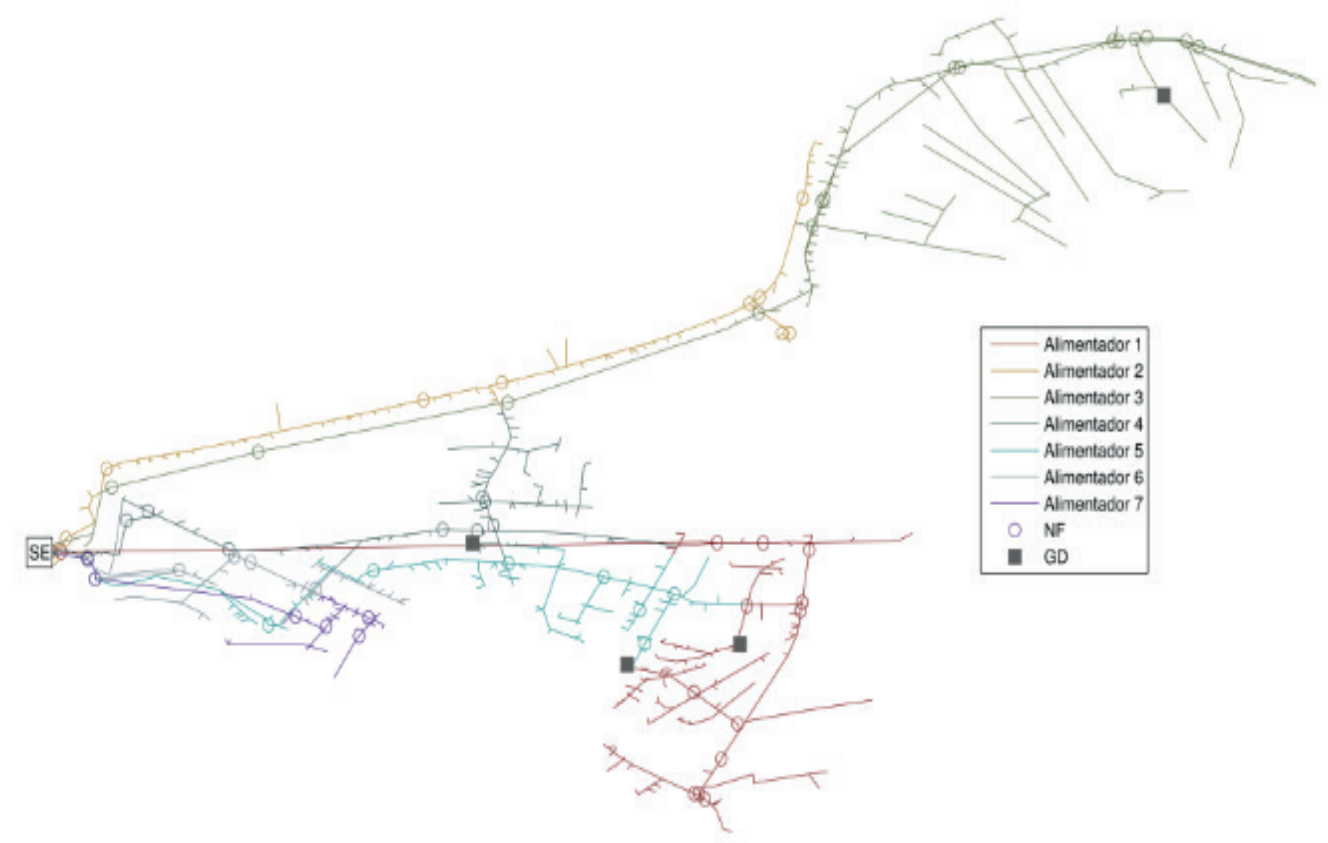

Fig. 3 Alimentadores CELESC com apresentação de posição chaves NFs e GDs.

O AG buscou alocar 7 chaves NFs automáticas no conjunto de alimentadores, sem restrição de número máximo de chaves por alimentador. Os parâmetros do AG utilizados para a solução do problema foram uma população com 40 indivíduos, uma taxa de elitismo de $25 \%$, uma taxa de migração de $2,5 \%$ com migrações a cada 20 gerações (iterações). Como critérios de parada, foram utilizados o número máximo de gerações ou a repetição da mesma população migratória.

Ademais foi utilizado o custo de $7000,00 \mathrm{R} \$$ para uma chave NF automática, um horizonte de planejamento de 10 anos e uma taxa de crescimento da carga de $7,5 \%$ ao ano. O custo da energia considerado foi de 0,43142 R $\$ / \mathrm{kW}$ (ANEEL, 2016). Os limites de indicadores foram retirados do site da Agência Nacional de Energia Elétrica (ANEEL, 2017b) e foram mantidos constantes durante todo horizonte analisado, pois a redução progressiva dos limites desses indicadores é realizada baseada no desempenho da concessionária.

O resultado obtido na alocação das chaves é descrito na Tabela II.

\begin{tabular}{cccccccc}
\hline & \multicolumn{7}{c}{ Alimentadores } \\
Parâmetro Avaliado & $\mathbf{1}$ & $\mathbf{2}$ & $\mathbf{3}$ & $\mathbf{4}$ & $\mathbf{5}$ & $\mathbf{6}$ & $\mathbf{7}$ \\
\hline \hline Quantidade de NFs & 1 & 0 & 1 & 1 & 1 & 3 & 0 \\
Barra Alocada & 209 & - & 118 & 159 & 50 & $11 ; 36 ; 63$ & - \\
Carga Máx. com GD Ilhada & 1,125 & - & 0,920 & 0,795 & 1,095 & - & - \\
$(M W)$ & & & & & & & - \\
Máx utilização \% da GD ilhada & $75 \%$ & - & $92 \%$ & $79,5 \%$ & $73 \%$ & - & - \\
\hline
\end{tabular}

TABELA II. Quantidade e Posições das Chaves Nos Alimentadores

É possível observar, a partir da Tabela II, que a ferramenta avaliou que alocação 
de mais chaves no alimentador 6 teria mais impacto que a distribuição igual das chaves pelos alimentadores. Como consequência, nenhuma chave foi alocada nos alimentadores 2 e 7. Já os alimentadores 1, 3, 4 e 5 receberam uma chave cada um, de forma a permitir o uso das GDs em modo ilhado. É visível que a alocação respeitou o limite de capacidade das GDs e inclusive manteve um fator de utilização máximo, quando ilhado inferior a $80 \%$ para todas as fontes, com exceção da presente no alimentador 3.

O efeito da alocação, em termos dos custos e do ganho financeiro a distribuidora, é explorado na Tabela III. O processo de alocação de chaves propiciou uma redução considerável nos custos com compensações no horizonte de planejamento, no entanto essa melhoria foi ainda mais significativa quando associada ao uso das GDs ilhadas. Isso implica que existe viabilidade econômica para o uso dessas fontes de geração nessa modalidade.

\begin{tabular}{|c|c|c|c|}
\hline \multirow[t]{2}{*}{ Solução } & \multicolumn{3}{|c|}{ Custo de Cada Caso } \\
\hline & Caso Base & Apenas Alocação das Chaves & Chaves+ GD \\
\hline Custo (106 R\$) & 13,0901 & 11,842 & 11,413 \\
\hline Redução & - & $1.248 .093,96$ & $1.677 .216,03$ \\
\hline Redução \% & - & $9,53 \%$ & $12,83 \%$ \\
\hline
\end{tabular}

TABELA III. Impacto da Alocação e da GD

Obviamente que o sistema teste utilizado apresenta ainda uma boa margem para melhoria nos indicadores de confiabilidade, que pode ser obtido também com a inserção de outros equipamentos automáticos, tais como religadores, o uso de outras filosofias de proteção ou de despacho de equipe de manutenção. Entretanto tais possibilidades não desqualificam o fato de que a GD é cada vez mais uma realidade do sistema de distribuição e sua utilização em situações de contingência traz um impacto positivo aos indicadores da rede, tal como é ilustrado na Tabela IV.

\begin{tabular}{ccccccccc}
\hline Indicador & \multicolumn{7}{c}{ Redução Percentual em cada Alimentador } \\
& $\mathbf{1}$ & $\mathbf{2}$ & $\mathbf{3}$ & $\mathbf{4}$ & $\mathbf{5}$ & $\mathbf{6}$ & $\mathbf{7}$ \\
\hline Máx(DIC) a & $13,32 \%$ & - & $1,09 \%$ & $0,01 \%$ & $13,82 \%$ & $12,35 \%$ & - \\
Máx(FIC) a & $11,16 \%$ & - & $2,78 \%$ & $0,2 \%$ & $24,16 \%$ & $22,33 \%$ & - \\
DEC & $16,31 \%$ & - & $1,70 \%$ & $1,98 \%$ & $27,77 \%$ & $53,85 \%$ & - \\
FEC & $13,78 \%$ & - & $3,73 \%$ & $0,18 \%$ & $25,66 \%$ & $32,82 \%$ & - \\
ENS & $14,66 \%$ & - & $6,65 \%$ & $3,32 \%$ & $23,80 \%$ & $38,63 \%$ & - \\
\hline
\end{tabular}

TABELA IV Impacto da Alocação e das GDs Ilhadas

${ }^{a}$ Máximo valor do indicador dentre todos os Clientes

A Tabela IV ilustra a redução percentual que o uso conjunto das chaves automáticas e das GD tiveram sobre os indicadores de cada alimentador. Como nenhuma chave foi alocada nos alimentadores 2 e 7, nenhuma redução foi obtida, no entanto a melhoria 
nos alimentadores 1, 5 e 6 foi considerável, principalmente quando analisados os indicadores coletivos, que ilustram a melhoria geral sobre todo o sistema. Mesmo assim houve melhora no pior caso do DIC e do FIC em todos esses alimentadores.

Além disso, a Tabela IV permite observar que o impacto das GDs no alimentado não está diretamente relacionada a capacidade da GD. O alimentador 5 com uma GD de $1 \mathrm{MW}$ teve mais ganho percentual que os alimentadores 1 e 4 que possuem gerações com maior capacidade. Ademais, voltando a observar a Tabela II, a GD do alimentador 5 apresenta ainda o menor fator de utilização quando em situação de ilhamento, o que parece também não ser fator determinante.

Sugere-se assim que outras características, que não foram analisadas neste trabalho, tais como a configuração da rede, a distribuição das faltas e a quantidade de chaves disponíveis durante uma situação de ilhamento tenham uma influência maior sobre a melhoria dos indicadores.

\section{I CONSIDERAÇÕES FINAIS}

Esse trabalho realizou a alocação de chaves de manobras automáticas em um conjunto de alimentadores, de forma a minimizar os custos com compensações e energia não suprida. Nesse processo, foi avaliada a operação ilhada de GD em situações de contingência durante a alocação, elucidando os ganhos possíveis nesse modo de operação. Assim, foram discutidas quais fontes são passíveis de aplicação nesse tipo de situação e do grau de complexidade decorrente do uso de cada uma delas.

Os resultados mostraram um ganho incremental no uso da geração distribuída de forma ilhada, o qual depende de dispositivos de manobra que permitam a separação da GD do resto da rede. Os ganhos podem ser inferiores em comparação a alocação de outros equipamentos na rede, o que reforçado pela discussão inicial, de que o cliente seria o proprietário da GD, desencorajam a inserção de fontes para uma melhora na confiabilidade da rede.

No entanto assumindo que tais fontes já estejam disponíveis, utiliza-las pode ser uma boa estratégia para melhorar (ainda mais) a confiabilidade da rede. Em um cenário em que as concessionárias estão, de extrema competitividade e incessante busca de retorno dos investimentos, tal resultado se torna importante para ampliar as discussões que levem a uma futura regulamentação sobre a operação de GD ilhada.

Muitos trabalhos futuros são possíveis desdobramentos deste, como a avaliação de sensibilidade da operação da GD ilhada em situações de contingência as variações das taxas de falhas, a avaliação de outras fontes de geração, já que nesse trabalho foi testado apenas biomassa ou mesmo de um conjunto com vários tipos de gerações. 


\section{I AGRADECIMENTOS}

Os autores agradecem a UFSM e ao programa de Pós-Graduação em Engenharia Elétrica da Instituição, ao IFPI, CAPES/PROEX Código de Financiamento 001, CNPq, FAPEMA, FAPERGS e INCT-GD pelo suporte ao desenvolvimento do trabalho.

\section{REFERÊNCIAS}

ADEFARATI, T.; BANSAL, R. C. Reliability assessment of distribution system with the integration of renewable distributed generation. Applied Energy, [s. I.], v. 185, p. 158-171, 2017.

ALLAN, R.; BILLINTON, R. Power system reliability and its assessment. III. Distribution systems and economic considerations. Power Engineering Journal, [s. I.], v. 7, n. 4, p. 185-192, 1993.

ANEEL. Resolução Homologatória no 2.120, de 16 de Agosto de 2016. Brasilia.

ANEEL. Módulo 8 - Qualidade da Energia Elétrica.Procedimentos de Distribuição de Energia Elétrica no Sistema Elétrico Nacional - PRODIST. Brasilia.

ANEEL. Indicadores de Continuidade por Município. 2017b. Disponível em: <http://www.aneel.gov. br/indicadores>. Acesso em: 19 mar. 2017.

BERNARDON, D. P. et al. Sistemas de Distribuição no Contexto das Redes Elétricas Inteligentes: uma abordagem para reconfiguração de redes. 1. ed. Santa Maria - RS: AGEPOC, 2015.

BILLINTON, R.; ALLAN, R. N. Reliability Evaluation of Engineering Systems: Concepts and Techniques. 2. ed. New York: Plenum Press, 1992.

GEORGILAKIS, P. S.; HATZIARGYRIOU, N. D. A review of power distribution planning in the modern power systems era: Models, methods and future research. Electric Power Systems Research, [s. I.], v. 12 , n. 1 , p. $89-100,2015$.

GOLDBERG, D. E. Genetic Algorithms in Search, Optimization, and Machine Learning. . Boston, MA.

KADURU, R.; GONDLALA, N. S. Reliability Evaluation of Distribution System Considering Distributed Generation. International Journal of Electrical, Computer, Energetic, Electronic and Communication Engineering, [s. I.], v. 9, n. 7, p. 710-715, 2015.

KNAK NETO, N. et al. The application of the logical structural matrix for reliability analysis in a distribution system planning environment. In: 23RD INTERNATIONAL CONFERENCE ON ELECTRICITY DISTRIBUTION - CIRED 2015, Lyon - France. Anais... Lyon - France

MA, T.; YANG, H.; LU, L. Performance evaluation of a stand-alone photovoltaic system on an isolated island in Hong Kong. Applied Energy, [s. I.], v. 112, p. 663-672, 2013.

RAJALAKSHMI, J.; DURAIRAJ, S. Review on optimal distributed generation placement using particle swarm optimization algorithms. In: 2016 INTERNATIONAL CONFERENCE ON EMERGING TRENDS IN ENGINEERING, TECHNOLOGY AND SCIENCE (ICETETS) 2016, Anais... : IEEE, 2016.

RAMBABU, T.; PRASAD, P. V. Optimal placement and sizing of DG based on power stability index in radial distribution system. In: 2014 INTERNATIONAL CONFERENCE ON SMART ELECTRIC GRID (ISEG) 2014, Guntur, India. Anais... Guntur, India: IEEE, 2014. 
REDDY, S. C.; PRASAD, P. V. N.; LAXMI, A. J. Reliability improvement of distribution system by optimal placement of DGs using PSO and neural network. In: 2012 INTERNATIONAL CONFERENCE ON COMPUTING, ELECTRONICS AND ELECTRICAL TECHNOLOGIES (ICCEET) 2012, Kumaracoil, India. Anais... Kumaracoil, India: IEEE, 2012.

ROCHA, L. F. Avaliação probabilística da confiabilidade de sistemas de distribuição incluindo aspectos dinâmicos do ilhamento. 2014. Universidade Federal do Rio de Janeiro, [s. I.], 2014.

SAYAS, F. C.; ALLAN, R. N. Generation availability assessment of wind farms. IEE Proceedings Generation, Transmission and Distribution, [s. I.], v. 143, n. 5, p. 507, 1996.

SPERANDIO, M. Planejamento da Automação de Sistemas de Manobra em Redes de Distribuição. 2008. Universidade Federal de Santa Catarina, [s. I.], 2008. 


\section{CAPÍTULO 16}

\section{COMO SELECIONAR TRANSISTORES DE POTÊNCIA PARA APLICAÇÕES EM CONVERSORES ESTÁTICOS?}

Data de submissão: 14/10/2019

Data de aceite: 03/01/2020

Edemar de Oliveira Prado Universidade Federal de Santa Maria - UFSM Santa Maria - RS http://lattes.cnpq.br/1774778404976935

Pedro Cerutti Bolsi Universidade Federal de Santa Maria - UFSM Santa Maria - RS http://lattes.cnpq.br/0324597211954149 Mateus José Tiburski Universidade Federal de Santa Maria - UFSM Santa Maria - RS http://lattes.cnpq.br/5498188421691529

Éder Bridi Universidade Federal de Santa Maria - UFSM Santa Maria - RS

http://lattes.cnpq.br/2790377192733673 Hamiltom Confortin Sartori Universidade Federal de Santa Maria - UFSM

Santa Maria - RS

http://lattes.cnpq.br/6722822162374884 José Renes Pinheiro Universidade Federal de Santa Maria - UFSM Santa Maria - RS http://lattes.cnpq.br/2333794966860226

RESUMO: Este artigo apresenta uma metodologia para seleção de transistores de potência para aplicações em conversores estáticos, avaliando perdas e comparando diferentes tecnologias. Esta análise baseia-se nos modelos térmicos e elétricos dos IGBTs e MOSFETs de Silício (Si), Carboneto de Silício (SiC) e Nitreto de Gálio (GaN) para determinar suas perdas, onde é avaliado o comportamento de cada tecnologia em diferentes faixas de frequência, níveis de potência e diferentes tempos de condução (duty cycles). Para isto foi desenvolvido um algoritmo capaz de calcular perdas por condução e comutação nos dispositivos, por meio de um processo de varredura de frequência, considerando diferentes níveis de potência e tempos de condução. Os resultados mostram as faixas de frequência, níveis de corrente e tempos de condução em que cada tecnologia apresentou melhor desempenho (menores perdas), indicando a tecnologia mais apropriada a ser utilizada em cada aplicação especifica.

PALAVRAS-CHAVE: Conversores, frequência, perdas, Transistores de potência.

\section{HOW TO SELECT POWER TRANSISTORS FOR STATIC CONVERTERS APPLICATIONS?}

ABSTRACT: This paper presents a methodology for select power transistors for static converters applications evaluating losses behavior and 
comparing different technologies. This analysis is based on thermal and electric models for determination of power losses in IGBTs and Silicon (Si), Silicon Carbide (SIC), CoolMOS and Gallium Nitride (GaN) MOSFETs, evaluating the behavior of each technology towards different frequency ranges, power levels, and different conduction times (duty cycle). For this, an algorithm was developed, which is able of modeling conduction losses and switching losses in the devices, through a scanning process for frequencies, considering different power levels and conduction times. Results show which frequency ranges, power levels and duty cycle where each technology presents better behavior (lower losses), indicating the most appropriate technology to be used in each specific application.

KEYWORDS: Converters, Frequency, Losses, Power transistors.

\section{I INTRODUÇÃO}

Nos últimos anos um assunto bastante abordado por engenheiros e projetistas é o aumento da densidade volumétrica de potência em conversores estáticos (BUSQUETSMONGE et al., 2004) (BIELA, KOLAR e DEBOY, 2010) (SARTORI, HEY e PINHEIRO, 2009) (SARTORI, 2015). Para isto, a operação em maiores frequências pode ser uma solução no que diz respeito à redução da área dos componentes magnéticos (em muitos casos, aparecem como o maior componente do circuito), entretanto, este aumento da frequência acaba resultando em maiores perdas no transistor de potência, podendo reduzir a eficiência total do sistema (BIELA, BADSTUEBNER e KOLAR, 2009 ) (SARTORI, BELTRAME e PINHEIRO, 2011).

Estudos elaborados por (ERICKSON, 2007) e (WANG, 2013), mostram que desde as primeiras fontes chaveadas, diferentes tecnologias de transistores foram utilizadas como elemento de chaveamento, como é o caso do transistor bipolar de junção, tiristores, entre outros. Porém com a demanda por maiores níveis de corrente e por maiores frequências de comutação, estes dispositivos passaram a ser gradualmente substituídos por IGBTs e MOSFETs.

Embora os MOSFETs apresentassem melhor rendimento em alta frequência do que outras tecnologias de transistores, em meados da década 90 eram comumente utilizados em aplicações de menores potências e em tensões de bloqueio de até 200 $\mathrm{V}$, por apresentarem comportamento resistivo do canal quando em condução e de suportarem menores tensões de bloqueio. Já os IGBTs aumentavam seu espaço no mercado da eletrônica de potência, sendo utilizados em operações de maiores potências, bem como tensões de bloqueio de até $3 \mathrm{kV}$ (SHENAI, 2009) e (BALIGA, 2010).

Nesse sentido, a indústria passou a desenvolver MOSFETs com diferentes estruturas e tecnologias de semicondutores para as mais diversas aplicações e faixas de operação (SARTORI, 2013) e (RASHID, 2017). Hoje em dia, o desenvolvimento de tecnologias a base de semicondutores de wide bandgap, como é o caso do Carboneto 
de Silício ( $\mathrm{SiC}$ ), e mais recentemente o Nitreto de Gálio (GaN), tornam possível que a operação em alta frequência, maiores potências e em maiores tensões de bloqueio ocorram de forma eficiente (WANG, 2013), (SARTORI, 2013) e (HU, 2015). Para dispositivos a base de Silício, a saída encontrada foi a modificação na estrutura do dispositivo. Criada pela fabricante Infineon®, a geração de dispositivos de superjunção CoolMOS, apresenta redução significativa na resistência de condução, tempos de comutação menores e aumento na capacidade de bloqueio de tensão (SARTORI, 2013) e (INFINEON, 2015).

A utilização da tecnologia SiC em transistores de potência, está diretamente associada a características físico-químicas do material, como a alta condutividade térmica, elevado campo elétrico de ruptura e a ampla banda proibida, o que torna sua utilização atrativa para situações onde há necessidade de operação em altas temperaturas, frequências e potências, aliados a elevadas tensões de bloqueio (RASHID, 2017) e (MILLÁN, 2013). Os semicondutores do tipo GaN possuem campo elétrico de ruptura e banda proibida similares aos dispositivos SiC, mas apresentam maior mobilidade dos portadores e menor condutividade térmica (MILLÁN, 2013). A influência dos portadores reduz os tempos de comutação e a capacitância de saída. Neste contexto, a tecnologia GaN apresenta uma certa vantagem em operações de alta frequência, já sua menor condutividade térmica traz desvantagens em situações onde há a necessidade de operação em altas potências, pois a temperatura de junção é diretamente proporcional a potência dissipada pelo dispositivo (SARTORI, 2013), (RASHID, 2017) (BALIGA, 2013) e (HUANG, 2013).

Com advento destas tecnologias de MOSFETs, a faixa de aplicações até então ocupada pelos IGBTs passa a também ser ocupada pelos transistores de efeito de campo, trazendo o desafio de definir qual tecnologia apresenta melhores resultados (menores perdas) para uma dada aplicação. Neste sentido, este artigo apresenta uma análise comparativa entre as tecnologias de transistores de potência supracitados, onde são avaliadas diferentes faixas de potência e frequências de operação.

O objetivo deste estudo é definir as faixas de frequência e níveis de potência onde cada tecnologia de transistor apresenta menores perdas em comparação direta, apontando claramente qual tecnologia apresenta melhor desempenho para uma aplicação específica. Para tanto, uma análise computacional para o estudo de caso de um conversor Boost CC-CC foi desenvolvida, onde as perdas em estado de condução e as perdas de comutação associadas a IGBTs e MOSFETs (Si, Superjunção, SiC e GaN) são avaliadas para potências de 500 W, 1500 W e 4500 W (diferentes níveis de corrente) e frequências de até $500 \mathrm{kHz}$ para diferentes ganhos (afetam diretamente nas perdas por condução do dispositivo).

Para a análise comparativa, o conversor foi considerado operando em modo de condução contínua (MCC), com ripple de corrente de $20 \%$ (pico a pico). Maiores ripples de corrente resultam em maiores correntes RMS, podendo resultar em maiores perdas em condução no transistor, deste modo, as condições de simulação também 
foram avaliadas para um ripple de $40 \%$ (pico a pico). Considerando que a potência e os tempos de condução são fixos em cada simulação, a indutância varia de acordo com a frequência de chaveamento, de modo a manter o ripple de corrente constante (SARTORI, BELTRAME, e PINHEIRO, 2011). Nesta análise o dissipador de calor foi projetado para manter a temperatura de junção em $100^{\circ} \mathrm{C}$ (outros valores podem ser utilizados).

Este artigo é organizado da seguinte forma: A Seção II descreve a metodologia de cálculo de perdas em MOSFETs e IGBTs. A Seção III mostra os critérios de seleção utilizados para elaborar o banco de dados. Seção IV apresenta a metodologia proposta para seleção e a Seção V mostra os resultados e as faixas de operação em que cada tecnologia apresentou melhor desempenho.

\section{I CÁLCULO DE PERDAS}

Transistores de efeito de campo e de porta isolada tem o contato de gate isolado do material semicondutor por meio de uma interface de dióxido de silício (SiO2), fazendo com que estes dispositivos apresentem alta impedância de entrada. Como este contato é isolado do restante do dispositivo, não há fluxo de corrente no gate, sendo assim, as perdas são dadas particularmente por condução e comutação. Estas perdas podem ser definidas com base em informações retiradas das folhas de dados do dispositivo (datasheet) (ERICKSON, 2007) e (SARTORI, 2013).

\section{A. Perdas por condução}

Os MOSFETs têm comportamento resistivo quando em condução, assim, a potência dissipada no dispositivo pode atingir níveis elevados, resultando em perdas significativas quando em condução (SARTORI, 2013). Estas perdas podem ser obtidas por meio de

$$
P_{\text {COND_MOS }}=R_{D S} I_{R M S}{ }^{2},
$$

onde RDS é a resistência drain-to-source em estado ligado e IRMS é a corrente RMS no MOSFET. O comportamento da resistência em função da temperatura de junção é definido através da regressão da curva drain-to-source (a curva RDS é disponibilizada pelo fabricante na folha de dados do dispositivo) (ERICKSON, 2007) e (RASHID, 2017).

Como os BJTs e os IGBTs apresentam comportamento similar ao do diodo, as perdas por condução nestes dispositivos são calculadas pela queda de tensão em função da corrente, obtidos nas das curvas VCE x ICE presentes na folha de dados do dispositivo (BUSQUETS-MONGE et al., 2004), (BALIGA, 2010) e (RASHID, 2017), assim 


$$
P_{\text {COND_IGBT }}=V_{C E} I_{M E D}
$$

onde VCE é a queda de tensão em função da corrente e da temperatura de junção no transistor.

A razão cíclica corresponde ao tempo de condução do transistor e pode ser obtido por

$$
D=1-\frac{V_{I}}{V_{o}}
$$

onde VI e VO são as tensões de entrada e saída do conversor respectivamente. A corrente RMS no conversor Boost é obtida pela seguinte relação

$$
I_{R M S}=\sqrt{\frac{1}{T} \int_{0}^{T} I_{S W}(t)^{2} d t}
$$

\section{B. Perdas por comutação}

As perdas na entrada em condução (turn-on) são compostas pela sobreposição de tensão e corrente (overlap) somadas as perdas capacitivas. Por outro lado, as perdas na saída de condução (turn-off) são compostas somente pela sobreposição de tensão e corrente. Os tempos em que ocorrem estas sobreposições são proporcionais a cargas e descargas de capacitâncias parasitas no transistor, e são determinantes para o cálculo das perdas.

Sendo assim, por meio dos tempos de subida (tr) e de queda (tf) fornecidos pelo fabricante, que são os tempos em que ocorrem as sobreposições de tensão e corrente no dispositivo, as perdas podem ser calculadas de forma simplificada em cada transição. Para a entrada em condução as perdas são obtidas de acordo com (5), e na saída por meio de (6) (BELTRAME, 2013):

$$
\begin{gathered}
P_{O N}=\frac{1}{2} I_{D E V} V_{O} t_{R} f_{s}+\frac{1}{2} C_{O S S} V_{O}^{2} f_{s} \\
P_{O F F}=\frac{1}{2} I_{D E V} V_{O} t_{f} f_{s}
\end{gathered}
$$

onde IDEV é a corrente de comutação instantânea no transistor e COSS é a capacitância de saída do transistor (COES para os IGBTs), estes dados são disponibilizados na folha de dados do dispositivo. A principal diferença na determinação das perdas por comutação entre MOSFETs e IGBTs está na saída de condução do IGBT, que apresenta uma corrente de cauda devido à recombinação dos portadores minoritários na junção PN (similar ao diodo), esta corrente de cauda implica no aumento 
do fall time da corrente (SHENAI, 1989) (BALIGA, 2010) e (SARTORI, 2013).

\section{Perdas totais}

Para determinar as perdas totais em cada transistor, é necessário estimar a parcela de perdas por condução e por comutação, assim, a potência total dissipada é representada por (7). As perdas por recuperação reversa no diodo podem influenciar nas perdas totais no transistor. Como esta análise pode ser aplicada em diferentes situações (diferentes topologias) as perdas por recuperação reversa não são avaliadas

$$
P_{\text {TOTAIS }}=P_{\text {COND }}+P_{\text {ON }}+P_{\text {OFF }}
$$

\section{I SELEÇÃO DOS TRANSISTORES}

A seleção dos transistores inclui as tecnologias até então apresentadas: IGBTs, e MOSFETs (Si, SiC, Superjunção e GaN), considerando os mesmos valores de potência, tensão de bloqueio e corrente no transistor para a temperatura de junção de $100^{\circ} \mathrm{C}$. Devido à grande variedade de dispositivos presentes no mercado, a resistência drain-to-source (para os MOSFETs), as curvas ID X VCE (para os IGBTs), capacitância de saída e tempos de overlap foram utilizados como critério de seleção, por influenciarem diretamente nas perdas por condução e comutação respectivamente.

Obedecendo estes critérios um vasto banco de dados foi elaborado para correntes de até $60 \mathrm{~A}$ com temperatura de junção de $100^{\circ} \mathrm{C}$ e tensões de bloqueio na faixa de $200 \mathrm{~V}$ a $1200 \mathrm{~V}$. Vale ressaltar, que o algoritmo proposto pode realizar a varredura de perdas para diferentes temperaturas de junção, desde que não exceda os limites estabelecidos na folha de dados.

A fim de exemplificar, a Tabela I mostra algumas características importantes de cada tecnologia (estes dispositivos são alguns dos que compõem o banco de dados). A resistência em estado de condução e a capacidade de corrente para a temperatura de junção especificada foram obtidas por meio da regressão das curvas disponibilizadas pelo fabricante, e para o caso dos IGBTs, a queda de tensão no canal foi obtida através da interpolação das curvas de $25^{\circ} \mathrm{C}$ e $175^{\circ} \mathrm{C}$. Este procedimento foi adotado para todos os dispositivos que compõem o banco de dados, servindo como ponto de partida para realizar a análise comparativa entre os transistores. 


\begin{tabular}{|c|c|c|c|c|c|}
\hline Part Number & $\begin{array}{c}\text { IXFR } \\
\text { 36N60P }\end{array}$ & $\begin{array}{l}\text { IPZ65 } \\
\text { R095C7 }\end{array}$ & $\begin{array}{c}\mathrm{SCT} \\
3120 \mathrm{AL}\end{array}$ & $\begin{array}{c}\text { NTP8G } \\
\text { 206N }\end{array}$ & $\begin{array}{c}\text { IKP08N65F } \\
5 \\
\end{array}$ \\
\hline Tecnologia & $\overline{\mathrm{Si}}$ & CoolMOS & $\mathrm{SiC}$ & $\mathrm{GaN}$ & IGBT \\
\hline Fabricante & IXYS $®$ & Infineon $®$ & $\mathrm{ROHM} \circledast$ & ONSemi $®$ & Infineon $®$ \\
\hline $\begin{array}{c}\text { Tensão de bloqueio } \\
\text { [V] }\end{array}$ & 600 & 700 & 650 & 600 & 650 \\
\hline $\begin{array}{c}\text { Capacidade de } \\
\text { condução a } 100^{\circ} \mathrm{C}[\mathrm{A}]\end{array}$ & 13 & 15 & 15 & 12 & 11 \\
\hline $\mathrm{R}_{\mathrm{DS}}$ a $100{ }^{\circ} \mathrm{C}[\Omega]$ & 0.42 & 0.18 & 0.14 & 0.24 & - \\
\hline $\mathrm{V}_{\mathrm{CE}}[\mathrm{V}]$ & - & - & - & - & 1.7 \\
\hline Coss p[F] & 570 & 33 & 35 & 44 & 16 \\
\hline$T_{R} n[s]$ & 25 & 8 & 21 & 4.5 & 3 \\
\hline
\end{tabular}

Tabela I. Características de cada tecnologia.

\section{I ANÁLISE COMPUTACIONAL}

Para a análise computacional, foi desenvolvido um algoritmo capaz de realizar uma varredura de perdas nos transistores que compõem o banco de dados em diferentes pontos de operação, com base nos procedimentos de cálculo de perdas apresentados até o momento e as características dos dispositivos selecionados, bem como diferentes tempos de condução.

O tempo de condução (3) no conversor Boost, está relacionado aos níveis de tensão de entrada e saída do sistema e influencia diretamente nas perdas por condução, como mostrado em (1) e (2). A fim de simplificar a análise de perdas, o algoritmo pode ser dividido em duas etapas principais: Na primeira etapa as simulações são realizadas para potências de $500 \mathrm{~W}, 1500 \mathrm{~W}$ e $4500 \mathrm{~W}$ (diferentes níveis de corrente), onde as perdas são calculadas de acordo com (1), (2), (5) e (6) por meio de uma varredura de perdas para frequências de até $500 \mathrm{kHz}$ e tensões de entrada e saída na ordem de 200 VCC e 400 VCC respectivamente. Na segunda etapa a tensão de entrada é 100 VCC, em vista de analisar o comportamento de cada tecnologia em diferentes tempos de condução e níveis de corrente, seguindo o mesmo procedimento listado acima.

A análise computacional pode ser descrita de acordo com o fluxograma apresentado na Figura 1: Inicialmente as variáveis de entrada são definidas pelo projetista (tensão de entrada e saída, potência e ripple de corrente no indutor, de acordo com a aplicação desejada), em seguida o algoritmo calcula a corrente no transistor e faz uma busca pelo banco de dados, selecionando os transistores que atendem as condições especificadas (tensão de bloqueio e nível de corrente), calculando as perdas individuais em cada dispositivo selecionado. Como o banco de dados é composto por uma grande quantidade de dispositivos de cada tecnologia, uma nova varredura é realizada, onde os dispositivos que apresentam menores perdas em cada faixa de frequência de cada tecnologia, são selecionados (a verificação é feita em steps de 1 
$\mathrm{kHz})$.

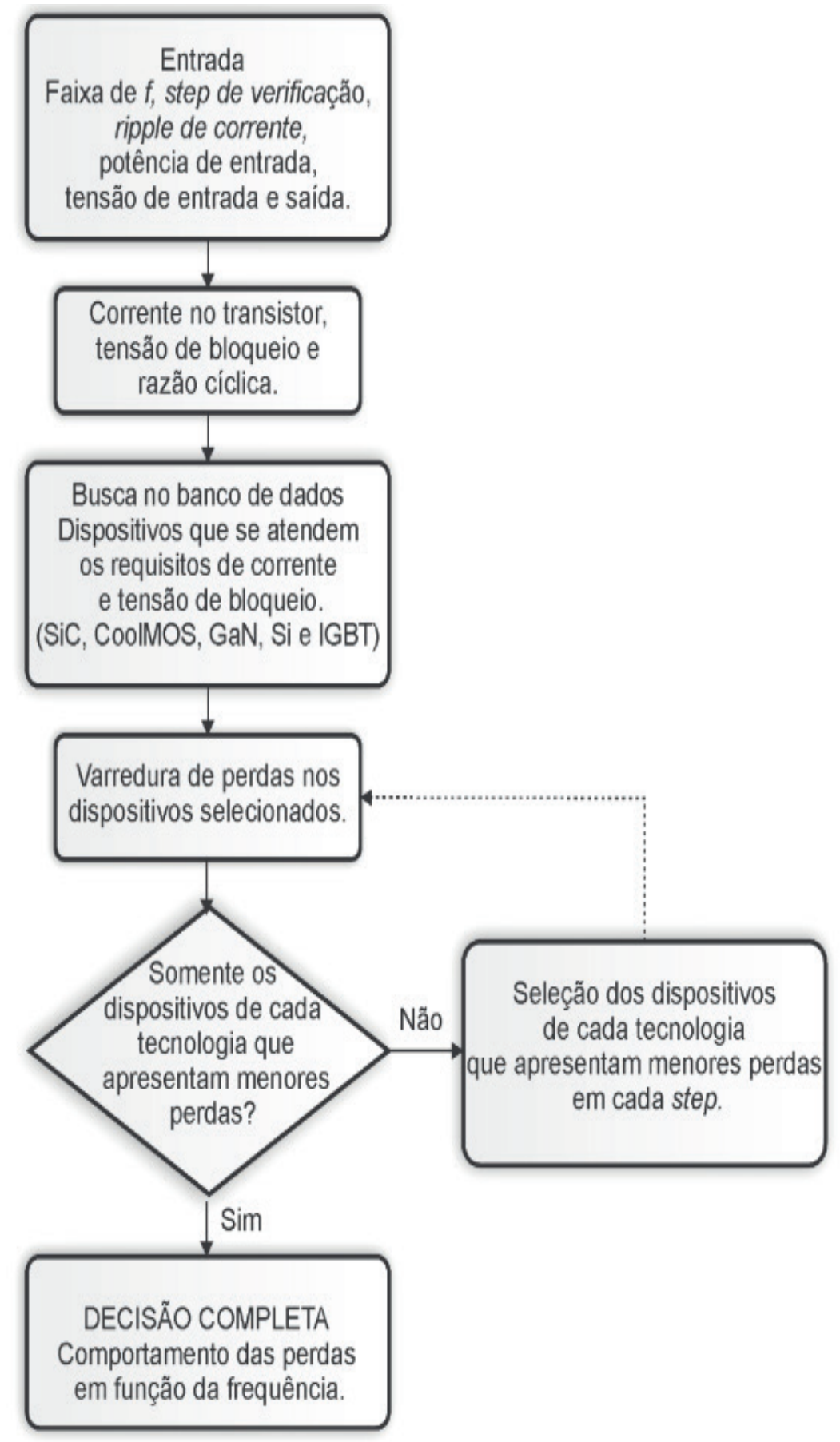

Figura 1: Fluxograma da simulação.

\section{I RESULTADOS}

Primeira etapa: O comparativo entre diferentes tecnologias de MOSFETs e IGBTs em cada ponto de operação para uma entrada de 200 Vcc (razão cíclica de 50\%) e potências de 500 W, 1500 W e 4500 W são mostrados na Figura 2. (a), (b) e (c), respectivamente.

Para as condições utilizadas na Figura 2 (a) com 500 W, a tecnologia de MOSFETs Si apresenta maiores perdas em frequências de até $300 \mathrm{kHz}$. Acima de 300 kHz, o IGBT é quem apresenta maiores perdas. Como pode ser visto, a tecnologia de MOSFETs GaN (NTP8G206N) mostra desempenho superior entre 


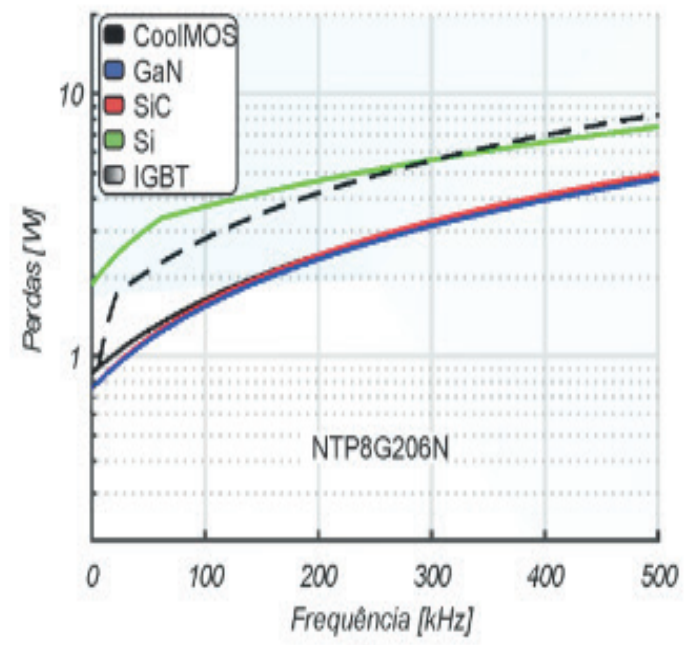

(a)

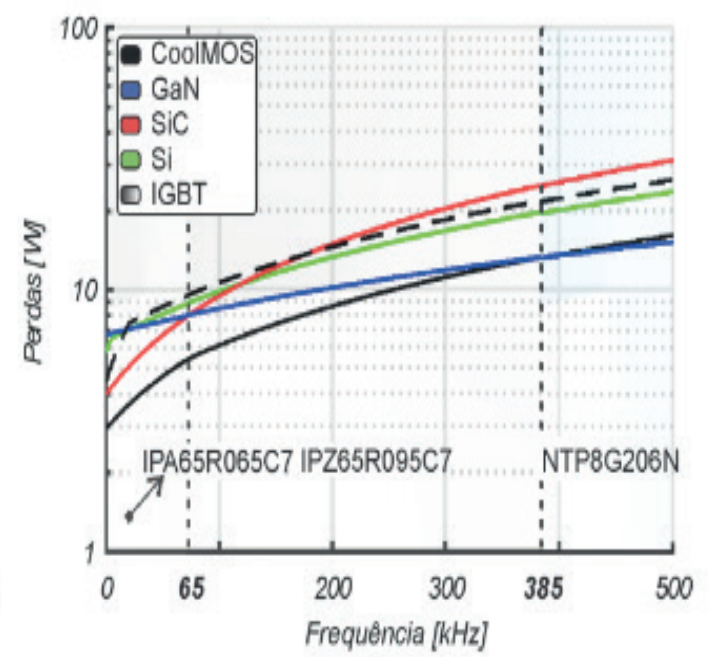

(b)

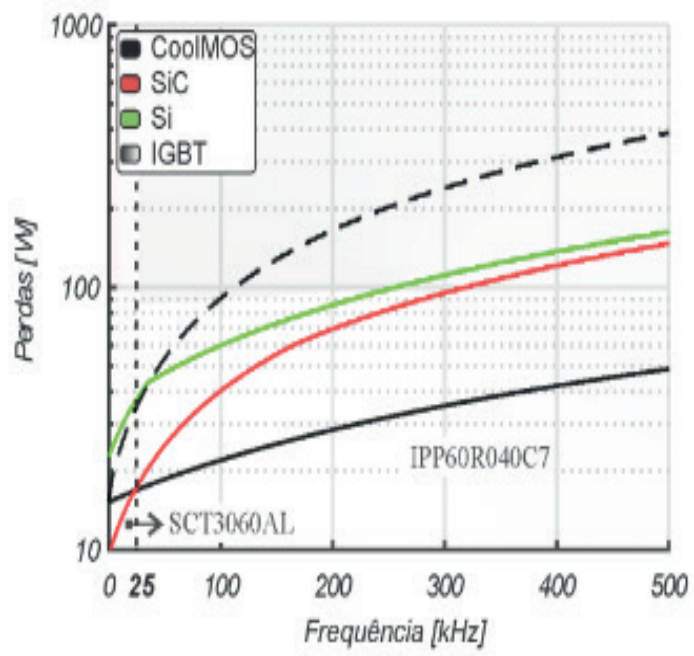

(c)

Figura 2: Perdas para 200 VCC: (a) 500 W, (b) 1500 W e (c) 4500 W.

Na Fig. 2. (b) as tecnologias com maior desempenho são CoolMOS (IPA65R065C7) até $65 \mathrm{kHz}$, CoolMOS (IPZ65R095C7) até 385 kHz e GaN (NTP8G206N) acima de $385 \mathrm{kHz}$. Neste caso, a razão cíclica é a mesma do caso anterior, porém com corrente de 7,5 A. Com o aumento da corrente, a tecnologia de transistors GaN mostra uma queda na eficiência, devido a maior resistência no canal (Tabela I), porém em maiores frequências, tem desempenho superior se comparado com as demais tecnologias, devido aos menores tempos de overlap no dispositivo.

Na Fig. 2 (c), o sistema é simulado com potência de 4500 W, correspondendo a uma corrente de 22,5 A. Como o GaN é a tecnologia mais recente entre as demais tecnologias, além de ser uma tecnologia ainda em desenvolvimento, a alta resistência no canal e consequentemente as maiores perdas em condução impõe limitações de corrente do transistor, portanto, não há transistores com esta capacidade de condução de corrente no banco de dados para esta tecnologia.

Por outro lado, características intrínsecas da tecnologia SiC proporcionam 
melhor desempenho em maiores níveis de corrente por apresentarem menores perdas por condução. Estas características podem ser observadas na Fig. 2 (c), onde a tecnologia SiC (SCT3060AL) apresenta melhor desempenho até $25 \mathrm{kHz}$ e o CoolMOS (IPP60R040C7) acima de $25 \mathrm{kHz}$.

Segunda etapa: Nos resultados apresentados até o momento, cada tecnologia apresentou níveis de potência e faixas de frequência onde apresentam menores perdas. Como mostrado em (7), estas perdas são obtidas por meio da soma das parcelas de perdas por condução e comutação em cada transistor, sendo que a razão cíclica influencia diretamente nas perdas por conduçã. Esta etapa consiste em avaliar a faixas de melhor rendimento em cada tecnologia, com tensão de entrada de 100 VCC e mesma tensão de saída do caso anterior (400 VCC), com isso, o tempo de condução e os níveis de corrente no transistor são afetados, neste caso a razão cíclica é de $75 \%$ e as correntes de entrada são de $5 \mathrm{~A}, 15 \mathrm{~A}$ e $45 \mathrm{~A}$, respectivamente.

$\mathrm{Na}$ Fig. 3 (a) para $5 \mathrm{~A}$, o melhor desempenho é da tecnologia CoolMOS (IPA65R095C7) até $215 \mathrm{kHz}$ e da tecnologia GaN (NTP8G206N) acima de $215 \mathrm{kHz}$.

Na Fig. 3 (b) com 15 A, o melhor desempenho é da tecnologia SiC (SCT3060AL) até $30 \mathrm{kHz}$ e CoolMOS (IPW65R080CFD) acima de $30 \mathrm{kHz}$. Na Fig. 2 (c) a corrente no transistor é de 22,5 A, enquanto que na Fig. 3 (b) é de $15 \mathrm{~A}$, fato que evidencia a influência da razão cíclica nas perdas dos dispositivos, já que, mesmo com menores níveis de corrente, com o aumento da razão cíclica de $50 \%$ para $75 \%$, a tecnologia SiC tem a faixa onde apresenta melhor rendimento aumentada de $25 \mathrm{kHz}$ para $30 \mathrm{kHz}$. Na Fig. 3 (c) com 45 A, a tecnologia SiC (SCT3022AL) apresenta melhor desempenho até 130 kHz. Para maiores frequências, o transistor CoolMOS (IPW65R037C6) apresenta menores perdas. 


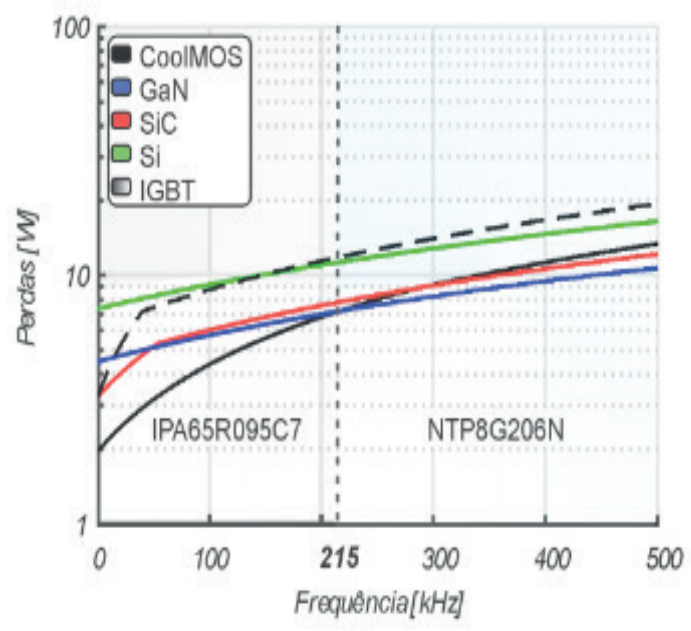

(a)

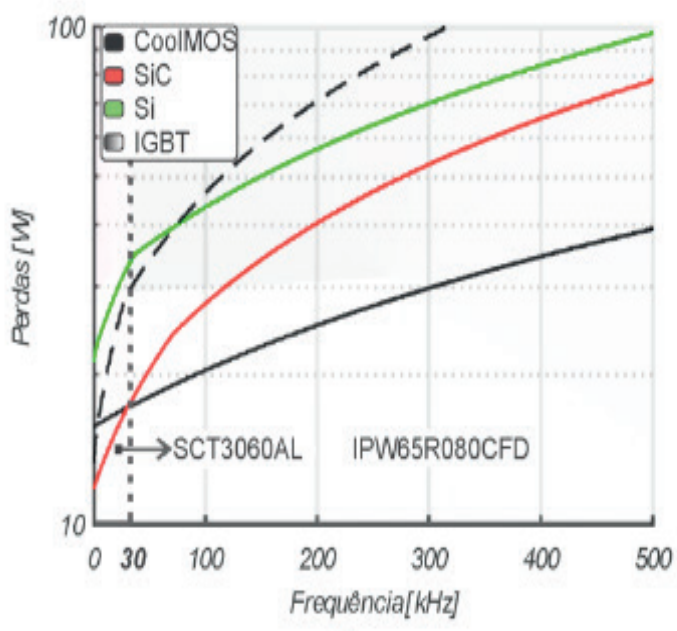

(b)

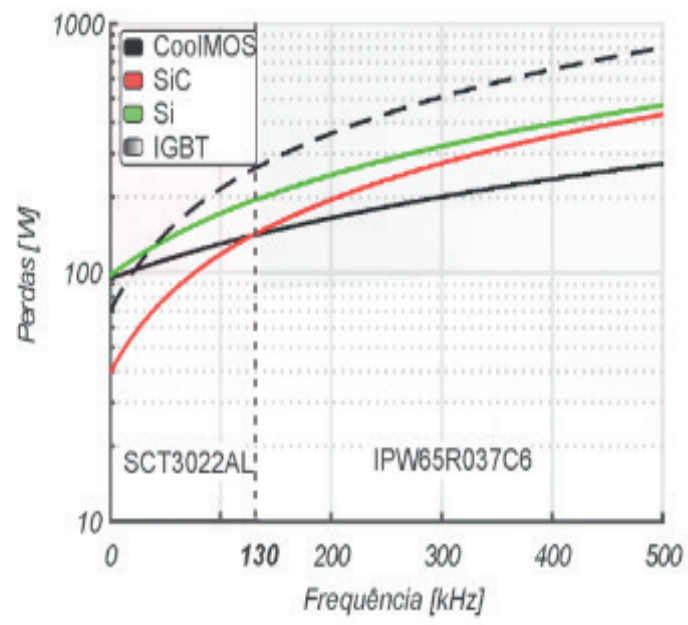

(c)

Figura 3: Perdas para 100 VCC: (a) 500 W, (b) 1500 W e (c) 4500 W.

\section{I DISCUSSÕES}

Como mostrado anteriormente, os IGBTs e os MOSFETs de $\mathrm{Si}$, SiC, CoolMOS e GaN apresentam diferentes comportamentos de acordo com o nível de corrente e a faixa de frequência a que são submetidos. Os resultados da comparação apresentada na Seção V são mostrados na Tabela II.

Com o aumento da potência e do tempo de condução, a faixa em que os transistores CoolMOS e SiC apresentam melhor desempenho são expandidas, enquanto a tecnologia GaN tem sua faixa de melhor desempenho reduzida (Figura 2). Analisando a Tabela I pode-se observar que a tecnologia GaN apresenta maior resistência drain-to-source quando em condução, se comparado com as tecnologias $\mathrm{SiC}$ e CoolMOS. Entretanto, os tempos de overlap no dispositivo são relativamente menores, o que caracteriza um melhor desempenho em maiores frequências. Assim, com o aumento da frequência, o desempenho do MOSFET GaN tende a melhorar, devido as menores perdas por comutação (Tabela II). 


\begin{tabular}{|c|c|c|c|c|c|}
\hline & $\mathrm{SiC}$ & Coolmos & $\mathrm{GaN}$ & Si & IGBT \\
\hline $2,5[A], D=50 \%$ & - & - & $\begin{array}{c}\text { Até } 500 \\
\mathrm{kHz}\end{array}$ & - & - \\
\hline $5[A], D=75 \%$ & - & $\begin{array}{c}\text { Até } 215 \\
\mathrm{kHz}\end{array}$ & $\begin{array}{c}\text { Acima de } \\
215 \mathrm{kHz}\end{array}$ & - & - \\
\hline $7,5[A], D=50 \%$ & - & $\begin{array}{c}\text { Até } 385 \\
\text { kHz }\end{array}$ & $\begin{array}{l}\text { Acima de } \\
385 \mathrm{kHz}\end{array}$ & - & - \\
\hline $15[\mathrm{~A}], \mathrm{D}=75 \%$ & Até 30 kHz & $\begin{array}{c}\text { Acima de } \\
30 \mathrm{kHz}\end{array}$ & - & - & - \\
\hline $22,5[\mathrm{~A}], \mathrm{D}=50 \%$ & Até $25 \mathrm{kHz}$ & $\begin{array}{c}\text { Acima de } \\
25 \mathrm{kHz}\end{array}$ & - & - & - \\
\hline $45[A], D=75 \%$ & $\begin{array}{c}\text { Até } 130 \\
\mathrm{kHz}\end{array}$ & $\begin{array}{c}\text { Acima de } \\
130 \mathrm{kHz}\end{array}$ & - & - & - \\
\hline
\end{tabular}

Tabela II. Faixas de operação $(\Delta \mathrm{I}=20 \%)$.

Por outro lado, a tecnologia SiC tem maiores tempos de overlap e menor resistência drain-to-source em estado ligado (Tabela I). Estes fatores fazem com que esta tecnologia tenha desempenho superior em maiores níveis de corrente e maiores tempos de condução (Tabela II), porém maiores frequências de chaveamento resultam em perdas significativas nos dispositivos.

A tecnologia CoolMOS apresenta valores intermediários, entre a tecnologia SiC e GaN, tanto na resistência de condução como nos tempos de overlap (Tabela I). Este comportamento pode ser observado na Tabela II, por meio da análise das faixas onde esta tecnologia apresenta melhor desempenho.

As tecnologias convencionais de Si e o IGBT apresentam rendimento inferior em todos casos simulados, porém se um comparativo entre eles for feito, pode-se perceber que os IGBTs apresentam rendimento superior em frequências de até 30 kHz em menores níveis de corrente, e de pelo menos $50 \mathrm{kHz}$ para maiores níveis de corrente, o que evidencia o crescimento e a superioridade destas novas tecnologias de transistores MOSFET neste campo de aplicações, onde há demanda por maiores capacidades de tensão de bloqueio, bem como maiores níveis de corrente no transistor.

Afim de analisar o impacto de diferentes ripples de correntes nas perdas dos transistores, a Tabela III traz um esboço das faixas de operação de cada tecnologia.

A análise feita para determinar estas faixas é a mesma que utilizada no caso anterior, porém com $\Delta \mathrm{i}$ de $40 \%$. Maiores ripples de corrente acarretam em maiores perdas no transistor, isto fica evidente quando é feita a comparação entre a Tabela II (20\% de ripple) com a Tabela III (40\% de ripple). Em virtude de maiores correntes RMS, pode-se observar que a faixa dos dispositivos que apresentavam melhor desempenho em maiores níveis de corrente é expandida em todos os casos, devido a influência da corrente RMS nas perdas por condução. 


\begin{tabular}{|c|c|c|c|c|c|}
\hline & $\mathrm{SiC}$ & Coolmos & GaN & $\mathrm{Si}$ & IGBT \\
\hline $2,5[A], D=50 \%$ & - & - & $\begin{array}{c}\text { Até } 500 \\
\mathrm{kHz}\end{array}$ & - & - \\
\hline $5[\mathrm{~A}], \mathrm{D}=75 \%$ & - & $\begin{array}{c}\text { Até } 240 \\
\mathrm{kHz}\end{array}$ & $\begin{array}{l}\text { Acima de } \\
240 \mathrm{kHz}\end{array}$ & - & - \\
\hline $7,5[A], D=50 \%$ & - & $\begin{array}{c}\text { Até } 400 \\
\mathrm{kHz}\end{array}$ & $\begin{array}{c}\text { Acima de } \\
400 \mathrm{kHz}\end{array}$ & - & - \\
\hline $15[A], D=75 \%$ & Até $35 \mathrm{kHz}$ & $\begin{array}{c}\text { Acima de } \\
35 \mathrm{kHz}\end{array}$ & - & - & - \\
\hline $22,5[A], D=50 \%$ & Até $30 \mathrm{kHz}$ & $\begin{array}{c}\text { Acima de } \\
30 \mathrm{kHz}\end{array}$ & - & - & - \\
\hline $45[\mathrm{~A}], \mathrm{D}=75 \%$ & $\begin{array}{c}\text { Até } 145 \\
\mathrm{kHz}\end{array}$ & $\begin{array}{c}\text { Acima de } \\
145 \mathrm{kHz}\end{array}$ & - & - & - \\
\hline
\end{tabular}

Tabela III. Faixas de operação $(\Delta \mathrm{l}=40 \%)$.

\section{I CONCLUSÃO}

A escolha da ideal tecnologia de transistor a ser utilizada em uma determinada aplicação não é tarefa simples. Parâmetros como frequência de operação, níveis de tensão, corrente, potência, razão cíclica, ondulação de corrente e temperatura de junção devem ser avaliadas. Os resultados obtidos neste artigo apontam a tecnologia de transistor SiC como a de menores perdas em situações onde há a necessidade de maior processamento de energia, menores frequências e maiores tempos de condução (ganhos). Já dispositivos CoolMOS apresentaram desempenho superior em situações onde há a demanda por maiores correntes e frequências. Dispositivos GaN demonstraram superioridade em menores potências e menores tempos de condução, apresentando melhores resultados em uma vasta faixa de frequências (Fig. 2).

Já os IGBTs apresentam melhor rendimento que o MOSFET tradicional (Si) para frequências de até $30 \mathrm{kHz}$ em menores níveis de corrente e de até $50 \mathrm{kHz}$ em maiores níveis de corrente, porém inferior ao rendimento das demais tecnologias avaliadas, fator que evidencia o crescimento e a superioridade destas novas tecnologias de transistores MOSFET onde há a demanda por maiores capacidades de tensão de bloqueio, bem como maiores níveis de corrente no transistor.

\section{I AGRADECIMENTOS}

Os autores gostariam de agradecer ao PPGEE PROEX/CAPES e ao projeto INCT-GD e aos órgãos financiadores (CNPq processo 465640/2014-1, CAPES processo no. 23038.000776/2017-54 - Código de Financiamento 001 e FAPERGS 17/2551-0000517-1). 


\section{REFERÊNCIAS}

BUSQUETS-MONGE, Sergio et al. Design of a boost power factor correction converter using optimization techniques. IEEE Transactions on Power Electronics, v. 19, n. 6, p. 1388-1396, 2004.

BIELA, J.; KOLAR, Johann W.; DEBOY, G. Optimal design of a compact 99.3\% efficient single-phase PFC rectifier. In: 2010 Twenty-Fifth Annual IEEE Applied Power Electronics Conference and Exposition (APEC). IEEE, 2010. p. 1397-1404.

SARTORI, Hamiltom Confortin; HEY, Helio Leaes; PINHEIRO, Jose Renes. An optimum design of PFC Boost Converters. In: 2009 13th European Conference on Power Electronics and Applications. IEEE, 2009. p. 1-10.

SARTORI, Hamiltom C. et al. Integrated methodology design to improve the efficiency and reduce volume of the CCM PFC boost converters with pre-sizing settings. In: 2015 IEEE 24th International Symposium on Industrial Electronics (ISIE). IEEE, 2015. p. 1378-1385.

BIELA, Juergen; BADSTUEBNER, Uwe; KOLAR, Johann W. Impact of power density maximization on efficiency of DC-DC converter systems. IEEE Transactions on Power Electronics, v. 24, n. 1, p. 288-300, 2009.

SARTORI, H. C.; BELTRAME, F.; PINHEIRO, J. R. A static converter comparative study taking into account semiconductor tecnologies and swicth auxiliary circuits: Optimized design. In: XI Brazilian Power Electronics Conference. IEEE, 2011. p. 280-285.

ERICKSON, Robert W.; MAKSIMOVIC, Dragan. Fundamentals of power electronics. Springer Science \& Business Media, 2007.

WANG, Gangyao et al. Performance comparison of 1200V 100A SiC MOSFET and 1200V 100A silicon IGBT. In: 2013 IEEE Energy Conversion Congress and Exposition. IEEE, 2013. p. 3230-3234.

SHENAI, Krishna; SCOTT, Robert S.; BALIGA, B. Jayant. Optimum semiconductors for high-power electronics. IEEE transactions on Electron Devices, v. 36, n. 9, p. 1811-1823, 1989.

BALIGA, B. Jayant. Fundamentals of power semiconductor devices. Springer Science \& Business Media, 2010.

SARTORI, Hamiltom Confortin et al. Evaluation of an optimal design for a single-phase boost PFC converter (CCM) considering different magnetic materials core. In: 2013 Brazilian Power Electronics Conference. IEEE, 2013. p. 1304-1310.

RASHID, Muhammad H. (Ed.). Power electronics handbook. Butterworth-Heinemann, 2017.

$\mathrm{HU}$, Ji et al. Robustness and balancing of parallel-connected power devices: SiC versus CoolMOS. IEEE Transactions on Industrial Electronics, v. 63, n. 4, p. 2092-2102, 2015. INFINEON. "600 V CooIMOS ${ }^{\mathrm{TM}}$ C 7 Design Guide". [S.I.], p. 28. 2015.

MILLÁN, José et al. A survey of wide bandgap power semiconductor devices. IEEE transactions on Power Electronics, v. 29, n. 5, p. 2155-2163, 2013.

BALIGA, B. Jayant. Gallium nitride devices for power electronic applications. Semiconductor Science and Technology, v. 28, n. 7, p. 074011, 2013.

HUANG, Xiucheng et al. Evaluation and application of $600 \mathrm{~V}$ GaN HEMT in cascode structure. IEEE Transactions on Power Electronics, v. 29, n. 5, p. 2453-2461, 2013. 
BELTRAME, Fernando et al. Efficiency optimization of DC/DC boost converter applied to the photovoltaic system. In: IECON 2013-39th Annual Conference of the IEEE Industrial Electronics Society. IEEE, 2013. p. 706-711. 


\section{METODOLOGIA DE PROJETO DE CONVERSORES BOOST PARA APLICAÇÕES DE ALTA EFICIÊNCIA E ELEVADO GANHO DE TENSÃO}

Data de submissão: 03/10/2019

Data de aceite: 03/01/2020

Mateus José Tiburski Universidade Federal de Santa Maria - UFSM Santa Maria - RS http://lattes.cnpq.br/5498188421691529

Éder Bridi Universidade Federal de Santa Maria - UFSM Santa Maria - RS http://lattes.cnpq.br/2790377192733673

Edemar Oliveira Prado Universidade Federal de Santa Maria - UFSM Santa Maria - RS http://lattes.cnpq.br/1774778404976935

Pedro Cerutti Bolsi Universidade Federal de Santa Maria - UFSM

Santa Maria - RS

http://lattes.cnpq.br/0324597211954149 Hamiltom Confortin Sartori Universidade Federal de Santa Maria - UFSM

Santa Maria - RS http://lattes.cnpq.br/6722822162374884 José Renes Pinheiro Universidade Federal de Santa Maria - UFSM Santa Maria - RS http://lattes.cnpq.br/2333794966860226
RESUMO: Este trabalho utiliza uma metodologia de projeto que combina o uso de um conjunto de componentes a busca da melhor solução através da maior eficiência. Esta metodologia, já consolidada, é aplicada através de um algoritmo que faz a varredura de diferentes pontos de operação do conversor. $O$ método avalia um conversor Boost de alta potência e alto ganho que realiza a interface entre uma célula combustível e um barramento CC. Em virtude do alto ganho de tensão, este conversor é incomum para esta aplicação, devido a limitação do ganho estático causado pelas resistências séries presentes nos componentes. Com isso, técnicas para minimização das resistências séries são expostas, buscando elevar o ganho do conversor. Após obter os resultados, um conversor Boost é projetado com mínimas perdas e máxima eficiência, permitindo o uso desta topologia em aplicações com alta potência e alto ganho de tensão.

PALAVRAS-CHAVE: Conversor Boost, Célula combustível, Rendimento.

\section{BOOST CONVERTER DESIGN METHODOLOGY FOR HIGH EFFICIENCY APPLICATIONS AND HIGH VOLTAGE GAIN}

ABSTRACT: This work uses a design methodology that combines the use of a set of components to find the best solution through the highest efficiency. This methodology, already 
consolidated, is applied through an algorithm that scans different operating points of the converter. The method evaluates a high power, high gain Boost converter that interfaces between a fuel cell and a DC bus. Due to the high voltage gain, this converter is unusual for this application due to the limitation of the static gain caused by the series resistances present in the components. Thus, techniques for minimizing series resistances are exposed, seeking to increase the gain of the converter. After obtaining the results, a Boost converter is designed with minimum losses and maximum efficiency, allowing the use of this topology in high power and high voltage gain applications.

KEYWORDS: Boost Converter, Fuel Cell, Efficiency.

\section{I INTRODUÇÃO}

A preocupação ambiental e a busca por fontes de energia que não degradam o meio ambiente vêm recebendo um destaque especial nas últimas décadas. Uma destas fontes de energia, a célula combustível, não emite poluentes e apresenta alta taxa de eficiência (RASID et al., 2016). No entanto, a energia elétrica produzida por uma célula a combustível possui baixa tensão. Por tanto, é necessário o uso de um conversor CC-CC que realize a interface entre a célula combustível e o barramento CC. Deste modo, aumentando a tensão a níveis adequados de conversão (350-450 VCC) e protegendo a fonte contra variações de carga (WANG et al., 2004; SAMAVATIAN e RADAN, 2015).

Contudo, para o ideal aproveitamento da energia gerada pela célula é necessário que estes conversores apresentem altas taxas de eficiência. Dessa forma, faz-se necessário o uso de técnicas que analisem a eficiência dos componentes do conversor. Ou seja, buscar dispositivos semicondutores e elementos passivos que minimizem as perdas durante o processamento da energia.

Com o advento de novas tecnologias de materiais semicondutores, como: Carbeto de Silício (SiC), Nitreto de Gálio (GaN) e o CoolMOS criou-se a possibilidade do desenvolvimento de conversores com uma maior eficiência e densidade de potência. Estes materiais trazem consigo promissores avanços, pois apresentam baixas resistências de condução e baixas capacitâncias parasitas. O que possibilita aumentar a frequência de chaveamento dos conversores e proporciona a redução do volume dos elementos magnéticos (SARTORI et al., 2013).

Contudo, a busca por um projeto ótimo ainda traz grandes desafios aos pesquisadores de hoje. Isto porque, aliar o dimensionamento dos elementos ativos aos elementos passivos de um conversor pode se tornar uma difícil tarefa, se realizada de maneira inadequada. Partindo deste pressuposto, este artigo visa buscar a aplicação de uma metodologia de projeto que aperfeiçoe a busca pela eficiência e minimize o tempo através do algoritmo apresentado em (SARTORI et al., 2015, PIVETTA et al., 2016).

Este algoritmo será utilizado na otimização de um conversor Boost convencional 
aplicado para a elevação da tensão de saída de uma célula combustível, conforme Figura 1(a). Esta topologia de conversor é utilizada pela simplicidade e o número baixo de componentes, o que torna este conversor interessante para a busca de uma melhor eficiência e densidade de potência. Devido ao alto ganho de tensão deste conversor, de 50 VCC, no pior caso da célula combustível, para 400 VCC, tensão do barramento CC, o maior esforço estará sobre a chave, pois $87,5 \%$ do tempo ela conduzirá, conforme (1), que descreve a equação do ganho estático ideal (M). Com base nesta afirmação, buscou-se também analisar o paralelismo de chaves e de capacitores (devido à alta corrente eficaz presente no capacitor e elevada resistência série), visando assim diminuir a corrente que passa por estes componentes e as perdas em condução.

$$
M=\frac{1}{1-D}
$$

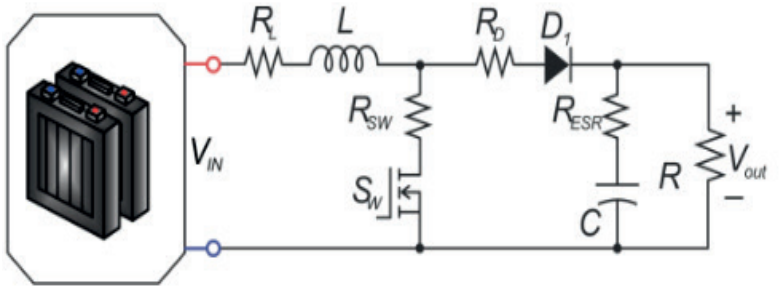

(a)

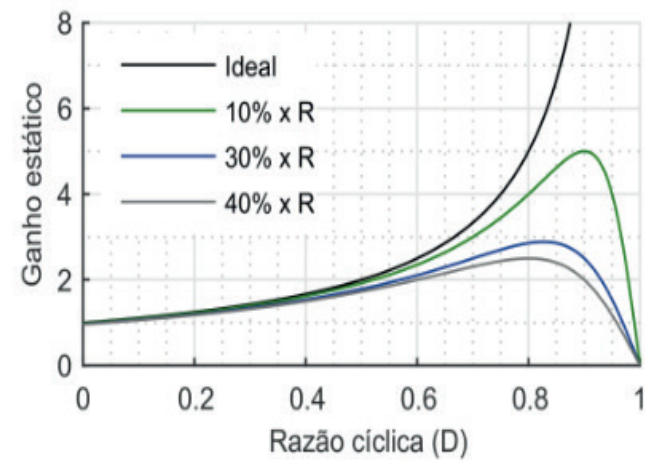

(b)

Figura 1 - Circuito do conversor Boost (a) e ganho estático (b).

Muitos trabalhos apresentam topologias de conversores para a elevação da tensão da célula combustível. Em Zhang et al. (2015), fez-se o uso da topologia do Boost Interleaved com duas fases, com multiplicador de tensão e estratégia de controle para minimizar os esforços nas chaves. Esta topologia para uma potência nominal de $1 \mathrm{~kW}$, alcançou um rendimento de 97,2\%. Já em Wu et al. (2017), a topologia estudada foi o conversor quasi-ressonante Push-Pull alimentado em corrente, ao qual buscava aumentar a confiabilidade e a diminuição do custo. Esta topologia apresentou rendimento máximo $96,12 \%$ para uma tensão de entrada de $50 \mathrm{~V}$ e potência de $510 \mathrm{~W}$. Por fim, em Taheri et al. (2017), utilizou-se a topologia isolada baseada na combinação de um Flyback e Forward que têm o mérito minimizar o tamanho do núcleo dos indutores acoplados. Por fim, um protótipo de $500 \mathrm{~W}$ é montado, alcançando um rendimento maior que $94 \%$.

Com base nos trabalhos apresentados anteriormente, nota-se que as principais formas de elevação da tensão da célula combustível baseiam-se em conversores isolados ou em multiplicadores de tensão. Além disso, estes trabalhos ressaltam que a utilização de um conversor Boost convencional para aplicação em alto ganho não é a ideal, pois devido aos elementos parasitas e as perdas associadas aos componentes 
do conversor, fazem com que o ganho estático seja limitado (ZHANG et al., 2014; WU et al., 2017; TAHERI et al., 2017; SIWAKOTI e BLAABJERG, 2017). Esta afirmação é ilustrada na Figura 1(b), onde apresenta a influência da resistência série do indutor $(R L)$ no ganho estático do conversor em relação percentual à resistência de carga (R). Com base nisso e tendo posse do algoritmo que varre parâmetros de operação do conversor e a busca a melhor solução para a aplicação, optou-se pela análise do conversor Boost convencional.

Para modelagem do ganho estático não ideal (Mef) descrita em (2), cada componente apresenta uma resistência série, conforme Figura 1(a). Sendo R a resistência da carga, $R S W, R L$ e $R D$ a resistência série da chave, do indutor e diodo, respectivamente. A equação (3) relaciona o rendimento com o ganho estático do conversor, sendo D' o complemento da razão cíclica (ERICKSON, 2000).

$$
\begin{gathered}
M_{e f}=\frac{1}{D^{\prime}}\left(\frac{1}{1+\frac{R_{L}+D R_{s W}+D^{\prime} R_{D}}{D^{\prime 2} R}}\right) \\
\eta=M_{e f} D^{\prime}
\end{gathered}
$$

\section{I METODOLOGIA DE PROJETO}

A metodologia baseia-se na escolha do melhor projeto, podendo ser selecionado a melhor solução através do menor volume, maior rendimento ou densidade volumétrica de potência. O algoritmo desenvolvido fundamenta-se na varredura de três variáveis, a frequência de chaveamento, ondulação de corrente no indutor e densidade de corrente no condutor. Estes três parâmetros variam de um ponto mínimo a um ponto máximo. Ao fim, este algoritmo escolhe o melhor projeto, selecionando o melhor ponto de operação. A Figura 2 apresenta de maneira sucinta o fluxograma do algoritmo, proposto em Matlabß. Primeiramente, são definidos os parâmetros de entrada e os componentes utilizados pelo conversor, após é realizado o projeto individual de cada componente e estimação de suas perdas. Ao final, as perdas e o volume são somados, a eficiência do conversor é calculada e a melhor solução é escolhida.

\section{I ANÁLISE DE PERDAS DE CADA COMPONENTE}

\subsection{Perdas no capacitor}

A energia dissipada pelo capacitor de saída do conversor Boost está relacionada à perda ôhmica na resistência série equivalente $R_{E S R}$. Esta resistência é vinculada a temperatura e a frequência da ondulação de corrente sobre o capacitor (BELTRAME et al., 2014). A equação que descreve o comportamento das perdas de condução no 
capacitor é definida em (4), sendo iC(t) a corrente instantânea sobre o capacitor.

$$
P_{\text {cap }}=\frac{1}{T} \int_{0}^{T} i_{C}^{2}(t) R_{E S R} d t
$$

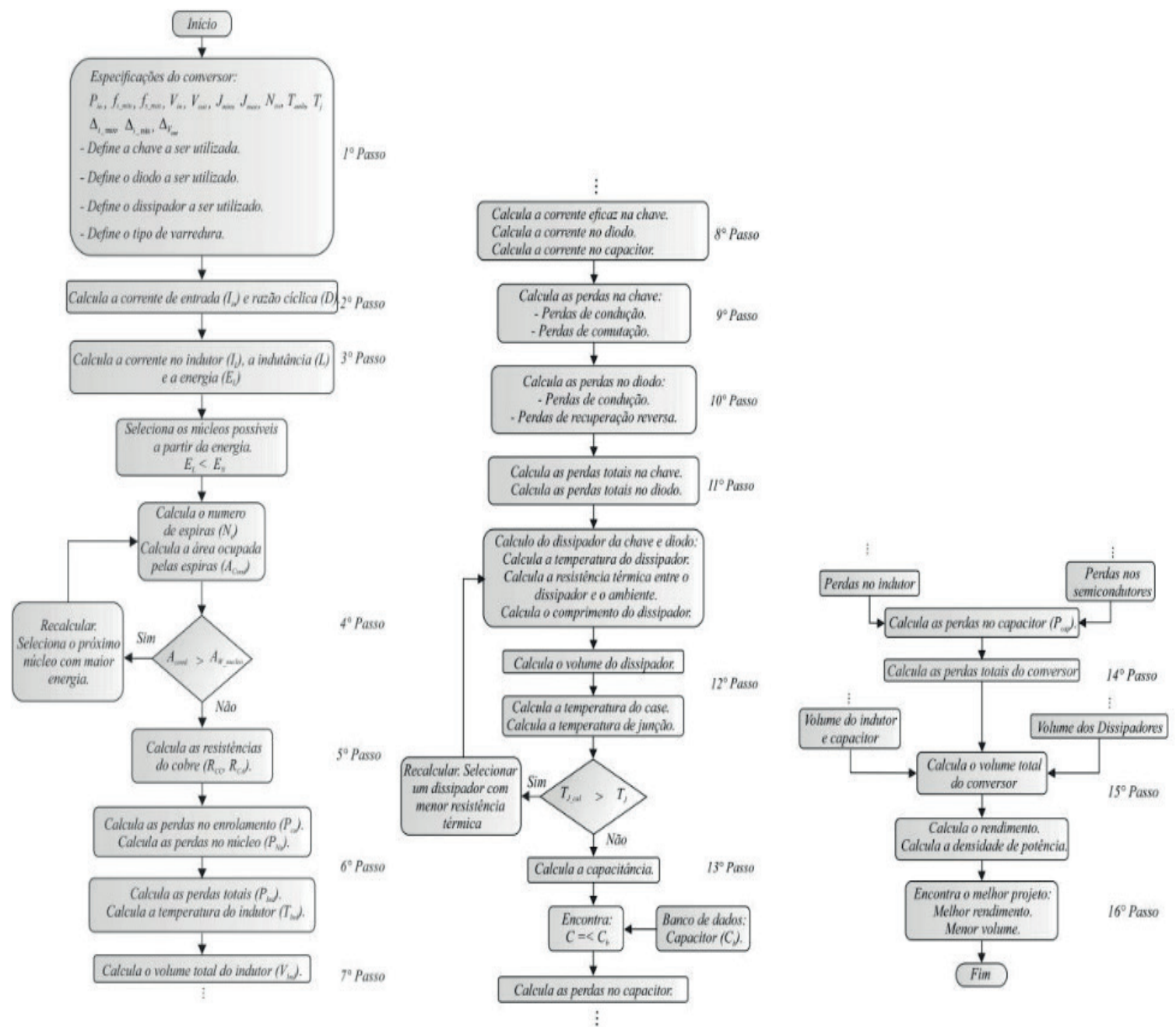

Figura 2 - Metodologia de projetos do conversor Boost.

\subsection{Perdas nos semicondutores}

A perda de condução no MOSFET está associada à resistência do canal no período de condução Rds(on). Esta resistência é diretamente ligada à temperatura de junção, sendo obtida do catálogo do fabricante (SARTORI et al., 2013). As perdas de condução são obtidas por meio de (5), sendo isw(t) a corrente instantânea que percorre o componente.

$$
P_{s w(\text { cond })}=\frac{1}{T} \int_{0}^{T} i_{S W}^{2}(t) R_{d s(o n)} d t
$$

As perdas de comutação do MOSFET são calculadas para cada período de transição. No momento em que o interruptor é ativado, as perdas são dadas por (6) e obtidas por (7) durante o bloqueio. As variáveis, $I_{\min }$ e $I_{\max }$ são as correntes mínima e 
máxima no semicondutor, respectivamente. $V_{\text {out }}$ é a tensão de saída ou sobre a chave, $t_{r}$ é o tempo de subida, $t_{f}$ é o tempo de descida e $C_{o s s}$ é a capacitância de saída do interruptor (BELTRAME et al., 2014).

$$
\begin{gathered}
P_{\text {sw (on ) }}=\frac{1}{2} I_{\min } V_{\text {out }} t_{r} f_{s}+\frac{1}{2} C_{\text {oss }} V_{\text {out }}{ }^{2} f_{s} \\
P_{s w(\text { off })}=\frac{1}{2} I_{\max } V_{\text {out }} t_{r} f_{s}
\end{gathered}
$$

As perdas totais na chave são obtidas pelo somatório das perdas de condução e comutação, conforme:

$$
P_{s w(\text { cond })}=P_{s w(\text { cond })}+P_{s w(o n)}+P_{s w(o f f)}
$$

As perdas de condução no diodo são calculadas em função da queda de tensão que ocorre quando o dispositivo semicondutor está em condução. Está queda de tensão depende tanto da corrente quanto da temperatura de junção que o diodo opera. Por outro lado, as perdas de comutação são determinadas a partir da carga de recuperação reversa $Q_{r r}$ do diodo durante o bloqueio, esta carga está relacionada com a corrente e a temperatura de junção do semicondutor (TJ) (BELTRAME et al., 2014). A partir disso, as perdas totais no diodo são calculadas por (9), onde vf(t) é a queda de tensão do semicondutor e id(t) é a corrente instantânea que flui no diodo.

$$
P_{s w(\text { cond })}=\frac{1}{T} \int_{0}^{T} v_{D}(t) i_{D}(t) d t+V_{o u t} Q_{r r} f_{s}
$$

\section{I PERDAS NO INDUTOR}

As perdas de enrolamento são obtidas em função da resistência CC e CA do condutor. A resistência CC do condutor é obtida por:

$$
R_{c c}=\frac{\rho l_{w}}{A_{w}}
$$

a qual depende da resistividade elétrica do fio, da área da seção transversal Aw e do comprimento do enrolamento $I_{w}$ (SARTORI et al., 2015)

Já a resistência CA é obtida para núcleos toroidais por:

$$
R_{c a}=\left(\frac{4}{\pi}\right)^{\frac{1}{4}} N_{e} l_{t} \sqrt{\frac{\rho \mu_{C} \pi f_{h}}{d_{w} t_{w}}}\left(1+\frac{2\left(N_{C}^{2}-1\right)}{3}\right)
$$


sendo, Ne o número de espiras, It o comprimento médio da espira, a permeabilidade relativa do Cobre, fh a frequência do harmônico, dw diâmetro do condutor, tw a distância entre dois condutores adjacentes e Nc o número de camadas de enrolamento (SARTORI et al., 2015)

Dessa forma, as perdas no enrolamento são dadas pela soma das perdas CC e CA, conforme:

$$
P_{W}=R_{c c} I_{L(r m s)}^{2}+\sum_{f=0}^{\infty} R_{c a}\left(f_{h}\right) I_{L}^{2}\left(f_{h}\right)
$$

Sendo $I_{L(r m s)}$ a corrente eficaz no indutor e $I_{L}(f h)$ a corrente de cada harmônico. Já as perdas relacionadas ao núcleo são dadas por

$$
P_{n u}=V_{n u} a\left(\frac{B_{n u}{ }^{b}}{\left(2 t_{o n}\right)^{c}} \frac{t_{o n}}{T_{s}}+\frac{B_{n u}{ }^{b}}{\left(2 t_{\text {off }}\right)^{c}} \frac{t_{o f f}}{T_{s}}\right)
$$

onde, a equação depende diretamente do volume do núcleo $V_{n u^{\prime}}$ do tempo de condução da chave $t_{o n}$, do tempo de condução do diodo $t_{\text {off }}$ do período $T_{s}$, da variação da densidade de fluxo magnético $B_{n u}$ e das características magnéticas de cada núcleo obtidas do catálogo (a, b, c) (SARTORI et al., 2015)

\section{I RESULTADOS}

Na Tabela 1 são determinados os parâmetros de projeto utilizados para a varredura do algoritmo. A ondulação de corrente máxima de pico-a-pico foi mantida até $10 \%$, para garantir baixa degradação da célula combustível. A chave utilizada é da família CooIMOS da fabricante Infineon (outras chaves poderiam ser analisadas, mas devido a característica de baixa resistência de condução, esta chave foi selecionada), o banco de capacitores eletrolíticos utilizado é da fabricante TDK Corporation ${ }^{T M}$.

$\begin{array}{lcc}\text { Parâmetros } & \text { Valor } & \text { Unidade } \\ \text { Frequência } & 1-50 & \mathrm{kHz} \\ \text { Variação de corrente } & 1-10 & \% \\ \text { Densidade de corrente } & 300-500 & \mathrm{~A} / \mathrm{cm}^{2} \\ \text { Número de chaves } & 1-10 & - \\ \text { Número de capacitores } & 1-10 & - \\ \text { Percentual de utilização da janela } & 40 & \% \\ \text { Potência de saída } & 3000 & \mathrm{~W} \\ \text { Tensão de entrada } & 50 & \mathrm{~V}\end{array}$


Tensão de saída

Variação da tensão de saída

Temperatura ambiente

Temperatura de junção

Núcleo

Chave

Diodo

Capacitores

Tabela 1 - Parâmetros de projeto do conversor Boost.

A resistência série total do indutor tem um papel fundamental no ganho estático do conversor Boost, ela está presente em ambos os estágios de operação do conversor, conforme (2). Uma maneira de diminuir seu valor é reduzir a densidade de corrente do condutor, fazendo com que a seção transversal do condutor aumente e, assim, reduzindo a resistência CC do cobre, conforme (10). A Figura 3(a) mostra a relação entre densidade de corrente do fio com as perdas totais e a resistência em série do indutor. Contudo, uma investigação para valores menores de densidade de corrente do fio pode causar projetos inviáveis, isto é, esta redução influencia no tamanho do núcleo magnético, o que pode tornar o indutor volumoso, pois o algoritmo entra em um laço, buscando encontrar um núcleo exequível, conforme $4^{\circ}$ passo, Figura 2. Pensando nisso, um limite de $\mathrm{Jmin}=300 \mathrm{~A} / \mathrm{cm}^{\wedge} 2$ foi determinado.

De acordo com (2), a chave também apresenta grande influência no ganho estático para razões cíclicas elevadas, pois sua resistência total é proporcional ao ciclo de trabalho (D). Além da busca por chaves com menor Rds(on), uma maneira de diminuir esta resistência é aplicar a técnica de paralelismo de chaves. Esta técnica mostra-se vantajosa nesta aplicação, pois reduz proporcionalmente a corrente que passa por este elemento, diminuindo as perdas de condução, conforme Figura 3(b), que relaciona o número de dispositivos em paralelo com a resistência total série e as perdas no interruptor. A resistência série equivalente e as perdas totais relacionadas ao número de capacitores em paralelo são mostradas na Figura 3(c), (os capacitores em adicionados em paralelo possuem mesma capacitância e resistência série). Esta resistência tem menor influência no ganho estático do conversor Boost, mas não deve ser negligenciada, pois afetam diretamente a eficiência do conversor. 


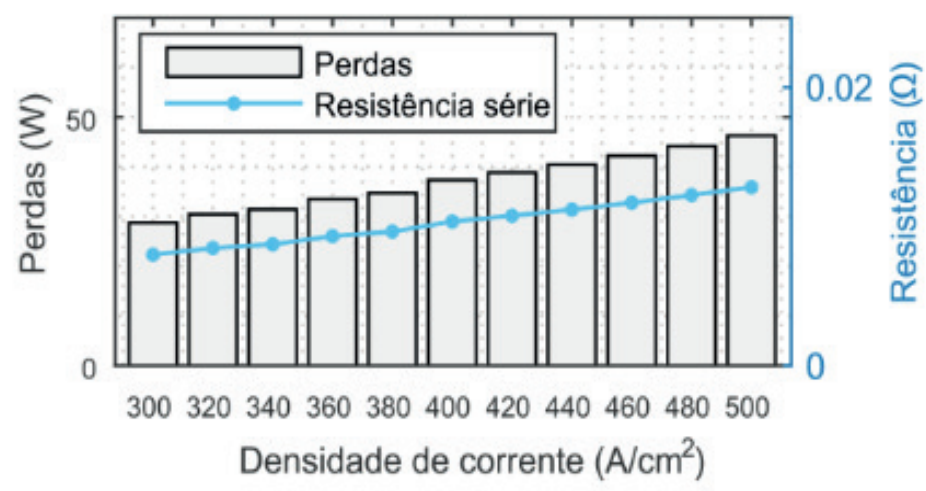

(a)

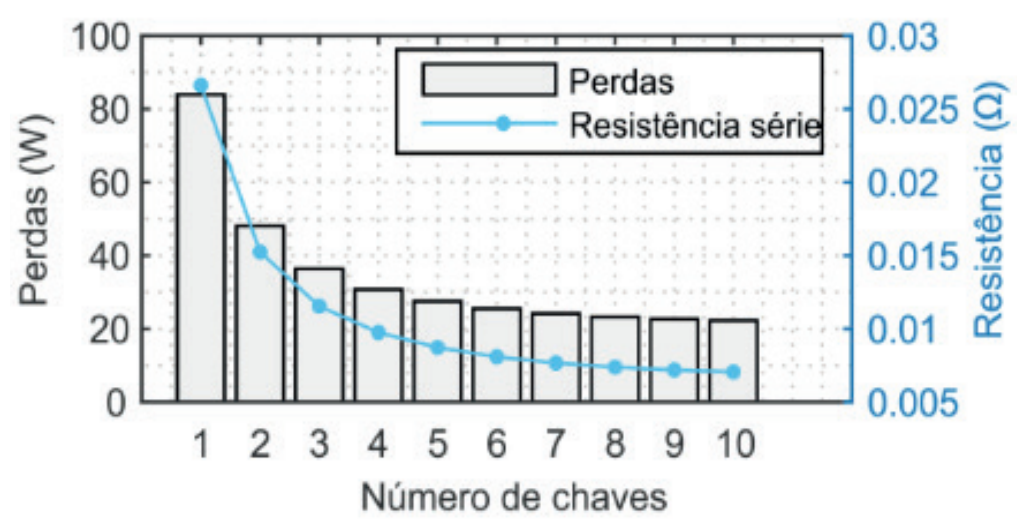

(b)

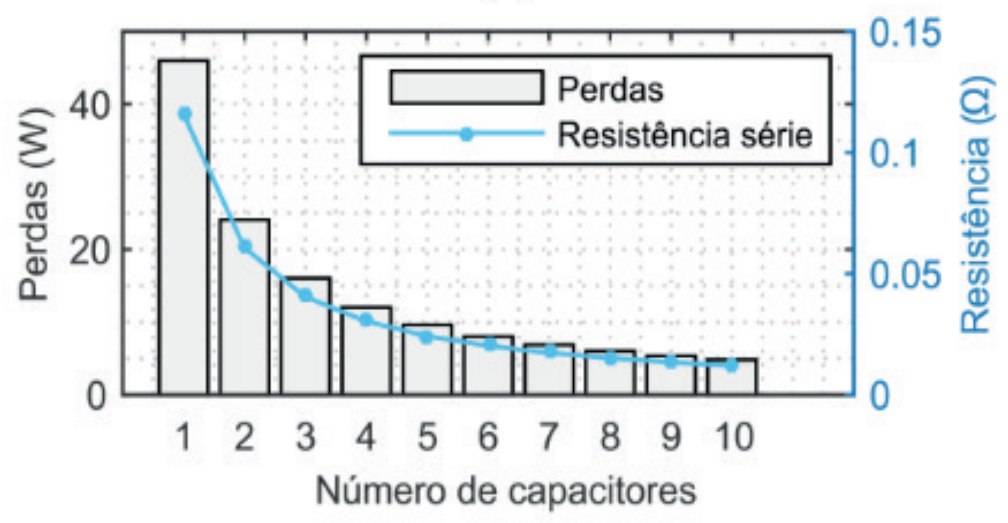

(c)

Figura 3 - Perdas vs resistência série sob variação da densidade de corrente (a), número de chaves (b) e de capacitores (c).

Embora que outros dispositivos semicondutores com melhor desempenho pudessem ser utilizados na análise, a alta corrente presente neste componente faz com que as perdas sejam ainda muito altas, mesmo com uma única chave de menor resistência série, havendo a necessidade da utilização de chaves em paralelo. A Figura 4 apresenta uma análise detalhada das perdas de cada componente do conversor, considerando o uso de até 10 chaves em paralelo com mesmo Rds(on). Observa-se que, para uma chave, as perdas relacionadas ao transistor representam cerca de $47,18 \%$ do total de perdas, utilizando material magnético High Flux. A adição de chaves em paralelo faz com que as perdas relacionadas no interruptor diminuam exponencialmente. Para os outros componentes, a contribuição para as perdas do 
conversor permanece constante, uma vez que o ponto de operação escolhido pelo algoritmo é o mesmo para todas as combinações de chaves.

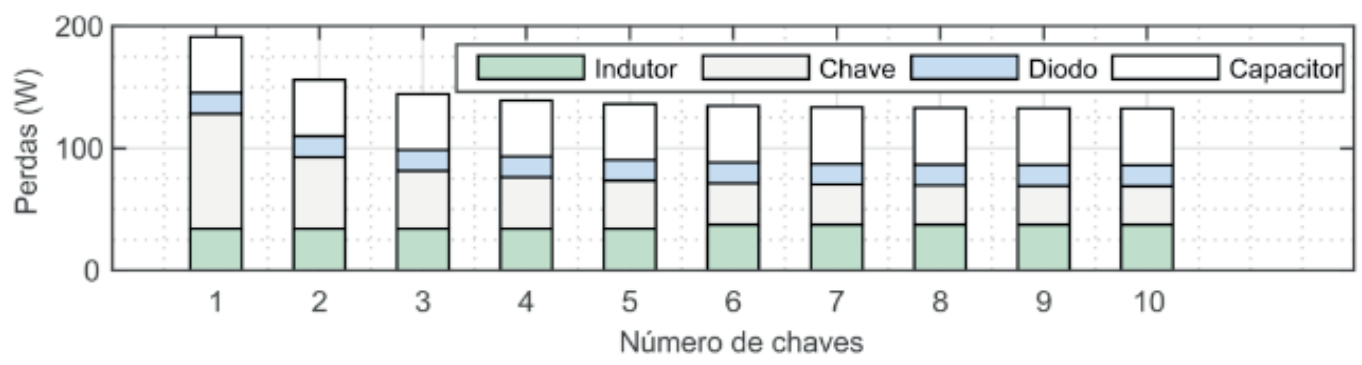

Figura 4 - Perdas nos componentes do conversor Boost para cada chave em paralelo.

Como visto na Figura 4 as perdas associadas ao capacitor apresentam uma grande contribuição nas perdas totais do conversor. Em vista disso, capacitores em paralelo para reduzir a corrente que flui através desses elementos são utilizados. A Figura 5 mostra uma análise de perdas do conversor considerando seis chaves em paralelo (este número máximo de interruptores é escolhido porque um aumento maior não apresenta uma diminuição significativa de perdas) e variando apenas o número de capacitores em paralelo. Como as perdas no capacitor são proporcionais à corrente quadrática (4), as perdas também diminuem exponencialmente com o acréscimo de capacitores paralelos.

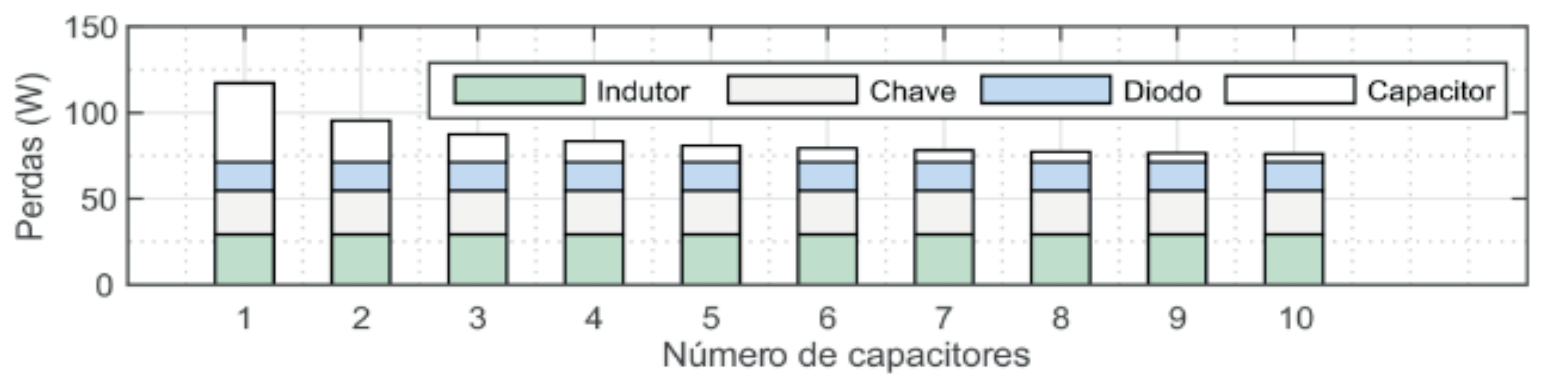

Figura 5 - Perdas nos componentes do conversor Boost para cada capacitor em paralelo.

No entanto, este número elevado de chaves e capacitores esbarra em outros problemas de otimização, o custo. A adição de chaves torna o sistema mais caro sem um aumento significativo no rendimento do conversor. Por outro lado, o aumento nas chaves traz consigo uma redução no volume do conversor, pois uma menor potência dissipada induz a um menor dissipador de calor para manter a temperatura de junção. A técnica de paralelismo torna-se interessante para esta aplicação em específico, onde a corrente nestes componentes é alta. No entanto, projetos com menor potência onde a variedade de componentes é maior, com dispositivos de melhor desempenho, o paralelismo não se torna a escolha ideal e sim a busca por componentes com melhor comportamento para a aplicação.

A Tabela 2 apresenta o resultado selecionado pelo algoritmo para o projeto do conversor com seis chaves e quatro capacitores em paralelo (com mesmo Rds(on) 
para chave e mesmo $R_{E S R}$ para o capacitor). Além disso, são expostas o projeto do indutor, as perdas e as resistências séries de cada componente.

$\begin{array}{llcc}\text { Parâmetros } & \text { Valor } & \text { Parâmetros } & \text { Valor } \\ \text { Rendimento } & 97,2236 \% & \text { AWG } & 20 \\ \text { Ondulação de corrente } & 10 \% & \begin{array}{c}\text { Número de fios em } \\ \text { paralelo }\end{array} & 33 \\ \text { Frequência } & 26 \mathrm{kHz} & \begin{array}{c}\text { Número de espiras } \\ \text { Densidade de Corrente }\end{array} & 300 \mathrm{~A} / \mathrm{cm}^{2} \\ \text { Número de chaves } & 06 & \text { Área de seção } & 79 \\ \text { Número de capacitores } & 04 & \text { Execução } & 0,2 \mathrm{~cm}^{2} \\ \text { Núcleo } & \mathrm{High} \mathrm{flux} & \text { Perda total } & 83.2907 \mathrm{~W} \\ \text { Capacitor } & 47 \mu \mathrm{F} & \text { Perdas no indutor } & 29.1731 \mathrm{~W} \\ \text { Indutância } & 291.67 \mu \mathrm{H} & \text { Interruptor } & 25.5046 \mathrm{~W} \\ \text { Part Number } & 58337 & \text { Perdas no diodo } & 16.5703 \mathrm{~W} \\ \text { Área da janela } & 47,1 \mathrm{~cm}^{2} & \text { Resistência do indutor } & 0.0081 \Omega \\ \text { Energia } & 2500 \mathrm{~m} \mathrm{HA}^{2} & \text { Resistência da chave } & 0.0081 \Omega \\ \text { Permeabilidade inicial } & 26 \% & \text { Resistência do diodo } & 0.0368 \Omega \\ & & \text { Resistência do } & 0.0305 \Omega\end{array}$

Tabela 2- Dados de projeto obtidos pelo algoritmo.

A Figura 6 apresenta o ganho estático do conversor para aplicação das técnicas de paralelismo de transistores e capacitores e variação da densidade de corrente, utilizando-se das equações (1), (2) e (3) apresentadas anteriormente. Observa-se que o ganho alcançado para a condição de trabalho imposta é de 7,802, alcançando uma tensão de saída de 390,1V acima dos 350,0V descritos em (WANG et al., 2004). O que afirma a utilização do conversor Boost e a aplicação de técnicas de redução das resistências séries expostas é possível obter altos rendimentos e ganhos de tensão para a aplicação analisada.
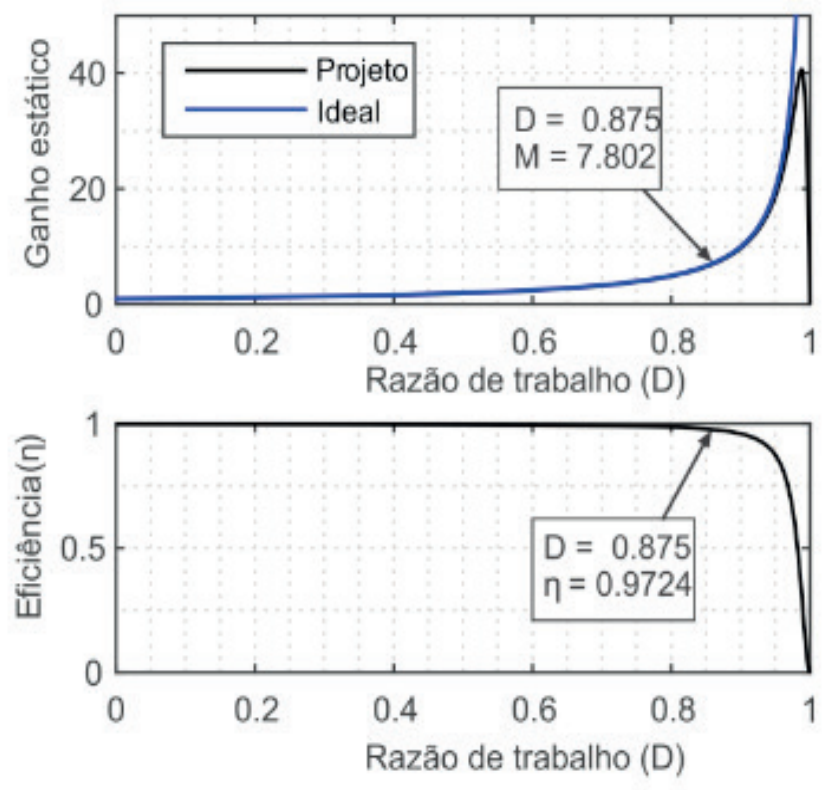

Figura 6 - Ganho estático e eficiência do conversor para os resultados da Tabela 2. 


\section{I CONCLUSÕES}

Este trabalho utilizou uma metodologia de projeto voltada à busca de uma melhor solução para um conversor Boost, aplicado a elevação da tensão de uma célula a combustível. Convencionalmente, devido às significativas perdas, esta topologia de conversor não é utilizada em aplicações com elevado ganho de tensão. Entretanto, a metodologia de projeto empregada aliada a técnicas de paralelismo e uma adequada escolha dos componentes possibilitaram o projeto de um conversor Boost com rendimento acima de $97 \%(97.22 \%)$.

A aplicação deste método, baseado na varredura de três parâmetros de projeto, ondulação e densidade de corrente no indutor e frequência de chaveamento, resultaram em projetos de alta eficiência. Além disso, buscando elevar o ganho técnicas de redução das resistências foram apresentadas. Logo, a aplicação da técnica de paralelismo de componentes resultou numa drástica diminuição nas perdas globais do projeto. Por exemplo, se compararmos o projeto proposto, Tabela 2, com o projeto que considera apenas uma chave e um capacitor (Figura 4), as perdas totais diminuíram em torno de 56\% o que acarretaram um aumento na eficiência de 3,29\%. Com base nos resultados obtidos são calculadas as resistências série de cada elemento do conversor e posteriormente, são apresentadas as curvas do ganho estático do conversor, evidenciando a possibilidade da utilização da topologia Boost em aplicações com alto ganho e alta potência. Por fim, vale ressaltar que o paralelismo de transistores e de capacitores pode reduzir as perdas e aumentar o ganho estático de conversores Boost.

\section{I AGRADECIMENTOS}

O presente trabalho foi realizado com apoio da Coordenação de Aperfeiçoamento de Pessoal de Nível Superior - Brasil (CAPES/PROEX) - Código de Financiamento 001.

\section{REFERÊNCIAS}

BELTRAME F., DUPONT F. H., SARTORI H. C. and PINHEIRO J. R.," Design methodology to improve the converters' efficiency applied to photovoltaic systems," IECON 2014 - 40th Annual Conference of the IEEE Industrial Electronics Society, Dallas, TX, 2014, pp. 1397-1403. doi: 10.1109/ IECON.2014.7048684

ERICKSON, R. W., 2000. Fundamentals of Power Electronics. Second Edition. Secaucus, NJ, USA: Kluwer Academic Publishers.

PIVETTA L. C., SARTORI H. C. and PINHEIRO J. R.," Designing power converters based on trade-offs and constrains," IECON 2016 - 42nd Annual Conference of the IEEE Industrial Electronics Society, Florence, 2016, pp. 3709-3714. doi: 10.1109/IECON.2016.7794001

RASID N., RAHIM N. A. and RAIHAN S. R. S.," Comparative study of DC-DC converters for fuel cell vehicle," 4th IET Clean Energy and Technology Conference (CEAT 2016), Kuala Lumpur, 2016, 
SAMAVATIAN V. and RADAN A.,"A High Efficiency Input/Output Magnetically Coupled Interleaved Buck-Boost Converter With Low Internal Oscillation for Fuel-Cell Applications: CCM SteadyState Analysis," in IEEE Transactions on Industrial Electronics, vol. 62, no. 9, pp. 5560- 5568, Sept. 2015. doi: 10.1109/TIE.2015.2408560

SARTORI H. C., BAGGIO J. E., H. L., PINHEIRO J. R. and BELTRAME F.," Integrated methodology design to improve the efficiency and reduce volume of the CCM PFC boost converters with presizing settings," 2015 IEEE 24th International Symposium on Industrial Electronics (ISIE), Buzios, 2015, pp. 1378-1385. doi: 10.1109/ISIE.2015.7281674

SARTORI H. C., BELTRAME F., FIGUEIRA H. H., BAGGIO J. E. and PINHEIRO J. R.,"Power density comparative analysis concerning to three transistor technologies applied to a CCM PFC BOOST converter using optimization techniques," 2013 Brazilian Power Electronics Conference, Gramado, 2013, pp. 1317-1323. doi: 10.1109/COBEP.2013.6785286

SIWAKOTI, Y. P.; BLAABJERG, F. Single switch nonisolated ultra-step-up dc-dc converter with an integrated coupled inductor for high boost applications. IEEE Transactions on Power Electronics, v. 32, n. 11, p. 8544-8558, Nov 2017. ISSN 0885-8993.

TAHERI M., MILIMONFARED J., ABBASI ARAND B. and SALEHI DOBAKHSHARI S.," high step-up dual full-bridge ZVS DC-DC converter with improved integrated magnetics and new resonant switched capacitor cell,"in IET Power Electronics, vol. 10, no. 6, pp. 606-618, 519 2017. doi: 10.1049/iet-pel.2016.0520

WANG J., PENG F. Z., ANDERSON J., JOSEPH A. and BUFFENBARGER R.," Low cost fuel cell converter system for residential power generation," in IEEE Transactions on Power Electronics, vol. 19, no. 5, pp. 1315-1322, Sept. 2004. doi: 10.1109/TPEL.2004.833455

WU Q., WANG Q., XU J., LI H. and XIAO L.," A High-Efficiency Step-Up Current-Fed PushPull Quasi-Resonant Converter With Fewer Components for Fuel Cell Application," in IEEE Transactions on Industrial Electronics, vol. 64, no. 8, pp. 6639-6648, Aug. 2017. doi: 10.1109/ TIE.2016.2638800

ZHANG L., Xu D., SHEN G., CHEN M., IOINOVICI A. and WU X.," A High Step-Up DC to DC Converter Under Alternating Phase Shift Control for Fuel Cell Power System," in IEEE Transactions on Power Electronics, vol. 30, no. 3, pp. 1694-1703, March 2015. doi: 10.1109/ TPEL.2014.2320290 


\section{INFLUÊNCIA DO PONTO DE OPERAÇÃO DE CONVERSORES ESTÁTICOS NO VOLUME E PERDAS DE DIFERENTES MATERIAIS MAGNÉTICOS}

Data de submissão: 14/10/2019

Data de aceite: 03/01/2020

Pedro Cerutti Bolsi Universidade Federal de Santa Maria - UFSM Santa Maria - RS http://lattes.cnpq.br/0324597211954149

Edemar de Oliveira Prado Universidade Federal de Santa Maria - UFSM

Santa Maria - RS

http://lattes.cnpq.br/1774778404976935

Mateus José Tiburski

Universidade Federal de Santa Maria - UFSM

Santa Maria - RS

http://lattes.cnpq.br/5498188421691529

Éder Bridi

Universidade Federal de Santa Maria - UFSM

Santa Maria - RS

http://lattes.cnpq.br/2790377192733673

Hamiltom Confortin Sartori

Universidade Federal de Santa Maria - UFSM

Santa Maria - RS

http://lattes.cnpq.br/6722822162374884

José Renes Pinheiro

Universidade Federal de Santa Maria - UFSM

Santa Maria - RS

http://lattes.cnpq.br/2333794966860226
RESUMO: Este artigo avalia e compara o comportamento elétrico e térmico de tecnologias de núcleos magnéticos através de um projeto de indutor. $\mathrm{O}$ objetivo é identificar os materiais de maior densidade volumétrica de potência e eficiência. As não linearidades causadas por variações na permeabilidade magnética dos materiais tornam 0 projeto complexo, e a visualização das relações entre os parâmetros de projeto é essencial. Projetos de indutor para núcleos de tecnologia MPP, $\mathrm{HF}, \mathrm{Kool} \mathrm{M} \mu{ }^{\circledR}, \mathrm{Kool} \mathrm{M} \mu \mathrm{MAX}{ }^{\circledR}$ e ferrite $\mathrm{P}$ são avaliados e comparados em uma varredura de pontos de operação (frequência e ondulação de corrente). Os resultados apresentam a relação entre volume, densidade de corrente, perdas no cobre e perdas no núcleo, apontando as faixas específicas nas quais cada material é recomendado.

PALAVRAS-CHAVE: Densidade de Corrente, Frequência, Núcleos Magnéticos, Perdas, Volume.

\section{COMPARISON OF CORE TECHNOLOGIES APPLIED TO POWER INDUCTORS}

ABSTRACT: This work evaluates and compares electrical and thermal behavior of magnetic material technologies applied to power inductors. The objective is to identify materials that have the highest volumetric power 
density and efficiency. The nonidealities caused by variations in magnetic permeability increase design complexity, and knowing the thermal, electrical and magnetic relations in project parameters is essential. Inductor designs for MPP, HF, Sendust, Kool M $\mu$ MAX and $\mathrm{P}$ ferrite materials are evaluated and compared over a span of operating points (frequency and current ripple). Results present the relationship between volume, current density, copper losses and core losses, pointing the specific ranges each material is recommended at. Design procedure is described, and discussions relate performance to cost.

KEYWORDS: Current Density, Frequency, Magnetic Cores, Losses, Volume.

\section{I INTRODUÇÃO}

A redução do tamanho e peso dos circuitos é de grande interesse em aplicações como veículos elétricos, veículos elétricos híbridos, e conversores fotovoltaicos. Os esforços de pesquisa voltados a essas aplicações se dirigem à otimização da quantidade de energia processada relativa ao volume (SARTORI, HEY e PINHEIRO 2009), (SARTORI et al., 2015), possível através da elevação da frequência de operação. No entanto, elevar a frequência resulta em mais perdas de comutação nos semicondutores (SARTORI, BELTRAME e PINHEIRO, 2011).

Atualmente, a operação eficiente em alta frequência tornou-se possível graças ao desenvolvimento de tecnologias de MOSFETs como os CoolMOS, GaN e SiC (WANG et al., 2013). À medida que os transistores têm seus limites operacionais aumentados, as tecnologias de materiais magnéticos encaram a demanda, e a oportunidade, de seguirem o mesmo caminho. Ao passo que os transistores evoluíam, o ferrite era o material mais empregado para aplicações em alta frequência, podendo ser encontrados em frequências de $10 \mathrm{kHz}$ a $1 \mathrm{MHz}$, com densidades de fluxo magnético na ordem de 0,05 T a 0,3 T (TENANT, ROUSSEAU, 1995). (ROSHEN et al., 1995).

Dado que indutores, em muitos casos, aparecem como o maior componente do circuito, a redução do seu volume está geralmente atribuída à máxima densidade de fluxo que o material magnético pode suportar sem atingir a saturação. Portanto, tecnologias de núcleo de pó de ferro (powder) tornam-se atrativas, devido às suas densidades máximas de fluxo de até 1,5 T (MAGNETICS 2017). Quando utilizando estes núcleos, a permeabilidade baixa e característica de saturação suave irão resultar em projetos que estarão na maioria das vezes limitados pela temperatura, ao invés de serem limitados pela saturação magnética (COX 2018).

Os esforços de pesquisa na direção do aumento da densidade volumétrica potência motivaram a descrição e comparação do desempenho de vários materiais de núcleo magnético até altas frequências. Para este fim, uma simulação computacional foi elaborada, na qual projetos de indutor são iterados para frequências de comutação de $5 \mathrm{kHz}$ a $1 \mathrm{MHz}$, e ondulações de corrente (ripple) de $10 \%$ a $80 \%$, utilizando densidades de corrente de $200 \mathrm{~A} / \mathrm{cm}^{2}$ e $600 \mathrm{~A} / \mathrm{cm}^{2}$. Materiais avaliados incluem ferrites 
P (MAGNETICS 2015); núcleos powder Molypermalloy (MPP); High Flux (HF); Kool $\mathrm{M} \mu \AA$; e Kool M $\mu$ MAX® (MAGNETICS 2017).

De forma a demonstrar o procedimento de projeto do indutor, uma topologia simples conversor foi usada, o conversor Boost. O procedimento de projeto (seção 2) e as discussões apresentadas (seção 3) podem ser aplicados a qualquer cenário que exija densidade de potência. Como entrada do circuito, um arranjo de cinco módulos solares policristalinos Kyocera KT265 é considerado, operando sob condições normais de operação (NOCT).

\section{I PROCEDIMENTO DE PROJETO DO INDUTOR}

Um banco de dados foi construído para a simulação contendo núcleos ordenados de forma crescente em capacidade de armazenamento de energia (COX, 2018), (MAGNETICS, 2017). Ao longo da simulação, a realizabilidade construtiva de um núcleo é verificada através de verificações de design e, quando uma decisão não atinge tais restrições de projeto, um núcleo mais volumoso e de maior energia substitui a escolha de núcleo prévia.

\section{A. Dimensionamento do Condutor}

O primeiro passo é projetar os condutores de forma a mitigar os efeitos pelicular (skin) e proximidade, reduzindo a parcela de resistência CA. Para isso, o fio litz é empregado. A profundidade pelicular $(\delta)$, em $\mathrm{cm}$, será usada para selecionar um diâmetro para os filamentos de cobre (SULLIVAN, 1999),

$$
\delta=\sqrt{\frac{\rho}{\pi \mu f_{\text {eff }}}} \cdot 10^{2}
$$

em que $\rho$ é a resistividade do cobre esmaltado em função da temperatura, em $\Omega . m, \mu_{o}$ a permeabilidade magnética do vácuo, em $\mathrm{H} / \mathrm{m}$, e $\mathrm{f}_{\text {eff }}$ a frequência efetiva nos enrolamentos, em Hz. Para o conversor Boost, que possui uma forma de onda não senoidal com nível CC, a Equação 1 deve ser aplicada utilizando uma frequência efetiva $\mathrm{f}_{\text {eff }}$, introduzida por (SULLIVAN, 1999).

O número de filamentos no agrupamento litz será o número de condutores em paralelo $\left(n_{p}\right)$ que compensa para a área de cobre dada a densidade de corrente $(J)$, em $\mathrm{A} / \mathrm{cm}^{2}$ e a corrente eficaz $\left(\mathrm{I}_{\mathrm{RMS}}\right)$, em $\mathrm{A}$, 


$$
n_{p}=\frac{\left(\frac{I_{R M S}}{J}\right)}{\left(\pi \frac{d_{c}^{2}}{4}\right)}
$$

em que dc é o diâmetro do filamento, em $\mathrm{cm}$. Para garantir a minimização da resistência $A C$, bons projetos de condutor litz utilizam filamentos de diâmetro menor que $\delta$. Um filamento de diâmetro (dc) 4 vezes menor que $\delta$ é escolhido, uma escolha frequente (SULLIVAN, 1999).

Para qualquer agrupamento de condutores isolados, aumentar o número de filamentos, ao passo que se diminui o diâmetro individual, é uma forma de reduzir a resistência CA. No entanto, à medida que o número de filamentos aumenta, a fração da janela ocupada pelo agrupamento de cobre reduz, e a fração ocupada pelo isolamento aumenta. Isso resulta numa elevação da resistência CC para um mesmo diâmetro (SULLIVAN, 1999).

Eventualmente, a resistencia CA é reduzida a um ponto em que a elevação da resistência CC não compensa. Portanto, existe um número ótimo de filamentos (nopt) que resulta na minimização da resistência CA sem comprometer a resistência CC, obtido analiticamente por (SULLIVAN, 1999),

$$
n_{\text {opt }}=\frac{\delta^{2} b}{N} \frac{\sqrt{192\left(F_{R}-1\right)}}{\pi d_{c}^{3}}
$$

em que $\delta$ é a profundidade pelicular, em $\mathrm{cm}, \mathrm{N}$ é o número de espiras, b é a largura da janela atribuída às espiras (bobbin breadth), em cm, e dc o diâmetro do filamento, em $\mathrm{cm}$. $F_{R}$ é a razão entre as resistências CA e CC.

O número ótimo de filamentos dado pela Equação (3) é uma indicação geral e não uma prescrição exata. A combinação de $n_{o p t}$ e $d_{c}$ que minimiza a resistência CA sem comprometer a resistência CC é obtida iterativamente, aproximando o fator de resistência $F_{R}$ da unidade, uma vez que,

$$
F_{R}=\frac{R_{c a}}{R_{c c}}=1+\frac{(\pi n N)^{2} d_{c}{ }^{6}}{192 \delta^{4} b^{2}} .
$$

\section{B. Capacidade de Armazenamento de Energia e Requisito de Indutância}

A Equação (5) é usada para selecionar o indutor para um conversor Boost em Modo de Condução Contínua (MCC) (SARTORI, BELTRAME, PINHEIRO, 2011), 


$$
L=\frac{V_{i n} D}{f \Delta i}
$$

em que $\mathrm{L}$ é o requisito de indutância, em $\mathrm{H}$, Vin é a tensão eficaz de entrada, em $V$, $D$ é a razão cíclica, f a frequência de chaveamento, em $\mathrm{Hz}$, e $\Delta \mathrm{i}$ o pico da corrente, em $A\left(I_{\text {Rus }}+\frac{\Delta i}{2}\right)$.

A Equação (5) é influenciada diretamente pelo ponto de operação (f, $\Delta \mathrm{i})$. Isso significa que maiores frequências (f) e ripples $(\Delta i)$ de corrente irão resultar em requisitos de indutância $(L)$ menores, potencialmente reduzindo o volume do indutor.

A indutância necessária para o $\mathrm{MCC}$ resulta em um requisito de capacidade de armazenamento de energia (En), em $A^{2} H$, para cada ponto de operação, obtido pela Equação (6),

$$
E n=\frac{1}{2}\left[L\left(I_{R M S}+\frac{\Delta i}{2}\right)^{2}\right]
$$

Como cada núcleo possui uma capacidade de armazenamento de energia de acordo com seu produto de área (Ap), em cm (MCLYMAN 2004), a Equação (6) é usada em combinação com a Equação (7) para selecionar os núcleos no banco de dados (MAGNETICS, 2017), (MAGNETICS, 2015),

$$
E n_{n u c}=\frac{A_{p} B_{m} J K_{u}}{2 \cdot 10^{4}}
$$

em que $B_{m}$ é a densidade de fluxo máxima, em $T$, e $K_{u}$ é o fator de utilização da janela, estimado por quatro fatores (MCLYMAN 2004),

$$
K_{u}=S_{1} \cdot S_{2} \cdot S_{3} \cdot S_{4}
$$

dos quais $\mathrm{S} 1$ diz respeito a área de janela que será utilizada pelo isolamento dos filamentos, sendo o fator da área de cobre nu sobre a área de cobre isolado; S2 corresponde ao fator de preenchimento das espiras, devido à geometria circular dos agrupamentos de condutores em paralelo, espiras de indutores estão sujeitas a espaços vazios entre as camadas, reduzindo a área eficaz; S3 considera o espaço necessário para o processo de enrolamento dos núcleos; e S4 diz respeito ao espaço tomado pelo isolamento de entre camadas de espiras, como no revestimento dos agrupamentos litz. 


\section{Número de Espiras e Ocupação da Janela}

O cálculo do número de espiras difere para cada tecnologia, devido à presença do entreferro nos ferrites e da característica de saturação suave dos núcleos powder.

Núcleos Powder: o número de espiras (N) é calculado,

$$
N=\sqrt{\frac{L l_{e}}{0,4 \pi \mu A_{e}}}
$$

no qual $l_{e}$ é o caminho médio magnético, em $\mathrm{cm}, A_{e}$, a área da seção transversal do núcleo, em $\mathrm{cm}^{2}$, e $\mu$ a permeabilidade magnética do material $\left(\mu_{r} \mu_{o}\right)$. Com o número de espiras determinado, a força magnetizante $(\mathrm{H})$, em $\frac{A \cdot e}{\mathrm{~cm}}$, pode ser estimada através da Equação (10),

$$
H=\frac{N\left(I_{R M S}+\frac{\Delta i}{2}\right)}{l_{e}} .
$$

Dada a característica de saturação suave dos núcleos powder, sua permeabilidade magnética diminui gradativamente em função de $\mathrm{H}$, com base nas curvas de permeabilidade vs. força magnetizante (MAGNETICS, 2017). Desta maneira, um número de espiras ajustado para a força magnetizante $\mathrm{Naj}(\mathrm{H})$ é calculado de forma a manter a indutância. Por outro lado, aumentar o número de espiras fará com que a força magnetizante aumente (Equação 10). Portanto, este processo é reiterado até que a indutância atenda ao objetivo dado pela Equação (5).

Para este processo iterativo de $\mathrm{N}$ e $\mathrm{H}$ é adotada uma tolerância de redução de permeabilidade de no máximo $50 \%$ na segunda iteração. Isto evita a operação próxima à saturação para o par $f, \Delta i$. Decisões de núcleo que apresentam redução de permeabilidade maior que $50 \%$ na segunda iteração são substituídos por outro núcleo de maior capacidade de armazenamento de energia.

Posteriormente, com base no número de espiras e dimensões do condutor, a segunda verificação de design é feita: caso a área total necessária para os enrolamentos for maior que a área da janela dado seu $\mathrm{K}_{\mathrm{u}}$, um núcleo de maior capacidade de energia é selecionado, até que todas as decisões de núcleo sejam realizáveis.

Para os núcleos powder, a elevação da frequência também afeta a permeabilidade magnética. Portanto, um número de espiras ajustado para a frequência $N_{a j}(f)$ é calculado com base nas curvas de permeabilidade vs. frequência, de forma a manter o valor da indutância (MAGNETICS, 2017).

Ferrites: um entreferro é empregado seguindo (MCLYMAN 2004). O número máximo de espiras (Npos) que podem ser enroladas na janela de um núcleo EE dado o seu $\mathrm{K}_{\mathrm{u}}$ é calculado por, 


$$
N_{p o s}=\frac{W_{a} K_{u}}{A_{w}}
$$

sendo $A_{w}$ a área ocupada por uma espira, e Wa a área da janela do núcleo, ambas em $\mathrm{cm}^{2}$. O comprimento do entreferro $\left(\mathrm{l}_{\mathrm{g}}\right)$, em $\mathrm{cm}$ é dado por (12),

$$
l_{g}=\frac{0,4 \pi N_{p o s} A_{e} 10^{-8}}{L}-\frac{l_{e}}{\mu} .
$$

A influência do fluxo de dispersão ao redor do entreferro é considerada através de um fator $(F)$,

$$
F=1+\frac{l_{g}}{\sqrt{A_{e}}} \ln \left(\frac{2 l_{t}}{l_{g}}\right)
$$

no qual It é o comprimento de uma espira, em $\mathrm{cm}$. O fluxo de dispersão reduz a relutância no entreferro, aumentando o valor de indutância. Portanto, as espiras são ajustadas para um valor menor, dado pela Equação (14),

$$
N_{f}=\sqrt{\frac{L 1_{g}}{0,4 \pi A_{e} F 10^{-8}}} .
$$

Como para os ferrites as espiras são projetadas de acordo com a janela disponível, e o entreferro determina a permeabilidade magnética do núcleo, nenhum ajuste no número de espiras é feito para compensar eventuais variações de permeabilidade causadas pela frequência e força magnetizante.

\section{Perdas e Temperatura}

A equação de Steinmetz é utilizada para o cálculo de perdas no núcleo dado uma excitação senoidal. Para conversores CC-CC, (SARTORI et al., 2013) mostra uma aproximação válida fazendo uso de uma versão levemente modificada. Para núcleos powder, a variação da densidade de fluxo $(\Delta \mathrm{B})$, em $\mathrm{T}$, é obtida das curvas de magnetização (BxH) (MAGNETICS, 2017); o $\triangle B$ dos ferrites é calculado seguindo (MCLYMAN, 2004). As constantes a, b e c da Equação (15) são obtidas diretamente das curvas de densidade de perdas para os núcleos powder (MAGNETICS, 2017); já para os ferrites os parâmetros de perdas no núcleo são obtidos em (MAGNETICS, 2015). O período de chaveamento é Ts, e ton e toff representam os estados ligado e desligado do transistor, 


$$
P_{\text {núcleo }}=a\left(\frac{\Delta B^{b}}{\left(2 t_{\text {on }}\right)^{c}} \frac{t_{\text {on }}}{T_{S}}+\frac{\Delta B^{b}}{\left(2 t_{\text {off }}\right)^{c}} \frac{t_{\text {off }}}{T_{S}}\right) V_{\text {nuc }} .
$$

Perdas no cobre em fios Litz são calculadas utilizando o fator Fr (Equação (4)),

$$
P_{c u}=R_{C C}{ }_{R M S}{ }^{2} F_{R}
$$

na qual,

$$
R_{C C}=\frac{l_{t} \rho N}{\pi\left(\frac{d_{c}}{2}\right)^{2} n_{p}} .
$$

Finalmente, dado que a temperatura ambiente $\left(T_{\text {amb }}\right)$ seja definida em $25^{\circ} \mathrm{C}$, a temperatura de operação $(T)$ é estimada pela relação empírica dada pela Equação (18) (SARTORI et al., 2015). A área da superfície de troca de calor $\left(A_{\text {surf }}\right)$ é aproximada considerando-se a contribuição adicional dos enrolamentos às dimensões do núcleo,

$$
T=T_{a m b}+\left(\frac{P_{c u}+P_{\text {núcleo }}}{A_{\text {surf }}}\right) .
$$

Materiais magnéticos diferentes estão avaliados para diferentes temperaturas máximas de operação $\left(100^{\circ} \mathrm{C}\right.$ para ferrites, $200^{\circ} \mathrm{C}$ para powder), portanto a terceira e quarta verificações de design são necessárias neste ponto.

Para os pares $f, \Delta i$ em que a temperatura está acima da máxima permitida, a decisão de núcleo é substituida pela próxima escolha de maior tamanho e maior capacidade de armazenamento de energia. Este processo também é feito iterativamente, selecionando núcleos maiores até que o requisito de temperatura seja atingido (terceira verificação de design). No entanto, como uma alta densidade de potência é o objetivo, o processo iterativo de substituição está limitado a subir a núcleos que possuam até, no máximo, o dobro do volume da decisão inicial (quarta verificação de design). Decisões que não atingem estes critérios são descartadas como não recomendadas para o par f, $\Delta \mathrm{i}$, fazendo com que a temperatura e o volume sejam as principais restrições de projeto.

Finalmente, para os núcleos powder, a temperatura também irá aumentar ou reduzir a permeabilidade magnética (MAGNETICS, 2017), o que também exigirá um ajuste de espiras e atualização dos cálculos. Núcleos de ferrite diferem, novamente, 
neste passo, pois para ferrites apenas o cálculo das perdas no núcleo é refeito, ajustado de acordo com a temperatura (MAGNETICS, 2015).

\section{I RESULTADOS E DISCUSSÕES}

Um conversor Boost operando em MCC é projetado para um arranjo de cinco módulos solares policristalinos Kyocera KT265 em NOCT. Este arranjo apresenta potência de entrada $P_{\text {in }}=955 \mathrm{~W}$, tensão de entrada $V_{\text {in }}=139,5 \mathrm{VDC}$, e saída de $\mathrm{V}_{\text {。 }}$ $=311$ VDC, corrente eficaz IRMS $=6,85 \mathrm{~A}$ e razão cíclica $\mathrm{D}=0,55$. A simulação itera simultaneamente equações de projeto para todas as tecnologias, com frequências variando de $5 \mathrm{kHz}$ a $1 \mathrm{MHz}$, com passo de $5 \mathrm{kHz}$, e ondulação de corrente de $10 \%$ a $80 \%$, com passo de $5 \%$.

Com Vin e D fixos, a indutância é dada somente pelo ponto de operação em $f$ e $\Delta i$ (Equação (5)). Uma vez que todos os indutores são projetados para atingir a indutância mínima dada pela Equação (5), o conceito de capacidade de armazenamento de energia, dado pelas Equações (6) e (7) (requisito e capacidade de energia, respectivamente), é usado como comparativo entre as tecnologias para cada ponto de operação avaliado. O conceito de capacidade de energia engloba mais propriedades do material, como densidade de corrente, dimensões e densidade de fluxo magnético.

De forma a tornar a comparação entre os materiais o mais justa possível, somente núcleos com uma permeabilidade de $60 \mu$ são escolhidos do banco de dados, e ferrites são projetados para um gap que resulte na mesma permeabilidade. Para um projeto de indutor, a escolha da permeabilidade do material é livre. No entanto, para uma análise comparativa, as características de cada tecnologia são mais visíveis ao manter-se a permeabilidade magnética fixa.

Inicialmente, será discutida somente a relação entre o ponto de operação (f, $\Delta \mathrm{i})$, a densidade de corrente $(\mathrm{J})$, o volume, e as perdas no cobre e núcleo. Para menores f, $\Delta$, há uma dominância das perdas no cobre sobre as perdas no núcleo. Por outro lado, à medida que $\mathrm{f}, \Delta \mathrm{i}$ se eleva, esta dominância se altera, as perdas no cobre diminuem enquanto as perdas no cobre diminuem enquanto as perdas no núcleo se elevam, eventualmente alterando a dominância completamente. A figura 1 ilustra este comportamento, usando o material Kool $\mathrm{M} \mu \mathrm{MAX} B$ como exemplo, para $\mathrm{J}=600 \mathrm{~A} / \mathrm{cm} 2$ e $\Delta$ i fixo em $40 \%$. 


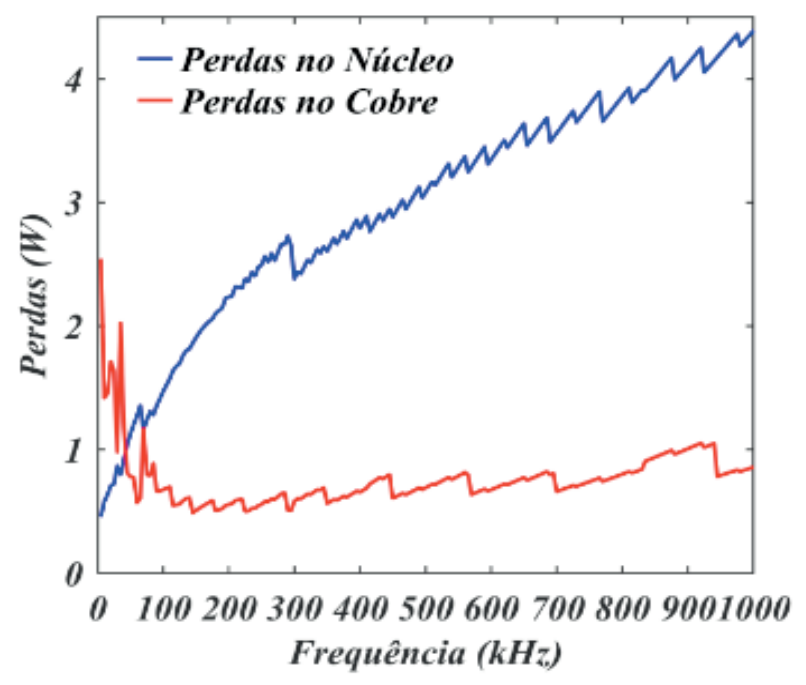

Figura 1. Comportamento das Perdas no Cobre e no Núcleo com relação à frequência.

As Figuras 2 e 3, de comparação de perdas, são utilizadas para ilustrar, além do desempenho dos materiais em termos de perdas, o seu alcance na extensão de $\mathrm{f}$ e $\Delta$ i. Esta limitação do ponto de operação decorre da combinação de dois fenômenos característicos de f e $\Delta \mathrm{i}$ elevados: (1) as perdas no núcleo se elevam; (2) os menores volumes reduzem a área de superfície de troca de calor. A consequência disso é uma elevação na temperatura (Equação (18)), que muitas vezes não atinge as restrições térmicas da seção 2-D. Portanto, o alcance operacional dos materiais fica limitado, representado pelas linhas pontilhadas nas Figuras 2 e 3.

Nas Figuras 2 e 3, as elevadas perdas (totais) das frequências iniciais são atribuídas às perdas no cobre. Este pico inicial se reduz até em torno de $50 \mathrm{kHz}$, ponto em que as perdas no material passam a subir gradativamente devido ao aumento das perdas no núcleo. As Figuras 2 e 3, de comparação de perdas, são utilizadas para ilustrar, além do desempenho dos materiais em termos de perdas, o seu alcance na extensão de $f$ e $\Delta \mathrm{i}$. Esta limitação dos pontos de operação decorre da combinação de dois fenômenos característicos de f e $\Delta i$ elevados: (1) as perdas no núcleo se elevam; (2) os menores volumes reduzem a área de superfície de troca de calor. A consequência disso é uma elevação na temperatura (Equação (18)), que muitas vezes não atinge as restrições térmicas da seção 2-D. Portanto, o alcance operacional dos materiais fica limitado, representado pelas linhas pontilhadas nas Figuras 2 e 3. 


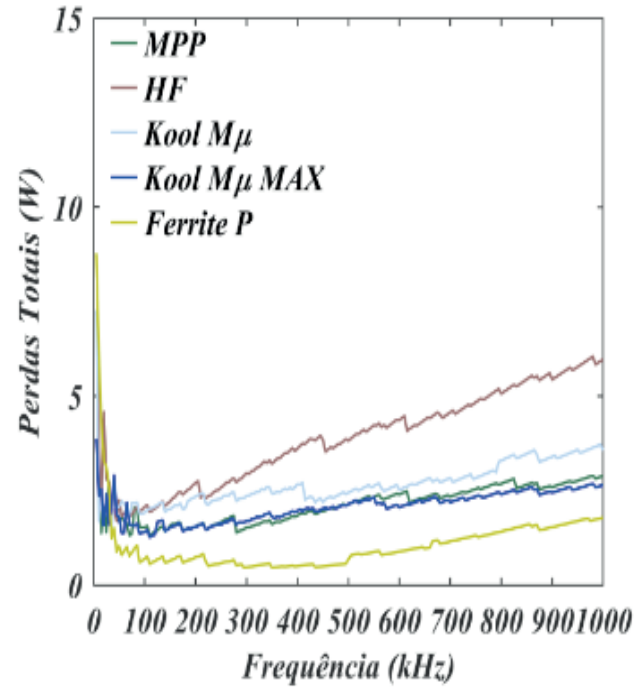

(a) $\Delta$ i fixo em $20 \%$

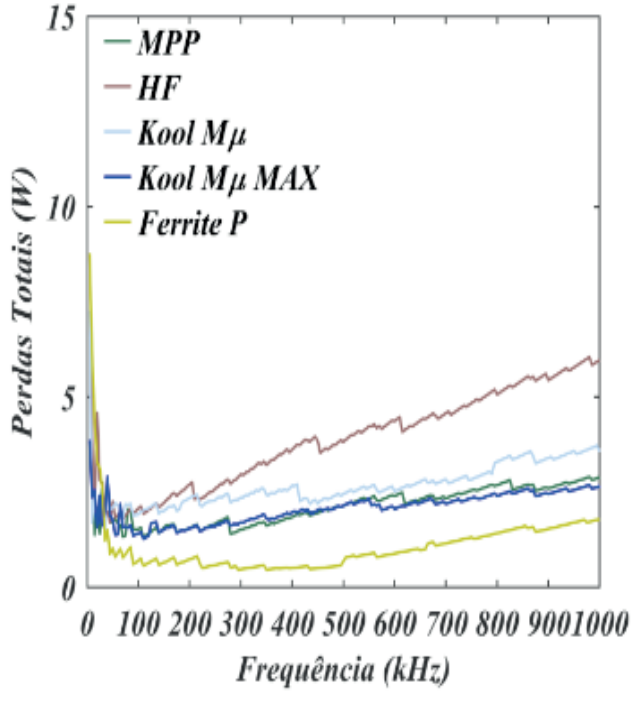

(b) $\Delta$ i fixo em $60 \%$

Figura 2. Perdas Totais com $\mathrm{J}=600 \mathrm{~A} / \mathrm{cm}^{2}$

Nas Figuras 2 e 3, as elevadas perdas (totais) das frequências iniciais são atribuídas às perdas no cobre. Este pico inicial se reduz até em torno de $50 \mathrm{kHz}$, ponto em que as perdas no material passam a subir gradativamente devido ao aumento das perdas no núcleo.

A Equação (7) aponta que utilizar uma Jelevada é útil, pois aumentar a capacidade de armazenamento de energia no indutor significa reduzir o volume. No entanto, devese observar que para uma $\mathrm{f}<50 \mathrm{kHz}$ e $\Delta \mathrm{i}$ em torno de $20 \%$, utilizar uma J alta resultará em elevação perdas no cobre, como visto na Figura 2(a).

Portanto, de forma a minimizar as perdas, a elevação da densidade de corrente (como em J $=600 \mathrm{~A} / \mathrm{cm}^{2}$ ), é recomendada em $\mathrm{f}>50 \mathrm{kHz}$ e $\Delta \mathrm{i}>20 \%$, pois para estas faixas as perdas no cobre (afetadas pela alta J) não são tão significantes. Ademais, elevar o ponto de operação de f, $\Delta$ i por si só reduzirá o volume (Equação (5)).

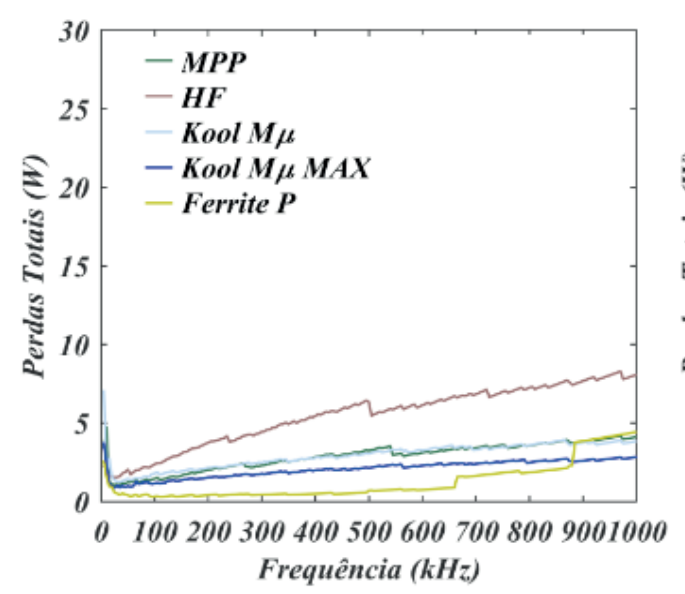

(a) $\Delta$ i fixo em $20 \%$

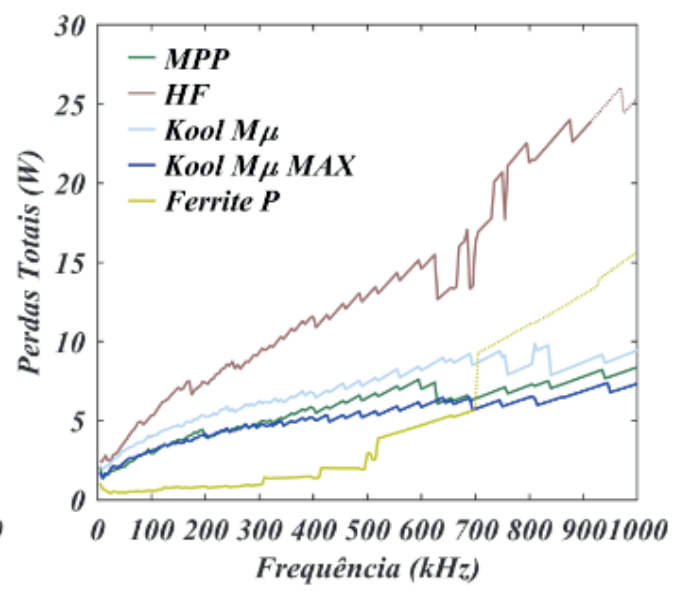

(b) $\Delta$ i fixo em $60 \%$

Figura 3. Perdas Totais com J $=200 \mathrm{~A} / \mathrm{cm}^{2}$ 
Inversamente, para uma baixa densidade de corrente (como em J = $200 \mathrm{~A} / \mathrm{cm}^{2}$ ) é indicado operar em frequências abaixo de $50 \mathrm{kHz}$ e $\Delta \mathrm{i} \leq 20 \%$, uma vez que as perdas nesta faixa são menores com relação a $\mathrm{J}=600 \mathrm{~A} / \mathrm{cm}^{2}$, como indica a Figura 3(a).

O impacto da densidade de corrente sobre o volume do indutor (núcleo e espiras) é ilustrado pelas Figuras 4(a) e 4(b). Nestas também está aparente o limite operacional de cada tecnologia para a extensão de $\mathrm{f}, \Delta \mathrm{i}$, dadas as restrições da seção 2-D.

Como uma $\mathrm{J}$ mais baixa $\left(200 \mathrm{~A} / \mathrm{cm}^{2}\right)$ irá resultar em menor capacidade de armazenamento de energia (Equação (7)), núcleos mais volumosos serão necessários (Figura 4(b)). Este fato implicará em perdas maiores no núcleo (Equação (15)), evidente ao comparar-se a faixa acima de $50 \mathrm{kHz}$ nas Figuras 2(b) e 3(b).

No entanto, devido às dimensões maiores, uma $\mathrm{J}=200 \mathrm{~A} / \mathrm{cm}^{2}$ faz com que os materiais abranjam uma faixa maior na extensão de f, $\Delta \mathrm{i}$ (Equação (18)). De modo inverso, para $\mathrm{J}=600 \mathrm{~A} / \mathrm{cm}^{2}$, a capacidade de armazenamento de en ergia aumenta e o volume necessário diminui (Figura 4(a)); volumes menores implicam em menos perdas, porém temperaturas mais elevadas.

Comparando materiais para ambas densidades de corrente, o material de maior densidade de potência é o High Flux, devido à sua elevada densidade de fluxo máximo $\left(B_{\text {sat }}\right)$, na ordem de 1, $4 \mathrm{~T}$. Uma maior $B_{\text {sat }}$ significa que, para o mesmo tamanho, este material possuirá maior capacidade de armazenamento de energia (Equação (7)) sem atingir a saturação magnética. A desvantagem do material HF é a elevação das perdas no núcleo à medida que o par f, $\Delta \mathrm{i}$ é aumentado. Este fenômeno limita a faixa de operação dos núcleos HF, pois os volumes reduzidos, característicos de f, $\Delta \mathrm{i}$ altos, em combinação com as dimensões naturalmente menores do material HF, influenciam diretamente a temperatura (Equação (18)).

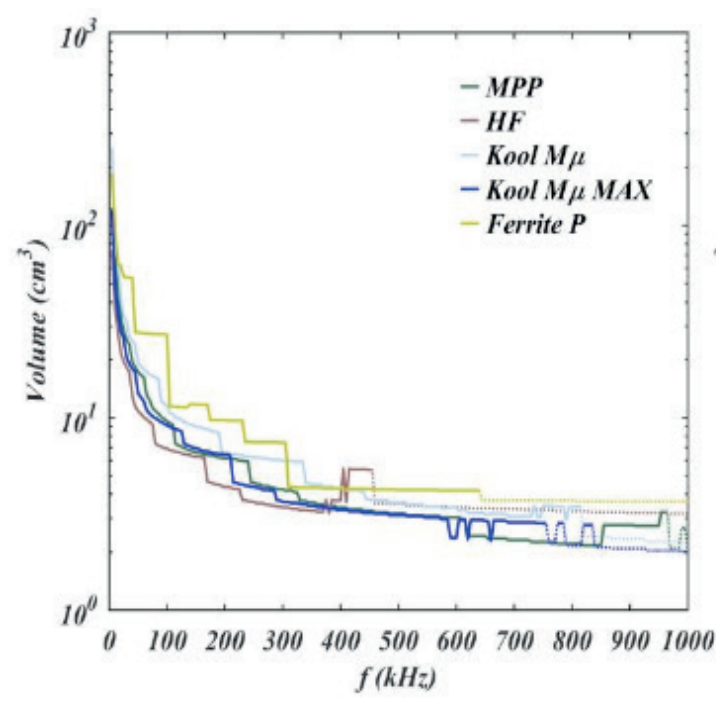

(a) $\mathrm{J}=600 \mathrm{~A} / \mathrm{cm}^{2}$

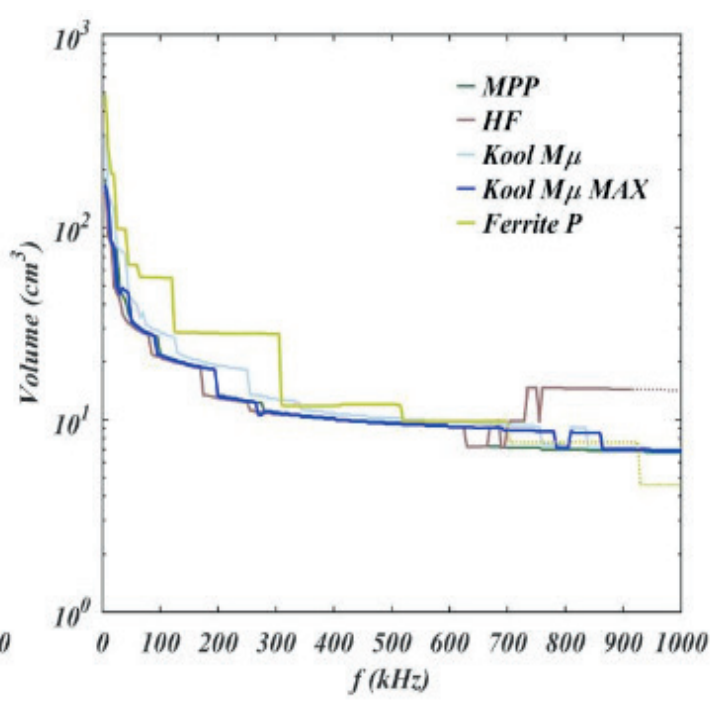

(b) $\mathrm{J}=200 \mathrm{~A} / \mathrm{cm}^{2}$

Figura 4. Volume dos materiais com $\Delta$ i fixo em $60 \%$

Para um par $\mathrm{f}, \Delta \mathrm{i}$ mais elevado, os núcleos mais eficientes são os de ferrite $\mathrm{P}\left(\mathrm{B}_{\text {sat }} \approx\right.$ 
$0,47 \mathrm{~T})$, os MPP $\left(\mathrm{B}_{\text {sat }} \approx 0,8 \mathrm{~T}\right)$ e os Kool $\mathrm{M} \mu \mathrm{MAX} \otimes\left(\mathrm{B}_{\text {sat }} \approx 1,0 \mathrm{~T}\right)$, respectivamente. Uma observação importante é que apesar do fato de os ferrites $\mathrm{P}$ apresentar as menores perdas para todas as faixas, seus volumes são os maiores entre todos os núcleos, ambos em virtude de seu baixo Bsat. Ademais, sua faixa de operação é restringida por seu limite de temperatura menor $\left(100{ }^{\circ} \mathrm{C}\right)$ relativo aos outros materiais $\left(200{ }^{\circ} \mathrm{C}\right)$. Portanto, ferrites $\mathrm{P}$ são recomendados para projetos que não possuam volume como uma restrição, e estejam focados primariamente em perdas baixas.

Dentre os núcleos powder, para f $>50 \mathrm{kHz}$ e $\Delta \mathrm{i}>20 \%$, os MPP e Kool M $\mu$ MAX® são os de menores perdas, como indicado pelas Figuras 2 e 3 . Em todas as faixas, os resultados de volume para os dois materiais são próximos, como visto nas Figuras 4(a) e 4(b). Tendo isso em vista, os núcleos MPP e Kool M $\mu$ MAX® são excelentes opções para um projeto de alta densidade volumétrica de potência. No entanto, destaca- se o fato de os MPP serem relativamente mais caros que todos os outros materiais analisados.

Por último, o material Kool $\mathrm{M} \mu \circledR\left(\mathrm{B}_{\text {sat }} \approx 1,0 \mathrm{~T}\right)$ se mostra regular em termos de volume e perdas. No entanto, é o material de menor custo relativo, por não possuir Níquel em sua liga (núcleos HF e MPP possuem 50\% e $81 \%$ respectivamente).

Um exemplo claro da situação supracitada, em que o método utilizado seleciona núcleos maiores ao se aproximar do limite de temperatura, é a forma como o material HF surge como o de maior volume ao ultrapassar $650 \mathrm{kHz}$, na Figura 4(b). Outro exemplo da mesma situação é como o ferrite $P$ deixa de ser o material de menores perdas a partir de 880 kHz, na Figura 3(a).

\section{I CONCLUSÃO}

As particularidades de cada material estudado foram apresentadas e discutidas. Com respeito às perdas, os ferrites $P$ apresentam os melhores resultados, sendo indicados para aplicações em que o volume não é um fator limitante, e/ou eficiência é crucial. De uma perspectiva de alta densidade de potência, pode ser dito que os ferrites $\mathrm{P}$ são competitivos com núcleos powder em situações que o requisito de armazenamento de energia é menor (ex: $f>300 \mathrm{kHz}$ com $\Delta \mathrm{i}$ em $60 \%$ ), devido à menor diferença em volume.

Dentre os núcleos powder, os núcleos HF e Kool M $\mu$ MAX® se destacam em termos de densidade volumétrica de potência, e são diferenciados por seu desempenho com respeito ao ponto de operação (f, $\Delta i)$. Para pontos de operação baixos ( $f<50$ $\mathrm{kHz}$ e $\Delta \mathrm{i}$ em torno de $20 \%$ ), o material $\mathrm{HF}$ apresenta perdas próximas aos outros materiais, porém com volume inferior. Portanto, núcleos HF são úteis em aplicações que requerem alta capacidade de armazenamento de energia com uma restrição de espaço.

À medida que se eleva o ponto de operação, os núcleos MPP e Kool M $\mu$ MAX® apresentam vantagem. Para todas as faixas, seu volume é comparável ao dos núcleos 
$H F$, e são os mais eficientes entre os núcleos powder em alta frequência. No entanto, os núcleos Kool M $\mu$ MAX® possuem menor custo que os MPP, tornando-os superiores. Em contrapontos ao material HF, ambos os materiais são recomendados acima de $50 \mathrm{kHz}$ e/ou 20\% de ondulação de corrente. Os núcleos Kool M $\mu \circledR$ apresentam desempenho intermediário em comparação aos outros materiais powder em termos de eficiência e tamanho, mas possuem custo menor. Portanto, são recomendados para aplicações onde uma solução custo efetiva é necessária.

Finalmente, resultados indicam que, independente do material magnético utilizado, para atingir-se uma alta densidade volumétrica de potência, deve-se associar um alto ponto de operação ( $f>50 \mathrm{kHz}$ e $\Delta \mathrm{i}>40 \%$ ) com um J elevado, minimizando as perdas e o volume.

\section{I AGRADECIMENTOS}

O presente trabalho foi realizado com apoio da Coordenação de Aperfeiçoamento de Pessoal de Nível Superior - Brasil (CAPES) - Código de Financiamento 001.

\section{REFERÊNCIAS}

SARTORI, Hamiltom Confortin; HEY, Helio Leaes; PINHEIRO, Jose Renes. An optimum design of PFC Boost Converters. In: 2009 13th European Conference on Power Electronics and Applications. IEEE, 2009. p. 1-10

SARTORI, Hamiltom C. et al. Integrated methodology design to improve the efficiency and reduce volume of the CCM PFC boost converters with pre-sizing settings. In: 2015 IEEE 24th International Symposium on Industrial Electronics (ISIE). IEEE, 2015. p. 1378-1385.

SARTORI, H. C.; BELTRAME, F.; PINHEIRO, J. R. A static converter comparative study taking into account semiconductor tecnologies and swicth auxiliary circuits: Optimized design. In: XI Brazilian Power Electronics Conference. IEEE, 2011. p. 280-285.

WANG, Gangyao et al. Performance comparison of 1200V 100A SiC MOSFET and 1200V 100A silicon IGBT. In: 2013 IEEE Energy Conversion Congress and Exposition. IEEE, 2013. p. 3230-3234.

TENANT, P.; ROUSSEAU, J.-J. Dynamic model for soft ferrites. In: Proceedings of PESC'95-Power Electronics Specialist Conference. IEEE, 1995. p. 1070-1076.

ROSHEN, Waseem A. et al. High-efficiency, high-density MHz magnetic components for low profile converters. IEEE Transactions on Industry Applications, v. 31, n. 4, p. 869-878, 1995.

MAGNETICS INC., "Powder Cores Catalog”, 2017.

J. COX., "Iron Powder Cores for Switchmode Power Supply Inductors", Micrometals INC., 2018.

SULLIVAN, Charles R. Optimal choice for number of strands in a litz-wire transformer winding. In: PESC97. Record 28th Annual IEEE Power Electronics Specialists Conference. Formerly Power Conditioning Specialists Conference 1970-71. Power Processing and Electronic Specialists Conference 1972. IEEE, 1997. p. 28-35.

MCLYMAN, Wm. T, "Transformer and Inductor design Handbook", 3rded, Idyllwild California, 2004, pp.269-274 
MAGNETICS INC., "Ferrite Cores Catalog", 2017. 


\section{Maryam Liaqat} Department of Physics University of Okara,

Pakistan

Sulman Joseph Department of Physics University of Agriculture,

Faisalabad, Pakistan

Shamsa Maqsood

Department of Physics University of Agriculture,

Faisalabad, Pakistan

Ali Raza

Department of Physics

University of Agriculture,

Faisalabad, Pakistan

Sana Aslam

Department of Physics

University of Agriculture,

Faisalabad, Pakistan

Waseem Imtiaz

Department of Physics

University of Agriculture,

Faisalabad, Pakistan

Muhammad Furqan Shoukat

Department of Physics

University of Agriculture,

Faisalabad, Pakistan
ABSTRACT: Wireless devices are not new; data become wireless long time ago. Because life of mobile phone device is always been a problem for the manufactures and people complain about it. Therefore scientists are rapidly trying to fulfill the demand of the people to charge safe and wirelessly. On demand of mobile users due to less charging time of android/cell phones, there is at most desire of wireless gadget for charging. In the design of a circuit a transmitter and a receiver circuit is used. The transmitter circuit has $A C$ to $D C$ rectifier circuit and then it is modulated to pulse width modulator circuit. Primary and secondary coils are connected by mutual induction and an emf is induced in a secondary coil. AC to DC bridge rectifier is used to transmit voltages to the mobile phone. Microcontroller with timer circuit is used to avoid over charging. It works on Faraday's law of electromagnetic induction for significant reasons.

\section{INTRODUCTION}

Mobile communication has become a great need of today. We have to communicate to other people via mobile phones, tabs, PADs, and laptop computers. And we can take these devices with us to any place any time. But these 
small machines also consume power and have to be recharged again and again. So we have to put the charger in the socket and have to attach our mobile phone to the charger for recharging it and a lot of time is wasted in this procedure.

Moreover the wires and cables used to transmit electrical power could be damaged which is also a serious issue. From this discussion we can see that we are facing a lot of problems through the use of wires and cables, and a lot of time is wasted is this whole procedure.

By the use of wireless systems of power transmission we can have following benefits which are simply amazing and can save

- People from many hazards.

- Battery of our portable devices.

- A lot of time.

- Our devices from damages of overcharging.

Moreover we can

- Use our devices with comfort.

- Take our device to the place where electricity is not available.

From the above discussion we can see that there are a lot of benefits of wireless system and we can say that in reality wireless system is a smart system. Let us have a brief look upon the methods of transferring power wirelessly. Now we will see that from how many ways we can transfer power wirelessly. So some of the ways of transferring power wirelessly are as follow:
1. Radio charging.
2. Resonance charging.
3. Inductive charging.

\subsection{Radio charging}

Radio charging is the process of transferring power wirelessly in which radio waves are used to 


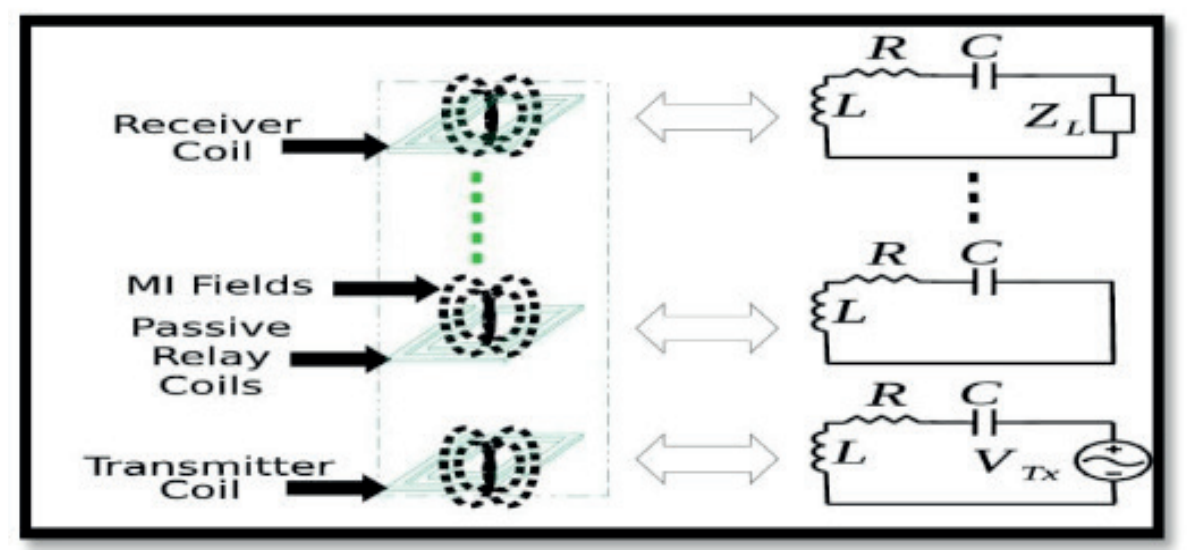

Figure 1: Transmitting coils

transfer power. Radio charging is a method used for transferring power and charging the devices which are small for example the battery of laptop computer requires enough power that radio charger cannot deliver. The range also limits the effectiveness of radio charging which works on the same principle as an AM/FM radio does. The reception will be better if receiver is closer to the transmitter. In this case of wireless radio charging better reception is translates to a stronger charge for the item.

\subsection{Resonance charging}

The devices such as robots, cars, laptop computers and vacuum cleaners etc., which requires large amount of power, can be charged wirelessly through resonance charging method. In this process of charging a copper coil is attached to the power source which is the sending unit and a other coil is attached to the device which have to be charge or recharge. The frequency for the coil must be same which makes it possible.

- A new method is developed in order to charge mobile phones by using micro waves.

\subsection{Inductive Charging}

Inductive charging is the process which is based upon Faraday's Law of electromagnetic induction and the process of mutual induction is used to transfer power from one place to another by wireless method. Now let us have a look that how energy is transferred from one place to another without any physical connection between two devices. What is the mechanism actually happening in this whole process?

Same question arises in the mind of Necolus Tesla and he started the research on this that could we transfer energy and after Wireless Power Technology is emerging as a practical solution for providing energy for devices at remote distances.

This paper will focus on the technology of inductively coupled wireless power transfer. This provides a safe, efficient, and convenient method of transferring power to remote static devices, or recharging portable devices. This revolves around the 
principle of Resonant Magnetic Coupling. Which can be applied to acquire maximum transfer of power contactless, thereby facilitating the individual to charge his electronic equipment efficiently.

WPT technology can provide charging systems with low maintenance costs, high reliability, and the ability to operate even in extreme environments. However, a wireless battery charging system requires more power stages than a wired battery charging system. The wireless battery charging system needs a WPT system that consists of a power transmitter and a power receiver. An exclusive controller is also required to regulate the output of WPT system since the power transferred to the receiver of WPT system is not regulated whenever the load changes. The inverter or converter in power electronics is usually controlled by three methods; pulse width modulation (PWM), frequency modulation (FM), and amplitude modulation. The AM method requires an additional stage for the DC-DC converter in order to control the amplitude of the input voltage. On the other hand, both PWM and FM need no additional stage since the inverter or converter uses power semiconductor switches for the power conversion.

For this reason, when PWM or FM is applied to the power transmitter of a WPT system, the power transferred to the receiver can be easily regulated. Nevertheless, high current stress and large power loss are generated since the voltage and current in the power transmitter are not in phase. Due to times, problem regulation circuits such as synchronous rectifiers or impedance tuners are necessary in the receiver of a WPT system. Furthermore, battery-charging circuits such as low-dropout (LDO) regulators or synchronous buck converters are required for the battery charging. Figure 1 shows a conventional wireless battery charging system. As mentioned above, the conventional system consists of the following five key power stages; AC-DC converter, power transmitter of WPT system, power receiver of WPT system, regulation circuit, and battery-charging circuit.

For the wireless battery charging system, the power receiver, regulation circuit, and battery charging circuit must be embedded inside portable electronic devices or electric vehicles, but there is usually not enough space for these power stages. In addition to this problem, the regulation and battery-charging circuits generate huge heat and raise the problem of thermal stress on the electronic devices while being charged. A direct wireless battery charging system is proposed. The regulation and battery charging proposed system is only made of AC-DC converter, power transmitter, and power receive. The type of the applied WPT system is a series-series compensated wireless power transfer (SS-WPT) system, and it is connected directly to the battery. Generally, the output of SS-WPT system has inherent characteristic as a current source. Hence, without the help of dedicated regulation and battery charging circuits, the battery can be charged directly from the WPT system by adjusting the output voltage of the existing AC-DC converter in front of the WPT system according to the constant-current constant-voltage (CC-CV) charging profile or a multi-step current charging profile.

The paper is organized the inherent current-source characteristics of the SS-WPT 
system are described. The implementation of the $\mathrm{CC}-\mathrm{CV}$ charging or MCC charging profile in the proposed wireless battery charging system is explained. Experimental verification is presented in Section 4, and finally, Section 5 draws the conclusions.

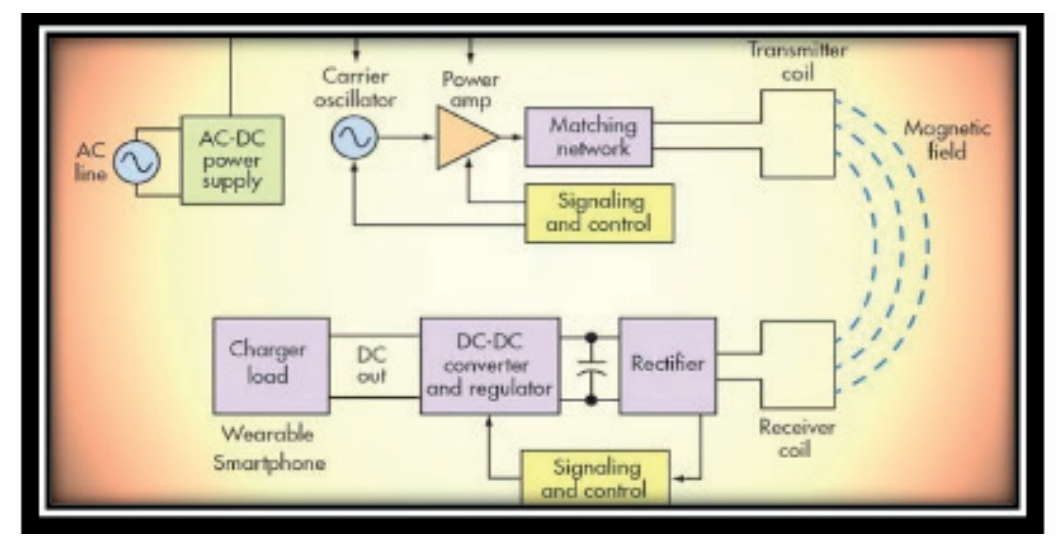

Figure 2: System Block Diagram

Wireless power transmission (WPT) is an efficient way for the transmission of electric power from one point to another through vacuum or atmosphere without the use of wire or any physical material. By using WPT, power can be transmitted using inductive coupling for short range, resonant induction for mid-range and Electromagnetic Wave power transfer. By using this technology, it is possible to supply power to places, which is hard to do using conventional wires. Currently, the use of inductive coupling is in development and research phases. The most common wireless power transfer technologies are the electromagnetic induction and the microwave power transfer. For efficient midrange power transfer, the wireless power transfer system must satisfy three conditions: (a) high efficiency, (b) large air gap, (c) high power. The microwave power transfer has a low efficiency. For near field power transfer this method may be inefficient, since it involves radiation of electromagnetic waves. Wireless power transfer can be done via electric field coupling, but electric field coupling provides an inductively loaded electrical dipole that is an open capacitor or dielectric disk. External objects may provide a relatively strong influence on electric field coupling. Magnetic field coupling may be preferred, since external objects in a magnetic field have the same magnetic properties as empty space. Electromagnetic induction method has short range. Since magnetic field coupling is a nonradioactive power transfer method, it has higher efficiency. However, power transfer range can be increased by applying magnetic coupling with resonance phenomenon applied on. A magnetic field is generated when electric charge moves through space or within an electrical conductor.

Solar energy is energy obtained from the Sun. Hence solar panels are used here to generate power and stored it in batteries. The stored energy is then used to charge mobile phone wirelessly as well as to supply energy for other home appliances. In order to avoid unnecessary use of energy, effective energy saving technique is used by using ARM7 LPC2148 microcontroller. To improve the easiness and efficiency of electrical 
appliances have been the main motivation throughout this paper. Since the power transmitter needs to be continuously informed about battery power needs and state of charge, a communication link is required. The communications channel is implemented through an amplitude modulation of the power drawn from the transmitter.

In the power transmitter section, an AC-DC stage converts the AC voltage provided by the electrical grid into a DC bus level. A DC-AC converter, supplied by the $D C$ bus level, generates the AC power signal. In the power receiver section, a rectifier converts the $\mathrm{AC}$ power signal out of the resonant tank into a $\mathrm{DC}$ voltage level, suitable for battery charging. The DC bus rail out of the rectifier has been chosen equal to a $7 \mathrm{~V}$ value. Information towards the power transmitter is generated through a power modulation of the coupling circuit resonant curve. The load modulation follows a differential bi-phase encoding scheme, as described in Qi-standard specifications. The amount of transmitted power is controlled by varying Figure 1 - General architecture of a wireless battery charger the frequency and duty-cycle of the half-bridge stage. A frequency range of $110 \mathrm{k} 205 \mathrm{kHz}$ and a duty-cycle range of $10 \% 50 \%$ are fixed by the PC standard. Since for low power levels the total power dissipation is mainly affected by switching losses, the half-bridge configuration is more suitable than a full-bridge one. Conduction losses could be reasonably neglected for the specific application.

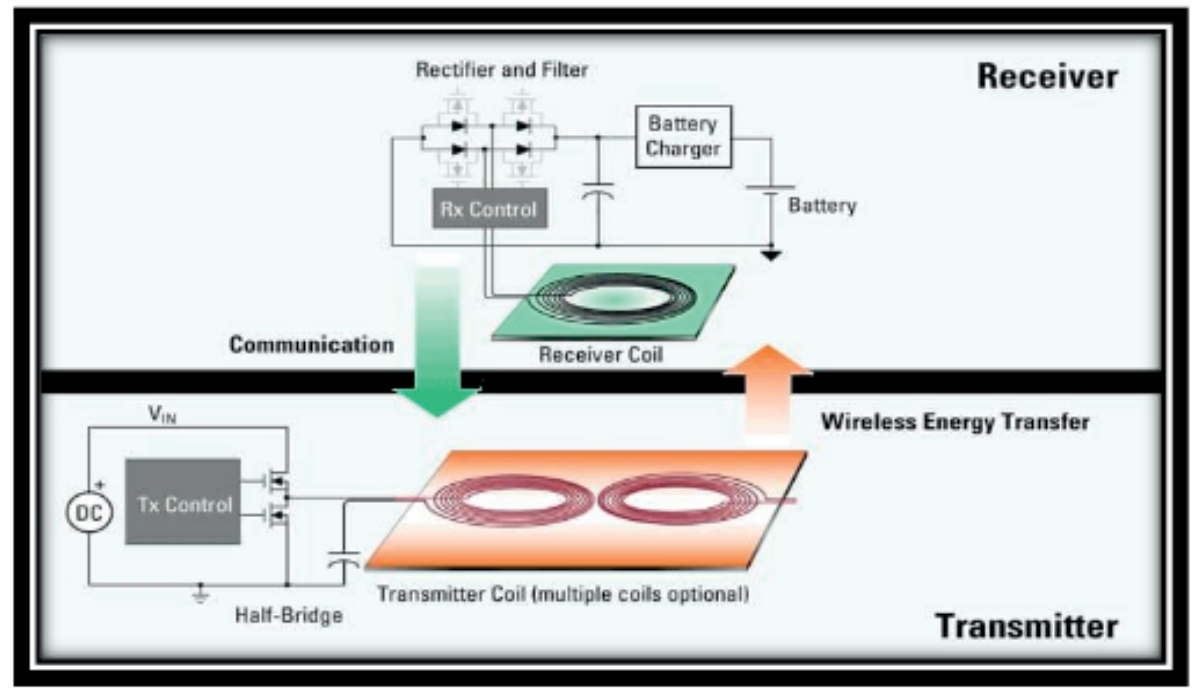

Figure 3: Transmission of Voltages

The modulation network consists of two parts: one is connected to the AC-side of the rectifier; the other is connected to the DC-side. The load device is modeled through a current generator. The system has been simulated in SPICE environment to evaluate system performances in terms of power conversion efficiency. Several simulation sessions have been carried out under different operating conditions.

\section{Faraday's Law of Mutual Induction:-}

Faraday's law of induction (briefly, Faraday's law) is a basic law of electromagnetism. 
It is the fundamental operating principle of transformers, inductors, and many types of electrical motors, generators and solenoids. The Maxwell-Faraday equation (listed as one of Maxwell's equations) describes the fact that a spatially varying (and also possibly time varying, depending on how a magnetic field varies in time) electric field always accompanies a time-varying magnetic field, while Faraday's law states that there is EMF (electromotive force, defined as electromagnetic work done on a unit charge

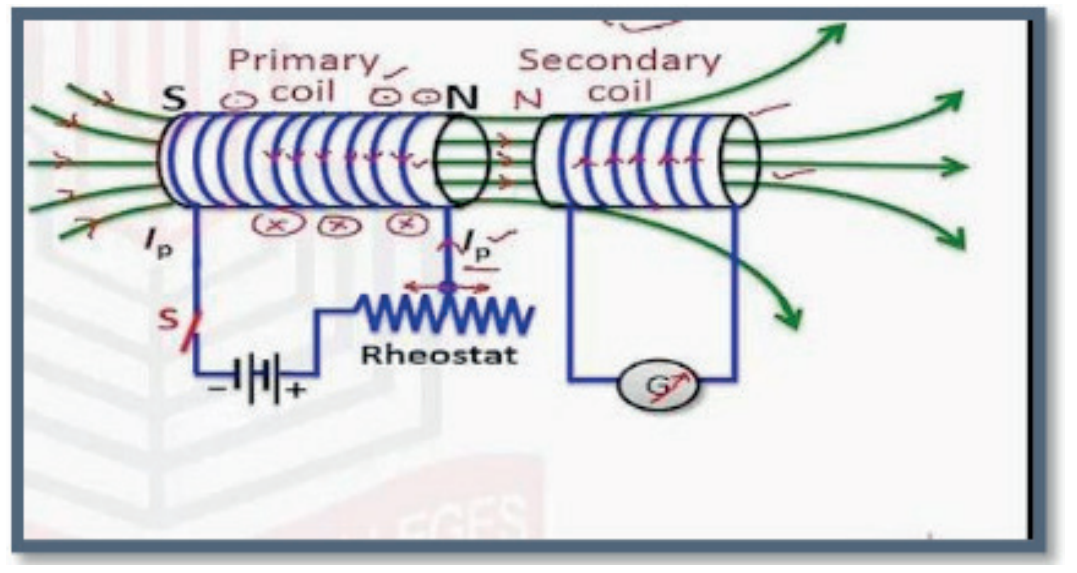

Figure 4: Mutual induction

when it has traveled one round of a conductive loop) on the conductive loop when the magnetic flux through the surface enclosed by the loop varies in time. Historically, Faraday's law had been discovered and one aspect of it (transformer EMF) was formulated as the Maxwell-Faraday equation later. Interestingly, the equation of Faraday's law can be derived by the Maxwell-Faraday equation (describing transformer EMF) and the Lorentz force (describing motional EMF). The integral form of the Maxwell-Faraday equation describes only the transformer EMF, while the equation of Faraday's law describes both the transformer EMF and the motional EMF. The changing magnetic flux of the left coil induces a current in the right coil. Faraday's disk is the first electric generator, a type of Homo polar generator.

Electromagnetic induction was discovered independently by Michael Faraday in 1831and Joseph Henry in 1832. Faraday was the first to publish the results of his experiments. In Faraday's first experimental demonstration of electromagnetic induction (August 29, 1831), the wrapped two wires around opposite sides of an iron ring (torus) (an arrangement similar to a modern transformer). Based on his assessment of recently discovered properties of electromagnets, he expected that when current started to flow in one wire, a sort of wave would travel through the ring and cause some electrical effect on the opposite side. He plugged one wire into a galvanometer, and watched it as he connected the other wire to a battery. Indeed, he saw a transient current (which he called a "wave of electricity") when he connected the wire to the battery, and another when he disconnected it. This induction was due to the change in magnetic flux that occurred when the battery was connected and disconnected. Within two months, Faraday had found several other manifestations of electromagnetic induction. For 
example, he saw transient currents when he quickly slid a bar magnet in and out of a coil of wires, and he generated a steady (DC) current by rotating a copper disk near the bar magnet with a sliding electrical lead ("Faraday's disk"). Michael Faraday explained electromagnetic induction using a concept he called lines of force.

However, scientists at the time widely rejected his theoretical ideas, mainly because they were not formulated mathematically. An exception was James Clerk Maxwell, who in 1861-62 used Faraday's ideas as the basis of his quantitative electromagnetic theory. In Maxwell's papers, the time-varying aspect of electromagnetic induction is expressed as a differential equation which Oliver Heaviside referred to as Faraday's law even though it is different from the original version of Faraday's law, and does noted scribe motional EMF. Heaviside's version (see Maxwell-Faraday equation below) is the form recognized today in the group of equations known as Maxwell's equations.

Lenz's law, formulated by Emil Lenz in1834,describes "flux through the circuit", and gives the direction of the induced EMF and current resulting from electromagnetic induction (elaborated upon in the examples below).

Faraday's experiment showing induction between coils of wire: The liquid battery (right) provides a current which flows through the small coil $(A)$, creating a magnetic field. When the coils are stationary, $\mathrm{n}$ current is induced. But when the small coil is moved in

or out of the large coil $(B)$, the magnetic flux through the large coil changes, inducing a current which is detected by the galvanometer (G).

Faraday's law

Qualitative statement: The most widespread version of Faraday's law states:

The closed path here is, in fact, conductive.

Quantitative: The electromotive force around a closed path is equal to the negative of the time rate of change of the magnetic flux enclosed by the path. The closed path here is conductive.

Quantitative: The definition of surface integral relies on splitting the surface $\Sigma$ into small surface elements. Each element is associated with a vector $\mathrm{dA}$ of magnitude equal to the area of the element and with direction normal to the element and pointing "outward" (with respect to the orientation of the surface).For a loop of wire in a magnetic field, the magnetic flux $\Phi B$ is defined for any surface $\Sigma$ whose boundary is the given loop. Since the wire loop may be moving. The definition of surface integral relies on splitting the surface $\Sigma$ into small surface elements. Each element is associated with a vector $\mathrm{dA}$ of magnitude equal to the area of the element and with direction normal to the element and pointing "outward" (with respect to the orientation of the surface).We write $\Sigma(t)$ for the surface. The magnetic flux is the surface integral:

$$
\Phi \mathbf{B}=\iint_{\Sigma(t)} B(t) \cdot d \boldsymbol{A}
$$


Where $d A$ is an element of surface area of the moving surface $\Sigma(t), B$ is the magnetic field and $B \cdot d A$ is a vector dot product representing the element of flux through $d A$. In more visual terms, the magnetic flux through the wire loop is proportional to the number of magnetic flux lines that pass through the loop. When the flux changes-because $B$ changes, or because the wire loop is moved or deformed, or both-Faraday's law of induction says that the wire loop acquires an EMF, E, defined as the energy available from a unit charge that has travelled once around the wire loop. (Note that different text books may give different definitions. The set of equations used throughout the text was chosen to be compatible with the special relativity theory.) Equivalently, it is the voltage that would be measured by cutting the wire to create an open circuit, and attaching a voltmeter to the leads. Faraday's law states that the EMF is also given by the rate of change of the magnetic flux:

\section{$\varepsilon=-\frac{d \Phi B}{d t}$}

Where is the electromotive force (EMF) and $\Phi \mathrm{B}$ is the magnetic flux. The direction of the electromotive force is given by Lenz's law. The laws of induction of electric currents in mathematical form was established by Franz Ernst Neumann in 1845. Faraday's law contains the information about the relationships between both the magnitudes and the directions of its variables. However, the relationships between the directions are not explicit; they are hidden in the mathematical formula of Left Hand Rule for Faraday's Law.

The sign of $\triangle \Phi B$, the change in flux, is found based on the relationship between the magnetic field $\mathbf{B}$, the area of the loop $A$, and the normal $n$ to that area, as represented by the fingers of the left hand. It is possible to find out the direction of the electromotive force (EMF) directly from Faraday's law, without invoking Lenz's law. A left hand rule helps doing that, as follows. Align the curved fingers of the left hand with the loop (yellow line). Stretch your thumb. The stretched thumb indicates the direction of $n$ (brown), the normal to the area enclosed of $t$ by the loop. If $\triangle \Phi B$ is positive, the direction of the EMF is the same as that of the curved fingers (yellow arrowheads). If $\triangle \Phi B$ is negative, the direction of the EMF is against the arrowheads.

Find the sign of $\triangle \Phi B$, the change in flux. Determine the initial and final fluxes (whose difference is $\triangle \Phi \mathrm{B}$ ) with respect to the normal $\mathrm{n}$, as indicated by the stretched thumb. If the change in flux, $\triangle \Phi \mathrm{B}$, is positive, the curved fingers show the direction of the electromotive force (yellow arrow heads). If $\triangle \Phi B$ is negative, the direction of the electromotive force is opposite to the direction of the curved fingers (opposite to the yellow arrowheads). For a tightly wound coil of wire, composed of $\mathrm{N}$ identical turns, each with the same $\Phi B$, Faraday's law of induction states that 


$$
\varepsilon=-N \frac{d \Phi B}{d t}
$$

Where $\mathrm{N}$ is the number of turns of wire and $\Phi B$ is the magnetic flux through a single loop.

\section{Maxwell-Faraday equation}

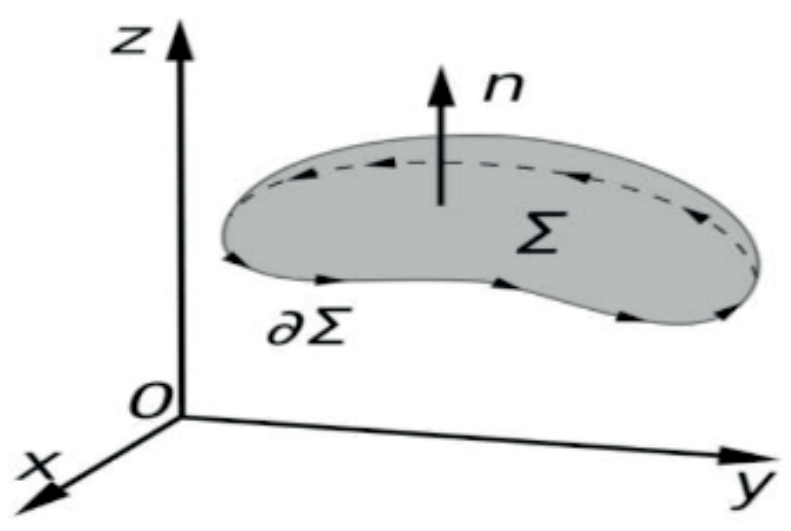

The Maxwell-Faraday equation states that a time-varying magnetic field always accompanies a spatially varying (also possibly time-varying), non-conservative electric field, and vice versa. The Maxwell-Faraday equation is (in SI units) where $\nabla \times$ is the curl operator

And again $E(r, t)$ is the electric field and $B(r, t)$ is the magnetic field. These fields surface $\Sigma$, its boundary $\partial \Sigma$, and orientation $\mathrm{n}$ set by the right-hand rule.

$$
\nabla \times E=-\frac{\partial B}{\partial t}
$$

Can generally be functions of position rand time $t$.

The Maxwell-Faraday equation is one of the four Maxwell's equations, and therefore plays a fundamental role in the theory of classical electromagnetism. It can also be written in an integral form by the Kelvin-Stokes theorem, thereby reproducing Faraday's law:

$$
\oint_{\partial \Sigma} E \cdot d l=-\int_{\Sigma} \frac{\partial B}{\partial t} \cdot d A
$$

Where as indicated in the figure: $\Sigma$ is a surface bounded by the closed contour $\partial \Sigma, E$ is the electric field, $B$ is the magnetic field. DI is an infinitesimal vector element of the contour $\partial \Sigma, \mathrm{Da}$ is an infinitesimal vector element of surface $\Sigma$. If its direction is orthogonal to that surface patch, the magnitude is the area of an infinitesimal patch of surface. Both $\mathrm{dl}$ and $\mathrm{dA}$ have a sign ambiguity; to get the correct sign, the right-hand rule is used, as explained in the article Kelvin- Stokes theorem. For a planar surface 
$\Sigma$, a positive path element dl of curve $\partial \Sigma$ is defined by the right-hand rule as one that points with the fingers of the right hand when the thumb points in the direction of the normal $n$ to the surface $\Sigma$. The integral around $\partial \Sigma$ is called a path integral or line integral.

Notice that a nonzero path integral for $E$ is different from the behavior of the electric field generated by charges. A charge generated E-field can be expressed as the gradient of a scalar field that is a solution to Poisson's equation, and has a zero path integral. See gradient theorem. The integral equation is true for any path $\partial \Sigma$ through space, and any surface $\Sigma$ for which that path is a boundary. If the surface $\Sigma$ is not changing in time, the equation can be rewritten:

$$
\oint_{\partial \Sigma} E \cdot d l=-\int_{\Sigma} \frac{\partial B}{\partial t} \cdot d A
$$

The surface integral at the right-hand side is the explicit expression for the magnetic flux $\Phi B$ through $\Sigma$. The electric vector field induced by a changing magnetic flux, the solenoid component of the overall electric field, can be approximated in the non-relativistic limit by the following volume integral equation: The four Maxwell's equations (including the Maxwell-Faraday equation), along with Lorentz force law, are a sufficient foundation to derive everything in classical electromagnetism. Therefore, it is possible to "prove" Faraday's law starting with these equations.

Proof:

The starting point is the time-derivative of flux through an arbitrary surface $\Sigma$ (that can move or be deformed) in space: (by definition). This total time derivative can be evaluated and simplified with the help of the Maxwell-Faraday equation and some vector identities; the details are in the box below: Consider the time-derivative of magnetic flux through a closed boundary (loop) that can move or be deformed. The integral can change over time for two reasons: The integrand can change, or the integration region can change. These add linearly, therefore: where t0 is any given fixed time. We will show that the first term on the right-hand side corresponds to transformer EMF, the second to motional EMF (from the magnetic Lorentz force on charge carriers due to the motion or deformation of the conducting loop in the magnetic field). The first term on the right-hand side can be rewritten using the integral form of the

Maxwell-Faraday equation: Next, we analyze the second term on the right-hand side:

The proof of this is a little more difficult than the first term; more details and alternate approaches for the proof can be found in the references. As the loop moves and/or the area swept out by a vector element $\mathrm{dl}$ of a loop $\partial \Sigma$ in time $\mathrm{dt}$ when it has moved with velocity vl. deforms, it sweeps out a surface (see the right figure). As a small part of the loop dl moves with velocity vl over a short time $\mathrm{dt}$, it sweeps out an area which vector is $d A$ sweep $=\mathrm{vl} d t \times d l$ (Note that this vector is toward out from the 
display in the right figure). Therefore, the change of the magnetic flux through the loop due to the deformation or movement of the loop over the time $d t$ is Here, identities of triple scalar products are used. Therefore, where $\mathrm{vl}$ is the velocity of a part of the loop $\partial \Sigma$. Putting these together results in,

The result is: where $\partial \Sigma$ is the boundary (loop) of the surface $\Sigma$, and $v l$ is the velocity of a part of the boundary.

In the case of a conductive loop, EMF (Electromotive Force) is the electromagnetic work done on a unit charge when it has traveled around the loop once, and this work is done by the Lorentz force. Therefore, EMF is expressed as where is EMF and $v$ is the unit charge velocity. In a macroscopic view, for charges on a segment of the loop, $v$ consists of two components in average; one is the velocity of the charge along the segment vt, and the other is the velocity of the segment $\mathrm{vl}$ (the loop is deformed or moved). Vt does not contribute to the work done on the charge since the direction of VT is same to the direction of Mathematically, since is perpendicular to as and are along the same direction.

Now we can see that, for the conductive loop, EMF is same to the time-derivative of the magnetic flux through the loop except for the sign on it. Therefore, we now reach the equation of Faraday's law (for the conductive loop) as where. With breaking this integral, is for the transformer EMF (due to a time-varying magnetic field) and is for the motional EMF (due to the magnetic Lorentz force on charges by the motion or deformation of the loop in the magnetic field). It is tempting to generalize Faraday's law to state: If $\partial \Sigma$ is any arbitrary closed loop in space whatsoever, then the total time derivative of magnetic flux through $\Sigma$ equals the EMF around $\partial \Sigma$. This statement, however, is not always true and the reason is not just from the obvious reason that EMF is undefined in empty space when no conductor is present. As noted in the previous section, Faraday's law is not guaranteed to work unless the velocity of the abstract curve $\partial \Sigma$ matches the actual velocity of the material conducting the EMF for non-thinwire circuit's electricity. The two examples illustrated below show that one often obtains incorrect results when the motion of $\partial \Sigma$ is divorced from the motion of the material.

Faraday's homo polar generator. The disc rotates with angular rate $\omega$, sweeping the conducting radius circularly in the static magnetic field $\mathrm{B}$ (which direction is along the disk surface normal). The magnetic Lorentz force $\mathrm{v} \times \mathrm{B}$ drives a current along the conducting radius to the conducting rim, and from there the circuit completes through the lower brush and the axle supporting the disc. This device generates an EMF and a current, although the shape of the "circuit" is constant and thus the flux through the circuit does not change with time. A wire (solid red lines) connects to two touching metal plates (silver) to form a circuit. The whole system sits in a uniform magnetic field, normal to the page. If the abstract path $\partial \Sigma$ follows the primary path of current flow (marked in red), then the magnetic flux through this path changes dramatically as the plates are rotated, yet the EMF is almost zero. After Feynman one can analyze like these by taking care that the path $\partial \Sigma$ moves with the same velocity as the material. 
Alternatively, one can always correctly calculate the EMF by combining Lorentz force law with the Maxwell-Faraday equation where it is very important to notice that (1) $[\mathrm{vm}]$ is the velocity of the conductor ... not the velocity of the path element $\mathrm{dl}$ and (2) in general, the partial derivative with respect to time cannot be moved outside, the integral since the area is a function of time".

\section{Two phenomena:}

Faraday's law is a single equation describing two different phenomena: the motional EMF generated by a magnetic force on a moving wire (see the Lorentz force), and the transformer EMF generated by an electric force due to a changing magnetic field (described by the Maxwell- Faraday equation). Faraday's law and relativity James Clerk Maxwell drew attention to this fact in his 1861 paper On Physical Lines of Force. In the latter half of Part II of that paper, Maxwell gives a separate physical explanation for each of the two phenomena.

A reference to these two aspects of electromagnetic induction is made in some modern textbooks. As Richard Feynman states: So the "flux rule" that the emf in circuit is equal to the rate of change of the magnetic flux through the circuit applies whether the flux changes because the field changes or because the circuit moves (or both) ... Yet in our explanation of the rule we have used two completely distinct laws for the two cases $-v \times B$ for "circuit moves" and $\nabla \times E=-\partial t$ B for "field changes".

\section{Wireless Battery Charger Circuit Advantages:}

Usage of separate charger is eliminated. Phone can be charged anywhere and anytime. It does not require wire for charging. Easier then plug into power cable.

\section{Wireless Power Transfer Circuit Application:}

Wireless charger scan be used to charge mobile, camera batteries, Bluetooth, headsets etc. This can be used in applications like car battery charger with little modification. This can also be used in medical devices.

\section{Limitations of the Circuit:}

Power is somewhat wasted due to mutual induction. It will work for very short distances only. If we want to use it for long distances, then the number of inductor turns should be high.

\section{Methodology:}

Inductive method for charging portable devices wirelessly is based upon Faraday's Law of mutual induction. The main principle upon which the design of our circuit is based have been

discussed in detail. The circuit diagram of our wireless battery charger is as follow.

\section{Wireless mobile charger circuit design:-}

Wireless battery charger circuit design is very simple and easy the circuit required only resisters, diodes, capacitors, copper coils, transformer and voltage regulator. In our wireless battery charger we use two circuits. The first circuit is transmitter circuit which is used to produce voltage wirelessly. The transmitter circuit consists of DC source, oscillator circuit and a transmitter coil. Oscillator circuit consist of two N-Channel 
MOSFETS IRF 540, 4148 diodes. When the DC power is given to the oscillator, current starts flowing through the two coils L1, L2 and drain terminal of the transistor. At the same time some voltage is appeared at the gate terminals of the transistors. One of the transistors is in on state while other is off state. Thus

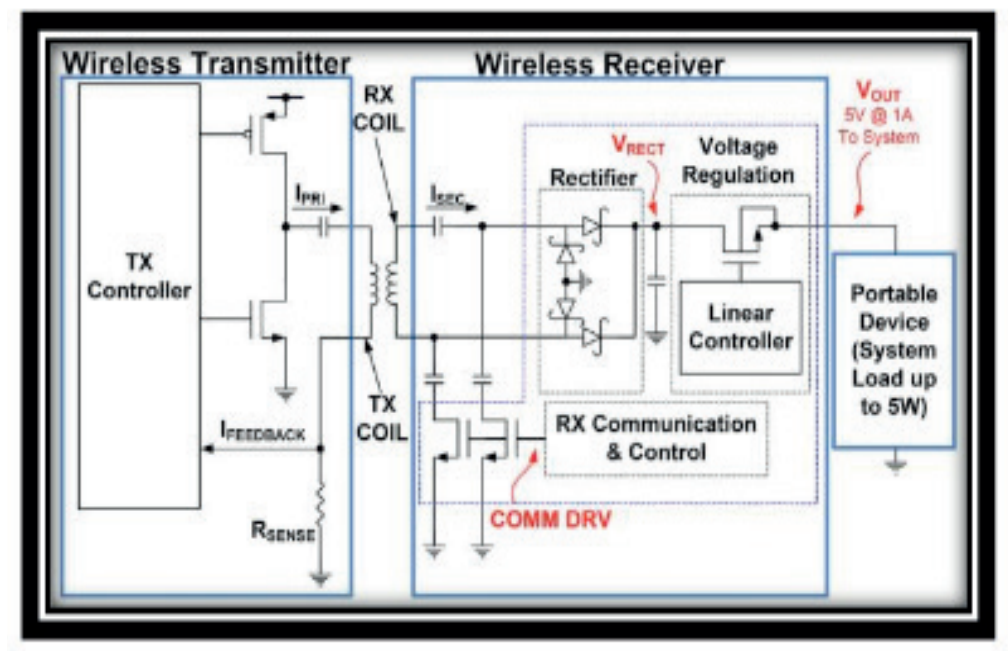

Figure 5: Wireless mobile circuit diagram

voltage at Drain of transistor which is in off state rises and it fall through the tank circuit made of $6.8 \mathrm{nf}$ capacitors and transmitter coil of 0.674 . Thus operating frequency is determined by using formula:

$$
F=1 /[2 \pi(L C)]
$$

In the second circuit that is receiver circuit consist of receiver coil, rectifier circuit and regulator. When the receiver coil is placed at distance near the inductor AC power is induced in the coil. This is rectified by the rectifier circuit and is regulated to DC 5 volt using 7805 regulator. The rectifier circuit consists of 1n4007 diode and capacitor $6.8 \mathrm{nf}$. The output of regulator is connected to the battery.

How to operate this Wireless Power Transfer Circuit?

Initially, connect the circuit as shown in the circuit diagram and switch on the supply. Connect the battery charger at the output of the circuit. Place the receiver coil near the transmitter coil. You can observe the charging of battery.

\section{CONCLUSIONS}

We discussed different wireless power transfer techniques and briefly overviewed inductive method of power transfer as it is best way to deliver power wirelessly to our portable devices. Wireless battery charging has many advantages in term of convenience because users simply need to place the device requiring power onto a mat or other surface to allow wireless charging to take place. We believe that our contribution in this work is successfully benefit society in terms of convenience, reduce wear of plugs and 
sockets, and application in medical environments. Reduced efficiency is one of the key challenges in wireless battery charging system due to resistive loses on the coil, stray coupling etc. Therefore inductive method was chosen to fulfill the requirements of the consumers because it is suitable for charging devices in both power and range level. The basic principle of this technology is explained, the last development and research are summarized, with an especial emphasis on inductive charging technology technical challenge and future development trends are also introduced.

It is concluded that power loss and efficiency are major problems for this design we noticed the potential problem whether the converted DC power will be significant enough to charge up the battery. Therefore the characteristics of the diodes should be mounted directly onto the antenna for a minimum power dissipation.

As the wireless technology is getting popular now a days the demand of battery is also increasing. The battery needs to recharged or changed eventually. Therefore I am inspired to design the wireless battery charger the wireless battery charger will eliminate all the hassle with the battery. As for now there are no known companies which develop the wireless battery charger. This means that the opportunity is very big. Also, people tend to spend more money for convenience. It gives more reason that this device will have a very good market.

\section{REFERENCES}

Poul,J.L., S.Sasirekha, D, N, Kumar D and P.S. Revanth. 2018. "A Working Model for Mobile charging using Wireless power Transmission”. Science Pubto, 7(3.12): 584-588.

Singla,N. 2014." Wireless Charging of Mobile Phone Using Microwave or Radio Frequency Signals”. ljarcst, 1(2): 2347-2350.

Shahnawaz, S., A. Waheed and S. M. Bhat. 2017. "Wireless Charging of Mobile Phones Using Microwaves". ljesmc, 6(6): 384-389.

Gupta, A., A.Tandon, A.Jeriya, N.Tanwar, R.Kumar and D.Kumar. 2016. "Automatic Wireless Mobile Charger". Research Publish, 1(4): 113-119.

Sharma, H. 2016. "Study \& Survey on Wireless Charging and Technology". ljerst, 10(12: 5281-5286.

Ansari, T. R., A. Khan and I. Ansari. 2015. "Wireless Charging of Mobile Battery via Optimization of RF Energy Harvesting System". Research Gate, 10: 14299-14307.

Lu, X. and P. Wang. 2014. "Wireless Charger Networking for Mobile Devices". Research Gate, 10: 1109-21125.

Qiu C., T. Chau, L.Chunhua and C.C. Chan. 2013. "Overview of Wireless Power for Electrical Vehicle Charging". Research Gate, 10: 1109-1118.

BR, P. 2018. "Wireless Charging of Implantable Pacemaker's Battery". Journal of Biosensors \& Bioelectronics, 10(9):4172-4174.

Wang, Z. and X. Wei. 2015. "Design Considerations for Wireless Charging Systems with an Analysis of 
Fitra, M. and E. S. 2017. "Wireless Power for Mobile Battery Charger". Indonesian Journal of Electrical Engineering and Computer Science, 10(6): 11591-11598.

Sadiku, M. N. O. (2007). "Elements of Electromagnetics". (4th ed.). New York \& Oxford: Oxford University Press. p. 386. ISBN 0-19-530048-3

KR, P.,R.Nerya and V.Kumar M. 2017. "Wireless Charging System for Electrical Vehicles". Research Gate, 10: 4273-4278.

Al-Jaber, S. 2011. "Path Integral Approach to Faraday's of Induction".

Research Gate, 10: 4233-4238.

Das, S. 2017. "Review paper on Wireless Power Transmission for Charging mobile devices". Research Gate, 10: 18535-18541.

Thakkar, V. 2015 . "Faraday's law in Moving Media”. Research Gate, 10: 13252-13263

Vaka, R. and R.K.Keshri. 2017. "Review on contact less Power Transfer for Electrical Vehicle Charging”. Mdpi, 10: 636-656.

Mahangade, S. and S. Mahangade. 2017. "Electrical Vehicle Wireless charging”. ljariit, 3:2454-2460

Giancoli, D. C. (1998). Physics: Principles with Applications (5th ed.). pp. 623-624.

Ulaby, F. (2007). "Fundamentals of applied electromagnetics". (5th ed.). Pearson: Prentice Hall. p. 255. ISBN 0-13- 241326-4.

Maxwell, C . J (1904). "A Treatise on Electricity and Magnetism". 2 (3rd ed.). Oxford University Press. pp. 178-179, 189.

Lenz, Emil (1834). "Ueber die Bestimmung der Rich Tung der durch elektodynamische Vertheilung erregten galvanischen Ströme". Annalen der Physics and Chemie. 107 (31): 483-494.

Giuliani, G. 2000. "On Electromengnetic Induction”. Research Gate, 10: 1038-1056.

Vashi, I. Y. D. 2017. "Wireless Mobile Phones Charging-A Comprehensive Study". International journal of Electromagnetics and Applications, 10: 5923-5930.

Jordan, Edward; Balmain, Keith G. (1968). "Faraday's Law, which states that the electromotive force around a closed path is equal to the negative of the time rate of change of magnetic flux enclosed by the path". Research Gate, 10: 5134-5138.

Hayt, William. (1989). "The magnetic flux is that flux which passes through any and every surface whose perimeter is the closed path". Engineering Electromagnetics (5th ed.). McGraw-Hill. p. 312. ISBN 0-07-027406-1.

Feynman, R. P.,R. B. Leighton and M. L. Sands. 2006. . "The flux rule" is the terminology that Feynman uses to refer to the law relating magnetic flux to EMF". Research Gate, 17(2):8053-8070.

Griffiths, David J. (1999). "Introduction to Electrodynamics". (3rd ed.). Research Gate ,pp. 301-303. ISBN 0-13-805326-X. 
Neumann and F.Ernst. 1846."Allgemeine Gesetze der inducirten elektrischen Strome". Bibcode:1846AnP...143...31N . doi:10.1002/andp.18461430103.

Yehuda S. 2014. "A Left Hand Rule for Faraday's Law”. The Physics Teacher. 52: 48. Bibcode:2014PhTea..52...48S . doi:10.1119/1.4849156 . 


\section{CAPÍTULO 20}

\section{TRANSFORMADOR DE ATERRAMENTO EM REDE DE DISTRIBUIÇÃO}

Data de aceite: 03/01/2020

\section{Djair Pamplona sos Santos} CENTRAIS ELÉTRICAS DO PARÁ S.A.

BELÉM-PARÁ-BRASIL djair.pamplona@gmail.com

$04 / 11 / 2019$

RESUMO: Este artigo apresenta estudo, projeto de implantação e acompanhamento da operação de um transformador de aterramento instalado em um alimentador rural de $34,5 \mathrm{kV}$, com objetivo de diminuir queimas de transformadores de distribuição. A Região Amazônica, no Estado do Pará, onde foi instalado o transformador de aterramento, apresenta particularidades com relação à eletrificação rural por possuir alimentadores de distribuição $34,5 \mathrm{kV}$ bastante longos com muitos circuitos Monofásicos com Retorno pela Terra (MRT) e que apresentam números excessivos de queimas de transformadores de distribuição. Entre 2012 e 2013, o alimentador RN-11 com $2.541 \mathrm{~km}$ de extensão, somando o tronco com todos os ramais, foi o que mais apresentou queimas, 446 . Deste total $88,4 \%$ foram queimas de transformadores monofásicos instalados em ramais monofásicos. Baseado na premissa técnica de que os parâmetros de impedância zero de um alimentador de distribuição cresce mais do que o de sequência positiva à medida que se distancia de subestação de potência, a tendência é que no final do alimentador a relação X0/X1 torna-se maior que 3 . A partir deste ponto ocorrem sobretensões nas fases sãs, durante faltas fase à terra, próximas de 1,4 p.u., principalmente se ramais MRT destes locais tiverem baixo carregamento. A partir da localidade de Casa de Tábua no final do alimentador, constatou-se os maiores valores de X0/X1 onde ocorrem maiores sobretensões, menores correntes de curtos circuitos e maior quantidade de transformadores queimados. A solução vislumbrada com os resultados dos estudos foi a de alterar as impedâncias de sequência zero do alimentador no local, para isto foi utilizado um transformador de aterramento do tipo utilizado em subestações, $V n=34,5 / \sqrt{ } 3$ kV, In=4.500 A, Pn (10s)=2.700 kVA, ligação zig-zag e impedância de sequência zero de $5,29 \Omega$.

PALAVRAS-CHAVE: Transformador de Aterramento, Alimentador, Isolamento de Neutro, Sobretensões, Relação X0/X1.

\section{GROUND TRANSFORMER IN DISTRIBUTION NETWORKS}

ABSTRACT: This paper presents the analysis, implementation project and operation monitoring 
of a ground transformer installed in a $34,5 \mathrm{kV}$ rural feeder, aiming to reduce failure in distribution transformers. The Amazon region, Para State, where the transformer is installed, presents particularities in relation to other rural electrification for having long distance $34,5 \mathrm{kV}$ distribution feeders with many ground return monophasic circuit which presents excessive cases of failuring of distribution transformers. Between 2012 and 2013, the $2.541 \mathrm{~km}$ range feeder $\mathrm{RN}-11$, counting the main circuit with its branch-lines, has presented the most frequent failures, 446 total. Which $88,4 \%$ were from monophasic transformers installed in monophasic branch-lines. Based on the technical premise that the impedance parameters zero of a feeder increases more than the positive sequence as the distances increases from the power substation, the trend is that in the end of the feeder the ratio $\mathrm{X} 0 / \mathrm{X}_{1}$ becomes greater than 3 , where overvoltages occurs in phases not affected during phase and ground shortcut, close to 1,4 p.u., mostly if ground return monophasic circuit from those places having low loading. From the end of the feeder, at Casa de Tábua locality, was observed that the highest values of $\mathrm{X} 0 / \mathrm{X} 1$ happens where most of overvoltages occurs, less short-circuit current and more failed transformers. The solution proposed with the results of this analysis is to change the sequence zero impedances of the feeder in the location. For this was used a ground transformer $\mathrm{Vn}=34,5 / \sqrt{3} \mathrm{kV}, \mathrm{In}=4.500 \mathrm{~A}, \mathrm{Pn}(10 \mathrm{~s})=2.700 \mathrm{kVA}$, and zero-sequence impedance of $5,29 \Omega$

KEYWORDS: Ground transformer, Feeder, neutral isolation, overvoltages, ratio x0/x1

\section{I INTRODUÇÃO}

Grande parte das redes (alimentadores) de distribuição 34,5 kV e 13,8 kV implantadas no Estado do Pará, Região Amazônica do Norte do Brasil, foram construídas através do Programa de Eletrificação Rural Luz Para Todos (PLPT) do Governo Federal. Estas redes trifásicas são bastante extensas, geralmente com baixo carregamento e com muitos ramais monofásicos MRT; sendo atendidas por subestações de força que apresentam transformadores abaixadores cujo tipo de ligação é delta na alta tensão (69 kV ou 138 kV) e estrela aterrada solidamente na média tensão (34,5 kV ou 13,8 kV) ou por transformadores elevadores 13,8/34,5 kV5/6,3 MVA, ligação estrela aterrada solidamente.

As implantações e expansões destes alimentadores são constituídas, inicialmente para atender localidades habitacionais rurais próximas às subestações de força, contudo com o passar dos anos foram crescendo muito em extensão e se distanciando cada vez mais das subestações.

As regiões por onde passam os alimentadores, são constituídas de florestas tropicais com grande quantidade de árvores e arbustos e outras com florestas abertas em função de desmatamentos para o plantio de pastagens destinadas à atividade pecuária e extração de minérios. Toda esta região tem em comum a alta densidade pluviométrica, principalmente durante o inverno amazônico, período de novembro a maio, quando acontece a maior incidência de curtos circuitos nas redes. 
O solo da região apresenta resistividade bastante variável, onde podemos encontrar áreas com resistividade do solo abaixo de $700 \Omega$.m e outras acima de 2.000

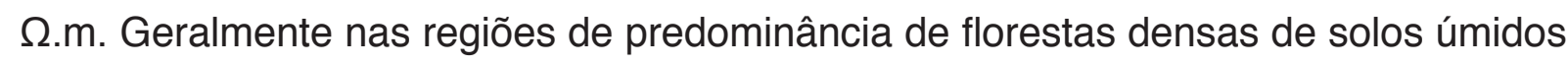
a resistividade é baixa, contudo é alta nas áreas de florestas abertas usadas para formação de pasto e extração mineral.

Somam-se ainda muitas dificuldades de trafegabilidade nas estradas vicinais que são de péssimas qualidades e por onde passam as redes de distribuição. Neste caso torna-se, extremamente dificultoso fazer serviços de manutenção no menor tempo possível e que não prejudiquem os índices de conformidade e continuidade de atendimento dos consumidores.

Dependendo da região por onde esteja situado o alimentador de distribuição 34,5 kV ou 13,8 kV, os aspectos citados contribuem para que sua extensão longa, com vários ramais $\mathrm{MRT}$, apresente um número elevado de queima de transformadores de distribuição monofásicos.

O objetivo deste artigo será apresentar as experiências obtidas com a implantação de um transformador de aterramento (padrão estação) em local determinado de um alimentador $34,5 \mathrm{kV}$ para diminuir a queima de transformadores de distribuição.

\section{I ESTATÍSTICA DE QUEIMAS DE TRANSFORMADORES}

Levantamento feito entre os meses de setembro de 2012 a agosto de 2013 apresentou uma quantidade excessiva de queima de transformadores de distribuição, principalmente em alimentadores de $34,5 \mathrm{kV}$ de grande extensão, conforme Tabela I.

Do total dos 135.678 transformadores de distribuição existentes nas redes 13,8 kV e 34,5 kV da rede elétrica do Estado do Pará, 5.352 transformadores foram danificados no período, o que representa uma taxa de $3,94 \%$ de queima. 


\begin{tabular}{|c|c|c|c|c|c|}
\hline Alimentador & \begin{tabular}{|c} 
Transformadres \\
queimados ( Set/12 \\
a Ago/13)
\end{tabular} & $\begin{array}{c}\text { Tensão } \\
\text { (kV) }\end{array}$ & $\begin{array}{l}\text { Extensão } \\
\text { MT (km) }\end{array}$ & $\begin{array}{c}\text { Tronco } \\
\text { (km) }\end{array}$ & $\begin{array}{l}\text { Bitola } \\
\text { Tronco }\end{array}$ \\
\hline $\mathrm{RN}-11$ & 624 & 34,5 & 2541 & 152 & $4 / 0$ \\
\hline RV-01 & 279 & 34,5 & 2932 & 165 & 336,4 \\
\hline AB-15 & 209 & 34,5 & 987 & 141 & 336,4 \\
\hline RM-05 & 195 & 34,5 & 1762 & 83 & $4 / 0$ \\
\hline TM-05 & 178 & 34,5 & 2019 & 149 & $4 / 0$ \\
\hline TI-16 & 154 & 34,5 & 1582 & 100 & $4 / 0$ \\
\hline MB-11 & 100 & 34,5 & 2935 & 278 & $4 / 0$ \\
\hline $\mathrm{XN}-10$ & 93 & 34,5 & 1513 & 63 & $1 / 0$ \\
\hline$\ldots$ & $\ldots$ & $\ldots$ & ... & $\ldots$ & ... \\
\hline$\ldots$ & $\ldots$ & $\ldots$ & $\ldots$ & $\ldots$ & ... \\
\hline $\mathrm{AE}-02$ & 1 & 13,8 & 8 & 3,5 & $1 / 0$ \\
\hline Total & 5.352 & & & & \\
\hline
\end{tabular}

Tabela I. Transformadores Queimados

Destes 5.352 transformadores, 1.832 (34,23\%) ocorreram somente em 8 alimentadores de 34,5 kV e 3.520 no restante dos 387 alimentadores da concessionária. O alimentador RN-11 com $2.541 \mathrm{~km}$ de extensão, somando o tronco com todos os ramais, foi o que mais apresentou queimas, 446 . Deste total $88,4 \%$ foram queimas de transformadores monofásicos de 19,918 kV/230-115 V-5, 10 e 15 KVA ou 19,918 kV/254-127 V-5, 10 e 15 KVA instalados em ramais monofásicos MRT.

\section{I ESTUDOS ELÉTRICOS}

Face às evidências de queimas exageradas no alimentador RN-11, passou-se a investigar as causas das mesmas através de estudos de análises com utilização de ferramentas computacionais de programa de cálculo de curto circuito. Procurou-se avaliar e quantificar os níveis de correntes na fase em falta e sobretensões sustentadas nas fases sãs, quando da ocorrência de curtos circuitos fase terra nas extremidades do alimentador, principalmente nos locais onde havia maior incidência das queimas.

$\mathrm{O}$ aterramento do sistema de distribuição, a partir dos barramentos $34,5 \mathrm{kV}$ ou 13,8 kV das subestações, tende a ficar comprometido com o distanciamento da subestação e, dependendo da bitola do cabo, pode provocar o isolamento do neutro para o final do alimentador [1].

Sistemas de distribuição com tendência ao isolamento de neutro apresentam sobretensões sustentadas e transitórias que provocam queima de equipamentos, assim como diminuição das correntes de falta à terra com baixa sensibilidade das proteções.

$\mathrm{O}$ isolamento de neutro começa a ser evidenciado quando a relação $\mathrm{XO} / \mathrm{X} 1$ no alimentador torna-se maior ou igual a 3 [2]. A partir deste ponto ocorrem sobretensões 
nas fases sãs, durante faltas fase à terra, próximas de 1,4 p.u.

Baseado nesta premissa técnica, idealizamos e concretizamos a instalação de um transformador de aterramento [3] em determinado ponto de um alimentador, com objetivo de diminuir a relação X0/X1 antes e após o local de sua instalação para diminuirmos as sobretensões nas fases sãs e aumentar a sensibilidade das proteções de neutro dos religadores da rede de $34,5 \mathrm{kV}$.

\subsection{O Alimentador RN-11}

O alimentador $\mathrm{RN}-11$, situado na região sudeste do Estado do Pará, tem seu caminhamento passando por áreas de florestas densas e abertas, propensas à incidência elevada de curtos circuitos, principalmente na época da estação de chuvas.

Atendido em 34,5 kV pela Subestação Redenção 138/13,8/34,5 kV, possui tronco com aproximadamente $152 \mathrm{~km}$, cabo 4/0 AWG e diversos ramais MRT de até $20 \mathrm{~km}$ em cabo 2 e 4 CA. Possui 2.410 transformadores, onde somente 92 são trifásicos $(3,81 \%)$ e o restante 2.318 monofásicos $(96,19 \%)$.

Na Fig.1 é mostrada a Região Amazônica do Brasil onde está localizado o alimentador RN-11 e na Fig.2 a topologia do alimentador com a indicação da subestação Redenção e a localidade de Casa de Tábua.

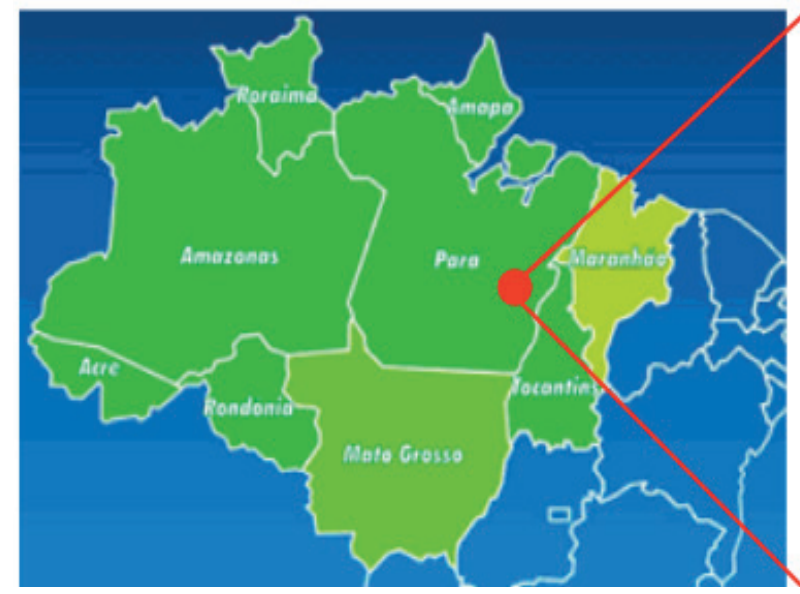

Fig.1. Região Amazônica do Brasil

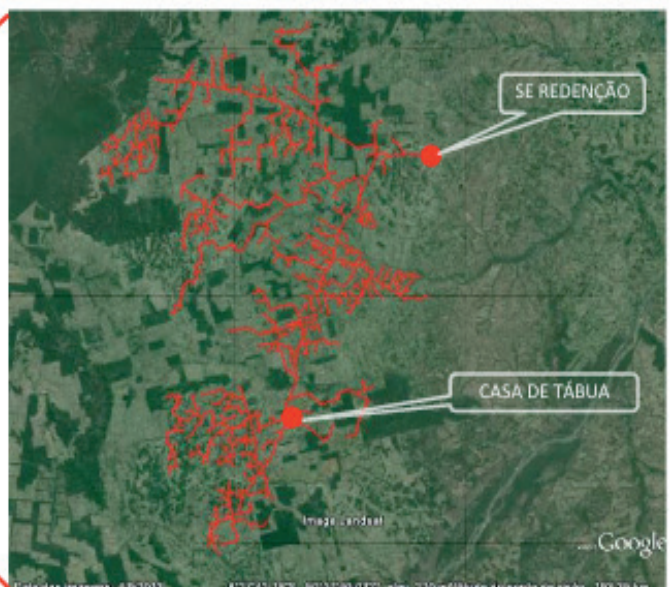

Fig.2. Topologia do alimentador RN-11

Como na maioria dos troncos trifásicos dos alimentadores rurais da região, o $\mathrm{RN}-11$ não possui condutor neutro multe aterrado[4], o que favorece as seguintes desvantagens:

- Elevação de potencial de neutro de transformadores monofásicos;

- Condição desfavorável para escoamento de surtos de tensão;

- Curtos circuitos de alta impedância no alimentador;

- Falta de sensibilidade para as proteções de terra;

- Potenciais de toque e passo próximo ao aterramento de transformadores; 
- Transformadores monofásicos com baixo carregamento.

Os problemas aumentam ainda mais nos ramais monofásicos MRT ligados ao tronco do alimentador, considerando as dificuldades em obter resistências de aterramento baixa para os transformadores, uma vez que na região a resistividade do solo está acima de $2.000 \Omega$.m.

A região abaixo da localidade de Casa de Tábua é onde ocorrem $70 \%$ da totalidade de queimas dos transformadores do $\mathrm{RN}-11$.

\subsection{Resultado dos Estudos de Curto Circuito}

A modelagem do alimentador RN-11, no programa de cálculo de curto circuito, foi representada todo o tronco principal e somente os ramais monofásicos MRT mais representativos, principalmente os mais longos. Consideraram-se as impedâncias equivalentes no barramento de 34.5 kV da SE Redenção 138/13,8/34,5 kV.

Vale observar que a modelagem utilizada nos cálculos de curto circuito não considerou nenhum valor de impedância de retorno pela terra, ou seja, a terra é ideal com impedância zero; assim como o sistema foi representado em vazio, sem carga, o que favoreceu obtermos valores de corrente e tensão um pouco conservativos.

Os resultados com valores de corrente, tensão e impedâncias de curto circuito e diagrama unifilar simplificado do alimentado RN-11, são mostrados na Tabela II.

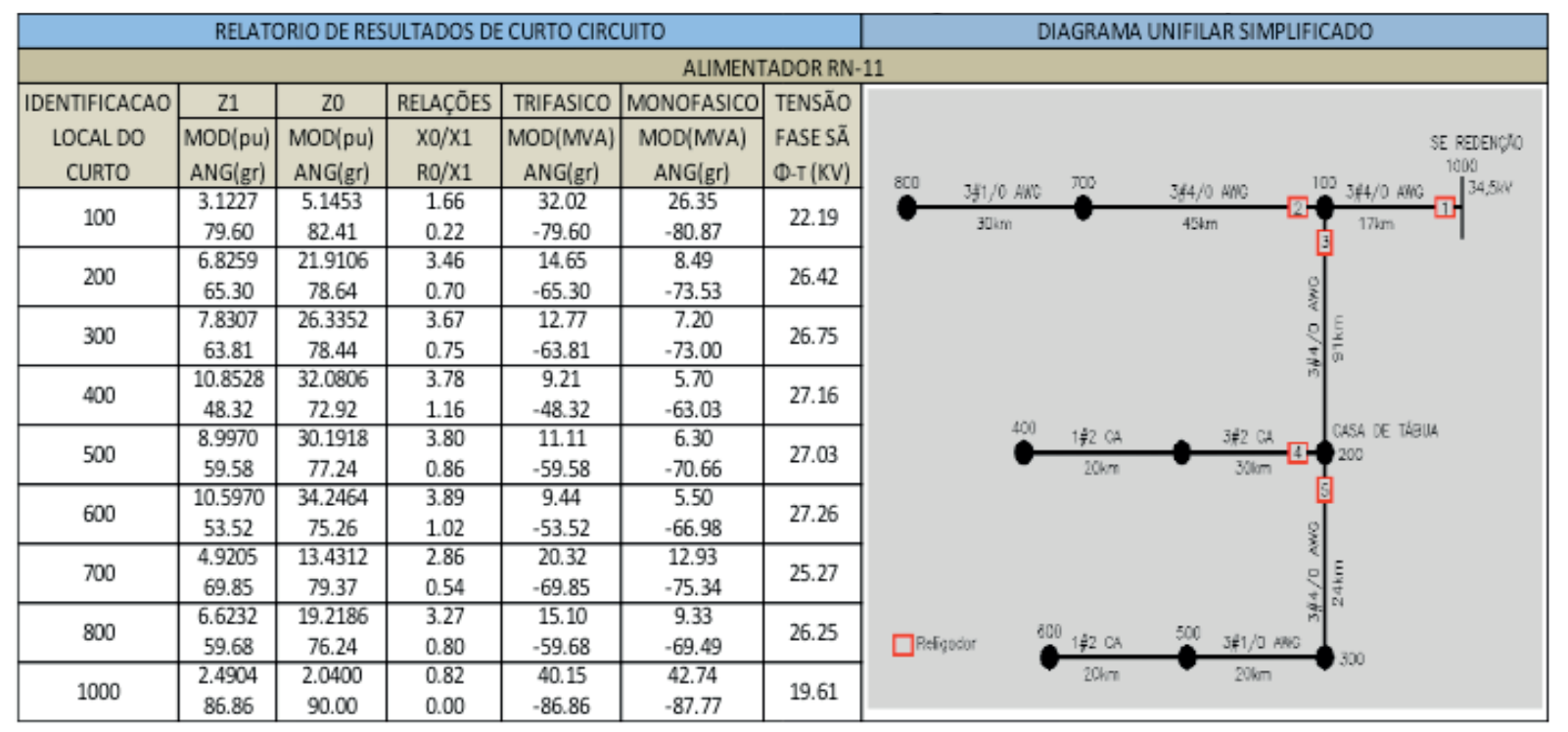

Tabela II. Resultados de Curto Circuito e Diagrama Unifilar Simplificado

Avaliando os valores resultantes de corrente, tensão e relações X0/X1 e R0/X1 para curtos circuitos fase terra em locais a partir de Casa de Tábua, pode-se concluir:

- Correntes de curto circuito fase terra - muito baixas para sensibilidade adequada das proteções de neutro dos religadores existentes no alimentador.

- Tensões nas fases sãs quando da ocorrência do curto circuito fase terra - 
muito elevadas para o funcionamento adequado dos para-raios e transformadores de distribuição, principalmente os monofásicos.

Pelo fato de não termos modelado as impedâncias de faltas nos cálculos de curto dos ramais MRT, espera-se que na prática as correntes sejam bem menores do que as calculadas; o que impõe maiores tempos de eliminação de defeito e consequentemente maior exposição a tensões elevadas aos equipamentos.

Os resultados de tensão com a não representação das cargas nos cálculos das tensões nas fases sãs; afetam bem pouco aos valores obtidos pelo fato dos transformadores monofásicos do MRT apresentarem carregamentos muito baixos.

Para resolvermos os problemas de tensão e corrente apresentados, teríamos a opção de estendermos o sistema 138 kV de Redenção até Casa de Tábua, onde seria construído uma subestação abaixadora 138/34,5 kV; contudo os custos de implantação seriam muitos elevados e sem viabilidade econômica em frente ao montante de demanda a ser atendido.

A opção encontrada foi a da instalação de um transformador de aterramento com objetivo de alterar os parâmetros elétricos da rede $34,5 \mathrm{kV}$ do alimentador, diminuindo a relação $X_{0} / X_{1}$ nos locais de maiores queimas de transformadores e, em consequência diminuindo as sobretensões e aumentando as correntes de curto circuito fase terra para dar maior sensibilidade e menor tempo de atuação para as proteções de neutro.

O transformador de aterramento empregado foi um do tipo utilizado em subestações de força, possuindo as seguintes características elétricas: $V n=34,5 / \sqrt{ } 3$ kV, In=4.500 A, Pn(10s)=2.700 kVA, ligação zig-zag e impedância de sequência zero de $5,29 \Omega$.

O local escolhido do alimentador, para instalar o transformador de aterramento, foi na localidade de Casa de Tábua, distante de $108 \mathrm{~km}$ da cidade de Redenção e da subestação de mesmo nome 138/13,8/34,5 kV.

Apresentamos $\mathrm{Na}$ Tabela III, os resultados com valores de corrente, tensão e impedâncias de curto circuito e diagrama unifilar simplificado do alimentado RN-11, para esta condição. 


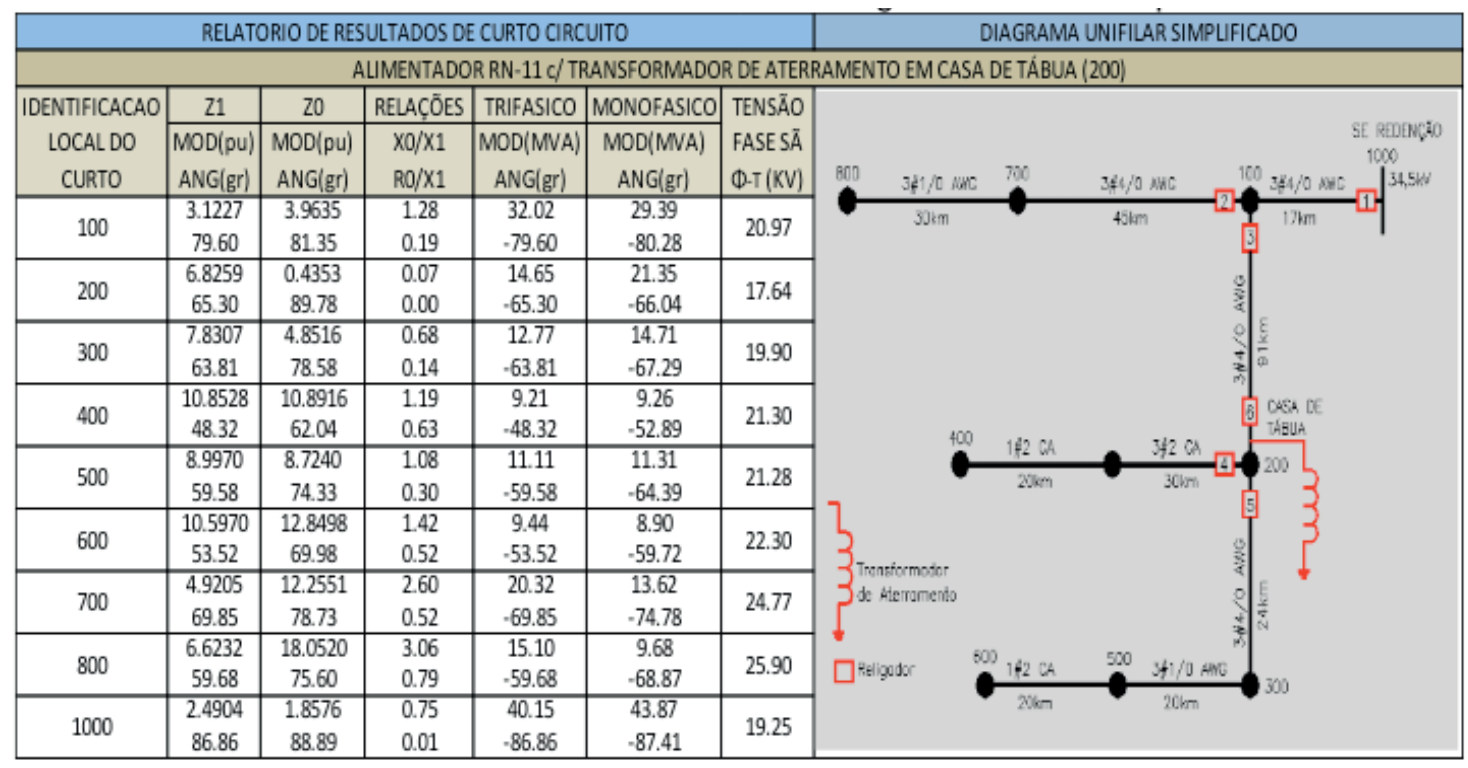

Tabela III. Resultados de Curto Circuito e Diagrama Unifilar Simplificado

Após a instalação do transformador de aterramento em Casa de Tábua podemos comparar, em relação ao alimentador sem o transformador, os valores resultantes de corrente, tensão e relações X0/X1 e R0/X1 para curtos circuitos fase terra em todo alimentador, onde se destaca:

Correntes de curto circuito fase terra - 151\% superior em Casa de Tábua (200) e $62 \%$ superior nos finais dos ramais (400) e (600). Possibilitando melhor sensibilidade para as proteções de neutro dos religadores existentes nos ramais.

Tensões nas fases sãs quando da ocorrência do curto circuito fase terra - 33\% inferior em Casa de Tábua, 21,6\% inferior no final do ramal (400) e 18,2\% inferior no final do ramal (600). Possibilitando o funcionamento adequado dos para-raios abaixo de sua máxima tensão de operação contínua.

Pelo exposto, a instalação do transformador de aterramento interferiu diretamente nas relações $\mathrm{X0/X1}$ de cada ponto do alimentador em curto circuito, com isso se garantiu um adequado retorno de correntes de curto circuito pela terra; principalmente para defeitos de alta impedância que trazem problemas com a falta de sensibilidade para as proteções de terra.

O aumento da sensibilidade das proteções de neutro permitiu abertura dos religadores em menor tempo, propiciando a diminuição de tempo com tensões elevadas nos transformadores de distribuição.

\subsection{Análise da Proteção}

O sistema de proteção do alimentador RN-11 é constituído, além do religador na saída da subestação, por outros religadores $34,5 \mathrm{kV}$ com relés de tensão e corrente instalados em pontos estratégicos, conforme diagramas unifilares das Fig's II e III.

Estes religadores devem estar coordenados uns com os outros para prover seletividade e sensibilidade da proteção, quando da ocorrência de curtos circuitos. 
Neste sentido, houve necessidade de instalarmos mais um religador 34,5 kV (№ 6) a partir da implantação do transformador de aterramento, uma vez que as correntes de sequência zero a montante dele diminuíram bastante, fazendo com que o religador № 3 perdesse sensibilidade da proteção de neutro para defeitos próximos ao religador № 6 , entretanto para as proteções de fase não houve alteração da sensibilidade.

O religador № 6 tem importância fundamental no desempenho da seletividade da proteção do alimentador, considerando que ele providencia a proteção de retaguarda aos religadores (№ 4 e 5, tabela) para o caso de curtos circuitos a jusante do transformador de aterramento.

Outro esquema de proteção foi pensado sem considerar a instalação do religador № 6; tal como a utilização das funções de proteção de fase e de sequência negativa do religador № 3 para proteção de neutro de curtos a montante do transformador de aterramento, contudo não acionamos esta opção por falta de confiabilidade do relé de sequência negativa do religador.

Após a instalação do transformador de aterramento em Casa de Tábua podemos comparar, em relação ao alimentador sem o transformador, os valores resultantes de corrente, tensão e relações X0/X1 e R0/X1 para curtos circuitos fase terra em todo alimentador, onde se destaca:

Correntes de curto circuito fase terra - 151\% superior em Casa de Tábua (200) e $62 \%$ superior nos finais dos ramais (400) e (600). Possibilitando melhor sensibilidade para as proteções de neutro dos religadores existentes nos ramais.

\section{I PROJETO ELETROMECÂNICO, CONSTRUÇÃO E MONTAGEM}

Concluído os estudos elétricos com os resultados apresentados, passamos a elaborar o projeto eletromecânico executivo para instalação do transformador de aterramento.

O transformador escolhido foi um do tipo utilizado em subestações de força, que a concessionária possui em reserva técnica, cujo peso total é de $8.000 \mathrm{~kg}$.

Como teríamos de ligá-lo na rede do alimentador sobre a via pública, inicialmente pensamos em instalá-lo em plataformas suspensas entre dois postes, contudo não seria possível devido ao peso elevado do mesmo. Como solução, tivemos de alugar um terreno nas margens da via pública com dimensões compatíveis para instalação em base apropriada no chão. O diagrama unifilar da conexão do transformador no alimentador é apresentado na Fig. 3. 


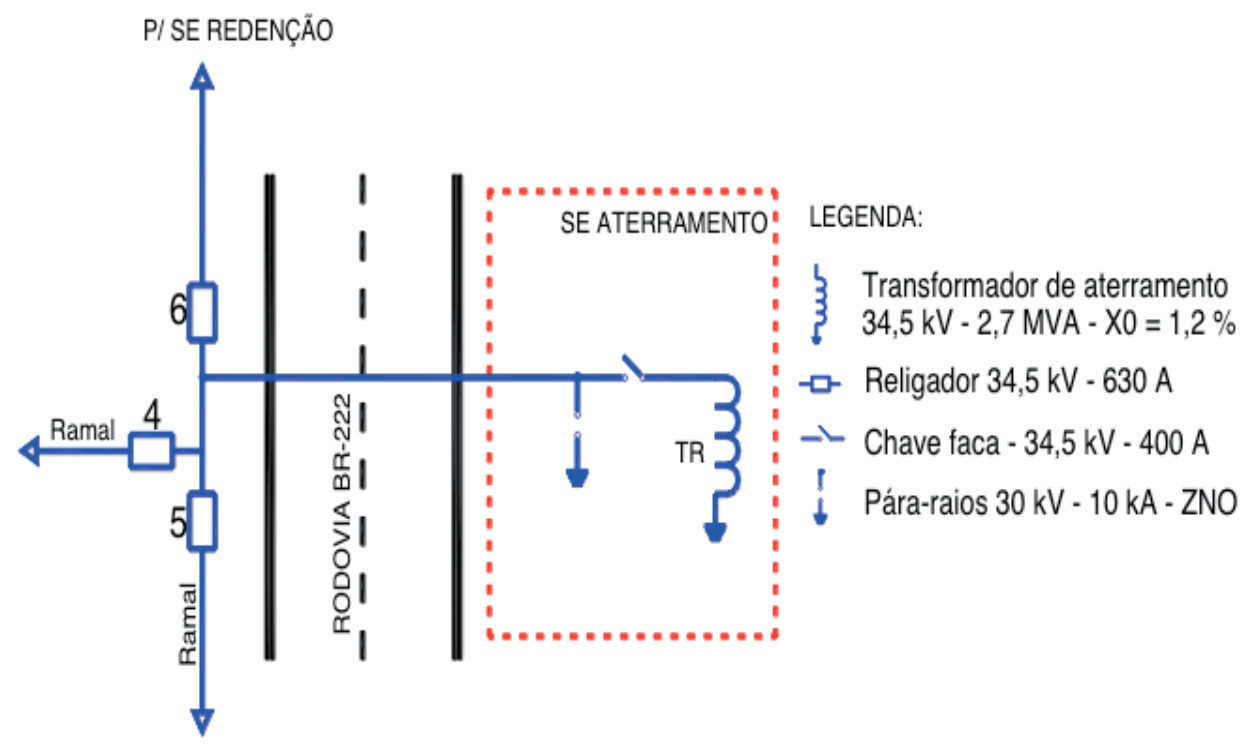

Fig.3. Conexão do transformador de aterramento no alimentador

O projeto concebeu terreno com dimensões $(10 \times 10 \mathrm{~m})$ para assentar em base no chão o transformador, e em poste foram instalados 03 para-raios de $30 \mathrm{kV}-10 \mathrm{kA}$ e 03 chaves tipo faca $34,5 \mathrm{kV}-400 \mathrm{~A}$.

As proteções inerentes do transformador não foram acionadas, ficando o religador №6 fazendo esta função. Na Fig. 4, são mostrados o arranjo básico e cortes da instalação.

As especificações dos equipamentos (para-raios e chaves) e materiais foram projetadas em padrão distribuição, com exceção do transformador de aterramento que é de padrão subestação.

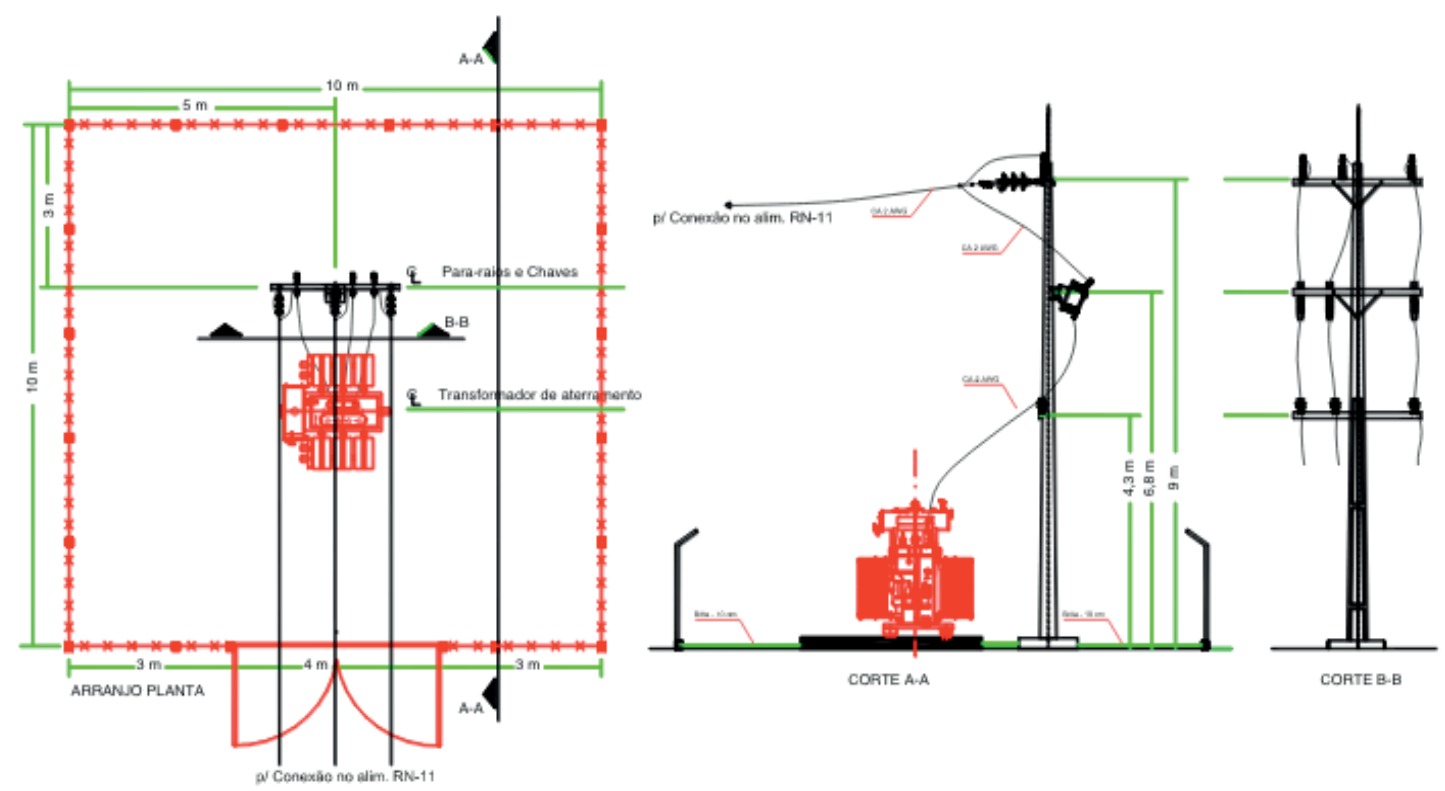

Fig.4. Arranjo básico e corte da instalação do transformador de aterramento

De fundamental importância no projeto de concepção da "pequena subestação" 
foi à malha de aterramento para conexão dos equipamentos, principalmente a do transformador.

Considerando que o solo da região apresenta alta resistividade (>2.000 $\Omega . \mathrm{m}$ ), foram feitas medições da resistência do solo no local para dimensionamento da malha de aterramento através de programa computacional de cálculos de malhas.

Visando assegurar menores valores possíveis para a resistência da malha, foram especificados materiais do tipo utilizados em subestações. Tais como: Cabos de cobre nu $70 \mathrm{~mm}^{2}$; conectores de cobre estanhados; haste cobreada para aterramento de $\varnothing$ 3/4" x 3,00m; conexões exotérmicas e etc..

Estando o projeto executivo concebido partimos para execução dos serviços de terraplenagem, construção civil do pátio, implantação da malha de aterramento e montagem eletromecânica dos equipamentos, conforme Fig.5.
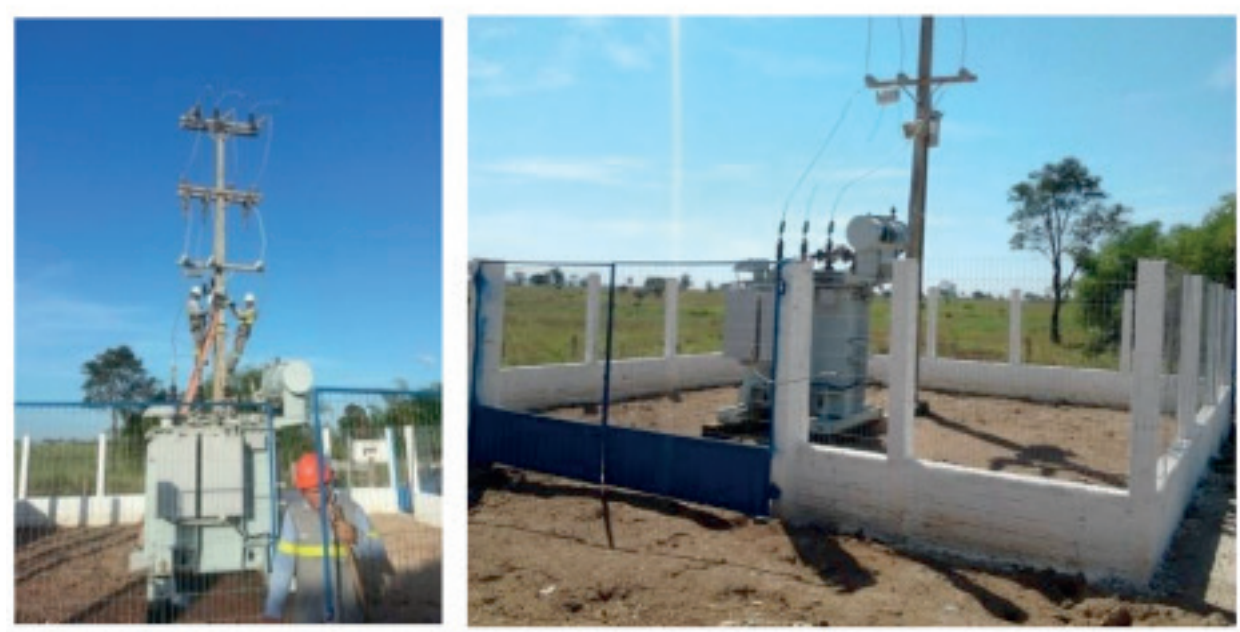

Fig.5. Fotos da instalação do transformador de aterramento

\section{I ACOMPANHAMENTO DOS RESULTADOS OBTIDOS}

Com a colocação em serviço do transformador, no dia 08 de maio de 2014, passamos a acompanhar as ocorrências de queimas de transformadores no alimentador RN-11, principalmente a partir da localidade de Casa de Tábua, local de implantação.

$\mathrm{Na}$ Fig.6, apresentamos os registros das queimas de transformadores no alimentador desde o ano de 2013 até o mês de abril de 2016.

Em relação a 2013, a diminuição de queima de transformadores de distribuição, a partir da instalação do transformador de aterramento, mostra que já em 2014 o total de queima reduziu em mais de 56\%, em 2015 a redução de $71 \%$ foi ainda maior e, para 2016 espera-se diminuir muito mais. Mostrando a eficiência do aterramento do alimentador em local onde ocorria situação de isolamento de neutro. 


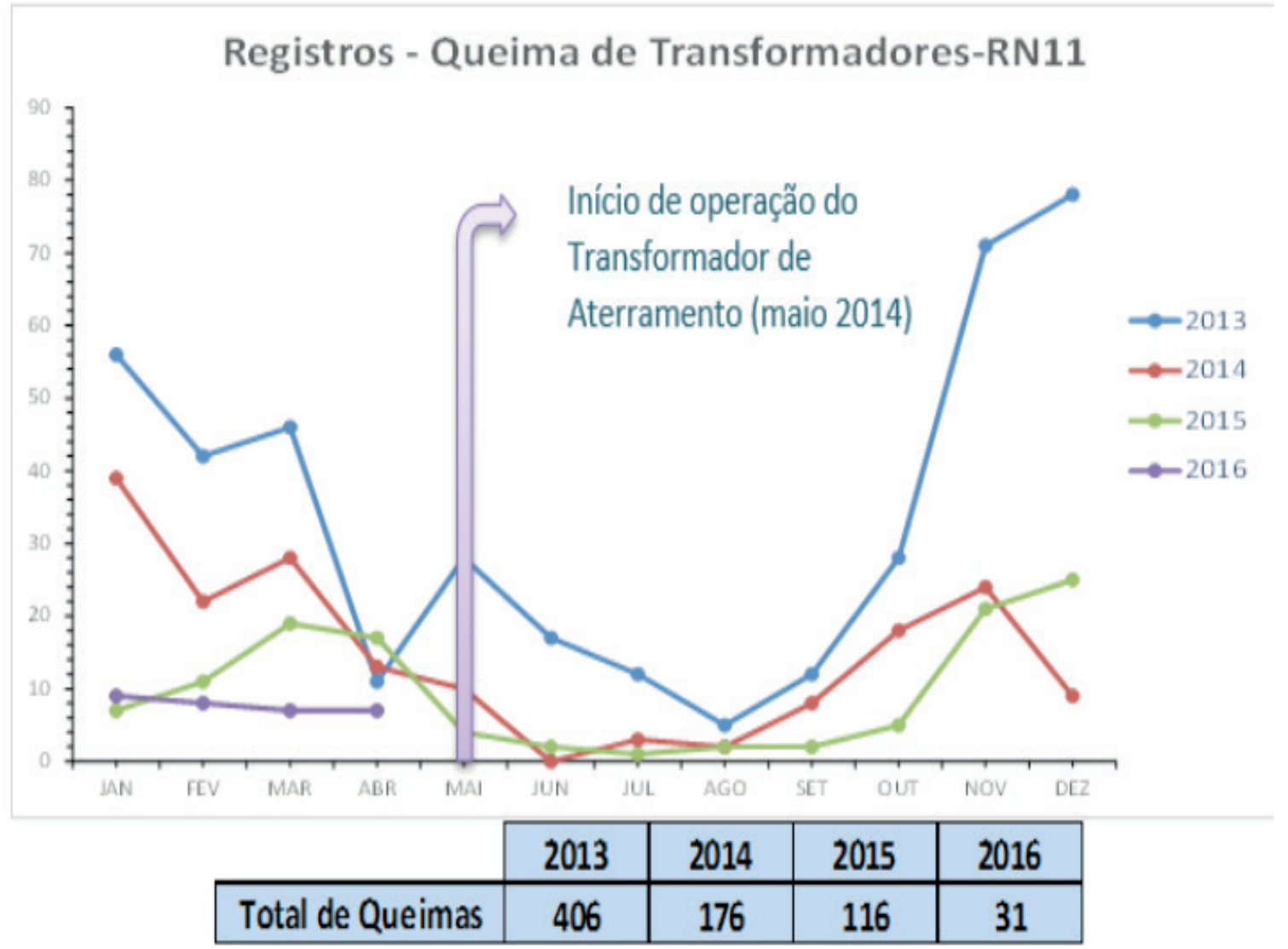

Fig.6. Registros das queimas de transformadores antes e após instalação do transformador de aterramento

O gráfico revela uma maior incidência de queimas durante o inverno amazônico, período que vai de novembro a maio do ano seguinte, quando acontece a maior quantidade de curtos circuitos nas redes.

Vale ressaltar que antes da instalação do transformador de aterramento, nos meses entre janeiro e maio de 2013 e 2014 a redução de queima foi devida a serviços de poda de vegetação no alimentador.

\section{I CONCLUSÕES}

Este trabalho apresentou uma proposta para diminuir as queimas de transformadores de distribuição e para-raios em um alimentador de 34,5 kV através da instalação de um transformador de aterramento.

Os resultados das queimas, nos períodos, a partir da instalação do transformador de aterramento, mostram uma diminuição em quantidade expressiva em relação ao que ocorria anteriormente.

Ressalta-se que os períodos de maiores queimas ocorrem em época de chuva na região Amazônica, aonde está implantada a rede do alimentador.

O enfoque teórico que apresentamos como os causadores das queimas, se confirmaram com os resultados dos estudos, assim como foram comprovados na prática com os resultados apresentados. 
Deveremos, de acordo com a eficácia dos resultados da aplicação do transformador, a partir da chegada do inverno amazônico, implantar mais transformadores em outros alimentadores. Contudo, estaremos desenvolvendo novas especificações do tipo padrão distribuição com dimensões e pesos apropriados para estes transformadores; considerando suas instalações em plataforma suspensa entre dois postes, como utilizado para bancos de reguladores de tensão em redes de distribuição.

\section{REFERÊNCIAS}

[1] S.B. Griscom, "Grounding of Power-System Neutrals", Electrical Transmission and DistributionReference Book, 1964.

[2] E.J. Robba, "Introdução a Sistemas Elétricos de Potência", São Paulo, 1973.

[3] A.E. Barros, "Seleção de Transformadores de Aterramento", Revista Mundo Elétrico, Fev. 1973.

[4] M.R. da Silva, "Avaliação de alternativa para eletrificação rural no contexto dos programas de universalização do atendimento de energia no Brasil” Abr. 2006. 


\section{OTIMIZAÇÃO DE CONVERSORES BOOST INTERCALADO DE ALTO GANHO DE TENSÃO E ALTA EFICIÊNCIA}

Data de submissão: 03/10/2019

Data de aceite: 03/01/2020

\section{Éder Bridi}

Universidade Federal de Santa Maria - UFSM

Santa Maria - RS

http://lattes.cnpq.br/2790377192733673

Mateus José Tiburski

Universidade Federal de Santa Maria - UFSM

Santa Maria - RS

http://lattes.cnpq.br/5498188421691529

Edemar Oliveira Prado

Universidade Federal de Santa Maria - UFSM

Santa Maria - RS

http://lattes.cnpq.br/1774778404976935

Pedro Cerutti Bolsi

Universidade Federal de Santa Maria - UFSM

Santa Maria - RS

http://lattes.cnpq.br/0324597211954149

Hamiltom Confortin Sartori

Universidade Federal de Santa Maria - UFSM

Santa Maria - RS

http://lattes.cnpq.br/6722822162374884

José Renes Pinheiro

Universidade Federal de Santa Maria - UFSM

Santa Maria - RS

http://lattes.cnpq.br/2333794966860226

RESUMO: Este trabalho utiliza uma metodologia de otimização para projeto de conversores CC/ CC Boost convencional e intercalado. O método se baseia na escolha do ponto ótimo de operação ( $\Delta \mathrm{iL} @ f s @ J)$, que serve como referência para a seleção dos materiais magnéticos, condutores, semicondutores, capacitores que compõem a topologia, além de definir as variações da arquitetura cujo arranjo propiciará o melhor rendimento global do sistema. Análise da variação da densidade de corrente no indutor (J) adicionada ao ponto de operação vem a ser um diferencial da metodologia. São apresentados os resultados de simulações e arranjos para conversores, juntamente com fluxograma completo do processo que serve como referência para demais projetos.

PALAVRAS-CHAVE: Otimização, Alto ganho, Boost, Intercalado.

\section{OPTIMIZATION OF INTELEAVED BOOST CONVERTERS WITH HIGH VOLTAGE GAIN AND HIGH EFFICIENCY}

ABSTRACT: This work uses an optimization methodology for conventional and interleaved high gain Boost CC/CC converters. This method is based on the choice of the optimum operation point ( $\Delta \mathrm{IL} @ f s @ J)$, which serves as reference for the selection of magnetic materials, conductors, semiconductors, capacitors that will compose topology. Variations of the architecture whose arrangement will provide the best overall system 
performance. Analysis of the inductor current density variation () added to the operating point is a differential of the methodology. Simulations results and arrangements for converters are presented along with a complete chart-flow diagram of the process, make this a reference for other projects.

KEYWORDS: Optimization, High gain, Boost converter, Interleaved.

\section{I INTRODUÇÃO}

Atualmente, emprega-se conversores de potência em diversas aplicações, dentre elas veículos elétricos, fontes ininterruptas de energia, iluminação pública, torres de telecomunicação, armazenamento de energia, sistemas de acionamento, células a combustível, painéis solares, dispositivos eletrônicos para conversão de energia (FRIVALDSKY et al., 2018). Para ser conectado as cargas, o sistema de condicionamento de potência deve adequar as baixas tensões de saída fornecidas por fontes de energia renovável com as requeridas pelas cargas. Esse sistema é normalmente composto por um conversor CC/CC e um inversor CC/CA. Em sistemas onde se processam altas correntes, algumas topologias Boost têm apresentado alto rendimento além de possuírem um arranjo relativamente simples (SHOE et al.; 2010; KIRUBAKARAN; JAIN; NEMA, 2009).

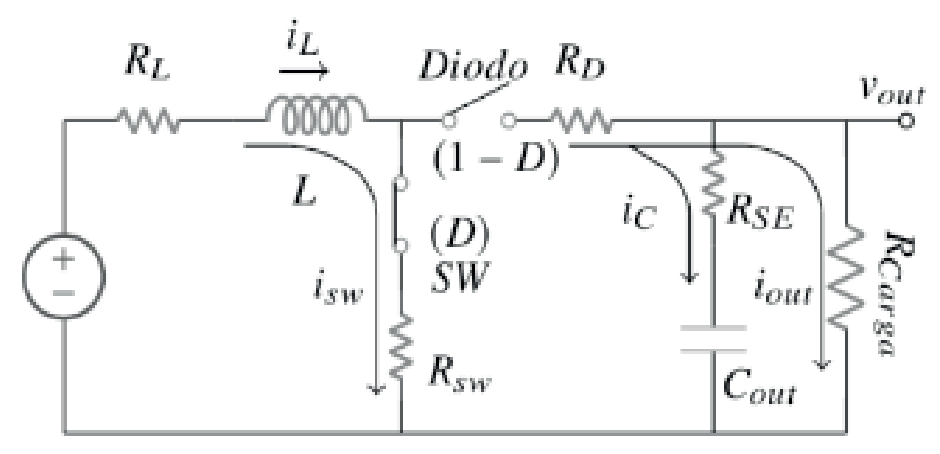

Figura 1 - Circuito do conversor Boost e ganho estático.

Conversores Boost convencionais possuem limites relacionados ao ganho de tensão, capacidade de potência e eficiência. Quando se faz necessário um elevado ganho de tensão, o conversor pode operar em condições que resultam em um desgaste muito elevado nos componentes e grandes perdas de potência na conversão (ROSASCARO et al., 2011; LEE et al., 2013; TSENG et al., 2015).

Para um conversor Boost, ideal, quando a razão cíclica é um, o ganho tende ao infinito. Na prática, isso não acontece já que existem as resistências parasitas intrínsecas de cada componente que são demonstradas na Figura 1. Para correntes elevadas de saída estas resistências são responsáveis pelas maiores perdas no conversor (KAZIMIERCZUK, 2015). Em regime permanente, a tensão de saída de um conversor Boost real pode ser obtida através do modelo médio mostrado na Figura 1. 
Nesta técnica de linearização (VORPÉRIAN, 1990), fontes controladas são utilizadas.

A proposta deste trabalho é uma metodologia de projeto aplicado a um conversor Boost convencional e intercalado. Executa-se uma varredura de parâmetros do projeto e partir disso seleciona-se um ponto ótimo de operação ( $\Delta / L @ f s @ J)$. Bancos de dados de componentes são utilizados de apoio aos cálculos.

\section{I DESCRIÇÃO DAS PERDAS DE POTÊNCIA}

Perdas no Capacitor: Ocorrem devido a energia dissipada por efeito térmico oriunda da circulação de corrente (i_cap) na resistência série equivalente RSE, que é dependente da temperatura de trabalho do capacitor e da frequência em que ele está operando (HAMI; BOULZAZEN; KADI, 2015). Estas perdas são calculadas através da equação (1) (HUIJIE et al., 2010)

$$
P_{C A P}=\frac{\omega}{2 \pi} \int_{0}^{\frac{2 \pi}{\omega}} i_{C A P}^{2}(t) R_{E S R}(f s, \theta) d t
$$

Perdas no Indutor: São a somatória das perdas nos enrolamentos $\left(P_{\text {cobre }}\right)$ e no núcleo $\left(P_{\text {nuc }}\right)$. As do núcleo dependem da densidade de fluxo magnético $\left(B_{p k}\right)$, volume do núcleo $\left(V_{\text {nuc }}\right)$, frequência de chaveamento $\left(f_{s}\right)$, das características construtivas e físico-químicas do material. Em núcleos de pó de ferro toroidais este cálculo é feito através da equação (2) onde os coeficientes de Steinmetz (a,b,c) são fornecidos pela folha de dados do fabricante (MAGNETICS, 2017).

$$
P_{n u}=V_{n u} a\left(\frac{B_{n u}^{b}}{\left(2 t_{o n}\right)^{c}} \frac{t_{o n}}{T_{s}}+\frac{B_{n u}^{b}}{\left(2 t_{o f f}\right)^{c}} \frac{t_{o f f}}{T_{s}}\right)
$$

As perdas nos enrolamentos são essencialmente oriundas de dois fatores como: Resistência CC $\left(R_{c c}\right)$ atrelada a parâmetros como resistividade, seção transversal, comprimento e temperatura do material, calculada segundo equação (3). E resistência $C A\left(R_{c a}\right)$ atrelada ao efeito pelicular e ao efeito de proximidade expressa pela equação (4).

$$
R_{c c}=\frac{\rho_{c o n d} w_{l}}{A_{w}}
$$

$\rho_{\text {cond }}$ - Resistividade do material condutor $(\Omega \mathrm{m}) ; \mathrm{w}_{1}$ - Comprimento do material condutor $(m) ; A_{w}$ - Área da seção transversal do condutor $\left(m^{2}\right)$.

$O$ efeito pelicular e o efeito de proximidade são os responsáveis pelo aumento da resistência efetiva de um material condutor. $O$ efeito pelicular é causado pela repulsão 
entre as linhas de corrente que criam a tendência desta fluir pela superfície do condutor. Da mesma forma, o efeito de proximidade também ocorre em virtude dessa repulsão, porém, entre dois condutores adjacentes. Esta resistência pode ser aproximada pela equação (4) (BARTOLI; REATTI; KAZIMIERCZUK, 1994).

$$
R_{c a(f)}=\left(\frac{4}{\pi}\right)^{\frac{1}{4}} N l_{e s p} \sqrt{\frac{\rho \mu \pi f}{d t_{d}}}\left(1+\frac{2\left(N_{l}^{2}-1\right)}{3}\right)
$$

lesp- Comprimento médio das espiras ( $\mathrm{m}) ; \rho$ - Resistividade do cobre $\left(\Omega \mathrm{mm}^{2} / \mathrm{m}\right)$;

$\mu$ - Permeabilidade relativa do cobre $(\mathrm{H} / \mathrm{m}) ; f$ - Frequência do harmônico em questão $(\mathrm{Hz})$; $\mathrm{d}$ - Diâmetro do condutor $(\mathrm{mm})$; td - Distância entre os centros de dois condutores adjacentes $(\mathrm{mm}) ; \mathrm{N} \_\mathrm{I}$ - Número de camadas do enrolamento.

A equação (4) pode ser aplicada apenas a núcleos com geometrias toroidais. Assim sendo, pode-se calcular as perdas no cobre pela equação (5).

$$
P_{\text {cobre }}=R_{C C} i_{L(r m s)}^{2}+\sum_{f=0}^{\infty}\left(R_{C A}(f) i_{L}(f)^{2}\right)
$$

$i_{L(r m s)}$ - Corrente rms no indutor $(\mathrm{A}) ; \mathrm{i}_{\mathrm{L}(\mathrm{f})}$ - Corrente do harmônico $(\mathrm{A})$;

Perdas nos Semicondutores: São caracterizadas pelas perdas de condução e de comutação.

As perdas por condução ocorrem devido a diferença de potencial (Vf) que surge no momento em que há circulação de corrente (IF) através da resistência (Rdson) do semicondutor, que varia por características construtivas, térmicas e da amplitude da corrente. Há o acréscimo das perdas do gate onde: $(\mathrm{Vg})$ é a tensão de gate e (Ig) é a corrente de gate. Os valores de referência são obtidos a partir das curvas disponibilizadas em folhas de dados dos componentes (DIMITROV; GARANOV; HVARCHILKOV, 2016). As perdas por condução da chave $\left(P_{\text {cond_sw }}\right)$ são representadas pela equação (6), já as perdas por condução do diodo $\left(P_{\text {cond__ }}\right)$ são representadas pela equação (7).

$$
\begin{gathered}
P_{\text {cond } \_s w}=\frac{1}{T_{s}}\left(\int_{0}^{T_{s}} V_{f} I_{f} d t+\int_{0}^{T_{s}} V_{g} I_{g} d t\right) \\
P_{\text {cond }_{-} D}=\frac{1}{T_{s}} \int_{0}^{T_{s}} V_{f} I_{f} d t
\end{gathered}
$$

Já as perdas por comutação, no caso do MOSFET, são obtidas através da 
identificação de cada transição de comutação (turn-on e turn-off) do dispositivo semicondutor, como apresentado em (BELTRAME; 2009).

$$
\begin{gathered}
P_{o n}=\frac{1}{2} i_{d e v} V_{o} t_{r} f_{s}+\frac{1}{2} C_{o s s} V_{o}^{2} f_{s} \\
P_{o f f}=\frac{1}{2} i_{d e v} V_{o} t_{f} f_{s}
\end{gathered}
$$

$\mathrm{P}_{\text {on }}$ - Potência dissipada no turn on (W); Poff - Potência dissipada no turn off (W); $\mathrm{i}_{\mathrm{dev}}$ - Corrente instantânea de comutação (A); Vo -Tensão sobre o dispositivo (V);

$\mathrm{t}_{\mathrm{r}}$-Tempo de subida (s); tf -Tempo de descida (s); fs - Frequência de chaveamento $(\mathrm{Hz})$; Coss - Capacitância de saída (F).

As perdas por comutação no diodo ocorrem no bloqueio. Nesse momento os portadores de carga devem se reordenar no dispositivo, para que o mesmo entre em estado de não condução (BARTOLI; REATTI; KAZIMIERCZUK, 1994).. Esta reordenação resulta em uma carga armazenada na junção (Qrr) e há circulação de uma corrente de recuperação reversa.

\section{I METODOLOGIA DE OTIMIZAÇÃO}

A metodologia proposta é desenvolvida a partir da varredura de parâmetros de projeto do conversor nos pontos de operação ( $\Delta \mathrm{IL} @ f \mathrm{fs} @ J)$ é a ondulação de corrente; $\mathrm{f}_{\mathrm{s}}$ é a frequência de chaveamento; $\mathrm{J}$ é a densidade de corrente. $\mathrm{O}$ projeto baseia-se no equacionamento das topologias Boost convencional e das Boost intercalado de duas a cinco fases. Desta forma, faz-se a escolha dos núcleos magnéticos, seções transversais de condutores, semicondutores, dissipadores, capacitores, etc. Assim sendo, a escolha adequada do ponto de operação ( $\Delta \mathrm{IL} @ \mathrm{fs} @ J)$ juntamente com as tecnologias que compõem o arranjo de componentes e arquiteturas, proporcionam resultados que são considerados ótimos, sendo expressos pelo máximo rendimento $\eta_{\mathrm{w}}$

A etapa do método de otimização que trata destas variáveis pode ser observada no Passo:01 da Figura 2. No caso de conversores CC-CC e especialmente arquiteturas que derivam da topologia Boost, é necessário determinar a potência de saída $\left(P_{\text {out }}\right)$; tensão de saída $\left(V_{\text {out }}\right)$; ondulação máxima na saída ; temperatura ambiente $\left(T_{\text {amb }}\right)$; temperatura máxima de operação do núcleo magnético $\left(T_{\text {mag }}\right)$; temperatura média na junção do semicondutor $\left(T_{j}\right)$, número máximo de núcleos empilhados $\left(N_{n e}\right)$; Vetor de frequências $\left(f_{s}\right)$; Vetor de ondulações de corrente de entrada por unidade $\left(\Delta i_{p u}\right)$; vetor de densidades de corrente (j); resistividade do material aplicado ao condutor enrolado ao núcleo magnético $(\rho)$; número máximo de fases para intercalamento $\left(N_{\text {fase }}\right)$. 


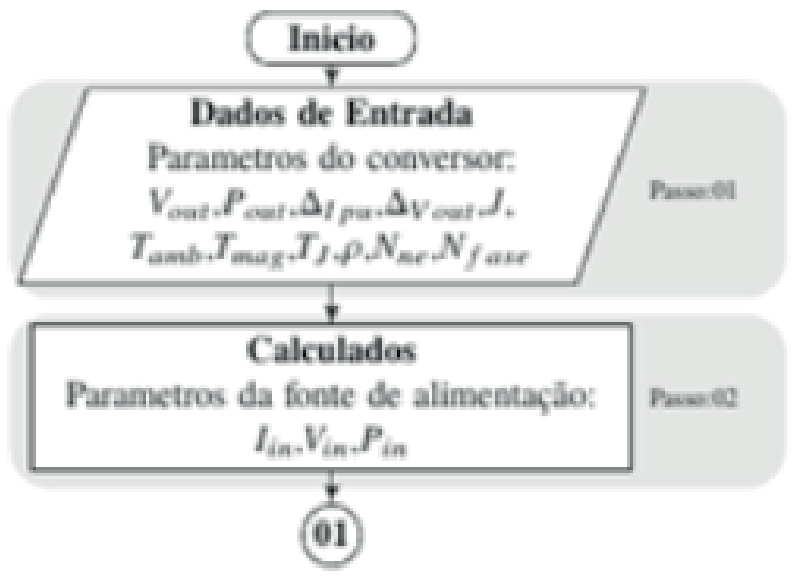

Figura 2: Fluxograma.

O núcleo magnético é selecionado em função da energia máxima que este pode armazenar Earm expressa pela equação (10), onde $\mathrm{I}_{L_{\max }}$ é o maior valor de corrente que o indutor será submetido e L é a indutância mínima necessária. Como mostrado no catálogo de núcleos magnéticos de pó de ferro do fabricante MAGNETICS esta energia armazenada é dada em $\left(\mathrm{mHA}^{2}\right)$. Neste catálogo são apresentadas curvas da capacidade de energia, para os diferentes núcleos Kool Mu, High Flux e Molypermalloy como também a permeabilidade magnética $(\mu)$ e seu número de série (Part number).

$$
E_{\text {Arm }}=L I_{L_{\max }}^{2}
$$

Neste método não há garantia que o indutor irá operar sem que haja sobreaquecimento em todas as possíveis condições de operação (ZIENTARSKI et al., 2009). Para garantir que o indutor não exceda o limite de temperatura e prejudique $o$ seu funcionamento e o de outros componentes em sua proximidade, é adotada uma temperatura máxima de trabalho. O indutor que exceder a temperatura pré-especificada será excluído do conjunto de soluções como apresentado em (BELTRAME, 2017). Assim sendo, para cada ponto de operação ( $\triangle \mathrm{IL} @ f \mathrm{fs@J)} \mathrm{define-se} \mathrm{uma} \mathrm{indutância}$ inicial. Como descrito em (ERICKSON e D. MAKSIMOVIC, 2007), esta é definida pela equação (11),

$$
L=\frac{V_{i n} D}{2 \Delta_{i L} f_{s}}
$$

O valor da corrente máxima no indutor é definido pelo pico da ondulação utilizada no projeto conforme a equação (12). 


$$
I_{L_{-} \max }=I_{L r m s}+\frac{\Delta_{i L}}{2}
$$

E a razão cíclica do conversor ideal é dada pela equação (13).

$$
D=1-\frac{V_{\text {in }}}{V_{\text {out }}}
$$

Tendo feito a seleção do núcleo ou do empilhamento de núcleos faz-se o cálculo do número inicial de espiras através da equação (14), onde $\mathrm{N}(\mathrm{k})$ é número inicial de espiras, le é o comprimento do caminho magnético referente ao núcleo selecionado, em cm, $A_{e}$ é a área de seção transversal do núcleo em $\mathrm{cm}^{2}$ e $\mu(\mathrm{k})$, é a permeabilidade relativa inicial referente ao núcleo selecionado. Segundo Beltrame (2017), caso sejam empregados núcleos empilhados deve-se multiplicar o valor de Ae pelo número de núcleos.

$$
N_{(k)}=\sqrt{\frac{L l_{e} 10^{8}}{0,4 \pi \mu_{(k)} A_{e}}}
$$

Próximo passo é determinar a intensidade de campo magnético $H(t)$ dado pela equação (15).

$$
\boldsymbol{H}_{(k)}=\frac{N_{(k)} \boldsymbol{I}_{L_{\text {pico }}}}{l_{e}}
$$

Pode-se então calcular a nova permeabilidade relativa do núcleo magnético $\mu(\mathrm{k}+1)$, através da equação (17), sendo os parâmetros $\mathrm{a}, \mathrm{b}, \mathrm{c}, \mathrm{d}$, e fornecidos pelo fabricante.

$$
\mu_{(k+1)}=\mu_{i(k)}\left(a+b H_{(k)}+c H_{(k)}^{2}+d H_{(k)}^{3}+e H_{(k)}^{4}\right)
$$

Por conseguinte, pela equação (17) calcula-se o número final de espiras do indutor.

$$
N_{(k+1)}=\sqrt{\frac{L l_{e} 10^{8}}{0,4 \pi \mu_{(k+1)} A_{e}}}
$$

Prever a elevação da temperatura de forma precisa necessita-se modelos com elevada complexidade, pois, além das perdas no indutor, esta estimativa envolve a área 
externa de dissipação, direção e velocidade do fluxo ar, como também a resistividade térmica dos materiais utilizados (ZIENTARSKI et al., 2009). Com o intuito facilitar o cálculo térmico a fabricante (MAGNETICS, 2017), apresenta a equação (18) que através um modelo simplificado permite estimar a elevação da temperatura do núcleo $\Delta T$ conhecendo somente das perdas e da área externa do magnético $A_{\text {ext }}$ (BELTRAME et al., 2014).

$$
\Delta_{T}=\left(\frac{P_{n u c}+P_{c o b r e}}{A_{e x t}}\right)^{0,833}
$$

A Figura 3 apresenta o fluxograma referente ao projeto do indutor.
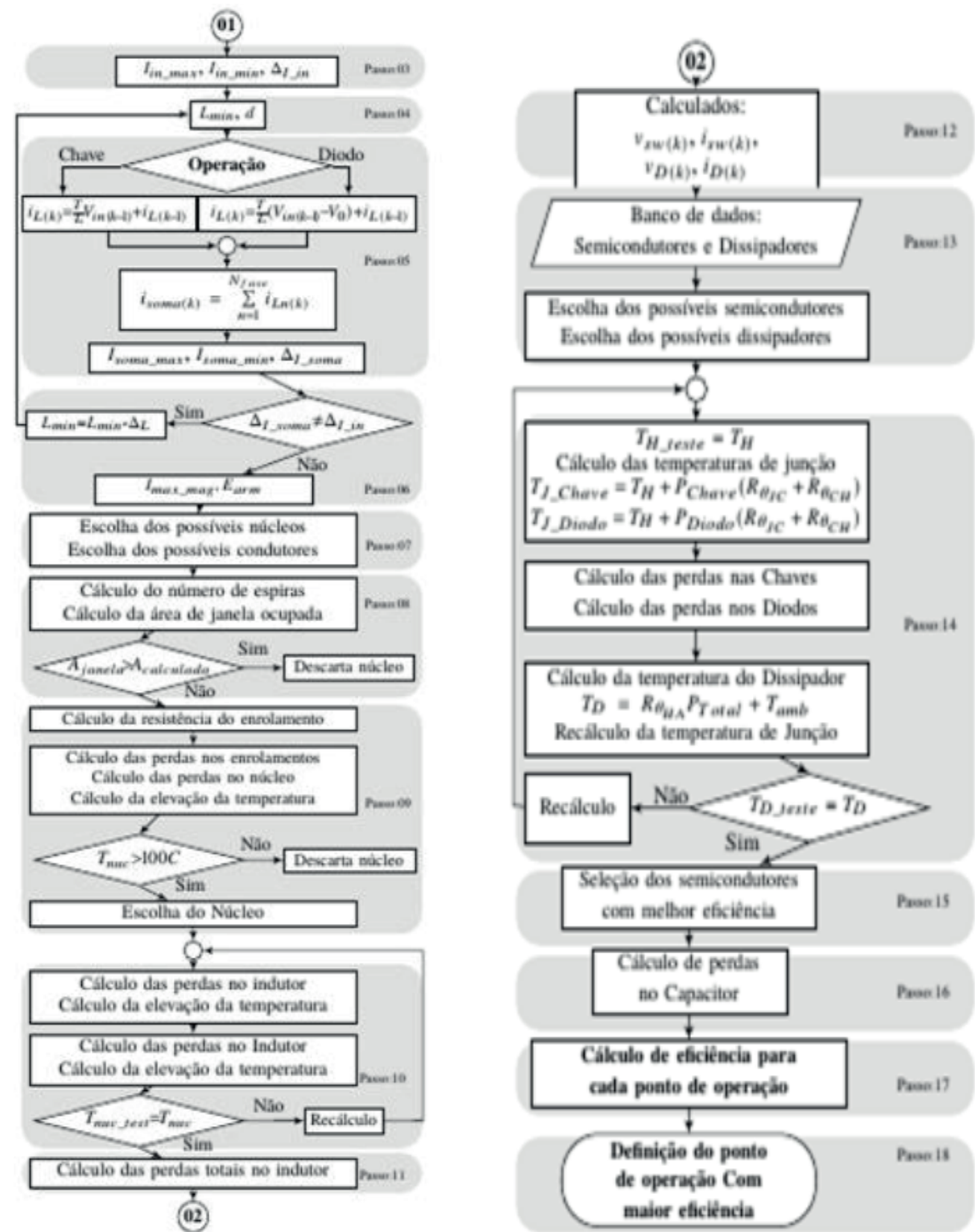

Figura 3: Fluxograma. 
Passo:03 Cálculo das correntes máximas $\mathrm{I}_{\text {in_max }}$, mínimas $\mathrm{I}_{\text {in_min }}$ e da ondulação de corrente pré especificada $\Delta \mathrm{I}_{\text {_in }}$.

Passo: 04 Cálculo da indutância mínima de projeto $L_{\min }$ e da razão cíclica (D).

Passo: 05 Cálculo da corrente instantânea no indutor $\mathrm{i}_{\mathrm{L}(\mathrm{k})}$. Somatória das correntes instantâneas em cada indutor $i_{\text {soma }}$. Cálculo da ondulação de corrente $\Delta f$ _soma em função da diferença entre o valor máximo $I_{\text {soma_max }}$ e $I_{\text {soma_min }}$.

Passo: 06 Comparação entre a ondulação desejada e calculada. Caso haja diferença entre os valores de ondulação é feito um decremento no valor de indutância até que a ondulação calculada atinja o valor esperado. Caso o valor da ondulação seja o esperado, é feito o cálculo da corrente máxima de magnetização $I_{\text {max_mag }}$ e da energia máxima admissível no núcleo $\mathrm{E}_{\mathrm{arm}}$.

Passo: 07 Escolha dos possíveis condutores considerando efeito pelicular e densidade de corrente $\mathrm{J}$, bem como a escolha dos possíveis núcleos ou empilhamento de núcleos.

Passo: 08 Cálculo do número de espiras e área de janela ocupada, comparação entre a máxima área de ocupação de janela desejada Ajanela e a área de ocupação de janela calculada Acalculada. Caso a área de janela desejada for menor que a calculada, escolhe-se novo núcleo. Caso contrário, executa-se o cálculo da resistência de enrolamento, a partir da resistividade do material condutor na temperatura de trabalho $R_{c c^{\prime}}$ efeito pelicular e de proximidade $R_{c a}$.

Passo: 09 Cálculo das perdas no enrolamento $P_{\text {cobre }}$ e no núcleo $P_{\text {nuc }}$ e da elevação da temperatura $\Delta T$. Se o núcleo escolhido exceder a temperatura de trabalho especificada, este é descartado. Caso a temperatura calculada do núcleo seja inferior a especificada, o núcleo é escolhido.

Passo: 10 Corrige-se da resistividade do material em função da temperatura no indutor até que a temperatura atual do núcleo calculada seja igual a calculada no passo anterior.

Passo: 11 Cálculo das perdas totais no indutor para todas as soluções possíveis para cada combinação ponto de operação.

Passo: 12 Cálculo das tensões e correntes instantâneas para os semicondutores.

Passo: 13 Escolha dos semicondutores que suportem a tensão de bloqueio pré especificada, corrente circulante e que seja compatível com a dinâmica térmica. Em um banco de dados são escolhidos alguns modelos de dissipadores cuja resistência térmica possibilite a transferência do calor como explicado anteriormente.

Passo: 14 Cálculo das perdas nos semicondutores. São calculadas considerando a temperatura de operação; Recorrência de cálculo até o equilíbrio de temperatura.

Passo: 15 É escolhido o semicondutor que apresenta menores perdas em um determinado ponto de operação.

Passo: 16 Nesta etapa é feito o cálculo das perdas nos capacitores.

Passo: 17 Combinação dos componentes da topologia (materiais magnéticos, condutores, semicondutores, capacitores) e variação do número de fases de entrada 
para o caso do intercalamento. Somatório das perdas de potência em cada elemento do conversor para cada ponto de operação $\left(\Delta_{i L} @ f_{s} @ J\right)$ dentro das especificações.

Passo: 18 Escolha do ponto ótimo de operação do conversor Boost convencional ou intercalado, que apresenta maior eficiência.

\section{I RESULTADOS}

Os parâmetros de projetos são apresentados na Tabela 1.

\begin{tabular}{|c|c|}
\hline Parâmetros & Valores \\
\hline Potência Nominal & $3000 \mathrm{~W}$ \\
\hline Tensão de entrada & $50 \mathrm{~V}$ \\
\hline Tensão de saída & $400 \mathrm{~V}$ \\
\hline Intervalo de $f s$ investigado & 5 a $200 \mathrm{kHz}$ \\
\hline Intervalo de $\Delta_{i L}$ investigado & 1 a $10 \%$ \\
\hline Máximo $\Delta_{V_{o}}$ & $1 \%$ \\
\hline Resistência de Gate & $10 \Omega$ \\
\hline Temperatura Ambiente & $50 \mathrm{C}$ \\
\hline Intervalo de $J$ investigado & 300 a $500 \mathrm{~A} / \mathrm{m}^{2}$ \\
\hline Intervalo de $N_{n e}$ investigado & 1 a 5 \\
\hline Intervalo de $N_{\text {f ase }}$ investigado & 1 a 5 \\
\hline $\mathrm{N}^{\circ}$ capacitores paralelos & 5 \\
\hline
\end{tabular}

(a)

\begin{tabular}{cc}
\hline Chaves & Diodos \\
\hline IPW60R017C7 & IDW40G65C5 \\
STW70N60DM2 & IDW30G65C5 \\
STW70N60DM2 & IDW20G65C5 \\
IXKK85N60C & Hyperfast15ETH06 \\
FCH041N60F & Ultrafast60APU04PbF \\
IGW30N65L5 & Fast RURG5060 \\
\hline
\end{tabular}

(b)

Tabela 1 - Parâmetros do Projeto (a) e semicondutores (b).

Para obtenção dos resultados foram considerados todos os núcleos magnéticos toroidais do tipo Kool Mu, High Flux e Molypermalloy e condutores de cobre (AWG) presentes no catálogo (MAGNETICS, 2017). Capacitores da Empresa TDK Epcos com nível de tensão entre quatrocentos e cinquenta e seiscentos e cinquenta volts. Os semicondutores utilizados são apresentados nas tabelas 2, 3 e 4. São apresentados o ponto ótimo de operação, bem como área de seção transversal e número de fios paralelos dos condutores, elementos semicondutores e capacitores do conversor intercalado cujo número de fases varia de um a cinco. Os semicondutores escolhidos pelo algoritmo foram: chave IPW60R017C7 e diodo IDW40G65C5. 


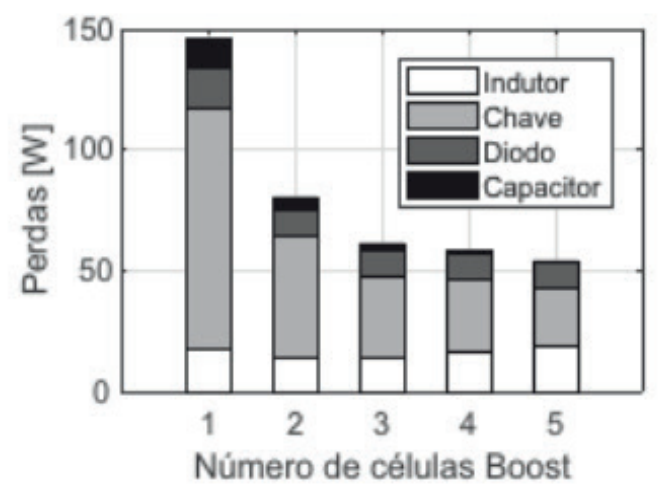

(a)

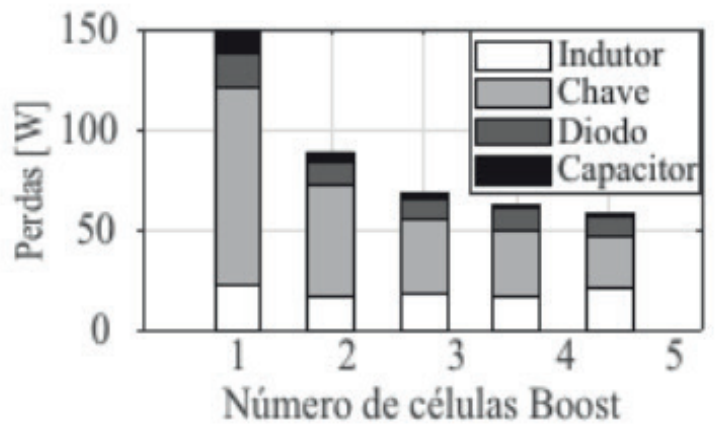

(b)

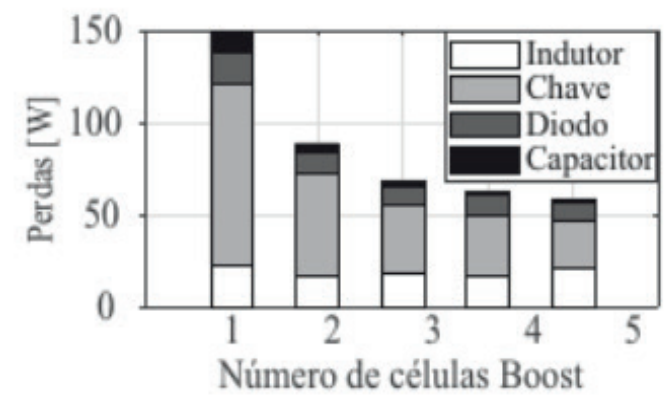

(c)

Figura 2 - Perdas nos conversores boost intercalados com núcleo magnético toroidal Molypermalloy (a), Kool Mu (b) e High flux (c).

\begin{tabular}{cccccc}
\hline & \multicolumn{5}{c}{ Número de células boost } \\
\cline { 2 - 6 } Seleção & $\mathbf{1}$ & $\mathbf{2}$ & $\mathbf{3}$ & $\mathbf{4}$ & $\mathbf{5}$ \\
\hline$\eta_{\omega}(\%)$ & 94,69 & 96,51 & 97,11 & 97,59 & 97,71 \\
$f s(\mathrm{kHz})$ & 29 & 14 & 10 & 19 & 10 \\
$\Delta_{i} \%$ & 10 & 10 & 9 & 7 & 6 \\
$J_{\left(\mathbf{A} / \mathrm{cm}^{2}\right)}$ & 300 & 300 & 300 & 300 & 300 \\
$L_{(\mu H)}$ & 251,44 & 449,8 & 583,19 & 315,65 & 137,37 \\
$\mathrm{Núcleo}$ & 58099 & 58099 & 58099 & 58090 & 58438 \\
$\mu i_{(H / m)}$ & 60 & 60 & 60 & 60 & 125 \\
$N_{n e}$ & 2 & 1 & 1 & 3 & 3 \\
Condutor & $31 x 19$ & $8 x 16$ & $4 x 14$ & $5 x 17$ & $2 \times 14$ \\
$\mathrm{~N}^{\circ}$ espiras & 23 & 49 & 54 & 38 & 28 \\
\hline
\end{tabular}

Tabela 2 - Núcleo Molypermalloy. 


\begin{tabular}{|c|c|c|c|c|c|}
\hline \multirow[b]{2}{*}{ Seleção } & \multicolumn{5}{|c|}{ Número de células boost } \\
\hline & 1 & 2 & 3 & 4 & 5 \\
\hline$\eta_{\omega}(\%)$ & 94,47 & 96,19 & 97,32 & 97,52 & 97,91 \\
\hline$f s(k H z)$ & 28 & 25 & 13 & 19 & 10 \\
\hline$\Delta_{i} \%$ & 10 & 10 & 10 & 8 & 7 \\
\hline$J_{\left(A / \mathrm{cm}^{2}\right)}$ & 300 & 300 & 300 & 300 & 300 \\
\hline$L_{(\mu H)}$ & 260,42 & 251,87 & 403,70 & 276,22 & 00000 \\
\hline Núcleo & 77337 & 77102 & 77102 & 77616 & 77616 \\
\hline$\mu i_{(H / m)}$ & 26 & 26 & 26 & 40 & 40 \\
\hline$N_{n e}$ & 1 & 1 & 1 & 2 & 2 \\
\hline Condutor & $31 \times 19$ & $13 \times 18$ & $5 \times 15$ & $5 \times 17$ & $2 \times 14$ \\
\hline $\mathrm{N}^{\circ}$ espiras & 51 & 50 & 63 & 28 & 36 \\
\hline
\end{tabular}

Tabela 3 - Núcleo Kool Mu.

\begin{tabular}{|c|c|c|c|c|c|}
\hline \multirow[b]{2}{*}{ Seleção } & \multicolumn{5}{|c|}{ Número de células boost } \\
\hline & 1 & 2 & 3 & 4 & 5 \\
\hline$\eta_{\omega}(\%)$ & 94,29 & 96,16 & 97,38 & 97,73 & 98,05 \\
\hline$f_{s}\left(k H_{z}\right)$ & 34 & 42 & 18 & 16 & 10 \\
\hline$\Delta_{i} \%$ & 10 & 10 & 10 & 9 & 7 \\
\hline$J_{\left(A / \mathrm{cm}^{2}\right)}$ & 300 & 300 & 300 & 300 & 300 \\
\hline$L_{(\mu H)}$ & 214,46 & 149,91 & 291,59 & 291,56 & 128,06 \\
\hline Núcleo & 55164 & 55617 & 55617 & 55617 & 55617 \\
\hline$\mu i_{(H / m)}$ & 14 & 60 & 60 & 60 & 60 \\
\hline$N_{n e}$ & 1 & 2 & 2 & 1 & 1 \\
\hline Condutor & $31 \times 19$ & $20 \times 20$ & $17 \times 7$ & $4 \times 16$ & $2 \times 14$ \\
\hline $\mathrm{N}^{\circ}$ espiras & 52 & 21 & 32 & 29 & 34 \\
\hline
\end{tabular}

Tabela 4: Núcleo High Flux.

\section{I CONCLUSÕES}

Este artigo propôs uma metodologia de otimização para projeto de conversores CC/CC Boost convencional e intercalado. Esta metodologia foi baseada em conceito de ponto ótimo de operação que baliza a escolha dos componentes integrantes do conversor. Além disso, percebe-se que pontos ótimos de operação para conversores de alto ganho estão diretamente relacionados com as resistências parasitas dos componentes, ligadas diretamente com a eficiência do conversor. Há uma limitação de ganho quando as resistências parasitas tem um valor expressivo frente a resistência de carga, conforme mostrado em toda a análise. Por fim, a implementação desta metodologia define um modelo padrão de projeto, uma vez que a eficiência é sempre alvo no desenvolvimento de conversores de potência.

Das simulações conclui-se que a arquitetura de maior desempenho é a intercalada de três fases utilizando o núcleo magnético High Flux com rendimento de 97,41\%, 
frequência de $18 \mathrm{kHz}$ e ondulação de corrente de entrada de $10 \%$.

\section{REFERÊNCIAS}

BARTOLI M., REATTI A., and KAZIMIERCZUK M. K., "Modelling iron-powder inductors at high frequencies," in Proceedings of 1994 IEEE Industry Applications Society Annual Meeting, Oct 1994, pp. 1225-1232 vol.2.

BELTRAME F., "Metodologia de projeto otimizado de conversores estáticos aplicados a sistemas fotovoltaicos," Ph.D. dissertation, Programa de Pós- Graduação em Engenharia Elétrica, Centro Tecnológico, Universidade Federal de Santa Maria, 112017.

BELTRAME F., DUPONT F. H., SARTORI H. C., and PINHEIRO J. R., "Design methodology to improve the converters' efficiency applied to photovoltaic systems," in IECON 2014 - 40th Annual Conference of the IEEE Industrial Electronics Society, Oct 2014, pp. 1397-1403.

BELTRAME R. C., "Metodologia de síntese de topologias zvt simplificada aplicadas a pólos pwm bidirecionais," Master's thesis, Programa de Pós- Graduação em Engenharia Elétrica, Centro Tecnológico, Universidade Federal de Santa Maria, 2009.

CHOE G.-Y., KIM J.-S., KANG H.-S., and LEE B.-K., "An Optimal Design Methodology of an Interleaved Boost Converter for Fuel Cell Applications," Journal of Electrical Engineering \& Technology, vol. 5, no. 2, pp. 319-328, 2010.

DIMITROV V., GORANOV P., and HVARCHILKOV D., "An analytical approach to model the switching losses of a power mosfet," in 2016 IEEE InternatiOnal Power Electronics and Motion Control Conference (PEMC), Sept2016, pp. 928-933.

FRIVALDSKY M., HANKO B., PRAZENICA M., and J MORGOS., "High gain boost interleaved converters with coupled inductors and with demagnetizing circuits," Energies, vol. 11, no. 1, p. 130, 2018.

ERICKSON R. W. and MAKSIMOVIC D., Fundamentals of power electronics. Springer Science \& Business Media, 2007.

HAMI F., BOULZAZEN H., and KADI M., "High frequency characterization and modeling via measurements of power electronic capacitors under high bias voltage and temperature variations," in 2015 IEEE International Instrumentation and Measurement Technology Conference (I2MTC) Proceedings, May 2015, pp. 334-339.

HUIJIE X., JINYING B., CHUNSHENG W., and HONGHUA X., "Design and implementation of a pv dc/dc converter with high efficiency at low output power," in 2010 International Conference on Power System Technology, Oct 2010, pp. 1-6.

KAZIMIERCZUK M. K., Pulse-width modulated DC-DC power converters. John Wiley \& Sons, 2015.

KIRUBAKARAN A., JAIN S., and NEMA R. K., "The PEM Fuel Cell System with DC / DC Boost Converter : Design , Modeling and Simulation," International Journal of Recent Trends in Engineering, vol. 1, no. 3, 2009.

LEE J.-P., CHA H., SHIN D., LEE K.-J., YOO D.-W., and YOO J.-Y., "Analysis and design of coupled inductors for two-phase interleaved dc Dc converters," Journal of power electronics, vol. 13, no. 3, pp. 339-348, 2013.

MAGNETICS. (2017) Powder cores design manual and catalog. 
ROSAS-CARO J.C., MAYO-MALDONAD J. C., SALAS-CABRERA R., GONZALEZ-RODRIGUEZ A., SALAS-CABRERA E. N., and CASTILLO-IBARRA R., "A family of dc-dc multiplier converters," Engineering Letters, vol. 19, no. 1, pp. 57-67, 2011.

TSENG K. C., CHEN J. Z., LIN J. T., HUANG C. C., and YEN T. H., "High step-up interleaved forward-flyback boost converter with three-winding coupled inductors," IEEE Transactions on Power Electronics, vol. 30, no. 9, pp. 4696-4703, Sept 2015.

VORPÉRIAN V., "Simplified analysis of pwm converters using model of pwm switch. ii. discontinuous conduction mode," IEEE Transactions on Aerospace and Electronic systems, vol. 26, no. 3, pp. 497-505, 1990.

ZIENTARSKI J. R. R., PINHEIRO J. R., HEY H.. L., BELTRAME R. C., and CANDIDO D. B., "A design methodology for boost inductor applied to pfc converters considering the core temperature rise and the conducted emi noise," in 2009 13th European Conference on Power Electronics and Applications, Sept 2009, pp. 1-10. 


\section{CAPÍTULO 22}

\section{DETERMINAÇÃO DE PROCEDIMENTO PARA AVALIAR A INCERTEZA NA PREVISÃO DE PRECIPITAÇÃO E VAZÃO AFLUENTE POR SISTEMAS HIDRO METEOROLÓGICOS PARA AUXÍLIO NA OPERAÇÃO DOS RESERVATÓRIOS E PLANEJAMENTO HIDROENERGÉTICO}

Data de submissão: 06/11/2019.

Data de aceite: 03/01/2020

Reinaldo Bomfim da Silveira Sistema Meteorológico do Paraná Centro Politécnico da UFPR S/N, Curitiba, Paraná, Brasil http://lattes.cnpq.br/7933681892702296

Anderson Nascimento de Araujo COPEL Geração e Transmissão S.A., Curitiba,

Paraná, Brasil

http://lattes.cnpq.br/6151143218847977

Mino Viana Sorribas

Sistema Meteorológico do Paraná

Centro Politécnico da UFPR S/N, Curitiba,

Paraná, Brasil

http://lattes.cnpq.br/5139867089386922

Camila Freitas COPEL Geração e Transmissão S.A., Curitiba,

Paraná, Brasil

http://lattes.cnpq.br/1712444462260155

Rafael Schinoff Mércio Pereira COPEL Geração e Transmissão S.A., Curitiba,

Paraná, Brasil

http://lattes.cnpq.br/6979507669724399

Ângelo Breda

Sistema Meteorológico do Paraná

Centro Politécnico da UFPR S/N, Curitiba,

Paraná, Brasil

http://lattes.cnpq.br/7979077865747791

José Eduardo Gonçalves
Sistema Meteorológico do Paraná

Centro Politécnico da UFPR S/N, Curitiba,

Paraná, Brasil

http://lattes.cnpq.br/1854511330365252

RESUMO: O objetivo do trabalho é a calibração de uma curva operacional ROC para facilitar a avaliação das simulações de chuva e vazão. $\mathrm{O}$ procedimento é aplicado à região Centro Sul do Brasil e também para a bacia do rio Iguaçu, no estado do Paraná e os dados de observação correspondem às estações hidrometeorológicas do Simepar e hidrológicas da COPEL. As previsões de chuva são fornecidas pelo modelo numérico de previsão do tempo COSMO (Alemanha), com espaçamento horizontal de grade de $7 \mathrm{~km}$ e $2.8 \mathrm{~km}$, para o período de 5 dias. Já a previsão de vazão é fornecida pelo Sistema de Previsão Hidrológica do Simepar, SISPSHI. Os anos de 2014 e 2015 foram selecionados para avaliação, por se tratarem de períodos com vários eventos de chuva expressiva, incluindo o episódio de cheia em União da Vitória. O modelo COSMO utilizou as fronteiras do global GME, no ano de 2014 e foi atualizado em 2015 com as fronteiras do modelo ICON. O impacto desta transição no modelo NWP também foi avaliado no trabalho.

PALAVRAS-CHAVE: Previsão-de-chuva, Vazão-afluente, COSMO, Verificação, ROC 
ABSTRACT: The purpose of the present work is the calibration of a Relative Operation Characteristic Curve (ROC) for helping in the evaluation of rainfall simulations. The procedure is applied to the Iguaçu river basin, in the Paraná state, Brazil. The verification is performed by using 5-day periods of rainfall simulation with the DWD COSMO NWP model, for $7 \mathrm{~km}$ and $2.8 \mathrm{~km}$ grid mesh, and observations from automatic weather stations of SIMEPAR, in the reservoirs operated by COPEL. A case study for years 2014 and 2015 is described, which were identified as years of strong precipitation events that occurred in the South of Brazil, including an event of flood at União da Vitória city. The NWP model was initiated in 2014 with GME hydrostatic global model and updated on 2015 with boundaries of ICON non hydrostatic model. We also evaluate the impact of such modification on streamflow simulation.

KEYWORDS: Precipitation forecasting, streamflow, COSMO, verification, ROC

\section{1 | INTRODUÇÃO}

A operação hidráulica de reservatórios depende da informação de previsão da vazão afluente, que por sua vez depende do acumulado de precipitação previsto e ocorrido a montante dos reservatórios. A expectativa por um dado valor de vazão acarreta várias decisões no planejamento hidroenergético, tanto na geração de energia como no controle de cheias. Em geral, esta expectativa é fornecida por um modelo hidrológico de simulação da vazão afluente, cujas entradas são as precipitações observadas da rede telemétrica, ou previstas com modelos numéricos de previsão do tempo, sendo obtidas no presente estudo com o modelo COSMO. Embora, na situação mais segura, o resultado do modelo numérico de tempo sofra verificação diária, contra os valores observados nas estações hidrometeorológicas, este processo requer uma medida objetiva para determinar o nível de confiança no valor daquela informação para o planejamento hidroenergético. Neste contexto, o trabalho, realizado conjuntamente pelo SIMEPAR e COPEL-GeT, através do PD ANEEL 6491-0333-2013, apresenta uma metodologia para determinar uma curva operacional de avaliação das simulações hidro meteorológicas, com base em dados históricos de vazões ocorridas e previstas, bem como observações e previsões de acumulados de precipitação. O objetivo é auxiliar o planejamento e operação hidráulica na escolha por um cenário de previsão mais adequado nas situações de acumulados de chuva e, consequentemente vazões, significativos. A metodologia foi testada em vários eventos de cheia na bacia do Alto Iguaçu, no Paraná, ocorridos entre 2013 a 2016. Em particular, serão apresentados resultados para os anos de 2014 e 2015, com vários eventos com acumulados expressivos de chuva, incluindo um episódio de cheia em União da Vitória, no período de 6 a 8 de junho de 2014, durante o qual houve excesso de chuva e a vazão em 
União da Vitória atingiu valores muito acima da média histórica (Camargo Correa et. al., 2014).

\section{I MÉTODOS E DADOS}

\subsection{Previsão Hidrológica}

O Sistema de Previsão e Simulação Hidrológica, SISPSHI, do Simepar, compreende um processo semi-distribuído, tendo por base o modelo Sacramento (Burnash, 1995) e adaptações locais, realizadas para resolver a propagação da água através de canais de grandes bacias. Este tipo de abordagem é conhecido por 3R, sigla para a expressão em inglês Rainfall Runoff e Rounting, conforme Guetter (1999). No SIMEPAR, o processo compreende as seguintes tarefas, conforme descrito por Breda (2008):

a) coleta e controle de qualidade dos dados de chuva;

b) composição de séries temporais de chuva e cálculo da chuva média nas bacias;

c) acoplamento com o modelo numérico COSMO de previsão do tempo;

d) cálculo da chuva prevista na bacia e

e) simulação hidrológica e a previsão de vazão afluente nos reservatórios.

O sistema de previsão hidrológica é alimentado com dados da rede de estações hidrológicas e meteorológicas localizadas dentro ou próximas à bacia do rio Iguaçu. No total são 27 estações hidrológicas na bacia do Iguaçu, as quais provêm dados de chuva e vazão nos pontos considerados mais representativos da bacia, além de outras 19 estações meteorológicas que complementam a rede pluviométrica da região. Para a área de estudo, que compreende a porção da bacia do rio Iguaçu que contribui para o reservatório da UHE Governador Bento Munhoz da Rocha Neto (Foz do Areia) são empregados 26 postos para monitoramento pluviométrico, 15 para monitoramento limnimétrico sendo 13 de cota de seções de rios e 2 para o nível do reservatório. Os dados de observação correspondem ao período de 2013 a 2016 e foram coletados nos pontos indicados na Figura 1, na qual indica-se as localizações das estações meteorológicas do Simepar e hidrológicas da COPEL.

As vazões são obtidas através da relação cota x vazão (curvas-chave), previamente determinada por estudos e levantamentos de campo dos postos fluviométricos. Especialmente para os postos União da Vitória e Santa Cruz do Timbó, é necessário considerar o efeito do remanso para determinar a vazão. Para o cálculo da chuva média em cada sub-bacia, todos os pluviômetros em um raio de até $50 \mathrm{~km}$ dos limites da sub-bacia são utilizados na contabilidade. Os dados, coletados a cada 15 minutos, 
são acumulados em volumes horários e a ponderação entre estes registros é feito pelo quadrado da distância entre os postos e o ponto central da sub-bacia.

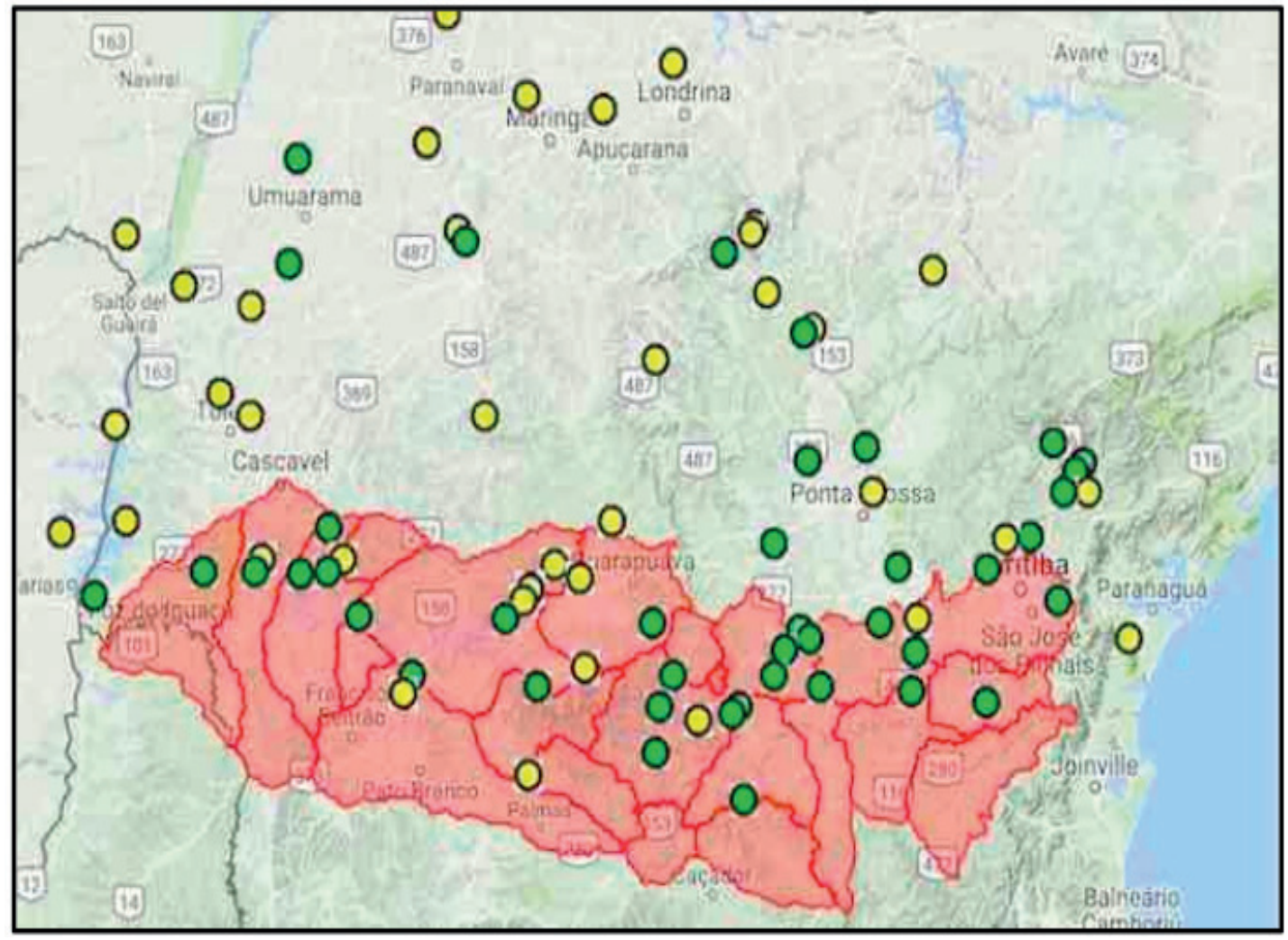

FIGURA 1 - Bacia do rio Iguaçu e localização dos postos de monitoramento automático, incluindo estações meteorológicas automáticas do Simepar e estações hidrológicas da COPEL.

\subsection{Previsão Numérica do Tempo}

Neste trabalho, o modelo atmosférico não hidrostático COSMO, conforme descrito por Baldauf et. Al. (2011), resultado de um consórcio europeu para modelagem numérica da atmosfera, foi calibrado para simulações com alta resolução espacial em regiões com as sub-bacias em foco. Este modelo permite a simulação de processos atmosféricos com escala temporal de algumas horas a dias e abrangência espacial de metros a centenas de quilômetros, além de ser aplicado tanto para previsão numérica do tempo como simulações climáticas. Em particular, o COSMO foi utilizado com uma grade com espaçamento horizontal $7 \mathrm{~km}$ sobre o Centro-Sul do Brasil e $2.8 \mathrm{~km}$ sobre a região Sul do Brasil. Por outro lado, como o COSMO é um modelo de área limitada (regional), necessita de dados nas fronteiras laterais, provenientes de um modelo atmosférico de escala global. Foram então utilizadas fronteiras de dois modelos globais, fornecidos pelo Serviço Meteorológico Alemão (DWD): GME e ICON. O primeiro é um modelo global hidrostático, com espaçamento horizontal de grade médio de $20 \mathrm{~km}$ e 90 níveis na escala vertical. Embora seja um modelo de grade, o GME foi planejado de modo a resolver o problema de singularidade nos polos, comum em modelos de grade regular latitude-longitude. No GME, as variáveis atmosféricas são resolvidas nos vértices de uma grade icosaédrica-hexagonal, conforme descrito por Majewski et. al. (2002). Por outro lado, no modelo global ICON, sigla para a expressão em 
inglês Icosahedrical Non-hidrostatic model, a grade é similar à do GME, mas o modelo é não-hidrostático. Assim, ao resolver a equação do movimento da atmosfera nãohidrostática, a circulação pode ser simulada com maior resolução do que no caso do GME, com a possibilidade de simular por exemplo, forte fluxo vertical dos ventos em nuvens convectivas (Wan et. al., 2013).

2.3 Processo de verificação e determinação da curva de avaliação da chuva prevista com modelo numérico

A verificação dos prognósticos de chuva e vazão foi realizada através do cálculo de índices de verificação, conforme descritos por Jolliffe e Stephenson (2003). Estes índices incluem o erro absoluto (EABS); viés (V); raiz do erro quadrático médio (RMSE); análise não paramétrica das distribuições previstas, comparadas às distribuições observadas; proporção de eventos classificados corretamente (PC); taxa de acerto (HR) e taxa de falso alarme (FAR).

O EABS é a medida pontual do erro na comparação da previsão de chuva (p) do modelo numérico e o valor observado (o) na estação telemétrica, tal que

$\mathrm{EABS}=\left(p_{i}-o_{i}\right)$

$[\mathrm{mm} / \mathrm{h}]$

$O$ viés $V$ contabiliza a correspondência entre a previsão (p) e observação (o), tal que

$\mathrm{V}=\frac{1}{n} \sum_{i=1}^{n}\left(p_{i}-o_{i}\right)$

$[\mathrm{mm} / \mathrm{h}]$

(2)

RMSE representa o desvio padrão amostral das diferenças entre os valores previstos e observados, sendo computado por

$\mathrm{RMSE}=\sqrt{\sum_{i=1}^{n}\left(p_{i}-o_{i}\right)^{2}}$

$[\mathrm{mm} / \mathrm{h}]$

(3)

\subsubsection{Curva de característica de operação (ROC)}

Em adição aos índices estatísticos anteriormente mencionados, uma medida de destreza dos modelos numéricos quanto à previsão do acumulado horário de chuva foi obtida com a determinação da Curva de Característica de Operação, termo para a sigla em inglês ROC, de Relative operating Characteristics. Conforme descrito por Jolliffe e Stephenson (2003), a curva ROC é uma medida conjunta da sensibilidade(S), quando 
o modelo previu corretamente um acumulado de chuva observado, produzindo uma verdade positiva (VP), e da especificidade(E), quando o modelo não previu chuva e de fato não ocorreu, produzindo uma verdade negativa (VN), conforme ilustrado na Tabela 1, de contingência dos possíveis resultados para o evento chuva/não chuva.

\begin{tabular}{cccc}
\hline PREVISTO & \multicolumn{4}{c}{ OBSERVADO } \\
\hline \hline & SIM & NAO & TOTAL \\
\hline SIM & a (VP) & b (FP) & $(a+b)$ \\
\hline NAO & $\mathrm{c} \mathrm{(FN)}$ & d (VN) & $(c+d)$ \\
\hline TOTAL & $(a+c)$ & $(b+d)$ & $(a+b+c+d)=n$ \\
\hline \hline
\end{tabular}

TABELA 1 - tabela de contingência com os possíveis resultados para um evento chuva/não chuva.

As células na Tabela 1, referem-se à avaliação de cada par (previsão, observação), onde SIM e NÃO referem-se a limiares de acumulados de chuva, por exemplo acumulado diário de chuva acima de $60 \mathrm{~mm}$. Além de VP e VN, já mencionados, existem as possibilidades do falso positivo (FP), quando o modelo previu chuva e o evento não foi observado e o falso negativo (FN), quando o modelo não previu chuva e o evento foi observado. Procede-se então com a determinação da destreza do modelo numérico em prever chuva, computando-se as quantidades a,b,c,d e $\mathrm{n}$ da Tabela 1 e, consequentemente, S e E. Vale observar que as medidas S e E são independentes entre si, dado que não são calculadas sobre os mesmos eventos, de maneira que

$$
\mathrm{S}=\frac{V P}{(V P+V N)}=\frac{a}{(a+c)}
$$

$\mathrm{E}=\frac{V N}{(F P+V N)}=\frac{d}{(b+d)}$

(5)

Uma medida utilizada para sintetizar a acurácia da previsão, dadas as quantidades descritas nas equações (4) e (5) e na Tabela 1, é a taxa de classificação errônea (CE), que é a proporção de todos os eventos classificados erroneamente dada por

$$
\mathrm{CE}=\frac{(F P+F N)}{(V P+F N+F P+V N)}
$$

(6)

Por outro lado, a quantidade (1-CE) é chamada proporção de corretos (PC), ou acurácia. Então 


$$
\mathrm{PC}=\left(1-\frac{F P+F N}{V P+F N+F P+V N}\right)
$$

(7)

$$
\mathrm{PC}=\frac{V P+V N}{V P+F N+F P+V N}=\frac{(a+d)}{n}
$$

O uso das quantidades CE e PC pode induzir erros na interpretação dos resultados, dada a contabilização do total em ambas as medidas. Assim, para manter a independência entre eventos verdadeiros e falsos, utilizamos as seguintes taxas

$$
\begin{aligned}
& \text { Taxa de acerto, } \mathrm{HR}=\frac{V P}{(V P+F N)}=\frac{a}{(a+c)},[0,1] \\
& \mathrm{e} \\
& \text { Taxa de alarme falso, } \mathrm{FAR}=\frac{F P}{(F P+V N)}=\frac{b}{(b+d)},[0,1]
\end{aligned}
$$

As quantidades HR e FAR são então duas medidas independentes e formam a base para a determinação da curva ROC, resultante do gráfico dos pares (FAR,HR), cujos pontos representam, no presente experimento, limiares de acumulados diários de chuva. A Figura 2 traz uma interpretação da curva ROC. Um sistema conservador de alta segurança, opera com baixa taxa de alarme falso, embora o acerto seja pouco acima da média. Por outro lado, o desafio por uma taxa de acerto maior, pode levar a um aumento da taxa de alarme falso, mas se permanecer ainda aceitável o sistema é considerado estar em uma condição ideal, ou região de conforto. Entre as duas condições, o sistema encontra-se em balanço, ainda que com menor acerto. Um sistema sem destreza permanecerá sobre a diagonal, identificada por uma linha tracejada na Figura 2. Sistemas com baixa performance ou com performance indesejável manterse-ão próximo ou abaixo da diagonal. 


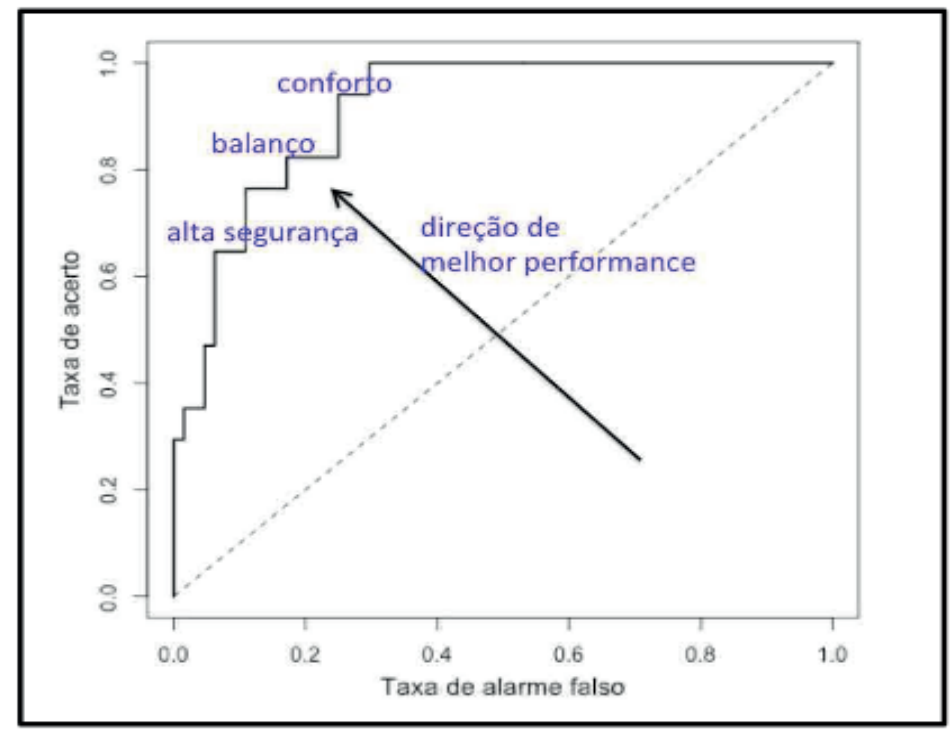

FIGURA 2: interpretação da curva característica de operação, ROC, obtida a partir do gráfico do par (FAR, HR). A reta diagonal tracejada indica um sistema sem destreza.

No trabalho, a curva ROC foi obtida para avaliar a precisão e acurácia do modelo COSMO, para eventos com acumulados diários de chuva: (i) acima de 40mm (L1); acima de $60 \mathrm{~mm}$ (L2) e acima de $80 \mathrm{~mm}$ (L3), considerando-se a ocorrência nas estações telemétricas com as observações de chuva.

Em adição, valores de $\mathrm{V}$ e RMSE foram calculados para avaliar a previsão vazão afluente aos reservatórios operados pela COPEL no rio Iguaçu, tendo como entrada a chuva prevista com os modelos numéricos. A referência é a vazão afluente calculada com séries temporais dos dados de chuva observados nos postos de coleta, para o período da previsão de chuva.

\section{I RESULTADOS}

Os resultados restringem-se à verificação da chuva prevista com o modelo numérico COSMO e sua utilização no sistema de previsão de vazão afluente, SISPSHI. O período de avaliação compreende os anos de 2014 e 2015, durante os quais vários eventos de chuva muito forte ocorreram na região Sul do Brasil. Em particular, no mês de junho de 2014, registrou-se uma cheia expressiva no rio Iguaçu, causando vários prejuízos materiais e inundações no município de União da Vitória.

Tais eventos de chuvas intensas, nos anos de 2014 e 2015, estão associados às condições anômalas do evento de El Niño, com expressiva manifestação sobre o Pacífico e indiretamente sobre as regiões Sul e Sudeste do Brasil. O fenômeno atingiu o ápice em 2015, sendo registrado como o mais intenso desde 1997.

Enquanto uma seca expressiva ocorreu nas regiões Nordeste e Sudeste do Brasil, nos anos 2014 e 2015, a região Sul sofreu com vários eventos de chuvas intensas e inundações associadas a cheias de rio. Entre os dias 6 e 8 de junho de 2014, choveu um total de 550 mm, em União da Vitória e Foz do Areia, na bacia do rio Iguaçu, o que 
levou à cheia na região, sendo considerada a terceira maior do histórico, com valores de vazão da ordem de $3500 \mathrm{~m} 3 / \mathrm{s}$, tendo a altura do rio na régua em União da Vitória, atingido 8,01m (5,37m acima do valor médio histórico).

\subsection{Verificação do desempenho do modelo COSMO para previsão de chuva e vazão afluente}

O modelo numérico COSMO foi utilizado para previsão da chuva, com duas versões de fronteiras laterais (GME e ICON) e para os domínios anteriormente mencionados, com malha de $7 \mathrm{~km}$ (Centro Sul do Brasil) e 2.8km (Paraná), respectivamente, 60 níveis na escala vertical e passo de tempo de 60s. Não foi possível obter os dados de fronteira para os dois períodos utilizados neste trabalho, dado que o GME foi descontinuado em 2015 e o ICON ainda não era operacional em 2014. Assim, no ano de 2014 utilizou-se a fronteira do modelo global GME, hidrostático com espaçamento horizontal médio de $20 \mathrm{~km}$ e no ano de 2015 , utilizou-se a fronteira do modelo global ICON, não hidrostático, com espaçamento horizontal de grade médio de $13 \mathrm{~km}$. Por outro lado, o sistema SISPSHI foi utilizado para previsão de vazão afluente em dois locais de interesse da COPEL: (i) na usina hidrelétrica Governador Bento Munhoz da Rocha Netto (Foz do Areia) e (ii) na cidade de União da Vitória, como ilustradas na Figura 3.

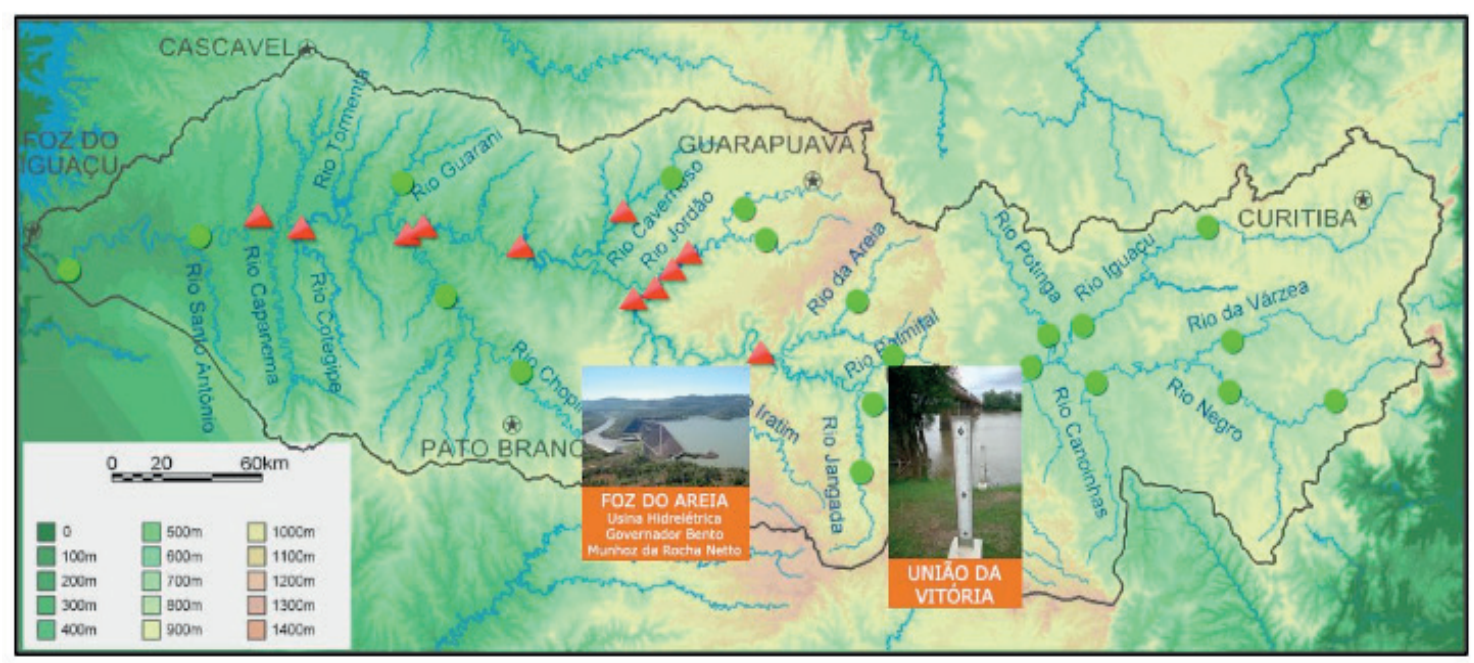

FIGURA 3 - UHE Governador Bento Munhoz da Rocha Netto (Foz do Areia) e posto fluviométrico União da Vitória, na bacia do rio Iguaçu, nos quais foram a previsão de chuva e vazão foram verificadas. Fonte: www.copel.com/monitoramento

O SISPSHI foi executado de maneira a produzir a vazão para o horizonte de 120 horas e a previsão foi então verificada contra vazão observada, calculada por um modelo de referência com base nas séries temporais de observação dos acumulados de chuva. Os gráficos na Figura 4 referem-se à comparação por quantil das distribuições não paramétricas das vazões prevista e observada, para o posto em União da Vitória (à esquerda) e em Foz do Areia (à direita), na bacia do Iguaçu. Cada 
gráfico contém quatro curvas, relativas ao período de 2014 (linha contínua e grossa), 2015 (linha contínua e fina), respectivamente e suas respectivas referências (linha tracejada grossa para 2014 e fina para 2015).

Observa-se do resultado para União da Vitória que a destreza do SISPSHI diminui com o aumento da vazão. Em particular, a concordância com a referência diminuiu a partir de 2000 m3/s. Observa-se ainda um desempenho melhor do sistema para o ano de 2015, quando comparado a 2014. Embora avaliar as causas para tal melhoria não seja objeto deste estudo, especula-se que uma possível causa está relacionada a alteração na previsão de chuva, devido à substituição da fronteira do modelo GME por um modelo mais sofisticado, de maior resolução e não hidrostático, - ICON. Os resultados para Foz do Areia, seguem padrão similar, com a ressalva de um desempenho inferior para o SISPSHI nesta sub-bacia, principalmente devido às características do reservatório, cuja investigação, no momento, também está fora do escopo deste trabalho.

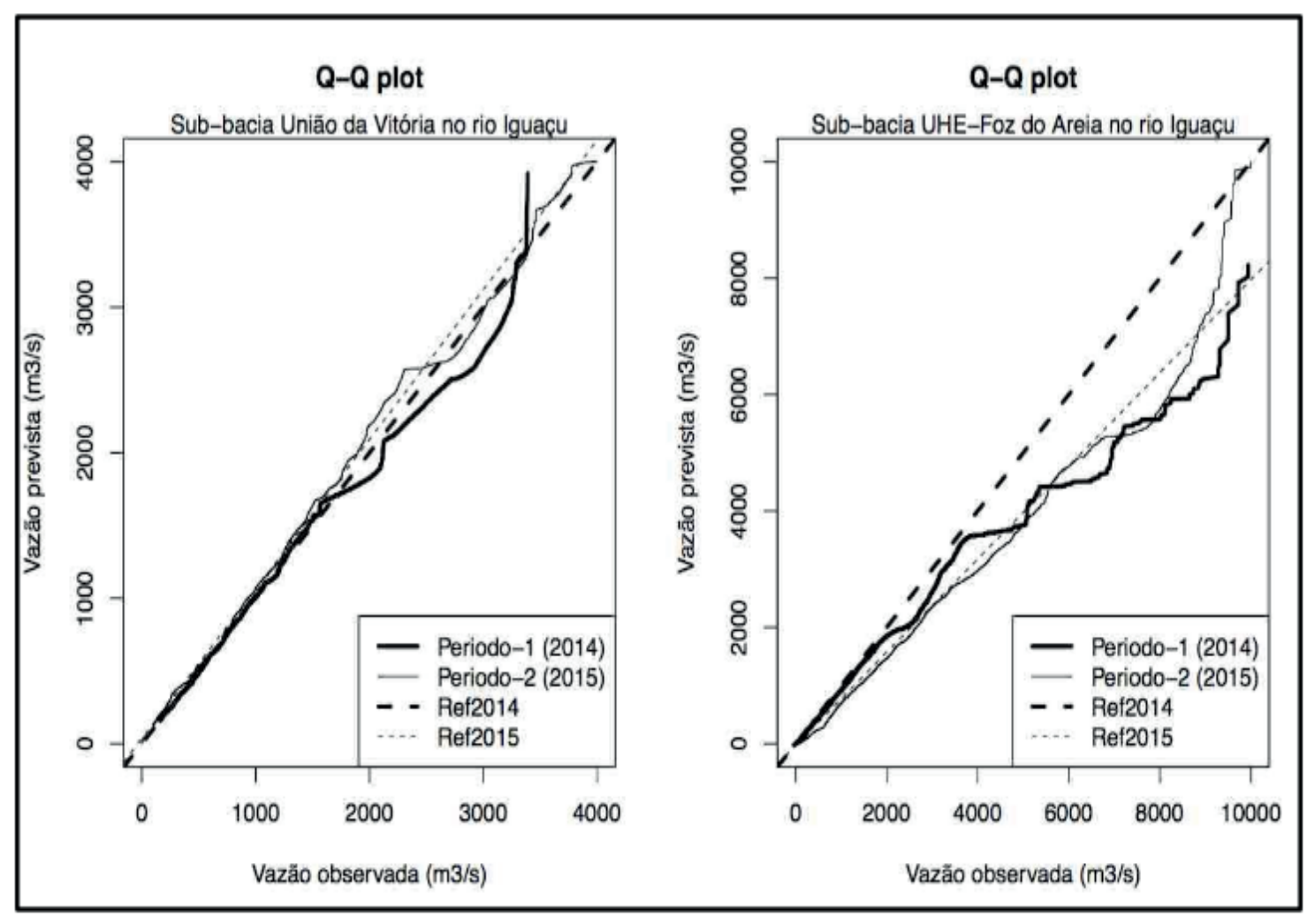

FIGURA 4 - Exame da distribuição dos valores de vazão afluente aos reservatórios em União da Vitória (à esquerda) e em Foz do Areia (à direita), para os períodos de 2014 e 2015, conforme explicação no texto e na legenda dos gráficos.

O SISPSHI foi também verificado quanto à previsão da vazão em períodos de 5 dias, para previsões nos anos de 2014 e 2015, tomando-se como entrada as previsões de chuva do modelo COSMO e o modelo de referência com base nas séries de chuva observada. Os gráficos na Figura 5 referem-se ao viés para os dois locais, em União da Vitória e em Foz do Areia. Enquanto não se objetiva comparar os resultados entre os dois reservatórios, devido às suas particularidades, observa-se que o desempenho 
do sistema diminui a partir do segundo dia de previsão. No entanto, tal como no exame anterior, no ano de 2015 o desempenho foi superior a 2014, para ambas as sub bacias, efeito possivelmente devido à melhoria da previsão de chuva, em resposta à alteração na fronteira proveniente do modelo atmosférico global. Contudo, é importante mencionar que os modelos numéricos tiveram um desempenho menor em 2014 devido às características das precipitações no período. O ano ficou marcado por diversos períodos com chuva muito forte, como o período de 6 a 8 de junho de 2014, anteriormente mencionado.

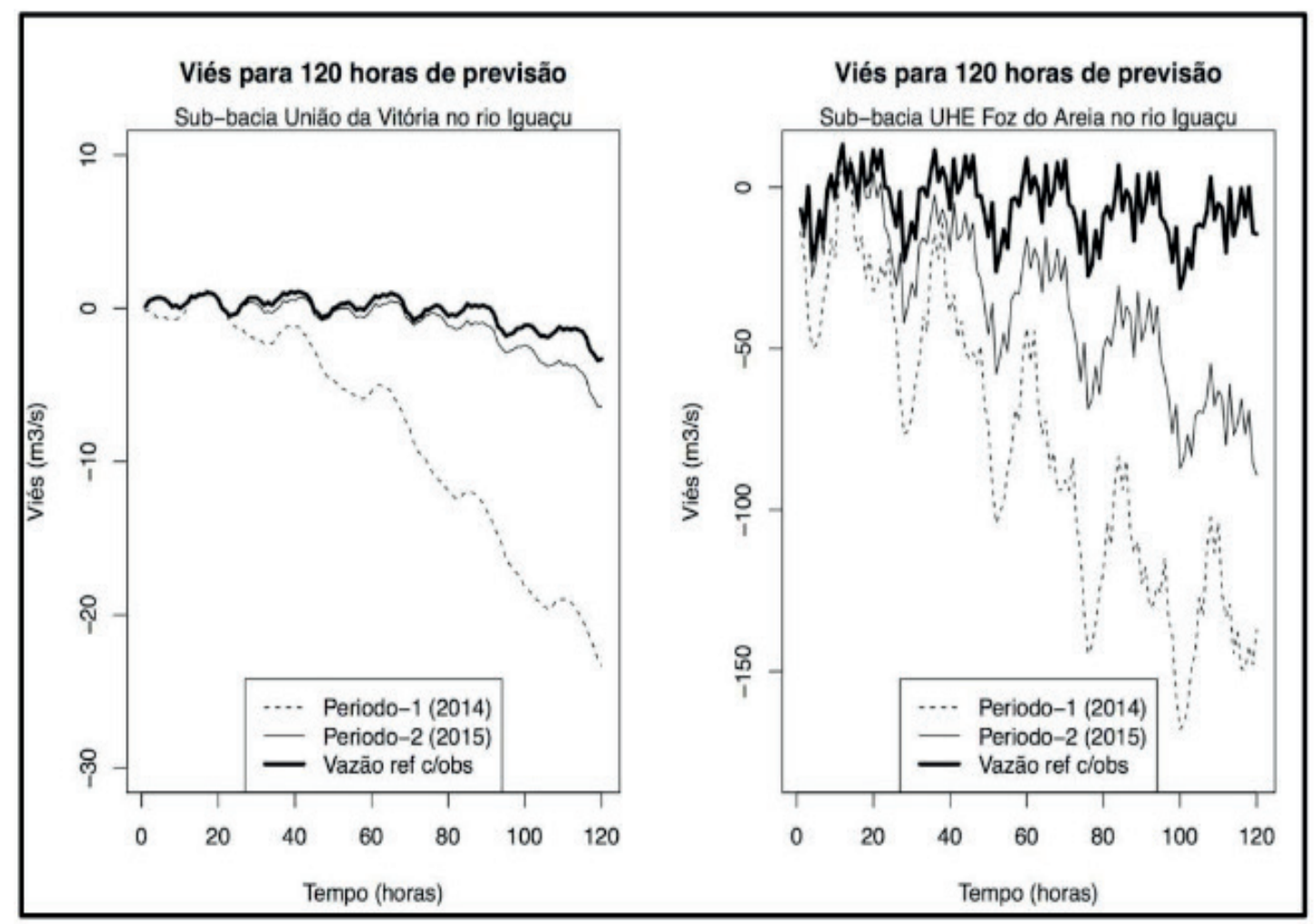

FIGURA 5 - Exame da previsão de vazão para períodos de 120 horas, durante os anos de 2014 e 2015.

\subsubsection{Curva operacional do modelo COSMO para previsão de limiares de} acumulados de chuva

Curvas ROC foram obtidas para avaliar o desempenho da previsão de chuva realizada com o modelo COSMO, para acumulados diários de chuva acima de $40 \mathrm{~mm}$ (limiar L1), 60 mm (limiar L2) e 80 mm (limiar L3). Nesta avaliação foram utilizadas previsões referentes ao domínio maior, com malha da grade com $7 \mathrm{~km}$ de espaçamento horizontal, o qual cobre as regiões Centro Oeste, Sudeste e Sul do Brasil. Os resultados, apresentados na Figura 6, referem-se aos anos de 2014 e 2015, com uso da fronteira do modelo global GME e ICON, respectivamente. Utilizando como referência a ilustração na Figura 2, nota-se que em 2014 (gráficos à esquerda na Figura 6), o modelo é conservador para previsão de chuvas mais intensas (L3), em especial para a região Sul. No entanto, o modelo aproxima-se da condição de conforto 
para as três regiões, para acumulados diários de chuva moderados ( L1 e L2), exceto para a região Sul, para a qual a previsão para o limiar L1 produziu uma alta taxa de alarme falso. Nos resultados para o ano de 2015, gráficos à direita, as condições são próximas ao ano anterior, mas com substancial melhora para L3, com aumento da taxa de acerto e diminuição da taxa de alarme falso, para as três regiões.

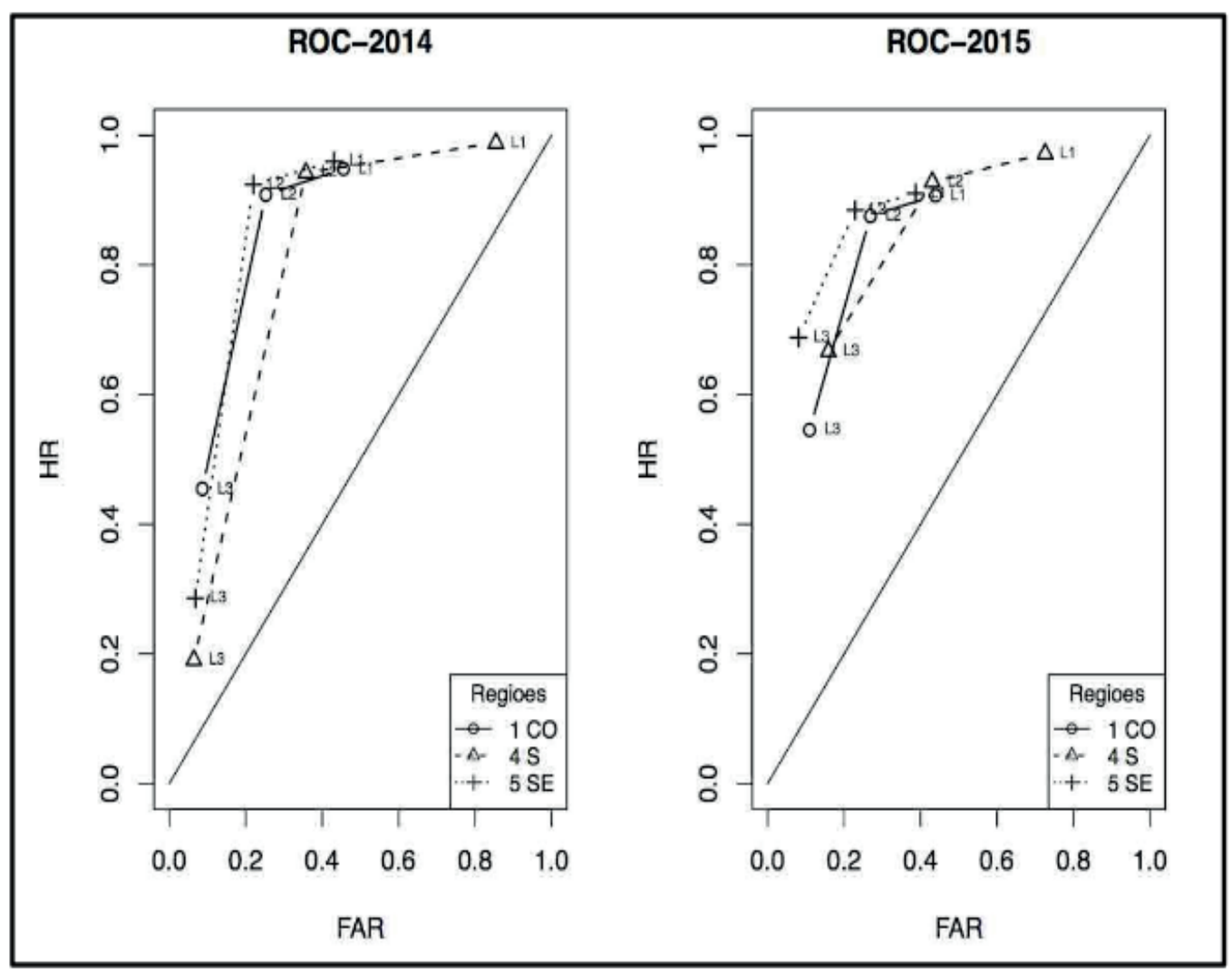

FIGURA 6 - Curvas ROC para três limiares de acumulados diários de chuva: acima de 40mm

(L1); acima de 60mm (L2) e acima 80mm (L3), previstos com o modelo COSMO, para as

regiões $\mathrm{CO}$, SE e S do Brasil. A reta diagonal ilustra o resultado para um modelo sem destreza.

\section{I CONCLUSÃO}

O modelo COSMO foi avaliado quanto ao uso das previsões de chuva no sistema de previsão hidrológica para a bacia do rio Iguaçu SISPSHI do Simepar. Índices estatísticos como erro absoluto; viés; raiz quadrada do erro quadrático médio; comparação das distribuições dos quantis observados e previstos e uma avaliação para limiares de chuva forte foram realizados. Resultados para os anos de $2014 \mathrm{e}$ 2015, anos com forte impacto do fenômeno El Niño na região Sul, foram apresentados. O que se observou destes resultados é que o modelo COSMO e consequentemente o SISPSHI tiveram desempenho pior no ano de 2014 do que no ano seguinte, como indica a comparação entre distribuições da vazão no posto fluviométrico em União da Vitória e na UHE Foz do Areia, bem como as análises do viés, sendo as diferenças possivelmente associadas a dois fatores - chuvas mais intensas e mais frequentes foram observadas no ano de 2014 e o modelo COSMO teve um aprimoramento no ano de 2015, com alteração nos dados de fronteira do modelo global GME para o modelo 
ICON. Infelizmente, dada a limitação em obter os dados de ambos os modelos globais para os dois períodos, não se pode dissociar tais causas, embora um dos fatores que colaboram para melhoria da previsão regional seja o aprimoramento nas condições de fronteira.

Curvas características de operação, curvas ROC, foram apresentadas para as regiões S, SE e CO do Brasil e para três limiares diários de chuva moderada e forte: acima de $40 \mathrm{~mm}$, acima de $60 \mathrm{~mm}$ e acima de $80 \mathrm{~mm}$. A curva sintetiza a avaliação global da acurácia e precisão do modelo numérico. Os resultados indicam que a performance do modelo é inferior para região Sul do Brasil, em relação às demais regiões. Contudo, as curvas estão dentro do esperado para este tipo de operação e são úteis para auxiliar em tomadas de decisão operacional, quando a escolha por determinado processo implica em maximizar o acerto, sem aumentar excessivamente o alarme falso. Em outros termos, implica ainda em tomar a decisão para a escolha de um sistema conservador, o qual inibe o alarme falso, ou por um sistema mais flexível em que se permite o alarme falso, mas aumenta o acerto. Os resultados indicam também que aprimoramentos no modelo têm forte impacto na curva operacional do sistema.

\section{I AGRADECIMENTOS}

Este trabalho apresenta parte dos resultados do Projeto P\&D 6491-0333-2013, executado pelo Simepar junto à COPEL GeT e dentro do Programa de Pesquisa e Desenvolvimento Tecnológico do Setor Elétrico, regulamentado pela ANEEL. Os autores agradecem também ao Serviço Meteorológico Alemão, DWD, por ceder os dados dos modelos globais GME e ICON, bem como por cederem o modelo COSMO, nas versões de pesquisa e avaliação.

\section{REFERÊNCIAS}

BALDAUF, M., SEIFERT, A., FÖRSTNER, J., MAJEWSKI, D. AND RASCHENDORFER, M. Operational Convective-Scale Numerical Weather Prediction with the COSMO Model: Description and Sensitivities. Monthly Weather Review, Vol 139, PP 3887-3905, 2011.

BREDA, A. Avaliação de melhorias para um sistema de previsão hidrológica horária. Dissertação (Mestrado em Engenharia de Recursos Hídricos e Ambientais) - Universidade Federal do Paraná, Curitiba. Disponível em http://www. ppgerha.ufpr.br/publicacoes/dissertacoes/files/140-Angelo_Breda. pdf, 2008.

BURNASH, R.J.C. The NWS River Forecast System - Catchment Modeling. Em: Vijay P. Singh (ed.), Computer models of watershed hydrology. Highlands Ranch, Colo.: Water Resources Publications de 1995.

CAMARGO CORREA, C.M., LEVASSEUR, J., MANTOVANI, L. E. Relatório Avaliação das áreas atingidas pelas inundações e alagamentos em União da Vitória/PR, em junho de 2014. CENACID - Centro de Apoio Cientifico em Desastres da UFPR: União da Vitória/PR. 2014.

GUETTER, A. K. Sistema de previsão hidrológica para suporte à operação dos reservatórios da 
bacia do Rio Iguaçu. Em: XV Seminário Nacional de Produção e Transmissão de Energia Elétrica. Foz do Iguaçu-PR, de 1999.

JOLLIFFE, I. T. AND STEPHENSON, D. B. Forecast Verification: A Practitioner's Guide in Atmospheric Science. 254pp, Wiley, 2003.

MAJEWSKI, D. ET AL. The operational global icosahedral-hexagonal gridpoint model GME: description and high-resolution tests. Monthly Weather Review, Vol 130, PP 319-338, 2002.

WAN, H. ET. AL. The ICON-1.2 hydrostatic atmospheric dynamical core on triangular grids Part 1: formulation and performance of the baseline version. Geosci. Model Dev., 6, 735-763, 2013. 
SOBRE OS ORGANIZADORES

João Dallamuta - Professor da Universidade Tecnológica Federal do Paraná (UTFPR). Graduação em Engenharia de Telecomunicações pela UFPR. MBAem Gestão pela FAE Business School, Mestre em engenharia elétrica pela UEL. Doutorando em Engenharia Espacial pelo INPE.

Henrique Ajuz Holzmann - Professor da Universidade Tecnológica Federal do Paraná (UTFPR). Graduação em Tecnologia em Fabricação Mecânica e Engenharia Mecânica pela Universidade Tecnológica Federal do Paraná. Mestre em Engenharia de Produção pela Universidade Tecnológica Federal do Paraná Doutorando em Engenharia e Ciência do Materiais pela Universidade Estadual de Ponta Grossa. Trabalha com os temas: Revestimentos resistentes a corrosão, Soldagem e Caracterização de revestimentos soldados. 


\section{A}

AIS 10,13

Ajustes de proteção 22, 28, 34, 103

Alocação de Recursos 161

Anarede 48, 49, 52, 54, 60

Anuidades 10, 11, 12, 13, 14, 15, 17, 18, 19, 20

B

BAR 10,225

Biodiesel 36, 37, 38, 39, 40, 41, 43, 44, 45, 46, 47

BRR 10

C

CAIMI 10, 12, 13, 15, 19

Capacidade Instalada 1, 2, 3, 8

Célula combustível 190, 191, 192, 196

Cenário Energético 1

Chave fusível 96, 98, 110, 114

Chaves Automáticas 161, 162, 163, 164, 167, 168, 171

Comunidades isoladas 36,38

Confiabilidade 20, 22, 24, 27, 49, 50, 53, 60, 84, 90, 121, 130, 136, 139, 145, 161, 162, 163, $165,166,167,171,172,174,192,243$

Continuidade do Fornecimento 108,163

Conversor Boost 190

Conversores 147, 148, 175, 176, 190, 191, 192, 201, 203, 204, 209, 248, 249, 252, 258, 259, 260 Conversores conectados à rede 147

Custo operacional $15,96,102$

D

DEC 90, 91, 92, 93, 94, 96, 97, 100, 101, 105, 106, 107, 111, 119, 164, 171

Densidade de Corrente 193, 196, 197, 198, 200, 201, 203, 205, 211, 213, 214, 248, 252, 256

Descargas atmosféricas 89, 90, 92, 93, 94

Desgaste de Contatos 128, 131

$\mathrm{E}$

Energia Solar Fotovoltaica 1, 2, 3, 6, 7, 8, 61

$\mathrm{F}$

Filtro LCL $147,148,149$

Fluxo de Potência 48, 49, 50, 51, 52, 53, 54, 55, 148

Frequência 90, 97, 140, 147, 148, 151, 156, 163, 164, 175, 176, 177, 178, 181, 184, 185, 187 , $191,193,196,200,201,203,204,205,207,208,209,212,216,250,251,252,260$ 
Geração de energia 3, 36, 38, 43, 45, 46, 263

Geração Distribuída 2, 3, 4, 6, 9, 61, 62, 64, 65, 72, 73, 161, 162, 167, 172

I

Ilhamento de Geração Distribuída 161

Indicadores de Qualidade de Serviço 108, 118

Índices operacionais 89, 94

Interrupções 89, 90, 91, 92, 93, 94, 105, 106, 108, 118, 120, 134, 135, 163

Isolamento $124,130,139,144,164,206,207,235,238,245$

M

Manutenção Preditiva 128, 129, 136

Monitoramento de Disjuntor 128

Monitoramento Digital 108

Monitoramento On-line 128, 129

$\mathbf{N}$

NERC PRC-027-1 21, 22

Núcleos Magnéticos 203, 252, 253, 257

0

Otimização por enxame de partículas 147, 148, 152

$\mathbf{P}$

Perdas 48, 49, 50, 52, 53, 55, 56, 57, 58, 59, 60, 142, 146, 175, 176, 177, 178, 179, 180, 181 , $182,183,184,185,186,187,190,191,192,193,194,195,196,197,198,199,200,201,203$, $204,209,210,211,212,213,214,215,216,249,250,251,252,254,255,256,257,258$

Perdas Técnicas 48, 49, 50, 52, 53, 55, 57, 58, 60

Proteção de Sistemas Elétricos 21, 22

PSS Sincal 21, 22, 30, 31, 32, 35

Q

Qualidade de Energia 96, 97, 107, 108, 109, 121

$\mathbf{R}$

Religador monofásico 96, 98, 99, 105

Rendimento 142, 143, 145, 176, 184, 186, 187, 190, 192, 193, 199, 200, 201, 248, 249, 252, 259

Resolução Normativa ANEEL Nº 482/2012 61

S

Siguard PSA 21, 22, 30, 31, 33 
Tecnologia PRE 89

Transformador a óleo 139, 141, 145

Transistores de potência 175,177

V

Vísceras de peixes $36,43,46$

Volume 43, 57, 141, 188, 191, 193, 196, 199, 202, 203, 204, 207, 210, 211, 213, 214, 215, $216,228,250$ 


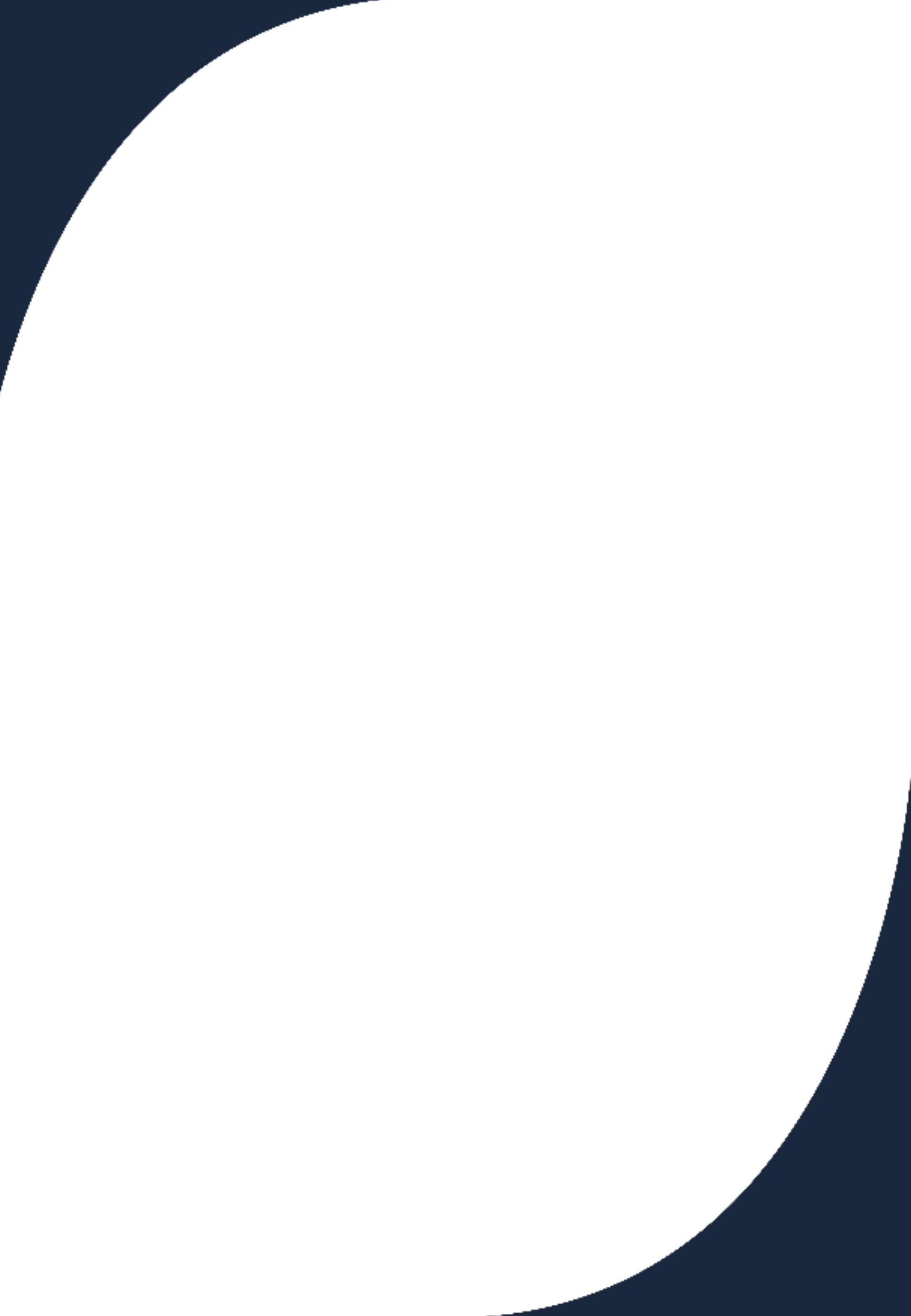

